Facultad de Humanidades y Ciencias delaEducación

Doctorado en Ciencias de la Educación

Tesis para la obtención del grado de Doctora en

Ciencias de laEducación

\title{
PENSAMIENTO COMPLEJO Y METACOGNICIÓN EN EL ÁREA CURRICULAR FILOSÓFICA DE LA EDUCACIÓN MEDIA CHILENA
}

\author{
Mg. Rosse Marie Vallejos Gómez \\ Directora: Dra. Analía M. Palacios \\ Co-directora: Dra. María Alejandra Pedragosa
}

Noviembre 2019

Ensenada, Argentina 


\section{DEDICATORIA}

A Claudina y Luis, pilares fundamentales de mi vida. Por su amor, cuidados y protección. Por creer siempre en mí y alentarme a seguir mis sueños, incluso cuando el mundo parecía en contra. Donde quiera que vaya sus recuerdos me acompañarán como fuente inagotable de fortaleza para luchar por mis convicciones frente a cualquier adversidad. 


\section{AGRADECIMIENTOS}

Deseo agradecer a todas las personas que de diferente manera me han acompañado en la construcción de mi camino académico y han permitido que esta tesis salga a la luz.

A la Universidad de Concepción, mi alma mater, porque desde el año 2002 me permite formarme en ella, abriendo espacios para la realización de sueños y convicciones que mueven mi vida profesional. A los estudiantes que han pasado por mi aula y que han compartido esos sueños instándome con sus propias convicciones a no decaer.

A la comunidad del Liceo Simón Bolívar de Hualpén, por los años que me cobijó con cariño y apertura. A mis ex estudiantes, pilar fundamental en mi desarrollo y crecimiento profesional y personal, lejos los más grandes maestros en mi vida.

A Don Oscar Nail Kröyer por su confianza, su paciencia, su nobleza y su apoyo desde mi formación de pregrado, valores que no son fáciles de encontrar en los tiempos que corren. El Profesor Nail se ha caracterizado por abrir espacios para que otros puedan alcanzar sus metas, con humildad y respeto,

A Analía Palacios, pilar fundamental en este proceso, por su compromiso, apoyo y generosidad, y porque solo un corazón noble como el de ella pudo motivarme a seguir adelante, a pesar de los contratiempos y la pena. Por abrir un espacio en su vida para compartirlo conmigo, por permitirme conocer y compartir con su hermosa familia. Esta tesis no hubiese sido posible sin Analía, quien con sabiduría e infinita paciencia me ayudó a conceptualizar problemas fundamentales de mi investigación, alegrándose incluso más que yo cada vez que avanzaba. Firmeza y ternura, así podría resumir este proceso al lado de Ani.

A Alejandra Pedragosa, mi querida policía "buena", por su mirada crítica y constructiva, por las lecturas detalladas y sus aportes significativos que me permitieron ver más allá. 
Gracias Ale por llevar alegría en esos momentos de alta tensión, por las conversaciones y los mates, y todos los sueños que surgieron de esos encuentros.

Sin duda Analía y Alejandra representan para mí un ejemplo de mujeres luchadoras, sabias, comprometidas con la educación y la humanidad. Sus orientaciones y apoyo fueron fundamentales para que esta tesis alcanzara sus propósitos.

A la Universidad Nacional de La Plata por abrir un espacio para mí, por hacerme sentir parte de esta gran Patria hermana en el sentido real de lo hospitalario

Mención especial a mi pequeño Bautista por su alegría e inocencia, porque en medio de este proceso y sus tensiones me robó risas que alivianaron la carga. 


\section{RESUMEN}

Esta tesis indaga el desarrollo del pensamiento complejo y la metacognición en el área curricular filosófica en Liceos de la Región del Bio Bio, Chile. En lo específico, analiza críticamente los Programas de Estudio, las concepciones de los profesores en ejercicio y las prácticas y actividades para el desarrollo del pensamiento complejo y la metacognición. Los fundamentos se nutren de aportes de la Filosofía para Niños, del desarrollo del currículum y la enseñanza de la Filosofía. En esta línea, recogen postulados de la Psicología Educacional, en una perspectiva cognitiva sociocultural. La metodología asume un enfoque cualitativo de cohorte descriptivo interpretativo de casos múltiples, mediante el análisis de documentos curriculares, observaciones y entrevistas. Los resultados obtenidos en el análisis de los Programas de Estudio consideran los objetivos, los contenidos, los aprendizajes esperados y la evaluación en función de los tipos de pensamiento creativo, ético, crítico- racional, crítico razonable y metacognitivo. Del mismo modo, exponen las concepciones de los profesores sobre las habilidades y disposiciones del pensamiento complejo y la metacognición y establecen relaciones con sus acciones de enseñanza. Finalmente, describen las formas de interacción verbal, de construcción de conocimientos y las principales estrategias para fomentar la participación en los procesos de las clases. La conclusión y la reflexión final aportan al mejoramiento del área curricular filosófica, como un espacio de desarrollo del pensamiento complejo y la metacognición para dar lugar a la producción subjetiva de personas autónomas, críticas y productoras de su propio conocimiento intelectual. También, a la revisión de las políticas en la formación inicial docente y la resignificación de la mirada hacia los profesores, como investigadores reflexivos que pueden contribuir de manera innovadora y creativa al cambio educativo, en las condiciones reales de la enseñanza en las aulas.

Palabras claves: pensamiento complejo - metacognición - currículum - educación filosófica. 


\section{INDICE}

Pág.

Resumen

Introducción

1. Justificación. 6

$\begin{array}{lr}\text { 2. Objeto y enfoque de estudio. } & 18\end{array}$

3. Organización y contenidos de la tesis. 20

Capítulo 1. Pensamiento complejo y metacognición 23

1.1. Introducción a las relaciones entre el pensamiento complejo y la 23 metacognición.

1.2. Estudios antecedentes del pensamiento complejo y la metacognición. 26

1.3. El aula como comunidad de indagación filosófica. 33

$\begin{array}{ll}\text { 1.3.1. Los aprendices del pensamiento. } & 40\end{array}$

1.3.2. Hacia un aula más reflexiva, participativa y colaborativa. 42

Capítulo 2: La educación filosófica como herramienta del pensamiento 50 complejo y la metacognición

2.1. El currículum como herramienta del pensamiento complejo y la metacognición.

2.1.2. La enseñanza de la Filosofía en la educación media chilena.

2.2. Propuestas curriculares orientadas al desarrollo del pensamiento y la metacognición. 
pensamiento complejo como forma de razonabilidad.

2.2.2. Proyecto "Aprender a pensar" del Instituto Pascal.

2.2.3. Proyecto Zero "Estrategias de aprendizaje y de pensamiento

en el aula”, Universidad de Harvard.

2.2.4. Proyecto "Pensamiento complejo y valores humanistas

laicos", Universidad de Concepción de Chile.

\section{Capítulo 3: Diseño metodológico}

3.1. Tipo de investigación

3.2. Objetivos

$\begin{array}{ll}\text { 3.3. Supuestos de partida } & 77\end{array}$

$\begin{array}{ll}\text { 3.4. Dimensiones de análisis } & 78\end{array}$

$\begin{array}{ll}\text { 3.5. Casos } & 80\end{array}$

$\begin{array}{ll}\text { 3.5.1. Profesores participantes } & 83\end{array}$

3.6. Herramientas de recolección de datos 84

3.6.1. Análisis documental de los Programas de Estudio 84

3.6.2. Entrevista en profundidad $\quad 86$

$\begin{array}{ll}\text { 3.6.3. Observación de clase } & 90\end{array}$

$\begin{array}{ll}\text { 3.6.4. Bitácora de Campo } & 93\end{array}$

3.7. Interpretación de los datos $\quad 94$

$\begin{array}{ll}\text { 3.7.1. Análisis de datos } & 94\end{array}$

3.7.2. Categorías de análisis 96 

media chilena

4.1. Caracterización de los Programas de Estudio

4.1.2. Contenidos

4.1.3. Aprendizajes esperados

4.1.4. Actividades

4.1.5. Evaluación

4.2. Tipos de pensamiento en los Planes y Programas de Filosofía

4.2.1. Pensamiento creativo

4.2.2. Pensamiento ético

4.2.3. Pensamiento crítico-racional

4.2.4. Pensamiento crítico-razonable

4.2.5. Pensamiento metacognitivo

Capítulo 5. Concepciones de profesores del área filosófica de la educación media chilena sobre el pensamiento complejo y la metacognición.

5.1. El pensamiento complejo y la metacognición como saberes teóricos y experienciales pedagógicos. teórico. 

cognitivas superiores.

5.1.3. El pensamiento complejo y metacognitivo como actitud.

5.2. Habilidades y disposiciones del pensamiento complejo y la metacognición

5.2.1. Habilidades cognitivas específicas del dominio curricular. asignaturas.

5.3. Acciones de los profesores en función de sus concepciones sobre el pensamiento complejo y la metacognición.

5.3.1. Estrategias y actividades

5.3.2. Recursos didácticos

5.4. Reflexiones de los profesores sobre la propuesta curricular filosófica de la enseñanza media chilena.

5.4.1. Sobre los enfoques propuestos en los Programas

5.4.2. Sobre los problemas, saberes y tipos de conocimientos.

5.4.3. Sobre las actividades y estrategias.

\section{Capítulo 6. Prácticas en las comunidades de aulas de la educación}

\section{media filosófica chilena}

6.1. Las formas de interacción en las clases áulicas.

6.2. Los problemas que se abordan en las clases.

6.3. Las discusiones y reflexiones en las clases.

6.4. Formas de participación y colaboración en las clases 
7. Conclusiones y discusión

7.1. Sobre los Programas de Estudio de la educación media filosófica chilena.

7.2. Las voces de los profesores sobre el pensamiento complejo y la metacognición

7.3. Las prácticas en las comunidades filosóficas de aulas actuales

7.4. Análisis crítico

7.5. Limitaciones y proyecciones del estudio

\section{Referencias bibliográficas}

\section{Índice de Cuadros}

1.Resumen de objetivos por nivel del Programa "Pensamiento complejo y valores Humanistas Laicos", Universidad de Concepción.

2. Preguntas generales focus group del Programa "Desarrollo pensamiento complejo y valores humanistas laicos”, Universidad de Concepción.

3. Objetivos a evaluar en cada pregunta específica del focus group del Programa "Desarrollo del pensamiento complejo y valores humanistas laicos”, Universidad de Concepción.

4. Profesores participantes del área filosófica en Liceos de la educación media chilena. 
5. Dimensiones de análisis e instrumentos para el estudio del pensamiento complejo y la metacognición en la educación media filosófica.

6. Guía de entrevista a profesores en ejercicio en área filosófica de la educación media chilena.

7. Las prácticas áulicas para el desarrollo del pensamiento complejo y la metacognición en cursos de enseñanza de la Filosofía.

8. Guía de observación de las prácticas y actividades áulicas para el desarrollo del pensamiento complejo y la metacognición.

9. Categorías de análisis e indicios para el estudio del pensamiento complejo y la metacognición en la educación media filosófica.

10. Los Programas de Estudio del área filosófica de la educación media chilena.

11. Elementos del pensamiento creativo en los Programas de Estudio del área filosófica de la educación media chilena.

12. Elementos del pensamiento ético en los Programas de Estudio del área filosófica de la educación media chilena.

13. Elementos del pensamiento crítico- racional en los Programas de Estudio del área filosófica de la educación media chilena.

14. Elementos del pensamiento crítico- razonable en los Programas de Estudio del área filosófica de la educación media chilena.

15. Elementos del pensamiento metacognitivo en los Programas de Estudio del área filosófica de la educación media chilena.

16. Concepciones de profesores sobre las habilidades del pensamiento complejo específicas del área curricular filosófica y las habilidades transferibles a otros espacios 
17. Estrategias, actividades y recursos de las prácticas del profesorado

para el desarrollo del pensamiento complejo y la metacognición

\section{Índice de Esquemas y Figuras}

Esquema 1. Dimensiones teóricas y metodológicas del estudio.

Esquema 2. Concepciones de profesores sobre el pensamiento complejo y la metacognición. Fuente: elaboración propia.

Figura 1. Modelo heurístico para el estudio del pensamiento complejo y la metacognición.

Figura 2. Mapa de las Comunas de la provincia de Concepción, Región del Bio Bio, Chile.

Figura 3. El desarrollo del pensamiento complejo y la metacognición en las prácticas del área curricular filosófica de la educación media chilena.

\section{ANEXOS}

1.Entrevista a Eva

2.Entrevista a Antonia

3.Entrevista a Pedro

4. Entrevista a Andrés

5. Entrevista a Sócrates

6. Entrevista a Federico

7. Entrevista a Claudio

8. Entrevista a Marcela 
9. Observación de clase de Eva

10.Observación de clase de Antonia

11.. Observación de clase de Pedro

12. Observación de clase de Andrés

13. Observación de clase de Sócrates

14. Observación de clase de Federico

15. Observación de clase de Claudio

16. Observación de clase de Marcela

404 


\section{INTRODUCCIÓN}

Habia aprendido sin esfuerzo el inglés, el francés, el portugués, el latín. Sospecho, sin embargo, que no era muy capaz de pensar. Pensar es olvidar diferencias, es generalizar, abstraer. En el abarrotado mundo de Funes no habia sino detalles, casi inmediatos. (Borges, "Funes el memorioso")

\section{Justificación}

Uno de los propósitos centrales de la educación formal y, en particular, del nivel medio, se orienta al desarrollo del pensamiento complejo y la metacognición de los estudiantes en las clases áulicas de los distintos espacios curriculares. Al respecto, la disciplina filosófica ofrece herramientas potenciales para este desarrollo que amplían las posibilidades y condiciones de la enseñanza y el aprendizaje en otras asignaturas curriculares, para la formación de la diversidad de sujetos y comunidades. En este marco, se circunscribe el objeto de estudio de esta tesis.

La preocupación por el desarrollo del pensamiento es de dominio público y, en especial, de los profesores que bregan por mejorar las experiencias escolares y superar el modelo unidireccional de enseñanza basado en la exposición y entrega de contenidos, donde los estudiantes son meros receptores de sus explicaciones. Este modelo promueve el pensamiento de tipo convergente "Preparar a los alumnos para que, en el futuro, puedan resolver problemas con eficacia, tomar decisiones bien meditadas y disfrutar de toda una vida de aprendizaje.” (Jay, Perkins \& Tishman, 1997. p. 13), prefabricado, descuidando el despliegue de la imaginación o creación para asimilar, comprender y dar significado a los conocimientos. Esta premisa conlleva a un cambio, entre otros, en los planes y programas 
de los cursos, las concepciones de los profesores sobre la enseñanza, las prácticas áulicas, las estrategias metodológicas y el tipo de interacciones en el contexto dinamizador del aula (De Luque \& Ontoria, 2004).

La relevancia del pensamiento complejo y la metacognición se orienta a la generación de conocimientos y formas de razonamiento sustantivas para la vida cotidiana, social y personal. La importancia de las habilidades implicadas en su desarrollo incide en las acciones y estrategias que los estudiantes emplean para aprender (Pintrich, 2000), la adquisición y retención de conocimientos (Ausubel, 2002), la reflexión fundada (Ennis, 1986) y la resolución creativa de problemas (Mayer, 1986), entre otros aspectos.

A niveles internacional y local, las reformas curriculares de la última década subrayan la necesidad de potenciar en los niños, niñas y jóvenes, el pensamiento como herramienta para la vida. Según Lipman (1998), uno de los problemas actuales de la educación reside en que: "El alumnado adquiere porciones aisladas de conocimiento [...]. Por tanto, los reformadores educativos se esfuerzan en conseguir que los/las niños/as construyan puentes que permitan la conexión de un campo a otro de conocimiento [...]. Se hace hincapié también en el desarrollo de destrezas generales que no son específicas de ninguna disciplina y que puedan ser transferibles de una materia a otra" (p. 219).

Desarrollar el pensamiento complejo y la metacognición de los estudiantes plantea un sinnúmero de desafíos pedagógicos que incluyen la consideración de un conjunto de factores inherentes a la dinámica y complejidad del escenario educativo, especialmente, del trabajo en las aulas de los distintos establecimientos educacionales.

El espacio de la asignatura Filosofía en los Planes de Estudio de la educación media chilena se ubica en los dos últimos de este nivel, de los cuales uno de ellos abarca el área de Psicología. Tradicionalmente, la enseñanza se restringe a la historia de la disciplina y, en especial, a la exposición de los sistemas filosóficos para que los estudiantes los 
memoricen e incluso lleguen a criticarlo, pero no atiende de manera suficiente a la generación de pensamientos propios y/o el cultivo de una inquietud de búsqueda en los estudiantes basada en las interrogantes que plantearon los grandes filósofos (Nail Köyer \& Vallejos Gómez, 2018).

La enseñanza de la Filosofía previamente construida aleja a los estudiantes no sólo de los grandes temas existenciales que preocuparon a los filósofos en todo tiempo, sino también, de la actividad filosófica frente a tales temas que promueve el cuestionar y cuestionarse, dudar, criticar o reflexionar sobre su vida cotidiana o futura. De este modo, la riqueza intrínseca de la Filosofía como herramienta del pensamiento aparece como un saber oscuro e inaccesible para ellos, en tanto a su utilidad académica o cotidiana.

El valor de la actividad filosófica atraviesa el ejercicio diario del pensamiento, susceptible de ser aplicado en todas las áreas de la educación y, en especial, de las asignaturas de la educación media, por sus aportes al desarrollo de las habilidades básicas necesarias para la comprensión de la lengua, las matemáticas, las ciencias sociales y naturales.

En la mayoría de los ámbitos educativos del mundo occidental se reconocen los aportes del método socrático y sus herramientas dialógicas derivadas, para que los estudiantes sean mejores generadores y constructores de sus propios aprendizajes en las experiencias y prácticas educativas, mediante el cuestionamiento y la construcción del significado de los contenidos, materias, reglas, normas y, finalmente, de la vida diaria.

En línea con el método socrático, los crecientes desarrollos en el campo de la Filosofía con niños, puesta en la escena educativa por Mattew Lipman a partir de 1969, en Estados Unidos, ofrece fundamentos y propuestas orientadas al despliegue de las habilidades de razonamiento, para que los estudiantes desde edades tempranas se orienten a pensar por sí mismos y usar sus propias razones en las situaciones cotidianas y, por consiguiente, se 
proyecten como adultos capaces de asumir el estilo de vida según la afirmación kantiana sapere aude (Kant, 1988).

El programa de Filosofía con Niños de Lipman (1969) ha cosechado resultados importantes en su aplicación a las áreas educativas. A juicio de su creador, las asignaturas parecen más fáciles de estudiar cuando su enseñanza está llena de un espíritu dispuesto a filosofar (Lipman, Sharp \& Oscayan, 1998). Sin embargo, diversos componentes de la educación tradicional atentan contra ello, entre otros, la formación del profesorado.

El profesorado ancla entre la política educativa que conjuga los aspectos institucionales y las modalidades de formación de un determinado país, y la realidad escolar del contexto de trabajo (Fullan, 1994; Honig, 2004). Entre esta política y la realidad, a menudo, se produce un hiato que permite explicar gran parte de la crisis que se vive en las aulas y que redunda en la calidad del proceso de enseñanza y aprendizaje "Vivimos en medio de la más extrema sinrazón. Tal vez más nítidamente en América Latina. Reina la más absoluta desigualdad. No hay política, no hay democracia en serio, sólo hay capital y mercado, o sea, barbarie y exclusión. (Kohan, 2007, p. 25)

En relación directa con la formación del profesorado, se distinguen los programas que establece el Ministerio de Educación, que constituyen el margen de los contenidos mínimos obligatorios de la enseñanza en los distintos niveles y subsectores. "Los profesores en Chile se relacionan con los niveles o modalidades del sistema escolar y toma consideración los sectores de aprendizaje del currículo escolar, dando origen a distintas carreras pedagógicas para formar docentes de Educación Parvularia, Básica, Diferencial y Media” (COMISIÓN SOBRE FID, 2005).

Un ejemplo de lo antes expuesto son las estructuras teóricas en torno a las taxonomías tradicionales que aún se continúan usando para la formulación de los objetivos educativos consignados en los Planes y Programas ministeriales de la educación chilena. Estos objetivos se establecen sobre la base de jerarquías de funciones cognitivas que deben ser 
desarrolladas por los profesores con sus estudiantes, en un orden que se considera lógico, desde los niveles más bajos o básicos hasta las funciones más altas, profundas o complejas.

Desde la Filosofía para Niños, las funciones cognitivas prescritas en los documentos ministeriales no favorecen un enfoque de la enseñanza reflexivo, activo y participativo dirigido a la orientación y facilitación del aprendizaje y la construcción de conocimientos y, en especial, a la movilización de las potencialidades de los estudiantes, para el desarrollo del pensamiento complejo y la metacognición.

"Los motivos que dominan el mundo de la filosofía para infantes suponen una forma específica de relación entre educación, política y filosofía. Estamos inmersos en una tradición muy fuerte que ha situado la filosofía al servicio de la formación política de los infantes" (Kohan, 2007, p.68)

\section{Objeto y enfoque de estudio}

En atención a las justificaciones expuestas, el objeto de nuestra investigación está centrado en el desarrollo del pensamiento complejo y la metacognición en educación filosófica de la educación media chilena. En lo específico, examina y establece relaciones entre las orientaciones de los Programas de Estudio, las concepciones de los profesores en ejercicio y las prácticas áulicas. El Esquema $N^{\circ} 1$ que se presenta a continuación ilustra las relaciones teóricas y metodológicas planteadas en la investigación. 


\begin{tabular}{|c|c|}
\hline $\begin{array}{c}\text { DIMENSIONES } \\
\text { TEÓRICAS }\end{array}$ & $\begin{array}{c}\text { DIMENSIONES } \\
\text { OBJETO DE ESTUDIO }\end{array}$ \\
\hline
\end{tabular}

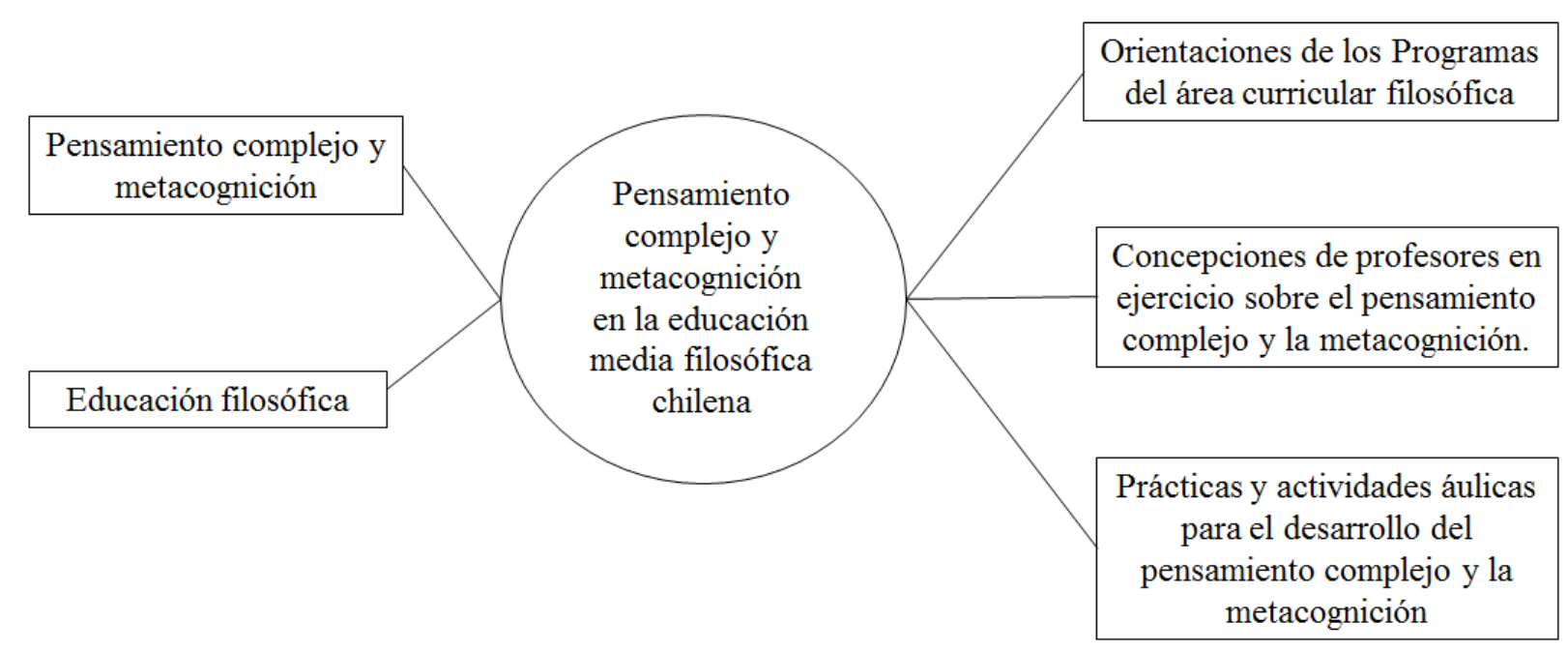

Esquema 1. Dimensiones teóricas y metodológicas del estudio Fuente: elaboración propia.

Las relaciones propuestas en la investigación procuran dar respuesta a los siguientes interrogantes:

- ¿Cómo se orienta el desarrollo del pensamiento complejo y la metacognición en los Programas de Estudio del área filosófica de la educación media chilena?

- ¿Qué concepciones tienen los profesores del área filosófica en ejercicio sobre el pensamiento complejo y la metacognición?

- ¿Qué características reúnen las prácticas áulicas para el desarrollo del pensamiento complejo y la metacognición en la educación media filosófica chilena?

- ¿Qué relaciones pueden establecerse entre las orientaciones de los Programas de Estudio, las concepciones de los profesores y las prácticas áulicas para el desarrollo del pensamiento complejo y la metacognición en la educación filosófica? 
Por una parte, la tesis recoge la extensa producción teórica y empírica en el campo de la Filosofía para Niños (Lipman, 1988), el desarrollo del currículum (Coll, 1997) y la enseñanza de la Filosofía (Cerletti, 2008). En esta línea de fundamentos, se suman los aportes de la autora derivados de su experiencia en la investigación del desarrollo del pensamiento complejo y de los valores humanistas laicos, en la Universidad de Concepción de Chile.

Por otra parte, se nutre de aportes de la Psicología Educacional, en una perspectiva cognitiva sociocultural. Especialmente, de los estudios sobre la enseñanza del pensamiento complejo (Perkins \& Tishman, 1997), los procesos psicológicos superiores y la mediación cognitiva (Vigotsky, 1978, Wertsch, 1988, Pedragosa, 2015, Palacios \& Pedragosa, 2018, Palacios, 2018), el aprendizaje colaborativo y la construcción compartida de conocimiento (Rogoff, 1977, Edwards \& Mercer, 1994), la cognición distribuida (Salomon, 2001), las comunidades de práctica, el aprendizaje situado y la formas de participación (Lave, 1997, Chaiklin \& Lave, 2001, Wenger, 2001).

\section{Organización y contenidos de la tesis}

El Capítulo 1, titulado "Pensamiento complejo y metacognición”, analiza las relaciones entre el pensamiento complejo y la metacognición en Filosofía. Ofrece un panorama de los estudios sobre el tema en el campo de la Filosofía de la mente y de la Psicología cognitiva y educacional. También, revisa los antecedentes conceptuales desde la Filosofía griega y establece relaciones con las habilidades que se ponen en juego en el proceso de enseñanza- aprendizaje. En esta línea, considera al aula como una comunidad de indagación filosófica y la colaboración como una herramienta del pensamiento. 
El Capítulo 2, titulado "La educación filosófica como herramienta del pensamiento complejo y la metacognición", aborda la estructura del conocimiento y la organización disciplinar en el currículum, desde una perspectiva cognitiva. Luego, caracteriza el área curricular filosófica de la educación chilena a partir de las últimas reformas. Finalmente expone diferentes propuestas curriculares, tanto internacionales como locales, orientadas al desarrollo del pensamiento complejo y la metacognición.

El Capítulo 3, titulado “Diseño Metodológico”, expone el diseño y las diferentes fases del estudio. En primer lugar, caracteriza los objetivos, las hipótesis, el enfoque de investigación y la población objeto de estudio. En segundo lugar, describe los tipos de instrumentos empleados para la recogida de datos. Por último, especifica el análisis de los aspectos cualitativos y justifica su pertinencia con los objetivos trazados y el procesamiento de la información, entre otros elementos.

El Capítulo 4, titulado "Los programas de estudio de la educación filosófica media chilena", expone los resultados del análisis de los planes y programas del área curricular filosófica de la educación media chilena, de acuerdo a las categorías propuestas en la investigación, que se corresponden con los tipos de pensamiento creativo, ético, críticoracional, crítico razonable y metacognitivo y los elementos propios de cada tipo en explicitación de los componentes curriculares.

EL Capítulo 5, titulado "Concepciones de profesores del área filosófica de la educación media chilena sobre el pensamiento complejo y la metacognición", aborda las ideas de los profesores sobre el pensamiento complejo y la metacognición que sustentan sus decisiones y desarrollos curriculares en los programas de estudio y prácticas de enseñanza de la Filosofía. Procura dar cuenta de la importancia que ellos asignan al desarrollo de conocimientos, habilidades, capacidades y disposiciones cognitivas y metacognitivas. 
Finalmente, el Capítulo VII, Conclusión y Discusión, contiene la discusión general de los resultados alcanzados en el trabajo empírico, expone las limitaciones del estudio y las perspectivas de investigación futura.

El estudio realizado no sólo procura ser una contribución al esclarecimiento de algunos aspectos esenciales no que también pretende colaborar con el corpus de conocimientos necesario para la formación y el ejercicio profesional de los docentes en el marco de un sistema sociocultural aún desigual. 


\section{CAPITULO 1 \\ PENSAMIENTO COMPLEJO Y METACOGNICIÓN}

"No puedo enseñar nada a nadie. Solo puedo hacerles pensar"

(Sócrates)

Para dominar, el dominador no tiene otro camino sino negar a las masas populares la praxis verdadera. Negarles el derecho de decir su palabra, de pensar correctamente.

(Paulo Freire)

\subsection{Introducción a las relaciones entre el pensamiento complejo y la metacognición}

El pensamiento complejo pone en juego habilidades cognitivas y disposiciones de conocimiento relevantes en la resolución de distintas situaciones, problemas y en la creatividad (Ennis, 2011, Mc Peck, 1990). Los especialistas vinculan estas habilidades con los procesos metacognitivos de reflexión y la toma de conciencia sobre el pensamiento, el aprendizaje, la memoria, el lenguaje que operan sobre la experiencia de los sujetos con un propósito (Nickerson, 1987, De Bono, 1990, Maclure, 1994).

En la educación, el desarrollo del pensamiento complejo y la metacognición se vinculan al logro de los objetivos educativos, la construcción del conocimiento y las concepciones del enfoque profundo y autorregulado del aprendizaje (Boekaerts \& Corno, 2005, Cleary \& Zimmerman, 2004, Carverm \& Scheier, 1998, Pintrich, 2000).

El estudio de las relaciones entre el pensamiento complejo y la metacognición se nutre del aporte de la Filosofía de la mente y de distintas disciplinas afines a como la Psicología Cognitiva y Educacional, advirtiendo que la trama o redes de relaciones de un proceso o construcción mental es siempre parcial y transitoria (Velilla, 2002).

La noción de pensamiento complejo fue acuñada por el sociólogo y filósofo parisino Edgar Morín (1984), con sustento en su idea de complejidad humana y sus escritos sobre método, educación, ciencia, entre otros. Según el autor, nos servimos de nuestra estructura 
de pensamiento para pensar y necesitamos servirnos de nuestro pensamiento para poder repensar la estructura, mediante un bucle interrogativo y crítico, de un yo sobre un yo mismo, sobre la realidad, la verdad. De este modo, el pensamiento complejo es "una manera de ver al ser humano en su multidimensionalidad, y consecuentemente, de tratarlo y concebirlo multidimensionalmente en el contexto organizacional” (Rivas, 2013, p. 110).

El asombro es la plataforma de despliegue del pensamiento complejo que procede a la pregunta, y desde ésta se deriva la urgencia de una respuesta. Precisamente, es la respuesta la que da origen al conocimiento. En palabras de Gadamer (2001):

En toda experiencia está presupuesta la estructura de la pregunta. No se hace experiencia sin la actividad de preguntar. No se hacen experiencias sin la actividad de preguntas. El conocimiento de que algo es así y no como uno creía implica evidentemente que se ha pasado por la pregunta de si es o no es así" (p.439).

Por su parte, la noción de metacognición fue acuñada por el epistemólogo y psicólogo estadounidense John Hurley Flavell (1976) en alusión tanto al conocimiento de los propios procesos del pensamiento como a la monitorización, regulación y ordenación de tales procesos, en relación con los objetos de estudio, datos o informaciones sobre los cuales operan. Por ende, esta noción presupone un sujeto consciente, activo y responsable frente a sus pensamientos, con capacidad para aprender a aprender (Ramos y Álvarez, 2015).

Por lo antes expuesto, la metacognición se relaciona con la conciencia de la propia actividad cognitiva (conocimiento metacognitivo) y con la autorregulación y supervisión del progreso de una tarea (control cognitivo). Ambos planos de la metacognición permiten al sujeto ser más conscientes de sus pensamientos y más estratégicos en las posibilidades de regularlos autónomamente (Bruning, Schraw \& Norby, 2012).

El pensamiento complejo y la metacognición no consisten en procesos para legitimar lo que ya se sabe, sino en emprender el saber cómo y hasta dónde sería posible pensar distinto 
(Foucault,1998). Los procesos cognitivos y metacognitivos reúnen conocimientos, habilidades, actitudes y formas habituales de comportamiento (Nickerson, Perkins \& Smith, 1993). Entre otras, usar evidencias en forma hábil e imparcial, organizar los pensamientos y articularlos en forma concisa y coherente; distinguir inferencias, suspender el juicio en ausencia de evidencias, diferenciar entre razonar y racionalizar, anticipar las consecuencias de acciones, distinguir creencias, saber cómo buscar información y actuar en consecuencia, advertir semejanzas y analogías, aprender en forma independiente, resolver problemas no convencionales, escuchar atentamente las ideas de otros, analizar argumentaciones, poner en tela de juicio los puntos de vista propios.

La construcción del conocimiento en una perspectiva constructivista es inevitable fuente de encuentro del pensamiento complejo y la metacognición. En esta línea, las acciones pedagógicas construyen posibilidades para la creación y recreación del pensamiento de los estudiantes y, por consiguiente, la creación y recreación de sujetos más capaces de gestionar su mundo de manera autónoma (Roger \& Regalado, 2016). Por tanto, el desarrollo del pensamiento complejo y la metacognición constituyen un desafío educativo y, en especial, del profesorado que es, a la vez, científico y filosófico, ético y político, teórico y práctico, académico y ciudadano (Najmanovich, 2013).

La enseñanza del pensamiento ((Nickerson et al,1993) requiere del uso de todas las herramientas didácticas disponibles considerando las características, las estrategias, los métodos y los aportes que cada una puede entregar. Puesto que, como dice Garcés (2013), "El maestro, en Filosofía, no forma ni adiestra, libera: libera de lo que nos impide pensar. El verdadero maestro es, en última instancia, el maestro que nos libera del maestro" (p.13).

En educación, la Filosofía ha devenido en una cuestión de disciplina concerniente a la adquisición y seguimiento de ciertos procedimientos de producción de saber (Sánchez, 2004), en muchos casos mecanizado, limitándose a la repetición o aplicación de métodos filosóficos, antes que a al encuentro de nuevas formas de filosofar. Con este propósito, la 
perspectiva del pensamiento complejo busca servir a la transformación de la realidad social y humana (Huertas \& Arboleda, 2016).

La teorización sobre el pensamiento complejo y la metacognición ha recibido renovada atención durante los últimos años en centros académicos de avanzada en el mundo. Nuestra indagación se nutre de aportes de los estudios en el campo de Filosofía de la mente y, en particular, de la Filosofía para niños (Lipman et. al, 2002, Lipman, 1991) y de trabajos en la rica tradición de las perspectivas cognitiva y sociocultural de la Psicología Educacional (Bruner, 1988, Piaget, 1977, Vygotsky 1991, Sternberg \& Detterman, 1988). Desde estas miradas, los debates actuales reflexionan sobre la complejidad del saber y su relación con el "enseñar a pensar" los contenidos curriculares de las asignaturas en el contexto del aula (Nickerson et al., 1993; Tishman \& Perkins, 1997).

\subsection{Estudios antecedentes del pensamiento complejo y la metacognición}

El interés por el estudio del pensamiento complejo y la metacognición encuentra sus raíces griegas en el diálogo socrático de Sócrates y en los postulados acerca del conocimiento y las representaciones mentales de Platón.

"Hablar con Sócrates parece ser, para los que se encuentran con la filosofía, un acto fundacional. Como si Sócrates instaurara, no sólo la filosofía, sino también la posibilidad de filosofar" (Kohan, 2004, p. 170) En el Menón, Sócrates indaga con persistencia a un joven esclavo acerca de sus conocimientos de geometría. El diálogo se centra en torno de muchas preguntas y respuestas, a la manera socrática consabida. Gracias a este intercambio, el filósofo logró en definitiva extraer del muchacho el conocimiento necesario para calcular las diversas relaciones geométricas puestas en juego en un problema geométrico.

El diálogo socrático no es una simple herramienta de indagación acerca de los grados de conocimiento de un sujeto, antes bien, constituye un postulado sobre la naturaleza del 
conocimiento y su representación mental. Para Platón (y presumiblemente también para Sócrates) la matemática y las ciencias exactas constituían el dominio por excelencia del conocimiento. En palabras de Gardner (1988), "las formas más puras de conocimiento eran arquetipos idealizados de los que sólo se podía tenerse un mero atisbo en la realidad mundana”.

René Descartes es quizás el antecedente filosófico más prototípico de los estudios del pensamiento. A comienzos de la era Moderna, en su libro Discurso del Método (2007) partió del método inductivo y la introspección para llegar a la conclusión de que la única verdad comparable con las verdades matemáticas de las que se puede tener plena certeza es el hecho de que estoy pensando (cogito ergo sum)". Examinado el contenido de su mente, Descartes creyó poder establecer el saber más válido, las ideas claras y distintas menos sujetas a cuestionamientos. Por esto, otorgó un lugar de privilegio a las ideas de la aritmética y la geometría. Además, porque estas ideas no habían llegado a su mente desde fuentes externas a ésta, antes bien habían sido generadas por la mente misma.

"Y con respecto a esto, lo que creo más importante es que encuentro en mí mismo una infinidad de ideas acerca de ciertas cosas de las que no puedo presumir que sean una pura nada, aunque tal vez, no tengan existencia fuera de mi pensamiento. Estas cosas son creaciones de mi imaginación, por más que yo puedo decidir pensar o no pensar en ellas; por el contrario, tienen una naturaleza propia, verdadera e inmutable. Así, por ejemplo, cuando imagino un triángulo, aunque quizá no haya ninguna figura igual en ningún sitio del mundo fuera de mi pensamiento, ni la haya habido jamás, pese a todo dicha figura no puede dejar de tener cierta determinada naturaleza (...) o esencia, inmutable y eterna, que yo no he inventado y que no depende en modo alguno de mi mente (Descartes, 1951, p.61).

Los aportes de Descartes y sus contemporáneos sentaron las bases para el estudio de la mente y la importancia de la misma en el conocimiento y el pensamiento (Peronard, 2009). 
Un pionero de los estudios actuales sobre el tema es Edgar Morin (1998), quien se contrapone a la búsqueda de la simplificación del entramado de la vida del ser humano. Para el autor, la complejidad se relaciona con lo caótico, inexplicable, las interacciones, los sistemas de organización dual desorden-orden del universo. En este sistema interaccionan objetos y sujetos, como unidades complejas que definen los sistemas, y éstos definen, a su vez, las unidades (Herrera, 2008). Esta capacidad se relaciona con la noción de autopoiesis descrita por el biólogo Humberto Maturana (2003) que se aplica en las ciencias sociales, entre otros, para explicar los procesos de conocimiento del sujeto como unidad autopoiética.

Para algunos especialistas la visión autopoiética es coherente con los postulados acerca de la disposición para aprender de manera significativa (Moreira, 2017, Ausubel, 2002). También, con la relación triádica planteada por Gowin (1981), entre el profesor, el estudiante y los materiales educativos, cuyo objeto es la captación de significados por parte del estudiante, que decide si va, o no a internalizarlos.

Diversos autores postulan que la Filosofía en el ámbito académico se caracteriza por abordar el análisis de la complejidad, para formar sujetos capaces de pensar por sí mismos (Sánchez, 2004). En este plano, nuestra tesis recoge los aportes de los estudios de Matthew Lipman (1991) en torno al pensamiento superior que "no es equivalente exclusivamente al pensamiento crítico, sino a la fusión entre el pensamiento crítico y el pensamiento creativo: “es especialmente evidente que tanto el pensamiento creativo como el pensamiento crítico se apoyan y refuerzan mutuamente" (p. 65).

El pensamiento crítico es un componente del pensamiento complejo y busca acercarse a la verdad, evitar el error y la falsedad. Por ello está al servicio de la auto orientación y autocorrección. Tres características básicas son:

1. Está basado en criterios, es decir, entrena a la razón para que sea atenta a los criterios que debe utilizar, los escoja y aplique de manera correcta y pertinente en un campo 
práctico, donde el conocimiento se une con la experiencia y constituye las decisiones y actos del individuo.

2. Es autocorrectivo, es decir, se preocupa por la verdad y validez de nuestras construcciones mentales. Esta tarea no sólo es una tarea individual, pues, la construcción comunitaria del conocimiento se facilita al ver los errores de los razonamientos de los demás, al mismo tiempo que se someten a evaluación y crítica los razonamientos propios, permitiendo una práctica analítica y correctiva del pensamiento.

3. Es sensible al contexto, es decir, quien piensa críticamente evalúa la situación en la que se encuentra, como también, es razonable al saber que las circunstancias y los escenarios cambian, que su pensamiento debe volcarse sobre la situación particular sin dejar de tener una visión global que le permita ubicar las partes en un todo, pues conoce bien que sus juicios no se pueden reducir a reglas generales cuando de un caso particular se trata. Quien piensa críticamente, en el sentido lipmaniano, sabe emplear los criterios adecuados en una situación concreta y se hace responsable de ello.

Lipman (2002) plantea que "los niños están naturalmente predispuestos a la adquisición de las habilidades cognitivas de la misma forma que adquieren el lenguaje, y la educación es necesaria para poder reforzar dicho proceso" (p.134), a su vez que postula cuatro tipos de pensamiento complejo: creativo, ético, crítico racional y crítico razonable, con un carácter de atención complementario en la labor educativa.

I. Pensamiento creativo: Desarrolla la creatividad como un método para resolver problemas de forma original. Favorece el despliegue de la imaginación y la aplicación de la reflexión como instrumento generador de diálogo y de prevención de la violencia. Su metodología se fundamenta en el juego y el diálogo. 
II. Pensamiento ético: Propicia la capacidad de hacer mejores juicios morales. Conduce a la reflexión sobre la capacidad humana de elegir, amplía la dimensión moral y fomenta la actuación autónoma.

III. Pensamiento crítico-racional: Tiene sus bases en la práctica científica, la aplicación de reglas de la lógica en la experiencia científica con el fin de razonar sobre la existencia y las múltiples respuestas para la solución de problemas, como también, razonar sobre el propio pensamiento y su organización para la claridad.

IV. Pensamiento crítico-razonable: Implica la capacidad de pensar por sí mismo, comprendiendo las implicancias de las acciones, como también, las limitaciones de la racionalidad científica para resolver temas relacionados con el actuar humano. Abarca el ejercicio del pensamiento complejo, para evaluar críticamente las implicancias de las propias acciones.

Las fuentes epistemológicas de los tipos de pensamiento postulados por Lipman (2002) se encuentran en la filosofía socrática. Desde este enfoque el autor recoge la consideración de que los niños cuentan con una inclinación natural al pensar, a la duda y al asombro.

El pensamiento complejo o de orden superior es un pensamiento consciente de los propios supuestos e implicaciones, así como de las razones y las evidencias en las que se apoyan sus conclusiones, examina sus metodología, procedimientos, perspectiva y punto de vista propios. Asimismo, está preparado para identificar los factores que llevan a la parcialidad, los prejuicios y el autoengaño (Lipman, 1998).

Con esta visión del pensamiento complejo y una postura pedagógica crítica Lipman (2002) se posiciona frente al dogmatismo, el autoritarismo, la tolerancia y el respeto. Pretende que los niños se encuentren con la razonabilidad y sean personas razonables. La razonabilidad se concibe constituida por un modo particular de entender el diálogo, el cuidado, la libertad, la crítica, la autonomía, el juicio, entre otros aspectos. 
"Para mí, la cosa más interesante del mundo es el pensamiento. Yo sé que hay también muchas otras cosas que son importantes y maravillosas, como la electricidad, el magnetismo y la gravitación. Pero, aunque nosotros las entendemos a ellas, ellas no pueden entendernos a nosotros. Por eso, el pensamiento debe ser algo muy especial [...] en el colegio pensamos en las matemáticas, en la ortografía, en la gramática... pero, ¿a quién se le ha ocurrido pensar en el pensamiento? [...] Si pensamos en la electricidad, la podemos entender mejor; pero si pensamos en el pensamiento, es como si nos entendiéramos mejor a nosotros mismos". (Lipman, 1998, p. 16).

Si bien, el pensamiento metacognitivo no está explicitado entre los tipos de pensamiento complejo propuestos por Lipman, en atención al sentido socrático del concepto - “conócete a ti mismo" - en esta tesis asume su estrecha relación con los tipos de pensamientos creativo, ético, crítico-racional y crítico-razonable.

En términos generales, la persona metacognitiva es aquella que se conoce a sí misma y que es capaz de gobernarse, de poner el pensamiento al mando de su vida. Es una persona reflexiva, equilibrada, moderada, y por tanto mejor ciudadana. Según Lattus (2009) sólo quienes son capaces de gobernarse a sí mismos son capaces de gobernar a los demás, sólo los buenos ciudadanos son buenos gobernantes.

En el plano estrictamente cognitivo, la metacognición se relaciona con "el pensamiento sobre el pensamiento". Esto último se designa como "metapensamiento" que abarca la reflexión y el meta razonamiento, como también, las posibilidades y limitaciones de estos procesos (Nickerson et al. 1993). Asimismo, forma parte de un autoconocimiento que permite reconocer las habilidades del pensamiento personales para realizar una tarea cognitiva y los recursos cognitivos necesarios para resolverla. En palabras de Flavell (1992) “es un proceso extremadamente rico, complejo y multifacético" ( p. 1).

El desarrollo del pensamiento metacognitivo comienza tardíamente en la infancia, en especial, durante la etapa de escolarización y se enfatiza en la adolescencia (Bruning, 
Schraw \& Norby, 2012). Diversos estudios dan a conocer que los niños durante los primeros años de escolarización y los últimos de la educación primaria aún no pueden supervisar adecuadamente una tarea, ni dar cuenta de sus procesos cognitivos (Buron, 2003). Esto no significa que no posean conocimientos metacognitivos, sino por el contrario, que los distintos procesos de la regulación pensamiento van mejorando a lo largo del tiempo en función de las características de los estudiantes, el tipo de tarea y sus condiciones y las estrategias de aprendizaje disponibles García Madruga, Gutiérrez Martínez \& Carriedo López, 2002).

Por otra parte, los estudios destacan que la metacognición es dependiente, entre otros aspectos, de las experiencias de los sujetos en las tareas, sus condiciones y demandas, las posibilidades de acceso reflexivo al conocimiento y su uso y el desarrollo de las habilidades lingüísticas y cognitivas (Nuñez Delgado 2015, Malbrán 2006).

Una investigación realizada por Palacios \& Pedragosa (2018) en escolares primarios argentinos examina distintos aspectos de la construcción de significados y la complejidad de los procedimientos de mediación como herramienta metacognitiva de la enseñanza. Las autoras aplican distintos métodos de evaluación dinámica del proceso de construcción, la identificación de clases y analogías, entre otros, por parte de los niños. Los resultados muestran que los escolares primarios son capaces de realizar abstracciones sorteando los contextos concretos de la aplicación de los conceptos. De este modo, postulan el potencial del pensamiento de los estudiantes a través del desarrollo de sus conocimientos y habilidades lingüísticas.

En función de lo antes expuesto, Palacios \& Pedragosa (2018) sostienen que la mediación cognitiva ubica a los niños en una situación reflexiva sobre sus producciones discursivas y los procesos de pensamiento involucrados. Esto favorece la toma de conciencia de tales procesos, la autoregulación, monitoreo y autoevaluación progresiva de las propias cogniciones. La reflexión metacognitiva amplía la capacidad de interrogación acerca de las 
nociones pertenecientes a las distintas áreas disciplinares, así como también, sobre los conocimientos lingüísticos y las formas discursivas para manejar esas nociones.

Los resultados recogidos por Palacios \& Pedragosa (2018) confirman lo demostrado en otras investigaciones acerca de cómo intervención desde la enseñanza en las estrategias cognitivas y metacognitivas mejora el desarrollo del pensamiento de los estudiantes y, en especial, la confianza y la conciencia sobre sus procesos cognitivos y metacognitivos, la autorregulación y el monitoreo en el aprendizaje (Gutierrez \& Schraw, 2014).

Los estudios sobre la metacognición en estudiantes de la educación media y superior, por una parte, revelan un conocimiento impreciso de sus percepciones sobre sí mismos sobre los procesos metacognitivos, como también, de las actividades y condiciones necesarias para el estudio. Asimismo, el predominio de estrategias vinculadas a la memorización de información, tales como la lectura y copia literal de fragmentos de textos. Esto último, es consistente con las imprecisiones respecto al uso de técnicas con el fin de reducir y/o condensar información, también, cómo hacer diagramas, cuadros, gráficos, dibujos para estudiar activamente, efectuar repasos y recordar mejor (Schraw \& Dennison, 1994, Palacios \& Schinella, 2017).

Los especialistas sostienen que, a menudo, los profesores en los cursos parten erróneamente del supuesto que los estudiantes ya desarrollaron las habilidades del pensamiento metacognitivo necesarias para el aprendizaje y el estudio independiente. Como consecuencia, esto afecta a sus posibilidades de autorregular sus aprendizajes, conocer y usar adecuadamente las estrategias cognitivas y metacognitivas.

\subsection{El aula como comunidad de indagación filosófica}

La noción de comunidad fue acuñada por Charles Sanders Peirce (1971) reconocido como el padre del pragmatismo. Para el autor, la verdad en una investigación científica sólo puede ser alcanzada a través del abandono del individualismo cartesiano que resulta popular 
en los ambientes académicos. Alejarnos del mundo para seguir una búsqueda propia de la verdad al estilo de las meditaciones metafísicas, no es la respuesta. Dicha verdad sólo puede ser alcanzada comunitariamente, es decir, es igual a la opinión final de una comunidad de investigación, opinión que según el filósofo debe ser unánime y unilateral dado que;

"Lo real no es lo que se nos pueda ocurrir pensar, sino aquello a lo que no le afecta lo que del mismo podamos pensar. [...] Tiene que haber una cosa, ya que nuestras opiniones nos vienen dadas; hay algo, por tanto, que influye en nuestros pensamientos y no ha sido creado por ellos" (Peirce, 1871).

Siguiendo la influencia de Peirce, su discípulo, John Dewey intenta llevar las ideas de su maestro a la sala de clase, planteando que el proceso educativo debe tomar como paradigma el método de la investigación científica.

"Dewey estaba convencido de que nuestra sociedad nunca estaría del todo civilizada y nuestras escuelas nunca serían del todo satisfactorias hasta que los estudiantes no se convirtieran en investigadores preparados para participar en una sociedad comprometida con la investigación" (Lipman, 2002. Pág. 162)

Dewey defendía la hipótesis de que el niño aprende sólo en la medida en que es parte en la producción del conocimiento, para esto es necesario invalidar todo método autoritario de enseñanza. El antiguo método norteamericano que concebía al alumno ideal con características tales como la disciplina y docilidad había dejado en evidencia su ineficacia, la educación norteamericana era pobre e insatisfactoria y no cumplía con el objetivo de preparar a los jóvenes para la vida democrática que en un futuro deberían enfrentar. Sin embargo, Dewey creía que sólo era posible educar para el futuro en la medida en que la educación que se está recibiendo tenga un sentido en el presente de los alumnos, la 
pedagogía debía estar al servicio de las necesidades educativas del niño, y por sobre todo no estar ajena a su realidad social.

Dewey es de seguro una de las influencias más importantes en el trabajo de Lipman \& Sharp, la filosofía de la educación considerada que la propuesta de filosofía para niños se deriva en su mayoría del trabajo de Dewey. Es decir que la filosofía de la experiencia en la que Lipman \& Sharp basan su trabajo, proviene de la idea de que no es posible enseñar al alumno a través de la dotación de un significado prefabricado, es el propio estudiante quien debe configurar el conocimiento a través de sus vivencias cotidianas. El niño debe establecer una relación completamente natural para con el saber, mientras menos sea consciente de su instrucción mejor será el resultado obtenido. La idea de comunidad de indagación propuesta por Lipman \& Sharp se puede anticipar en el trabajo de Dewey, así también; la idea kantiana de medios y fines, y la conexión necesaria que debe darse entre estos, la noción de que aprender es descubrir e incluso la idea de un pensamiento reflexivo anterior a la acción son herencias Deweyanas.

Según Lipman (2002) la Filosofía entrega herramientas para razonar, investigar y formar conceptos que son indispensables para la educación de los niños y jóvenes. En esta línea, propone que las salas de clases se conviertan en unas comunidades de indagación o investigación filosófica.

\footnotetext{
"Por investigación entendemos, por supuesto, constancia en la exploración autocorrectiva de temas que se perciben al mismo tiempo como algo problemático e importante. De ningún modo queremos decir que la investigación ponga mayor interés en el descubrimiento que en la invención o en actividades gobernadas por reglas que en actividades improvisadas" (Lipman, 2002, p. 42).
}

Los procesos al interior de las comunidades filosóficas de aulas colaboran con la formación de nuevos ciudadanos para que ellos sean capaces de enfrentarse, con respecto, 
a la diversidad y los conflictos que el mundo de hoy presenta (Lipman, 2002). Dichos procesos se enriquecen con los aportes actuales de las perspectivas cognitiva y sociocultural de la Psicología Educacional. Gran parte de ellos provienen de la obra del psicólogo ruso Lev Vygotsky (1978) sobre los procesos psicológicos superiores, en buena parte vinculados al pensamiento complejo y la metacognición.

La enseñanza representa para Vygotsky (1991) el medio a través del cual progresa el desarrollo cognitivo y el pensamiento reflexivo. En esta línea, nuestra tesis se nutre del constructo "zona de desarrollo próximo" (ZDP) definido como la distancia entre el nivel de desarrollo real, la capacidad para resolver independientemente un problema, y el nivel potencial, determinado a través de la resolución bajo la guía en colaboración con un adulto o un par más capaz. Este constructo se extiende más allá de las edades evolutivas y se aplica a distintos campos o dominios curriculares de la enseñanza, como el de la Filosofía.

Las funciones mentales superiores se originan en la vida social cuando los niños interactúan con los adultos o con iguales más competentes (Vygotsky, 1978). Este postulado resalta el papel del contexto social en el aprendizaje y el desarrollo del pensamiento.

Otra de las contribuciones importantes de Vygotsky a la reflexión sobre el desarrollo cognitivo fue el concepto del lenguaje como una de las herramientas sociales y cognitivas más importantes. El reconocimiento creciente en el terreno educativo de la importancia del contexto social de la cognición y de los usos del lenguaje favorecieron las prácticas pedagógicas orientadas hacia la discusión en el aula, en la construcción del conocimiento compartido (cita) y de nuevas formas de pensar. "En efecto, sólo cuando nadie quiere tenerla, la razón se torna una posibilidad. Y abre también puertas del aprender, en la medida en que sólo un igual comprende a un igual.” (Kohan, 2004, pp. 222-223). Esto último se relaciona especialmente con el constructivismo dialéctico (Moshman, 1982), el cual subraya la importancia de las interacciones sociales en el desarrollo del conocimiento y del pensamiento y ayuda a identificar los elementos más convenientes para crear una clase 
reflexiva, donde los profesores y los estudiantes interactúan para la construcción del conocimiento.

Los especialistas acuerdan que el lenguaje de profesores y estudiantes y sus formas de interacción en las actividades educativas es una de las claves para comprender la enseñanza, el aprendizaje y el desarrollo del pensamiento en el contexto del aula (Cazden 1991, Palacios, 2015).

Algunas tendencias señaladas por Agudo \& Rosetti (1994) en los actos de habla de los profesores en el aula son:

- Requerir la participación de los estudiantes más activos que responden correctamente, descuidando a los menos activos de la clase.

- Dar información acerca de la organización del trabajo, preguntar o impartir órdenes antes que promover una actividad interiorizada para el aprendizaje.

- Convertir situaciones de diálogo en una "mayeútica imperfecta", sin la formulación de problemas que ejerciten los esquemas de asimilación que poseen los estudiantes en la elaboración de las nociones.

- Enfatizar el conocimiento de hechos y datos, más que los procesos de comprensión.

- Realizar exposiciones breves seguidas por preguntas, limitándose los estudiantes a contestar.

- Descartar aportes de los estudiantes sin analizarlos, perdiendo oportunidades para ayudarlos a reelaborar sus ideas.

- Plantear el trabajo en la clase en torno a una misma tarea, sin organizar en forma simultánea subgrupos que desarrollen diversas actividades.

- Proscribir comportamientos en el aula para mantener la disciplina con escaso desarrollo de la autonomía responsable en los estudiantes. 
En contrapunto con lo expresado anteriormente, los especialistas acuerdan las siguientes premisas para favorecer el desarrollo del pensamiento en el aula (Grambell, citado por Palacios, 2015):

- La participación de los estudiantes en discusiones acerca de los textos tiene como resultado una mejor comprensión lectora, mayor capacidad de reflexión y aumento de la motivación para la lectura y escritura.

- El aprendizaje es activado cuando los estudiantes tienen la posibilidad de hablar sobre sus ideas y responder acerca de las ideas de los otros.

- Las conversaciones en pequeños grupos ayudan a que los estudiantes se comprometan intelectualmente con el texto.

- La creación de oportunidades para que los estudiantes interactúen entre ellos y cuestionen las ideas de los demás fomenta un alto nivel de reflexión. Este tipo de intercambios contribuye a mejorar sus habilidades de reflexión, al escuchar y ser escuchados.

- Los estudiantes se involucran más en la lectura cuando tienen la posibilidad de responder y cuestionar diferentes interpretaciones, el estilo del autor, compartir sus opiniones sobre el texto y analizar su sentido.

- La lectura de textos de interés para los estudiantes, los ayuda a participar e involucrarse en las charlas y debates.

- Las actitudes autoritarias de un integrante del grupo influyen negativamente en la participación de otros integrantes en el debate: dice qué hacer, cómo hacerlo, acapara la atención, no deja hablar a los otros porque habla todo el tiempo.

- El rol de liderazgo en una conversación supone una persona respetuosa, responsable y con actitud positiva de inclusión. 
En la perspectiva de Vygotsky (1979) el diálogo en la comunidad de aula permite a los profesores cooperar con los estudiantes para que ellos se desempeñen en su ZDP y puedan establecer relaciones de significación y/o sentido que no podrían hacerlo solos. Estas construcciones en colaboración, luego son internalizadas como formas de desarrollo individual. Tal como lo expresa su ley de la doble formación del desarrollo cultural:

"Toda función aparece dos veces: primero, a nivel social, y, más tarde, a nivel individual; primero entre personas (interpsicológica), y después, en el interior del propio niño (intrapsicológica). Esto puede aplicarse igualmente a la atención voluntaria, a la memoria lógica y a la formación de conceptos. Todas las funciones psicológicas superiores se originan como relaciones entre seres humanos" (p.133).

El contexto social del pensamiento y el conocimiento en el aula ha recibido una creciente atención de teóricos e investigadores en el campo de la Psicología Educacional, a partir de las décadas de 1980 y 1990 (Lave, 1988, Newman, Griffi y Cole, 1991, Rogoff, 1993). La noción de los estudiantes como aprendices activos que construyen su propio conocimiento y reflexionan sobre sus pensamientos y aprendizajes, con ayuda de colaboradores con más experiencia, ha ampliado la concepción de la enseñanza en el aula y las ideas en torno al papel del profesor. También, ha cambiado el papel asignado tradicionalmente al profesor de proveedor de información, actuando como orientador, guía o mediador de la construcción del conocimiento por los estudiantes.

El énfasis creciente sobre el contexto social del aula y los efectos de la cultura sobre el desarrollo del pensamiento y el aprendizaje condujo a los investigadores a considerar nuevos enfoques como el de la participación guiada (Rogoff , 1993) y el modelo de la práctica reflexiva de Shön (1987).

Ahora bien, el diálogo será el mejor aliado al momento de instalar en aula comunidades de indagación filosóficas, cuyo propósito es pensar con otros haciendo uso de las propias experiencias. 
"La indagación filosófica es una búsqueda de sentido en la que la indagación en comunidad tiende a preparar a los sujetos para ser "razonables" y actuar con criterio, alentándolos al diálogo (dos logos) -no la mera conversación- y al análisis de las ideas con flexibilidad, adaptabilidad y creatividad" (Purita et al 2008, p. 5).

El diálogo utilizado, particularmente, por la filosofía con niños, es el diálogo genuino; comprendido como aquello que sustenta una auténtica discusión filosófica, en la cual, dejando de lado las inflexiones personales, se genera una confrontación de opiniones e ideas, mediante las cuales se trasciende de lo obvio, dando paso a la construcción conjunta de un nuevo saber. Sin embargo, para lograr tan ansiado momento se deben dar cita diversas disposiciones, tanto físicas como emocionales e intelectuales, que le permitan al niño someterse a la labor filosófica de forma voluntaria.

"Muchas de nosotras maestras evitamos que nuestros alumnos $<$ charlen $>$ en clases, pues creemos que eso perjudicar al desarrollo del trabajo. El hecho es que, al generalizarlo, no permitiendo tampoco que los niños se expresen frente a un determinado asunto, estamos formando ciudadanos sin opinión propia, pasivos frente al mundo". (Kohan, W. \& Olarieta, 2013. p. 65)

\subsubsection{Los aprendices del pensamiento}

Barbara Rogoff y sus colaboradores (Rogoff, 1990, Rogoff \& Angelillo, 2002) postulan que el desarrollo del pensamiento tiene lugar cuando los niños son guiados por los adultos en actividades sociales que amplían su comprensión de las herramientas de la cultura dominante y de las habilidades para utilizarlas. De este modo, cuando los niños interactúan con sus iguales y con los adultos se convierten en "aprendices del pensamiento".

El desarrollo del pensamiento se construye sobre la base de "la internalización por el principiante de los procesos cognitivos compartidos, apropiándose de lo que ha sido realizado en colaboración, a fin de ampliar el conocimiento y las habilidades disponibles" 
(1990, p 141). Por tanto, dicho desarrollo es de naturaleza inherentemente social y requiere la implicación mutua de colaboradores con mayor competencia. Este proceso colabora con la imaginación, la creatividad y ayuda a los niños a proyectarse en situaciones de interacción nuevas en actividades comunitarias.

La autora destaca que los sujetos a menudo se implican mutuamente en procesos y sistemas de participación guiada, en tanto participantes en una actividad culturalmente significativa. Esto incluye no sólo la interacción "cara a cara" sino también la participación conjunta "codo con codo", muy frecuente en la vida cotidiana y en las coordinaciones de actividades a distancia que no exigen co-presencia ofrecidas por la cultura y los valores sociales, como por los miembros del grupo social (Rogoff, 1995).

En la relación del adulto con los niños, por lo general, los procesos de participación guiada se organizan y guían los esfuerzos del niño en un contexto social y éste les transfiere gradualmente la solución de un problema (Rogoff, 1977). La propuesta de participación guiada se nutre de la noción de andamiaje propuesta por Bruner (1988) con sustento en el concepto de ZDP de la teoría de Vygotsky (1973). Esta noción alude a que las intervenciones del adulto deben mantener una relación inversa con el nivel de competencia del niño en la tarea; es decir, a menor nivel de competencia más ayuda y a mayor nivel, menos ayuda. Esto hace que al inicio del proceso su participación sea altamente dependiente de las orientaciones del adulto, quien ofrece solo ayuda, dado que el verdadero artífice del proceso de aprendizaje es el niño.

En la participación guiada, los estudiantes aprenden a resolver problemas en el contexto de las interacciones sociales, por lo tanto, supone siempre la comunicación interpersonal en torno a un propósito común y el establecimiento de relaciones entre lo que lo ya conocen y la información nueva a la que se enfrentan para alcanzar aprendizajes significativos (Ausubel, 2002). 
En este marco se resalta la función del profesor en términos de mediador o guía de los procesos de pensamiento. En una perspectiva psicopedagógica, Pedragosa (2015) analiza los modos de intervención en las tutorías de los profesores, en carácter de apoyo o acompañamiento de los estudiantes para la resolución de actividades, trabajos de campo, prácticas etcétera. Según la autora la tutoría es un dispositivo psicopedagógico, una práctica situada de cooperación en el desarrollo formativo de los estudiantes que forma parte de las acciones de orientación educativa. Dos principales características de la tutoría son la contingencia de las intervenciones a las necesidades, posibilidades y expectativas del tutorizado y la alta interactividad e intercambio activo de significados. El tutor comparte experiencias estableciendo una relación cálida y apropiada, correspondiendo en todo momento a la motivación y necesidades particulares del tutorizado.

\section{.1.3.2, Hacia un aula más reflexiva: la colaboración como herramienta del pensamiento.}

La filosofía tiene por misión poner en acto el pensamiento (Cerletti, 2008) y cuando un niño pone en acto su pensamiento, el aula se convierte en una comunidad de investigación. Una genuina comunidad de indagación se basa en el respeto mutuo y el compromiso voluntario por parte de sus integrantes en una búsqueda común. La comunidad de indagación filosófica es, entonces, un espacio en donde sus integrantes se prestan especial atención y consideran sus pensamientos, lo que promueve la creación de otros pensamientos, representaciones, concepciones, con lo cual se robustece la razón, la argumentación y la convivencia.

"La comunidad de indagación pretende que los niños y los jóvenes puedan desarrollar a partir de un trabajo cooperativo donde se da lugar al intercambio de concepciones y se entra en el proceso reflexivo, crítico, y analítico que dan lugar a formas más complejas de pensamiento, totalmente diferente al 
sujeto cartesiano en el que el pensar se fundamenta en el sujeto mismo". (Cardona, 2011)

El niño inscrito en una comunidad de indagación debe experimentar un cambio de actitud inclinado a:

- $\quad$ Dar razones y distinguir las buenas de las malas.

- $\quad$ Hacer preguntas.

Escuchar a otros.

- $\quad$ Entender relaciones: partes-todo, medios-fines, causa-efectos, etc.

- $\quad$ Identificar, cuestionar y justificar supuestos.

- $\quad$ Construir explicaciones.

- $\quad$ Esforzarse en busca de la consistencia.

- $\quad$ Formular y usar criterios.

- $\quad$ Corregir el propio pensamiento.

- $\quad$ Buscar evidencias y probabilidades.

- $\quad$ Hacer (cuando sea apropiado, no tener y expresar) juicios de valor.

- $\quad$ Definir y analizar conceptos.

- $\quad$ Hablar confiadamente y fluidamente.

- $\quad$ Encontrar ejemplos y contraejemplos.

- $\quad$ Analizar, predecir y explorar consecuencias.

- $\quad$ Reconocer contradicciones.

- Detectar falacias. 
- Generar y comprobar hipótesis.

- $\quad$ Explorar alternativas y soluciones.

- $\quad$ Comprometerse con el valor de la verdad y de la indagación.

- $\quad$ Entender la importancia de ser razonable.

- $\quad$ Respetar a las personas y sus puntos de vistas.

- $\quad$ Ser cuidadoso en los procedimientos de indagación.

El “aula reflexiva" se asocia al postulado de comunidad de indagación o de investigación, en términos de un espacio en que tanto estudiantes como profesores se escuchan con respeto, construyen sus ideas incorporando las ideas de los demás, se desafían para fortalecer sus argumentos, se ayudan a producir inferencias y a descubrir supuestos subyacentes. Una comunidad de indagación o de investigación aborda los problemas del conocimiento sin apego a las fronteras disciplinarias, se mueve con libertad y deja que el pensamiento descubra su propio recorrido dentro de los márgenes del diálogo.

La perspectiva de la comunidad de indagación enlaza la noción de "cogniciones distribuidas", en el campo de la Psicología Cognitiva, desarrollada a mediados de 1980 por Edward Hutchins (1995). Según el autor, la cognición y las formas de conocer no se limitan a la individualidad de un sujeto, sino que se distribuyen a través de todo lo que rodea a dicho sujeto y la relación que se da entre todo aquello.

El objetivo de la cognición distribuida es describir la coordinación que existe entre los individuos y los objetos, para ello propone que el conocimiento humano y la cognición no están circunscritos exclusivamente en el individuo, sino también en espacios de memoria distribuidos, en hechos, o en el conocimiento de los objetos de nuestro entorno. 
Para Hutchins (1995), una buena caracterización de la cognición distribuida no requiere tener en cuenta los procesos que ocurren en la mente de los agentes cognitivos, sino en los objetos. Sin embargo, este planteamiento no es compartido por todos los investigadores del área. Salomon (2001), por ejemplo, plantea que el contenido y el proceso de pensamiento están distribuidos entre los individuos y, a la vez, encerrados en ellos.

Los desarrollos más específicos de la cognición distribuida pueden ubicarse históricamente entre las décadas del 1920 y 1930. Uno de sus principios fundamentales, dados en dicha época, es el siguiente: "el proceso del desarrollo histórico del comportamiento humano y el proceso de la evolución biológica no coinciden; uno no es la continuidad del otro. Antes bien, cada uno está gobernado por sus propias leyes" (Vigotsky, 1978, p. 71).

La cognición distribuida, desde los aportes que recoge desde el constructivismo, plantea que la cognición se genera contextualmente en un entorno de interacciones entre seres humanos y artefactos. A su vez, éstos poseen como marco una determinada actividad sociocultural. Lo que propone este nuevo enfoque es que, a partir de la actividad interactiva, por un lado, se va generando una especie de red de relaciones, y que el contenido y, por otro, el proceso del pensamiento se distribuye entre los diferentes agentes que configuran la red. E1 conocimiento es comprendido, entonces, como un proceso dinámico, complejo e interactivo, que se construye a partir de las interacciones.

Salomon (2001) sostiene que la inteligencia debe concebirse como ejecutada y no como poseída. La cognición humana posee propiedades distribuidas y resulta

de procesos relacionales y sociales. Dichos procesos se despliegan en una dinámica en red, en función del carácter interactivo de la información y del carácter complejo, dinámico y abierto de la comunicación, como espacio de construcción del conocimiento. 
La psicología histórico-cultural es útil para reconocer las dimensiones en las que se distribuye la cognición, a saber:

a) Cognición entre las personas. Los conocimientos y las formas de pensamiento no están distribuidas de manera uniforme entre las personas. Tales conocimientos y formas dependen de la constitución cultural de los acontecimientos donde ellas participan. La variedad de actividades posibles está condicionada en parte por la estructura y los aspectos sensibles y simbólicos de los acontecimientos. "Cualquiera que haya observado detenidamente la cognición en la práctica, debe entender que la mente rara vez trabaja sola. Las inteligencias que se revelan a través de las prácticas están distribuidas -entre mentes, personas, y los ambientes físico y simbólico, tanto natural como artificial" (Bredo 1994, p. 29).

b) Cognición en el medio cultural. La manera como la mente está distribuida depende de las herramientas mediante las cuales las personas interactúan con el mundo, de acuerdo a los objetivos que se proponen. La combinación de objetivos, las herramientas y el medio cultural conforma el contexto del comportamiento y las maneras en que la cognición está distribuida en ese contexto. Schwartz (citado por Elam, 1973) sostiene que la cultura necesariamente es un fenómeno distribuido en la medida que, como se la aplica y se la adquiere en las interacciones cotidianas entre los hombres, no hay dos de ellos que compartan la totalidad de la cultura del grupo al que pertenecen.

c) Modelos de la cognición. La cultura se ajusta a pautas y no es uniforme. Se la experimenta en interacciones locales y cara a cara, por consiguiente, los modelos de distribución de la cognición son heterogéneos tanto respecto de la cultura como un todo, como de las partes del conjunto instrumental de la cultura, tal como la experimenta cualquier individuo. 
d) Cognición en el mundo social. Los componentes de la cognición de un individuo se sitúan tanto en el entorno como en la actividad y sus acciones. Los procesos cognitivos conllevan acciones inmediatas no sólo en lo cotidiano inmediato, sino también, en lo cotidiano mediato. Las cogniciones distribuidas no tienen un lugar único dentro del individuo, sino, que están “desparramadas", “en medio de” (Cole, 1997; Lave, 1988); están en y se reúnen en un sistema donde hay individuos, pares, docentes o herramientas suministradas por la cultura, a diferencia de lo que sostenían que la cognición dependía de capacidades dentro del individuo. La aclaración del concepto de cogniciones desparramadas alude a que la modificación en un factor afectará a todos los demás factores de la situación.

e) Cognición en el tiempo. La proyección del futuro se convierte en un importante condicionamiento, ya sea material o cultural, organizativo de las experiencias de vida en el presente. Los supuestos de que el futuro cultural ha de ser más o menos como el pasado cultural y que sólo se puede proyectar un futuro basado en la experiencia pasada mediada culturalmente (lo cual viene a significar lo mismo) proporcionan una base esencial de continuidad a la vida mental humana.

Ahora bien, los postulados de la perspectiva de las cogniciones distribuidas comparten una importante cualidad: el producto de la relación intelectual es resultado de la distribución de cogniciones entre los individuos, es decir, un producto común emergente. Al respecto, surgen varios interrogantes, entre otros, ¿hay cogniciones que no están distribuidas? Y si las hay, ¿en qué casos podría afirmarse que lo están y en qué casos no podría hacerse esta afirmación?

Con respecto al primer interrogante se sostiene que no todas las cogniciones están distribuidas todo el tiempo en todos los individuos, sea cual sea la situación, el objetivo, propósito, etcétera. Si las cogniciones están distribuidas, entonces necesariamente están situadas, es decir, dependen de aportes situacionales. Por ello, su distribución dependerá de 
las condiciones situacionales y de otros aportes particulares. Por lo tanto, si a veces están distribuidas y otras no, ninguna teoría puede ignorar los casos u ocasiones en que no lo están.

Con respecto al segundo interrogante, Salomon (2001) explica que las cogniciones que pueden no estar distribuidas forman parte del conocimiento de orden superior de un campo específico, son pertenencia del individuo. Cualquier máquina puede querer reemplazar al individuo. Sin embargo, ésta simulará la sintaxis del pensar, ya que no tiene la semántica de los símbolos que manejan los individuos. Aunque la máquina pueda observar las reglas sintácticas, no entiende el contenido semántico de la serie de símbolos que produce. Los subsistemas de una máquina — por ejemplo, un sistema experto- pueden llegar a compartir una determinada organización de las representaciones mentales que contienen conocimiento, sin tener un acceso a la semántica de esas representaciones.

En atención a que las cogniciones pueden estar distribuidas y que la acción humana es contextual, se postula la construcción del conocimiento como un proceso evolutivo en curso. En la vida estamos en un constante proceso de conocimiento como parte real de la actividad que se está desarrollando en el mundo, por lo tanto, es imposible separar los procesos de sus productos, los elementos estáticos de los elementos dinámicos del pensar. Por ello, resulta necesario tomar en cuenta las propiedades de los individuos que actúan en contextos donde las cogniciones están distribuidas.

Las cogniciones distribuidas y las cogniciones de los individuos se conciben en una relación de influencia y de desarrollo mutuos como, por ejemplo, compartir autoridad, lenguaje, experiencias, tareas, conocimiento y herencia cultural. En este proceso participan interactivamente diferentes factores, pero con énfasis distintos. Si la actividad cognitiva se realiza en un contexto donde las determinaciones de la comunidad no ejercen un grado de influencia causal decisivo - por ejemplo, cuando un estudiante realiza sus tareas fuera de 
la situación de la clase-, dominarán las representaciones, las capacidades y las exigencias del individuo. En cambio, en una actividad entre individuos dentro de una comunidad - el mismo estudiante en la situación de aula-, dominará la asociación y las competencias sociales o tecnológicas.

Lo importante no es lo que los estudiantes han aprendido a hacer solos, sino, el modo en que la asociación, a través de cogniciones distribuidas, modifican lo que hacen y el modo en que lo hacen.

Es necesario mencionar que, en contraposición a la metodología o pedagogía individualista, según la cual que los fenómenos sociales son en principio explicables desde los individuos o agentes cognitivos, sus metas, creencias y acciones, en la cognición distribuida la unidad básica de análisis no es el individuo en singular ni los procesos cognitivos, sino la acción recíproca entre individuos y entre estos y los artefactos que forman parte de la situación. El producto emergente de estas interacciones es el aprendizaje. Por ello, se propone una concepción de desarrollo en espiral para el logro de aprendizajes, donde el sistema distribuido en el que se sitúa es más que la suma de las partes y, por lo tanto, no puede entenderse analizando partes aisladas entendidas como componentes diferenciados.

A modo de síntesis, en la perspectiva de la cognición distribuida, el aprendizaje se entiende como los cambios en las formas de comprensión y participación de los sujetos en una actividad conjunta. Se comprende como un proceso multidimensional de apropiación cultural, ya que se trata de una experiencia que involucra al sujeto en integridad. La cognición distribuida puede servir y dar paso a una teoría del aprendizaje, en la que el desarrollo del conocimiento es el resultado de un sistema formado por la relación existente entre los agentes humanos y los objetos con los que interactúan. 


\title{
CAPÍTULO 2
}

\section{LA EDUCACIÓN FILOSÓFICA COMO HERRAMIENTA DEL PENSAMIENTO COMPLEJO Y LA METACOGNICIÓN}

\begin{abstract}
[...] sería un error considerar el pensamiento y la palabra como dos procesos sin conexión que pueden ser paralelos o cruzarse en ciertos puntos influyéndose mecánicamente. La ausencia de un vínculo primario no implica que entre ellos sólo pueda formarse una conexión mecánica. La futilidad de muchas investigaciones anteriores se debió en gran parte a la presunción de que el pensamiento y la palabra eran elementos aislados e independientes y el pensamiento verbal un fruto de su unión externa. (Vygotski,1993)
\end{abstract}

\subsection{El currículum como herramienta del pensamiento complejo y la metacognición}

Tradicionalmente, en línea con una mirada enciclopédica de la educación, los estudios cognitivos del currículum centraron la atención en el rol del conocimiento, en particular, en el orden lógico asignado a la organización de la estructura de conceptos y principios que caracterizan los distintos campos disciplinares, las conexiones y derivaciones que hacen que una idea siga a otra antes que en los procesos cognitivos complejos que operan en la construcción de esa estructura (Elam, 1973). Gran parte de esta mirada ha guiado y guía la estructura de los diseños curriculares de las últimas décadas (León, Aguilar \& otros, 2000), influenciados por las características evolutivas del pensamiento postuladas por Bruner (1970), Taba (1970), Piaget (2018) y otros.

Schwab (citado por Elam 1973) fue uno de los pioneros en plantear los problemas de la organización de las disciplinas y, en especial, de la identificación de las estructuras conceptuales que activan los procesos de pensamiento. Según el autor dos aspectos importantes son, en primer lugar, reconocer la estructura conceptual que subyace a un 
cuerpo determinado de conocimientos para determinar la clase de problemas que es posible abordar en la enseñanza. En segundo lugar, la necesidad de incluir dicha estructura en el curriculum, como parte del contenido que deben comprender los estudiantes. Para el autor, identificar las disciplinas y sus relaciones curriculares posibilita identificar los diversos recursos de enseñanza.

Las miradas cognitivas más actuales sobre el currículum y los modos de enseñar reconocen que ambos tienen lugar en determinadas coordenadas de tiempo y lugar, por tanto, son productos históricos y sociales que conducen a profundos debates (Eisner, 1998). Al respecto, Resnick \& Klopfer (2007), indican que si se pretende desarrollar el pensamiento a través del currículum es necesario comprender que el aprendizaje implica el pensamiento, este último puede nutrirse y cultivarse en todos los estudiantes, desde el jardín de infantes en adelante, tanto en las clases de matemática como las de historia, lectura, filosofía, incluyendo las de arte, entre otras. Los autores señalan que la conformación de disposiciones para el pensamiento requiere de comunidades sociales que faciliten las habilidades cognitivas de nivel superior, a través de actividades cooperativas, de crítica mutua durante el trabajo compartido de resolución de problemas y de construcción de significados. Para Kohan (2007), la amistad juega un papel importante en las disposiciones para el pensamiento.

"Hay necesidad de que haya amistad para que exista pensamiento [...]La amistad es algo asì como una condición del pensar, de un pensar que valga la pena. Una especie de inicio, un viejo inicio, pero también un nuevo inicio: no pensamos sino a partir de una cierta afinidad en el propio pensamiento". (p. 76).

En una perspectiva cognitiva, esta tesis se interesa por la intencionalidad del currículo para promover distintos procesos del pensamiento complejo y metacognitivo de los estudiantes. Con esta finalidad examina las conceptualizaciones y prácticas vinculadas al 
pensamiento complejo y la metacognición en el área curricular filosófica de la educación media chilena.

Otro aspecto fundamental de la filosofía en el currículum escolar es el desarrollo del pensamiento ético. "Cuando se trata de desarrollo ético - esto es, el desarrollo de los rasgos que hacen posible buenos juicios sobre cómo actuar y cómo vivir-, son fundamentales las relaciones recíprocas que unen los pensamientos, sentimientos y acciones dirigidos a los otros" (Splitter, 1996, p. 224).

Las disciplinas contribuyen de diferentes maneras a la orientación en el mundo, no sólo en cuanto a la información de hechos, sino en la manera específica de pensar que emplean, en el uso de un lenguaje especial, en el nivel de abstracción y en su consiguiente impacto mental. Tales diferencias se expresan también en la forma de tratar los hechos e ideas, en el equilibrio entre inducción y deducción y en la medida en que las generalizaciones son dignas de confianza y universales. En consecuencia, se desprende que el proceso de pensamiento no es igual en los distintos campos de estudio. (Taba, 1987, p.179)

En Filosofía, según Sánchez (2004, p.153), “no se trata ahora de buscar el pensamiento detrás de la filosofía sino de ver cómo el pensamiento funciona en el trabajo de la disciplina filosófica y cómo desde allí abre posibilidades hacia nuevas formas de vivir. En este sentido, la disciplina filosófica parece permitir la interrogación de cuestiones que parecen indiscutibles para otros saberes no porque pretenda proponer un nuevo saber sino porque busca reabrir la posibilidad de recomenzar continuamente el proceso de producción del saber por parte del pensamiento". Por tanto, el pensamiento está esencialmente unido a la filosofía y desde ésta nace la oportunidad de ser recursivos en los procesos de pensamiento con apoyo en el uso de estrategias metacognitivas.

El análisis curricular de la enseñanza en el área de la filosofía incluye la comprensión de las realidades socio-culturales y económicas de los establecimientos educacionales y 
aulas, como también, de las motivaciones, los intereses y las experiencias sociohistóricas de los estudiantes. "En este sentido, la perspectiva de cada hombre se singulariza no sólo por el pensamiento, sino también, por la realidad histórica en la que cada cual se encuentra. Podría decirse que esta imagen de la filosofía, que se dibuja a partir de la conciencia histórica en nuestro autor, nos ofrece el espectáculo de un concierto de perspectivas históricas irreductibles entre sí e irrepetibles para consigo mismas” (González, 2010, p. 92). Así, se reconoce en primera instancia la singularidad de cada sujeto, pero también ser capaz de entender esas diferencias, respetarlas e incluirlas en el aula como un nuevo espacio de aprendizaje, ya que cada uno de los sujetos construirá su aprendizaje respondiendo a su propio contexto temporal y espacial.

Según Borroto (2015, p. 31), "la forma de asumir el paradigma de la complejidad como una forma de pensar el mundo tiene necesariamente que incluir el concepto de sistema complejo adaptativo, hacer suyo la necesidad de un diálogo continuado entre las distintas formas de conocimiento, y negar la existencia de formas de conocimientos más simples que otras. Para asumir esta tarea desde el plano de la educación, como hemos afirmado, hay que hacerlo desde la transdisciplinariedad". El autor propone para abordar la complejidad el uso del diálogo, compartir y comprender con otros las experiencias dispares y ajenas. Argumenta que la instrucción directiva y la segmentación de las asignaturas han procurado especificar cada conocimiento, pero cada área de estudio se encuentra ligada a otras, por lo que se reúnen y deben hacerlo para respetar y continuar con el sistema de complejidad. Por ende, sostiene la promoción de la interdisciplinariedad en el desarrollo del curriculum como paso previo de la transdisciplinariedad.

La perspectiva de la complejidad ha cobrado especial interés en consideración de la realidad que se vive tanto en el campo de la ciencia como en la educación, "en los debates científicos de hoy se ha generado una rigurosa y sistemática reflexión con respecto a la 
complejidad y su relación con el saber para enseñar a pensar los contenidos que se diseñan curricularmente en el contexto del aula" (Pulido, 2009, p. 235), el curriculum ha tomado parte también de esta perspectiva intentando abordar la complejidad para llevarla al aula. Pero el pensamiento y el desarrollo del mismo no sólo se da en el aula, no es un espacio cerrado, sino más bien permeable ya que "No solamente el ser humano en su integridad biológica es un ser complejo, también la sociedad en sí misma es un ejemplo de complejidad." (p. 681), por lo tanto, se vuelve necesario reconocer el rol que la sociedad tiene en los cambios de enfoque que se generan tanto en el campo educativo como científico.

La escuela ha seguido el camino de la ciencia, segmentando las áreas de conocimiento, en la búsqueda de especialización del aprendizaje y consigo, de la enseñanza, "Desde la óptica compleja, la educación implica su relación con otros saberes, pero sobre todo con la sociedad. Para nadie es desconocido que la enseñanza se ha hiperespecializado, imposibilitando un diálogo recíproco entre la parte y el todo.” (Aguilar, 2017, p. 359), el impedir que el diálogo entre el conocimiento fluya de manera natural se niega la complejidad que es inherente al conocer, se vuelve por tanto más difícil la adquisición de conocimientos y la enseñanza de los mismos.

Aguilar (2016) comenta que "la educación es un fenómeno complejo puesto que sus interacciones muestran diversas formas no lineales, y por su carácter multidimensional (social, política, económica, legal) necesita de políticas públicas que tomen en cuenta varios centros explicativos que responden a multiplicidad de factores." (p. 367). El autor reconoce que múltiples estadios de conocimiento influyen en el proceso educativo, pero dichos estadios son regulados externamente, entre otros, por las políticas públicas que rigen al sistema educativo, que son decididas por pocas personas a cargo, lo que conlleva que en muchas ocasiones los objetivos propuestos para la educación no se condigan con las necesidades de la misma. 
Dentro del aula está constantemente puesto en práctica el rol del pensamiento desde sus distintas acepciones y usos. Desde esta experiencia en el aula, Salazar, Funes \& Farzaneh (2018) comentan para el aprender a pensar se requiere llevar a la práctica el proceso, mediante una distendida pero significativa discusión un docente puede apuntar a estos objetivos "Y en este conversar siempre surge el comentario del tipo ¿cuándo vamos a trabajar? o ¿cuándo vamos a hacer algo?” (Salazar, Funes \& Farzaneh, 2018, p. 70) frente a procesos que los estudiantes no consideran corrientes o pertenecientes a un sistema escolar que ya ha sido internalizado, el desarrollo del pensamiento por sobre la memorización parece una pérdida de tiempo.

Estas mismas situaciones sirven al docente como otra instancia para el enseñar a pensar, motivando a los estudiantes a reflexionar sobre su propia construcción del conocimiento "En este sentido nuestra labor es hacerles pensar — ¿de verdad? — ¿Es cierto que solamente aprendemos con un libro de texto, un lápiz y una libreta? Si les dejamos hablar observaremos que estas cuestiones no les son inalcanzables, ni mucho menos" (Salazar, Funes \& Farzaneh, 2018, p. 70), dotando de sentido la actividad sólo que en una línea distinta que podría o no apuntar a un enriquecimiento conceptual como suele acostumbrarse en un espacio escolarizado.

En un primer momento el docente deberá aprender a aprender, para que luego pueda aprender a pensar y sólo desde ahí podrá enseñar a pensar, ya que es un proceso que no sólo viven los estudiantes, sino también el docente, comprendiendo la importancia que el desarrollo del pensamiento tiene y cómo llevarlo a cabo "La verdadera educación no sólo consiste en enseñar a pensar sino también en aprender a pensar sobre lo que se piensa y este momento reflexivo - el que con mayor nitidez marca nuestro salto evolutivo respecto a otras especies - exige constatar nuestra pertenencia a una comunidad de criaturas pensantes." (Savater, 1997, p. 16), el estudiante y el docente deberán encontrar sentido en 
su propio pensamiento al proceso vivido y al espacio que se comparte, sintiéndose parte de una comunidad que permite y apoya el desarrollo del pensamiento.

\subsubsection{La enseñanza de la Filosofía en la educación media chilena}

La presencia de la Filosofía en el área curricular de la educación media en Chile se desarrolla durante los dos últimos años de la etapa escolar. A saber, existen dos Programas de estudios asociados al área filosófica: Psicología, el cual se trabaja en el curso de tercer año medio, y Filosofía, para el curso de cuarto año medio.

La presencia de la Filosofía en el Marco Curricular Nacional chileno ha estado marcada por, al menos, dos instancias de cuestionamiento y debate respecto al carácter que debe tener esta área dentro del currículum nacional. La primera fue durante el proceso de construcción de dicho Marco Curricular durante la reforma de los noventa. En ella hubo una propuesta inicial de Formación General Científico-Humanista que no incluía la asignatura de Filosofia, quedando como asignatura electiva u opcional dentro de la Formación Diferenciada. Sin embargo, en el año 1997 se implementó un proceso de consulta el cual provocó “cambios decisivos en la propuesta” (Chile, Ministerio de Educación, 2004).

De dicha consulta surgió, en 1998, el Decreto 220 que “estableció la Filosofía, la Educación Física, un subsector de Educación Artística y dos de los tres subsectores de Ciencias Naturales como partes de la Formación General obligatoria" (Ministerio de Educación, 2004, p.11). Sin embargo, no se incluyó la asignatura dentro de la formación Técnico Profesional.

Durante el año 2001 tuvo lugar una comisión de expertos, en la que diversos representantes de profesores y del mundo académico solicitaron ante el Ministerio de Educación de Chile aumentar las horas que estaban contempladas en el Marco Curricular Nacional inicialmente. 
Lo expuesto anteriormente intenta sintetizar el conflicto entre el Ministerio y los profesores de Filosofía de Chile, conflicto en el cual existen, además, notables divergencias sobre el rol y el sentido que tendría la Filosofía en el aula chilena surgiendo críticas desde el mundo académico y del profesorado. Por ejemplo, Oyarzún (2006) en el artículo "La Filosofía en la Enseñanza Media”, enfatiza el hecho de que la propuesta ministerial del Programa es insuficiente para lograr aquello que la nueva formulación del currículum se proponía.

Durante el año 2016, con el inicio de la construcción de las nuevas Bases Curriculares para tercer y cuarto año de Enseñanza media, aparece el segundo momento de tensión. La propuesta inicial contemplaba, una vez más, instalar la asignatura como parte del área electiva.

En el año 2018, el Consejo Nacional de Educación (CNED) a cargo de revisar y aprobar la propuesta del Ministerio de Educación respecto de la malla curricular de formación general para tercer y cuarto año medio de la educación media, indicó que "si bien existe consenso en que las asignaturas Filosofía y Ciencias Naturales son necesarias y aportan significativamente al desarrollo del pensamiento crítico, lógico y científico de los estudiantes, no existe acuerdo entre los consejeros acerca de la pertinencia de que formen parte de la formación general común para todos los estudiantes de III y IV medio" (CNED, 2018, p. 3).

En gran mayoría, el profesorado del área rechazo a esta propuesta, y frente a esto las autoridades ministeriales respondieron "Se trabajará Filosofía en Formación Ciudadana, que fue lo que recomendó la Comisión Engel. No es que se vaya a sacar completamente Filosofía como ramo», explicó Alejandra Arratia, coordinadora de la Unidad de Currículum y Evaluaciones del Mineduc (UCE)” (Guzmán, Bustos \& Mardones, 2018). 
Esta disputa dio origen a una nueva propuesta de Bases Curriculares, la cual contempla la asignatura de Filosofía dentro de la formación común, y se incluyen otras tres asignaturas de profundización de la Filosofía: Poder, Conocimiento y Estética. Estas tres tendrían un carácter optativo. Cabe señalar, además, que Filosofía recupera espacios y logra instalarse nuevamente en otras modalidades de Educación Media, además de la Científico Humanista, a saber: Técnico profesional y Educación artística.

En línea con las disputas expuestas anteriormente, Garces (2013) argumenta que "es obvio que la transformación de las instituciones educativas, la reducción de los presupuestos públicos y el desarrollo del mercado, tanto cultural como del conocimiento, son los elementos de una corriente que empuja, con fuerza, en una única dirección: la marginalización de la Filosofía dentro de los programas docentes, las estructuras académicas y los rankings de excelencia universitaria” (2013, p. 29). El autor explica cómo las políticas públicas tienden a apuntar hacia el exilio de la Filosofía de los planes educativos, ya que por su composición esencial no responde al modelo impuesto o no presta utilidad para los fines propuestos.

Finalmente, las nuevas Bases Curriculares para tercer y cuarto año de enseñanza media proponen vincular la asignatura con el desarrollo del pensamiento crítico:

"El sentido de la asignatura de Filosofía en el Plan Común de $3^{\circ}$ y $4^{\circ}$ medio consiste en procurar que las y los estudiantes comprendan e imaginen nuevas formas de lo dado, fortaleciendo así su autonomía a través del desarrollo del pensamiento crítico sobre el estado de las cosas; esto es, revisar, cuestionar e interrogar ideas, nociones, creencias y valores predominantes que subyacen a diversos saberes y prácticas sociales y culturales”. (MINEDUC, 2017, p.31)

Esta declaración explicita la relevancia del desarrollo del pensamiento crítico dentro de los propósitos formativos de la asignatura, no obstante, no implicaría que ésta sea la única 
a cargo de realizar aquella tarea. De hecho, el mismo documento explicita al pensamiento crítico como un conjunto dentro de las "habilidades centrales" que harían posible esta propuesta (Chile, Ministerio de Educación, 2017c). Aquí hay una arquitectura en la que cada asignatura contempla el desarrollo de las habilidades centrales de pensamiento crítico, comunicativas; creativas, de colaboración y participación.

A la fecha de realización de este documento, las bases ya se encuentran aprobadas y a la espera de implementarse el año 2020 para tercer año medio y el 2021 para cuarto año de educación media.

La enseñanza de la Filosofía se vislumbra, entonces, como respuesta a la complejidad y herramienta para el desarrollo de habilidades del pensamiento suele vislumbrarse como un espacio de construcción y colaboración. "Lo que la filosofía como práctica educativa plantea es que educar no es adquirir competencias, transmitir conocimientos ni escolarizar pensamientos. Consiste, fundamentalmente, en un desplazamiento, en un cambio de lugar que renueva el deseo de pensar y el compromiso con la verdad" (Garcés, 2013, p. 35). Esto requiere ser acompañado de un estilo docente en particular que rompa la lógica de reproducción de conocimientos en el aula.

Los planes y programas de Filosofía y Psicología oficiales ofrecen orientaciones didácticas a los docentes para el desarrollo de las asignaturas. En este orden, se sostiene que “el planteamiento de la asignatura debe tener un aspecto teórico, que lleve a la adquisición de un conocimiento preciso de conceptos fundamentales. Debe considerar además un aspecto práctico que posibilite acceder a un nivel de discusión y reflexión desde la experiencia, de tal manera que cada estudiante pueda visualizar los problemas que surgen a partir de los temas en discusión, tomando posición frente a ellos.” (MINEDUC, 2004, p. 13). Por tanto, las asignaturas exigen, entre otros, una base teórica sustentable desde la cual partir la discusión, el uso preciso del lenguaje para evitar ambigüedades o bagajes en la comprensión y la discusión por parte de los estudiantes. 
En la Asignatura Psicología se trabaja en base a cuatro grandes unidades:

1. El ser humano como sujeto de procesos psicológicos

2. El individuo como sujeto de procesos psicosociales

3. Individuo y sexualidad

4. Bienestar biopsicosocial

Por otro lado, en la asignatura Filosofía las líneas de trabajo responden a las siguientes unidades:

1. La filosofía

2. El problema moral

3. Fundamentos de la moral

4. Ética social

\subsection{Propuestas curriculares orientadas al desarrollo del pensamiento complejo y la} metacognición

La integración de estrategias para el desarrollo de habilidades y mejora del pensamiento se materializa en propuestas curriculares tales como: el Programa de Filosofía para Niños de Matthew Lipman en Estados Unidos, el Proyecto “Aprender a pensar” del Instituto Pascal de Madrid y el Proyecto Zero de la Universidad de Harvard. A nivel local, en el Proyecto del pensamiento complejo y los valores humanistas laicos de la Universidad de Concepción de Chile. 


\subsubsection{El Programa de Filosofía para niños de Matthew Lipman: el pensamiento complejo como forma de razonabilidad}

"La filosofía formando parte del currículum aporta un potencial tan grande a la educación que sus consecuencias son ilimitadas" (Lipman, M. 1998).

El trabajo de Lipman se encuentra fuertemente afectado por el trabajo de psicólogos tales como Piaget $(1977,2018)$ y Vygotsky $(1978,2001)$. El primero de estos es de especial importancia en los orígenes del programa Filosofía para Niños, un ejemplo de esto es el hecho de que "El descubrimiento de Harry", uno de los primeros cuentos creados por Lipman, se ajusta al modelo de desarrollo cognitivo propuesto por Piaget. Sin embargo más adelante se abandonara por completo las nociones del desarrollo cognitivo propuesto por el psicólogo Suizo. Debiéndose lo anterior a que Filosofía para niños se caracteriza por ser propuesta completamente contraria a la idea de la existencia de etapas cualitativamente distintas e inamovibles dentro del desarrollo cognitivo humano.

El trabajo de Vygotsky (1978) será, sin embargo, el que más influencia ejerce en el hacer pedagógico de la Filosofía para Niños. El psicólogo insiste en la necesidad de "[...] provocar a los niños con desafios intelectuales para conseguir su crecimiento personal”. (García, F. 2011. P. 25).

Otro de sus valiosos aportes es lo relacionado al constructivismo social; el cual es considerado ampliamente por Lipman y Sharp al momento de sentar las bases metodológicas de la Filosofía para Niños. Según Vigotsky (1978) el conocimiento es un proceso donde interactúan el sujeto y el medio, entendiendo a este último como algo que trasciende a lo físico, identificándose con lo social y lo cultural. Finalmente, Lipman rescata del psicólogo ruso la importancia de la dimensión social en el crecimiento personal, lo que constituye el fundamento de las llamadas comunidades de indagación filosófica. 
El programa de Filosofía para Niños asume el estudio de la Filosofía como un pensar acerca del pensar, en donde se pretende con la metodología de la comunidad indagación el mejoramiento del pensamiento, "a partir de investigar, explorar y cuestionar los procesos que surgen en estas mismas actividades que se generan a partir de las discusiones, preguntas, juicios y razonamientos que los participantes van teniendo.” (Zabala, 2014, p. 61). Está diseñado para niños y jóvenes, entre 6 y 18 años y consta de siete programas y dos tipos de materiales, a saber:

a) El libro de lectura del estudiante constituido por siete novelas filosóficas que tratan de relatos donde los personajes cuentan sus experiencias. Los personajes discuten entre sí sus ideas y opiniones respecto a lo que sucede a su alrededor, siempre con una base conceptual filosófica, por ejemplo: filosofía social y política, metafísica, estética, entre otros.

b) Los manuales para el profesor (siete en total) estructurados en función de los libros de lectura del estudiante, aportando orientaciones didácticas, actividades, propuestas de discusión y evaluación.

El currículum escolar propuesto por Lipman busca ordenar y sistematizar aspectos filosóficos coherentes con el desarrollo cognitivo de los estudiantes. La propuesta apunta a transformar la filosofía en un eje transversal dentro de la enseñanza obligatoria, dado que el pensamiento crítico y creativo impacta al conjunto de las disciplinas curriculares.

La aplicación de este Programa dista de ser simple, antes bien, responde a múltiples factores y relaciones entre éstos para la construcción y el desarrollo del pensamiento, lo cual requiere de un esfuerzo distinto al de memorizar o repetir ideas. En palabras del autor, "mejorar el pensamiento en el aula significa primordialmente mejorar el pensamiento en el lenguaje y ello supone la necesidad de enseñar el razonamiento, tradicionalmente una subdisciplina de la filosofía" (Lipman, 1998, p. 70). 
El razonamiento se concibe como una herramienta esencial para el pensamiento, ayuda a su orden, estructura y expresión, y genera progresos en otras habilidades.

Lipman (1998) considera que los niños están naturalmente predispuestos a la adquisición de las habilidades del razonamiento de la misma forma que adquieren el lenguaje. Entre estas habilidades, en primer lugar, se distinguen las de investigación caracterizadas como una práctica autocorrectiva. Dichas habilidades investigativas se evidencian cuando los niños

"Aprenden a explicar, predecir, identificar causas, medios, fines $\mathrm{y}$ consecuencias, así como a distinguirlos entre sí. Aprenden también a formular problemas, a estimar, valorar y desarrollar las innumerables capacidades asociadas a los procesos de investigación” (Lipman, 1998, p. 86).

En segundo lugar, se reconocen las habilidades del razonamiento relacionadas con la experiencia cotidiana. Para Lipman (1998) los conocimientos se originan en la experiencia, en virtud de las limitaciones de la adquisición de tales conocimientos en el contexto experiencial de los sujetos, una forma de ampliarlo cuando no se recurre a la experiencia es mediante el razonamiento a través del diálogo.

En tercer lugar, las habilidades de información y organización permiten organizar la información (por medio de oraciones, conceptos y esquemas, entre otros), pero también, adquirir formas de expresar los significados de la experiencia por medio de la descripción y la narración. "Las exigencias de una eficiencia cognitiva nos obligan a ser capaces de organizar la información que recibimos en unidades o conjuntos significativos" (Lipman, 1998, p. 87).

Por último, las habilidades de traducción que implica traspasar un contenido de una lengua a otra sin perder significado. Estas habilidades juegan un papel esencial en el proceso de comprensión mutua e intercambios entre los sujetos. 
"El hecho es que las habilidades de traducción capacitan para emprender viajes de ida y vuelta entre diferentes lenguas y ello no es menos importante que el descubrimiento o la construcción de significado en el lenguaje" (Lipman, 1998, p. 92).

Lipman (1988) relaciona el desarrollo de estas habilidades cognitivas con "la sabiduría" que se desprende de la cultura griega antigua, muy cercana a la construcción de juicios. En esta perspectiva, un buen juicio es una determinación que se expresa de distintas maneras en el pensamiento, el habla, la acción o la creatividad. Esta última se presenta como una característica subyacente al pensamiento complejo orientado al contexto. Al respecto, "la Filosofía es un asunto de crear, decir y/o hacer” (Lipman, 2002, p. 342).

Las habilidades cognitivas y los tipos de pensamiento descritos se engloban en noción de pensamiento complejo del Programa de Filosofía para Niños. "El objetivo central del programa de Filosofía para Niños es ayudar a los niños a aprender a pensar por sí mismos” (Lipman, 2002, p. 127).

El propósito del buen pensar es alcanzar la excelencia en el pensamiento, es decir, pensar de la mejor forma posible. Este pensamiento de orden superior lo identificamos como pensamiento complejo, el cual surge de la fusión del pensamiento crítico y el pensamiento creativo. Este pensamiento ideal debe ser racional y crítico por un lado e ingenioso y flexible por el otro. La filosofía con niños trabaja el pensamiento creativo, crítico y ético, con la intención de alcanzar en los estudiantes la excelencia cognitiva, deriva de esto el pensamiento complejo un pensamiento rico conceptualmente.

A partir de la creación del Programa de Lipman surgieron numerosos grupos de trabajo, centros y asociaciones para crear comunidades de indagación en las escuelas, entre los más destacados en España, uno es el Institut de Recerca per 1'Ensenyament de la Filosofia (IREF) de Barcelona y, otro, el Centro de Filosofía para Niños en Madrid. También, la 
fundación Sophia, para el avance de la Filosofía con los Niños, con sede en Amsterdam, representando a países de la comunidad europea.

\subsubsection{Proyecto "Aprender a pensar" del Instituto Pascal}

El Programa "Aprender a Pensar" ha sido elaborado por un equipo de profesores, psicólogos y pedagogos especializados en Educación Primaria. Parte del Proyecto Curricular sobre Estrategias de Aprendizaje (PROCESA-PASCAL), en el que se determina qué estrategias de aprendizaje hay que enseñar en cada nivel educativo y cómo llevarlo a la práctica.

Este programa tiene sus bases en los enfoques cognitivo y socio-cultural. Del enfoque cognitivo asume que los diferentes procesos del aprendizaje pueden ser explicados a través del análisis de los procesos mentales. Supone que por medio de dichos procesos cognitivos el aprendizaje resulta más fácil. Respecto al enfoque socio-cultural, este Programa asume que el aprendizaje es un proceso que se da en la interacción entre el sujeto y su medio social y cultural

“Aprendiendo a pensar” está dirigido a estudiantes de educación primaria, de entre 6 y 11 años aproximadamente. Busca que los niños sean más autónomos y capaces de tomar decisiones, de resolver mejor los problemas de cada día, de pensar por sí mismos y de aplicar todo lo que van aprendiendo.

Las actividades están diseñadas para enseñar al niño a planificar su acción antes de iniciar una actividad, a regular sus pensamientos y decisiones durante su realización y a evaluar no sólo los resultados, sino también la validez del proceso que ha seguido. Por otro lado, se propone desarrollar las habilidades básicas de pensamiento: motivación, observación, concentración, memoria, reflexión, lenguaje y comprensión. 
E1 Programa “Aprendiendo a pensar” combina tres dimensiones básicas del aprendizaje:

a) Las habilidades de pensamiento.

b) Las estrategias de aprendizaje.

c) Los tipos de contenidos escolares (conceptos, procedimientos y actitudes). Estos contenidos se corresponden con los del Documento Curricular Base.

La finalidad del Programa es que los alumnos aprendan a ser Estratégicos en su aprendizaje y sepan qué procedimientos y habilidades necesitan desarrollar para una mejor asimilación de los contenidos de las áreas curriculares, cómo tienen que utilizarlos de forma adecuada para rentabilizar su esfuerzo y cuándo tienen que utilizar unas habilidades y no otras.

En definitiva, enseña al estudiante a utilizar las estrategias de aprendizaje en función de las habilidades de pensamiento que debe desarrollar según su edad, el tipo de contenido que tiene que aprender y sus objetivos de aprendizaje.

El material de trabajo de este Programa está conformado por un conjunto de actividades diseñadas a partir de las tres dimensiones mencionadas anteriormente (habilidades cognitivas, contenidos escolares y estrategias). Por otro lado, este material se complementa con un manual para el profesor, el cual permite diferentes posibilidades para reorganizar las actividades o crear otras.

\subsubsection{Proyecto Zero "Estrategias de aprendizaje y de pensamiento en el aula". Universidad de Harvard}

El Proyecto Zero fue creado en el año 1967 por el filósofo Nelson Goodman en la Harvard Graduate School of Education para estudiar y mejorar la educación en las artes. Goodman creía que el aprendizaje de las artes debería estudiarse como una actividad cognitiva seria, pero descubrió que el conocimiento general comunicable sobre la educación artística era 
cero. Goodman, por lo tanto, le dio al proyecto su nombre "zero", ya que es desde donde comenzó.

Desde sus inicios, el Proyecto adoptó una visión cognitiva de las artes, al considerar que la actividad artística involucra procesos mentales tan poderosos y sutiles como los utilizados en las ciencias o las políticas públicas. Durante este período inicial, se realizaron experimentos sencillos. Los resultados de esta primera fase de trabajo se capturan en un informe final para la Oficina de Educación de los Estados Unidos, preparado por Goodman, Perkins y Gardner, titulado "Habilidades básicas requeridas para la comprensión y la creación en las artes" (1972).

En 1971, Perkins asumió la dirección y en 1972 se unió Gardner. En la década siguiente, los investigadores centraron su atención principalmente en el trabajo empírico en el área de la psicología cognitiva, con un énfasis continuo en cuestiones artísticas. Sin embargo, el Proyecto también comenzó a examinar cuestiones que iban más allá de las artes, para analizar cuestiones como la resolución de problemas, el pensamiento crítico y la organización del cerebro.

Para 1990, la investigación y el desarrollo en Proyecto Zero eran de una naturaleza claramente aplicada, y comenzaron a trabajar con escuelas basadas en inteligencias múltiples; "escuelas inteligentes" que fomentaron el pensamiento creativo y crítico. Una de las líneas de investigación aplicada en la educación más extendida hoy en su uso son las llamadas "Rutinas de Pensamiento" (2008). Se definen como estrategias cognitivas bastante fáciles de seguir en los procesos de enseñanza-aprendizaje, que consisten en preguntas o afirmaciones abiertas que promueven el pensamiento en los estudiantes. Algunos ejemplos:

1. ¿Qué te hace decir eso? (Rutina para Interpretar y Justificar).

2. Pensar-Cuestionar-Explorar (Rutina para Profundizar y Cuestionar). 
3. Pensar-Juntarse-Compartir (Rutina para Razonar y Explicar).

4. Círculos de Puntos de Vista (Rutina para Explorar distintas perspectivas).

5. Solía Pensar - Ahora Pienso (Rutina para Reflexionar sobre ¿Cómo? y ¿Por Qué? nuestro pensamiento ha cambiado).

6. Ver-Pensar-Preguntar (Rutina para Explorar Estímulos Visuales).

A partir de este tipo de estrategias y rutinas de pensamiento se orienta a los docentes a replantearse su trabajo desde la pedagogía para la comprensión.

En el Proyecto Zero se albergan una serie iniciativas en la línea del desarrollo del pensamiento, entre otras:

1. Hacer visible el pensamiento. Cuyo propósito es crear culturas de aprendizajes en las escuelas utilizando la documentación como una herramienta para profundizar y extender el aprendizaje.

2. Culturas de pensamiento. Cuyo objetivo es mejorar el aprendizaje y la colaboración al perfeccionar los procesos de pensamiento grupales e individuales.

3. Enseñar para comprender. Busca el diseño de un currículo y evaluación que fomente una comprensión profunda y duradera para los estudiantes.

4. Aprendiendo a pensar, pensar en aprender. Su objetivo es ayudar a las escuelas a crear culturas de pensamiento y aprendizaje.

5. Pensamiento ingenioso. Su objetivo es experimentar y apreciar el arte como una forma de ayudar a los estudiantes a desarrollar formas de pensar que apoyen el aprendizaje reflexivo.

6. Creando comunidades de investigación. Busca desarrollar una cultura de enseñanza y aprendizaje basada en la investigación.

7. Re imaginando la migración. Busca asegurar que los jóvenes crezcan entendiendo la migración como una condición compartida de nuestro pasado, presente y futuro 
para desarrollar el conocimiento, la empatía y la mentalidad que sustentan comunidades inclusivas y acogedoras.

\subsubsection{Proyecto "Pensamiento complejo y valores humanistas laicos", Universidad de Concepción de Chile}

A nivel local, entre los años 2015 y 2018 la Universidad de Concepción desarrolló el proyecto "Desarrollo del pensamiento complejo y valores humanistas laicos a partir del Programa Filosofía con Niñas, Niños y jóvenes: una experiencia de creación e implementación en la escuela pública", cuyo objetivo es desarrollar el pensamiento creativo, ético y crítico para llevar al niño, a la niña a la razonabilidad.

En el marco de los proyectos de tipo asociativo de la Vicerrectoría de Investigación y Desarrollo, de la Universidad de Concepción, y entre los años 2015 y 2018, se desarrolló el proyecto "Desarrollo del pensamiento complejo y valores humanistas laicos a partir del Programa Filosofía con Niñas, Niños y jóvenes: una experiencia de creación e implementación en la escuela pública", código 216.161.008-1.0, cuyo objetivo fue desarrollar el pensamiento creativo, ético y crítico para llevar al niño o niña a la razonabilidad. "La educación entonces ha de verse como el gran laboratorio de la racionalidad, pero es mucho más realista si la vemos como aquel contexto en el que los jóvenes aprenden a ser razonables para que puedan crecer como ciudadanos razonables, compañeros razonables y padres razonables” (Lipman M., 2002, p. 58).

La búsqueda de la razonabilidad se fue instalando en las salas de clases como comunidades de indagación o investigación filosófica fundadas en la reflexión y el diálogo genuino, comunidades que buscan brindar espacios para generar condiciones y posibilidades para el reconocimiento del otro, entre otras cuestiones. Los especialistas 
sostienen que, en una comunidad de indagación filosófica, el docente es quien dirige el diálogo genuino de los niños hacia la importancia de la convivencia, la tolerancia y el respeto mediante preguntas que se vinculen con la cotidianidad de éstos, "pues es en ella donde están las preguntas" (Freire, 1986, p. 57). De esta manera, la comunidad no sólo abarcaría el desarrollo del pensamiento complejo o multidimensional, sino que entraría a reforzar valores para la vivencia de la ciudadanía.

El proyecto chileno nació a partir de una problemática suscitada en una institución educativa, donde los estudiantes cuyos padres habían optado por la no participación de ellos en las clases de religión, no eran atendidos, lo que implicaba la necesidad de preparar una oferta curricular alternativa. Se planteó entonces la implementación de un programa curricular para desarrollar y potenciar las habilidades del pensamiento y los valores humanistas laicos de estudiantes de quinto a octavo año básico del Liceo República del Brasil de la comuna de Concepción, vale decir niños y niñas entre 10 y 14 años. Se consideró que el desarrollo de dichas habilidades no sólo tiene un impacto positivo en el desarrollo de los procesos cognitivos y en la formación valórica, sino que también impactan en las diferentes asignaturas, dado que el pensamiento y razonabilidad anteceden el aprendizaje significativo.

La implementación de esta propuesta fue recibida como una invitación a romper con los paradigmas de la enseñanza de la filosofía en la escuela, las clases están pensadas de un modo no convencional, donde los estudiantes y el profesor pudieran tener una relación de simetría, es decir, ser coautores del conocimiento en el aula. Lo que representó un nuevo enfoque centrado en pensar el propio pensamiento, lo cual incluyó un componente crítico y metacognitivo.

Para lograr lo anterior se diseñaron sesiones pedagógicas de 90 minutos, en las cuales los estudiantes trabajaron en torno al desarrollo de distintos tipos de pensamientos. Quinto, 
sexto, séptimo y octavo básicos años trabajaron pensamiento creativo, ético, crítico-racional y crítico-razonable respectivamente, todos con un enfoque humanista-laico y con una metodología basada en la reflexión, el diálogo genuino y diversas actividades, lúdicas, creativas, que facilitaban la reflexión, la participación y el diálogo. Se utilizaron múltiples recursos como: noticias, obras de arte, novelas, cortometrajes, canciones, extractos de películas, dinámicas, comics y experimentos científicos. En particular, el juego se utilizó como herramienta para desarrollar la creatividad y la ciencia para abordar el pensamiento racional, todo esto con el fin de fomentar el pensamiento complejo y, como consecuencia, la razonabilidad de los estudiantes.

Los resultados esperados de la propuesta estaban orientados al desarrollo de habilidades de pensamiento, potenciando y fortaleciendo las habilidades de orden superior, esto es recordar, comprender, y aplicar, y analizar, evaluar y crear respectivamente (Bloom \& Andreson 2001). Desde la perspectiva de los valores, estas habilidades se manifiestan en el ejercicio de la libertad del pensamiento, con una actitud crítica y una postura basada en la tolerancia, el respeto y convivencia armónica.

El Cuadro $\mathrm{N}^{\circ} 1$ que se presenta a continuación resume los objetivos que se plantea el "Proyecto" en correspondencia con cada nivel educativo y el tipo de pensamiento a desarrollar: 


\section{Cuadro 1.}

\section{Resumen de objetivos por nivel del Programa "Pensamiento complejo y valores humanistas laicos, Universidad de Concepción.}

Quinto Básico

Pensamiento Creativo
Sexto Básico

Pensamiento Ético
Séptimo Básico

Pensamiento Racional
Octavo Básico

\section{Pensamiento \\ Razonable}

\begin{tabular}{|c|c|c|c|}
\hline $\begin{array}{l}\text { Desarrollar el pensamiento de tipo } \\
\text { creativo con bases en el juego y el } \\
\text { diálogo. } \\
\text { Se persigue que los niños, niñas y } \\
\text { jóvenes utilicen la creatividad } \\
\text { como un método para resolver } \\
\text { problemas de forma original. } \\
\text { Favorecer el desarrollo de la } \\
\text { imaginación y aplicar la reflexión } \\
\text { como instrumento generador de } \\
\text { diálogo y herramienta de pre- } \\
\text { vención de la violencia. }\end{array}$ & $\begin{array}{l}\text { Fomentar el pensamiento ético } \\
\text { en los niños, niñas y jóvenes con } \\
\text { el fin de propiciar la capacidad } \\
\text { de hacer mejores juicios mora- } \\
\text { les. } \\
\text { Para lo anterior se reflexionará } \\
\text { sobre la capacidad humana de } \\
\text { elegir, se busca, por lo tanto, } \\
\text { ensanchar la dimensión moral de } \\
\text { los alumnos y fomentar el actuar } \\
\text { autónomo. }\end{array}$ & $\begin{array}{l}\text { Desarrollar el pensamiento } \\
\text { lógico racional con bases en la } \\
\text { práctica científica. } \\
\text { Niños, niñas y jóvenes aplicarán } \\
\text { las reglas de la lógica en la ex- } \\
\text { periencia científica, con el fin de } \\
\text { razonar sobre la posibilidad de } \\
\text { existencia de múltiples respues- } \\
\text { tas para la solución de un proble- } \\
\text { ma. Así como también sobre el } \\
\text { propio pensamiento, para poder } \\
\text { pensar este mismo de manera } \\
\text { estructurada y clara. }\end{array}$ & $\begin{array}{l}\text { Promover la capacidad de los } \\
\text { estudiantes de pensar por sí mis- } \\
\text { mo, comprendiendo las impli- } \\
\text { cancias de sus acciones. } \\
\text { Los estudiantes reflexionan so- } \\
\text { bre las limitaciones de la racio- } \\
\text { nalidad científica para resolver } \\
\text { temas relacionados con el actuar } \\
\text { humano. Ejercitarán el } \\
\text { pensamiento complejo, para así } \\
\text { lograr evaluar críticamente las } \\
\text { implicancias de sus propias } \\
\text { acciones. }\end{array}$ \\
\hline
\end{tabular}

Fuente: Elaboración propia 
La evaluación de la experiencia, cuyo propósito era conocer el impacto durante el proceso y al final del programa para develar los cambios que han ocurrido en los participantes de la experiencia filosófica con el objetivo de analizarlos e interpretarlos, desde diferentes perspectivas, esto es del propio niño, del apoderado y del profesor de curso y considerando el análisis fenomenográfico de los asuntos estudiados. Lo anterior se llevó a cabo mediante focus groups, cuyo objetivo conocer la percepción de los niños, niñas y jóvenes de 5to a 8vo básico del Colegio Republica del Brasil respecto a su participación en los talleres de filosofía con niños.

Los focus group estuvieron compuestos por preguntas generales planteadas a todos los estudiantes, más preguntas específicas por nivel. El Cuadro 2 ejemplifica las preguntas y el Cuadro 3 presenta los objetivos vinculados a las preguntas, asociados al tipo de pensamiento desarrollado en cada nivel: 


\section{Cuadro 2.}

Preguntas generales y específicas focus group del programa “Desarrollo del pensamiento complejo y valores humanistas laicos”,

\section{Universidad de Concepción.}

\begin{tabular}{|c|c|c|}
\hline Nivel & Preguntas generales & Preguntas específicas \\
\hline $\begin{array}{l}5^{\circ} \text { año } \\
\text { básico }\end{array}$ & $\begin{array}{l}\text { ¿Qué aprendizajes has construido en } \\
\text { los Talleres de Filosofía? } \\
\text { ¿Cuáles son los cambios que has tenido } \\
\text { producto de la participación en el Taller de } \\
\text { Filosofía? } \\
\text { ¿Cuáles son las dificultades que has tenido } \\
\text { en el Taller de Filosofía? } \\
\text { ¿Cómo describirían sus clases de filosofía? } \\
\text { ¿Creen que es importante seguir teniendo } \\
\text { estos talleres?, ¿Por qué? }\end{array}$ & $\begin{array}{l}\text { ¿En el taller de filosofía se les permitió desarrollar su imaginación y } \\
\text { creatividad?, ¿de qué forma? } \\
\text { ¿Consideras importante reflexionar y usar la creatividad para resolver } \\
\text { conflictos? ¿Cómo se resuelven estos conflictos si no reflexionamos ni } \\
\text { usamos la creatividad? }\end{array}$ \\
\hline $\begin{array}{l}6^{\circ} \text { año } \\
\text { básico }\end{array}$ & & $\begin{array}{l}\text { ¿Qué significa actuar o decidir de manera éticamente correcta? } \\
\text { ¿El taller de filosofía les ha entregado herramientas que ayuden a resolver } \\
\text { los conflictos con sus compañeros, amigos o familiares de una manera } \\
\text { diferente?, ¿cuáles? }\end{array}$ \\
\hline $\begin{array}{l}7^{\circ} \text { año } \\
\text { básico }\end{array}$ & & $\begin{array}{l}\text { ¿Qué caracteriza el conocimiento obtenido a partir de la ciencia? } \\
\text { ¿Qué es el pensamiento crítico?, ¿para qué sirve? } \\
\text { ¿Hay más de una manera de resolver un mismo problema?, ¿Cuáles? }\end{array}$ \\
\hline $\begin{array}{l}8^{\circ} \text { año } \\
\text { básico }\end{array}$ & & $\begin{array}{l}\text { ¿Puedes definir lo que es la Razón y cuál es su utilidad en la vida diaria? } \\
\text { ¿Por qué crees que es importante evaluar las consecuencias de una acción? } \\
\text { ¿Qué consecuencias crees que tendría actuar de manera irracional para ti y para } \\
\text { los demás? }\end{array}$ \\
\hline
\end{tabular}

Fuente: Elaboración propia 


\section{Cuadro 3.}

Objetivos a evaluar en cada pregunta específica del focus group del programa "Desarrollo del pensamiento complejo y valores

humanistas laicos”, Universidad de Concepción.

\begin{tabular}{lll}
\hline Nivel & Foco a evaluar & Objetivos \\
\hline $5^{\circ}$ año básico & Pensamiento Creativo & La creatividad como un método para resolver problemas \\
& & La reflexión como instrumento generador de diálogo \\
& La prevención de la violencia. \\
& Pensamiento Ético & La capacidad de realizar juicios morales. \\
$6^{\text {o }}$ año básico & El actuar autónomo. \\
& Pensamiento Racional & Las reglas de la lógica en la experiencia científica \\
$7^{\circ}$ año básico & Las múltiples respuestas para la solución de un problema. \\
& Pensamiento Razonable & Las implicancias de las acciones. \\
& & Las implicancias de las propias acciones. \\
\hline
\end{tabular}

Fuente: Elaboración propia 


\section{CAPÍTULO 3}

\section{DISEÑO METODOLÓGICO}

\subsection{Tipo de investigación}

Esta investigación asumió un enfoque cualitativo de cohorte descriptivo interpretativo sobre el análisis de casos múltiples con variados instrumentos para la recolección de datos. Este tipo de investigación busca especificar las propiedades importantes de personas, grupos, comunidades o cualquier otro fenómeno que se desee someter a análisis (Hernández Sampieri, Collado Fernández, \& Batista, 2003).

Los análisis recogieron aportes desde la etnometodología (Rockwell, 1987, Guber, 2001) para relacionar las perspectivas de significado de los profesores y las acciones áulicas (Erickson, 1989; Hernández et al., 2006). En particular, se nutrieron de contribuciones metodológicas de los estudios del discurso aplicados a la conversación, la producción de textos orales y escritos, los actos de habla, las interacciones y la cognición (Van Dijk, 1999), para el desarrollo y análisis de entrevistas a profesores, observaciones de clase y planes y programas de estudio de Filosofía.

Desde este enfoque se analizaron diversas conceptualizaciones vinculadas al desarrollo del pensamiento complejo y la metacognición en programas oficiales del área filosófica de la educación media, las concepciones de los profesores, como también, las distintas prácticas de enseñanza áulicas. Estos análisis permitieron establecer algunas relaciones sustantivas entre las explicitaciones curriculares, las concepciones y las prácticas del profesorado de Filosofía en la educación media chilena. 


\subsection{Objetivos}

\subsubsection{General.}

Indagar el desarrollo del pensamiento complejo y la metacognición en el área curricular filosófica en Liceos de la Región del Bio Bio, Chile.

\subsubsection{Específicos.}

a) Examinar las orientaciones de los Programas de Estudio del área curricular filosófica para el desarrollo del pensamiento complejo y la metacognición.

b) Identificar las concepciones del pensamiento complejo y la metacognición de los profesores en ejercicio.

c) Caracterizar las prácticas áulicas de enseñanza-aprendizaje para el desarrollo del pensamiento complejo y la metacognición.

d) Analizar críticamente los Programas de Estudio, las concepciones de los profesores en ejercicio y las prácticas y actividades para el desarrollo del pensamiento complejo y la metacognición.

\subsection{Supuestos de partida}

Nuestro estudio parte de tres supuestos:

I. En primer lugar, el desarrollo del pensamiento complejo y la metacognición en el área curricular filosófica de la educación media chilena no se encuentra orgánica y sistemáticamente considerado en el profesorado y en sus prácticas áulicas cotidianas. 
II. En segundo lugar, las argumentaciones de los profesores sobre el pensamiento complejo y la metacognición, en gran mayoría, son retóricas, amplias y/o vagas y no contienen una visión profunda de sus alcances para la formación de los estudiantes.

III. En tercer lugar, las prácticas de la educación filosófica presentan estrategias y actividades fragmentadas y desarticuladas que apuntan a objetivos diversos y en poco grado al desarrollo del pensamiento complejo y la metacognición.

\subsection{Dimensiones de análisis}

En línea con los fundamentos teóricos y los objetivos específicos trazados en esta tesis, la indagación del desarrollo del pensamiento complejo y la metacognición en cursos de Filosofía de la educación media chilena se apoya en la delimitación de 3 (tres) dimensiones de análisis, a saber:

I. Los Programas de Estudio de la educación filosófica media chilena.

II. Las concepciones de los profesores sobre el pensamiento complejo y la meta- cognición en la enseñanza de la Filosofía

III. Las prácticas áulicas para el desarrollo del pensamiento complejo y la metacognición en cursos de enseñanza de la Filosofía. 
Estas dimensiones de análisis responden a las siguientes preguntas:

- ¿Cómo enfocan los Programas de Estudio de la educación media filosófica chilena el desarrollo del pensamiento complejo y la metacognición?

- ¿Qué idea tienen los profesores del área curricular filosófica de la educación media chilena sobre el pensamiento complejo y la metacognición?

- ¿Qué prácticas y actividades áulicas se llevan a cabo para el desarrollo del pensamiento complejo y la metacognición?

Estas cuestiones atienden a una mirada tridimensional del desarrollo del pensamiento complejo y la metacognición en la educación filosófica, que se ilustra en la siguiente figura.

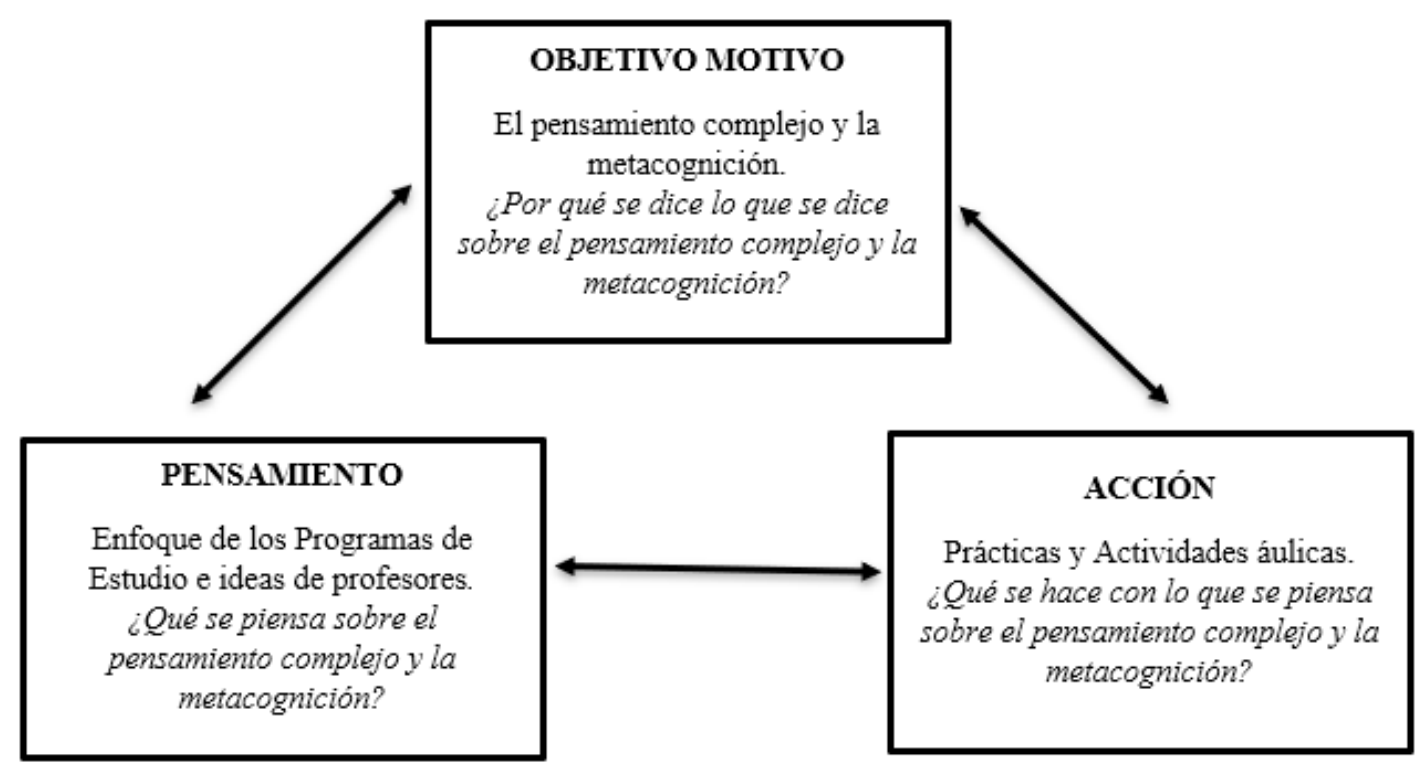

Figura 1 Modelo heurístico para el estudio del pensamiento complejo y la metacognición. Fuente: elaboración propia

En cuanto a la primera cuestión planteada nuestra investigación procuró develar el objeto y los motivos de las orientaciones curriculares y, en especial, del desarrollo de las habilidades del pensamiento complejo (Lipman, 2002), tales como, realizar inferencias 
perceptuales, lógicas y causales, hacer asociaciones y analogías, formular hipótesis, efectuar distinciones significativas, considerar alternativas, buscar razones, explicaciones y supuestos, hacer preguntas. También, para el desarrollo de habilidades metacognitivas que posibilitan aprender sobre el aprendizaje, conocer, revisar y controlar los propios procesos cognitivos, reflexionar sobre las actividades de aprendizaje y conocimiento, entre otras.

Con respecto al pensamiento de los profesores se pusieron en tensión sus concepciones sobre el pensamiento complejo y la metacognición y los significados en torno al objeto y a los motivos de la educación filosófica, como también, las acciones, en términos de prácticas y actividades en las situaciones áulicas donde se produce el discurso de interés para nuestro estudio.

En cuanto a las prácticas educativas nuestra investigación procuró dar cuenta de sus relaciones con el objeto y los motivos de la educación filosófica, como también, las justificaciones en torno a los modos de desarrollo del pensamiento complejo y la metacognición en las aulas para romper la lógica de la reproducción de conocimientos y la escolarización del pensamiento.

\subsection{Casos}

El grupo de casos investigados se conformó por ocho (8) profesores que tienen a su cargo las asignaturas de Filosofía y Psicología del área curricular filosófica de la educación media chilena, en ocho (8) establecimientos de Dependencia Administrativa Municipal representativos de las comunas Concepción, Hualpén, Talcahuano, Coronel San Pedro de la Paz, de la Provincia de Concepción, Chile. 


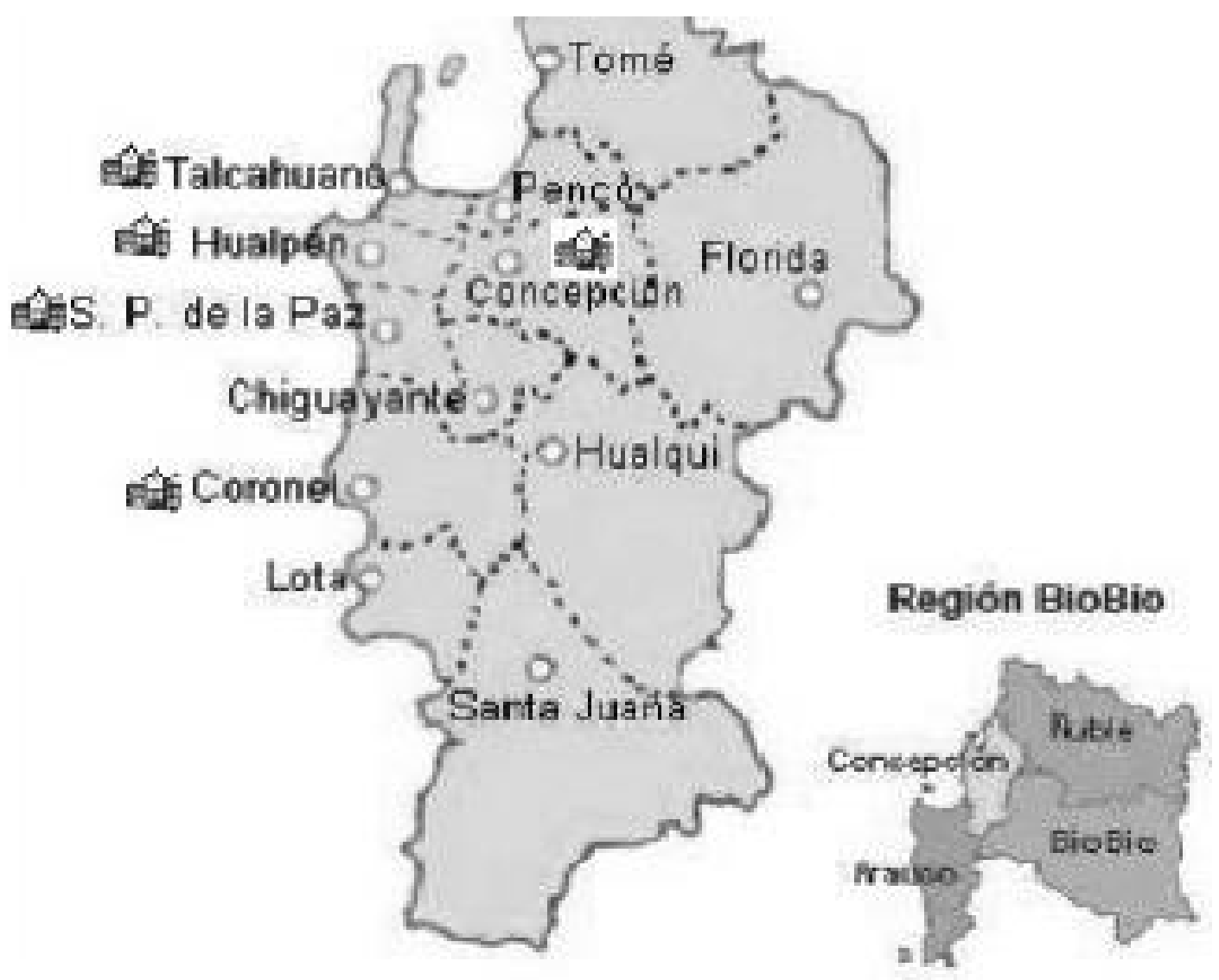

Figura 2. Mapa de las Comunas de la provincia de Concepción, Región del Bio Bio, Chile.

En total, la conformación de los casos incluyó 5 hombres y 3 mujeres. Las edades oscilaron en un rango de 30 años y 47 años, con un promedio de experiencia docente en el dictado de la Asignatura de 10.5 años.

La selección de los casos fue intencionada y se correspondió con la técnica de muestreo no probabilístico, debido a que la selección de los sujetos del estudio tomó en consideración ciertas características y/o criterios, a saber:

a) Los participantes del estudio son profesores de Filosofía que tienen a su cargo el desarrollo de los Programas de Estudio oficiales de formación general en Filosofía y Psicología, en aulas de tercero y cuarto años de la educación media, de establecimientos educativos de distintas comunas de la Provincia de Concepción. 
b) El escenario (o área) del estudio abarcó siete (7) establecimientos educativos de cinco comunas correspondientes a la Octava Región del Bio Bio, a saber:

- Liceo 1, Comuna de Talcahuano

- Liceo 2, Comuna de Concepción

- Liceo 3, Comuna de Hualpén

- Liceo 4, Comuna de San Pedro de La Paz.

- Liceo 5, Comuna de Concepción.

- Liceo 6, Comuna de Coronel.

- Liceo 7, Concepción.

- Liceo 8, Comuna de Concepción. 


\subsubsection{Profesores participantes.}

El Cuadro 4 describe los profesores que participaron del estudio, los Liceos donde desarrollan su actividad para el área de educación filosófica y los respectivos cursos donde fueron observados.

\section{Cuadro 4}

Profesores participantes del área filosófica en establecimientos de la educación media chilena.

\begin{tabular}{llc}
\hline Profesores* & \multicolumn{1}{c}{ Liceos } & Curso \\
\hline Liceo 1, Comuna de Talcahuano & Cuarto año \\
Liceo 2, Comuna de Concepción & Tercer año \\
Liceo 3, Comuna de Hualpén & Tercer año \\
Liceo 4, Comuna de San Pedro de La Paz. & Cuarto año \\
Liceo 5, Comuna de Concepción. & Tercer añow \\
Liceo 6, Comuna de Coronel. & Tercer año \\
Liceo 7, Concepción. & Cuarto año \\
Liceo 8, Comuna de Concepción & Tercer año \\
\hline
\end{tabular}

*A fin de resguardar la confidencialidad de los entrevistados en esta investigación se utilizan seudónimos

Fuente: elaboración propia 


\subsection{Herramientas de recolección de datos}

Las herramientas utilizadas en este estudio fueron: análisis documental de los Programas de Estudio, entrevistas en profundidad, observación de clase y bitácora de campo. El siguiente Cuadro $\mathrm{N}^{0} 5$ presenta las herramientas aplicadas en correspondencia con las dimensiones de análisis del estudio.

\section{Cuadro 5}

Dimensiones de análisis $e$ instrumentos para el estudio del pensamiento complejo y la metacognición en la educación media filosófica.

\begin{tabular}{lll}
\hline \multicolumn{1}{c}{ Dimensiones de análisis } & Instrumentos de indagación & \\
& & Bitácora \\
\hline Los Programas de Estudio de la & Análisis documental. & \\
educación media filosófica chilena. & Entrevistas a profesores. & \\
Las concepciones de los profesores & Entrevistas a profesores. \\
sobre el pensamiento complejo y la & \\
metacognición. & \\
Las prácticas áulicas para el & Observación de clases. \\
desarrollo del pensamiento complejo & \\
y la metacognición. & \\
\hline
\end{tabular}

Fuente: elaboración propia

\subsubsection{Análisis documental de los Programas de Estudio.}

El análisis documental de los Programas de Estudio parte de la consideración de los fundamentos del enfoque crítico propuesto por Van Dijk (2012) para la indagación de problemas sociales y del papel del discurso. Según el autor, este análisis contempla las 
propiedades del entorno de la investigación erudita, tales como, creencias e intereses de sujetos y grupos. Tales propiedades no impiden que la información se recoja de modo sistemático, objetivo, replicable y válido. Esto último resultó de especial cuidado para los propósitos de esta tesis orientados a la indagación del pensamiento complejo y la metacognición en la enseñanza de la Filosofía.

El discurso escrito, como fuente de información, aporta datos importantes para explorar y comprender un fenómeno. "La exploración de un texto depende a menudo tanto de centrarse en lo que se dice $-\mathrm{y}$ en cómo se desarrolla un argumento, idea o concepto específico- como de centrarse en lo que no se dice, los silencios, las pausas o las omisiones" (Rapley, 2014, p. 148), es similar a la comunicación oral, porque esconde, omite o modifica información, hay datos que se encuentran implícitos en el mismo texto y, si bien se lleva a cabo de manera distinta a la transmisión oral, aun así responde a intencionalidades.

Los documentos escritos tienen la "capacidad para albergar un contenido que, leído e interpretado adecuadamente nos abre las puertas al conocimiento de aspectos y fenómenos de la vida social de otro modo inaccesibles.” (Ruiz, 2012, p. 192) son, por lo tanto, una fuente de información que da testimonio de las características del fenómeno a investigar.

Los documentos analizados en esta tesis son planes y programas curriculares para la enseñanza de la Filosofía en la educación media chilena. En estos documentos nuestra investigación consideró las intenciones, los objetivos, los contenidos y las metodologías consignadas por los profesores y estableció relaciones con la información recogida en las entrevistas y observaciones de las situaciones áulicas, que activan los procesos del pensamiento complejo y la metacognición, en especial, los problemas, los tipos de conocimientos, los procesos de pensamiento y reflexiones, el uso del lenguaje, las experiencias sociohistóricas y las prácticas que se desarrollan en las clases. 
En función de lo antes expuesto se propuso indagar en los diversos componentes de los documentos curriculares el grado de presencia de los elementos propios del pensamiento complejo y la metacognición, a saber:

- Fundamentos de la enseñanza de la Filosofía.

- Objetivos

- Aprendizajes esperados.

- Selección y justificación del contenido.

- Actividades, estrategias y recursos didácticos de la enseñanza programados.

- Evaluación.

\subsubsection{Entrevista en profundidad.}

La entrevista en profundidad como técnica de investigación cualitativa se sustenta en un enfoque dialógico que reconoce a las actividades humanas relacionadas al uso del lenguaje, que es siempre flexible y dinámico. Al decir de Batjin (2008) "toda comprensión de un discurso vivo, de un enunciado viviente, tiene un carácter de respuesta (a pesar de que el grado de participación puede ser muy variado); toda comprensión está preñada de respuesta y de una u otra manera la genera: el oyente se convierte en hablante" (p.254).

Este tipo de entrevista puede concebirse como un diálogo con propósito. "Es una técnica de obtener información, mediante una conversación profesional con una o varias personas para un estudio analítico de investigación” (Ruiz, 2012, p. 165), por tanto, implica un proceso comunicativo en el cual los partícipes pueden influirse entre 
sí. El investigador causa un efecto en los entrevistados que participan del estudio, al interactuar con ellos de un modo natural. Tal efecto, no se puede eliminar, pero sí controlar y reducir al mínimo (Malbrán \& Palacios, 2007).

Las entrevistas que se aplicaron en este estudio se nutren de la experiencia metodológica de Pedragosa (2018 a, 2018 b) tendiente a la exploración de las concepciones de los profesores en torno al conocimiento sobre la enseñanza y su construcción. Siguiendo a la autora se concibieron como prácticas conversacionales tendientes a la explicitación y el enriquecimiento del pensamiento expandiendo de este modo las posibilidades epistémicas y metacognitivas que ofrece esta herramienta. Entre las características principales de la aplicación de esta herramienta en nuestro estudio, se destaca:

- Fueron previstas con una secuencia dialógica flexible, que se fue ajustando de acuerdo a las respuestas de los entrevistados, procurando mantener el foco a la vez que la fluidez de la conversación en torno a los tópicos de la indagación.

- Se desarrollaron como una conversación fluida antes que un intercambio formal de preguntas y respuestas, sin interferir en el contenido o emitir valoraciones de ellas, ya que "la entrevista en profundidad, en definitiva, es una técnica para obtener que un individuo transmita oralmente al entrevistador su definición personal de la situación.” (Ruiz, 2012, p. 166).

- La entrevistadora se esforzó por comprender las palabras del entrevistado, controlar sus propias pulsiones y hacer preguntas en el momento justo, sin afectar la perspectiva de sus argumentos.

- Intentaron desencadenar el relato del entrevistado a partir de una pregunta inicial para dejar hablar y luego repreguntar para obtener precisiones sobre determina- dos temas. Dejar hablar al entrevistado, no interrumpir permanentemente, fue una regla básica (Sautu, Boniolo, Dalle \& Elbert, 2005). 
- Se concibieron como una interacción situada, como una práctica social o como un tipo de comunicación que se da en una situación social, cultural, histórica o política. Por tanto, se consideró necesario no sólo tomar en cuenta lo que expresaron los entrevistados en la conversación, sino que también, dónde, porqué y cuando.

La preparación de las entrevistas contempló la elaboración de una guía organizada según las dimensiones de análisis, por tanto, apuntó a la indagación de distintos aspectos de los planes y programas para la enseñanza en cursos de Filosofía de la educación media chilena, las concepciones de los profesores sobre el pensamiento complejo y la metacognición y las prácticas áulicas.

La versión preliminar de la guía de entrevista contó con el juicio experto de algunos colegas y su prueba con profesores de otros liceos. Esta iniciativa posibilitó la realización de ajustes referidos principalmente a las preguntas y su secuencia. También, para la mejor preparación de la investigadora en el posicionamiento del diálogo que se estableció en las entrevistas. Como, por ejemplo, el aprovechamiento de la repregunta para profundizar la reflexión de los profesores sobre las cuestiones que se le presentaron.

En la versión final de la guía se revisó el contenido y el estilo de las preguntas y su organización en torno a las dimensiones de análisis de la investigación, para posibilitar la mayor relación entre ellas y, también, flexibilidad en su presentación según el discurrir del entrevistado. La secuencia de encadenamiento de las preguntas favoreció la conversación y profundización en las argumentaciones de los profesores.

El proceso de construcción de la entrevista abarcó las siguientes fases:

- Elaboración de la guía preliminar de entrevista: formulación de preguntas de acuerdo a las dimensiones de análisis 
- Validación de las preguntas mediante el juicio de expertos.

- Ensayo de la versión preliminar de la entrevista con profesores de otros Liceos.

- Elaboración de la versión final de la guía de entrevista: revisión, ajuste y selección de preguntas de acuerdo a las dimensiones de análisis.

\section{Cuadro 6}

Guía de entrevista a profesores en ejercicio en área filosófica de la educación media

chilena.

Dimensiones de

Preguntas orientativas

análisis

Los Programas de ¿Cuál es el propósito fundamental que tiene la enseñanza de la

Estudio del área

Filosofía en los planes y programas?

curricular filosófica

de la educación

¿Cómo aborda los distintos componentes curriculares en la enseñanza

media chilena. de la Filosofía?

¿Qué aspectos de los planes y programas abona el desarrollo del pensamiento de los estudiantes en la enseñanza de la Filosofía?

Las concepciones de ¿Qué es el pensamiento complejo y la metacognición?

los profesores sobre

el pensamiento

complejo y la

metacognición en la

enseñanza de la

Filosofía.

¿Qué habilidades, capacidades y disposiciones pone en juego el pensamiento complejo y la metacognición?

¿Qué estrategias, actividades y recursos didácticos de la enseñanza favorecen el desarrollo del pensamiento complejo y la metacognición?

Las prácticas áulicas

¿Qué tipo de conocimientos, problemas, razonamiento y niveles de para el desarrollo del discusión y reflexión se plantean en sus clases de Filosofía?

pensamiento

complejo y la

metacognición en la

enseñanza de la

Filosofía

¿Qué tipos de actividades y/o estrategias de enseñanza utiliza para el desarrollo de sus clases?

¿Cuáles son las formas de interacción, cooperación y participación en sus clases?

¿De qué formas se usa el lenguaje en sus clases?

¿Qué materiales y recursos didácticos usa en clases?

Fuente: elaboración propia 


\subsubsection{Observación de clase.}

La observación es "el proceso de contemplar sistemática y detenidamente cómo se desarrolla la vida social, sin manipularla ni modificarla, tal cual ella discurre por sí misma.” (Ruiz, p. 125). En atención a ello en esta investigación se consideró necesaria la planificación de los distintos momentos de observación de clase, la atención a la diversidad de actores, la información a dichos actores del objetivo de la observación, como también, los controles de veracidad, objetividad, fiabilidad y precisión de lo observado a partir del juicio de expertos (profesores de educación media y especialistas en el tema).

La observación de clases realizada tuvo como finalidad indagar las prácticas áulicas de los docentes para el desarrollo del pensamiento complejo y la metacognición como fuente de constatación de los elementos aportados durante las entrevistas. Los registros resultaron de utilidad para establecer relaciones entre los enfoques de los Programas de Estudio, las concepciones de los profesores y de las prácticas áulicas.

Se aclaró a los docentes que el propósito de la observación no era juzgar sus actividades de enseñanza a través de un análisis externo. La finalidad del registro era producir un texto de las acciones de la clase orientadas al desarrollo del pensamiento complejo y la metacognición.

El registro de las observaciones se realizó de modo abierto. En las notas de campo se recogieron todos los acontecimientos de las clases con foco en las acciones de los profesores tales como actividades, recursos, usos del lenguaje, formas de cooperación, participación e interacción. Para el registro de la observación se utilizó la grabación de audio, la cual fue transcrita a fin de facilitar a la investigadora la identificación de elementos indagados y su respectivo análisis. 
Un aspecto relevante de la observación residió en que otorgó la posibilidad de presenciar la actuación "in situ", lo cual dotó de mayor densidad a las cuestiones que se preguntaron sobre la enseñanza de la Filosofía, el desarrollo del pensamiento complejo y la metacognición, a la luz de los aspectos situacionales y áulicos que surgieron.

Por otra parte, la observación de clases consideró la dinámica de las interacciones verbales. Siguiendo a Cazden (1991), la observación procuró identificar las prácticas discursivas en el aula y sus variaciones que visibilizan los cambios operados en los procesos de pensamiento de los estudiantes y de los docentes, aunque en menor medida.

Los actos de habla adquirieron sentido en función de los contextos comunicativos. Así, la observación permitió indagar esos contextos para la valoración de dichos actos, en palabras de Van Dijk (2007, p. 60) "un acto de habla debe evaluarse con respecto a un contexto (pragmático)". De este modo, las interacciones que se dieron en cada aula respondieron a las características específicas del contexto, por tanto, fue necesario analizarlas según sus propias condiciones que validan la comunicación.

La observación de clase procuró dar cuenta de las múltiples interacciones, hechos, acciones o situaciones que promueven el desarrollo complejo y la metacognición. "E1 propósito de la observación sistemática en el aula es proporcionar una descripción precisa de una selección de características de las actividades y de las interacciones dentro de la misma" (Croll, 1986, p. 20).

Los aspectos observados se focalizaron en las unidades de análisis proyectadas y procuraron recoger información sustantiva para otorgar sentidos a estas unidades (Cuadro 7). Por otra parte, se nutrieron de un estudio previo de la autora sobre el desarrollo del pensamiento complejo y los valores humanistas laicos en una escuela pública, que abarcó 103 estudiantes de entre 10 y 13 años, cursantes de quinto y octavo 
año de Enseñanza General Básica del Liceo República del Brasil de la comuna de Concepción, Región del Biobío (Vallejos \& Coll, 2017). La metodología del estudio se basó en la implementación de una propuesta curricular para las clases áulicas tendiente el desarrollo de distintos tipos de habilidades mediante el uso de múltiples recursos didácticos como experimentos, presentaciones, dramatizaciones, exposiciones, juegos, dinámicas grupa- les y acertijos, entre otros.

\section{Cuadro 7.}

Las prácticas áulicas para el desarrollo del pensamiento complejo y la meta-cognición en cursos de enseñanza de la Filosofía.

\begin{tabular}{ll}
\hline \multicolumn{1}{c}{ Instrumento } & \multicolumn{1}{c}{ Preguntas orientativas } \\
\hline Observación de clases & $\begin{array}{l}\text { ¿Qué tipo de conocimientos, problemas, razonamiento y } \\
\text { niveles de discusión y reflexión se plantean en las } \\
\text { actividades de la clase de Filosofía? }\end{array}$ \\
& $\begin{array}{l}\text { ¿Qué tipos de actividades y/o estrategias de enseñan- za se } \\
\text { utilizan en el desarrollo de las clases de Filoso- fía? }\end{array}$ \\
& $\begin{array}{l}\text { ¿Cuáles son las formas de interacción, cooperación y } \\
\text { participación presentes en las clases de Filosofía? }\end{array}$ \\
& $\begin{array}{l}\text { ¿Qué uso se da al lenguaje, los materiales y los recur- sos } \\
\text { didácticos en las clases de Filosofía? }\end{array}$
\end{tabular}

Fuente: elaboración propia 


\section{Cuadro 8.}

Guía de observación de las prácticas y actividades áulicas para el desarrollo del pensamiento complejo y la metacognición.

Tema principal de la clase.

Planteamiento de los objetivos de la clase.

Enfoque de la enseñanza de la Filosofía en la clase áulica.

- Habilidades, capacidades y disposiciones que ponen en juego las actividades de la clase.

- Conocimientos y problemas planteados.

- Estrategia de enseñanza: actividades de inicio, desarrollo y cierre de la clase.

- Usos del lenguaje: preguntas que ayudan a la discusión, debate y/o reflexión

- $\quad$ sobre el tema y a la metacognición.

- Carácter de las interacciones y participación en la clase: atmósfera horizontal (cooperación, colaboración y participación en el grupo) o vertical de trabajo en la clase.

- Materiales y recursos didácticos.

Fuente: elaboración propia

\subsubsection{Bitácora de Campo.}

Los registros del proceso de investigación deben realizarse de manera pronta y ordenada, resulta conveniente tomar fotografías, elaborar mapas, diagramas sobre el contexto, de acuerdo con las distintas fuentes informativas que se perciban en el proceso de observación.

Las bitácoras de campo (Hernández et al. 2003) se componen por la descripción de aquello que se percibe directamente, comentarios interpretativos sobre los hechos, 
anotaciones temáticas relacionadas a ciertos tópicos como hipótesis, categorías, ideas, conclusiones, anotaciones personales referentes a sensaciones o emociones del investigador, anotaciones respecto a la reactividad de los participantes y aspectos del desarrollo de la investigación.

Este recurso investigativo ayuda a compilar la mayor cantidad de información posible de manera fidedigna recogiendo aquellas percepciones desde la perspectiva del investigador que complementa los otros métodos de recolección de información y permiten alcanzar una mejor comprensión del panorama completo de la situación en un movimiento de objetivación de la interpretación del investigador.

En nuestro estudio, la bitácora de campo se utilizó a lo largo de toda la investigación con especial énfasis en las observaciones de clases. La bitácora de campo contiene las siguientes temáticas: conceptos, enfoques, práctica, que son a su vez identificados en el terreno de trabajo del investigador: las clases de Filosofía.

\subsection{Interpretación de la información}

\subsubsection{Análisis de la información.}

La investigación tomó una visión tridimensional del análisis que integra al mismo tiempo el texto documental de los Programas de Estudio, las argumentaciones de los profesores y las prácticas áulicas, enmarcadas en un tiempo y un espacio sociocultural determinados.

El análisis discursivo abarcó lo escrito consignado en el diseño curricular de los Programas de Estudio y las declaraciones orales sobre el pensamiento complejo y la meta- cognición de los profesores. También, aquellos discursos que operaron en las 
interacciones de prácticas áulicas en el área curricular filosófica. Estos últimos, entendidos como discursos de la acción que se desarrollan en contextos sociales, como el de las aulas y constituyen una base empírica observable en los enunciados que circulan (Ricour, 1981, Austin, 1962).

En el proceso de análisis de la información se asumió que el discurso no puede ser reducido a un simple instrumento de comunicación o expresión de un saber sino a un medio de producción de conocimiento. Si bien, las palabras y los enunciados portan significado, éste no se encuentra sólo en el conjunto de palabras y enunciados expresados en los textos orales o escritos (Van Dijk 1999).

En atención a ello, las concepciones y prácticas discursivas que se analizaron en esta tesis procuraron revelar los significados en torno al desarrollo del pensamiento complejo y la metacognición en la educación filosófica. El análisis de los discursos de los profesores dio cuenta de distintas realidades cognitivas (Montañés Serrano, 2001a) y sociales. "Lo que los humanos dicen y hacen es derivado de cómo interpretan su mundo social" (Ruiz 2012, p. 15),

En los enunciados analizados no sólo se consideró la información explícita, sino también la implícita, cuya interpretación aportó un recurso valioso para la investigación. Siguiendo a Montañés Serrano (2001) en las interpretaciones se prestó atención a las condiciones contextuales de producción de los significados.

El análisis de los Programas de Estudio se focalizó en sus aportes al desarrollo del pensamiento complejo y la metacognición. Es decir, en la forma en que se vislumbra a la enseñanza en el área curricular filosófica como una herramienta para el desarrollo de los procesos superiores del pensamiento (Garcés 2013). En particular, en el papel que se otorga al conocimiento y la práctica filosófica para el desarrollo de la razonabilidad (Lipman, 1998), la construcción y expresión del pensamiento, las habilidades investigativas, de información y organización, de traducción vinculadas con el pensamiento creativo, ético, crítico racional y crítico razonable, entre otros. 
En cuanto a las concepciones de los profesores se analizaron las ideas o supuestos con que ellos sustentan sus prácticas para el desarrollo curricular de los Programas de Estudio de la educación media filosófica chilena. También, el reconocimiento y la importancia que asignan al desarrollo de habilidades, capacidades y disposiciones cognitivas y metacognitivas propias del pensamiento complejo y la metacognición.

En referencia a las prácticas áulicas se focalizaron las formas de interacción y cooperación, los problemas que se abordan en las clases, los tipos de razonamiento, los niveles de discusión y reflexión, las formas de participación, los usos del lenguaje, las rutinas o mecanización de formas de trabajo, entre otros aspectos, que facilitan el des- pliegue de los procesos del pensamiento complejo y la metacognición.

\subsubsection{Categorías de análisis.}

El Cuadro $\mathrm{N}^{\circ} 9$ enuncia los tipos de pensamiento desarrollados en el Capítulo 1 que constituyeron las categorías de análisis con las cuáles se abordaron las tres dimensiones del estudio (programas, concepciones de los profesores y prácticas áulicas). También, se presentan los indicios a través de los cuales se identificó la presencia de cada tipo de pensamiento. 


\section{Cuadro 9}

Categorías de análisis e indicios para el estudio del pensamiento complejo y la metacognición en la educación media filosófica.

\begin{tabular}{|c|c|}
\hline Categorías de análisis & Indicios \\
\hline Pensamiento creativo & $\begin{array}{l}\text { Hacer preguntas. Dar razones. Construir Explicaciones. Encontrar } \\
\text { ejemplos y contraejemplos. Explorar Alternativas y soluciones. }\end{array}$ \\
\hline Pensamiento ético & $\begin{array}{l}\text { Escuchar a otros. Distinguir razones adecuadas e inadecuadas. } \\
\text { Esforzarse en busca de la consistencia de los argumentos. Formular } \\
\text { juicios de valor. Comprometerse con el valor de la verdad y de la } \\
\text { indagación. }\end{array}$ \\
\hline $\begin{array}{l}\text { Pensamiento crítico- } \\
\text { racional }\end{array}$ & $\begin{array}{l}\text { Entender relaciones: parte/todo, medios/fines, causa/efecto/ etc. } \\
\text { Buscar evidencias y probabilidades. Detectar falacias. Generar y } \\
\text { comprobar hipótesis. Reconocer contradicciones. Ser metódico en los } \\
\text { procedimientos de indagación. }\end{array}$ \\
\hline $\begin{array}{l}\text { Pensamiento crítico- } \\
\text { razonable }\end{array}$ & $\begin{array}{l}\text { Identificar, cuestionar y justificar supuestos. } \\
\text { Formular y usar criterios. } \\
\text { Definir y analizar conceptos. } \\
\text { Analizar, predecir y explorar consecuencias. } \\
\text { Entender la importancia de ser razonable. Respetar a las personas y } \\
\text { sus puntos de vista. }\end{array}$ \\
\hline $\begin{array}{l}\text { Pensamiento } \\
\text { metacognitivo }\end{array}$ & $\begin{array}{l}\text { Reconocer las propias fortalezas y debilidades para razonar, conocer, } \\
\text { pensar. Autorregular la actuación al resolver una tarea. } \\
\text { Reconocer la propia comprensión y reflexionar sobre ella. Tomar } \\
\text { conciencia de las propias estrategias de pensamiento. Revisar las } \\
\text { propias ideas y argumentaciones. } \\
\text { Corregir el propio pensamiento. } \\
\text { Adecuar las estrategias de pensamiento a partir de la reflexión } \\
\text { independiente. } \\
\text { Autoevaluar el pensamiento y la actuación. }\end{array}$ \\
\hline
\end{tabular}

Fuente: elaboración propia 


\subsection{Proceso de análisis de los datos}

El análisis de los datos se llevó adelante a partir de las categorías señaladas tomando el material simbólico proveniente tanto de los Programas como de las entrevistas y observaciones de clases. Luego de realizada la categorización se identificaron núcleos de problematización en torno a estas categorías que dieron origen a los análisis presentados en los siguientes capítulos, como así también a las relaciones que se podían establecer entre las diversas dimensiones a la luz de dichas categorías.

El trabajo inicial de codificación de las citas nos permitió construir conglomerados de significados que fueron dando lugar a la elaboración del análisis interpretativo.

\subsubsection{Análisis de contenido de los Programas de Estudio.}

El análisis de contenido de los Programas de estudio del área curricular filosófica de la educación media chilena consistió en una exploración a partir de las categorías delimitadas conceptualmente en la investigación relacionadas con el pensamiento complejo y la metacognición. El procedimiento abarcó dos niveles: una de análisis textual propiamente dicho y, otra, de validación mediante el juicio experto de Profesores de Filosofía.

\section{Primer nivel de análisis}

En este primer nivel, el proceso de codificación se realizó mediante el etiquetamiento y la desagregación de pasajes textuales de los Programas de Estudio, que dan cuenta de conocimientos, concepciones, habilidades y acciones relativas a la enseñanza de la 
Filosofía, bajo la forma de frases, oraciones y otros segmentos discursivos de los documentos. La dinámica de este proceso fue circular y flexible (Ruiz, 2012) y tomó en consideración las reglas del procesamiento del modelo de construcción - integración del discurso propuesto por Kintsch \& Van Dijk (1996). De acuerdo a estas reglas se suprimió información que no resultó necesaria para interpretar lo que sigue en el texto, se seleccionó la información relevante dentro del sentido global del discurso y se generalizaron los aspectos comunes encontrados en algunos enunciados. A continuación, se exponen algunos ejemplos.

- La expresión "Pensar, monitorear y evaluar el propio aprendizaje", se redujo a "Evaluar el propio aprendizaje”, puesto que se consideró que el término evaluar engloba pensar y monitorear".

- La expresión "Reconocen en la relación de pareja la vivencia de valores" se redujo a "Reconocen valores en la relación de pareja".

- El objetivo "Desarrollar habilidades de investigación y comunicación en base a variadas temáticas de interés", se redujo a "Desarrollar habilidades de investigación y comunicación".

- El aprendizaje esperado “Observan y reconocen en sí mismos y en otras personas la manifestación de los procesos estudiados y aplican en forma inicial pero adecuada los conceptos y distinciones fundamentales sobre percepción, memoria, lenguaje, pensamiento, aprendizaje e inteligencia" se redujo a "Observan, reconocen y aplican los conceptos y distinciones sobre percepción, memoria, lenguaje, pensamiento, aprendizaje e inteligencia”. 
- Los objetivos "Entender al ser humano como un sujeto que piensa, aprende, percibe, siente, actúa e interactúa con otros" y "Entender al ser humano como sujeto de procesos de comunicación y significación, comprendiendo la complejidad de la interacción humana en contextos interaccionales inmediatos" se redujo y generalizó en "entender al ser humano como sujeto de procesos de comunicación y significación, comprendiendo la complejidad de la interacción humana”.

- Los aprendizajes esperados "identifican valores y actitudes que se asocian con la sexualidad responsable en la adolescencia" y "desarrollan capacidades que les orientan hacia una toma de decisiones responsables en relación a la propia sexualidad" se redujeron a la expresión "identifican valores y actitudes de una sexualidad responsable orientados a la toma de decisiones responsable”.

Segundo nivel de análisis: validación mediante juicio experto

Los resultados del proceso de codificación de la información analizada en los Programas fueron validados mediante el juicio experto de profesores de Filosofía que se desempeñan en el nivel universitario y medio, quienes se pronunciaron la claridad de la reducción e integración de los enunciados y sobre la pertinencia de los pasajes seleccionados, de acuerdo a los tipos de pensamiento indagados en la investigación. A continuación, se exponen algunas de las observaciones de los profesores.

- El contenido de cuarto año "Métodos de reflexión filosófica" no necesariamente es creativo, depende de la conducción y las actividades propuestas por el docente en torno a este contenido.

- El objetivo "Usar formas de expresar ideas" parece muy ambiguo y no necesariamente es creativo ya que podría reutilizar formas ya creadas. 
- El objetivo "Desarrollar la iniciativa y creatividad en el trabajo" no está necesariamente relacionado a la creatividad ya que alguien que trabaja de manera mecánica también puede tener iniciativa.

- En la evaluación "Reconocer en un personaje literario la inteligencia", el verbo reconocer no apunta a procesos de creatividad necesariamente, puede responder más bien a simple aplicación.

Para finalizar, la información analizada fue organizada en configuraciones que permitieron cotejar las informaciones relevadas en los Programas de Estudio, en las situaciones de entrevista a los profesores y en las observaciones de clases, en función de los interrogantes planteados en la investigación, para extraer significados representativos de las voces, sentidos, realidades y circunstancias inherentes a la enseñanza de la disciplina filosófica en el contexto sociohistórico actual. 


\section{CAPÍTULO 4}

\section{LOS PROGRAMAS DE ESTUDIO DE LA EDUCACIÓN FILOSÓFICA}

\section{MEDIA CHILENA}

No piensan de modo constructivo, flexible y creativo; Experimentan dificultades cuando tratan de encontrar razones que sustenten sus opiniones, o para examinar con ojo crítico sus propios puntos de vista o los de los otros; No aceptan de buen agrado el cuestionamiento y los desafíos a sus opiniones; No logran distinguir entre conocimientos y creencias - $\mathrm{O}$ al menos entre creen- cia bien fundada y mera opinión. Divagan sin buenas razones en discusiones y ensayos (Splitter,1996)

En este capítulo se exponen los resultados del análisis de los Programas del área curricular filosófica de la educación media chilena. La presentación se ordena de acuerdo a las categorías propuestas en la investigación, que se corresponden con los tipos de pensamiento creativo, ético, crítico- racional, crítico razonable y metacognitivo.

En primer lugar, se caracteriza la explicitación de objetivos, contenidos, aprendizajes espera- dos y evaluación en los Planes y Programas correspondientes al tercer y cuarto años.

En segundo lugar, se considera la presencia de los elementos propios e indicios de cada tipo de pensamiento en concordancia con lo trazado en la metodología de estudio.

Finalmente, se coteja la información analizada sobre los tipos de pensamiento abordados en los Planes y Programas con la opinión de los profesores entrevistados. 


\subsection{Caracterización de los Programas de Estudio}

\subsubsection{Objetivos}

Los Programas de estudio de la educación media para el área de Filosofía abarcan la enseñanza de fundamentos psicológicos en el tercer año y filosóficos, en el cuarto año medio. Se organizan a partir de la formulación de dos tipos de objetivos. Por una parte, los objetivos fundamentales transversales (OFT) definidos como aquellos que "definen finalidades generales de la educación referidas al desarrollo personal y la formación ética e intelectual de los estudiantes. Su realización trasciende a un sector o subsector específico del currículum y tiene lugar en múltiples ámbitos o dimensiones de la experiencia educativa, que son responsabilidad del conjunto de la institución escolar" (Mineduc, 2001, p.13).

Las dimensiones señaladas se desprenden del marco curricular nacional y corresponden a una explicitación ordenada de los propósitos formativos de la Educación Media en cuatro ámbitos: crecimiento y autoafirmación personal (conocimiento de sí mismo, autoestima, interés y capacidad de conocer la realidad, utilizar el conocimiento y seleccionar información relevan- te), desarrollo del pensamiento (investigación, comunicación, resolución de problemas, análisis, interpretación y síntesis de información y conocimiento), formación ética (respetar y valorar las ideas y creencias distintas de las propias en los espacios escolares, familiares, comunitarios, reconocer el diálogo como fuente permanente de humanización, superación de diferencias y acercamiento a la verdad), y persona y entorno (valorar la vida en sociedad como un elemento esencial del crecimiento de la persona).

Por otra parte, los objetivos fundamentales (OF) definidos como aquellos que se dirigen específicamente al logro de competencias en determinados dominios del saber y del desarrollo personal. Entre otros, entender al ser humano como un sujeto que piensa, aprende, percibe, siente, actúa e interactúa con otros, evaluar visiones alternativas sobre los fundamentos de la moral y valorar la importancia de las normas morales para el desarrollo espiritual. 


\subsubsection{Contenidos.}

Los Programas para tercero y cuarto año medio del área curricular filosófica introducen a los estudiantes a conceptos, problemas, temas, autores y corrientes de pensamiento, así como a habilidades cognitivas superiores que permiten reflexionar de manera fundada y documentada acerca de la condición humana, su sentido y las maneras en las cuales los individuos se relacionan unos con otros.

De acuerdo al Marco Curricular Nacional de Enseñanza Media de la Educación Chilena los estudiantes en tercer año se introducen por primera vez al campo de la Psicología para adquirir algunos conocimientos y habilidades de base que sirvan para la mejor comprensión de sí mismos y de sus relaciones con los demás. En esta línea, los contenidos distinguen distintos factores involucrados en la conformación de su propia identidad y de la interacción con otros, así como algunas claves asociadas a los procesos de autocuidado y crecimiento personal desde una perspectiva psico-social. Se busca desarrollar la autocomprensión y el entendimiento del comportamiento humano a través de la reflexión explícita sobre la experiencia moral y la formación del juicio práctico y la autodeterminación. Esto último se profundiza en el programa de cuarto año medio de Filosofía.

Los contenidos psicológicos del tercer año se organizan en cuatro unidades, a saber:

- El ser humano como sujeto de procesos psicológicos, tanto cognitivos como afectivos.

- El individuo como sujeto de procesos psicosociales y miembro de categorías sociales, en las cuales la comunicación adquiere un papel fundamental. 
- El individuo y la sexualidad. Esta unidad se, organiza en torno a tres temas: sexualidad, identidad y género, elección de pareja y sexualidad adolescente responsable.

- El bienestar biopsicosocial, cuyo propósito principal es desarrollar e implementar estrategias de prevención y autocuidado frente a problemas psicosociales frecuentes en la adolescencia.

El Programa de estudio de cuarto año medio fundamenta la selección de contenidos en una meta ambiciosa y múltiple, por un lado, ofrecer experiencias filosóficas genuinas y documentadas, por otro, conocer algunas de las preguntas de la Filosofía a lo largo de su historia, cuyas respuestas aluden al sentido de la vida humana y desarrollan las capacidades de reflexionar, tanto de manera oral como por escrito.

Uno de los propósitos de este Programa es el desarrollo de habilidades analíticas, argumentativas e interpretativas, así como la toma de posiciones fundamentadas, coherentes y comprometidas, a través de procesos de interpretación y aplicación a la propia experiencia de los estudiantes en su contexto social y cultural. Para apoyar este logro, los contenidos se organizan, en primer lugar, en torno a una introducción a los problemas planteados por la Filosofía contrastando sus preguntas con las preguntas empíricas y formales y también, en la adquisición del vocabulario básico filosófico. En segundo lugar, se abordan aspectos del pensamiento práctico, distinguiendo la opinión de la reflexión filosófica. En este marco los temas de la ética asumen una perspectiva propiamente filosófica.

El Cuadro $\mathrm{N}^{\mathrm{o}} 10$ expone las unidades y contenidos de los Programas de estudio del área filosófica en los tercer y cuarto años de la educación media. 


\section{Cuadro 10.}

\section{Los Programas de estudio del área filosófica de la educación media chilena.}

\begin{tabular}{|c|c|c|c|}
\hline Programa & Año & Unidad & Contenidos \\
\hline \multirow[t]{6}{*}{ Psicología } & $3^{\circ}$ & $\begin{array}{l}\text { El ser humano como sujeto } \\
\text { de procesos psicológicos }\end{array}$ & $\begin{array}{l}\text { Visión integradora de los procesos psicológicos. Procesos cognitivos: percepción, memoria, } \\
\text { lenguaje, pensamiento, inteligencia, aprendizaje. } \\
\text { Emociones y vínculos afectivos. }\end{array}$ \\
\hline & & El individuo como sujeto & Socialización e individuación. Procesos de influencia social. \\
\hline & & de procesos psicosociales & Identidad personal y el otro. Relaciones interpersonales y comunicación. \\
\hline & & Individuo y sexualidad & Sexualidad desde la perspectiva psicológica: sexualidad identidad y género. \\
\hline & & & Sexualidad y cultura: - relación de pareja; sexualidad responsable \\
\hline & & Bienestar biopsicosocial & $\begin{array}{l}\text { Salud mental como bienestar psicológico. Lo normal y lo anormal: concepto de crisis normativa. Lo } \\
\text { psicopatológico en el ser humano y el concepto de resiliencia. Sociedad contemporánea y salud mental: } \\
\text { problemas Psicosociales frecuentes en la adolescencia. }\end{array}$ \\
\hline
\end{tabular}

Fuente: elaboración propia 


\begin{tabular}{|c|c|c|c|}
\hline Programa & Año & Unidad & Contenidos \\
\hline \multirow[t]{19}{*}{ Filosofía } & $4^{\mathrm{o}}$ & La Filosofía & Los ámbitos empírico, formal y filosófico. La filosofia como una reflexión sobre preguntas \\
\hline & & & que afectan el sentido de la vida humana. El problema metafísico en Platón y Aristóteles. El \\
\hline & & & problema epistemológico en Locke y Descartes. \\
\hline & & & Los métodos de la reflexión filosófica: el diálogo, el análisis de conceptos, la búsqueda de \\
\hline & & & supuestos, la formulación de situaciones ficticias, desarrollo y crítica de argumentos \\
\hline & & & El Mundo Moral: acciones, prácticas y costumbres. La Moral: los sistemas morales \\
\hline & & El problema Moral & normativos. El Bien. La Ética: los sistemas filosóficos como reflexión acerca de la Moral. \\
\hline & & & Identificación de problemas morales en la experiencia cotidiana del alumno. Distinción entre \\
\hline & & & normas cultura- les y normas morales. Relación entre Moral y sentimientos. La Regla de Oro. \\
\hline & & Fundamentos de la Moral & Algunos conceptos morales básicos: El bien, la virtud. La felicidad. Los valores: \\
\hline & & & Polaridad y jerarquía. Libertad y responsabilidad como condiciones necesarias para toda \\
\hline & & & moral. El compromiso. Morales autónomas y morales heterónomas. \\
\hline & & & Fundamentos de la moral: naturaleza humana, deber, amor, utilidad, \\
\hline & & & contrato. Universalismo, relativismo y pluralismo \\
\hline & & Ética Social & Instituciones sociales y conciencia moral. Poder y sociedad. Democracia y estado de \\
\hline & & & derecho. La doctrina de los derechos humanos. La participación ciudadana. El concepto \\
\hline & & & de justicia. La justicia distributiva. Justicia e igualdad. Justicia y sanción penal. \\
\hline & & & Problemas de ética social contemporánea: bioética, ética y medio ambiente, ética y \\
\hline & & & técnica. \\
\hline
\end{tabular}

Fuente: elaboración propia 


\subsubsection{Aprendizajes esperados.}

Estos aprendizajes son definidos como aquellos elementos que ayudan a la organización del contenido, la selección de estrategias y métodos de aprendizaje. Su importancia radica en que es el elemento del marco curricular que define de forma concreta, precisa y visualizable lo que se espera que los estudiantes logren al finalizar una unidad, pudiéndose evaluar de forma objetiva y transparente.

Al finalizar el tercer año de la asignatura Psicología, entre otros aprendizajes esperados, los estudiantes:

- Comprenden los procesos psicológicos como una actividad con base biológica específica en el cerebro y sus estructuras, compartida en parte con otros seres vivos, pero especialmente desarrollada en el ser humano.

- Comprenden que las emociones pueden ser reguladas voluntariamente por la reflexión y el aprendizaje.

- Entienden que las personas aprenden el lenguaje y los códigos culturales necesarios para su integración social a través del proceso de socialización.

- Analizan la dimensión psicológica de la sexualidad: la identidad sexual.

- Identifican valores, conductas y actitudes que se asocian con la sexualidad responsable en la adolescencia.

- Identifican el concepto de bienestar biopsicosocial.

- Evalúan el desarrollo de su propio proyecto vital, de sus redes sociales y de ciertas habilidades sociales o "habilidades para vivir".

Para el caso del cuarto año de la asignatura Filosofía, entre otros, aprendizajes esperados, los estudiantes: 
- Comprenden la estructura de la filosofía como los temas éticos, metafísicos y epistemológicos.

- Reconocen que frente a una pregunta filosófica existe un rango abierto, pero acotado de respuestas que son por igual inteligibles y racionalmente defendibles.

- Comprenden el conocimiento como un ámbito que suscita problemas filosóficos. Reconocen la dimensión metodológica de la actividad filosófica.

- Distinguen la Moral de la Ética.

- Conocen diferentes propuestas acerca del fundamento de la moral.

- Conocen las características de los valores.

- Aplican conceptos morales y éticos a su realidad.

- Reconocen el papel de las instituciones sociales en la formación de la conciencia moral.

- Reconocen que las instituciones forman la conciencia moral inculcando valores.

- Reconocen y aplican los principios de la bioética.

\subsubsection{Actividades.}

Al igual que los demás componentes curriculares, las actividades propuestas en los Planes y Programas de Psicología y Filosofía se prescriben en el marco curricular nacional e incluyen estrategias y recursos didácticos que apuntan tanto a la adquisición de conceptos fundamentales como a la discusión y reflexión desde la experiencia, de tal manera que cada estudiante pueda visualizar los problemas, tomando posición frente a ellos. Por ende, las actividades que se ofrecen como ejemplos para el docente remiten a situaciones prácticas, a partir de las cuales surgen las nociones básicas y las interrogantes 
que se plantean desde las diversas escuelas de pensamiento. La metodología sugerida se basa en la participación activa de los estudiantes en los temas en discusión.

En particular, el programa de tercer año propone que las actividades de los estudiantes antecedan las explicaciones de los profesores, de manera que los conceptos a ser aprendidos puedan ser contextualizados con las experiencias personales previas, adquiriendo así una mayor significatividad para fortalecer el compromiso del estudiante con los temas de la disciplina. Entre otras actividades se citan:

- Interpretación y descripción de imágenes (ejemplo, la joven y la vieja, un jarrón $\mathrm{y}$ dos personas de perfil).

- Discusión grupal (ejemplo, sobre emociones en hombres y mujeres y sus variaciones en la forma de expresarlas).

- $\quad$ Entrevistas a diferentes personas acerca de interrogantes.

- Lectura de textos (ejemplo 'Las facciones del amor', de José Ortega y Gasset).

- Elaboración de ensayos sobre personajes de algún cuento, novela, película o teleseries.

Las actividades propuestas en el programa de Filosofía del cuarto año medio, recogen los conocimientos y las reflexiones psicológicas acerca de los componentes y características de la vida humana., para apoyar y contrastar la reflexión filosófica. El análisis de textos, el debate grupal y la reflexión personal constituyen actividades centrales para la identificación de los conceptos e ideas básicas de los distintos autores, así como los argumentos de apoyo. Del mismo modo, la construcción de objeciones y contraejemplos que contribuyan a la evaluación crítica de las distintas posiciones.

Como parte de los recursos didácticos, al final del programa se anexan textos utilizados en las propuestos en las actividades tales como, "Sentido y sin sentido" de Carla Cordua, "Ensayo sobre el entendimiento humano" de John Locke, "Libertad y Resentimiento" de Srawson, "El Existencialismo es un Humanismo" de Jean Paul Sartre, "La ideología 
alemana" de Karl Marx. También, documentos de apoyo para abordar temas específicos. Por ejemplo, una selección de textos sobre universalismo, relativismo y pluralismo: "Reflexiones americanas" de Marcos García de la Huerta, "Naturaleza y política" de Joaquín García-Huidobro, "El derecho, ¿es el objeto de la justicia?” en Suma de teología de Tomás de Aquino.

Entre las estrategias se citan:

- Clasificación de una serie de preguntas en términos empíricos y formales, justificando su clasificación.

- Análisis y debates de películas, como "Blade Runner", "Matrix".

- Lectura de un artículo para debatir acerca de la pregunta por el sentido de la vida humana.

- $\quad$ Discusión de dilemas morales.

- Identificación de distintos tipos de situaciones de conflictos e intereses vinculadas a resoluciones normativas.

\subsubsection{Evaluación.}

En los Planes y Programas analizados no se especifica el enfoque de la evaluación. En la presentación de cada unidad, se detallan los contenidos, aprendizajes esperados y actividades. Al final de esta presentación, se ofrecen algunos indicadores vinculados a los aprendizajes esperados y un listado de prácticas de evaluación a modo de sugerencias tales como:

- Elaboración de un ensayo, a partir del análisis de un personaje de una novela, obra de teatro o película, identificando los diferentes procesos psicológicos. 
- Invención de un cuento o situación en que estén presentes los fenómenos psicológicos que el docente indique, señalando en qué conducta se manifiesta ese fenómeno.

- Realización de un trabajo de investigación profundizando un tema.

- Identificación en un problema planteado el tipo de pensamiento y estilo cognitivo que utilizan para resolverlo.

- Resolución de una prueba, con apuntes a la vista, dando dan cuenta de la incidencia de los procesos psicológicos en algún tipo de aprendizaje.

- Caracterización en un personaje de la literatura el tipo de inteligencia predominante y sus manifestaciones.

- Análisis de una noticia nacional o internacional, señalando los comportamientos que identifican a diferentes grupos sociales.

- Descripción de las causas de una situación de conflicto y señalando los comportamientos que podrían llevar a su resolución.

- Análisis y comentario de un programa de televisión, identificando los mensajes implícitos y explícitos de valores de convivencia.

- Paneles y autoevaluación de la capacidad personal para propiciar un clima adecuado de trabajo, respetar las opiniones, escuchar atenta y empáticamente, etc.

Las sugerencias de evaluación descritas fijan, de alguna manera, algunos criterios comunes para el trabajo de los profesores en los distintos cursos, sin homologar las formas de juzgar los resultados y/o derivar notas lo más equivalente posible. En gran mayoría, las prácticas sugeridas son de carácter cualitativo e individual y versan sobre el aprendizaje alcanzado por los estudiantes al finalizar cada unidad. Esto último proporciona al estudiante la libertad para expresar su individualidad en las producciones y libertad a los profesores para dejarse guiar por sus preferencias individuales. Al 
respecto, en la cuarta unidad del programa titulada "Bienestar biopsicosocial" se sugiere al profesor no realizar controles o pruebas objetivas, sino evaluar la pertinencia y profundidad de la reflexión del estudiante en la elaboración de un ensayo sobre su plan de vida.

El programa de cuarto año, por su parte, señala que "los estudiantes deben desarrollar competencias lingüísticas argumentativas y reflexivas que tienen que estar presentes en general en las instancias de evaluación” (MINEDUC, Año 2001, Pág. 13). En atención a ello, sugiere a los profesores no utilizar instrumentos de selección múltiple o similar, para promover el desarrollo del pensamiento y la expresión, tanto oral como escrita. Las estrategias de evaluación consideran, además, los aspectos formales del uso del lenguaje en exposiciones escritas (ortografía, gramática) y orales.

A diferencia del tercer año, las sugerencias de actividades de evaluación en el cuarto año de Filosofía preceden a la definición de las dimensiones evaluativas en función de los objetivos de la asignatura, con ejemplos de aplicación. Las modalidades que puede asumir la evaluación son:

- Debates organizados en clase, con duración previamente asignada, en que se evalúa: la coherencia en la argumentación, la atención a los argumentos de otros y el hacerse cargo de ellos, la aplicación de conceptos a situaciones concretas y la pertinencia.

- Trabajo escrito de síntesis. Se evalúa: la competencia lingüística, la estructura de la exposición del tema, la comprensión de los contenidos.

- Prueba escrita. Se evalúa: el dominio de contenidos, la competencia lingüística, la pertinencia, la aplicación a situaciones concretas.

- Comentario de texto. Se evalúa: la articulación de la argumentación, la fundamentación de la opinión personal, la pertinencia. 
Las actividades de evaluación sugeridas establecen con mayor claridad el propósito del programa de cuarto año, el cual explicita objetivos relacionados con el desarrollo de ciertas competencias asociadas al pensamiento, la argumentación y la comunicación. Para lo anterior el programa se apoya en el reconocimiento, por parte de los estudiantes, de ciertas posiciones que han planteadas por filósofos a lo largo de la historia. En su gran mayoría las prácticas de evaluación sugeridas al profesor examinan más el proceso formativo antes que el desempeño del estudiante al finalizar el desarrollo de una unidad didáctica.

\subsection{Tipos de pensamiento en los Planes y Programas de Filosofía}

\subsubsection{Pensamiento creativo.}

Como se aprecia en Cuadro 11, las habilidades y disposiciones del pensamiento creativo emergen en los objetivos transversales del plan de tercer año, en términos de desarrollo de la iniciativa y creatividad en el trabajo aplicado a contenidos referidos a la percepción, las relaciones interpersonales, el conflicto, la construcción de acuerdos y sentidos compartidos, por cuanto implica la construcción o reconstrucción de ideas y conceptos.

En la línea de la creatividad, las actividades, estrategias y recursos didácticos se orientan, entre otros, al análisis de la percepción en láminas, la interpretación y el análisis de citas, y la dramatización de las emociones. Estas actividades favorecen los procesos creativos porque requieren la elaboración original de ideas y sentimientos, incorporando otros significados y sentidos. Por su parte, la evaluación de este tipo de pensamiento contempla inventar situaciones sobre fenómenos psicológicos y caracterizar la inteligencia de un personaje literario. En el primer caso, la invención inherente a creatividad y la caracterización de una persona desarrolla la capacidad de imaginación.

En el cuarto año, el pensamiento creativo se observa en el objetivo de usar distintas formas para expresar ideas. Aquí la creatividad aparece ligada al desarrollo de las competencias comunicativas empleando los métodos de la reflexión filosófica, que se citan 
en los contenidos del plan de estudio. Las actividades y la evaluación se plantean en una perspectiva dialéctica que acompaña el objetivo, relatar acciones frente a cambios, defender posiciones, escribir un ensayo, interpretar una afirmación. 


\section{Cuadro 11.}

\section{Elementos del pensamiento creativo en Programas de Estudio del área filosófica de la}

\section{educación media chilena.}

\begin{tabular}{|c|c|c|c|c|c|c|c|c|c|c|}
\hline \multirow[t]{2}{*}{$\begin{array}{l}\text { Categorías } \\
\text { de análisis }\end{array}$} & \multicolumn{2}{|l|}{ Objetivos } & \multicolumn{2}{|c|}{ Aprendizajes esperados } & \multicolumn{2}{|c|}{ Contenido } & \multicolumn{2}{|c|}{$\begin{array}{l}\text { Actividades, estrategias } \\
\text { y recursos didácticos }\end{array}$} & \multicolumn{2}{|c|}{ Evaluación } \\
\hline & Tercer año & Cuarto año & Tercer año & Cuarto año & Tercer año & Cuarto año & o Tercer año & Cuarto añ & Tercer año & Cuarto año \\
\hline \multirow[t]{3}{*}{$\begin{array}{l}\text { Pensamiento } \\
\text { creativo }\end{array}$} & $\begin{array}{l}\text { Desarrollar } \\
\text { iniciativa } \\
\text { y creativi- } \\
\text { dad en el } \\
\text { trabajo. }\end{array}$ & $\begin{array}{l}\text { Usar } \\
\text { formas de } \\
\text { expresar } \\
\text { ideas. }\end{array}$ & $\begin{array}{l}\text { No } \\
\text { especifica }\end{array}$ & $\begin{array}{l}\text { No } \\
\text { especifica }\end{array}$ & Percepción. & $\begin{array}{l}\text { Métodos } \\
\text { de la } \\
\text { reflexión } \\
\text { filosófica. }\end{array}$ & $\begin{array}{l}\text { Análisis de } \\
\text { la percep- } \\
\text { ción en } \\
\text { láminas }\end{array}$ & $\begin{array}{l}\text { Relatar } \\
\text { reacciones } \\
\text { frente a } \\
\text { cambios } \\
\text { históricos. }\end{array}$ & $\begin{array}{l}\text { Inventar } \\
\text { situaciones } \\
\text { sobre } \\
\text { fenómenos } \\
\text { psicológi- } \\
\text { cos }\end{array}$ & $\begin{array}{l}\text { Defender la } \\
\text { posición de } \\
\text { Locke y } \\
\text { Descartes. }\end{array}$ \\
\hline & & & & & $\begin{array}{l}\text { Relaciones } \\
\text { interper- } \\
\text { sonales y } \\
\text { conflicto. }\end{array}$ & & $\begin{array}{l}\text { Interpre- } \\
\text { tación y } \\
\text { análisis de } \\
\text { citas. }\end{array}$ & & $\begin{array}{l}\text { Reconocer } \\
\text { en un } \\
\text { personaje } \\
\text { literario la } \\
\text { inteligen- } \\
\text { cia. . }\end{array}$ & $\begin{array}{l}\text { Escribir un } \\
\text { ensayo. }\end{array}$ \\
\hline & & & & & $\begin{array}{l}\text { Construc- } \\
\text { ción de } \\
\text { sentidos } \\
\text { compartidos. }\end{array}$ & & $\begin{array}{l}\text { Dramati- } \\
\text { zación de } \\
\text { emociones }\end{array}$ & & & $\begin{array}{l}\text { Interpretar } \\
\text { una afirma- } \\
\text { ción. }\end{array}$ \\
\hline
\end{tabular}

Fuente: elaboración propia 


\subsubsection{Pensamiento ético.}

Como se aprecia en el Cuadro 12, el desarrollo del pensamiento ético en los Planes y Programas de estudio de Filosofía del tercer año de la educación media chilena, se nutre de fundamentos psicológicos para la comprensión de las propias acciones y opciones morales. Al respecto, proponen como objetivos conocerse a sí mismo, valorar modos e identidades personales, ejercer libertad y autonomía, respetar ideas y creencias y valorar el diálogo. Los aprendizajes esperados colaboran con estos propósitos para reconocer emociones, vínculos afectivos, la constitución moral del ser humano, factores de protección y bienestar biopsicosocial, entender la autonomía en valores y normas morales, cuestionar la discriminación, valorar la identidad, convivencia social, resolución de conflictos, acuerdos, influencias en las opiniones y comportamientos, evaluar lo que se hace y cómo se hace en materia de discriminación, relación de pareja y sexualidad responsable entre otros.

En línea con los objetivos y actividades, los contenidos prescritos para este nivel aportan a la comprensión de acciones a partir del estudio de emociones y vínculos afectivos, identidad personal y la cuestión del otro, relaciones intergrupales: estereotipos, prejuicios y discriminación, tolerancia y diálogo en las relaciones sociales, normal, anormal y patológico en la cultura. Las actividades se focalizan en tres aspectos comunes: el análisis de distintas situaciones, la argumentación y el trabajo colaborativo grupal. La evaluación se concentra, también, en el análisis aplicado a comportamientos, causas y resoluciones de conflictos, mensajes verbales implícitos y explícitos, y la realización de trabajos específicos.

En los fundamentos del cuarto año, el pensamiento ético se enmarca en el respeto por las diversas posiciones y vivencias. En concordancia con dichos fundamentos, en los 
objetivos se suman a los del año precedente, la suspensión de juicios sin información, la comprensión de normas y evaluación de visiones de la moral. Las actividades recogen aportes filosóficos para el análisis y la argumentación respecto a normas éticas y morales, respuestas y sentimientos, libertad responsable, la aplicación de la regla de oro a situaciones concretas, de los conceptos de Bien, virtud y felicidad y la relación entre ética y bioética. Respecto a evaluación cabe señalar se plantea en los términos de la actividad ya descrita. 
Cuadro 12. Elementos del pensamiento ético en Programas de Estudio del área filosófica de la educación media chilena.

\begin{tabular}{|c|c|c|c|c|c|c|c|c|c|c|}
\hline \multirow[t]{2}{*}{$\begin{array}{l}\text { Categorías de } \\
\text { análisis }\end{array}$} & \multicolumn{2}{|c|}{ Objetivos } & \multicolumn{2}{|c|}{ Aprendizajes esperados } & \multicolumn{2}{|c|}{ Contenido } & \multicolumn{2}{|c|}{$\begin{array}{l}\text { Actividades, estrategias y } \\
\text { recursos didácticos }\end{array}$} & \multicolumn{2}{|c|}{ Evaluación } \\
\hline & Tercer año & Cuarto año & Tercer año & Cuarto año & Tercer año & Cuarto año & Tercer año & Cuarto año & Tercer año & Cuarto año \\
\hline \multirow[t]{3}{*}{$\begin{array}{l}\text { Pensamiento } \\
\text { ético }\end{array}$} & $\begin{array}{l}\text { Conocerse a } \\
\text { sí mismo. }\end{array}$ & $\begin{array}{l}\text { Suspender } \\
\text { juicios sin } \\
\text { información }\end{array}$ & $\begin{array}{l}\text { Reconocen } \\
\text { las } \\
\text { emociones. }\end{array}$ & $\begin{array}{l}\text { Valoran } \\
\text { posiciones } \\
\text { filosóficas } \\
\text { para el } \\
\text { pensamiento } \\
\text { argumentos. }\end{array}$ & $\begin{array}{l}\text { Emociones } \\
\text { y vínculos } \\
\text { afectivos }\end{array}$ & $\begin{array}{l}\text { Filosofía } \\
\text { como } \\
\text { reflexión } \\
\text { sobre el } \\
\text { sentido de } \\
\text { la vida } \\
\text { humana. }\end{array}$ & $\begin{array}{l}\text { Conversación y } \\
\text { reflexión } \\
\text { grupal. }\end{array}$ & $\begin{array}{l}\text { Argumentació } \\
\mathrm{n} \text { respecto al } \\
\text { sentido de la } \\
\text { vida humana. }\end{array}$ & $\begin{array}{l}\text { Analizar una } \\
\text { noticia } \\
\text { señalando } \\
\text { comportamient } \\
\text { os de grupos } \\
\text { sociales. }\end{array}$ & \\
\hline & $\begin{array}{l}\text { Valorar } \\
\text { modos e } \\
\text { identidades } \\
\text { personales. }\end{array}$ & Ídem & $\begin{array}{l}\text { Identifican } \\
\text { vínculos } \\
\text { afectivos. }\end{array}$ & $\begin{array}{l}\text { Comprende } \\
\text { n normas y } \\
\text { respuestas } \\
\text { morales. }\end{array}$ & $\begin{array}{l}\text { Identidad } \\
\text { personal y } \\
\text { la cuestión } \\
\text { del otro. }\end{array}$ & $\begin{array}{l}\text { Situaciones de } \\
\text { reflexión } \\
\text { moral }\end{array}$ & $\begin{array}{l}\text { e Análisis } \\
\text { grupal de } \\
\text { causas y } \\
\text { efectos de } \\
\text { emociones. }\end{array}$ & $\begin{array}{l}\text { Defensa y } \\
\text { justificación } \\
\text { de posturas. }\end{array}$ & $\begin{array}{l}\text { Hacer un } \\
\text { trabajo sobre } \\
\text { conducta de un } \\
\text { personaje } \\
\text { señalando } \\
\text { influencias del } \\
\text { grupo social }\end{array}$ & \\
\hline & $\begin{array}{l}\text { Ejercer } \\
\text { libertad y } \\
\text { autonomía. }\end{array}$ & Ídem & $\begin{array}{l}\text { Reconocen } \\
\text { la moral } \\
\text { como } \\
\text { constitutiva } \\
\text { del ser } \\
\text { humano. }\end{array}$ & $\begin{array}{l}\text { Aplican la } \\
\text { regla de oro } \\
\text { a } \\
\text { situaciones } \\
\text { concretas. }\end{array}$ & $\begin{array}{l}\text { Relaciones } \\
\text { intergrupales: } \\
\text { estereotipos, } \\
\text { prejuicios, } \\
\text { discriminacio } \\
\text { nes }\end{array}$ & $\begin{array}{l}\text { Fundamentos } \\
\text { de la moral. }\end{array}$ & $\begin{array}{l}\text { Análisis de } \\
\text { prejuicios y } \\
\text { estereotipos } \\
\text { en la } \\
\text { comunidad. }\end{array}$ & $\begin{array}{l}\text { Análisis de } \\
\text { valores en las } \\
\text { acciones de } \\
\text { personajes }\end{array}$ & $\begin{array}{l}\text { Describir un } \\
\text { conflicto, } \\
\text { causas y } \\
\text { resolución. }\end{array}$ & \\
\hline
\end{tabular}


Respetar ideas Idem $\mathrm{y}$ creencias.

Valorar el Ídem
diálogo.

Entienden la Conocen los autonomía sentimiento en valores y $\mathrm{s}$ en la

normas

Moral

\begin{tabular}{|c|c|c|c|c|c|c|}
\hline Ídem & $\begin{array}{l}\text { Cuestionan } \\
\text { la } \\
\text { discriminaci } \\
\text { ón }\end{array}$ & $\begin{array}{l}\text { Aplican los } \\
\text { conceptos } \\
\text { de Bien, } \\
\text { virtud, } \\
\text { felicidad. }\end{array}$ & $\begin{array}{l}\text { Normal, } \\
\text { anormal y } \\
\text { patológico } \\
\text { en la } \\
\text { cultura. }\end{array}$ & $\begin{array}{l}\text { Contractualis } \\
\text { mo como } \\
\text { superación de } \\
\text { conflictos. }\end{array}$ & $\begin{array}{l}\text { Relacionar } \\
\text { sexualidad y } \\
\text { vivencia de } \\
\text { valores. }\end{array}$ & Debates. \\
\hline $\begin{array}{l}\text { Comprender } \\
\text { normas } \\
\text { morales }\end{array}$ & $\begin{array}{l}\text { Valoran } \\
\text { identidad, } \\
\text { convivencia } \\
\text { social, } \\
\text { resolución } \\
\text { de } \\
\text { conflictos, } \\
\text { acuerdos. }\end{array}$ & $\begin{array}{l}\text { Reconocen } \\
\text { la libertad } \\
\text { como base } \\
\text { de la } \\
\text { responsabili } \\
\text { dad. }\end{array}$ & & $\begin{array}{l}\text { Autonomía } \\
\text { personal. }\end{array}$ & $\begin{array}{l}\text { Plenario } \\
\text { iniciación } \\
\text { en las } \\
\text { relaciones } \\
\text { sexuales. }\end{array}$ & $\begin{array}{l}\text { Justificación } \\
\text { relación } \\
\text { bioética - } \\
\text { ética. }\end{array}$ \\
\hline $\begin{array}{l}\text { Evaluar } \\
\text { visiones de la } \\
\text { moral }\end{array}$ & $\begin{array}{l}\text { Evalúan } \\
\text { influencia } \\
\text { del grupo en } \\
\text { opiniones y } \\
\text { comportami } \\
\text { entos. }\end{array}$ & $\begin{array}{l}\text { Reconocen } \\
\text { el valor del } \\
\text { compromiso } \\
\text { en la Moral. }\end{array}$ & & $\begin{array}{l}\text { Fundamentos } \\
\text { filosóficos de } \\
\text { derechos } \\
\text { humanos y } \\
\text { sociedad } \\
\text { democrática. }\end{array}$ & $\begin{array}{l}\text { Campaña } \\
\text { informativa } \\
\text { sobre } \\
\text { trastornos } \\
\text { alimentarios } \\
\text {, abuso de } \\
\text { sustancias, } \\
\text { violencia. }\end{array}$ & $\begin{array}{l}\text { Decisiones en } \\
\text { situaciones } \\
\text { éticas. }\end{array}$ \\
\hline
\end{tabular}
diálogo en las

relaciones sociales.

Normal, anormal y patológico

en la

cultura.

Contractualis

mo como

superación de valores.

conflictos.

Fundamentos filosóficos de derechos

humanos y

sociedad

democrática.

\begin{tabular}{|c|c|c|c|c|c|}
\hline $\begin{array}{l}\text { Comprender } \\
\text { normas } \\
\text { morales }\end{array}$ & $\begin{array}{l}\text { Valoran } \\
\text { identidad, } \\
\text { convivencia } \\
\text { social, } \\
\text { resolución } \\
\text { de } \\
\text { conflictos, } \\
\text { acuerdos. }\end{array}$ & $\begin{array}{l}\text { Reconocen } \\
\text { la libertad } \\
\text { como base } \\
\text { de la } \\
\text { responsabili } \\
\text { dad. }\end{array}$ & $\begin{array}{l}\text { Autonomía } \\
\text { personal. }\end{array}$ & $\begin{array}{l}\text { Plenario } \\
\text { iniciación } \\
\text { en las } \\
\text { relaciones } \\
\text { sexuales. }\end{array}$ & $\begin{array}{l}\text { Justificación } \\
\text { relación } \\
\text { bioética - } \\
\text { ética. }\end{array}$ \\
\hline $\begin{array}{l}\text { Evaluar } \\
\text { visiones de la } \\
\text { moral }\end{array}$ & $\begin{array}{l}\text { Evalúan } \\
\text { influencia } \\
\text { del grupo en } \\
\text { opiniones y } \\
\text { comportami } \\
\text { entos. }\end{array}$ & $\begin{array}{l}\text { Reconocen } \\
\text { el valor del } \\
\text { compromiso } \\
\text { en la Moral. }\end{array}$ & $\begin{array}{l}\text { Fundamentos } \\
\text { filosóficos de } \\
\text { derechos } \\
\text { humanos y } \\
\text { sociedad } \\
\text { democrática. }\end{array}$ & $\begin{array}{l}\text { Campaña } \\
\text { informativa } \\
\text { sobre } \\
\text { trastornos } \\
\text { alimentarios } \\
\text {, abuso de } \\
\text { sustancias, } \\
\text { violencia. }\end{array}$ & $\begin{array}{l}\text { Decisiones en } \\
\text { situaciones } \\
\text { éticas. }\end{array}$ \\
\hline
\end{tabular}

\section{Análisis}

Análisis y

justificación

de la regla de

en la

comunicaci

ón entre

padres e

hijos,

profesores y

alumnos.

Relacionar

Debates.

Hacer trabajo sobre procesos psicológicos individuales y sociales de discriminación. 
Reconocen Aplican

valores y

actitudes en

conceptos

conceptos

de pareja y realidad.

de

sexualidad

responsable.

Reconocen

factores de

protección y

bienestar

biopsicosoci

al.
Derecho a la

participación

ciudadana,

justicia social,

solidaridad y

diversidad

social y

cultural. 


\subsubsection{Pensamiento crítico-racional}

Como se aprecia en el Cuadro $\mathrm{N}^{\circ} 13$ los fundamentos del pensamiento crítico racional en los Planes y Programas de estudio de Filosofía del tercer año de la educación media chilena toman en consideración los procesos psicológicos cognitivos, afectivos y sociales de las personas. En línea con ello, los objetivos se proponen desarrollar el interés por conocer la realidad, las habilidades de investigación y comunicación, analizar la propia experiencia, los criterios de salud mental y las acciones que la favorecen. Los indicios de este tipo de pensamiento emergen en los aprendizajes esperados referidos a la comprensión de la base biológica de los procesos psicológicos de los conceptos de percepción, memoria, lenguaje, pensamiento, aprendizaje, inteligencia, emociones, bienestar biopsicosocial. También, emergen en la distinción de prejuicios manifiestos y encubiertos, etapas de la relación de pareja estable, salud física y salud mental, etapas y características de la adolescencia normal. Los contenidos que aportan a estos aprendizajes aluden a la memoria y su relación con el aprendizaje, la sexualidad, las dimensiones de lo psicopatológico y la salud en sentido amplio.

Entre los procedimientos de indagación propios de este tipo de pensamiento, las actividades proponen análisis grupal de textos y ejemplos, encuestas, exposiciones de problemas elaboración de informes. La evaluación apunta a la reflexión sobre la incidencia de procesos y la integración de los aprendizajes esperados.

Los fundamentos del cuarto año se enmarcan en las habilidades analíticas de argumentación e interpretación y en las concepciones y posiciones de defensa racional. En esta línea, los objetivos propuestos apuntan a desarrollar, al igual que en el caso del tercer año, el interés por conocer la realidad, investigar y comunicar ideas. Además, a analizar, interpretar información basada en el contexto y resolver problemas éticos aplicando métodos de la filosofía, de forma reflexiva y metódica. 
Los aprendizajes esperados se relacionan con los objetivos y, proponen la distinción entre preguntas empíricas y formales, la moral y la ética, la identificación de nociones epistemológicas sobre empirismo, racionalismo, idealismo, realismo, del pensamiento de Sócrates y Aristóteles. También, el reconocimiento de las instituciones sociales y la valoración de la precisión del lenguaje en la argumentación filosófica.

Los contenidos que posibilitan estos aprendizajes aluden a problemas morales, conceptos de justicia, justicia distributiva, justicia e igualdad, problemas contemporáneos de ética social, bioética, ética y economía, ética y medio ambiente, ética e informática, ética y técnica. Como actividades se proponen la definición, relación y ejemplificación de conceptos, la categorización de preguntas, la comparación entre propuestas, la lluvia de ideas y lectura de textos. La evaluación apunta a la comparación de conceptos, corrientes, métodos entre lo que se entiende en la actualidad y la tradición aristotélica. 
Cuadro 13. Elementos del pensamiento crítico-racional en los Programas de estudio de área filosófica de la educación media chilena.

\begin{tabular}{|c|c|c|c|c|c|c|c|c|c|c|}
\hline \multirow[t]{2}{*}{$\begin{array}{l}\text { Categoría de } \\
\text { análisis }\end{array}$} & \multicolumn{2}{|c|}{ Objetivos } & \multicolumn{2}{|c|}{ Aprendizajes esperados } & \multicolumn{2}{|l|}{ Contenido } & \multicolumn{2}{|c|}{$\begin{array}{l}\text { Actividades, estrategias y recursos } \\
\text { didácticos }\end{array}$} & \multicolumn{2}{|l|}{ Evaluación } \\
\hline & $\begin{array}{l}\text { Tercer } \\
\text { año }\end{array}$ & $\begin{array}{l}\text { Cuarto } \\
\text { año }\end{array}$ & Tercer año & Cuarto año & Tercer año & Cuarto año & Tercer año & Cuarto año & $\begin{array}{l}\text { Tercer } \\
\text { año }\end{array}$ & $\begin{array}{l}\text { Cuarto } \\
\text { año }\end{array}$ \\
\hline \multirow[t]{2}{*}{$\begin{array}{l}\text { Pensamiento } \\
\text { crítico- } \\
\text { racional }\end{array}$} & $\begin{array}{l}\text { Desarro } \\
\text { llar el } \\
\text { interés } \\
\text { de } \\
\text { conocer } \\
\text { la } \\
\text { realidad } \\
\text {. }\end{array}$ & Idem. & $\begin{array}{l}\text { Comprenden la } \\
\text { base biológica } \\
\text { de los procesos } \\
\text { psicológicos. }\end{array}$ & $\begin{array}{l}\text { Distinguen } \\
\text { preguntas } \\
\text { empíricas } \\
\text { y formales }\end{array}$ & $\begin{array}{l}\text { La memoria } \\
\text { como } \\
\text { proceso } \\
\text { constructiv } \\
\text { o y } \\
\text { reconstructi } \\
\text { vo. }\end{array}$ & $\begin{array}{l}\text { El } \\
\text { problema } \\
\text { moral: } \\
\text { conceptos } \\
\text { morales } \\
\text { básicos }\end{array}$ & $\begin{array}{l}\text { Análisis } \\
\text { grupal de } \\
\text { textos. }\end{array}$ & $\begin{array}{l}\text { Ejemplificación } \\
\text { de conceptos }\end{array}$ & $\begin{array}{l}\text { Prueba } \\
\text { escrita } \\
\text { con } \\
\text { apuntes a } \\
\text { la } \\
\text { vista, sob } \\
\text { re } \\
\text { incidenci } \\
\text { a } \\
\text { de proce } \\
\text { sos } \\
\text { psicológi } \\
\text { cos }\end{array}$ & $\begin{array}{l}\text { Respon } \\
\text { den las } \\
\text { pregunt } \\
\text { as } \\
\text { indicada } \\
\text { s por el } \\
\text { docente, } \\
\text { utilizan } \\
\text { do sus } \\
\text { apuntes. }\end{array}$ \\
\hline & $\begin{array}{l}\text { Desarro } \\
\text { llar } \\
\text { habilida } \\
\text { des de } \\
\text { investig } \\
\text { ación y } \\
\text { comuni } \\
\text { cación }\end{array}$ & Idem. & $\begin{array}{l}\text { Describen los } \\
\text { procesos } \\
\text { cognitivos } \\
\text { fundamentales. }\end{array}$ & $\begin{array}{l}\text { Valoran la } \\
\text { precisión del } \\
\text { lenguaje en } \\
\text { la } \\
\text { argumentaci } \\
\text { ón } \\
\text { filosófica. }\end{array}$ & $\begin{array}{l}\text { Memoria y } \\
\text { aprendizaje. }\end{array}$ & $\begin{array}{l}\text { El concepto } \\
\text { de justicia. } \\
\text { La justicia } \\
\text { distributiva. } \\
\text { Justicia e } \\
\text { igualdad. }\end{array}$ & Plenarios & $\begin{array}{l}\text { Categorización } \\
\text { de preguntas. }\end{array}$ & $\begin{array}{l}\text { Trabajo } \\
\text { acerca de } \\
\text { la } \\
\text { medición } \\
\text { de la } \\
\text { inteligenc } \\
\text { ia }\end{array}$ & $\begin{array}{l}\text { Compar } \\
\text { an cómo } \\
\text { se } \\
\text { entiende } \\
\text { hoy la } \\
\text { política } \\
\text { con el } \\
\text { concept } \\
\text { o } \\
\text { aristotél } \\
\text { ico de } \\
\text { ella. }\end{array}$ \\
\hline
\end{tabular}




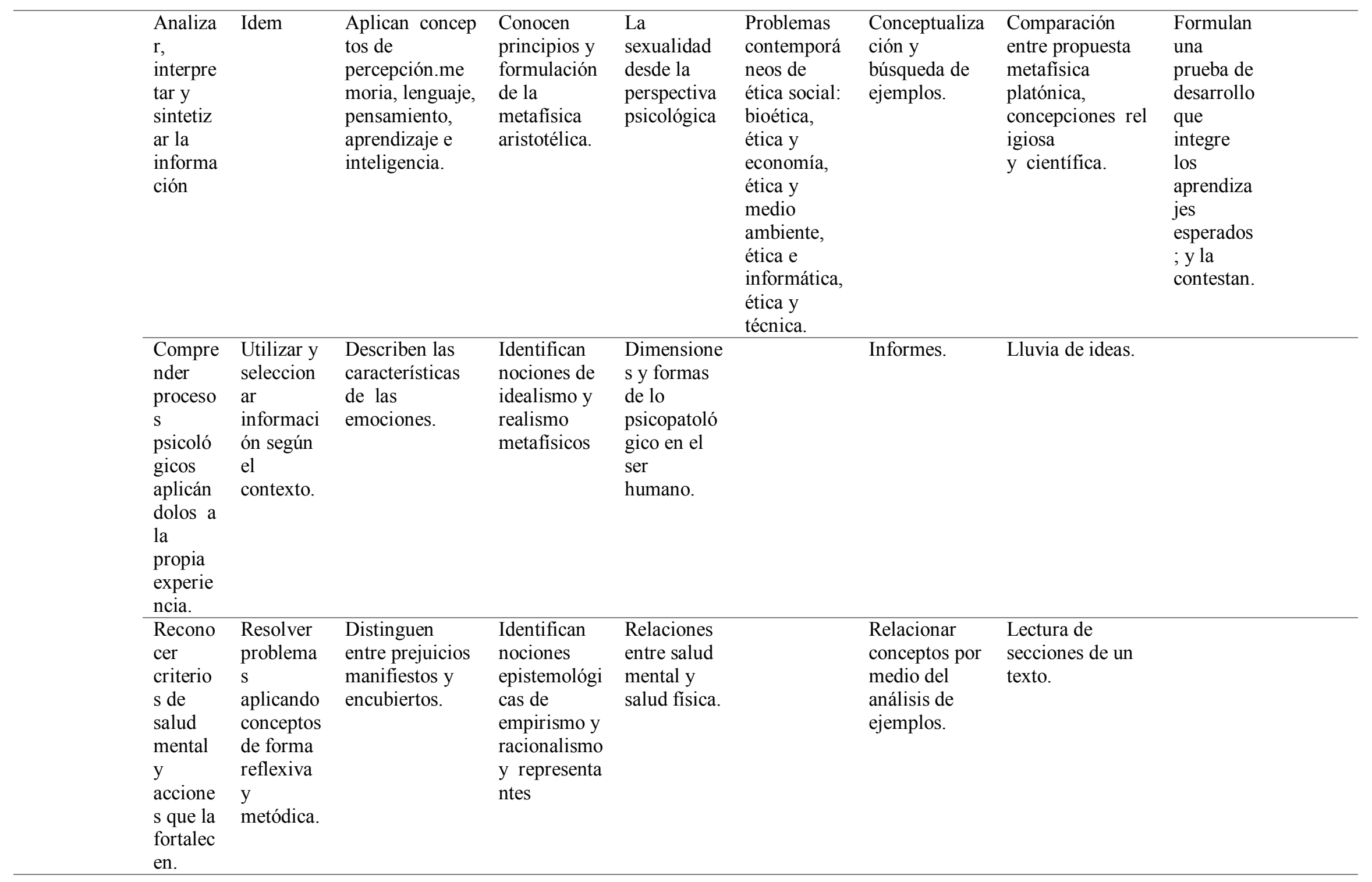




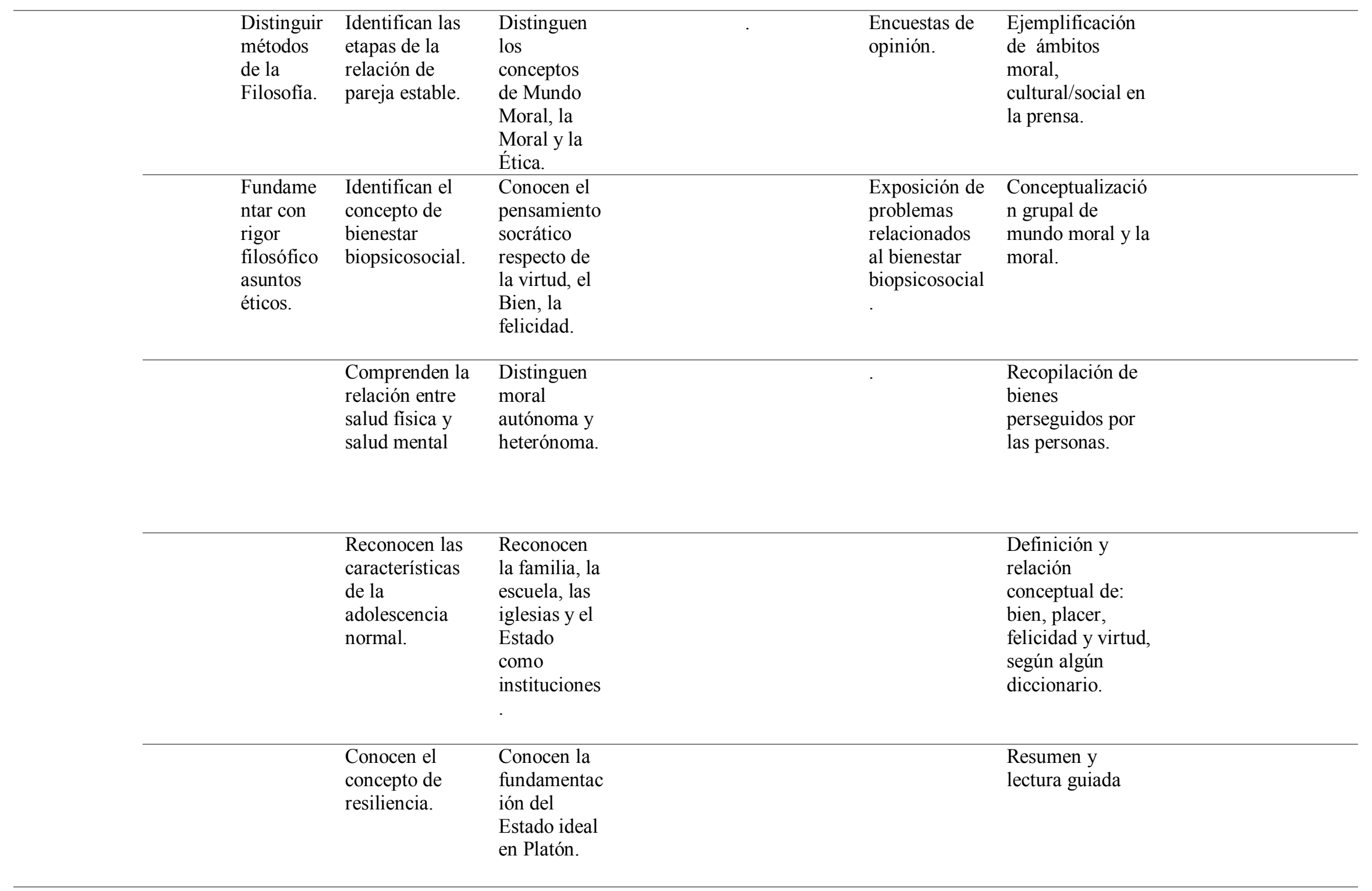




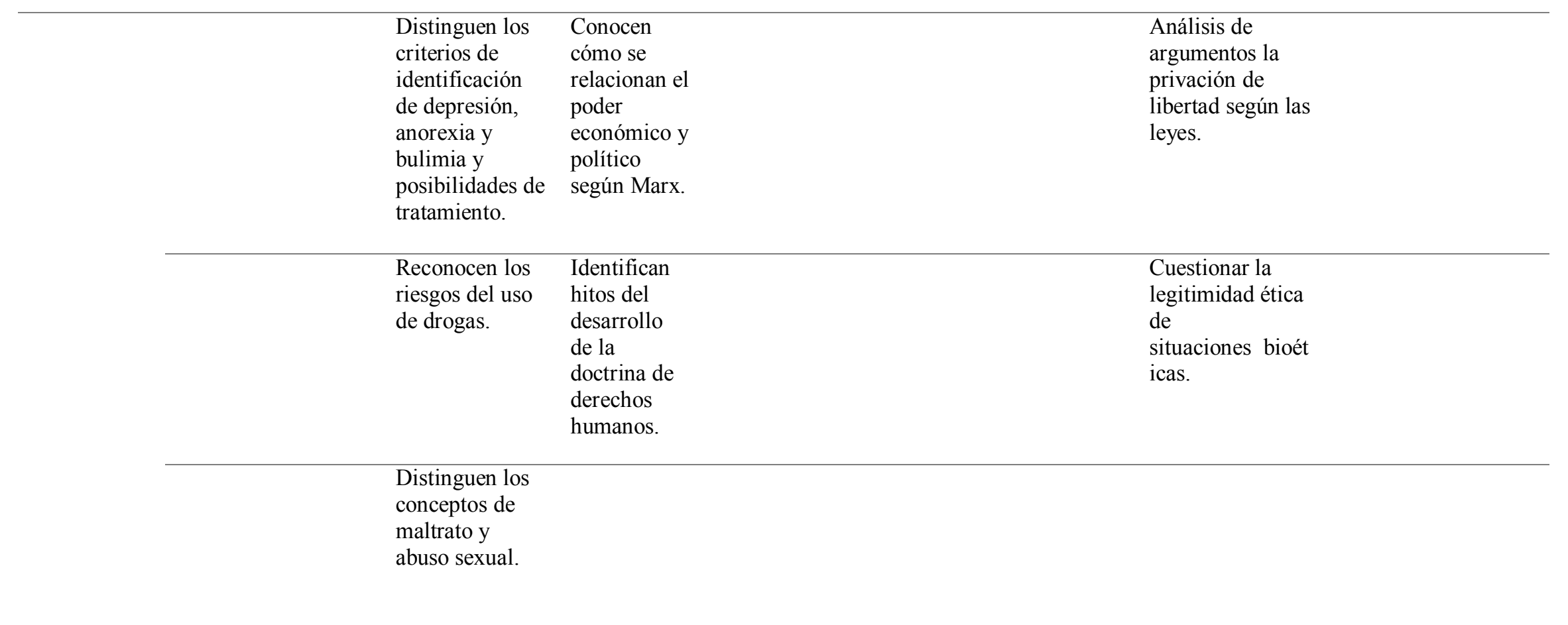

Fuente: elaboración propia 


\subsubsection{Pensamiento critíco-razonable}

Como se aprecia en el Cuadro 14, el desarrollo del pensamiento críticorazonable en los Planes y Programas de estudio de Filosofía del tercer año de la educación media chilena, se fundamenta en la conformación de la identidad, la complejidad de las personas y los medios sociales, la tolerancia y el respeto y sus implicancias en las acciones. Los objetivos planteados proponen entender al ser humano en la complejidad de los procesos de comunicación e interacción, valorar la vida en sociedad, resolver distintos problemas y analizar la sexualidad como dimensión constitutiva del desarrollo personal. En concordancia con los fundamentos y objetivos, los aprendizajes esperan que los estudiantes aprecien las características del grupo social de origen del sujeto, que entiendan el lenguaje y los códigos culturales del proceso de socialización, identifiquen prejuicios, aspectos cognitivos, afectivos y conductuales.

Los contenidos que aportan a este pensamiento abarcan la medición $\mathrm{y}$ evaluación de la inteligencia, el individuo como miembro de categorías sociales y como sujeto moral, la personalidad e identidad, los procesos de individuación y socialización. Las actividades consideran el análisis y la discusión de conceptos y valores. Para ello, se proponen entrevistas y ejercicios de simulación grupal para la resolución de problemas. La evaluación se orienta, por una parte, a analizar en un personaje diferentes procesos psicológicos y, por otra, a señalar en determinados problemas el pensamiento y los estilos cognitivos de resolución.

En el cuarto año, los fundamentos articulan con el año precedente. En los objetivos se plantea analizar problemas éticos de la sociedad, visiones alternativas dando opiniones fundamentadas y entender la Filosofía como forma de pensamiento crítico para la comprensión de la realidad y la orientación reflexiva de la conducta. 
Los aprendizajes esperados se basan en conocer, comprender y distinguir el conocimiento como ámbito de problemas filosóficos, normas morales, sociales y culturales, en la función normativa y expresiva del derecho y en el pensamiento aristotélico del bien.

Los contenidos prescritos para este nivel parten de la distinción entre normas culturales y morales, la relación entre sentimientos morales y la regla de oro, los conceptos morales básicos, el papel de las instituciones sociales en la formación de la conciencia moral y la relación entre poder y política. En las actividades se propone el análisis y la discusión de propaganda publicitaria, la identificación de conflictos en la vida estudiantil y la discusión acerca de su relación con los valores. En la evaluación se sugieren lecturas, comentarios y argumentaciones de fragmentos de textos y la generación de ensayos. 
Cuadro 14. Elementos del pensamiento crítico- razonable en los Programas de estudio del área filosófica de la educación media chilena.

\begin{tabular}{|c|c|c|c|c|c|c|c|c|c|c|}
\hline \multirow[t]{2}{*}{$\begin{array}{l}\text { Categorías } \\
\text { de análisis }\end{array}$} & \multicolumn{2}{|l|}{ Objetivos } & \multicolumn{2}{|c|}{ Aprendizajes esperados } & \multicolumn{2}{|l|}{ Contenido } & \multicolumn{2}{|c|}{$\begin{array}{l}\text { Actividades, estrategias y } \\
\text { recursos didácticos }\end{array}$} & \multicolumn{2}{|l|}{ Evaluación } \\
\hline & Tercer año & Cuarto año & Tercer año & Cuarto año & Tercer año & Cuarto año & Tercer año & Cuarto año & Tercer año & Cuarto año \\
\hline \multirow[t]{2}{*}{$\begin{array}{l}\text { Pensamient } \\
\text { o crítico } \\
\text { razonable }\end{array}$} & $\begin{array}{l}\text { Resolver } \\
\text { distintos } \\
\text { problemas. }\end{array}$ & $\begin{array}{l}\text { Exponer } \\
\text { ideas de } \\
\text { manera } \\
\text { coherente y } \\
\text { fundamentad } \\
\text { a. }\end{array}$ & $\begin{array}{l}\text { Aprecian } \\
\text { las } \\
\text { característi } \\
\text { cas del } \\
\text { grupo } \\
\text { social de } \\
\text { origen del } \\
\text { sujeto. }\end{array}$ & $\begin{array}{l}\text { Conocen e } \\
\text { interpretan } \\
\text { la Teoría } \\
\text { de las Ideas } \\
\text { de Platón. }\end{array}$ & $\begin{array}{l}\text { La } \\
\text { inteligencia. } \\
\text { Medición y } \\
\text { evaluación. }\end{array}$ & $\begin{array}{l}\text { Distinción } \\
\text { entre normas } \\
\text { culturales y } \\
\text { morales. }\end{array}$ & $\begin{array}{l}\text { Análisis del } \\
\text { concepto de } \\
\text { pensamiento } \\
\text { y su relación } \\
\text { con } \\
\text { percepción y } \\
\text { memoria }\end{array}$ & $\begin{array}{l}\text { Análisis y } \\
\text { discusión sobre } \\
\text { la realidad y el } \\
\text { conocimiento }\end{array}$ & $\begin{array}{l}\text { Analizan en un } \\
\text { personaje } \\
\text { diferentes } \\
\text { procesos } \\
\text { psicológicos. }\end{array}$ & $\begin{array}{l}\text { Leen, comentan } \\
\text { y argumentan un } \\
\text { fragmento. }\end{array}$ \\
\hline & $\begin{array}{l}\text { Valorar la } \\
\text { vida en } \\
\text { sociedad. }\end{array}$ & $\begin{array}{l}\text { Entender la } \\
\text { Filosofía } \\
\text { como forma } \\
\text { de } \\
\text { pensamiento } \\
\text { crítico para } \\
\text { la } \\
\text { comprensión } \\
\text { de la } \\
\text { realidad y }\end{array}$ & $\begin{array}{l}\text { Entienden } \\
\text { el lenguaje } \\
\text { y los } \\
\text { códigos } \\
\text { culturales } \\
\text { del proceso } \\
\text { de } \\
\text { socializaci } \\
\text { ón. }\end{array}$ & $\begin{array}{l}\text { Comprende } \\
\mathrm{n} \text { el } \\
\text { conocimien } \\
\text { to como } \\
\text { ámbito de } \\
\text { problemas } \\
\text { filosóficos. }\end{array}$ & $\begin{array}{l}\text { Lo } \\
\text { individual y } \\
\text { lo social. } \\
\text { Socializació } \\
\text { n e } \\
\text { individuació } \\
\text { n. }\end{array}$ & $\begin{array}{l}\text { Relación } \\
\text { entre } \\
\text { sentimientos } \\
\text { morales, } \\
\text { reciprocidad } \\
\text { y la regla de } \\
\text { oro. }\end{array}$ & $\begin{array}{l}\text { Ejercicio de } \\
\text { simulación } \\
\text { grupal para } \\
\text { la resolución } \\
\text { de } \\
\text { problemas. }\end{array}$ & $\begin{array}{l}\text { Análisis e } \\
\text { interpretación } \\
\text { del texto } \\
\text { "Alegoría de la } \\
\text { caverna". }\end{array}$ & $\begin{array}{l}\text { Señalan en un } \\
\text { problema el } \\
\text { tipo de } \\
\text { pensamiento y } \\
\text { estilo } \\
\text { cognitivo de } \\
\text { resolución.. }\end{array}$ & $\begin{array}{l}\text { Escriben un } \\
\text { ensayo sobre la } \\
\text { familia }\end{array}$ \\
\hline
\end{tabular}


orientación

reflexiva de

la conducta.

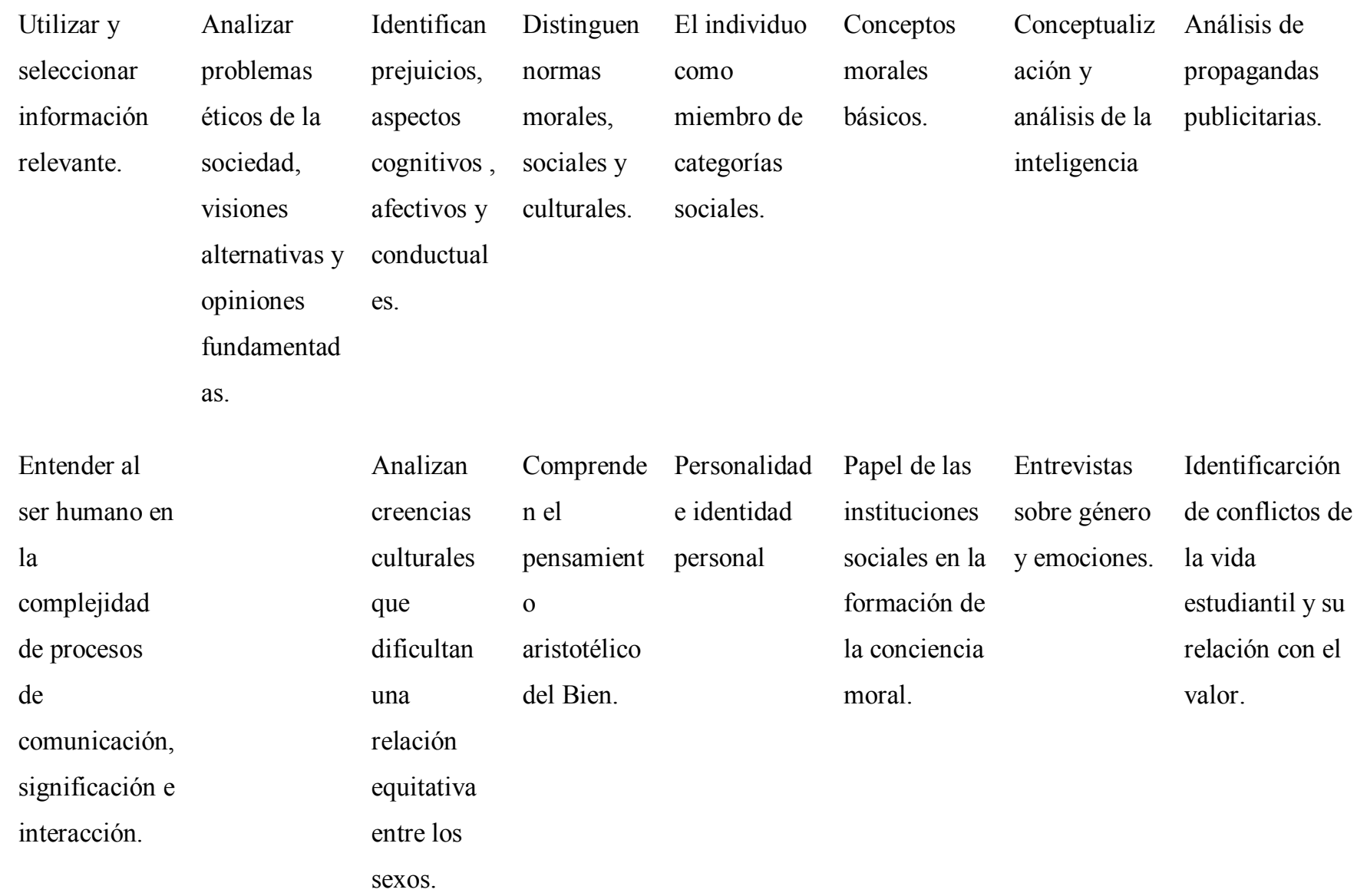




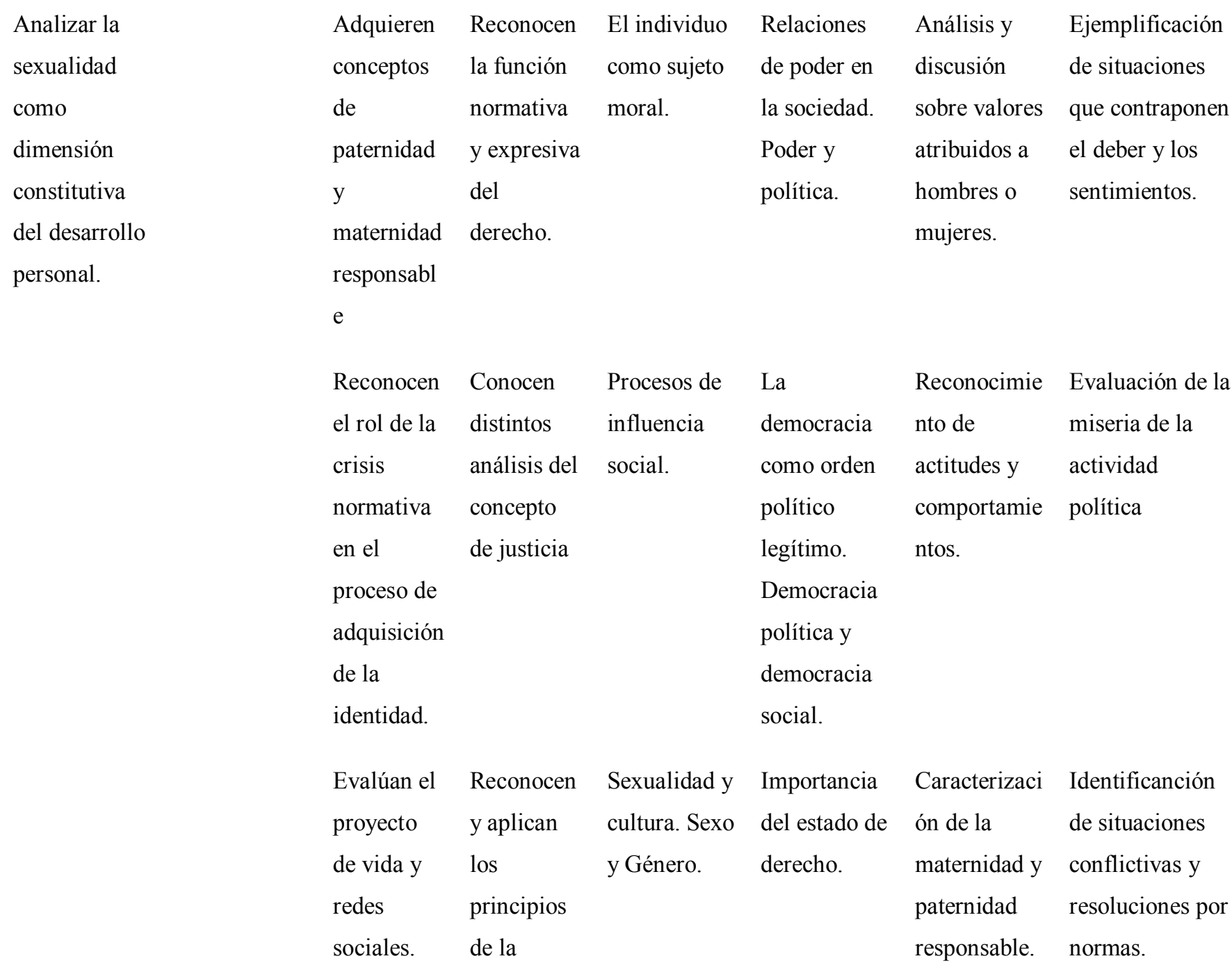


Comprende Tabúes y

n que la mitos sobre

técnica la

modifica el sexualidad.

entorno

humano y

sus

consecuenc

ias

sociales,

culturales y

morales.

\section{Exposiciones Reconocimiento \\ grupales \\ de normas del \\ establecimiento \\ educacional.}

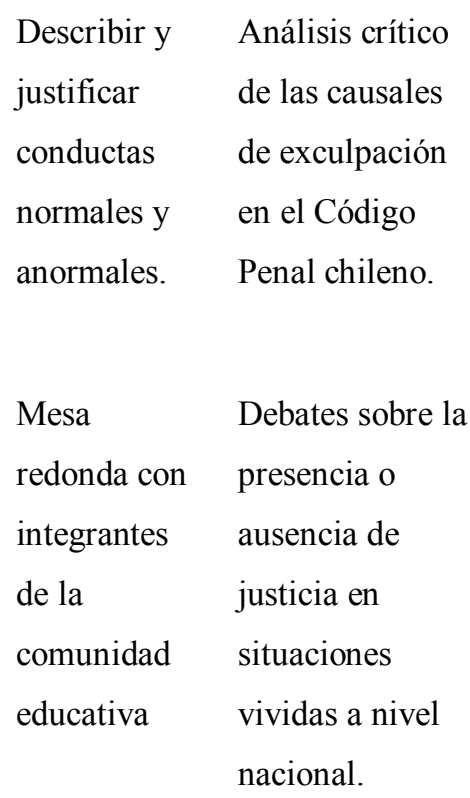


Análisis de la

responsabilidad

con futuras

generaciones 


\subsubsection{Pensamiento metacognitivo}

Como se aprecia en el Cuadro 15, el objetivo que apunta al desarrollo del pensamiento metacognitivo en cursos de tercer año de Filosofía es evaluar comportamientos e informaciones, aplicando conceptos psicológicos y psicosociales. Este objetivo se apoya en aprendizajes donde se espera que los estudiantes reconozcan problemáticas existenciales y derivadas del conocimiento, las creencias erróneas sobre la naturaleza y el funcionamiento de los procesos cognitivos, comprendan la regulación voluntaria de las emociones mediante reflexión, así como también, la importancia de distinguir entre identidad personal y social, y las modalidades de elaboración de la crisis de identidad. Los contenidos abarcan el estudio de procesos cognitivos vinculados al aprendizaje, la inteligencia, el pensamiento y la cognición, la resolución de problemas, el juicio y la toma de decisiones, el razonamiento, la creatividad, el lenguaje y la salud mental.

Entre las actividades consignadas se destaca el análisis y la descripción de formas individuales de la percepción. También, la identificación de las dificultades singulares en el aprendizaje, las ayudas personales y los relatos de la propia vivencia de socialización primaria. Como evaluación se propone trabajar con autoevaluaciones grupales, paneles y ejemplificación.

Por su parte, los objetivos del cuarto año aspiran a clarificar, evaluar y generar ideas, evaluar el propio aprendizaje, manejar la incertidumbre y adaptarse a los cambios. En atención a este logro, en los aprendizajes se espera que los estudiantes comprendan que las reflexiones metafísicas y científicas no deben argumentarse sólo sobre la base de la autoridad de un texto sagrado. Del mismo modo, que las reflexiones metafísicas y religiosas no se argumentan sólo sobre la base de los descubrimientos científicos. Por otra parte, se espera que ellos apliquen los conceptos a la propia 
experiencia y valoren el análisis ético con el apoyo del contenido para abordar los problemas específicos de la reflexión filosófica.

Entre las actividades se cita: el análisis en grupo, la identificación y la comparación de conceptos, teorías e ideas de filósofos y el reconocimiento de influencias de las instituciones sociales que ejercen poder e inculcan una moral. La evaluación apunta a la realización de trabajos escritos a partir de la identificación de elementos en la publicidad y la producción de juicios de valor que incluyen opiniones sobre ellos y su historia personal, como también, la aplicación de conocimientos acerca de los valores. 


\section{Cuadro 15.}

Elementos del pensamiento metacognitivo en los Programas de estudio del área filosófica de la educación media chilena.

\begin{tabular}{|c|c|c|c|c|c|c|c|c|c|c|}
\hline \multirow[t]{2}{*}{$\begin{array}{l}\text { Categorías de } \\
\text { análisis }\end{array}$} & \multicolumn{2}{|l|}{ Objetivos } & \multicolumn{2}{|c|}{ Aprendizajes esperados } & \multicolumn{2}{|l|}{ Contenido } & \multicolumn{2}{|c|}{$\begin{array}{l}\text { Actividades, estrategias } \\
\text { y recursos didácticos }\end{array}$} & \multicolumn{2}{|l|}{ Evaluación } \\
\hline & Tercer año & Cuarto año & Tercer año & Cuarto año & Tercer año & Cuarto año & Tercer año & $\begin{array}{l}\text { Cuarto } \\
\text { año }\end{array}$ & Tercer año & Cuarto año \\
\hline $\begin{array}{l}\text { Pensamiento } \\
\text { metacognitivo }\end{array}$ & $\begin{array}{l}\text { Utilizar y } \\
\text { seleccionar } \\
\text { informació } \\
\text { n relevante. }\end{array}$ & $\begin{array}{l}\text { Clarificar, } \\
\text { evaluar y } \\
\text { generar } \\
\text { ideas. }\end{array}$ & $\begin{array}{l}\text { Reconocen } \\
\text { problemáti } \\
\text { cas } \\
\text { existencial } \\
\text { es y del } \\
\text { conocimien } \\
\text { to }\end{array}$ & $\begin{array}{l}\text { Comprenden } \\
\text { que las } \\
\text { reflexiones } \\
\text { metafísicas y } \\
\text { científicas no se } \\
\text { deben } \\
\text { argumentar solo } \\
\text { sobre la base de } \\
\text { la autoridad de } \\
\text { un texto } \\
\text { sagrado. }\end{array}$ & $\begin{array}{l}\text { El } \\
\text { aprendizaje } \\
\text { humano }\end{array}$ & $\begin{array}{l}\text { Problemas } \\
\text { específicos } \\
\text { de la } \\
\text { reflexión } \\
\text { filosófica }\end{array}$ & $\begin{array}{l}\text { Análisis y } \\
\text { descripción } \\
\text { de formas } \\
\text { individuale } \\
\text { s de la } \\
\text { percepción. }\end{array}$ & $\begin{array}{l}\text { Identifica } \\
\text { n bienes } \\
\text { relaciona } \\
\text { dos } \\
\text { felicidad } \\
\text { y los } \\
\text { comparan } \\
\text { con las } \\
\text { ideas de } \\
\text { Sócrates } \\
\text { y } \\
\text { Aristótele } \\
\text { s. }\end{array}$ & $\begin{array}{l}\text { Realizan un } \\
\text { panel sobre } \\
\text { la formación } \\
\text { de la } \\
\text { identidad y } \\
\text { el grupo } \\
\text { social de } \\
\text { origen. }\end{array}$ & $\begin{array}{l}\text { Realizan un } \\
\text { trabajo escrito } \\
\text { individual } \\
\text { sobre una } \\
\text { propaganda de } \\
\text { felicidad a } \\
\text { cambio de } \\
\text { adquirir } \\
\text { ciertos bienes }\end{array}$ \\
\hline
\end{tabular}




$\begin{array}{lllll}\text { Evaluar } & \text { Evaluar el } & \text { Reconocen } & \text { Comprenden } & \text { Inteligenci } \\ \text { comportam } & \text { propio } & \text { creencias } & \text { que en las } & \text { a y } \\ \text { ientos e } & \text { aprendizaje } & \text { personales } & \text { reflexiones } & \text { pensamient } \\ \text { informacio } & . & \text { erróneas } & \text { metafísicas y } & \text { o. } \\ \text { nes, } & & \text { sobre la } & \text { religiosas no se } & \\ \text { aplicando } & \text { naturaleza } & \text { argumenta solo } & \\ \text { conceptos } & \text { y } & \text { sobre la base de } & \\ \text { psicológico } & & \text { funcionami } & \text { descubrimientos } \\ \text { s y } & \text { ento de los } & \text { científicos. } & \\ \text { psicosocial } & & \text { procesos } & \\ \text { es. } & & \text { cognitivos } & \end{array}$

$\begin{array}{llll}\text { Manejar la } & \text { Comprende } & \text { Aplican los } & \text { Dominios } \\ \text { incertidum } & \text { n que las } & \text { conceptos } & \text { de la } \\ \text { bre y } & \text { emociones } & \text { aprendidos a su } & \text { actividad } \\ \text { adaptarse a } & \text { pueden ser } & \text { propia } & \text { del } \\ \text { los } & \text { reguladas } & \text { experiencia } & \text { pensamient } \\ \text { cambios. } & \text { voluntaria } & & \text { o: } \\ & \text { mente por } & \text { resolución } \\ & \text { la reflexión } & \text { de } \\ & \text { y el } & \text { problemas, } \\ & \text { aprendizaje } & \text { juicio y } \\ & & \text { toma de } \\ & & \text { decisiones, } \\ & & \text { razonamien }\end{array}$

\begin{tabular}{|c|c|c|c|}
\hline Análisis & Analizan & Autoevalúan & Producen una \\
\hline del & de & la propia & lista de juicios \\
\hline aprendizaje & manera & capacidad & de valor que \\
\hline identifican & grupal la & de: propiciar & incluye \\
\hline do & presencia & un clima & opiniones \\
\hline dificultades & o & adecuado de & sobre ellos, su \\
\hline y ayudas & ausencia & trabajo, & historia \\
\hline personales. & de la & respetar las & personal y \\
\hline & libertad & opiniones & aplicación de \\
\hline & en la & etcétera. & conocimientos \\
\hline & toma de & & acerca de los \\
\hline & decisione & & valores. \\
\hline
\end{tabular}

Relato de Reconoce Ejemplifican

la propia $\mathrm{n}$ las actividades

vivencia de institucio de

la nes autoevaluaci

socializaci sociales ón y

ón que evaluación

primaria. ejerciero grupal.

sobre

ellos para

inculcar

una

moral. 


$\begin{array}{lll}\begin{array}{l}\text { Comprende } \\ \text { n la }\end{array} & \begin{array}{l}\text { Valoran el } \\ \text { análisis ético de }\end{array} & \begin{array}{l}\text { to, } \\ \text { creatividad } \\ \text { importanci }\end{array} \\ \text { la técnica. } & \begin{array}{l}\text {. Lenguaje, } \\ \text { pensamient }\end{array} \\ \text { distinguir } & \text { o y } \\ \text { entre } & \text { cognición. } \\ \text { identidad } & \\ \text { personal y } & \\ \text { social. } & \\ \text { Distinguen las } & \\ \text { modalidades } & \text { ¿Qué se } \\ \text { de elaboración } & \text { entiende } \\ \text { de la crisis de } & \text { por 'salud } \\ \text { identidadident } & \text { mental' } \\ \end{array}$

idad

Fuente: elaboración propia 


\title{
CAPÍtulO 5
}

\begin{abstract}
CONCEPCIONES DE PROFESORES DEL ÁREA FILOSÓFICA DE LA EDUCACIÓN MEDIA CHILENA SOBRE EL PENSAMIENTO COMPLEJO Y LA METACOGNICIÓN.

"La palabra es irreversible, esa es su fatalidad. Lo que se ha dicho no puede recogerse, salvo para aumentarlo: corregir, en este caso, quiere decir, cosa rara, añadir. Cuando hablo, no puedo nunca pasar goma, borrar, anular; lo más que puedo hacer es decir anulo, borro, rectifico, o sea, hablar más" Roland Barthes, El susurro del lenguaje.
\end{abstract}

Este capítulo aborda las concepciones de los profesores sobre el pensamiento complejo y la metacognición y establece relaciones con sus acciones de enseñanza en el área curricular filosófica de la educación media chilena, a partir de la información recogida y analizada en las situaciones de entrevistas en profundidad.

En primer lugar, distingue entre saberes teóricos y experienciales pedagógicos de los profesores, con especial referencia al pensamiento complejo como forma de conocimiento, capacidad, habilidades cognitivas superiores y actitud.

En segundo lugar, describe las habilidades y disposiciones del pensamiento complejo y la metacognición según el juicio de los profesores. Diferencia las habilidades cognitivas específicas del dominio curricular de otras habilidades superiores transferibles a otras asignaturas.

En tercer lugar, describe las acciones de los profesores en función de sus concepciones sobre el pensamiento complejo y la metacognición, en particular, las estrategias y actividades y los recursos didácticos empleados.

Finalmente, presenta el análisis que realizan los profesores en torno a los programas de estudio del área curricular filosófica y la propuesta de su enfoque, los problemas, saberes, y 
tipos de conocimiento que se plantean en cada unidad de trabajo y las sugerencias de las actividades y estrategias establecidas en los Programas, que buscan potenciar el desarrollo del pensamiento complejo y la metacognición.

\subsection{El pensamiento complejo y la metacognición como saberes teóricos $y$ experienciales pedagógicos.}

En nuestro estudio, las opiniones de los profesores recogidas en situación de entrevista revelan que ellos tienen una serie de saberes sobre el tema adquiridos en su formación inicial docente con distintos grados de relación, más débil o fuerte, con otros sabe- res construidos en la realidad escolar del trabajo pedagógico en las aulas. Es decir, son saberes teóricos y saberes experienciales que surgen en sus discursos y acciones, como veremos más adelante, en el análisis de las observaciones de clases. Según se aprecia en Sócrates, quien relaciona el pensamiento complejo con el pensamiento abstracto que se desarrolla psicogenéticamente durante la adolescencia y posibilita aprender, por ejemplo, la teoría metafísica. Este pensamiento se potencia a través de las prácticas y las actividades áulicas que resulten entretenidas para los estudiantes, entre otras, videos y películas.

“El pensamiento complejo, se refiere al abstracto ¿verdad? Al... al pensamiento filosófico ¿ya? ¿Cómo se puede enseñar eso? Ya... emm... uno...eh... los niños, los adolescentes ya tienen un pensamiento abs- tracto, por lo tanto, no se les haría complicado aprender la teoría... metafísica, si hablamos de esencia, si hablamos de... de... alguna, cómo cuestiones... llamémosle, más abstractas ¿ya? Porque ellos ya tienen desarrollado eso// que hacer es potenciarlo no más, y ¿cómo lo podemos potenciar? Con la ayuda de actividades que sean entretenidas ¿ya? Por medio de un video, una película eh... que ellos reflexionen y que hagan todo ese proceso intelectual cognitivo" (Sócrates, curso tercero medio). 
En cuanto a la metacognición, Sócrates la define como una comprensión sobre la comprensión que permite dar cuenta de las mejores estrategias para aprender.

“Bueno, la metacognición es muy importante porque... a partir de ahi yo me puedo dar cuenta de los propios procesos... de aprendizaje, porque la metacognición es una comprensión sobre la comprensión// puedo dar cuenta de cuáles son las mejores estrategias para aprender/ a lo mejor me doy cuenta, de porque el niño no aprende de esta manera, es como un entrenador ¿cierto? (Sócrates, tercer año medio).

En palabras de Sócrates, el desarrollo del pensamiento metacognitivo a través de la enseñanza es como un proceso de entrenamiento de un jugador, para sacarle el mejor rendimiento en el campo de juego.

"Yo estoy entrenando a alguien, entonces yo veo ahí... emm... en qué parte yo lo puedo poner, si es un jugador, para sacarle el mejor rendimiento. A lo mejor él es un delantero, quizá si lo pongo de defensa, no va rendir. Por lo tanto, yo tengo que ver ahí, qué es lo que le puedo... ofrecer, cómo le puedo sacar todo el potencial ah, cosa que dentro de treinta, cuarenta alumnos en una... en una sala de clases eso es... es... no es muy viable ah, porque igual hay que dar una clase a cuarenta o a treinta, y uno no puede ver focalizan-do todo, a no ser que esté con diez alumnos, y ahí sea personalizado, uno podría sacar todo ese... rendimiento que tienen, y todo ese potencial ¿ya?" (Sócrates, tercer año medio).

En la misma línea de opinión, Sebastián fue el más cercano en reconocer a la metacognición en relación a regulación de las estrategias de aprendizaje.

"La metacognición es muy importante porque a partir de ahí yo me puedo dar cuenta de los propios procesos de aprendizaje, porque la metacognición es una comprensión sobre la comprensión // entonces me puedo dar cuenta de cuáles son las mejores estrategias para aprender, porque a lo mejor me doy cuenta de por qué el niño no aprende de esta manera, es como un entre- nador ¿cierto?” (Sebastián, tercer año medio). 
Por otra parte, hemos visto que, en gran mayoría, los profesores reflexionan de manera escasa sobre sus opiniones, las cuales giran más en torno al pensamiento complejo.

Dichas opiniones se presentan como saberes conceptuales desconectados de sus prácticas pedagógicas. Tal es caso de Antonia, que asocia al pensamiento complejo con la abstracción y la metacognición con el darse cuenta de lo que se está aprendiendo, pero no pudo trascender estas ideas a su propia práctica ante las preguntas insistentes de la entrevistadora.

"El pensamiento complejo (repite dubitativa). Es como la capacidad de... eeh... pensar ya de manera abstracta y... ay no sé” / La metacognición es llegar a darme cuenta de lo que estoy aprendiendo, el por qué lo estoy aprendiendo" (Antonia, cuarto año)

La brecha entre los saberes conceptuales y los saberes experienciales en algunos profesores, como Pedro, se muestra como incertidumbre o sospecha respecto tanto a las posibilidades de logro de los estudiantes como de sí mismo, en carácter de profesor.

“Tiene que ver para mi con el autoanálisis, la revisión de uno mismo, sobre las prácticas. Pero en el tema de la filosofía de repente por ahí es como bastante complejo que los estudiantes lo logren // me deja una duda, o sea pero para personal, cómo lo estaba llevando yo últimamente" (Pedro, tercer año).

La sospecha sobre el logro de los estudiantes del pensamiento complejo y la metacognición, también se detectó en las declaraciones de Eva, quien asocia dicho logro a la adquisición de una base conceptual sólida y el pensamiento de los filósofos.

“A propósito de ese contenido yo creo que nace la metacognición o lo que pueden crear ellos, o desarrollar, o reflexionar o analizar. Por eso que es tan dificil, porque los chiquillos manejan muy poco conocimiento, entonces la primera tarea que una hace es tratar de instalar en ellos conocimiento. Estoy hablando de pensamiento de filósofos, teorías, en ese sentido. Porque claro si uno les dice "eh ya chiquillos pensemos" el cono- cimiento duro que ellos tienen es muy poquito, es muy limitado para poder saltar a otros tipos de ideas y niveles de análisis “(Eva, cuarto año) 
En lo que respecta al pensamiento complejo, existe gran diversidad de concepciones entre los profesores que pueden ser agrupadas en torno a las ideas de: a) forma de conocimiento, b) capacidad o habilidades y, c) actitudes, como veremos seguidamente.

\subsubsection{El pensamiento complejo como forma de conocimiento teórico.}

Las entrevistas revelan que algunos profesores conciben al pensamiento complejo como un conocimiento teórico, abstracto, fruto de los años de escolaridad, cuya adquisición se asocia a un modelo pedagógico transmisionista de enseñanza. Así, muestran la tendencia a considerar importante el conocimiento de su materia de estudio para el desarrollo del pensamiento complejo en los estudiantes $\mathrm{y}$, como contraparte, señalan el escaso conocimiento disciplinar de ellos, como un obstáculo para la enseñanza dirigida a la capacidad de reflexión sobre los temas. Así, las expresiones “conocimiento duro o teórico" son usadas por los profesores, en alusión a la complejidad de los contenidos de la asignatura (por ejemplo, racionalismo, empirismo, procesos cognitivos). Tal es el testimonio de Eva, quien relaciona al pensamiento complejo con la adquisición del co- nocimiento filosófico necesario para el desarrollo de habilidades de análisis y reflexión específicas.

"El pensamiento complejo tiene que ver con conocimiento duro, teórico,

objetivo// propósito de ese contenido yo creo que nace la metacognición o lo que pueden crear ellos, o desarrollar, o reflexionar o analizar. Por eso que es tan difícil, porque los chiquillos manejan muy poco cono- cimiento, entonces la primera tarea que una hace es tratar de instalar en ellos conocimiento // Porque claro si uno les dice "eh ya chiquillos pensemos" el conocimiento duro que ellos tienen es muy poquito, es muy limitado para poder saltar a otros tipos de ideas y niveles de análisis”, (Eva, tercer año medio).

En la misma línea, otros testimonios también resaltan la importancia del conocimiento disciplinar pero, a diferencia de lo anterior, plantean la independencia de este conocimiento respecto a las habilidades del pensamiento, en particular, de aquellas 
generales vinculadas al desarrollo evolutivo de los estudiantes. Así, por ejemplo, Sebastián señala que el pensamiento complejo refiere a lo abstracto, como capacidad ya instalada en los estudiantes, que se debe aprovechar para la enseñanza de contenidos duros" de la disciplina. De este modo, la enseñanza potenciaría al desarrollo evolutivo, para que ellos vayan regulando sus procesos de conocimiento.

“El pensamiento complejo se refiere al abstracto, Al pensamiento filosófico. Los niños, los adolescentes ya tienen un pensamiento abstracto, por lo tanto, no se les haría complicado aprender la teoría. Metafísica, por ejemplo, si hablamos de esencia, si hablamos de algunas cuestiones más abstractas. Porque ellos ya tienen desarrollado eso y lo que hay que hacer es potenciarlo no más, y ¿cómo lo podemos potenciar? Con la ayuda de actividades que sean entretenidas. Por medio de un video, una película que ellos reflexionen y que hagan todo ese proceso intelectual cognitivo, para que ellos mismos vayan regulando sus propios procesos de conocimiento “, (Sebastián, tercer año medio).

\subsubsection{El pensamiento complejo como capacidad vs. habilidades cognitivas} superiores.

En otros testimonios, se sostiene que la enseñanza en el área curricular filosófica posibilita el desarrollo de la capacidad de pensar de manera abstracta, como lo expresa Pedro, "El pensamiento complejo es como la capacidad de pensar ya de manera abstracta". Según Claudio, el pensamiento complejo permite lograr un estado de madurez o desarrollo.

“El pensamiento complejo aborda o lo podemos encontrar en un compendio, un conjunto de elementos que nos permiten obtener un grado, tal vez de, no sé si llamarlo madurez o desarrollo" (Claudio, cuarto año medio). 
En la opinión de Marcela, es la capacidad de desarrollo de las habilidades cognitivas de nivel superior que posibilita a los estudiantes advertir la utilidad y el sentido de los conocimientos aprendidos para su mundo.

"Es la capacidad primero de desarrollar habilidades cognitivas superiores y, no solamente quedarse con la materia como una cuestión mecánica, sino que extrapolar aquellos pensamientos a la propia vida particular de los alumnos, que de verdad hagan la pregunta de qué, por qué, para qué estoy aprendiendo lo que estoy aprendiendo, cómo la filosofía me sirve o lo que diga éste o determinados autores, me sirve para cues- tionar en el mundo en el que vivo", (Marcela, tercer año medio).

En cuanto a las habilidades del pensamiento complejo, en otros casos, como el de Andrés, se argumenta que éstas tienen que ver con el establecimiento de relaciones complejas o implícitas en preguntas, para reflexionar y resolver problemáticas.

"Pensamiento complejo tiene que ver con el desarrollo de ciertas habilidades que van más allá de la comprensión, tiene que ver con relaciones complejas o con relaciones de preguntas que están implícitas que los estudiantes puedan sacar reflexiones, a partir de ciertas problemáticas y resolver ciertas problemáticas, utilizando ciertas habilidades básicas”, (Andrés, cuarto año medio).

\subsubsection{El pensamiento complejo y metacognitivo como actitud.}

Pensar y reflexionar filosóficamente, para algunos profesores posibilita el desarrollo de actitudes o disposiciones para juzgar, evaluar, valorar, respetar, discernir, analizar la realidad, como lo expresan Federico y Antonia, a partir de las problemáticas y reflexiones que favorecen la adopción de una postura crítica.

"Los desarrollos actitudinales a partir de la filosofía van muy de la mano. Que ellos puedan desarrollar ciertas habilidades que solamente se dan el plano oral/juzgar, evaluar, valorar aspectos, contextos, situaciones, pero que el programa no los propone y que uno a partir de la práctica, del ejercicio pedagógico, de la retroalimentación que se da con otros colegas de la misma 
asignatura, o de otras asignaturas, las va desarrollando y las va aplicando”, (Federico, tercer año medio).

"En la filosofía se ponen en juego todos los elementos para desarrollar el pensamiento complejo y la metacognición/l se plantean problemáticas filosóficas, intelectuales que les permiten a los chiquillos ponerse en una actitud como de pensar para poder reflexionar, para poder criticar”, (Antonia, tercer año medio).

\subsection{Habilidades y disposiciones del pensamiento complejo y la metacognición}

\subsubsection{Habilidades cognitivas específicas del dominio curricular.}

En general, los profesores reconocen que la enseñanza en el área curricular de la Filosofía pone en juego todas las habilidades cognitivas, desde las más básicas a las más complejas, pero no especifican con claridad la distinción entre ellas, ni la relación que establecen entre sí para el desarrollo del pensamiento y la metacognición.

Acuerdan que las habilidades específicas del dominio curricular son: diálogo, argumentación, análisis, reflexión, autocrítica, resolución de problemas y creatividad. Argumentan que las problemáticas filosóficas pueden ser abordadas desde diferentes perspectivas y esto permite adoptar una actitud crítica y reflexiva. Los pensamientos de Sebastián, Eva, Pedro y Antonia ilustran esta observación.

“El diálogo, que es lo más importante, la argumentación, también el pensamiento abstracto. Es que igual hay conceptos bastante abstractos que tienen que tomar la otra habilidad que ponen”, (Sebastián, tercer año medio).

“En la filosofía se ponen en juego todos los elementos para desarrollar el pensamiento complejo y la metacognición // porque tiene problemáticas objetivas, hay una diversidad de ideas de autores, que hace que los chiquillos despierten a algunas ideas que por sí solos no pueden llegar// les permiten 
ponerse en una actitud de pensar para poder reflexionar, criticar”, (Eva, cuarto año medio).

"Pone en juego la reflexión, la autocrítica. La autocrítica en la resolución de problemas también”, (Pedro, tercer año medio).

"El pensamiento crítico y la capacidad de resolver problemas a través del pensamiento", (Antonia, tercer año medio).

También, los profesores reconocen la elaboración de inferencias, a partir del análisis conceptual, la conclusión, la extrapolación, la sintesis, comparación como se aprecia en los testimonios de Federico y Marcela.

"La enseñanza de la filosofía involucra habilidades de orden superior, inferenciales que a partir del desarrollo conceptual uno va desarrollando y va través de estos conceptos, desglosando gruesas temáticas, o diversos conceptos que tienen implícito en estas temáticas, y siempre son del orden, digamos de la inferencia, del análisis, la conclusión, son cuestiones a la base del desarrollo, o de la enseñanza de la filosofía en este caso”, (Federico, tercer año medio).

"Básicamente el análisis, la capacidad de extrapolar, por ejemplo, de ir sitúando pensamientos antiguos en situaciones cotidianas, la capacidad de sintetizar y de comparar autores importantes para ellos, la relación que eso tenga con su propio pensamiento, y la capacidad de creación también, porque hay creación de pensamiento propio, a partir de lo que los autores dicen”, (Marcela, tercer año medio).

\subsubsection{Habilidades cognitivas superiores transferibles a otras asignaturas.}

En las opiniones recogidas, una minoría reconoce que el abordaje de los contenidos propios del área curricular posibilita el desarrollo de la comprensión lectora, la expresión oral y el vocabulario, por ende, la metodología didáctica se encamina a este logro, como 
base para el desarrollo del pensamiento. Así lo revelan los testimonios de Claudio y Sebastián.

"Sin duda la filosofía incorpora a todas las habilidades. Sí, porque también insisto mucho en los contenidos, pero independiente de cuáles sean desarrollan las habilidades. Por ejemplo, hay algunas habilidades que yo he tratado de ejercitar mucho con ellos, que tiene que ver por ejemplo con la comprensión lectora, porque trato de trabajar mucho con textos, porque trato de que mejoren su vocabulario de que el ejercicio del leer también les permite incorporar nuevas ideas, pero también hay otras habilidades que tienen que ver, por ejemplo, con la expresión, con las exposiciones orales”, (Claudio, cuarto año medio).

"Creo que una de las habilidades que veo carencias acá es la comprensión lectora, porque todo esto de la filosofía parte por el texto, y si los niños no tienen una capacidad comprensiva, que es la grave falencia que yo noto en la enseñanza de la filosofía, no les gusta leer. Por lo tanto, si no les gusta leer ¿cómo pueden incorporar un pensamiento que es abstracto? Entonces, eso sería también lo que pone en juego, la capacidad lectora, el análisis, la síntesis, el resumen", (Sebastián, tercer año medio.

También, algunos profesores, como Andrés, reconocen la importancia del desarrollo de la metacognición a lo largo de la enseñanza para que los estudiantes tomen conciencia de sus propios aprendizajes, pensamiento y comportamiento.

"El trabajo metacognitivo creo que va por el lado de decirles (a los estudiantes) que se den cuenta y que piensen cómo aprenden, que piensen cómo se comportan, que piensen en lo que hacen, y bueno la filosofia es útil en ese sentido porque al final les digo "ya, pero esto que me estás diciendo ¿lo dices porque tú lo crees? ¿Cuáles son tus argumentos? ¿O estás repitiendo otra cosa? Entonces es una habilidad que yo creo útil, que se cuestionen un poco las cosas, que vean cuál es su rol de estudiante y vean cómo es el proceso educativo del cual son partícipes. Creo que es un ejercicio que ellos no hacen. Entonces yo creo que más que la metacognición que se enseña a hacer en el cierre de la 
clase yo trato de hacer una metacognición más general con respecto al proceso entero", (Andrés, cuarto año medio).

\subsection{Acciones de los profesores en función de sus concepciones sobre el pensamiento complejo y la metacognición}

\subsubsection{Estrategias y actividades.}

Las estrategias de enseñanza que los profesores dicen emplear en las aulas para favorecer el pensamiento complejo y la metacognición se expresan en actividades tales como: trabajo en proyecto, trabajo autónomo dirigido, elaboración de ensayos, investigaciones, construcción y/o análisis de vídeos, activa y usar ideas previas, diálogos dirigidos, debates y simposios. Esta observación se ilustra con los testimonios de Andrés, Marcela. y Eva.

"Va a depender bastante del tipo de curso con el cual uno trabaje, pero este año en particular he encontrado bastantes beneficios en el trabajo en proyecto, en el trabajo autónomo Respecto a los recursos didácticos no creo que haya recursos didácticos específicos, yo trato de usar de todo en realidad, creo que el recurso didáctico independiente de si es tecnológico o no es que esté en sintonía con ellos", (Andrés, cuarto año medio).

"El trabajo individual dirigido, por ejemplo, como en un ensayo donde hay una pregunta abierta, yo a veces lo que hago es poner las tesis en discusión para que elijan una o creen la propia. También, el debate, por- que ahi hay desarrollo de ideas, y de posturas propias, de puntos de vista fundamentados. La investigación también, porque trabajamos harto con problemas éticos contemporáneos // la construcción de vídeos, el análisis de películas o de cortometrajes// por ejemplo que trabajamos con simpo- sio, entonces fuimos trabajando en grupo, las alumnas fueron opinando, en base a sus opiniones, 
iban siendo evaluadas y el resto tenía que seguir opinando, digamos como una mesa común”, (Marcela, tercer año medio)

"El tema más significativo es el del trabajo directo de los estudiantes, así como a ellos se les entrega un contenido, un pensador para que puedan desarrollar el pensamiento complejo y trabajar con las ideas que ellos comprenden, no trabajar con ideas que el profe cree que el estudiante ha comprendido, ahi se produce un aprendizaje mucho más significativo que estar hablando o decirles a los chiquillos "lo que deberían haber entendido es esto". La idea es que avancen por sí solos, no suponer que entendió lo que uno le quiere explicar en el aula porque o si no se está perdiendo el tiempo no más (Eva, cuarto año).

Los profesores reconocen la centralidad de la lectura, el análisis de textos y el diálogo para desarrollar los contenidos de su materia. Como se aprecia en las opiniones de Federico, Eva y Antonia.

"Primero la lectura de textos es una de las estrategias básicas, que tiene que ver con el desarrollo de las habilidades que involucra la filosofía, (Federico, tercer año medio). "la estrategia tiene que ver con la participación horizontal, siempre en diálogo, en conversaciones, en discusiones // siento que el recurso didáctico en filosofía es el diálogo, eso es lo principal, la actitud de diálogo, la actitud de crítica, más allá del material audiovisual, de hecho hay harto material audiovisual que se puede utilizar pero mientras no se converse, no se dialogue en la formación para mí no hay un mayor aprendizaje significativo”, (Eva, cuarto año medio).

"El diálogo es super importante, que las chiquillas dialoguen, y eso también es una de las cosas que a ellas les gusta de las clases de filo-sofía, porque es de las pocas clases en las que ellas pueden expresarse libremente, pueden dialogar formando grupo, porque pueden lograr un conocimiento más elaborado, un pensamiento más elaborado. Trabajo grupal, trabajo en parejas, las disertaciones en todas las clases", (Antonia, tercer año medio) 
Con relación a la lectura, algunos profesores, como Eva, manifiestan que intentan trabajar la comprensión a partir de textos más sencillos, para ejercitar niveles más complejos metacognitivos. Para Pedro, el análisis de los textos filosóficos los pone de lleno ante el conocimiento del vocabulario.

"Teoría del conocimiento en tercero medio es súper complejo para los chicos, entonces qué es lo que hago yo analizamos un texto muy simple, que pueden ser dos planas ¿qué entendieron? Y todo lo que entendieron sobre eso yo asiento conocimiento. Y recién ahi siento que pueden ir avanzando para poder llegar a niveles más complejos o metacognitivos”, (Eva, cuarto año medio).

"El análisis de textos filosóficos quizá fuese lo ideal en trabajar, pero se vuelve tremendamente complejo, por el tema del vocabulario, de la comprensión lectora de los estudiantes, entonces si lo vemos en perspectiva de repente el tema de plantear un problema, plantear un caso y como ese caso se relaciona con cierta visión de la filosofía es mucho más efectivo, (Pedro, tercer año medio).

En este marco, resulta importante señalar la opinión de algunos profesores respecto a las "buenas prácticas". Al respecto, Andrés las relaciona con las actividades que permiten evidenciar el proceso de enseñanza y aprendizaje, en oposición a la memorización de conocimientos.

"Yo creo que buenas actividades son aquellas que nos permiten al profesor junto con los alumnos evidenciar un proceso. Todas las actividades, por ejemplo, que uno las evalué como una evaluación de proceso, creo que ayuda mucho// en una prueba está mucho esto de la calificación, una nota, y que muchas veces eso los lleva a memorizar los contenidos y luego bueno, perfectamente los olvidan. En cambio, cuando uno establece actividades que dan cuenta de todo un proceso, creo que se le fija aún más, sean los contenidos el desarrollo de una determinada habilidad, escrita, oral, etcétera", (Claudio, cuarto año medio). 


\subsubsection{Recursos didácticos.}

Los profesores declaran una amplia variedad de recursos audiovisuales como películas de internet, vídeos, cortometrajes, canciones, documentales, reportajes, imágenes. El uso de estos recursos apoya el proceso de enseñanza y aprendizaje y, en especial, la discusión y reflexión sobre temas, casos, problemas, situaciones, fenómenos sociales. La observación se ilustra con los testimonios de "Antonia, Pedro, Federico y Sebastián.”

"Después de haber visto la materia, ellas pueden reflexionar en torno a lo que están viendo, que se cuestionen. ¿Qué haría usted en el caso de...? // ¿recursos audiovisuales? pues guías, trabajos, videos, cortos, cortometrajes, escuchar una canción, que les haga sentido lo que están escuchando, que sean capaces de relacionarlo con lo que estamos viendo", (Antonia, tercer año medio).

"En internet hay mucho material visual, hay mucho texto interesante hoy en día que uno puede tener acceso fácil, hay mucho material no sola-mente videos, hay imágenes, depende a veces de básicamente la disposición del profesor, pero en sí, por ejemplo los planes y programas es muy ilimitado lo que tiene”, (Pedro, tercer año medio).

"Otras de las estrategias de enseñanza que son efectivas es el uso de re-cursos audiovisuales: videos, películas, y en el uso de tecnologías de la información y de la comunicación, contribuyen de forma satisfactoria a la enseñanza de la filosofía. Dependiendo del argumento de cada una de estos videos y de estas películas, es posible hacer el contraste a través de la formulación de diversas preguntas que pueden ir desde lo más simple a lo más complejo contrastando las diversas perspectivas filosóficas, de algunos autores con las temáticas que involucran estos videos por ejem- plo, o estos estos filmes", (Federico, tercer año medio).

"Los vídeos, una buena película/l. Por ejemplo, estábamos pasando en cuarto medio el chacal de Nahueltoro, entonces ahi veíamos un problema moral a 
partir de un vídeo// Si estamos hablando de la percepción, de la realidad nos vamos a Platón y ahí podemos ver una película como Matrix donde ellos dilucidan “a ver, ¿qué es lo que es la realidad, realmente?”. Llevarlos a un punto donde se cuestionen, sobre las cosas mismas que perciben Entonces, esos recursos audiovisuales son muy buenos como para enseñar la filosofía. Aparte de los textos, por supuesto que le dan pie”, (Sebastián, tercer año medio).

\subsection{Reflexiones de los profesores sobre la propuesta curricular filosófica de la enseñanza media chilena}

Los profesores presentan una mirada crítica y dudosa respecto a lo que se plantea, desde los Programas del área filosófica, en cuanto a los enfoques, saberes y actividades propuestas para desarrollar o promover el pensamiento complejo y la metacognición.

Hay consenso entre ellos respecto a los enfoques desactualizados que señalan plantea la propuesta curricular oficial para el área filosófica, en donde el énfasis está puesto, a la vista de ellos.

\subsubsection{Sobre los enfoques propuestos en los Programas.}

Los segmentos que se presentan a continuación plantean detectar una contradicción en los Programa, puesto que declaran dentro de sus objetivos el desarrollo del pensamiento. Sin embargo, el enfoque tiende a ser tradicional al apostar por el conocimiento y comprensión de algunos contenidos filosóficos, adscribiendo a una perspectiva histórica de la Filosofía y la historia del pensamiento, sin asociarlos a la vida cotidiana.

Para Eva existe una contradicción entre lo que se declara en los Programas y lo que sucede en la práctica. Pues el programa propone conocer y comprender conceptos 
filosóficos, lo cual limita las posibilidades de la Filosofía para trabajar niveles cognitivos más altos. Dado lo anterior es que ella reconoce modificar la propuesta curricular oficial.

"Se supone que debería ser más analítico, como de crítica, que es lo que declara; sin embargo, en realidad son super básicos, no sale mucho del conocer y comprender por lo que en la práctica una termina haciendo otras cosas pues la filosofía es puramente compleja y metacognitiva entonces si quiero llevar a mis estudiantes a esos niveles de pensamiento no puedo quedarme solo con lo que me dice el programa. O sea, es un enfoque más tradicional que apuesta por la comprensión de algunos contenidos filosóficos. En el caso de tercer año donde se trabaja psicología es más crítico eso. trabajamos los procesos psicológicos, sociales, etc pero se mandata que desde una mirada más teórica. otra cosa es lo que una realmente hace en el aula para trabajar el pensamiento complejo y desarrolle una opinión personal ¿ya? Porque como te decía lo que a una le entrega el ministerio son niveles básicos, poco trabajan con los niveles cognitivos más altos, y en filosofía no nos podemos quedar a ese nivel ojalá podamos trabajar a nivel de analogía, al menos en mi aula, que ellos sean capaces de hacer analogías con otras asignaturas o con los diferentes pensadores que se ven dentro del aula. Pero ojo que eso no lo exige el programa, para nada” (Eva, 18 años de experiencia)

Para Sócrates y Federico, en cambio, el Programa sólo busca el conocimiento de contenidos básicos de la Filosofía, adquiriendo un enfoque histórico y academicista. Cuestión que limita el papel de la Filosofía como disciplina que ayuda a reflexionar. Federico incluso, menciona la taxonomía de Bloom para ejemplificar los niveles básicos en los que se orienta la propuesta curricular.

"En resumidas cuentas lo que busca el programa, es que se pasen unos contenidos mínimos, de los cuales eh... generalmente nunca se pasan completamente. Por lo tanto, uno siempre va quedando con... con... con contenidos rezagados y no se cumple el objetivo, que es el desarrollo del pensamiento crítico, que al final se comienza a hablar de filosofía como una historia de la filosofía, pero no de la filosofía en sí... que le va servir al joven para que reflexione... para que enfoque de otra manera, para que sea crítico, inclusive es contraproducente que acá el sistema educativo plantee la filosofía 
como un modo ¿verdad? Reflexivo en los alumnos, pero no se les enseña a pensar” (Sócrates, 22 años de experiencia)

“Los planes y programas solamente muestran una visión histórica de... la filosofía ¿ya? Lo que uno enseña es una visión histórica de la filosofía, pero los objetivos que están planteados en el programa, no están eh... eh... enmarcados dentro del desarrollo de habilidades ¿ya? De orden superior o la... o las habilidades que... eh... implica digamos el pensamiento crítico, solamente se ubican en... en el área, si... es necesario por ejemplo utilizar una taxonomía, podemos nombrar la más común que es la de Bloom, solamente se queda en el ámbito del conocimiento, solamente se queda en el ámbito del conocimiento (repite) $y . .$. eh... los objetivos como bien digo, no están eh... señalados o encaminados hacia el desarrollo de habilidades superiores como la inferencia, el análisis, la evaluación, la síntesis." (Federico 7 años de experiencia)

Por otro lado, hay quienes, como Antonia y Andrés, acusan una desactualización en las propuestas de los Programas, siendo demasiado conceptual y asignándoles demasiado tiempo a algunas unidades por sobre otras innecesariamente.

"Es desactualizado porque es muy conceptual y a las chiquillas no les hace mucho sentido, no...no ven lo práctico de la enseñanza de la filosofía... como programa, porque uno si se la da después. Ellos... ellas si logran comprender, pero el programa eeh... es super complejo // El de tercer año es mucho más práctico, pero eeh... Le dan muy poca importancia a la cuestión social y mucha a lo conceptual, muchoa loo eeh... al ¿cómo se llama? Al sujeto como proceso psicológico y no sociales, que en realidad nosotros no extendemos mucho más, pero como programa eeh... son seis semanas. Y eso no da para seis semanas, da para mucho más”. (Antonia, 10 años de experiencia)

"De partida el programa // es más instructivo, más como que los chicos tengan conocimientos técnicos... más que... que tengan una... una reflexión” (Andrés, XXX años de experiencia)

(Pedro) 
"Los problemas son de distinta índole, dependiendo del programa, si se trata de... psicología o filosofía. En el caso de... filosofí... (corrige) psicología en tercero medio, uno se encuentra con problemas... eh... ¿cómo llamarlos? Quizá mm... de índole personal de ellos, em... problemas que pueden guardar relación con respecto a su salud. Eh... en cambio en cuarto medio de filosofía, los problemas que... eh...por los contenidos que uno aborda ... eh... sin duda, entre ellos son los de índole moral, los dilemas morales... eh... el desarrollo del... sujeto como sujeto moral, eh... pero insisto depende mucho, emm... parte de los problemas se presentan de acuerdo a lo que uno vea ¿mmg?”(Claudio)

"Lo que tiene que ver con los problemas éticos, si la concepción de la moral, el tema de la moral social, cómo se.... Cómo nos vinculamos como individuos y sociedad, y.... algunos dilemas éticos contemporáneos por ejemplo”. (Marcela)

El siguiente segmento de la entrevista permite identificar un análisis centrado en la desactualización metodológica de los programas por ser, tal vez, de los años 90. Sin embargo, se reconoce que los profesores deben darle contexto, "enlazar" el contenido con la vida cotidiana de los estudiantes.

"El ejercicio que hay que hacer y que... por lo menos, lo que hemos conversado con docentes, es el tema de hacer la... eh.... (Ruido de notificación de celular) el enlace con la vida cotidiana, y.... con la vida contemporánea, porque básicamente el programa está situado a elementos bastante clásicos de la filosofía, falta eh... reflexión más situada por ejemplo, no hay pensamiento latinoamericano, eh... aparece solamente un texto de una mujer, eh... en... en el libro de... de psi...de psicolo.... (corrige) de filosofía, no hay textos de mujeres, en el libro de psicología por ejemplo como sugerido, entonces eh... el enlace que hay que hacer es fundamentalmente a lo... a los alumnos situarlos eh... con esos conceptos, que son atemporales, por ejemplo el mito de la caverna es atemporal, y uno lo sitúa (sonido de notificación de celular) desde el mito, desde la lectura de.... La República hasta la vida contempora ... hasta la vida de ellos ahora, con su contexto, con sus visiones particulares, qué podría representar la caverna por ejemplo, y ese es el ejercicio que hay que hacer, no es algo que venga muy explicitado desde la ... el programa como fue concebido 
en el ministerio, entendiendo que estos programas son del año noventa y ocho aproximadamente y que no ha habido cambios sustanciales en ellos. (Marcela)

Finalmente, el testimonio de Claudio relaciona los problemas y el saber propuesto en los programas con las formas de evaluar que allí se sugieren, puesto que la evaluación sería una herramienta clave para monitorear habilidades:

“ ¿En los programas? Eh ... yo... he percibido... de que eh... de alguna manera, cada unidad hay sugerencias para evaluar, por ejemplo eh... en ciertas unidades de los pra... (corrige) de los programas por ejemplo, se nos sugiere por ejemplo no hacer pruebas escritas, pudiendo no hacerlas... pero, eh... me da la impresión que también eso quiere eh... darle un sello tal vez,o una cierta orientación, por ejemplo, no sé, individuo y sexualidad ¿mmg? Evitar tal vez... la prueba, no sé sea una prueba mixta u otra. Yo por ejemplo, lo que utilizo... bueno, he... he abu- sado de ese... el recurso de los textos, pero eh... juego también con ello, por ejemplo no siempre hago el mismo tipo de pruebas, hay veces por ejemplo que les hago una prueba situacional, y al final de esa prueba, por ejemplo, los mandatos ¿mmg? No necesariamente tiene que ser una prueba mixta o de desarrollo, entonces eh... yo creo que eh... en parte también eh... si bien no se hacen estas sugerencias, dependiendo de la unidad, bueno no deja de ser la decisión de cada profesor el cómo los va evaluar, yo creo que también hay que tener en consideración... a los estudiantes (Claudio)

\subsubsection{Sobre las actividades y estrategias.}

En cuanto a la identificación de propuestas de actividades y estrategias establecidas en los Programas de estudio, tendientes a desarrollar o promover el desarrollo del pensamiento complejo y de la metacognición los profesores señalan desconocer orientaciones tan claras respecto a aquello, mientras que otros acusan de utilizar recursos y estrategias desactualizados, de otra época. 
El segmento de la entrevista que se presenta a continuación representa el desconocimiento del profesor sobre las prácticas pedagógicas propuestas en los Programas de Estudio que orienten a procesos asociados con los tipos de pensamiento complejo y metacognitivo. El profesor reconoce que, si es que existe algo relacionado, él no lo sigue puesto que de cualquier forma sería poco práctico.

“No sé si en los programas hay... alguna que... que entregue... eso... eso tan claramente. Obviamente hay algunas cosas que dicen que los alumnos reflexionen, que... los alumnos eh... aquí se puede dar esta dinámica, como que el... si uno lee los planes, lo que dice... como que algunos reflexionen y estar ahí, que pueda aparecer y que se dé. Pero eso ya no está en sintonía con los niños de ahora. Yo... a mi me pasó con una actividad que hice la primera vez que hice clases, como que me apoyé bastante en los planes al principio porque uno es inexperto y trata como de aferrarse a cosas que quizá puedan estar probadas y ya no funcionan. Lo que el plan dice que puede pasar en una clase no sucede, entonces yo no creo que lo... lo... en ... a estas alturas por lo menos, donde... es todo tan utilitario, donde los chicos están consien... donde a los chicos se le entrena y se les... presiona por la prueba estandarizada, obviamente ellos pretenden encontrar en las asignaturas algo más eh... más pragmático, más útil para... para lo que a ellos les dicen que es importante, a pesar de que las notas valen lo mismo, las notas de lenguaje, de historia, valen lo mismo que la nota de filosofía si lo vemos en términos prácticos, pero los niños lo ven... lo ven distinto, entonces... eh... la... lo... los planes no... no están en sintonía con ... con esa... con esa área del estudiante, con el área más pragmática. Entonces yo no siento que los planes... (corrige) ósea, si pretenden hacer eh... desarrollo del pensamiento crítico, pensamiento complejo, ya no... ya no sirve lo que ellos proponen, ya no... no funciona”. (Andrés)

En oposición al caso presentado anteriormente nos encontramos con miradas como las de Antonia y Sócrates, quienes reconocen que el Programa de Estudio del área curricular filosófica sí plantea actividades y estrategias en sus sugerencias metodológicas. Sin embargo, para Antonia, todo ello va acompañado de recursos desactualizados al proponer, por ejemplo, películas “antiguas", lo que hace inútil este punto si buscamos desarrollar el 
pensamiento complejo y la metacognición. Sócrates, por su parte, destaca la lectura como estrategia base para desarrollar pensamiento complejo y otras habilidades fundamentales.

"El programa eeh... da algunas actividades super especificas, que en la práctica no es posible llevarlo a cabo. Yo ja... nunca, si no (..) eeh... las actividades que están en la... el programa, porque no me sirven. Además de algunas películas que yo pueda tomar, ya están desactualiza-das las películas. Entonces está (tono irónico, risa leve) como ponerle no sé, matrix. Ya están en otra época de Chile, a lo mejor la Isla tiene más sentido para ellos que matrix. Entonces noo... casi nunca ocupo los loo... las actividades de ahi”. (Antonia) “Bueno, generalmente qué sugiere... es el propio análisis crítico de la lectura, en lectura es lo que más yo le inculco a los alumnos, porque es lo que... la base de todo pu... entonces análisis de textos ¿no cierto? Eh... podemos hacer ensayos, también sugiere ensayos que los niños puedan hacer ensayos ¿verdad? Aprender la estructura del ensayo, análisis de textos. Bueno, aparte de eso podría considerar también emm... eh... otro tema de evaluación eh... evaluarlas... emm ... mm... las pruebas ¿no cierto? Que es un instrumento que yo no lo podría dejar de usar (Antonia).

\subsubsection{Sobre las actividades y estrategias}

En cuanto a la identificación de propuestas de actividades y estrategias establecidas en los Programas de estudio, tendientes a desarrollar o promover el desarrollo del pensamiento complejo y de la metacognición los profesores señalan desconocer orientaciones tan claras respecto a aquello, mientras que otros acusan de utilizar recursos y estrategias desactualizados, de otra época.

El segmento de la entrevista que se presenta a continuación representa el desconocimiento del profesor sobre las prácticas pedagógicas propuestas en los Programas de Estudio que orienten a procesos asociados con los tipos de pensamiento complejo y metacognitivo. El 
profesor reconoce que, si es que existe algo relacionado, él no lo sigue puesto que de cualquier forma sería poco práctico.

"No sé si en los programas hay... alguna que... que entregue... eso... eso tan claramente. Obviamente hay algunas cosas que dicen que los alumnos reflexionen, que... los alumnos eh... aquí se puede dar esta dinámica, como que el... si uno lee los planes, lo que dice... como que algunos reflexionen y estar ahí, que pueda aparecer y que se dé. Pero eso ya no está en sintonía con los niños de ahora. Yo... a mi me pasó con una actividad que hice la primera vez que hice clases, como que me apoyé bastante en los planes al principio porque uno es inexperto y trata como de aferrarse a cosas que quizá puedan estar probadas y ya no funcionan. Lo que el plan dice que puede pasar en una clase no sucede, entonces yo no creo que lo... lo... en ... a estas alturas por lo menos, donde... es todo tan utilitario, donde los chicos están consien... donde a los chicos se le entrena y se les... presiona por la prueba estandarizada, obviamente ellos pretenden encontrar en las asignaturas algo más eh... más pragmático, más útil para... para lo que a ellos les dicen que es importante, a pesar de que las notas valen lo mismo, las notas de lenguaje, de historia, valen lo mismo que la nota de filosofía si lo vemos en términos prácticos, pero los niños lo ven... lo ven distinto, entonces... eh... la... lo... los planes no... no están en sintonía con ... con esa... con esa área del estudiante, con el área más pragmática. Entonces yo no siento que los planes... (corrige) ósea, si pretenden hacer eh... desarrollo del pensamiento crítico, pensamiento complejo, ya no... ya no sirve lo que ellos proponen, ya no... no funciona”. (Andres)

En oposición al caso presentado anteriormente nos encontramos con miradas como las de Antonia y Sócrates, quienes reconocen que el Programa de Estudio del área curricular filosófica sí plantea actividades y estrategias en sus sugerencias metodológicas. Sin embargo, para Antonia, todo ello va acompañado de recursos desactualizados al proponer, por ejemplo, películas “antiguas”, lo que hace inútil este punto si buscamos desarrollar el pensamiento complejo y la metacognición. Sócrates, por su parte, destaca la lectura como estrategia base para desarrollar pensamiento complejo y otras habilidades fundamentales. 
“el programa eeh... da algunas actividades super específicas, que en la práctica no es posible llevarlo a cabo. Yo ja... nunca, si no (..) eeh... las actividades que están en la... el programa, porque no me sirven. Además de algunas películas que yo pueda tomar, ya están desactualizadas las películas. Entonces está (tono irónico, risa leve) como ponerle no sé, matrix. Ya están en otra época de Chile, a lo mejor la Isla tiene más sentido para ellos que matrix. Entonces noo... casi nunca ocupo los loo... las actividades de ahi”. (Antonia)

“Bueno, generalmente qué sugiere... es el propio análisis crítico de la lectura, en lectura es lo que más yo le inculco a los alumnos, porque es lo que... la base de todo pu... entonces análisis de textos ¿no cierto? Eh... podemos hacer ensayos, también sugiere ensayos que los niños puedan hacer ensayos ¿verdad? Aprender la estructura del ensayo, análisis de textos. Bueno, aparte de eso podría considerar también emm... eh... otro tema de evaluación eh... evaluarlas... emm... mm... las pruebas ¿no cierto? Que es un instrumento que yo no lo podría dejar de lado ¿verdad? Porque ahí yo veo si realmente se aprendieron los contenidos o no, pero sería comprensión lectora, los ensayos, las pruebas eh... también podría ser los trabajos de investigación ¿no cierto? Las exposiciones, que es otra cosa más que tendríamos como recurso ahi para evaluar eh... los debates, que es muy importante también eso, los debates para ver si... eh... hay buenos argumentos ahí, y... bueno así, bastante. (Socrates) 


\title{
CAPÍTULO 6
}

\section{PRÁCTICAS EN LAS COMUNIDADES DE AULA DE LA EDUCACIÓN MEDIA FILOSÓFICA CHILENA}

\begin{abstract}
Como miembros de la civilización humana, somos herederos, no de una pregunta sobre nosotros mismos y del mundo, ni de un cuerpo acumulador de información, sino de una conversación iniciada en el bosque primitivo y extendida y convertida cada vez más en algo articulado a lo largo de los siglos. Es una conversación que continúa en público y en el interior de cada uno de nosotros. La educación, estrictamente hablando, es una iniciación a la habilidad y a la participación en esta conversación, en la que nosotros aprendemos a conocer las voces, a distinguir las formas correctas de expresión, y a través de la cual adquirimos los hábitos intelectuales y morales apropiados a la conversación. Y es esta conversación la que, finalmente, da paso y carácter a toda actividad humana y a toda expresión. Michael Oakeshott, 1962 (En Richards, 1991)
\end{abstract}

Este Capítulo recoge las observaciones realizadas en clases del área curricular filosófica de la educación media chilena, así como también, del análisis de las formas de interacción verbal y construcción compartida de conocimientos, de las principales estrategias y participación en los procesos de las clases. Los comentarios se ilustran con segmentos de las observaciones.

En primer lugar, se describen las formas de interacción más frecuente. No nos detenemos en los pormenores de las secuencias interactivas verbales dado que, conforme a los objetivos trazados, nuestra investigación de campo no ha descendido al nivel de análisis de los diálogos de las clases observadas.

En segundo lugar, se abordan los rasgos más sobresalientes de los problemas los problemas que se abordan en las clases, las discusiones y reflexiones colectivas.

Finalmente, se distinguen dos niveles de participación y trabajo en las clases, alta y baja participación que se corresponden con el mayor o menor control de los profesores de los intercambios y de la centración en el estudiante del proceso de enseñanza y aprendizaje. 


\subsection{Las formas de interacción en las clases áulicas}

Las formas de interacción predominantes en las clases de la educación media filosófica chilena, parten de explicaciones de los profesores o lecturas seguidas de preguntas centradas en los contenidos consignados en los Programas de Estudio. Lo cual supone un marcado control por parte de los profesores de los procesos de pensamiento de los estudiantes.

En gran medida las preguntas de los profesores están centradas en el contenido y, además son preguntas de comprobación, que no tienen similitud con las preguntas que se producen en la experiencia de vida cotidiana de los estudiantes. Esto conduce en ocasiones a ideas fragmentadas que ocasionan dispersiones e interrupciones en la clase. Muy raramente los estudiantes hacen una pregunta por propia iniciativa, salvo en la enseñanza mutua o recíproca entre iguales que, a su vez, es una situación de clase excepcional.

Por ejemplo, en el siguiente fragmento de una clase de cuarto año de Filosofía, el profesor intenta diferenciar conceptualmente la ética de la moral, recuperando algunos saberes de los estudiantes del ámbito de la política y, luego, formula una pregunta sobre los elementos que se ponen en juego respecto de la ética.

-Profesor: La palabra moral ¿ya? viene del griego moris que significa... eh...costumbre o norma, la forma en que una persona es... ¿ya? cuando vimos la filosofía de la moral ¿cierto? y vimos los dilemas éticos, por ejemplo, eh...teníamos que ver cómo la gente se comportaba, la cultura... dijimos que dentro de la moral tenía que ver la política, cómo se comporta un gobernante o cómo se comporta una institución ¿ya? Y la palabra ética, que es una palabra de origen latina, pero la palabra ética es... es griega, significa

básicamente lo mismo. Ética viene de Ethos, que es también forma de ser o forma de... actuar...

(Ruido de mesas) 
-Profesor: Entonces dentro de la moral, las conversaciones que ustedes tienen con respecto a la ética, ¿qué elementos surgen? ¿Qué otros conceptos eh... se ponen en juego?

En el siguiente fragmento de una clase de Psicología de tercer año de la educación media filosófica, el profesor presenta los objetivos y los conceptos que se están trabajando y formula preguntas para monitorear la comprensión de esos conceptos, sin establecer relaciones con las experiencias y los saberes cotidianos de los estudiantes:

- Profesor: ya, conocer y analizar las teorías psicológicas de la personalidad ¿no cierto? porque estamos viendo ese aspecto y después de esta actividad va a ser eh... el documento que les voy a pasar. Eeh... ya, eso es lo que vemos hoy día y lo voy a tratar de pasar lo más rápido posible. Vamos a hacer el resumen, si ustedes me dicen que falta algo volvemos atrás. ¿Ya? nosotros estuvimos viendo a... Freud, ustedes lo pueden escribir Freud, ¿cierto?, que con él iniciamos nuestro estudio sobre la personalidad, puesto que hemos visto hartas actividades de personalidad. Y lo otro, que fue lo que dijimos principalmente, que la estructura de personalidad de Freud se divide en ¿cuántas partes a ver? La estructura...

En la misma línea, en una clase de Psicología el profesor realiza preguntas, a partir de la lectura de un texto, dirigidas a la comprensión de conceptos.

- Profesor: ya... hagamos una pequeña lectura de esto y me van ayudando algunos ¿ok?

-Estudiante 1: ¿o qué?

-Profesor: ¡ya!... ya primero, yo voy a empezar a leer y quiero que me siga... eh... 
Villegas

-Estudiante 2: (lee)

-Profesor: ya... detengámonos ahí un segundo, ¿recuerdan hace unas clases anteriores? Antes de... la semana pasada, cuando estuvieron en paro y todo eso, estuvimos viendo lo... el... caso de tres tribus... en nueva guinea, y las tres tribus tenían comportamientos diferentes ¿recuerdan esos comportamientos? -Estudiante 3: sí...

-Profesor: ¿cuáles eran algunas a ver?

Como contrapunto de los ejemplos anteriores, en una clase Psicología el profesor aborda el contenido a partir de recuperar experiencias de vida para mostrar distintas formas de abordarlas.

-Profesor: Hoy día vamos... a hacer mención entre otras cosas acerca del carácter ¿ya? y van a ver que el carácter es algo que se va haciendo, se va formando, se va forjando ¿ya? Sobre todo, en relación a las experiencias de vida que ustedes vayan teniendo.... ¿Qué te parece?

-Estudiante: que lo que dice está... está en lo correcto... eh... tenía razón -Profesor: A ver, les voy a preguntar... a unos cuantos, le podría preguntar a cualquiera de ustedes... ¿ah? Pero... la idea es la siguiente. Teniendo eso en cuenta, de que muchas situaciones que le toca vivir a uno también las pueden vivir otras personas. Yo sé que por ejemplo la muerte de un ser querido eh... para mí por lo menos es algo personal ¿ya? yo creo que el dolor que uno siente... es parte eh... lo vivido también, lo mucho que se amó, lo mucho que se quiso ¿ya? Pero sé que es una experiencia personal y cada uno lo vive a su manera, hay quienes lloran, hay quienes no. ¿Consideran que han tenido momentos de adversidad difíciles en la vida? 


\subsection{Los problemas que se abordan en las clases}

En general, los problemas trabajados en las clases se basan en temas y conceptos establecidos en los Programas de Estudio del área curricular filosófica vinculados, por ejemplo, con la ética, la libertad, la moral, la identidad, la sexualidad, entre otros. El abordaje de los problemas, por lo general, parte de la revisión de un conocimiento conceptual y, luego, la problematización de situaciones relacionadas con contextos de los estudiantes.

En el siguiente fragmento de una clase de Filosofía la profesora revisa el concepto de libertad y reflexiona con los estudiantes sobre situaciones cotidiana vinculadas con la responsabilidad escolar.

-Profesora: Autonomía, ¿qué es la autonomía?

(Murmullos)

-Estudiante 1: es... alguien que es responsable por su decisión

-Profesora: ya... alguien que hace... se hace cargo de su decisión ¿cierto?

-estudiante 2: y la toma por iniciativa propia

-Profesora: lo hace por iniciativa propia, no porque alguien se lo imponga, (estudiante tose) y si bien puede haber reglas que son impuestas...

-Estudiante 1: pero yo decido aceptarlo

-Profesora: yo decido si lo acepto o no, muy bien... ¿ya? A diferencia de la (estudiante tose) heteronomía que es eeh... la acción de hacer lo que el otro me dice que haga, sin mucha conciencia (sonidos de hojas de cuaderno) sin pensar lo que está sucediendo y sobre todo sin hacerme responsable, (sonidos de conversaciones) porque en la heteronomía la responsabilidad es compartida, tengo responsabilidad yo, pero también tiene responsabilidad 
quien me dijo que lo hiciera. Cuando ustedes en la tarde (sonidos de murmullos y conversaciones), en la tarde se corrian de clases... ish...! (hace callar a las estudiantes) y les preguntaban “por qué te corriste de clases? Es que mi compañera me dijo"

-Estudiante 1: es verdad

-Estudiante 2: dependen de quien me diga

-Estudiante 3: las malas juntas

-Estudiante 4: nunca me he corrido de clases... no, de verdad

(Murmullos y conversaciones)

-Profesora: cuando ustedes se sacan una mala nota y no asumen la responsabilidad... de que no hayan estudiado y dicen "todo... el curso se sacó mala nota.

En el siguiente fragmento de una clase de cuarto año medio de Filosofía, el profesor, a partir de la construcción de definiciones en grupos, problematiza el concepto de moral relacionándolo con la ética.

-Profesor: ya, vamos a volver a nuestros asientos. A ver eh...Bueno, ¿les costó definir los conceptos en primer lugar?

-Estudiante 1: sii...

-Profesor: ¿y a medida que fueron conversando con más gente fue más fácil o más difícil?

-Estudiante 2: más difícil

-Estudiante 3: fue más difícil porque lo que uno decía, el otro no lo tenía -Profesor: ya, ¿cómo definieron bueno ustedes en la vida?

-Estudiante 2: algo que produce alegría o satisfacción

-Estudiante 3: hacer lo que nos beneficia para alcanzar lo que creemos bien 
-Estudiante 4: ahí tengo duda porque puede no estar bien

-Estudiante 1: es malo po

-Estudiante 3: pero estoy hablando de lo bueno po

-Profesor: vamos a levantar la mano para que hablen bien

-Estudiante 2: nosotros buscamos el objetivo para ver que estuviera bien

-Estudiante 1: es que ellos vieron algo general, nosotros vimos algo más

personal. Al parecer en nosotros lo bueno nos produce alegría como no sé,

ayudar a alguien. En cambio, lo de beneficio suena como más a interés

-Profesor: ya, muy bien. Eh...Difícilmente vamos a llegar al concepto, pero

ahi pueden ver un punto en común. Lo malo, a ver que pusieron en lo malo

-Estudiante 3: algo que afecta negativamente al entorno en cualquier aspecto

y a ti mismo estudiante 2: algo que no está bien respecto a la sociedad, por

ejemplo, no es bueno robar o botar basura en la calle

-Profesor: el punto de diferencia es que usaron la palabra sociedad, pero la sociedad igual toma decisiones así que no creo que sea tanta diferencia.

En el siguiente fragmento de una clase de Psicología, el profesor problematiza cuestiones conceptuales, sobre la base de las ideas inconclusas u opiniones contradictorias de los estudiantes.

-Profesor: ¿Alguien más? A ver... Víctor

-Estudiante 1: ¿Qué?

-Profesor: Usted... ¿Qué entiende por el concepto de sexualidad?

(estudiantes conversan y ríen)

-Profesor: ;Shh!

-Estudiante 1: (murmura) lo que te identifica... (alza la voz y repite) Lo que te identifica 
-Profesor: Pero, ¿Qué significa para usted?

(estudiantes ríen y murmuran)

-Profesor: con sus palabras, de la forma más simple posible.: No se complejice, yo no le estoy pidiendo una definición de diccionario, estamos...todavía empezando y tratando de...

-Estudiante 1: Profesor no lo sé... no sé profe...

-Profesor: Pablo...

(estudiantes/os ríen)

-Profesor: Estudiante 2... ¿qué entiende usted por el concepto de sexualidad?

¿Con qué lo relaciona? ¿Con qué lo puede vincular?

(estudiantes bromean y ríen)

-Profesor: ;Sh!

(estudiantes/as ríen y conversan)

-Profesor: ;Silencio, shh!

(estudiantes/as ríen en voz baja)

-Profesor: ¿Con qué podría vincularlo? A ver...

-Estudiante 2: Cuando eh... algo como que habla del hombre y mujer...algo del hombre y mujer

-Profesor: Ya... ¿Qué pasa entre el hombre y la mujer? ¿Cómo pueden tener... (estudiantes/as ríen a coro)

-Profesor: pero, no sea tan... tan académico, tan antiguo... trate de ser lo más completo posible

-Estudiante 2: No estamos en sexto para revisar el libro de biología (estudiantes/as discuten) -Profesor: ¡shh! ¿Cómo podríamos decir... relaciones entre hombre y mujer? estudiante 2: sexo..." 
En el próximo ejemplo, de una clase de Psicología se presentan diversos tipos de situaciones. En algunas de ellas los problemas presentados se resuelven únicamente respondiendo desde la teoría. Otras situaciones requieren de las estudiantes respuestas con base en problemáticas que pertenecen a su propio contexto.

-Profesora: ¿cuál es el origen de estas características sexuales secundarias?

-Estudiante 1: (murmura) las hormonas...

-Profesora: Las hormonas... testosterona en los varones, progesterona y estrógeno en las mujeres.

(estudiantes murmuran)

-Profesora: ¡Chicas! Y... la diferencia más evidente... son los genitales, lo que más se diferencia, en términos sexuales ¿sí? Porque decíamos que...para la gratificación de algo, en el macho o hembra, ¿tiene que ver con? Las gónadas... ¿sí? Que son los organismos reproductores. Ahora, si hago la diferencia con... el género, ¿qué elementos tiene el género?

-Estudiante 3: identidad

-Profesora: Ya, pero ¿cómo caracterizamos el género?

-Estudiante 2: con la forma... de comportamiento

-Profesora: A ver... tipos de comportamiento, ¿qué determina el género? Si la biología determina el sexo, ¿qué determina el género?

-Estudiante 3: la sociedad

-Estudiante 1: nuestros gustos

-Profesora: ya... nuestros gu...

-Estudiante 4: los establece la sociedad

-Profesora: y están influenciados como dice Bárbara por... la sociedad ¿sí?

Ósea... lo que se considera masculino ofemenino, tiene que con... una 
construcción cultural ¿sí?

(estudiantes murmuran y conversan)

-Profesora: A diferencia... de esta diferenciación que hacemos entre... sexo (estudiantes murmuran y conversan)

-Profesora: el sexo biológico, chicas... ¿puede cambiar?

-Estudiante 2: si...

-Estudiante 1: si

-Estudiante 3: no...

-Profesora: ¿ah?

-Estudiante 3: biológico no...

-Estudiante 4: biológico, no

(estudiantes discuten)

-Profesora: ¿cambia el sexo biológico chiquillas?

-Estudiantes a coro: No...

-Estudiante 2: oh, me perdí...

-Estudiante 1: no me acuerdo...

-Profesora: el sexo biológico no cambia.... La construcción del género, ¿puede cambiar?

-Estudiantes a coro: sii...

-Profesora: ósea, ser mujer a principios del siglo veinte, en Chile, ¿es igual que ser mujer ahora? Por ejemplo...

-Estudiantes a coro: No..." 


\subsection{Las discusiones y reflexiones en las clases}

Los registros sobre las discusiones y reflexiones en las clases observadas del área curricular filosófica de la educación media chilena revelan que las dinámicas de estas interacciones tienen como principal propósito aplicar los conceptos enseñados a ejemplos de la vida cotidiana de las estudiantes.

Resulta importante señalar que los momentos de discusión y reflexión ocupan un lugar menor o nulo en las clases, dado que la mayor parte de tiempo de las clases es ocupado por los profesores con sus exposiciones, ya sea para desarrollar los temas o aclarar las dudas de los estudiantes.

En cuanto a las configuraciones de las discusiones y reflexiones, en algunas clases se generan a partir de la exposición o preguntas de los estudiantes, donde el profesor actúa como mediador de los intercambios. En estas situaciones es donde se aprecia el proceso de negociación de significado y la construcción compartida de saberes en las comunidades de aulas. Tal como se aprecia en el siguiente segmento de una clase de Psicología, donde se aborda el tema "la moral". Luego de realizar una lectura guiada por el profesor, los estudiantes analizan las ideas principales del tema.

-Profesora: ¿Entienden lo que es el amor como fundamento de la moral

-Estudiante 2: no

-Estudiante 3 y 4: siiii

-Estudiante 5: si

-Profesora: ¿quién no entiende?

-Estudiante 3: no, no entendí profe... es que empezaron a hablar de amores y me confundí

-Profesora: pero el amor está relacionado aquí con el actuar. SI yo actuó de manera desinteresada y por amor hacia el otro 
-Estudiante 1: ah, ese es el amor maduro

-Profesora: soy capaz... si, lo que dije al principio, está relacionado con el amor maduro. Por ejemplo, una mamá eh...

(estudiantes conversan)

-Estudiante 2: ¡cállense!

-Profesora: ¡shhh! Que dice amar de manera desinteresada a un hijo, cuando el hijo se quiere independizar, no debería decirle "hijo no te vayas, que sin ti, me va dar depresión"

-Estudiante 3: ¡Oy! Es como cuando mi mamá me dice que vuelva a dentista para que me arregle los dientes

-Estudiante 4: las mamás nunca dicen eso, pero siempre lo sienten...

-Estudiante 5: es hablar de manipulación

-Profesora: no, pero una cosa es que lo sientan, pero el hecho de que impida que el otro se pueda realizar como persona...

-Estudiante 5: por eso po

-Profesora: (continúa la idea) ... es amor propio y no hacia el otro

-Estudiante 5: pero no lo dicen...

-Profesora: una mamá... una mamá que tiene un amor maduro, no lo dice... o “yo quiero que estudies derecho porque a mí me hubiese encantado estudiar derecho y no pude"

-Estudiante 1: jayy eso es amor propio! No amor maduro

-Profesora: eeh...s amor adolescente

-Estudiante 2: típico de mamá

-Profesora: ... amor romántico

-Estudiante 3: ¿ah?

-Estudiante 4: ¡Quéee! 
-Profesora: No es amor maduro...

-Estudiante 2: mi mami dice eso

(estudiantes conversan en voz alta)

-Profesora: yaa... continué leyendo eeh... Moya.

En el próximo ejemplo, las discusiones en el marco de una clase de Filosofía tienen como propósito negociar definiciones de conceptos, para luego reflexionar sobre la complejidad del proceso de intercambio dialógico.

-Profesor: ¿Qué tiene esa cosa que a ti te hace considerarlo algo bueno?

(estudiantes/os conversan)

-Profesor: Recuerden que no hay respuestas buenas o malas si estamos haciendo un vocabulario...

-Estudiante 1: justo, ¿a qué se refiere? A justo de justicia o a justo de... así como...

-Profesor: de preciso...

-Estudiante 1: de preciso para lo justo...ah ya...

(estudiantes/as rien)

(Comienzan a conversar)

-Profesor: ya... ¿estamos listos?

-Estudiante 2: profe, ¿a qué se refiere con legalidad?

-Estudiante 1: el juicio, es el juicio de juzgar a una persona o a...

-Profesor: Qué es lo que es lo legal

-Estudiante 3: y el juicio, ¿a qué se refiere por juicio?

-Profesor: no al jurídico...

-Estudiante 3: ah...

-Profesor: a tu juicio lo que, por ejemplo, haces... 
-Estudiante 3: ah ya...

-Estudiante 1: profe... ¿uno puede usar la misma palabra si está definiendo algo?

-Profesor: eh... ¿cómo?

-Estudiante 1: si yo estoy definiendo algo, ¿puedo usar la misma palabra que estoy definiendo?

-Profesor: ¿cómo en qué? Por ejemplo

-Estudiante 1: como mi mano o...

-Estudiante 3: (bromea) y se la pasa por la oreja...

(estudiantes ríen)

(Conversan, bromean y rien)

-Profesor: ya, oye...

-Estudiante 2: concepto de libertad, ¿a qué se refiere con libertad?

-Profesor: A lo que...

-Estudiante 3: ser libre

-Estudiante 1: ven que se repite

-Estudiante 3: (bromea) acción de ser libre

(estudiantes rien)

-Profesor: por algo los dejé

-Estudiante 1: libertad...

(Silencio)

-Estudiante 2: (murmura) ¿qué es la libertad?

(Ruido de sillas y mesas)

-Estudiante 2: (murmura) libertad...” 
En otras clases de Filosofía, la forma de generar discusiones y reflexiones surge de la exposición de temas por parte de los estudiantes, mientras que la profesora actúa mediadora de las discusiones:

-Estudiante 1: a veces hay factores que te condicionan las poblaciones, por ejemplo, en dictadura cuando se metió la pasta base a las poblaciones ¿para qué era la pasta base? antes si una rescata imágenes o fotografías antes las poblaciones estaban con banderas anarcas o banderas de movimiento y todo y ahora es súper peligroso andar por ahí. Es súper fácil decir que uno se esfuerza y sale adelante si tú naciste en un lugar donde todo estaba bien, las calles estaban bien pavimentadas, fuiste a un buen colegio, donde luego fuiste a una universidad, donde nunca tuviste un problema en tu alimentación, problemas familiares. Pero si tu naces en una población donde ves pasta base todos los días, no tienes un buen colegio o tus papás te tratan mal porque así mismo sus padres los trataron mal a ellos obviamente hay un círculo vicioso ahi, y desde nuestra postura no es suficiente la igualdad de oportunidades porque la igualdad de oportunidades no automáticamente arregla ese círculo vicioso.

-Estudiante 7: igual es más difícil pero no imposible

-Estudiante 1: no imposible de manera individual, pero de manera colectiva si porque dentro del sistema económico por una razón obvia y es que hay personas que son dueñas y otras que son trabajadoras y nunca todos van a poder ser dueños, hay alguien que va a ser dueño y otros que van a ser trabajadores

-Estudiante 8: si poh, de hecho, con eso tiene que ver cuando decimos que se condiciona a la población porque al final una persona que busca y no encuentra pega la culpa es del estado, pero como el estado ahora no es el que 
controla los medios de producción es culpa del privado, en cambio que la persona esté fumando pasta no es culpa ni del estado ni del privado es culpa de la sociedad. Entonces se ven los problemas como algo abstracto que no se pueden combatir

-Profesora: a mi me gustaría plantear tres preguntas como para reflexionar no más. Primero con respecto a eso que se dice y que uno escucha de manera muy natural que es que la gente que es pobre lo es porque quiere serlo preguntémonos, sin responder por supuesto, si alguno de ustedes le gustaría ser pobre entiéndase como se entienda la frase porque si nos ponemos a discutir sobre la pobreza necesitamos 90 minutos más para acordar algo, estaríamos aquí hasta como las 7 más o menos, si a alguno de ustedes le gustaría ser pobre porque eso que a la gente que es pobre es porque le gusta nos tienen convencidos desde una mirada capitalista de eso. Segundo por qué somos individualistas, si eso es una opción personal o hay ahi también una maquinación de parte de un sistema ¿cierto? Y tercero que cada vez que nombran al estado yo me pregunto ¿existe el estado aquí en Chile?, ¿hay estado aqui en Chile? ¿hay dineros públicos aqui en Chile? esas tres preguntas".

\subsection{Formas de participación y colaboración en las clases}

En el análisis de las clases observadas se distinguen dos niveles de participación de los estudiantes, en atención a las posibilidades que otorgan los profesores para que esto ocurra: alta y baja participación. 
La participación de nivel alto agrupa aquellas situaciones áulicas en donde el proceso de enseñanza-aprendizaje se centra en el estudiante como protagonista y otorga espacios para la discusión, el debate, negociación de significados mediados por el profesor. El nivel bajo agrupa aquellas situaciones en la que los estudiantes tienen baja o nula participación, ya sea porque es el docente quien conduce y controla tales procesos.

En cuanto a las formas de trabajo, en términos generales se distinguen para nivel las estrategias observadas, entre otras: los trabajos colaborativos, la discusión guiada, la resolución de guías de aprendizaje, las imágenes de apoyo y las clases expositivas del docente.

\subsubsection{Clases con nivel de participación y colaboración alta}

El segmento que se presenta a continuación corresponde a una clase de cuarto año medio de Filosofía, donde los estudiantes exponen un tema investigado previamente en equipos. La profesora media en la interacción entre los compañeros, realiza consultas sobre sus procesos de investigación, las conclusiones a las que llegaron y las relaciones con sus propias vivencias. También, motiva a la discusión grupal respecto a los temas que van surgiendo.

-Profesora: ¿y todo este rato? estamos hablando de la desigualdad en Chile, Daniela, ¿qué opina usted? que opina por ejemplo que hoy día si nosotros estamos conversando cerca de las 5 de la tarde sobre la desigualdad y que haya otros países más desiguales es porque tenemos necesidades satisfechas para estar hablando de esto, porque si tuviéramos sueño y hambre no podríamos ¿cierto? y sin embargo nosotros igual estamos en un ambiente privilegiado ¿qué opna que usted tenga derecho a eso y que otro niño o niña 
igual que usted no tenga derecho? ¿qué le parece a usted eso por ejemplo? Hágalo tan bien como baila cueca

-Estudiante 1: opino que está mal pues profe

-Profesora: a ver Daniela ¿por qué está mal?

-Estudiante 1: no porque eh no tienen la como la posibilidad de estudiar en este colegio no todos

-Profesora: ¿y?

Estudiante 2: está mal eso porque todos deberían poder tener acceso a estudiar en un buen colegio.

-Profesora: o sea todas las personas deberíamos tener acceso a una buena educación porque esa es la base

-Estudiante 3: mal poh

-Profesora: alguien más quiere opinar algo

-Estudiante 4: y sobre la manera de solucionarlo a ver Javier cómo se soluciona esto

-Estudiante 5: con la dictadura del proletariado, la única dictadura válida que existe para nivelar la desigualdad

-Estudiante 1: ¿ustedes creen que se debe eliminar la desigualdad al 100\%? y si es si ¿cómo se hace? La desigualdad económica digamos, porque cuando hablamos de desigualdad no significa que todos se tengan que vestir igual -Estudiante 5: yo propondría una redistribución de los ingresos -Estudiante 6: según yo si se quiere llevar esta cosa de la desigualdad económica para todos no podía instaurarlo en nada en la actualidad porque el humano primero se acostumbra a los estímulos y después. evolucionar. desde que el humano existe que existe la jerarquía, existe un alfa representando el poder al que siguen los demás. entonces lo primero es 
terminar con ese arraigo cultural que existe con la jerarquía, eliminarla de toda relación y por ejemplo otra cosa que igual es de desigualdad es que los adultos mayores en la actualidad son los que tienen los menos ingresos y la solución que se les da es que sigan trabajando y el argumento que a nosotros nos dan es que son los abuelos los que quieren seguir trabajando y na que ver porque si ellos quieren seguir trabajando no tiene nada que ver con que reciban una pensión mísera igual siguen trabajando, produciendo un país pero ganando un dinero estable y que si dejan de trabajar no les afecte -Estudiante 1: hay abuelos también que tienen que esforzarse a seguir trabajando porque dicen yo gano un palo pero si dejo de trabajar ganaré solo cien lucas

-Profesora: mientras el sistema de previsión siga así tal cual es como el ejemplo que dio Diego

-Estudiante 2: esto me recuerda también a cómo la televisión actúa super fuerte en todo esto porque siempre salen noticias "ooh miren este señor que tienen 65 años, que es esforzado" tirándole como puras flores y eso no debería ser, ese señor de 65 años en edad de jubilar no debería trabajar toda la semana dia y noche, es importante evitar eso y que las personas a esa edad tengan más tiempo para relajarse.

En el segmento que se presenta a continuación muestra que la interacción entre los estudiantes y entre los estudiantes y la profesora es constante. Los estudiantes trabajan construyendo en conjunto las ideas. La profesora los motiva a trabajar de este modo durante toda la clase y en todo momento busca hacer participar al grupo de la clase en las actividades propuestas, entre otras, la lectura y la discusión de textos. 
-Profesora: El día de hoy comenzaremos a ver cuáles son los fundamentos de la moral. Dentro de lo que funda la moral está... eeh... la naturaleza humana, el deber como fundamento moral, el amor, el contrato social...

-Estudiante 1: ¿Contrato social?

-Profesora: si, para eso les voy a traer una guía. Y también la utilidad (murmullos). ¿Es útil o no es útil lo que estoy haciendo?

-Estudiante 2: siii

-Estudiante 3: ¿Qué está haciendo?

-Estudiante 4: enseñándote po

-Profesora: es una pregunta retórica

-Estudiante 3: ah //

-Estudiante 5: profe... (Otra Estudiante tose)

-Estudiante 6: Profe, no lo entiendo...

-Profesora: ¿Quién puede comenzar a leer la guía?

(Estudiantes se sorprenden)

-Profesora: Ya, la Javiera... Y atentas que cualquiera puede seguir la lectura... (Murmullos y conversaciones) ... Ya comience Javiera.

-Estudiante 7: Los fundamentos de la moral, la naturaleza humana. Existen diversas posiciones respecto a los fundamentos de la moral humana. La primera, que examinaremos... a continuación es de la propia naturaleza humana. Raúl y Roberto discuten respecto al derecho de propiedad. Raúl siguiendo una tesis marxista afirma que él... ah, creer que una persona tenga propiedades de ciertos bienes, especialmente de producción, le da un poder sobre otras personas, lo que determina una situación injusta. Roberto dice que el derecho a la propiedad es un derecho natural del hombre y que es parte de su libertad. Supone Roberto que existe una naturaleza humana y 
que hay ciertos derechos in... inherentes a esta naturaleza. Sócrates y Aristóteles pensaron que esta naturaleza humana era la base de la moral. Por eso que Sócrates afirmaba que el actuar moral del hombre se fundamentaba en el conocimiento de la naturaleza y en un actuar conforme a ella. Aristóteles se preocupaba de buscar qué era lo que realmente distinguía a esta naturaleza y lo encontraba a en la vida intelectual. Ambos filósofos, como también lo hacen después... los filósofos cristianos, piensan que existe una naturaleza humana y que ella nos da la pauta acerca, de lo que es bueno o malo para el hombre. La dificultad que tiene esta posición es poder determinar cuáles son las verdaderas características que forman parte $d$...de la naturaleza humana y cuáles son características culturales que pertenecen, en las diferentes culturas, se... ser esenciales a esta naturaleza.

-Profesora: Muy bien, ¿recuerdan lo que decía Aristóteles y Sócrates?

-Estudiante 1: Si

-Profesora: ¿Qué?... A ustedes que les fue tan bien en la prueba

-Estudiante 2: ¿cuándo? (murmura)

-Estudiante 3: cuando hizo la prueba...

(Estudiante ríe)

-Profesora: por eso no lo digo de manera irónica

-Estudiante 1: ¿no?

-Profesora: noo... lo digo de verdad (ríe)... no todas, pero... la mayoría sí (Estudiantes murmuran y conversan)

-Profesora: ¿qué dice Aristóteles y Sócrates sobre... con respecto a la... naturaleza humana?

-Estudiante 1: eeh...el bien y el mal, y eso...

-Estudiante 2 y 3: que era la base de la moral (a coro) 
-Estudiante 4: que era la base de la moral... en una poli

En el segmento siguiente de una clase de Psicología el profesor solicita a los estudiantes evaluar su propia interacción. La autoevaluación se lleva a cabo de manera colaborativa guiada por el profesor. La tarea pone en juego aspectos del pensamiento metacognitivo. Durante la clase, el profesor utiliza variadas técnicas y estrategias para desplegar el pensamiento de los estudiantes, tales como: lluvia de ideas, toma de notas breves, construcción compartida de conceptos, trabajo grupal para comparar, consensuar o evaluar el propio proceso de creación y consenso.

-Profesor: ¡Ya! eh... ahora... nos vamos a... juntar en parejas, excepto acá que ya se nos definió un grupo, busquen una pareja, ¿ya? ¿sí? puede ser en duplas o si quieren pueden trabajar de más ¿ya?

(Estudiantes conversan)

-Estudiante 1: (bromea) ¿únanse o unan sed?

-Profesor: pueden trabajar con las chiquillas...

-Estudiante 2: yo no sé con quién...

-Estudiante 3: con la... con la Estudiante nueva

-Profesor: puede ser con cualquiera...

-Estudiante 4: jella va quedar sola!

Estudiante 3: acá somos cuatro...

-Profesor: pero por eso, hagan un grupo...

-Estudiante 2: el Gustavo...

-Profesor: ya Gustavo...

(Estudiantes conversan)

-Estudiante 3: los tres aquí...

-Profesor: con su pareja, van a comparar la definición que tienen ¿ya? 
-Estudiante 4: ya...

-Profesor: y en la hoja nueva, van a escribir la definición que salga del consenso de ustedes

(Estudiantes conversan, ruido de sillas y mesas)

-Estudiante 4: Ya Tania...

-Profesor: la idea es que conversen, se escuchen...

(Estudiantes conversan)

-Profesor: no quiero la misma definición, la idea es que conversen, tienen que haber diálogo...

(Los grupos conversan)

\subsubsection{Clases con nivel de participación y colaboración baja}

Los segmentos de clases que se presentan a continuación muestran niveles de participación limitada tanto de los estudiantes entre sí, como entre estudiantes y profesores. En general, se caracterizan por el acentuado papel protagónico de los profesores, con explicaciones que reducen la enseñanza a un monólogo y, como consecuencia, dispersan la atención de los estudiantes y su interés en los temas.

En el ejemplo que se presenta a continuación de una clase de Filosofía, el profesor realiza un trabajo retórico y, posteriormente, se apoya en la visualización de un video cuyo contenido que debe ser analizado por los estudiantes en función de sus explicaciones. Se advierte en los estudiantes poca motivación por la clase, se presentan discusiones entre ellos por temas ajenos al tópico de la clase y expresiones de complicidad tales como "cállense culiaos". El profesor se limita a hacer un llamado al orden y amenazar con amonestaciones escritas para mantener el orden en la clase. 
-(Ruido de sillas)

(Estudiantes conversan)

(Ruido de sillas)

(Estudiantes conversan)

- Profesor: hoy ¿estamos a...?

- Estudiante 1: a ocho...

(Ruido de sillas)

(Estudiantes conversan)

(Ruido de sillas y mesas)

(Sonido de flauta)

(Estudiantes conversan)

(Sonido de música)

-Profesor: ¿podría... apagar sus celulares por favor?

(Música deja de sonar)

-Profesor: Gracias

(Estudiantes conversan)

(Estudiante silba)

(Ruidos de pasos)

(Estudiantes conversan)

-Profesor: A ver Estudiantes... eh, bueno... saludarlos nuevamente, tengan buenos días

-Estudiante 1: buenos días...

-Profesor: Eh... han pasado ya un par de semanas que no nos habiamos visto. Espero que eh... en el transcurso de ese tiempo, bueno... haya podido... hacer otras cosas, disfrutar a su familia ¿cierto? hubo varios dias que puede ser, usaron para el descanso, el estudio u ordenar. Eh... ya podemos decir que el tiempo que nos queda de clases, es como la recta final para el término de año... emm... no descuiden sus notas, emm... yo eh... al comenzar este día, quiero hacer un comentario eh... un comentario, una especie de reflexión a propósito de... las cartas que... escribieron... eh... luego quiero hacer, una especie de repaso de algunas ideas, para brevemente abordar eh... los contenidos de la clase y el objetivo que en este caso va ser... que reconozcamos a los individuos, a las personas como sujetos morales ¿ya? Eh... tengo la intención de que... eh... casi al término de la clase, veamos un video y... eh... les voy a entregar 
una actividad emm... antes de ello eh... voy a pasar la lista, así nos desocupamos de eso y les quiero dar el calendario o la calendarización de las fechas para el mes de... noviembre y diciembre. Eh... (suspira) dicho esto, emm... recordarles eh... de que van a encontrar en las eh... fechas, de que... eh... yo les dije que les iba a traer un set de material y que a contar del momento en que lo tuvieran, eh... iban a contar de dos semanas y luego iban a tener una evaluación. En la calendarización aparecen para la próxima semana, pero les recuerdo... como yo dije que iban a tener un periodo de dos semanas, en el momento en que dispongan de ese material, van a correr ¿no cierto? de ahí las dos semanas.

(Estudiantes murmuran y conversan con garabatos)

-Profesor: Atención a la lista...

(Estudiantes murmuran)

-Profesor: Eh... para el desarrollo de esta clase, lo que quiero de ustedes es tener... bueno, entre otras cosas es su atención, su silencio, y su disposición... a ver, a escuchar... pero... a una escucha por decirlo de alguna manera... activa ¿ya? Eh... lo primero que cabe decir, como les decía... es hacer un comentario a propósito de sus cartas. Eh ... a ver, hay muchas situaciones en la vida eh... que son adversas, son difíciles eh... hay un aspecto trágico en la vida, nos vamos a encontrar en algún momento por ejemplo con el fallecimiento de algún ser querido eh... entre otras. Lo que

diferencia... creo yo, está por ejemplo en que vivan esas vivencias en este momento y... a diferencia de que la vivan más adelante, es que tal vez, más adelante... más adelante van a estar mejor preparados... porque van a tener un cumulo de experiencias que de alguna manera, les va a posibilitar poder enfrentarlas de mejor manera. Todas las personas sufren... ahora, en lo personal, yo no estoy contra el sufrimiento, porque de alguna manera... muchas veces las cosas cuando cuestan o cuando exigen cierto esfuerzo eh... mejor nos preparan para la vida. Se dice por ejemplo, que ustedes son una generación... em... bueno, entre otras cosas que son....

(Estudiantes/os murmuran)

-Estudiante 1: ;shh!

(se escuchan garabatos) 
-Profesor: ... o vienen siendo, de aquellas que... tienen mayores estímulos o han sido durante un tiempo eh... afectados por estímulos tanto visuales, eh... auditivos ¿no? El uso del celular, las pantallas... antes esas cosas no se veían, así como ahora. Se dice que estamos mejor comunicados, pero... las relaciones personales, no creo que... hayan mejorado del todo. Eh... el video que en algún momento van a ver es del ex presidente de Uruguay eh... José Mujica, y entre otras cosas les va hablar del tiempo de vida ¿ya? Nos señalará que por ejemplo en la medida en que nosotros trabajemos, si bien recibimos una remuneración, pero nosotros entregamos a ese trabajo no tan solo nuestro esfuerzo, nuestras energías, sino también nuestro tiempo... y eso no se recupera jamás. Vean en lo que ustedes invierten su tiempo eh... como les digo, hay cosas en la vida que van a requerir cierto esfuerzo emm... por ejemplo, para aprender un idioma, no es solo que uno vaya...

a comprar al almacén, ustedes están acostumbrados a lo inmediato, tal vez a las cosas que... sean más fáciles ¿ya? Pero no siempre en la vida les van... se les van a presentar esas situaciones. Emm... un filósofo por ahí decía "quién sabe lo que es vivir bien, si antes no sabe lo que es luchar y vencer” Darle un valor al sacrificio ¿ya? Muchas veces las cosas se valoran aún más cuando cuestan. No es lo mismo si uno trabajo todo un mes, qué se yo... como jornal, qué se yo... en la fruta, para comprase un nuevo poleron, que aquel que simplemente se lo regalan. Tal vez, no sé...

lo cuidará más. Demos una vuelta a esas cosas... tal vez, hay algunos que vivan momentos de crisis y están en una etapa que eh... son normales ¿ah? Pero tienen que también considerar de que, las cosas y la vida cambian ¿ya? Piensen, en ese tiempo de vida que ustedes tienen...

(Estudiantes murmuran)

-Profesor: porque... en algún momento va llegar a quien... con estos momentos que nos toca conocer, vivir...

(Ruido de sillas y mesas)

-Profesor: La muerte... de alguna manera, ósea no de alguna manera, lisa y llanamente la muerte le da sentido a la vida humana.

(Ruido de sillas)

-Profesor: Emm... yo pensaba en... traerles una reflexión, estuve buscando ¿cierto? por ejemplo, hay un... hay una escuela filosófica que conocí, son los 
estoicos... estuve buscando a... algunos vídeos, que se los voy a subir emm... hay un vídeo sobre... el propio Nietzsche y el sufrimiento, y que apuntaba a esta idea de no ver el sufrimiento como algo negativo eh.... Bueno él ahí por ejemplo, el ejemplo de lo que cuesta por ejemplo la preparación de una bailarina de ballet emm ... y si para algunos de ustedes... a veces la vida pierde sentido, aunque la vida no tenga sentido, hay que seguir ante la adversidad ¿mmg? Así que muchachos... eh... la vida, desde una perspectiva existencial es algo que ustedes tienen que hacer... emm ... yo siempre les he dicho que ustedes tienen que ir haciendo su vida, ir construyendo... uno siempre necesita soñar, a... que vayan tras

sus sueños, que... ustedes pueden ser en la vida lo que ustedes quieran hacer, pero eso... las cosas no se les van a dar así como así, va requerir reitero después de su sacrificio... ¿O ustedes creen por ejemplo que un músico para prepararse... es algo que él hace en cuatro días? O un bailarín, no sé... ¿Qué piensas al respecto Juan?... o no sé, esto es... espero que no esté hablando por hablar ¿no? Pero me preocupa, a veces... ese estado en el cual ustedes se encuentran de... fragilidad, por llamarlo de alguna manera, de alguna manera los veo que no están preparados, de que tienen facilidad ante la frustración... que no tienen o no han podido desarrollar del todo su resiliencia, esa capacidad que tiene el ser humano para sobreponerse a la adversidad...

(Estudiantes murmuran)

En la siguiente clase de Psicología se observa que las estudiantes no participan activamente, pero conversan mucho entre ellas. Sus interacciones con la profesora son distantes, con escasos intercambios dirigidos a responder las preguntas o cuestionamientos de ella. Muestran un bajo compromiso e interés por el tema, objeto de estudio. Como puede apreciarse en el ejemplo, durante el desarrollo de la clase hay una discusión guiada, resuelven en pareja una guía de aprendizaje con imágenes de apoyo que aporta la profesora y, al finalizar, ésta realiza algunas preguntas sobre sus dificultades en la labor propuesta.

-Profesora: lo femenino... se entendía de una manera bastante distinta, a principios del siglo veinte ¿sí? Por ejemplo... la ... visión de la importancia del matrimonio era muy distinta ¿si? 
(Estudiantes murmuran y conversan)

-Profesora: Fíjense que hay una canción de Violeta Parra ... ¿cómo se llama? Arréglate Juana Rosa, y dice algo así como... "ya vas a cumplir veinticinco, te queda... te vas a quedar solterona" ¿sí? Veinticinco años... solteronas...¿Cuántas de ustedes están pensando por ejemplo en... la posibilidad de casarse más adelante?

-Estudiantes a coro: whhh....

-Estudiante 1: (tose en forma de repulsión)

(Estudiantes conversan)

-Profesora: A ver... piensa en el matrimonio, si lo proyectaras y te fueras a casar o... a vivir en pareja con alguien, ¿a qué edad lo harías más o menos?

-Estudiante 2: como a los treinta....

-Profesora: ósea...

-Estudiante 2: no, porque después está la $U$, y todo eso... ¿y me voy a casar?

-Profesora: Imagínense la canción de Violeta Parra, de veinticinco años como solterona, te vas a quedar para vestir santos...

(Estudiantes conversan)

-Profesora: se te pasó el tren después de los veinticinco...

(Estudiantes murmuran y conversan)

-Profesora: No creo que ninguna de ustedes tenga como la prioridad a los

veinticinco años de estar casada probablemente

(Estudiantes discuten)

-Estudiante 2: con suerte voy a estar estudiando todavía...

(Estudiantes ríen y luego discuten sobre el tema)

-Estudiante 3: ósea, para algunas mujeres a esa edad es prioridad...

-Profesora: y sobre todo para los varones, cuando nos damos cuenta, por ejemplo, que sobre todo en las abuelas de ustedes o en las mamás de sus abuelas... que la maternidad les llegó mucho antes... ya a esta edad, varias habían sido mamás...

-Estudiantes a coro: si...

-Profesora: eh... a los veinticinco años ya uno veía como... tener una vida resuelta, hecha y derecha, hacerse cargo de una casa, en la crianza de los hijos... Eeh... muchos han dicho que por ejemplo la adolescencia, que es un 
estado psicológico y no solo biológico, eh... se ha ido eh... ampliando, más en los varones que en las mujeres

(Estudiantes murmuran y conversan)

-Estudiante 2: son inmaduros...

-Profesora: y todavía a los veintiún años, todavía encontramos adolescentes

(Estudiantes conversan)

-Profesora: Vamos anotando, vamos sintetizando lo que dijimos...

(Estudiantes se quejan)

(..)

Estudiante 1: oye...esto es muy estresante

Profesora: (...) eso es lo que les estoy pidiendo, la atracción se define de esa manera. Shh... Como yo, a ver y la expresión...Chiquillas, me ponen atención. Vean las características de ustedes, que para mí es importante reflejar o expresarles a los demás... Revisamos mañana.

(Estudiantes conversan entre sí)

Profesora: ehh...Chicas revisamos mañana y vamos acotando ¿sí?, denle una vuelta, tráiganlo completo hasta la clase de mañana, porque hay varias que se complicaron con eh... Escribir. Recuerden que el que no tiene nombre es la expresión de género. Particularicen

(Estudiantes conversan entre si)

-Profesora: ehh...Chiquillas el próximo jueves hacemos la evaluación.

-Estudiante 1: mañana

-Profesora: La evaluación va a ser habilitación... ;Shh!... La ... el próximo jueves va a ser la evaluación. Vamos a analizar un cortometraje y el cortometraje lo que vamos a hacer con el cuaderno, con lo que hemos escrito y lo que hemos analizado ya explicando los conceptos dentro del corto. Así que para que le vayan dando vuelta, la tarea la voy a revisar mañana. Llévensela, denle una vuelta a los tres conceptos, particularicen

-Estudiante 2: tiene que ser con decimas... 


\section{CONCLUSIÒN Y DISCUSIÓN}

Nuestro estudio indagó el desarrollo del pensamiento complejo y la metacognición en la educación media filosófica chilena. Con esta finalidad, examinó las orientaciones de los Programas de Estudio del área curricular filosófica, las concepciones de profesores de Filosofía en ejercicio y las prácticas áulicas.

En sus fundamentos recogió aportes de la Filosofía para Niños (Lipman, 2004. 2016), de Programas y Proyectos curriculares a niveles internacional y nacional como también, de la experiencia de la autora en investigaciones precedentes sobre el tema en la Universidad de Concepción de Chile. También dialogó con contribuciones procedentes del campo de la Psicología Educacional, que enriquecieron la mirada cognitiva y sociocultural del desarrollo del pensamiento complejo y la metacognición en la educación media filosófica de los estudiantes.

En lo metodológico asumió un enfoque cualitativo de cohorte descriptivo - interpretativo basado en el análisis curricular de los Programas de Estudio del área filosófica, la aplicación de entrevistas a ocho profesores y la observación de sus prácticas de enseñanza en aulas de Enseñanza Media mención Filosofía en las Asignaturas de Filosofía y Psicología, en ocho establecimientos representativos de las comunas de Concepción, Hualpén, Talcahuano, Coronel y San Pedro de la Paz, de la Provincia de Concepción, Chile.

\subsection{Sobre los Programas de Estudio de la educación media filosófica chilena}

Como se aprecia en el Capítulo 4, el área curricular filosófica de la educación media chilena integra a la Psicología, por cuanto se la reconoce como una disciplina con raíces 
históricas afines. La propuesta curricular pone énfasis en la enseñanza de los conocimientos psicológicos en el tercer año, de manera articulada con los de Filosofía en el cuarto año.

En general, se advierte que los Programas están atravesados por una mirada enciclopédica de la formación filosófica, es decir, que centran su atención en la adquisición de conocimientos, antes que en el desarrollo de los procesos del pensamiento complejo y metacognitivo. No obstante, nuestro estudio detectó indicios que dan cuenta de una incipiente tendencia a este desarrollo, en especial, de algunos tipos de pensamiento abordados en las dimensiones de análisis.

En el tercer año y cuarto año, las justificaciones curriculares se concentran en el desarrollo de habilidades vinculadas a los tipos de pensamiento crítico-racional, críticorazonable y metacognitivo. También, en las habilidades del pensamiento ético, de manera más marcada en el cuarto año con foco en la promoción de ciertos valores morales, por ejemplo, "tratar con respeto a posiciones distintas, personas, otras formas de vivir". En ambas instancias curriculares no se alude al desarrollo del pensamiento creativo.

En lo referido al pensamiento crítico-racional, en el tercer año, se aboca a la comprensión de procesos neurofisiológicos y de otros vinculados con la edad, la biografía y la cultura en que se desarrollan las personas. En el cuarto año, este pensamiento se desplaza hacia el desarrollo de habilidades analíticas, argumentativas e interpretativas, de la toma de distancia crítica y del reconocimiento de distintas concepciones y posiciones susceptibles de defensa racional.

El pensamiento crítico razonable emerge en el tercer año focalizado en la propia persona $\mathrm{y}$ en los otros sujetos estableciendo relaciones con el medio social, la identidad, el autocuidado, la tolerancia y el respeto. En el cuarto año se centra en las habilidades de reflexión oral y escrita, la identificación y el análisis de supuestos, creencias, actividades y sentidos de la experiencia humana, entre otras cuestiones. 
En cuanto al pensamiento metacognitivo, en el tercer año aparece relacionado con los conocimientos y las habilidades para la comprensión de sí mismos y de los demás, la propia experiencia del estudiante, la autoestima, la moral, el juicio crítico y la autodeterminación. En el cuarto año, se observa la misma tendencia, pero referenciada a otorgar sentido a las opciones en los campos del intelecto, la ética y la política.

En términos de resultados de aprendizajes esperados, en general, encontramos que las habilidades de logro están focalizadas en el conocimiento y la comprensión de los contenidos establecidos y no a la producción intelectual en línea con lo esperado para el desarrollo integral de un pensamiento complejo y metacognitivo. En otras palabras, se aprecia que los Programas de Estudio actuales están atravesados por una mirada tradicional de la enseñanza que no ayudan a los estudiantes a hacer la transición entre "saber Filosofía" a "saber cómo pensar, aprender y resolver problemas con la Filosofía".

¿Para qué sirve la Filosofía en la escuela? En palabras de Kohan (2019) ese espacio ayuda a que los estudiantes piensen un poco más en lo que están aprendiendo en la escuela y en la vida que viven dentro y fuera de ella, que se hagan preguntas que a lo mejor no se pueden hacer en otro lugar. Del mismo modo, a los profesores, la Filosofía puede ayudarlos a pensar un poco más en lo que están enseñando en la escuela y a hacerse algunas preguntas que a lo mejor no pueden hacerse en otro lugar. La Filosofía, por tanto, es un lugar de encuentro entre las singularidades de los estudiantes y los profesores.

Lo expresado anteriormente supone el desafío de resignificar el currículum y la enseñanza de la Filosofía en la educación media chilena, que ha sido el primer espacio sacrificado en comparación con otros espacios curriculares, como el de las letras o el de la historia. Prueba de ello es que el área filosófica ocupa sólo tres horas cátedras semanales en el tercer y cuarto año.

La filosofía sigue siendo uno de los elementos clave de la formación escolar para juzgar, criticar, cuestionar y discernir. En este sentido, los problemas que plantea su enseñanza y el 
aprendizaje se convierten también en un problema filosófico respecto a su significación, especialmente, para los desarrollos curriculares y la formación docente. Gran parte de los interrogantes pueden ser esclarecidos con el aporte de las experiencias curriculares del Programa de Filosofía para Niños de Lipman, el Proyecto Zero de Harvard, el Programa “Aprender a Aprender" del Instituto Pascal, Madrid y, en particular, el Proyecto "Desarrollo del Pensamiento Complejo y Valores Humanistas Laicos” implementado en el ámbito local.

\subsection{Las voces de los profesores sobre el pensamiento complejo y la metacognición}

La información recogida en las entrevistas a los profesores del área curricular filosófica de la educación media chilena reveló la persistencia de algunos problemas clásicos del quehacer educativo, entre otros, los distintos grados de apropiación por parte de los docentes de los Programas de Estudio, como también, de las variaciones en las percepciones de los contenidos mínimos obligatorios como herramientas potenciales para el desarrollo de las habilidades del pensamiento complejo y metacognitivo.

Los testimonios recogidos mostraron el predominio de concepciones amplias e imprecisas del pensamiento complejo y, en menor grado, de la metacognición. En relación a lo anterior, parecería existir cierto desconcierto en el cuerpo de profesores sobre las implicancias que tiene la consideración de los procesos del pensamiento complejo y de la metacognición en la enseñanza y, en especial, sobre la activación de tales procesos mediante las estrategias, las actividades y los recursos didácticos en las aulas.

El análisis expuesto en el capítulo 5 nos permite distinguir tres perspectivas en las concepciones del profesorado, que se ilustran en el Esquema 2. 
La primera perspectiva en las concepciones de los profesores asocia el desarrollo del pensamiento complejo a las posibilidades de adquisición de un conocimiento teórico abstracto que derivan de la madurez cognitiva de los estudiantes. Tal vez esta concepción se podría comprender al explorar la formación inicial docente, que se basa en explicaciones del funcionamiento intelectual como resultado de una maduración psicobiológica, en la cual los estudiantes alcanzan ciertas disposiciones que los habilitan para el aprendizaje de una asignatura de estudio como la Filosofía o la Psicología. En tal caso, el profesorado descuida en la enseñanza el modo en que los estudiantes deben ser introducidos en las asignaturas, porque consideran que son dependientes de la experiencia empírica concreta y, por lo tanto, no han alcanzado aún en el nivel de escolaridad donde se ubica la asignatura las posibilidades cognitivas para desplegar operaciones complejas del pensamiento.

Por otra parte, la perspectiva del profesorado entrevistado no concibe el conocimiento de la asignatura como una herramienta para potenciar el desarrollo del pensamiento y la metacognición. Entre otras cuestiones, esto implica reducir el rol activo y constructivo de los estudiantes en el aprendizaje de la Filosofía, a partir del uso y reflexión de sus propios procesos de pensamiento y conocimiento. Así, entonces, su madurez cognitiva definiría la posibilidad de acceso a un pensamiento complejo más que a procesos de aprendizaje activo o una enseñanza directa de dichos procesos de pensamiento para el logro de los objetivos fundamentales y/o transversales establecidos en los Programas de Estudio.

La segunda perspectiva de los profesores caracteriza al pensamiento complejo en términos de capacidad general para pensar y, también, de habilidades superiores que posibilitan a los estudiantes advertir la utilidad y sentidos de los conocimientos, el aprendizaje, las relaciones explícitas e implícitas, el razonamiento y la resolución de problemas aplicados a la vida cotidiana. En contrapunto a la posición anterior, esta concepción visualiza la posibilidad de mejorar las habilidades cognitivas superiores de los 
estudiantes a través de la enseñanza del conocimiento filosófico, en especial de aquellas referidas a los pensamientos crítico racional y razonable.

La tercera perspectiva en las concepciones del profesorado relaciona el pensamiento complejo con las actitudes y/o disposiciones de los estudiantes para juzgar, evaluar, valorar, respetar, discernir, analizar la realidad, a partir de las problemáticas derivadas de los temas disciplinares. Las opiniones recogidas se acercan a la concepción precedente, en términos de constituir un logro factible de ser alcanzado con los desarrollos curriculares. En relación a los tipos de pensamiento, gran parte de estas actitudes se vinculan con las habilidades del pensamiento ético y, en menor medida, del crítico razonable.

En lo que respecta a las concepciones de los profesores sobre la metacognición, esta noción aparece limitada a la capacidad general de autoanálisis, reflexión sobre el aprendizaje, conocimiento y comprensión de los contenidos curriculares. Parecería que ellos tienen escasos conocimientos respecto de los procesos cognitivos y metacognitivos implicados en la enseñanza y el aprendizaje de los contenidos curriculares específicos de la Filosofía. Como también, sobre los modos que tienen los estudiantes de reflexionar sobre sus propios saberes y la forma en que los construyen. Esto último, lo señalan los profesores en relación a la dificultad que observan en sus estudiantes para reconocer los aspectos epistemológicos que intervienen en la formación y desarrollo del pensamiento complejo.

Los comentarios anteriores ponen en tensión la formación docente inicial, como también, las propuestas de los Programas de Estudio, por cuanto los procesos cognitivos y metacognitivos no suelen ser objeto de reflexión por parte del profesorado para su construcción en el aula. 


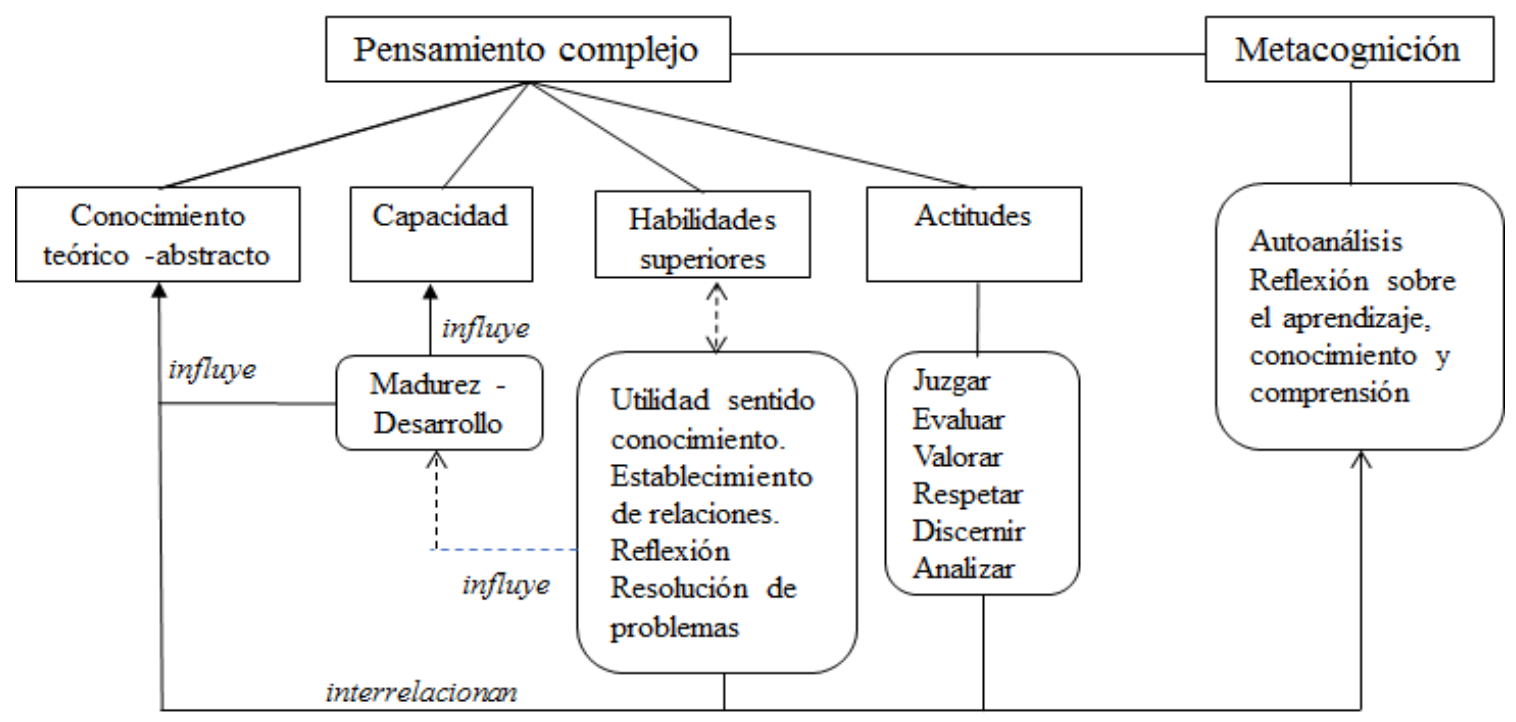

Esquema 2. Concepciones de profesores sobre el pensamiento complejo y la metacognición. Fuente: elaboración propia.

Otro aspecto saliente de las opiniones de los profesores recogidas en nuestra tesis es la distinción que ellos establecen entre las habilidades del pensamiento complejo específicas del área curricular y las habilidades transferibles a otras áreas del currículum. Este hallazgo muestra una discrepancia entre lo prescrito en los Programas de Estudio y las concepciones que tienen los profesores sobre habilidades vinculadas a determinados dominios del saber. Estas habilidades de dominio se expresan en los Programas en términos de objetivos fundamentales (OF) vinculados a contenidos teóricos específicos a diferencia de las habilidades generales que se derivan de los objetivos fundamentales transversales (OFT). Los profesores, por lo general señalan como específicas habilidades que los Programas de Estudio consideran como transversales.

En el siguiente cuadro podemos observar la clasificación que realizan los profesores. 


\section{Cuadro 16.}

\section{Concepciones de profesores sobre las habilidades del pensamiento complejo específicas del área curricular filosófica y las habilidades transferibles a otros espacios curriculares.}

Habilidades específicas del área curricular filosófica
Habilidades transferibles a otras áreas curriculares
Diálogo

Argumentación

Análisis

Reflexión Autocrítica

Resolución de problemas

Creatividad

Inferencias

Conceptualización

Conclusiones Extrapolaciones

Síntesis

Comparación

\section{Comprensión lectora}

Expresión oral

Vocabulario

Metacognición: conciencia de sus propios aprendizajes, pensamiento y comportamiento.

Fuente: elaboración propia

El Programa de tercer año medio de Psicología propone como objetivos transversales desarrollar las habilidades cognitivas superiores que permiten reflexionar, entre otras cuestiones, sobre la condición humana y su sentido, la comprensión de sí mismos y de sus relaciones con los demás, el autocuidado y crecimiento personal, la experiencia moral, la formación del juicio práctico y la autodeterminación. Por su parte, el Programa de estudio de cuarto año medio propone como objetivos transversales el desarrollo de habilidades analíticas, argumentativas e interpretativas para la toma de posiciones fundamentadas, 
coherentes y comprometidas, a través de procesos de interpretación y aplicación a la propia experiencia de los estudiantes en su contexto social y cultural.

En los testimonios recogidos, los profesores señalan que algunas de las habilidades propuestas en los Programas de Estudio les generan ciertas dudas, tanto en su comprensión como en su implementación áulica. Por ejemplo, “desarrollar la iniciativa y creatividad en el trabajo", "expresar ideas", "desarrollar competencias comunicativas empleando los métodos de la reflexión filosófica" y "utilizar y seleccionar información relevante". En este sentido, el reto profesional que se le presenta al profesorado consiste en un mayor acercamiento a los Programas de Estudio y su análisis crítico.

Nuestro estudio ha podido dar cuenta que las estrategias, las actividades y los recursos que los profesores declaran conformar sus propuestas didácticas están discursivamente en línea con la propuesta de Lipman (1998), por cuanto ponen en juego las habilidades de investigación, las habilidades del razonamiento relacionadas con la experiencia cotidiana, las habilidades de información y organización, las habilidades de traducción, entre otras. En el Cuadro 17 se exponen las estrategias, actividades y recursos que los profesores dicen conformar sus prácticas. 
Cuadro 17. Estrategias, actividades y recursos de las prácticas del profesorado para el desarrollo del pensamiento complejo y la metacognición.

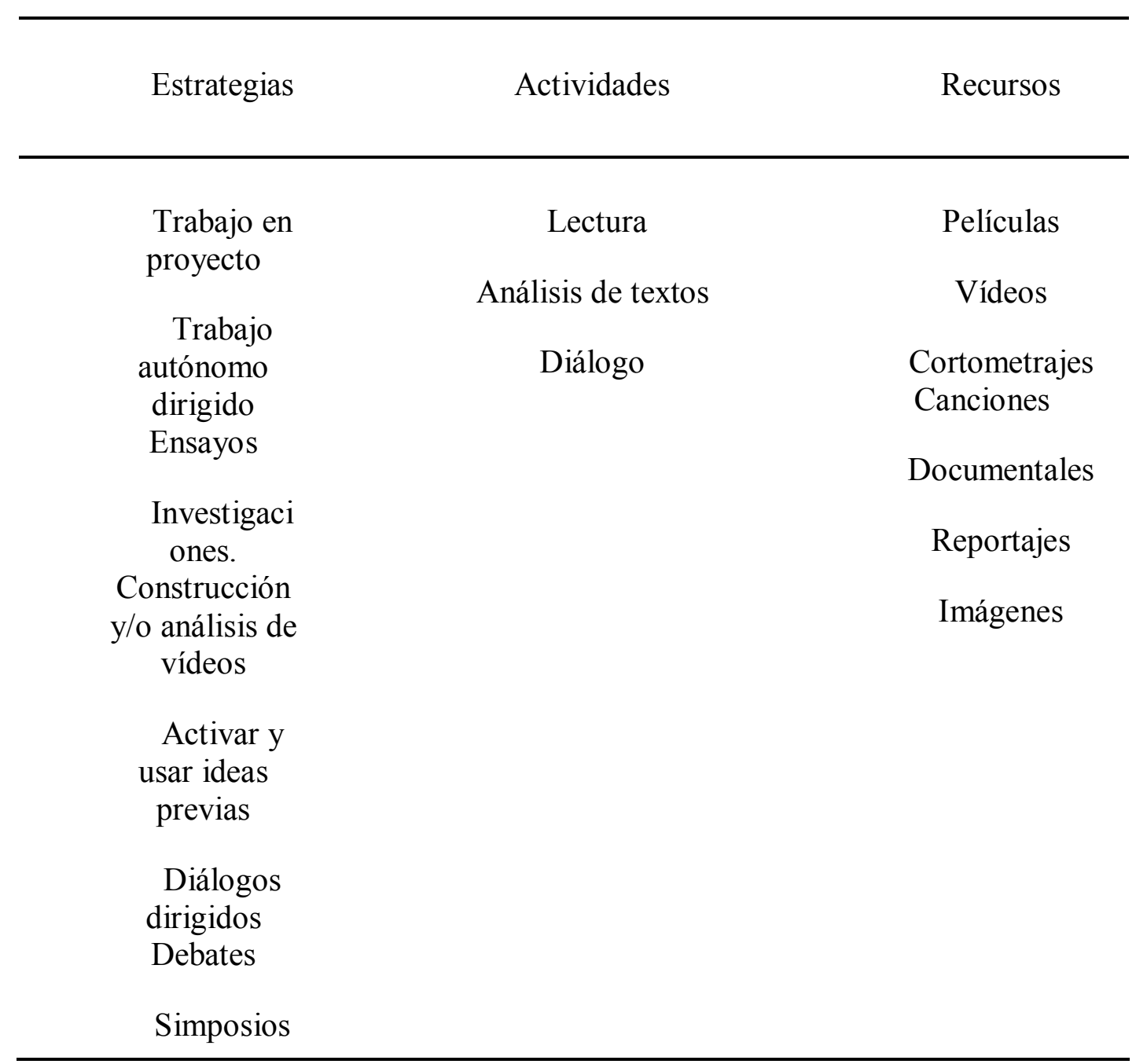

\subsection{Las prácticas en las comunidades filosóficas de aulas actuales}

La enseñanza como mera transmisión de conocimientos y la creciente oposición a esta metodología, a lo largo del siglo pasado, ha sido un tema recurrente en el análisis de las prácticas educativas, del cual el profesorado del área curricular filosófica no ha sido ajeno. 
En la actualidad continúan ocupando la mayor parte del tiempo de la clase las explicaciones seguidas por preguntas centradas en los contenidos que limitan la participación de los estudiantes, los intercambios dialógicos para aprender y la construcción compartida del conocimiento.

En primer lugar, en la mayoría de las clases hemos observado que la participación de los estudiantes es casi inexistente o meramente residual. Sus iniciativas se reducen a pedirle al profesor que le explique algo que no han entendido o pedirle su autorización para alguna actividad rutinaria. Otro aspecto saliente son las dispersiones e interrupciones en la clase, el escaso compromiso y ausencia de iniciativas por parte de los jóvenes para aprender de manera significativa.

En segundo lugar, en menor medida, encontramos clases en donde los profesores actúan como mediadores de los intercambios, dan lugar a la enseñanza mutua o recíproca entre iguales, negocian los significados a través de un proceso dialógico, establecen relaciones con las experiencias y los saberes cotidianos de los estudiantes, problematizan los contenidos con situaciones de sus contextos cotidianos, aplican los conceptos enseñados a ejemplos de la vida cotidiana, generan discusiones y reflexiones sobre los temas.

De acuerdo a la configuración de las clases observadas, hemos distinguido dos niveles de participación, reflexión y colaboración: bajo y alto. La figura 3 tipifica las prácticas, estrategias y actividades observadas en las clases, de acuerdo a las coordenadas que relacionan los niveles de participación, reflexión y colaboración con el desarrollo del pensamiento complejo y la metacognición. 


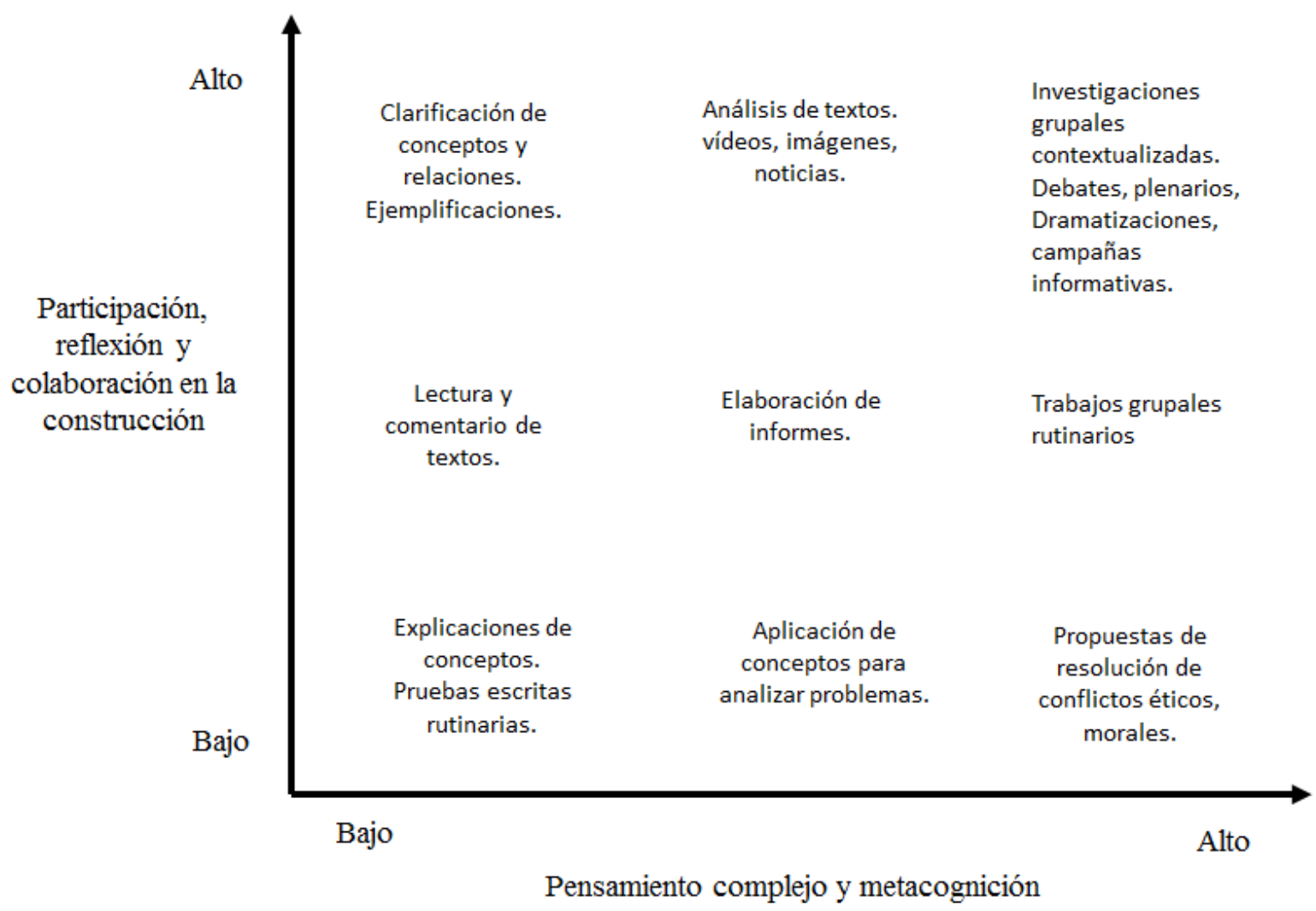

Figura 3. El desarrollo del pensamiento complejo y la metacognición en las prácticas del área curricular filosófica de la educación media chilena.

Fuente: elaboración propia.

Es importante señalar que si bien clasificamos en un nivel medio de participación a la lectura esta práctica puede pasar a un nivel alto si se acompaña de actividades y estrategias metacognitivas, tales como realizar un foro o un debate para establecer asociaciones, analogías, comparaciones, derivaciones de una teoría, contextualizar el pensamiento de un autor, identificar argumentaciones lógicas o empíricas, falacias, contradicciones, supuestos implícitos y explícitos etcétera. Estas sugerencias se pueden expandir al resto de las actividades y estrategias para potenciar el pensamiento complejo y la metacognición. 


\subsection{Análisis crítico}

Nuestra investigación pudo dar cuenta de la prevalencia de un enfoque enciclopédico de las conceptualizaciones propias del campo en los Programas de Estudio del área curricular filosófica de la educación media chilena. Dichos Programas parecerían estar orientados a la formación de las conciencias de los adolescentes mediante la transmisión de ciertos contenidos mínimos obligatorios, en lugar de aspirar al desarrollo de la mente crítica.

Así, la enseñanza de la Filosofía asumiría un orden persuasivo justificado en la educación de las facultades lógicas del libre juicio, que se asemeja más a la transmisión de doctrinas políticas o confesionales. Al respecto, se ha detectado un posicionamiento que refuerza el pensamiento conservador antes que crítico, tal como es el caso de la tercera unidad del Programa de Psicología, "Individuo y Sexualidad", en donde se plantea al sujeto y a las cuestiones sobre el género desde una mirada binaria promoviendo la abstención como única forma responsable de vivir la sexualidad.

Lo antes expuesto se deriva, además, del hecho que en los Programas no se explicita el desarrollo del pensamiento complejo y la metacognición como finalidad prioritaria de la enseñanza, ni tampoco el potencial de la Filosofía, como herramienta para este desarrollo. También, que los objetivos fundamentales del área están orientados a saberes propios de la Filosofía escasamente contextualizados en situaciones o procesos personales, sociales, éticos y ciudadanos.

Las concepciones de los profesores revelan distintos grados de apropiación de los Programas, a la vez, que la posesión de ideas limitadas sobre el pensamiento complejo y la metacognición, justificando los obstáculos de la enseñanza para su logro, en algunos casos, en imposibilidades cognitivas evolutivas de los estudiantes para pensar filosóficamente. Más allá de lo prescrito en los Programas, en tanto marco legal de la enseñanza media chilena, éstos confieren cierta libertad a los profesores para realizar una apropiación crítica 
de los contenidos propuestos. Este postulado tensiona la formación inicial docente atravesada por una mirada evolutiva del sujeto y de sus aprendizajes escolares.

Otra cuestión para señalar es que, si bien en las consideraciones curriculares se presentan multiplicidad de prácticas para la enseñanza de la Filosofía, en las prácticas observadas se detectan el uso mayoritario de una dinámica comunicativa de la enseñanza tradicional con poca diversidad de estrategias, actividades y recursos. Esto claramente atenta a la contribución que puede aportar la enseñanza de la Filosofía al desarrollo de tipos de pensamiento que no solo pertenecen a la reflexión filosófica propiamente dicha, sino que contribuyen al desarrollo cognitivo de los estudiantes en el marco de otras asignaturas de la educación media.

La educación en el área curricular filosófica es una fuente esencial para el desarrollo del pensamiento complejo y metacognitivo, especialmente, para la adquisición de las habilidades y herramientas más formales del lenguaje y del pensamiento, para formar pensadores libres con actitudes críticas, responsables y capacidad para transformar sus realidades.

Enseñar sobre el pensamiento filosófico implica orientar a los estudiantes para que ellos puedan tomar conciencia de sus propios procesos y estrategias mentales (metacognición) para lograr controlarlos (autonomía), mejorando sus procesos personales de aprender a aprender. Esto requiere, entre otras cuestiones, incorporar como objetivo de aprendizaje a las habilidades del pensamiento dentro del currículo filosófico de la educación media chilena.

Tarea propia de la Filosofía, precisamente, es poner en acto el pensamiento para que el aula se vuelva una comunidad de indagación, la cual se basa en valores como el respeto mutuo y el compromiso voluntario por parte de sus integrantes en una búsqueda común.

Las disposiciones simbólicas del aula donde se desarrollan las clases, a nuestro juicio, son otro elemento relevante para generar condiciones que impacten en el desarrollo del 
pensamiento complejo y la metacognición. Romper la lógica tradicional de estas disposiciones implicaría convertir las aulas en comunidades de indagación, donde sus integrantes valoren el intercambio, la significación y resignificación de sus pensamientos, representaciones y concepciones, en beneficio de la razón, la argumentación y la convivencia. Al respecto, los tipos y las modalidades de prácticas y actividades en las clases tienen marcadas implicancias en la construcción del conocimiento y el desarrollo del pensamiento y la metacognición. En este sentido, el análisis y la revisión de las propuestas didácticas es una herramienta potente para hacer posibles las comunidades de indagación.

\subsection{Limitaciones y proyecciones del estudio}

Los resultados obtenidos en este estudio requieren ser considerados a la luz de algunas de sus limitaciones. Una primera limitación está relacionada con el carácter situado de la indagación y, por consiguiente, no permite hacer generalizaciones de sus resultados. En este sentido, resultaría de interés contrastar la indagación con otra muestra de profesores procedentes de otras instituciones educativas nacionales.

En otro orden, las restricciones de este estudio están vinculadas a los propios ritmos de los establecimientos educacionales, a la información presentada en los Programas de Estudio y a la indagación de la investigadora en las respuestas de los profesores.

Respecto a la información presentada en los Programas de Estudio podemos señalar que el acentuado énfasis en aspectos conceptuales y en la poca claridad sobre la diferencia de ciertos elementos metodológicos, tales como actividades, estrategias, recursos y evaluación, nos llevaron a profundizar aún más en el estudio de dichos Programas y de nuestras propias categorías de análisis. 
Por otro lado, los ritmos de los establecimientos, llevaron a suspender y reprogramar en más de una ocasión la visita al aula debido a situaciones emergentes, incluso ajenas al mismo establecimiento, por ejemplo, la visita del Secretario Regional Ministerial, evaluaciones estandarizadas, actividades de aniversario, entre otras.

En cuanto a las entrevistas, resultó ser un elemento altamente dificultoso, para la investigadora, el buscar fundamentos teóricos y/o acciones de enseñanza en torno al pensamiento complejo y la metacognición, sobretodo cuando los profesores no reconocen y, en algunos casos, tampoco les parece relevante dar cuenta de ello. Aquí cabe preguntarse hasta qué punto la insistencia de la repregunta logra desarrollar un pensamiento que devele realmente el conocimiento que la entrevistadora busca.

Por otra parte, se menciona la influencia de los factores de atribución de los profesores, las respuestas de aquiescencia y las reticencias o temores a la socialización de sus opiniones en los resultados de la investigación.

Las conclusiones alcanzadas en esta investigación resultan de interés para continuar profundizando en la indagación del objeto de estudio en nuevos escenarios, más amplios. Para esto, resultará indispensable contar con el apoyo político y financiero por parte de organismos a nivel provincial, nacional o internacional, para asegurar las condiciones exigidas por este tipo de estudios, especialmente en materia de recursos humanos de apoyo a la investigación.

Desde la política pública educativa surge la necesidad de repensar el currículum de la educación media chilena, es decir, de desarrollar un diseño curricular que recupere y reposicione a la Filosofía como un espacio de desarrollo del pensamiento complejo y la metacognición para dar lugar a la producción subjetiva de personas autónomas, críticas, productoras de su propio conocimiento intelectual.

Como complemento de lo anterior, se impone la revisión de las políticas en la formación inicial docente, en línea con un enfoque de la Filosofía como herramienta del pensamiento 
complejo y la metacognición. Esta revisión incluye la resignificación de la mirada hacia los profesores como investigadores reflexivos que pueden contribuir de una manera innovadora y creativa al cambio en las condiciones reales de la enseñanza en las aulas. Esto último permitiría articular la macropolítica escolar con la micropolítica de las aulas como terreno de juego de las propuestas curriculares. 


\section{REFERENCIAS BIBLIOGRÁFICAS}

Agudo de Córsico, M. C. y Manacorda de Rosetti, M. (1994). Interacción lingüística entre profesores y estudiantes. Buenos Aires: AZ Editora.

Anderson, L., Krathwohl, D. (2001). A Taxonomy for learning, teaching, and assessing: A revision of Bloom's Taxonomy of educational objectives. New York, Estados Unidos: Longman.

Ausubel, D. (2002). Adquisición y retención del conocimiento. Una perspectiva cognitiva. Barcelona: Paidós.

Aguilar Astorga, C. R. (2017). Crítica desde el pensamiento complejo a los métodos cuantitativos para el análisis educativo. El caso de los rendimientos educativos. Educación Y Humanismo, 19(33), 357-368. https://doi.org/10.17081/eduhum.19.33.2649

Aníbal L., Aguilar, R., Duque, E., Rojas, G \& Suescún, W. (2000). Estructuras del currículum y del conocimiento en educación básica. Revista de Teoría y Didáctica de las Ciencias Sociales, Universidad de los Andes Mérida, Venezuela (vol 5), pp. 179- 205.

Bakhtin, M.. (1981). The dialogic imagination. Four essays by M.M. Bakhtin. Austin: University of Texas Press. 
Bajtín, M. (2008). El problema de los géneros discursivos. Estética de la creación verbal (2da ed. argentina revisada, pp. 245-290). Buenos Aires: Siglo XXI Editores, S.A.

Boekaerts, M. and Corno, L. (2005). Self-Regulation in the Classroom: A Perspective on Assessment and Intervention. Applied Psychology: An International Review, 54 (2), pp. 199-231.

Borroto López, Lino T. Conocimiento, pensamiento complejo y universidad. Rev. Cubana Edu. Superior [online]. 2015, vol.34, n.2, pp.28-33. ISSN 0257-4314.

Bredo, E. (1994). Reconstructing educational psychology: Situated cognition and Deweyian pragmatism. Educational Psychologist, vol 29 (I), pp. 23-35)

Brubacher, J., Case, C. W., Reagan, T. (2005). Cómo ser un docente reflexivo: La construcción de una cultura de la indagación en las escuelas. Barcelona: Editorial Gedisa.

Bruner, J. (1984). Acción, pensamiento y lenguaje. Madrid: Alianza.

Bruning, R., Schraw, G. \& Norby, M.(2012) Psicología cognitiva y de la instrucción (5º Edición). Madrid: Pearson Educación S. A.

Buron, O. (1993). Enseñar a aprender introducción a la metacognición. España, Mensajero. 
Carver, C. \& Scheier, M.F. (1998). On the self-regulation of behavior. New York: Cambridge University Press.

Cazden C. (1991). El discurso en el aula. El lenguaje de la enseñanza y del aprendizaje. Barcelona: Paidós.

Cerletti, Alejandro (2008), La enseñanza de la filosofía como problema filosófico. Buenos Aires: Libros del Zorzal.

Chaiklin, S. \& Lave, J. (2001). Estudiar las prácticas. Buenos Aires: Amorrortu.

Cleary, T. \& Zimmerman, B.(2004). Self-Regulation Empowerment Program: A SchoolBased Program to Enhance Self-Regulated and Self- Motivated Cycles of Student Learning. Psychology in the Schools, Vol. 4 (5), pp.537-550.

CNED, 2018, Acuerdo Nº54/2018. No de resolución: 135/2018. Tipo de acuerdo: Educación Escolar - Currículum - Marco Curricular y Bases Curriculares Institución. Fecha: 4 de abril de 2018

Cole, M. \& Engeström Y. (2001). A cultural-historical approach to distributed cognition. En: Salomón, G. (comp.). Distributed cognitions: psychological and educational considerations. Cambridge: Cambridge University Press.

Coll, C. (1997). Psicología y currículum. 6ta reimpresión. Barcelona: Editorial Paidós.

COMISIÓN SOBRE FORMACIÓN INICIAL DE DOCENTES (2005). Informe Comisión sobre Formación Inicial Docente, Santiago: Ministerio de Educación y 
Organización de Estados Iberoamericanos para la Educación, la Ciencia y la Cultura (OEI).

Corno, L. (2001). Volitional aspects of self-regulated learning. In B.J. Zimmerman and D.H. Shunk (Eds), Self-regulated learning and academic achievement: Theoretical perspectives (2 $2^{\text {nd }}$ edn., pp 191-226). Mahwah, NJ: Lawrence Erlbaum.

Croll, P. (1986). La observación sistemática en el aula. Madrid: Editorial La Muralla.

De Bono, E. (1990). Aprender a pensar. Barcelona: Plaza \& Janes.

Descartes, R. (2007) El discurso del método (1ºdición). Madrid:Ediciones Akal

Descartes, R. (1951) Meditation of First Philosophy, trad. Lafluer, F. Nueva York: Library of Liberal Arts.

Dewey J. (1988), Democracia y educación (3º edición). Madrid: Ediciones Morata.

Dewey, J. (1989). Como pensamos. Barcelona: Paidós.

Díaz, F. y Hernández, C. (2002). Estrategias para un Aprendizaje Significativo. Una Interpretación Constructivista. Ciudad de México, México: Editorial McGraw-Hill.

Edwards, D. \& Mercer, N. (1994). El conocimiento compartido: El desarrollo de la comprensión en el aula. Barcelona: Paidós. 
Eisner, E. (1998). Cognición y currículum. Una visión nueva. Argentina: Amorrortu Editores.

Elam, S. (1973). La educación y la estructura del conocimiento. Bogota: El Ateneo.

Ennis, R. H. (2011): "The nature of critical thinking: An outline of critical thinking dispositions and abilities". Presentation at the Sixth International Conference on Thinking at MIT, Cambridge, MA, July, 1994. Last revised May, 2011.

Erickson, F. (1989). Métodos cualitativos de investigación sobre la enseñanza. En Wittrock, M.C, La investigación de la enseñanza II. Barcelona: Paidós.

Flavell, J. (1971). First's Discucssants comments: what is memory development the development of?. Human Development, Vol.14, pp. 272-278.

Flavell, J. (1976). Metacognitive Aspects of Problem Solving. En Resnick, L. (ed.). The Nature of Intelligence. Hillsdale, N.J: Erlbaum.

Flavell, J. (1979). Metacognition and cognitive monitoring: A new area of cognitivedevelopmental inquiry. American Psychologist, Vol.(34), pp. 906-911.

Foucault, M. (1998). El uso de los placeres. Madrid: Siglo XXI.

Fourés, C. (2011). Reflexión docente y metacognición. Una mirada sobre la formación de formadores. Zona próxima. Vol. (14), pp. 150-159

Freire, P. (1986). La Educación como práctica de la libertad. Madrid: Siglo XXI. 
Fullan, M. (1994). Coordinating bottom-up and top-down strategies for education reform. In R. Elmore \& S. Fuhrman (Eds.), The governance of curriculum (pp. 186-202). Alexandria, VA: Association for Supervision and Curriculum Development.

Gadamer, H. (2001). Verdad y método. Fundamentos de una hermenéutica filosófica (5º edición). Salamanca: Ediciones Sígueme.

Garcés Mascareñas, Marina (2013). La estandarización de la escritura. La asfixia del pensamiento filosófico en la academia actual. Athenea Digital, Vol. 13(1), pp.29-41. Extraido de http://psicologiasocial.uab.es/athenea/index.php/atheneaDigital/article/view/1039Garces el 20 de agosto de 2017

García, F. (2011), Filosofía para niños: Genealogía de un proyecto, Revista internacional de filosofía aplicada HASER, N². Editorial de la Universidad de Sevilla.

Gardner, H. (1993). Estructuras de la mente: la teoría de las inteligencias múltiples. México: F. C. E.

González, G. (2010). La transición entre teoría y campo de investigación en la didáctica de las ciencias sociales. En Ávila, R., Rivero, P., Domínguez, P. (eds.). Metodología de investigación en Didáctica de las Ciencias Sociales.

Gowin, D. (1981). Educating. Cornell University Press: Ithaca, New York

Guber, R. (2001). La etnografía. Método, campo y reflexividad. Bogotá, Norma editorial. 
Gutierrez, A. \& Schraw, G. (2014). Effects of Strategy Training and Incentives on Students Performance, Confidence, and Calibration. The Journal of Experimental Education, pp. 1-19.

Hernández Sampieri, R., Collado Fernández, C. \& Batista, P. (2003). Metodología de la investigación. México: Mac Graw Hill.

Huertas Díaz, Omar y Arboleda López, Adriana Patricia. (2016) Educación ciudadana en el marco del pensamiento complejo. Revista Lasallista de Investigación, Vol.13 (2), pp. $128-135$.

Herrera Torres, Isaías. (2008). Reflexión filosófica en torno a la educación y su mediación cultural: una perspectiva desde el pensamiento complejo. Tesis de Doctorado. La Habana: Editorial Universitaria, MES.

Honig, M. I. (2004). The new middle management: The role of intermediary organizations in complex education policy implementation. Educational Evaluation and Policy Analysis, 26 (1).

Hutchins, E. (1995). Cognition in the wild. cambridge, Mass.: MIT Press.

Kintsch, W, (1996), "El rol del conocimiento en la comprensión del discurso: un modelo de construcción-integración", en Kenneth Goodman y Walter Kintsch, Textos en Contexto 2. Los procesos de lectura y escritura Buenos Aires, Kapeluz, pp. 71 -133.

Kohan, W. (2004). Infancia entre educación y filosofía. España: Editorial Laertes. 
Kohan, W. (2007), Infancia, política y pensamiento: Ensayos de filosofía y educación. Buenos Aires: Del estante editorial.

Kohan, W. Y Olarieta, F. (2013). La escuela pública apuesta al pensamiento. Ediciones HomoSapiens. Santa Fe, Argentina.

Kohan, W. (15 de junio de 2019). Walter Kohan: La filosofia ayuda a tener gente pensante dentro de las escuelas. La voz. de https://www.lavoz.com.ar/ciudadanos/walter-kohan-filosofia-ayuda-tener-gentepensante-dentro-de-escuelas

Lattus J. (2009). Conócete a tí mismo como base fundamental de la formación humana. Revista obstétrica ginecológica. vol 4 (2): pp. 163-172

Lave, J. (1988). Cognición en la práctica. Barcelona: Paidós.

.Lipman, M. (1988). El Programa de Filosofía para Niños. Manual del profesor. Madrid: Ediciones de la Torre.

Lipman, M. (1989). El descubrimiento de Harry. Madrid: Ediciones de la Torre.

Lipman, M. (2016 [2003]) El lugar del pensamiento en la educación. Barcelona: Editorial Octaedro.

Lipman, M. (2002). Pensamiento complejo y educación. Madrid: Ediciones de la Torre. Segunda Edición

Lipman, M. et al (2003). La filosofía en el aula. Madrid: Ediciones de la Torre. Tercera edición.

Lipman, M. et al. (1988). Investigación filosófica. Manual del profesor para acompañar a El descubrimiento de Harry Stottlemeier. Madrid: Ediciones de la Torre. 
LIPMAN, Matthew (2004). Natasha: aprender a pensar con Vygostky. Una teoríanarrada en clave de ficción. Barcelona: Gedisa

Lipman, M. (2016). Escribir: cómo y por qué (Manual). Madrid, pág. 27.

Maclure, S. \& Davies, P. (1994). Aprender a pensar, pensar en aprender. Barcelona: Gedisa.

McPeck, John E. (1990). Teaching Critical Thinking: Dialogue and Dialectic. Front Cover. John E. McPeck. Routledge, Chapman \& Hall, Incorporated, 1990 Education - 135 pages.

Malbrán, M. \& Palacios, A. (2007). La entrevista en profundidad. Actas de International Association for Dialogue Analysis. IADA. Facultad de Humanidades y Cs. de la Educación. Universidad Nacional de La Plata.

Maturana H. \& Varela, F. (2003). De máquinas y seres vivos. Buenos Aires: Editorial Universitaria Lumen

MINEDUC, (2001), Programa de estudio Cuarto año medio. Formación General Educación Media. Santiago de Chile: Ministerio de Educación.

MINEDUC, (2001), Programa de estudio Tercer año medio. Formación General Educación Media. Santiago de Chile: Ministerio de Educación.

Montañés, M. (2001). Introducción al análisis e interpretación de textos y discursos. En Prácticas de Creatividad Social. Construyendo ciudadanía/2.Barcelona: E1 Viejo Topo. 
Moshman, D. (1982). Exogenous, endogenous, and dialectical constructivism. Developmental Review, Vol (2), pp. 371-384.

Moreira, M. (2017). El aprendizaje significativo como un referente para la organización de la enseñanza, En, Palacios, A y Pedragosa, M (comp.) Aprendizaje y enseñanza en clave de significatividad. Archivos de Ciencias de la Educación, 11(12).

Morin, E. (1984). Ciencia y conciencia de la complejidad. Francia: Aix-en-Provence.

Morin, E. (1998). Epistemología de la complejidad (2º reimpresión). En Fried, D.

(coompiladora) Nuevos paradigmas: Cultura y subjetividad. Buenos Aires: Paidós.

Najmanovich D. (2013). Viaje a la complejidad. Volumen 4: La complejidad de lo social. La trama de la vida. Nivel de integración social. Biblioteca Nueva, Madrid.

Nickerson, R.; Perkins, D. \& Smith, E.(1993). Enseñar a pensar: aspectos de la aptitud intelectual. Buenos Aires: Paidós.

Núñez Delgado, M.P. (2015). Metacognición, habilidades metalingüísticas y aprendizaje. En Palacios, A. comp. Claves para incluir: Aprender enseñar y comprender. Colección: Ensayos y Experiencias.Noveduc.

Newman, D., Griffi, N. y Cole, M. (1991). La zona de construcción del conocimiento: trabajando por un cambio cognitivo en educación. Madrid: Morata. 
Prigogine, I. (1994b), De los relojes a las nubs. En: D. Fried Schnitman. Nuevos paradigmas, cultura y subjetividad. Buenos Aires: Paidós, 395-419.

Oroval, E. y Escardíbul, J. (1998). Economía de la Educación. España: Editorial Encuentro. Recuperado el 20 de mayo de 2011 en: http://books.google.com/books?hl=es\&lr=\&id=BHbEz5jF3 IC\&oi=fnd\&pg=PA119 $\underline{\& d q=e c o n o m i ́ a+d e+l a+e d u c a c i o ́ n \& o t s=F f R h 8 e U r 7 t \&}$

Osses Bustingorry, Sonia, \& Jaramillo Mora, Sandra. (2008). METACOGNICION: UN CAMINO PARA APRENDER A APRENDER. Estudios pedagógicos (Valdivia), 34(1), 187-197. https://dx.doi.org/10.4067/S0718-07052008000100011.

Palacios, A. (2015). Lenguaje, interactividad y aprendizaje en el aula. En, Palacios, A. (Comp.). (2015). Claves para incluir. Aprender, Enseñar y Comprender. Buenos Aires: Noveduc.

Palacios, A. (2018). Potencialidades de las estrategias de mediación en la lectura. Pilar Nuñez Delgado (Comp). Literacidades y secuencias didácticas en la enseñanza de la lengua y la literatura. Madrid: Octaedro.

Palacios, A. \& Pedragosa, M. A. (2018). Lenguaje y pensamiento: la mediación como herramienta metacognitiva. En Vallejos, R. \& Kröyer, O. Pensar, dialogar y reflexionar juntos desde la Filosofía: desafios pendientes en la Escuela. Universidad de Concepción, Chile. 
Palacios, A. y Schinella, G. (2017). Diseño y validación de un instrumento para evaluar la metacognición sobre el estudio en estudiantes de Medicina. Revista de Educación de la Universidad de Granada, Vol. 24, pp. 9-28

Pedragosa, M. A. (2018a). Una mirada psicoeducativa sobre la construcción del conocimiento profesional docente. En: Palacios, A. M., Pedragosa, M.A. y Querejeta, Maira. Encuentros en la encrucijada Psicología, Cultura y Educación, pp. 38-52, La Plata: Edulp.

Pedragosa, M. A. (2018b). El conocimiento sobre la enseñanza y su construcción en docentes universitarios. Obtención de grado: Doctora en Ciencias de la Educación. FaHCE, UNLP, Consultado el 17 de octubre de 2018. En: http://sedici.unlp.edu.ar/handle/10915/70661

Pedragosa, M. A. (2015). Las tutorías desde un enfoque psicopedagógico. En, Palacios, A. (2015). Claves para incluir. Buenos Aires: Noveduc.

Peirce, C. (1988). "Algunas consecuencias de cuatro incapacidades", (1868), traducción de Jose Vericat Esta traducción se publicó originalmente en: Charles S. Peirce. El hombre, un signo (El pragmatismo de Peirce), José Vericat (trad., intr. y notas), Crítica, Barcelona 1988, pp. 88-122.

Perkins, D. (1986). Knowledge as Design. EE.UU. Edición Lawrence Erlbaum Associates

Perkins, D. y Tishman, S. (1997). Un aula para pensar. Aprender y enseñar en una cultura de pensamiento. Buenos Aires: AIQUE. 
Peronard Thierry, M. (2009). Metacognición: mente y cerebro. Boletín de Filología, Vol. pp. 263-275.

Perry, E. Et al. (2002) Investigating teacher-student interactions that foster self-regulated learning. Educational Psychologist, Vol.(37), pp. 5-16.

Piaget, J. (1977). El criterio moral en el niño. Barcelona: Fontanella.

Piaget, J. (2018) Seis estudios de Psicología. 1ª edición. Ciudad autónoma de Buenos Aires:Siglo XXI Editores Argentina.

Peirce, S. (1871). The Works of George Berkeley. North American Review. CP 8.7-38, W 2.462-487, EP1.83-105. Traducción de José Vericat, 1988.

Pintrich, P. (2000). The role of goal orientation in sealf-regulated learning. In M. Boekaerts, P. R. Pintrich \& M. Zeidner (Eds.). Handbook of self-regulation. San Diego, CA: Academics Press.

Purita, G.; Testasecca, I.; Arrobas, M.; Matthaeis, M. (2008). Una aproximación Filosófica para y con niños del Nivel Inicial. Dirección General de Cultura y educación. Buenos Aires la Provincia, La Plata.

Ramírez, H. \& Flores,V. (2006). CTSyV y pensamiento complejo: más allá de lo disciplinario. I Congreso Iberoamericano de Ciencia, Tecnología, Sociedad e Innovación CTST+1, Palacio de Minería 13-23 de junio. 
Rapley, (2014), Los análisis de la conversación, del discurso y de documentos en investigación educativa. Madrid: Ediciones Morata. p. 148

Resnick \& Klopfer (2007). Currículum y cognición. Buenos Aires: Aique.

Resnick, L. \& Klopfer, L. (1996). Curriculum y cognición. Buenos Aires: Aique.

Ricoeur, P. (1981). El discurso de la acción. Madrid: Cátedra.

Rivas Montoya, L. (2013). Exploración sobre las decisiones estratégicas desde el pensamiento complejo. Revista Universidad y Empresa, [S.1.], v. 15, n. 25, p. 107 129.

Rockwell, Elsie (1987). Reflexiones sobre el proceso etnográfico. Colección Documentos del DIE, Vol.(3) México: DIE.

Roger Ciurana, E., \& Regalado Lobo, C. (2016). Pensamiento complejo y educación. Aclaraciones y confrontaciones. México: FronterAbierta.

Roggoff, B. (1977). Los tres planos de la actividad sociocultural: apropiación participativa, participación guiada y aprendizaje. En, Wertsch, J. (comp..). La mente sociocultural. Aproximaciones teóricas y aplicadas. Madrid: Fundación Infancia y Aprendizaje.

Rogoff, B. (1993). Aprendices del pensamiento. El desarrollo cognitivo en el contexto social. Buenos Aires: Paidós.

Rogoff, B., \& Angelillo, C. (2002). Investigating the coordinated functioning of multifaceted cultural practices in human development. Human Development, Vol, 45, pp. 211-225. 
Román Sánchez, J. \& Gallego Rico, S. (1994) ACRA. Escalas de Estrategias de Aprendizaje. Madrid: TEA Ediciones, SA.

Ruiz Olabuénaga J. (2012). Metodología de la investigación. Universidad de Deusto.

Sáiz, Maria-Consuelo; Flores, Valle \& Román, José-María (2010). Metacognición y competencia de "aprender a aprender" en Educación Infantil: Una propuesta para facilitar la inclusión. REIFOP, Vol 13 (4). (Enlace web: http://www.aufop.com) Fecha consulta

Salazar, Funes y Farzaneh, (2018). El Aula, un Lugar para Aprender a Pensar y Aprender a Convivir. Revista Interuniversitaria de Formación del Profesorado, 92 (32.2) (2018), $69-80$ p. 70

Salomon, G. (2001). Cogniciones Distribuidas: Consideraciones psicológicas y educativas. Buenos Aires: Amorrortu Editores.

Sánchez M. (2004) Ética para la vida cotidiana. España: Editorial Del Orto.

Sautu, R.; Boniolo P., Dalle P. y Elbert, R, (2005), Manual de metodología. Construcción del marco teórico, formulación de los objetivos y elección de la metodología. Buenos Aires, Argentina: CLACSO, Colección, Campus Virtual. Consultado el 9 de Mayo de 2018 desde http://biblioteca.clacso.edu.ar/ar/libros/campus/metodo/metodo.html).

Savater, F. (1997). El valor de educar. 2da. ed. Barcelona: Ariel

Sayago, S. 2014. El análisis del discurso como técnica de investigación cualitativa y cuantitativa en las ciencias sociales. Cinta moebio 49: 1-10 
Shaffer, H. (1972). Una crítica al concepto de capital humano. En Blaug, M. (editor) Economía de la Educación. Madrid: Tecnos.

Shutz, Th. (1963). The economic value of Education .New York: Columbia University Press.

Shutz, Th. (1971). Investment in human capital: role of education and research. New York: Free Press.

Simon, H. (s/f). Administrative behavior: A study of decision-making processes in administrative organization. New York: Macmillan Publishers.

Sternberg, R. \& Detterman, D. (1988). ¿Qué es la inteligencia? Enfoque actual de su naturaleza y definición. Madrid: Pirámide.

Taba, H. (1987). Elaboracion del curriculo: Teoria y práctica. Troquel

Tishman, S., \& Perkins, D. N. (1997). The language of thinking. Phi Delta Kappan, Vol. 78(5), pp. 368-374.

Tomlinson, J. (1999). Globalización y cultura. Oxford: Oxford University Press.

Touraine, A. (1998). ¿Podremos vivir Juntos? La discusión pendiente: el destino del hombre en la Aldea Global. Argentina: FCE . 
Urra et al, (2013). El análisis del discurso como perspectiva metodológica para investigadores de salud Enfermería Universitaria, vol. 10, núm. 2, abril-julio, 2013, pp. 50-57. Universidad Nacional Autónoma de México. Distrito Federal, México.

Vallejo-Gómez, N. (2002). Morin, pensador de la complejidad. En: Velilla, MA. (compilador) Manual de iniciación pedagógica al pensamiento complejo. París: ICFES/UNESCO. pp. 80-90.

Vallejos y Coll, (2017). Filosofía con niños, niñas y jóvenes: una experiencia en el desarrollo del pensamiento complejo y valores humanistas laicos en una escuela pública. Revista Paideia. Vol. 61. pp. 101- 117.

Van Dijk A. (1999), El análisis crítico del discurso In: Anthropos (Barcelona), 186, septiembre-octubre 1999, pp. 23-36.

Van Dijk, A. (2007). Racismo y discurso en América Latina. Barcelona: Gedisa.

Van Dijk, A. (2012). Discurso y contexto. Un enfoque sociocognitivo. Barcelona, España, Editorial Gedisa.

Velilla, M. A. (2002). Manual de iniciación pedagógica al pensamiento complejo. Corporación para el Desarrollo Complexus. Unesco: Ediciones Jurídicas.

Vigotsky, L. (1978). El desarrollo de los procesos psicológicos superiores. Barcelona: Grijalbo 
Vygotski, L. (1991). Obras Escogidas. Tomo I. Madrid: Visor.

Wenger, E. (2001). Comunidades de práctica. Aprendizaje, significado e identidad. Barcelona, Paidós.

Wertsch, J. (1988). Vygotsky y la formación social de la mente. Buenos Aires: Paidós.

Zabala, H. (2014). El desarrollo de las habilidades de pensamiento en el programa de filosofía para niños. Espiral. Revista de docencia e investigación, Vol. 4(1), pp. 5970.

Zimmerman, B. (1994). Dimensions of Academic Self-Regulation. In Schunk, D.H. \& Zimmerman, B.J. (Eds.), Self-Regulation of Learning and Performance. Issues and Educational Applications. Hillsdale, New Jersey, Lawrence Erlbaum Associates, Publishers.

Zimmerman, B. \& Martinez Pons (1988). Construct validation for a strategy model of student self-regulated learning. Journal of Educational Psychology, Vol 80(3), pp. 284-290 
Anexos 


\section{ANEXO 1. ENTREVISTA A EVA}

RV: Buenas tardes profesora Srta. Angélica tengo el agrado de dirigirme a Ud., para saludarla cordialmente y a la vez manifestarle que, conocedores de su trayectoria académica y profesional, la hemos elegido como juez experto para aplicar y revisar el contenido de los instrumentos que utilizaremos en la investigación sobre "Pensamiento complejo y metacognición en filosofía" en establecimientos educacionales de la provincia de Concepción.

Este instrumento ha sido creado en el marco de la investigación doctoral de la Profesora Rosse Marie Vallejos G., dirigida por la Dra. Analía Palacios de la Universidad Nacional de La Plata, Argentina. Por esta razón, y con la finalidad de determinar la validez de contenido, solicitamos responder las preguntas y permitir la visita al aula. A continuación le adjunto la documentación que respalda los objetivos de la investigación y definiciones conceptuales de las variables.

Es importante señalar que este proceso garantiza confidencialidad de sus respuestas. Los documentos que ahora le entrego corresponden a la carta de presentación y los anexos que detallan los objetivos de la investigación y la caracterización de las unidades de análisis.

Bien.. la primera pregunta profesora dice así: ¿Qué enfoques, (aclarar lo que se quiere decir con enfoque) predominan en los Programas de Filosofía para el desarrollo del pensamiento complejo y la metacognición? como se concibe la enseñanza de la filosofia en los programas.

AG: oh pero ¿los enfoques tienen que ser así con un nombre específico? O mmmh es que no entiendo bien la pregunta ¿qué enfoque tienen?

RV: cuando preguntamos por los enfoques, que en el campo nuestro es una pregunta compleja conceptualmente porque no tenemos delimitado técnicamente un nombre, pero lo que quiero que usted me diga es lo que predomina al momento de revisar nuestros programas oficiales qué predomina, en sus sugerencias conceptuales, metodológicas, evaluativas ¿cómo podemos llamarle a ese enfoque?

AG: se supone que debería ser más analítico, como de crítica, que es lo que declara; sin embargo en realidad son super básicos, no sale mucho del conocer y comprender por lo que en la práctica una termina haciendo otras cosas pues la filosofía es puramente compleja y metacognitiva entonces si quiero llevar a mis estudiantes a esos niveles de pensamiento no puedo quedarme solo con lo que me dice el programa. $\mathrm{O}$ sea, es un enfoque más tradicional que apuesta por la comprensión de algunos contenidos filosóficos. En el caso de tercer año donde se trabaja psicología es más crítico eso. trabajamos los procesos psicológicos, sociales, etc pero se mandata que desde una mirada más teórica.. otra cosa es lo que una realmente hace en el aula para trabajar el pensamiento complejo y desarrolle una opinión personal ¿ya? Porque como te decía lo que a una le entrega el ministerio son niveles básicos, poco trabajan con los niveles cognitivos más altos, y en filosofía no nos podemos quedar a ese nivel ojalá podamos trabajar a nivel de analogía, al menos en mi aula, que ellos sean capaces de hacer analogías con otras asignaturas o con los diferentes pensadores que se ven dentro del aula. Pero ojo que eso no lo exige el programa, para nada.

Recomendación: preguntas aclaratorias por ejemplo ¿qué quiere decir con eso de analogía?

uso de la paráfrasis, re pregunta... uso e importanci $\rightarrow$ marco metodológico 
RV: ¿Qué tipo de problemas, conocimientos, procesos de pensamiento, reflexiones, uso del lenguaje se ponen en juego en los Programas de estudio? abrir la pregunta, especificar, pedir ejemplos

AG: $\mathrm{mmm}$ mmmm yo siento que la propuesta de los programas oficiales de Filosofía presenta problemas súper escuetos, no hay una dirección clara, el programa por ejemplo de Teoría del conocimiento yo lo podría hacer en un semestre e incluso las unidades se sobreponen con las de Psicología. ¿qué tipos de problemas, conocimientos, procesos de pensamiento? Ya es que los procesos de pensamiento son los básicos según yo, creo que deberían ser mucho más exigentes y de reflexión mmh no, no mucho, menos. No se llegan a esos niveles en los programas. Y en las problemáticas por ejemplo estoy pensando en los programas de psicología que tiene que ver, o sea, lo que te exige el Ministerio en realidad son contenidos mínimos muy básicos, demasiado básicos y los chicos demás que pueden dar más. Respecto al uso del lenguaje, mmm, ahí no sé, no sabría qué decirte..

contra-preguntar ¿por qué?. es un diálogo!

$\mathrm{RV}$ : ¿Qué tipo de prácticas y/o actividades de enseñanza y evaluación se programan para el desarrollo del pensamiento complejo y la metacognición? abrir las preguntas, especificando cada elemento para que el entrevistado de la mayor cantidad de información

AG: aah si poh, aquí el tema más significativo que yo creo es el del trabajo directo de los estudiantes, asi como a ellos se les entrega un contenido, un pensador para que puedan desarrollar el pensamiento complejo y trabajar como con las ideas que ellos comprenden, no trabajar con ideas que el profe cree que el estudiante ha comprendido de lo que está estudiante, sino más bien las ideas que se explicitan en el aula, con esas ideas trabajar y ahí se produce, para mi gusto, un mayor aprendizaje, un aprendizaje mucho más significativo que estar hablando o decirle a los chiquillos "lo que deberían haber entendido es esto.." y partir de eso, a diferencia de lo que ellos comprenden de lo que están estudiando, entonces como que la práctica tiene que ser más de parte de una intervención directa de parte del estudiante, y cuando uno por ejemplo se da cuenta que el estudiante se quedó solo en un análisis de nivel básico ayudarlo un poco, entregarles algunas herramientas pero la idea es que avancen por sí solos, no suponer que entendió lo que uno le quiere explicar en el aula porque o sino yo siento que ahí se está perdiendo el tiempo no más. Por ejemplo teoría del conocimiento en tercero medio es súper complejo para los chicos, súper, entonces qué es lo que hago yo analizamos un texto muy simple, que pueden ser dos planas ya ¿qué entendieron? Y todo lo que entendieron sobre eso yo asiento conocimiento, ni inferior a eso, ni superior a eso. Y recién ahí yo siento que pueden ir avanzando

$\mathrm{RV}$ : ¿Cómo caracteriza al pensamiento complejo y la metacognición los profesores de filosofía?que es para ud. el pc y la me en la filosofia?

AG: ¿Cómo caracterizaría al pensamiento complejo y la metacognición los profesores de filosofía? Mmh es que aquí la dificultad que hay para trabajar el pensamiento complejo tiene que ver con el bagaje que tienen los estudiantes, entonces para mí el pensamiento complejo tiene que ver con conocimiento duro, teórico para mi gusto porque o sino ¿de dónde se establecen relaciones de idea? Tiene que ver con eso, primero con un bagaje de conocimiento teórico, objetivo y de ahí, a propósito de ese contenido yo creo que nace la metacognición o lo que pueden crear ellos, o desarrollar, o reflexionar o analizar. Por eso que es tan difícil, porque los chiquillos manejan muy poco conocimiento, entonces la primera tarea que una hace es tratar de instalar en ellos conocimiento. Estoy hablando de pensamiento de filósofos, teorías, en ese sentido. Porque claro si uno les dice "eh ya chiquillos pensemos" el conocimiento 
duro que ellos tienen es muy poquito, es muy limitado para poder saltar a otros tipos de ideas y niveles de análisis

RV: ¿Qué habilidades, capacidades y disposiciones del pensamiento complejo y la metacognición pone en juego la enseñanza de la filosofía?

AG: ya pero es que aquí en la filosofía yo siento que se ponen en juego todos los elementos para desarrollar el pensamiento complejo y la metacognición. Están todos, está todo en juego, todo lo que se necesita para el pensamiento complejo la filosofía lo tiene porque tiene problemáticas objetivas, hay una diversidad de ideas de autores, de autoras que hace que los chiquillos despierten a algunas ideas que por sí solos no pueden llegar, entonces para mi gusto en la filosofía se encuentran no sé si todos pero la mayoría de los elementos que permiten desarrollar el pensamiento complejo y la metacognición. Creo que no hay otra asignatura, fijate tú, que cumpla con todos los requisitos porque aquí al menos se plantean problemáticas filosóficas, intelectuales que les permiten a los chiquillos ponerse en una actitud como de pensar para poder reflexionar, para poder criticar, están todos los elementos, insisto. cuáles son esos elementos? contrapregunta

RV: ¿Qué estrategias, actividades y recursos didácticos favorecen el desarrollo del pensamiento complejo y la metacognición en la enseñanza de la filosofía?

AG: la estrategia tiene que ver así coomoo que sea de participación horizontal, o sea todos por igual, siempre en diálogo, en conversaciones, en discusiones en el buen sentido de la palabra, yo siento que el recurso didáctico en filosofía es el diálogo, eso es lo principal, la actitud de diálogo, la actitud de crítica, más allá de, bueno igual uno lo usa, el material audiovisual, de hecho hay harto material audiovisual que se puede utilizar pero mientras no se converse, no se dialogue en la formación para mí no hay un mayor aprendizaje significativo.

$R V: ¿ Q u e ́$ tipos de actividades y/o estrategias de enseñanza utiliza durante el desarrollo de sus clases de filosofía?

AG: ya, bien, la primera parte siempre es teórica por lo mismo que te decía denante siempre hay una, los tres primeros meses son de conocimiento duro, conocimiento de autores, de pensadores de teorías que los chiquillos tienen que tratar de integrar una serie de ideas incluso de carácter de una línea histórica como van cambiando los paradigmas, como son las ideas que priman. Es sumamente teórico primero, por tanto son clases frontal, siempre de conversación ahí en la primera parte como que yo ocupo el protagonismo para poder ayudarlos en eso, luego viene todo el proceso de autonomía porque ya luego ellos empiezan a elaborar en parejas generalmente trabajan y son ellos los actores de lo que se está planteando, de lo que se está analizando.

$\mathrm{RV}$ : ¿Cuáles son las formas de interacción, cooperación y participación que se dan en las clases de filosofía?

AG: es que son frontales, yo solo soy una canalizadora, y eso por decir porque entre ellos mismos van descubriendo, van conversando, se van planteando, cuando ocurren ideas erróneas por ejemplo ahí intervengo, esa es mi intervención para procurar que no estén confundiendo la idea, este autor quiso decir tal o cual cosa, como clasificándolos la parte teórica, pero son todas de conversación y principalmente son de crítica, hay una actitud crítica frente a lo que se está planteando donde el objetivo es que ellos comprendan por ejemplo el autor o la teoría que se está discutiendo pero no necesariamente que se hagan parte, ellos una vez que la comprenden tienen que tomar una postura como personal respecto a lo que se está diciendo porque tampoco se pretende que digan que sí a todo lo que plantean los autores como "ah si yo estoy de acuerdo, no está bien", sino que una vez que han comprendido lo que el autor propone ellos puedan tener una postura crítica, me gustó por esto o no me gustó por esto. "Formas de cooperación y participación" 
RV: ¿Qué tipo de conocimientos, problemas, razonamiento y niveles de discusión y reflexión se plantean en las actividades de la clase de filosofía? dividir la pregunta e ir indagando

AG: bueno las problemáticas en cuarto medio principalmente tienen que ver o son de carácter ético, todo ronda en relación a eso, la primera parte son todos los sistemas éticos de la historia y luego ellos elaboran un documental con temáticas de carácter contingente, un documental objetivo, donde luego nosotros discutimos acerca de esa situación.

RV: ¿Qué uso se da al lenguaje, los materiales y los recursos didácticos en las clases de filosofía? Dividir la pregunta e ir indagando

AG: Lo más importante es el uso del lenguaje en la clase de filosofía, eh los materiales y el recurso didáctico como te decía denante es como más que nada motivarlos para que sigan la conversación, que traten de seguir también cuando existe problemáticas complejas para que se pueda entender y puedan así tener una opinión, más allá de material concreto como guías o power o videos, va más allá de eso, principalmente tiene que ver con la oratoria, yo trabajo harto esa parte,

RV: Finalizamos entonces la entrevista muchas gracias. 


\section{ANEXO 2. ENTREVISTA A ANTONIA}

P1: ¿Cómo concibe usted, o bien, ¿cómo cree que se concibe la enseñanza de la filosofía en los programas?

R: Eeh... (Suspiro)... ¿En los programas que tenemos nosotros? Esss eeh... desactualizada. P2: ¿Por qué consideras que es desactualizada?

$\mathrm{R}$ : porque es muy conceptual y a las chiquillas no les hace mucho sentido, no...no ven lo practiqui, lo práctico de la enseñanza de la filosofía... como programa, porque uno si se la da después. Ellos... ellas si logran comprender, pero el programa eeh... es super complejo.

P3: ¿Cuál es la complejidad y con qué lo asocias?

R: La complejidad es conceptual, sobre todo por ejemplo en cuarto medio eeh... la primera materia es muy conceptual, muy abstracta y a ellas les cuesta mucho la abstracción.

P4: Y por ejemplo, ¿qué conceptos abstractos son los que más les complican a las estudiantes de esas primeras unidades?

$\mathrm{R}$ : Eeem por ejemplo eees la metafísica, con suerte logran entender lo material, lo inmaterial es casi imposible. Ya el mundo de las ideas es una cuestión casi fantástica para ellas, es como si uno estuviese hablando en chino.

P5: ¿Y con el programa de tercer año de psicología?

R: El de tercer año es mucho más práctico, pero eeh... Le dan mucha, muy poca importancia a la cuestión social y mucha a lo conceptual, mucho a loo eeh... al ¿cómo se llama? Al sujeto como proceso psicológico y no sociales, que en realidad nosotros no extendemos mucho más, pero como programa eeh... son seis semanas. Y eso no da para seis semanas, da para mucho más.

P6: ¿Qué tipo de problemas o de conocimientos se ponen en juego en los programas de filosofía?

R: El que ellas no tengan conocimientos previos en filosofía dificulta la enseñanza de la misma, no... (Suena el timbre) les cuesta... lo que te decía al principio, la cuestión abstracta. En filosofía es abstracta, sobre todo la primera materia de filosofía, es muy abstracto entonces le cuesta mucho.

P7: Y por ejemplo, estas temáticas que se trabajan tanto en tercero como en cuarto, ¿qué tipo de problemas les plantea a las estudiantes?

R: El pensar, el que ellas tengan que reflexionar, como que no están acostumbrabas a eso. Uno sale de la clase y le dice "profesora eeh... me hierve la cabeza de haber pensado, ¿por qué nos hace pensar tanto?" Esa es la idea de la filosofía, si ustedes tienen que cuestionar, y no están acostumbradas a cuestionar, están acostumbradas que se le diga qué es lo que hay que hacer, cómo hay que hacerlo, por qué, a lo mejor, pero no... no cuestionan el cómo se le está enseñando, por qué se les está enseñando, de qué les sirve y en filosofía hacemos eso constantemente.

P8: ¿Y los conocimientos asociados a eso?

R: Lo relacionan un poco eeh... A ver en tercero medio con biología sobre todo al principio, ¿ya? Pero en realidad psicología (sonidos de voces, conversaciones, y tacones) les es mucho más fácil a ellas porque es parte de su vida cotidiana. Entonces ellas si los pueden relacionar con sus vivencias.

P9: ¿Qué procesos de pensamiento tú ves que se ponen en juego en estos programas de estudio?

$\mathrm{R}$ : Procesos de pensamiento (repite dubitativa)

P10: ¿O reflexiones? 
R: no sé, no es bien simple, ellas no logran metacognición con los conocimientos dee... no todas, solo algunas.

P11: ¿Y los programas ponen en juego, por ejemplo, el uso del lenguaje? En las metodologías, por ejemplo, que propone.

R: No mucho, no mucho, es más bien un lenguaje... poco filosófico encuentro yo, le falta... además que estamos enfocados en eeh... por ejemplo cuarto medio, que eeh... tenemos que pasar casi materia dee... comportamiento ciudadano, educación cívica que antes se pasaba, que no logramos eeh... Pasarlo bien, eeh... falta la reflexión, falta que el que ellas puedan darse cuenta de la... de la realidad en la que viven, las situaciones que están sucediendo a su alrededor, y relacionarlo con la materia.

P12: Y estos programas de estudio, las propuestas metodológicas que plantea, ¿abren posibilidad a la interacción entre los estudiantes?

R: (silencio) Poco, porque en realidad eeh... el programa eeh... da algunas actividades super específicas, que en la práctica no es posible llevarlo a cabo. Yo ja... nunca, si no encartono eeh... las actividades que están en la... el programa, porque no me sirven. Además de algunas películas que yo pueda tomar, ya están desactualizadas las películas. Entonces está (tono irónico, risa leve) como ponerle no sé, matrix. Ya están en otra época de Chile, a lo mejor la Isla tiene más sentido para ellos que matrix. Entonces noo... casi nunca ocupo los loo... las actividades de ahí.

P13: ¿Y las actividades de evaluación que se programan para el desarrollo del pensamiento complejo y la metacognición? Propuestas por el programa.

R: No, mm no, nada, no tomo nada de ahí (risa nerviosa) porque no...

P14: ¿Qué propone, por ejemplo, el programa en las sugerencias de prácticas, actividades de enseñanza y evaluación?

R: Emm por ejemplo toman evalu... ensayos, ensayos y las chiquillas no tienen idea de cómo hacer un ensayo. Entonces toman eeh... actividades quee... suponen que las chiquillas ya conocen, pero no es así, entonces cuesta mucho que ellas puedan desarrollar ese tipo de actividades. Porque además ha (sonidos de voces conversando, y pasos) tenidoo... eeh... muchas... eeh... muchos cambios los planes y programas de los otros, los... las bases curriculares de las otras asignaturas. Cuando por ejemplo ensayo viene a tomarse en cuarto medio recién por materia y ellas necesitan hacer ensayos en tercero medio. Entonces en tercero no se puede, nosotros no somos los encargados tampoco de entregar esas herramientas, que si bien lo podemos hacer en una guía, eeh... no tiene mucho sentido.

P15: Y en esta programación que propone el programa de tercero medio de psicología, y el de cuarto medio de filosofía, ¿en qué se diferencia uno del otro?

$\mathrm{R}:$ ¿En cuánto al programa?

P16: Si, y que uno pueda pensar éste está más orientado al desarrollo efectivo de habilidades de pensamiento, por ejemplo.

R: El de tercero es más bien autoconocimiento y comprensión, de sí mismo, desde la realidad en la que están viviendo y... el de cuarto medio ess... eeh... básicamente pensamiento ético y comportamiento igual, pero... mmn... no hac.. no las hace cuestionarse constantemente, osea esto es así, ¿por qué? Porque tal persona lo dijo, "ah profesora pero usted está diciendo que" no, yo estoy diciendo "el filosofo tanto", a ellas les cuesta quee... uno simplemente les dee... conceptos para que ellas se formen su idea, y... que... dee... eeh.. que no sea, estarán acostumbradas a que se les da la materia, y eso es, sin cuestionamientos, no que ellas formen una idea a través de los conocimientos que uno le entrega.

P17: Isabel, ¿qué es para ti el pensamiento complejo y la metacognición?

R: Eh... (suspira) la metacognición ess... eeh... llegar a darme cuenta de lo que estoy aprendiendo, el por qué lo estoy aprendiendo, y... eh... ay no sé (ríe fuerte). 
P18: ¿Y el pensamiento complejo?

R: El pensamiento complejo (repite dubitativa). Es como la capacidad de... eeh... pensar ya de manera abstracta y... ay no sé, se me... (risa nerviosa) se me fue la...

P19: ¿Cómo podrías definir tú en el ejercicio de la filosofía, en tu concepción detrás de eso, R: Eeh... ¿qué es el pensamiento en su nivel más complejo?

P20: ¿Qué deberían realizar los estudiantes?

$\mathrm{R}$ : Crear, la creación de algo.

P21: La filosofía, específicamente, ¿qué habilidades, capacidades y disposiciones, de este pensamiento complejo y de la metacognición, pone en juego?

R: El pensamiento crítico y... eh... la capacidad de resolver problemas a través del pensamiento.

P22: ¿Cómo influye la disposición del estudiante hacia el pensamiento complejo, la metacognición, el pensamiento filosófico, en la filosofía?

R: (grita una persona) Ellas tienen la disposición, ellas quieren, pero les cuesta.

P23: ¿Por qué?

R: Les cuesta porque tienen eeh... carencias, carencias de conocimiento, carencias de... de critica constante. Ellas no se cuestionan, son muy heterónomas y en cuarto medio aún son heterónomas. Entonces ¿Por qué viene a clase? Porque mi mamá dice que venga a clases, no ven más allá, no ven que venir a clases eeh... tiene, es un medio para, no, la mamá las obliga. Entonces como no se cuestionan desde la casa es difícil que puedan crear algo; porque todo se lo dan... (risa nerviosa) entoncee... Y a... el programa tampoco ayuda como a que ellas puedan crear ciertaa... cierta respuesta, todo está ahí, no hay nada que... que ellas puedan agregar. Yo doy por ejemplo a veces textos eeh... ¿cómo se llama? Ecuatorianos, de filosofía que son super buenos. Y textos que entrega el gobierno, para el pueblo ecuatoriano, en el que si las lleva a poder crear, a realizar proyectos para, pero acá noo... no se da eso, o el tiempo no se da para que uno pueda... realizar ese tipo de actividades con las chiquillas.

P24: ¿Qué estrategias y actividades favorecen el desarrollo del pensamiento complejo y la metacognición en la enseñanza de la filosofía?

R: El dialogo, para mí el dialogo es super importante, a mi me cuesta... eeh... que las chiquillas no dialoguen, y eso también es una de las cosas que a ellas les gusta de las clases de filosofía, porquee... es de las pocas clases en las que ellas pueden expresarse libremente, pueden dialogar y ellas que... formando grupo, yo siempre las hago trabajar en grupo eeh... pueden lograr un conocimiento más... más elaborado, un pensamiento más elaborado.

P25: ¿Qué actividades favorecen?

R: Eeh... trabajo grupal, trabajo en parejas, eeh... las disertaciones, en todas las clases quee... eeh... después de haber visto la materia, ellas pueden reflexionar en torno a lo que están viendo, que se cuestionen. ¿Qué haría usted en el caso de...? Por ejemplo, que ellas piensen, ese... eeh...

P26: ¿Qué recursos didácticos facilitan el desarrollo del pensamiento complejo y la metacognición en la enseñanza de la filosofía?

R: Eeeh... recursos audiovisuales, eeh.. guias, trabajos. Eso más que nada utilizamos mucho acá, porque están los medios para que nosotros podamos ver, por ejemplo, videos, cortos, cortometrajes, eeh... poder escuchar una canción, que les haga sentido lo que están escuchando, que... que sean capaces de relacionarlo con lo que estamos viendo.

P27: Isabel, ¿Qué tipo de actividades de enseñanza utilizas tú, más frecuentemente, durante el desarrollo de tus clases de filosofía? 
R: Eeh... Guía de aprendizaje, utilizoo... eeh.. power point, y... eeh... el dialogo de lo que estamos viendo. Yo constantemente le estoy preguntando a las chiquillas, y dando mucho ejemplo eehm... contingente.

P28: Esas son tus actividades, ¿y las estrategias de enseñanza, Isabel, que tú utilizas durante el desarrollo de tus clases?

R: Eeh... estrategias (repite dubitativa) ... no sé (ríe nerviosa) ¿Cómo cuáles? No sé, como que estoy...

P29: ¿Cuáles son las herramientas más comunes, como estrategia, para llamar por ejemplo la atención, para motivar?

R: El dialogo, siempre el dialogo. La pregunta, la pregunta que... eeh... (suena el timbre) el preguntarles y el cuestionarlas constantemente hace que ellas puedan reflexionar más a fondo.

P30: Y en función, ese dialogo, esa pregunta, ese cuestionamiento, ¿En función de qué principalmente?

R: Es que es como el... A ver, es como la mayéutica socrática, que a través del diálogo y la pregunta ellas sean capaces de eeh... obtener la respuesta, o lo que yo espero de la... dentro de un contexto de clase.

P31: ¿Y La experiencia, los conocimientos previos de los estudiantes, son un elemento metodológico a considerar que favorezca el desarrollo del pensamiento complejo y la metacognición?

R: Sii, sii.

P32: ¿Por qué?

R: Porque uno llega eeh... acá al liceo por lo menos a cuarto me... a tercero medio por ejemplo, eeh... con carencias de conocimientos, a ellas le faalta haarto... el cuestionarse, las chiquillas acá no se cuestionan, nada, entonces acá están contra el sistema, pero en realidad su eeh... enojo contra el sistema es solo por ir en la contra de... y no porque en realidad tenga conocimiento de algo. Que también denota su heteronimia, solo estoy en contra porque él lo dice que lo haga, entonces yo no lo hago, entonces ahí eeh... les cuesta... y cuando llegan a cuar... tercero, cuarto medio y recién comienzan a cuestionarse es como que se les alumbra una ampolletita y dicen "¡aaaah! Siii profe tiene razón” y creen que uno es super sabia porque en realidad las hace cuestionarse (ríe mientras habla) "¡ooh profe usted que saaabe!" (cita a las alumnas) no es tanto si uno deduce, pero ellas no deducen nada (rie nerviosa) Esta esto y está esto otro, como que no hace relación, y eso les falta.

P33: Y esa carencia, ¿a qué se debe según tú, de establecer una relación, de deducir?

R: Yo creo que nuestro sistema educacional hace que no... los chicos no se cuestionen, porquee... le damos todo eeh... casi pregunta para que responda sin posibilidades eeh... de cuestionar. Pero también hay una cuestión del hogar, que es mucho más fácil que el hijo haga las cosas porque yo lo digo, a que le explique por qué razón tiene que hacerlo. Porque yo, soy con mi hija por ejemplo eeh... siempre hemos cuestionado todo, siempre la hago que se cuestione y de hecho ella es capaz de eeh... cuestionar eeh... actividades que le dan los profesores. Yo agradezco cuando un niño o una... una estudiante me cuestiona lo que yo estoy diciendo, porque me s... doy cuenta de que en realidad si está atento, si le interesa, si está eeh... si tiene habilidades para. Pero si no, eeh... cuesta porque ellos creen todo lo que uno les dice. Sii yo hay incluso clases que "¡ooh profee, ooh profe!" (cita a las estudiantes) (Ríe nerviosa) y cuando ellos podrían dar más, podrían trabajar más para.

P34: Isabel, ¿Podrías describir cómo son las formas de interacción y de participación que se dan en las clases de filosofía?

R: Eeeh... A ver las chicas en las clases preguntan harto, siempre y cuando lo que estemos viendo les interese. Si les hace sentido, ellas cuestionan, preguntan, relacionan. Pero 
si no... es supeer... también va depender de la motivación, del día, de la... pero en general eeh... si encuentran sentido a lo que uno les explica.

P35: Y por ejemplo, en tus clases Isabel, ¿entre ellos dialogan, confrontan ideas?

R: No. No, es super complejo. Si bien pueden preguntar y cuestionar un poco lo que uno está diciendo, no hay mucha contraposición de ideas entre ellos. Porque en realidad... están todas tan a la par, que no se cuestionan entre ellas, es super difícil que tengan posiciones contrarias.

P36: ¿Y las formas de cooperación entre ellos?

R: Eeeh... (Personas hablando alrededor) Si hay colaboración entre ellas, pero solamente entre los grupos de amigas. Muy poco es como curso, a menos que tengan un problema, $\mathrm{y} . .$. eeh... un problema que las afecte a todas, o una situación que las afecte a todas, en las que si... colaboran entre sí. Pero que tengan contraposición de argumentos por ejemplo, no es com... eh... es raro, se da pero es raro.

P37: ¿Qué tipo de conocimientos y problemas se plantean en las actividades de la clase de filosofía?

R: Problemas contingentes, problemas de la vida cotidiana de ellas, cuando estamos viendo materia les hace sentido eeh... no sé por ejemplo en psicología, cuando le hablamos sobre los estereotipos, los prejuicios, ellas relacionan todo lo que están viviendo con la materia. Si tiene sentido, en filosofía igual. Sobre todo autonomía y heteronomía con lo que ellas están pasando, están como dejando de ser heterónomas, para ser, para alcanzar cierta autonomía eeh... si son situaciones que a ellas le... se sienten identificadas.

P38: ¿Y los niveles de discusión que acompañan aquello?

R: No son muy profundos, ¿ya? Porque ellos tampoco son capaces de profundizar mucho. Si uno plantea una pregunta demasiado... que presente demasiada dificultad, no la responden, porque les faltan habilidades de... pensamiento... crítico.

P39: Respecto al razonamiento y la reflexión que se plantean en las actividades de la clase de filosofía Isabel, ¿Podrías describirlos?

R: Eeh... ¿Cómo? ¿Es cómo qué?

P40: ¿Qué tipo de razonamiento y reflexiones se ponen en juego?

R: Eeh... (suspiro ahogado) A ver por ejemplo cuestionamientos sociales, ¿ya? Eeh... ellas son... a ver yo no puedo hablar por ejemplo de... eeh... critica contingente social, porque no ven noticias. Y este o no este... uno las ve todo el día con el celular en la mano, "si, pero es que no, no veo noticias" (cita una alumna) ¿Y qué hace? "No, veo fotos, veo..." (vuelve a citar) entonces mucho contenido no hay para discutir. Cuando se logra discutir eeh... es... es raro ¿ya?, pero... no sé, es que...

P41: Cuando logras instalar esas discusiones, ¿cuáles son las reflexiones que van acompañadas?

R: No hay debates entre ellas, ellas no se... nunca están en... un grupo por ejemplo en contra de otro, a menos, por lo menos contingente, a menos que sea un problema del curso en el que yo si las puedo... si puedo intervenir, pero que ellas me lo planteen, ahí si se puede darla discusión, pero si no, no.

P42: ¿Qué uso se da al lenguaje en las clases de filosofía?

$\mathrm{R}$ : mmm... eeh... sirve como principal medio de... poder comunicar sus ideas, ¿ya? Y el lenguaje en cuanto a... formalidad del lenguaje eeh... yo lo utilizo e intento que ellas sean capaces de hacerlo así, tanto oral como escrito. ¿Por qué? Porque da sentido a lo que están diciendo, entonces yo soy super crítica con respecto al lenguaje con ellas, y eso al final lo agradecen, pero al principio les molesta, porque no están acostumbradas a que uno les corrija todo lo que están diciendo, o cómo lo están diciendo o por qué lo están diciendo. Las expresiones que ellas ehh... las expresiones que ellas utilizan 
eeh... muchas veces no son las más adecuadas, pero... se acostumbran después al ritmo de uno (ríe nerviosa).

P43: ¿Cuáles son los materiales y los recursos didácticos más frecuentes con los que nos encontramos en la clase de filosofía?

R: Eeh... guía de aprendizajes, guía de trabajo que realizamos nosotros acá, eeh... data show que es un recurso super útil, los parlantes que están todos instalados en las salas de clases.

P44: ¿Y qué uso se le da? ¿Cómo configuras un recurso mediador en el fondo?

$\mathrm{R}$ : mmm... (suspiro ahogado) a ver por ejemplo estamos viendo una materia determinada y para poder contextualizar la materia, la podemos ver parte de eeh... una película, por ejemplo, y que ellas si puedan relacionar la película con la materia. Le hace mucho más sentido que solamente leer una guía o que solamente eeh... leer un filósofo, porque mucho texto de filosofía tampoco... yo les puedo mostrar, porque hay textos demasiaadoo largo eeh... con un vocabulario que no es el de ellas, entonces más allá de una explicación simple es super complejo, por ejemplo, que yo les vaya a leer no sé eemm... en filosofía eeh... la duda metódica de Descartes. No lo van a entender, entonces ¿Qué hacer? Le explicamos nomás a Descartes, lo mismo con Kant, que no... ellas no... aparte que son tan largo a veces que eehmm... cortar los textos que están en el programa hace que pierdan sentido, entonces tampoco podemos utilizarlos mucho. $\mathrm{Y}$ a veces lo utilizamos como último recurso, pero no porque sea una herramienta útil para nosotros poder utilizarlo. 


\section{ANEXO 3. ENTREVISTA A PEDRO}

P1: ¿Cómo Concibe usted la enseñanza de la filosofía en los programas oficiales? ¿Cómo se plantea?

$\mathrm{R}: \mathrm{mmm} \ldots$ ¿A la estructura?

P1: si...

R: emm... (suspira) a ver mira lo que considero, por lo menos, bueno en tercero medio eeh... se aleja de lo que es la filosofía en sí, porque tiene un enfoque más a la psicología emm... tiene algunas pinceladas en algunos tópicos que eeh... se acerca a la filosofía eeh... y más allá de eso, respecto a la estructura de... lo que es tercero medio considero que... eeh... que... es paulatino, está bien estructurado, hay una introducción que permite a los estudiantes ir asimilando los conceptos y... ir forjando un... una idea de lo que es la asignatura, no así emm... en el caso de filosofía en cuarto medio. Considero que eeh... la introducción es algo que emm... primera unidad es algo un poco... desorganizada emm... no permite a los estudiantes eeh... ir eeh... acercándose o aproximándose a los conceptos básicos, a un lenguaje común, como.... Como que un poco entrecortada, podría decirlo, ¿ya? Y.... de ahí en adelante los tópicos están... exceptuando la primera unidad que esta podría ser mejorable quizá y de hecho uno lo hace, tratando de hacer am... quizá una unidad cero eeh... mmm... después los tópicos emm.. Quizá.... Están bien estructurados... los objetivos... algunos quizá se alejan... mmm... sobre los intereses de los estudiantes considerando por ahí la.... Los años que se forjaron los planes y programas que llevan par de décadas ¿cierto? Y... están obviamente desactualizados eeh... de sobre todos los intereses que son jóvenes, entonces una cosa tiene que ver con los contenidos ¿cierto? Y otra tratar de acercarlo un poco más... a las realidades actuales de los chicos, cosa que uno igual siempre está modificando pero... pero también se agradecería que... que los planes estuvieran un poco más actualizados en ese sentido. ¿No sé si respondo?

P1: si, si... pero respecto a lo que establece... lo que nos entrega el programa ¿cierto?

$\mathrm{R}$ : mm... (Interrumpe con sonido de asentimiento)

P2: ...sus enfoques, y esta concepción que tú me señalas ¿Qué elementos establecen que puedan garantizar o favorecer el desarrollo del pensamiento complejo y la metacognición?

R: mmm... (Respira fuerte) pasa que si me pongo a... en ese sentido, creo que está bastante en desventaja... voy a hacer esta comparación ¿bueno? Eeh... respecto a otros... respecto a otros planes y programas, que son lo... de otras asignaturas que han sido modificados $y$, en ese sentido tienen otras herramientas que... eh... que les permiten a los profesores emm... poder estructurar y estar más atento a... a ese objetivo que es el de eeh... me dijiste el de...

P2: de pensamiento complejo y metacognición

R: si... ¿Por qué? Porque... emm... en los planes, por lo menos los que yo he visto eh... de otras asignaturas eh... están relacionados con habilidades en, sin embargo nuestros planes y programas se quedaron en objetivos de aprendizaje y... a... hasta ahí nomás llega, no hay indicadores eeh... eeh... de logros, no hay todo un entramado que pueda ayudar al profesor a ir evidenciando ciertos logros en los estudiantes... respecto a esos aprendizajes, entonces como que se quedo muy básico ese planes y programas. Así que por ese lado yo diría que es... como que está en una desventaja respecto a lo he visto en otros planes y programas emm... ¿qué más? ¿Me puedes repetir la pregunta? Porque quizá me fui un poco a.... 
P2: no, no... la pregunta tiene que ver con los elementos o las concepciones de estos programas ¿cierto? Que favorecerían el desarrollo del pensamiento complejo y la metacognición, si es que hay algún elemento.

R: ah, ósea.... elementos... también obviamente hay pu', obviamente eeh... se plantean algunos objetivos eeh... ósea se lo... lo... lo objetivos que están en el plan y programas emm... ayudan a... a poder desarrollar un poco el... a desarrollar el pensamiento complejo. El ¿cómo? Quizá carece de eso, porque una cosa es los objetivos y otra lo que propone el plan y programa... el cómo desarrollarlo, quizá por ahí creo eeh... mm... decae ¿ya? Eso

P3: ¿Qué tipo de conocimientos y de problemas ponen en juego los planes y programas?

$\mathrm{R}$ : ¿Qué tipo de conocimiento y...?

P3: y problemas...

$\mathrm{R}:$ ¿ponen en juego?

P3: los programas de filosofía y psicología

$\mathrm{R}$ : eeh... el conocimiento respecto a la filosofía (con todo agudo) eeh... hay un aspecto... en bueno sobre filosofía contemporánea no hay casi nada ¿ya? Eeh... como actual no hay.... Eeh... mm... no hay, no está muy cercano a eso, pero si tiene un enfoque bien... mmm... eeh... digamos clásico ¿ya? Eeh... eso es super notorio emm... por lo menos en cuarto medio mmm... a ver (murmura)... respecto a los problemas eeh... en la unidad, hay una unidad, una subunidad que habla sobre los métodos de la filosofía y por ahí se plantean algunas... metodologías y... que uno las puede ir llevando a problemas ¿ya? Habla emm... sobre hacer ensayos ¿cierto? No sé si apunta o eeh... apunta sobre problemáticas filosóficas dentro de...

P3: problemáticas filosóficas por ejemplo, que pudiesen ser discutidas... ¿sí?

R: ah... (aliviado) ya... si, si... eeh... por ejemplo está la... bueno s... tendría que ir haciendo un repaso (ríe leve) ... bueno en la unidad número uno que eh... que nos va introduciendo en la filosofía eeh... hay algunas problemáticas sobre el sentido del ser humano ¿cierto? Sobre el sentido de la vida, obviamente lo que busca es eh... evidenciar un poco, evidenciar eso, hacer la pregunta a los muchachos sobre eso ¿ya? Eh... por ahí también lo podríamos relacionar con el tema de la adolescencia, la búsqueda de la identidad... emm... haciendo algunos saltos, después pasamos... de hecho hay una unidad que se llama "la problemática moral" que de hecho eh... eh... es bastante interesante en ese sentido porque se acerca bastante a temas contingentes, uno lo puede llevar muy fácilmente a temas eeh... visuales, prácticos ¿ya? Y por lo general, las actividades relacionadas ahí, tienen que ver con eso, con investigación, con exposición, con análisis de casos ¿cierto? ¿Ya? (murmura) Son bastante interesantes por lo demás al estudiante esa unidad, en comparación de otras, que de repente pueden ser un poco más... quizá tediosas para ellos porque representa un poco más de mmm.... De teoría ¿ya? Así que.... Después pasamos a fundamentos de la moral que aún sigue... aún podría uno eeh... ir entrelazando con eeh... un enfoque... práctico o problemático ¿ya? Por ejemplo... de hecho en esa unidad estábamos hoy, estamos viendo cómo aplicar algunas corr... algunas teorías éticas a... por ejemplo a un... a un capítulo de los Simpsons, por ejemplo ¿Ya? Para ase... para asimilarlo más... que son problemáticas que igual están cercanas a ellos y son interesantes, así que no sé si eh... a ver después llegamos a la última unidad que siempre es un desafío en realidad, pero... (Alza la voz) como necesariamente, es casi nada lo que uno alcanza a ver en eso.

P4: Claro... profesor respecto a los procesos de pensamiento y reflexiones que pone en juego los programas de filosofía, ¿Cómo lo caracterizaría? Si es que evidencia que efectivamente hay una manifestación en la propuesta curricular para... 
$\mathrm{R}$ : (interrumpe la pregunta) mira mi percepción a grande rasgos es que cuando lo llevamos por ejemplo a... a objetivos de aprendizaje no sé que busquen reflexión, que busquen eeh... eh... analizar eh... como que decae un poco $\mathrm{mmm}$... como que si uno revisa los planes, va ir constatando que la gran mayoría son... no busca procesos cognitivos tan complejos mm... (asiente) eeh... de repente uno igual se encuentra con... por lo menos emm.... Mi realidad contextual igual hace mucho más complejo el tratar de desarrollar eh... habilidades más... más superiores, porque... necesita... se necesita una cosa básica que es la comprensión lectora (ríe breve) y... obviamente eh... y según la estadística y algunos estudios que también hemos hecho en el liceo eh... está muy decaído, entonces eso hace mucho más complejo el tratar de desarrollar ese otro tipo de habilidades.

P5: ¿Y los usos del lenguaje que se ponen en juego en los programas?

$\mathrm{R}:$ emm... ite refieres a...?

P5: lenguaje formal, escrito...

R: ah... (Suspira leve) ya... emm...

P5: todo lo que tenga que ver con la interacción, cómo se comunican...

$\mathrm{R}$ : hay propuestas (suspira leve), ósea hay propuestas (repite) de hecho eh... al final de cada unidad hay una pauta, pero es muy básica eh... si es como muy, muy demasiado básica eeh... en la propuesta que hay, de hecho eh... la adecuación que uno hace es $\mathrm{mmm} .$. . yo diría (ríe breve) que es como el noventa por ciento de lo que uno... en propuestas de actividades eh... lo que uno... lleva a cabo, respecto al programa. Por lo mismo, porque uno se ve en la necesidad de ir modificando, ir actualizando, hacer más atrayente a los estudiantes, así que eh... mm... demasiado básico lo que... lo que propone el plan y programa en ese sentido.

P6: Bien, ¿Qué tipo prácticas o de actividades de enseñanza se plantean en el programa, que específicamente apunten al desarrollo del pensamiento y la metacognición? Que no necesariamente está explicitado de esa manera, pero que uno al revisar de da cuenta de que va más allá del puro conocimiento conceptual.

R: (ríe breve) Claro... eh... bueno, hay debates... hay, propone algunas actividades de ensayo emm... Mmm.... (Tararea ritmo) ¿Qué otro? (murmura) que... mmm... creo que hasta ahí nos quedamos, no sé... eh... por lo que recuerdo, en este momento, eh... me quedo como en eso, como que ese tipo de actividades, debates, ensayos...

P7: ¿Y respecto a las estrategias de evaluación?

R: Eh... ¿qué propone el plan y programa?

P7: si...

R: mmm... hace menc... bueno, hay menciones a... trabajos grupales eso, si... también eso, esto de utilizar ensayos eeh... hay análisis de textos, pero.... Pero carece... de indicadores de evaluación no a... por ejemplo, hay un libro, hay un manual de filosofía que está hecho para la enseñanza media de acuerdo a los planes y programas y en... dentro de las evaluaciones eeh... incluso ese libro, propone algunos indicadores de evaluación, igual no son detallados como uno quisiera ni nada, pero... pero ese libro los tiene, y no así por ejemplo los planes y programas.

P8: Muy bien, profesor ¿Qué es para usted el pensamiento complejo y la metacognición en la filosofía?

$\mathrm{R}$ : emm... pensamiento complejo para mi, tiene que ver con eeh... el desarrollo de ciertas habilidades que van más allá de... de la comprensión eeh... tiene que ver con eeh... relaciones complejas o in... in... a... eeh... con... relaciones de preguntas que están implícitas que los estudiantes puedan sacar eeh... reflexiones.... Reflexiones a partir de... de ciertas problemáticas y resolver ciertas problemáticas, utilizando ciertas habilidades ¿cierto? Básicas eeh... tiene que ver con eso. 
P8: ¿Y la metacognición?

R: ¿la metacognición? Eeh... tiene que ver para mi eh... con mmm... el... autoanálisis eeh... mm... el... la revisión de uno mismo eeh... sobre las prácticas, pero en el tema de la filosofía de repente por ahí es como bastante complejo que los estudiantes lo logren, pero no sé si está eeh... m... (Suspira leve y brevemente) $\mathrm{mm}$... me... me deja una duda, ósea pero para personal, cómo... cómo lo estaba llevando yo últimamente... eso.

P9: Pero, ¿En la filosofía como disciplina?

R: como disciplina ¿en sí? Mm...

P9: ¿Apunta al desarrollo...?

$\mathrm{R}$ : ah, ¿si los planes y programas apuntan, eso o yo...yo?

P9: No, desde tu concepción

R: mmm... sí creo que sí, si... porque de hecho las clases siempre tienen un tópico que... (sonido de persona escribiendo en un teclado) que generan una interrogante en ellos y... y en el término de clases que es el momento en donde uno (sonido de persona escribiendo en un teclado) eeh... desarrolla la metacognición, quizá no necesariamente se generen las respuestas precisas que uno quiera, pero... pero deja ahí la pregunta, la interrogante quizá la... eeh...(sonido de tecleo) la duda respecto a... lo que se estaba desarrollando, entonces (mismo sonido de teclado) eeh... tiene que ver con eso, tiene que ver con eso, con...quizá claro uno buscaría que hicieran procesos de reflexionar, de poder generar esa... respuesta o autorespuesta, pero quizá de repente también está el tema de que quede la duda y la pregunta.

P10: ¿Qué habilidades, del pensamiento complejo y la metacognición, que tú muy bien ahora acabas de mencionar, pone en juego la enseñanza de la filosofía?

R: pone en juego... eh... la reflexión eeh... em... la auto... la critica ¿cierto? La autocritica eeh... mm... el... (Sonido de tecleo) resolución de problemas también.

P11: ¿Y qué capacidades y disposiciones del mismo pensamiento complejo y la metacognición pone en juego la enseñanza de la filosofía?

$\mathrm{R}$ : que sin ella no pudiese... no pudiese... haber filosofía, eso... básicamente emm... tiene que ver con... creo que si un proceso $\sin .$. sin habilidades reflexivas eeh... y de análisis como profundo no... ósea, por lo menos si no hay un análisis profundo de una situación o de un contenido eh... no... difícilmente habría filosofía.

P12: ¿Qué estrategias y actividades favorecen el desarrollo del pensamiento complejo y la metacognición en la enseñanza de la filosofía?

R: El análisis de caso es... es bastante... emm... ¿cómo es que se llama? Emm... certero o... o... ¿cómo es que se llama? Emm... efectivo ¿ya? Cuando uno quiere... cuando uno plantea un problema y ojala este problema eeh... tome cierto contenido y ese contenido esté relacionado con cierto contexto sim... a... similar al del estudiante es bastante emm... efectivo en la comprensión que llevan ellos mismos eeh... (Sonido de tecleo) eso es... eso por un lado. El otro tema eeh... (Sonido de tecleo) tiene que con eh... el análisis de textos eh... filosóficos (sonido de teclado) eeh... quizá uno esperaría que fuese lo ideal... (Sonido de tecleo) en trabajar eeh... (Sonido de tecleo) pero... se vuelven tremendamente complejos, uno por el tema del vocabulario, de la comprensión lectora de los estudiantes (suspira), entonces si lo vemos en perspectiva de repente el... (Sonido de tecleo) el tema de plantear un problema, plantear un caso y como ese caso se relaciona con cierta visión de la filosofía (sonido de teclado) es mucho más efectivo (sonido de teclado).

P13: Y en esa misma línea profesor, ¿Los recursos didácticos que nos favorecen para el desarrollo del pensamiento complejo?

$\mathrm{R}$ : eeh... bueno en... prácticamente internet está eh... uno tiene que tener la disposición de buscar nomás lo... los medios, hay mucho material visual, hay mucho... hay mucho 
texto interesante hoy en día que uno puede tener acceso fácil eeh... mmm... hay mucho material vi... eh... no solamente videos, hay imágenes... hay eeh... cosa de... básicamente la disposición del profesor, pero en sí, por ejemplo los planes y programas es muy delimitado lo que tiene.

P14: Profesor, ¿me podría describir las actividades o estrategias de enseñanza que usted utiliza durante el desarrollo de sus clases?

R: Las clases emm... bueno siem... por lo general hay... utilizo recursos audiovisuales, bueno hay un... siem... por lo general estam... soy muy estructurado en eso, hay una presentación que... hay una presentación que puede ser en PPT o presi emm... donde hay eeh... se plantean lo... obviamente los objetivos, hay alguna actividad inicial, algún video corto, algún tipo de problema, pregunta eh... (sonido de tecleo) después viene el desarrollo de la clase eh... (sonido de tecleo) si vamos a ver un tópico obviamente está la disposición de ese tópico o tema. Lo... (sonido de tecleo) por lo general el foco de la case... de la clase, está en la actividad que... durante estos últimos años he tratado de desarrollar am... mm... tratar de diversificar un poco más la... la metodología de las actividades, por ejemplo no sé utilizar mapas mentales eeh... trabajar... últimamente estamos haciendo... trabajando el formato de una tarjeta squash que también por ahí el tema kinestésico, en los estudiantes ayuda al interés eeh... relacionando, después viene la otra tarea que es el contenido, pero... pero va ayudando a... a poder desarrollar mejor el interés de los estudiantes que también afecta en el desarrollo después de lo que viene en el contenido.

P15: Por ejemplo los mapas mentales, que es la segunda estrategia que usted menciona, ¿cómo los trabaja?

$\mathrm{R}:$ eeh... respecto a...

P15: Al contenido por ejemplo...

$\mathrm{R}:$ ¿Al contenido?

P15: si...

R: ah ya... primero hay una presentación de un contenido ¿cierto? Luego eh... (sonido de teclado) se le entrega la pauta de... de evaluación obviamente eeh... se explica lo que... a recordar un poco de qué se trata y cómo hacer un mapa mental y dar algunos tips eeh... y... empiezan ellos a relacionar eeh... relacionar ideas ¿ya? Y... por lo general trabajan en... en parejas o en grupos, lo cual les ayuda eeh... los otros tópicos tienen que ver con ir desarrollando por ejemplo en el tema de la tarjeta squash, por ejemplo en desarrol... desarrollar ciertas preguntas o ciertos cuestionarios y plasmar eso a través de la... la tarjeta simplemente es un... es un medio para poder plasmarlo ahí... mm... eso.

P16: Perfecto, ¿me puede describir las formas de interacción, de cooperación o participación que se dan en sus clases de filosofía?

$\mathrm{R}$ : mm... si, algunas clases en donde revisamos algunos tópicos, por ejemplo hacemos mm... grupos de trabajo en donde hay un eh... designamos a un eeh... mediador eeh... ese mediador va dando paso a las preguntas y van desarrollando con los estudiantes eeh... cuando dein... otros trabajan en parejas, en algunas oportunidades eeh... mm... hemos... (sonidos de teclado) cuando vamos a la sala de computación también, por un tema también de espacio y recursos, también se trabaja en grupos eeh... hemos trabajado también otro tipo de... eh... dinámicas en donde se le entrega... diferentes textos y diferente numeración a los estudiantes y se hacen especialistas todos los números uno se juntan luego, se forman grupos de cuatro, uno, dos, tres, cuatro, y... luego se forman grupos de especialistas, todos los uno juntos, desarrollan el tema, todos los dos juntos desarrollan el tema, (baja el tono de voz) todos los tres juntos, todos los cuatros juntos, desarrollan el tema, y después (suspira) el cierre de esa actividad es volver a los grupos iniciales uno, dos, tres, cuatro y cada... cada 
estudiante eeh... expone eh... lo que trabajaron y se volvieron expertos en su grupo de trabajo.

P17: ¿y la cooperación entre ellos?

R: (suspira) eeh... ¿cómo funciona? En algunas ocasiones es eh... mm... es mucho más eh... son más accesibles, en otras no tanto por ejemplo en la última actividad eh... hay cursos que son más predispuestos a hacer eso eh... a movilizarse a salir de su zona de confort, de los amigos, y otros cursos son muy reacios, muy... muy... muy, tanto de que no.. quizá no funcione. Eeh... pero y... respecto de la cooperación emm... eh... tengo, bueno hay cursos que son eh... trabajan entre ellos cooperativamente, pero otros que son... emm... designan, así como que descansan en eeh... en algunos, aunque he ido ul... eeh... umm... eh... un poco quizá socavando esas ideas que tiene de... eh... a través de... la misma pauta de evaluación, el tema de la participación ir...ir castigando por ahí y forzando un poco más a ayudar al compañero y... también me he dado cuenta que... han ido siendo más consientes de eso y algunos ya no trabajan con... con ciertos compañeros... por lo mismo.

P18: ¿Y en las clases los estudiantes participan?

R: mmm... si... (afirma dubitativo) hay... un rango de participación eh... considero igual alto, yo diría como eeh... lo que pasa que hay algunos cursos, por lo menos mi... mi experiencia este año en el liceo es que eeh... de los cuatro cursos que tengo hay un curso que quizá es mm... es muy reacio a... a participar y a... a cumplir, un tema de responsabilidad que arrastran hace... décadas(en voz baja), pero... ósea de años (corrige), pero.... Pero al resto de los cursos hay una participación buena mm...

P19: En las actividades que se plantean durante la clase de filosofía ¿qué tipo de conocimiento y problemas están dadas?

$\mathrm{R}$ : ¿Cómo dadas? ¿En qué sentido?

P19: ¿qué tipo de problemas de conocimientos usted plantea en las actividades de la clase de filosofía?

R: emm.... Sobre... (suspira) de conocimiento... digamos ¿cultura general o aplicada a la filosofía?

P19: En general

$\mathrm{R}:$ ¿en general?

P19: Si, si...

R: bueno, siempre hay un tema de cultural general que... que está... es innato igual en la filosofía que... que uno puede... llevarlo a la contingencia, por ejemplo, digamos... un tema $\mathrm{x}$ sobre las virtudes, por ejemplo en Platón eh... o en Aristóteles o en Sócrates... inmediatamente uno lo puede llevar por ejemplo a... al plano actual mmm... de no sé eh... cuál debiera ser eh... son o no son virtuosos según como dice Platón eh... nuestros políticos hoy en día, qué... qué podemos ver en las noticias esta última semana y... ahí uno lo puede llevar por ejemplo a los temas de corrupción o... algunos casos por el estilo, entonces ¿son así? Eh... O los mismos productores son... ¿tienen templanza? O... se coluden entre ellos, entonces ahí uno va... y son al final... se man... se supeditan al tema de la ju... a la virtud de la justicia como dice Platón y... ahí uno obviamente... puede ir emm... apoyándose en temas de cultural general actual, igual hay... algunos tópicos que permiten... entrelazarse con asignaturas, por ejemplo con historia tenemos algunos alcances por ejemplo cuando vemos... el paso... de la época medieval a la época moderna con el tema de eh... el cuestionamiento al método científico ¿cierto? René Descartes eh... por ahí hay todo un contexto que es necesario comprender eh... por qué... por qué empieza a resurgir la ciencia, empieza a resurgir estas nuevas visiones, entonces por ahí eh... también tiene que... podemos apoyarnos con... con historia ¿ya? Sobre... sobre eh... Lutero, Copérnico, por ciencias también... emm... también por ahí hay... hay un tipo de 
conocimiento que podemos entrelazar emm... y sobre la filosofía eh... uno siempre está... el...el programa tiene eso que... que... qué decir es bueno, que... se ven algunos tópicos al principio que desp... o algunos filósofos que después vamos a volver a retocar o a ver en otra perspectiva y... y ahí hay que estar recordando, hay que estar eeh... mm... retomando algunos... algunos contenidos que ya hemos visto, no sé si...

P19: si, si...

R: ¿sí?

P20: Y en esa misma línea profesor, donde usted me describe los tipos de conocimientos, de problemas que pone en juego en las actividades que diseña en sus clases, detrás de eso me gustaría que me describiera los razonamientos a los que busca llevar a sus estudiantes y los niveles de discusión y reflexión.

$\mathrm{R}: \mathrm{mmm} .$. niveles de razonamiento... emm... mm.... (tararea prolongadamente) Respecto a... ¿razonamientos... de qué tipo?

P20: No busco una clasificación conceptual...

$\mathrm{R}:$ ya...

P20: (continua la idea)... sino ¿hacia dónde los quiere llevar cuando le plantea estos problemas a los estudiantes? A que hagan un razonamiento.

$\mathrm{R}$ : emm... tipos de razonamiento eeh... mm... ¿cuáles son las otras cosas? Por mientras... P20: los niveles de discusión y reflexión

$\mathrm{R}:$ ah...

P20: lo que está detrás en el fondo de esta problematización que usted hace con ellos en sus actividades a partir de este conocimiento conceptual

R: Aha... (Asiente) ósea para dónde vamos eeh... tiene que ver con eh... obviamente lo que uno quiere es que eso lo asuma, puede ser ese tipo de razonamiento o el nivel que alcancen de... reflexión... que sea... que se apropien de ello, obviamente eso es lo que uno busca. El... o el ideal es que lo tomen y lo hagan de suyo, pero... tiene que ver con eso... con... con apropiarse, con... el uso más eh... constante de eh... de ese tipo de reflexiones que... que sean llevadas a la vida práctica $\mathrm{y} . . . \mathrm{mm} . .$. que permitan visualizar quizá ciertas problemáticas... eh... que son propias a... a ser ciudadano, a la vida personal eeh... a la vida en comunidad, que les permitan y le den herramientas... ese tipo de herramientas para poder resolver eh... o a buscar una vía de reso... para poder resolver esos problemas... (sonido de tecleo) o de plantear esos problemas también.

P21: Profesor, ¿qué usos se da a los materiales y los recursos didácticos en la clase de filosofía?

R: Eh... ¿cómo?

P21: (repite) ¿qué usos se le da a los materiales y a los recursos didácticos en sus clases de filosofía?

R: ¿Qué uso? Eeh... mm... sobre las mismas actividades tendría eh... está... pensado su uso. Eh... bueno materiales didácticos por lo general utilizamos hojas de cuadernillo eh... cartulina emm... diarios, revista emm... eh... ¿qué más? Papelógrafo... también tiene que ve... recursos mm... más tecnológicos, obviamente utilizamos eh... la sala de computación, eh... asistimos a... a biblioteca, he tratado un poco más de entrelazar la filosofía con... con algunos textos de literatura, por ejemplo el primer semestre tuve una buena experiencia viendo a... fuimos a leer el otro de Borges, si no me equivoco... ¿sí? De... es un cuento y... mm... por ahí entrelazarlo con Heráclito sobre este... este con... cambio constante, entonces he tratado un poco más de acercar también la filosofía a la literatura, también ese... bueno aprovechar los recursos que están en... en... a disposición en el colegio, pero... mm... eso ¿qué más?

P22: ¿y el uso del lenguaje? 
R: el uso del lenguaje eh...

P22: en las clases de filosofía

R: sobre.... Diccionarios eeh... si... si también utilizamos, de hecho uno de los problemas del... de nuestro... del estudiantado que está en el liceo es... y que está relacionado con la comprensión lectora tiene que ver con lenguaje y... dentro de... de los acuerdos... conversaciones que hemos en... llevado a cabo en... en consejo de profesores es tratar de eh... al inicio de una subunidad, unidad eh... dar un... un vocabulario, un pequeño... eh... mm... una serie de conceptos que son eh... abordables dentro de la unidad o subunidad que se va a tratar y... el uso del diccionario eh... por ahí ocupando un poco más el tema de la tecnología, porque... bueno los chicos todos tienen... o la gran mayoría tiene celular, entonces al momento de que aparece un... un concepto eh... o una.. Eh... o... yo se los puedo... los puedo definir o lo otro es que lo busquen a través del celular.

P23: ¿Algo más que quiera aportar?

R: mmm... no... no sé, no... algo que... ¿qué más? ¿nada más?

Cierre: Nada más, agradezco mucho la participación y damos por finalizada la entrevista. 


\section{ANEXO 4. ENTREVISTA A ANDRÉS}

P1: ¿Cómo cree usted que se concibe la enseñanza de la filosofía en los programas de estudio?

R: Eh... bueno, yo se lo comento a los niños cuando les leo el programa, que... obviamente existe un interés más que nada moralizante, sobre todo en el plan de cuarto medio, que hay... hay dos grandes unidades que son de... eh... de moral, ética y moral, y yo siento que el... el programa como fue creado, quizá su intención era... no sé quizá tener una pincelada filosófica sobre todo en cuarto medio, pero... bueno no hablo...no hablo de tercero medio porque $\mathrm{mm}$... la filosofía no está ahí presente... al cien por ciento.

P1: pero lo puedes desarrollar

R: ya... emm... pero yo veo eso, veo más que nada una intención moralizante en...en el programa de cuarto medio sobre todo y de filosofía instructiva, sobre todo el tema de la pregunta formal, la pregunta filosófica... que es más que nada como instrucción de conocimiento filosófico más que filosofía como tal y... bueno en tercero medio, si bien yo encuentro valor en el conocimiento que se entr... que se quiere entregar en... en... en las primeras dos unidades por lo menos eh... obviamente filosofía no es, pero yo creo que todos nosotros tratamos de fil... de hacer filosofía con un poquito de lo que... de lo que se entrega.

P1: ¿y en el caso de tercer año?

R: En el caso de tercer año eh... bueno no creo que esté la filosofía como tal ahí presente, pero... yo por lo menos trato de que las cosas sean un poco más filosóficas, sobre todo en las dos unidades de tercero medio, que a mí en particular me gustan harto, porque eh... siento que de ahí pueden surgir varias preguntas filosóficas sobre todo con el tema de los sentidos, cómo valoramos la inteligencia, cómo ellos valoran la inteligencia o la misma memoria eh... yo siempre hago el vínculo con un poco de filosofía de la mente ahí, entonces siento que, a pesar de que... trato de hacerlo lo mejor que se puede filosóficamente con los temas que se entregan y las dos unidades, las dos últimas que son de... casi como... de consejo de curso que podríamos decirse que es sexualidad, la unidad de sexualidad y bienestar eh... bienestar psicológico, trato de que, a pesar de que no están en el área filosófica, de que... de que ellos... les sea de ayuda, sobre todo el tema de sexualidad y el tema de bienestar psicológico que, bueno se sabe que en esas... en esas ellos están en la edad donde todas estas cosas se... se presentan.

P2: ¿Consideras que hay un enfoque claro en los programas, tanto de tercero como de cuarto, que direccione un trabajo hacia el desarrollo del pensamiento complejo y la metacognición?

R: yo... yo tomé la decisión de tomar los programas como una guía, entonces... si bien lo... los temas en sí mismos podrían no tener eso claro, yo creo que en la didáctica si se puede hacer, con... tomando solamente el contenido puro, porque si uno ve las actividades que el... el... bueno, de partida el programa no tiene habilidades para todas las clases, sino que tiene dos, tres actividades propuestas por... por tema o por unidad, o subunidad eh... pero como... como dije al principio, es más instructivo, más como que los chi...chicos tengan conocimiento técnicos... más que... que tengan una... una reflexión, obviamente en uno de los objetivos transversales de los planes es el pen... el desarrollo del pensamiento crítico, pero siento que esa responsabilidad queda en el profe, y no está explicita claramente en el... en las actividades que se dan.

P3: ¿Qué conocimientos y tipos de problemas se ponen en juego en estos programas de estudio? 
R: Eh... bueno, en tercero medio... yo la ma... la verdad desde que empecé a hacer clases pocas veces he podido desarrollar el... el programa completo, siempre quedo en tercero medio en... en... en la mitad de la primera, quizá empezando la última uni... ósea de la tercera y quizá terminando la última unidad o eh... en cuarto medio, rara vez he podido llegar a política, que es la última... la última unidad que es...que está propuesta. Eh... bueno, por... por toda la dinámica de la educación... pública que siempre hay cosas que ahí van un poco eh... enalteciendo el proceso. Eh... p... entonces yo... siento que... lo que a mí... bueno de partida el plan de tercero...de cuarto medio (corrige) yo lo modifiqué, entonces parto por una introducción a la filosofía eh... filosofía actual, unas solamente unidad de... de ética y la última de política, entonces yo insisto, creo que los planes no... son como un temario, un pequeño temario solamente y yo trato de... de yo con esas... con esas como cuatro... cuatro temas importantes que son las unidades, trato de que el conocimiento que se entrega o las habilidades que se entregan, yo creo que me centro... centro más en las habilidades porque el contexto en el cual yo me desenvuelvo eh... no creo que dé para el conocimiento, los chicos vienen con un prejuicio muy claro hacía la filosofía como algo... como demasiado abstracto o demasiado aburrido, entonces yo trato de ponerme en sintonía también con lo que ellos esperan de la asignatura o entregar habilidades que puedan servir, se sabe que los conocimientos que quedan después de la enseñanza media son bastante pocos en comparación con las habilidades en el desarrollo del tiempo, entonces yo trato un poco de... de... aprovechar al máximo las habilidades más que el contenido que entrega el plan, entonces a pesar de que yo creo que los planes son bastante deficientes en...s.. en su estructura eh... trato de que las habilidades que... que... que yo entrego o que trato de entregar, sean filosóficas en sentido reflexivo o en sentido de que ellos se... se den cuenta de... de por qué las cosas pueden ser de una u otra forma, o que ellos saquen conclusiones que yo pueda... pueda quizá no estar de acuerdo con ellas, pero que sean de ellos, entonces... no creo que las habilidades y conocimientos que entrega el plan o que pretende entregar el plan, se cumplan sino que va depender del profe cómo él quiere abordar los contenidos del plan.

P4: Muy bien, ¿qué tipo de prácticas o actividades de enseñanza usted distingue que se programan para el desarrollo del pensamiento complejo y la metacognición en los programas?

R: (ruido de silla) mmm... no sé si en los programas hay... alguna que... que entregue... eso... eso tan claramente. Obviamente hay algunas cosas que dicen que los alumnos reflexionen, que... los alumnos eh... aquí se puede dar esta dinámica, como que el... si uno lee los planes, lo que dice... como que algunos reflexionen y estar ahí, que pueda aparecer y que se dé. Pero eso ya no está en sintonía con los niños de ahora. Yo... a mi me pasó con una actividad que hice la... el primer... la primera vez que hice clases, como que me apoyé bastante en los planes al principio porque uno es inexperto y trata como de aferrarse a cosas que quizá puedan estar probadas y ya no funcionan. Lo que el plan dice que puede pasar en una clase no sucede, entonces yo no creo que lo... lo... en... a estas alturas por lo menos, donde... es todo tan utilitario, donde los chicos están consien... donde a los chicos se le entrena y se les... presiona por la prueba estandarizada, obviamente ellos pretenden encontrar en las asignaturas algo más eh... más pragmático, más útil para... para lo que a ellos les dicen que es importante, a pesar de que las notas valen lo mismo, las notas de lenguaje, de historia, valen lo mismo que la nota de filosofía si lo vemos en términos prácticos, pero los niños lo ven... lo ven distinto, entonces... eh... la... lo... los planes no... no están en sintonía con... con esa... con esa área del estudiante, con el área más pragmática. Entonces yo no siento que los planes... (corrige) ósea, si pretenden hacer eh... 
desarrollo del pensamiento crítico, pensamiento complejo, ya no... ya no sirve lo que ellos proponen, ya no... no funciona.

P5: Y respecto a lo mismo, ¿qué pasa con las propuestas evaluativas que establece el programa?

R: Yo no... nunca las he considerado.

P6: ¿Por qué?

R: yo... porque... bueno, obviamente va depender mucho del tipo de curso cómo yo decida mi evaluación. Por ejemplo ahora me pasa que tengo dos terceros medios y con un... y trataba de siempre ir a la par, de hacer cosas bastante similares, pero me pasó que con un tercero medio eh... las... las cosas más... individuales son las cosas más como inmediatas no me servían. Si con el otr... con el otro tercero, y lo que sí me funciona con el tercero son los trabajos en proyecto, entonces siento que mi... mi... mi evaluación va depender mucho del tipo de estudiante más que... de la propuesta del plan curricular. Por ejemplo, con los niños de un tercero estuvimos un mes completo haciendo una investigación eh... mixta, cualitativa y cuantitativa por ejemplo de qué es lo que es la inteligencia, en cambio en el otro curso tuve que hacer un trabajo un poco más... más inmediato, porque... obviamente sus sintonías son distintas, entonces más que... que los planes me propongan una... (ruido de taladro) una evaluación, la evaluación yo la... la... la determino por el tipo de estudiantes que tengo y siemp... y nunca (corrige) ligada a la instrucción que propone el plan, sino más que nada el desarrollo de habilidades; y al final termino evaluando cosas formales... porque... las habilidades, se dan en el trabajo continuo, entonces no... difícilmente voy a evaluar como lo propone el plan.

P7: ¿Y qué propuestas traen los planes?

R: Buenos los planes... las propuestas de trabajo son casi todas basadas en textos, si uno ve los planes al final hay millones de anexos que... que tienen eh... varios textos que, algunos son de dudosa procedencia también (respira fuerte) eeh... pero la recomendación... bueno, el plan es tan antiguo, que tampoco tiene propuestas evaluativas tan claras, sino que son como... “aquí se podría hacer esto, aquí podrían conversar de esto" (cita los planes y programas) pero... una... pero una propuesta evaluativa... bueno, no sé con una rúbrica o con una base clara, creo que no tiene.

P8: ¿Qué es para usted el pensamiento complejo y la metacognición?

R: bueno, emm... (ríe) en... estuve en unas clases el semestre pasado, donde... evitaba la verdad metacognición, porque es un proceso mentalmente muy complejo que... como que ellos no están de acuerdo, sin embargo obviamente la palabra se utiliza en... en educación para que los chicos se... se den cuenta de lo que pasó o que se den cuenta de lo que aprendieron (respira fuerte) eeh... y el pensamiento complejo... la verdad no... no me atrevería a dar una definición... de él.

P9: Pero, cuando te hablo de pensamiento complejo ¿qué se tiene a la cabeza por ejemplo? ¿Con qué lo asocias?

R: Yo lo asocio a... a...al... al análisis, lo asocio a que exista... una especie de... de escepticismo primario ante las cosas, eso se me viene a la cabeza.

P10: ¿Qué habilidades o capacidades del pensamiento complejo y la metacognición pone en juego la enseñanza de la filosofía?

$\mathrm{R}$ : bueno, yo... para... repetir un poco lo que dije de la actividad con el tercero medio... siempre soy bastantes claro con los... con los chicos en... en qué es lo que estoy haciendo, en cómo yo los veo, en cómo funciona la educación en general. Trato de ser bastante trasparentes en decirles... en por ejemplo que... que están... ultra entrenados para comportarse como estudiantes, de que están eh... condicionados por ejemplo a que... haya una respuesta correcta solamente. Me pasa mucho que... les pido su opinión y me preguntan $\mathrm{d}$... escriben dos líneas y me preguntan “¿profe está bien, 
profe está bien?" (cita a sus alumnos) como que necesitan la... constante aprobación y piensan siempre que... hay solamente una respuesta correcta, cuando yo les digo que quiero saber cuál es su opinión como... salvo que esté escrita no sé con... con muchas faltas, difícilmente va estar mala. Y.... y me gusta decirles claramente que... que eso es puro entrenamiento, yo trato de decirles que... que la... las cosas que... que ellos hacen, su comportamiento como estudiantes está... determi... (ruido de taladro) está determinado por todo el entrenamiento que han tenido durante la enseñanza eh... bueno, los años de enseñanza media y la enseñanza básica completa, entonces el... el trabajo metacognitivo entre comillas eh... yo creo que va... va por ese lado, como ser totalmente transparente con ellos y decirles que se den cuenta y que piensen cómo aprenden, que piensen cómo se comporten, que piensen en lo... en.. en... en lo que hacen, y bueno la filosofía es útil en ese sentido porque al final eh... le digo "ya, pero esto que me estás diciendo tú, ¿tú lo dices porque... tú lo crees? ¿Cuáles son tus argumentos? O... o... ¿o qué sucedió? ¿O estás repitiendo otra cosa?" (se cita a sí mismo) entonces ese... ese proceso de... desaprendizaje si se quiere eh... yo ahí, me encargo harto de eso, que igual es una habilidad que... que yo creo útil, que es que igual se cuestionen un poco las cosas, que vean cuál es su rol de estudiante y vean cómo el proceso educativo que están... del cual son participes (corrige) le está... les pasa, que yo creo que es un... es un ejercicio que ellos no hacen. Entonces yo creo que, más que... la metacognición... que se enseña a hacer en el cierre de la clase... yo... trato de hacer una metacognición más general con respecto al proceso entero.

P11: ¿Qué estrategias y actividades cree usted que favorecen el desarrollo del pensamiento complejo y la metacognición en la enseñanza de la filosofía?

R: bueno yo, creo que va depender bastante del... del tipo de curso por el... con el cual uno trabaje eh...pero yo... pero yo en este año en particular he encontrado bastante... beneficios en el... en el trabajo en proyecto y sobre todo en el trabajo autónomo (respira hondo) eh... los chicos se burlan de mi porque... les digo que sean autónomos y... es como casi una muletilla entonces, alguien me pregunta algo y todos repiten "autonomía" (cita a sus alumnos) porque... saben que les voy a decir eso, eh... pero yo creo que en lo... lo que más yo he trato de hacer este... este año en particular es darles libertad y los chicos un poco se asustan cuando uno... les da completa libertad para hacer las cosas y... bueno, al principio me costó porque no... no asumían su libertad, no asumían su... que pudieran hacer lo que quisie... no lo que quisieran (corrige), pero lo que... lo que estaba dentro de la actividad y... ahora yo creo que están un poco más sueltos, que ya toman decisiones... autónomas, y creo que ese... ese ha sido el aliado este año por lo menos en... en términos de... de... metacognición.

P12: ¿Y respecto a los recursos didácticos que van a favorecer el desarrollo del pensamiento complejo y la metacognición en la enseñanza de la filosofía?

R: No creo que hayan recursos didácticos... específicos, yo trato de usar... de todo en realidad eh... yo creo que el recurso didáctico independiente de... si es tecnológico o no eh... es uno que esté en sintonía en con ellos, yo trato harto de... de... de estar como al día en las cosas que les gustan, las cosas que... que les interesan, más que en ocupar... no sé por decir alguna pizarra digital porque es tecnológico, yo trato más de... de que sea un elemento que esté en sintonía con ellos independiente de... de cuándo fue creado, si es viejo, antiguo o es nuevo o es... no sé innovador.

P13: Perfecto, profesor ¿qué tipo de estrategias de enseñanza y actividades utiliza usted durante el desarrollo de las clases?

R: eeh... bueno, ya nombré el trabajo en proyectos que... (ruido de alarma de auto) que... bueno, para... para decir algo que... que dije al principio, yo creo que por eso a veces uno... yo me atrasó en entregar los planes porque nos demoramos más de lo 
propuestos en hacer las actividades sobre todo en el trabajo en proyectos, trato de que los niños no lleven cosas para la casa porque... difícilmente se van a juntar a hacer las cosas, entonces yo prefiero que trabajen en clases (respira hondo) pero, aparte del trabajo en proyectos también he trabajado harto con textos. Es difícil trabajar con textos con los niños porque... en general no les gusta leer, pero... eh...(susurra) pero si yo les explico por ejemplo, que esta cosas es importante o que... este texto eh... les puede servir o que... o... o... o derechamente que ellos elijan el texto que quieren... con el que quieren trabajar (corrige) eh... funciona, sobre todo con textos complejos que después yo leo con ellos, así que ellos pueden después tener la satisfacción de que ellos pudieron entenderlo, pero insisto, yo trato de trabajar con cosas que a ellos les gusten o que ellos sientan que... que van a entender más con algo en particular, siento que varía... ósea hay ideas que siempre hago todos los años pero... me encontrado con cursos que trabajan mejor con cosas de... super estructuradas y super claras y metodológicas, hay otros cursos que son más libres, otros cursos que funcionan más como cursos pequeños, entonces es bastante variado en realidad.

P14: Perfecto, profesor me puede describir ¿cómo son las formas de interacción, de cooperación y de participación que se dan en las clases?

R: Yo lo... lo primero que le digo a los niños cuando... cuando me enfrento a un curso nuevo es tratarles de explicarles que yo no soy el enemigo, porque a veces se da esa... esa... como ese antagonismo entre el profesor y el alumno, ellos son relativamente jóvenes entonces igual como que siento que los niños tienen otra disposición (respira hondo), entonces siempre trato de ser emm... de ser... lo más claro posible y lo más honesto posible y... de ser honesto también, yo creo lo... a los chicos se les ocultan muchas cosas en... en la enseñanza media sobre todo eh... y bueno, una decisión que tomé este año que... que solamente duró el primer semestre, es que hice puros trabajos en grupos, lo... los sentaba de cierta forma determinada y el... y bueno, a veces era... era bastante el ruido, pero la comunicación entre ellos al poder verse las caras subió bastante y... y yo creo que eso igual ayudó al principio sobre todo en cursos que... que llegan muchos niños nuevos o un curso que era... el tercero B que era la mezcla de dos cursos que no se conocían y que se llevaban un poco mal (respira hondo), pero todos los niños saben que... que en mi clase por lo menos, en la palabra siempre está disponible, que... yo cuando pido silencio, no pido silencio para yo poder hablar, sino que es para que ellos se escuchen entre... entre ellos. Y... siento que he creado un ambiente donde ellos pueden decir las cosas clar... sin tener miedo a que yo... no sé me vaya a ofender o que lo vaya a encontrar mal... cuesta al principio, pero creo que... que lo he logrado.

P15: ¿Qué tipo de conocimientos y problemas, se plantean en las actividades de la clase principalmente?

$\mathrm{R}:$ emm... cómo de... cómo de... ¿en la materia o... en la disciplina?

P15: En la disciplina, en las clases específicamente, ¿qué tipo de conocimientos buscas poner en juego y qué problemas asociados?

R: Bueno, yo lo que... lo que más me gusta poner en juego es justamente su... la condición de estudiantes. Creo que hay... es uno... es uno de los principales como... ámbitos donde yo me he aprovechado de que ellos se... se... se vean como estudiantes y cuál es el rol que cumplen, y yo... el... el problema que yo más me encuentro es justamente que... ellos están asumiendo un rol de estudiantes super estáticos, super... eh... bueno, que es lo... que es lo que para lo que están entrenados, me ha pasado por... yo no soy de... llegar a la sala y por ejemplo que los chicos se paren y saluden, y después se sienten. A mí no me...me gusta mucho eso, pero ha pasado que a veces yo llego a la sala $y . .$. y quedo en silencio esperando a que igual... que guarden... que se sienten, que lleguen todos, y ven que estoy ahí, se empiezan a parar y... y a cumplir el rol... 
casi militar de estar ahí como siendo... se quedan todos parados hasta que yo les digo algo y les pregunto por qué... por qué se paran, por qué están así. Y ellos obviamente dicen... les digo "están entrenados, yo no dije nada y ustedes solo cumplen el rol que... que aparentemente les entregaron" (se cita a sí mismo), entonces yo... me aprovecho harto de eso, me aprovecho de... de... de que ellos problematicen, qué rol tienen, cuál es el rol del profesor y que.... Y que es raro que... ellos vean al profe como enemigo, siendo que... ambos velan por el mismo... fin, eh... podría ser el aprendizaje... el aprendizaje de ellos, entonces yo... de eso me aprovecho un poco, de... de que problematicen en frente a su rol... al rol que tienen, al rol que cumplen.

P16: Respecto a los niveles de discusión, de reflexión y razonamiento que se plantean en las actividades de la clase de filosofía, me gustaría que usted me pudiera señalar algo, ¿cómo lo describiría?

R: Cuesta... cuesta harto porque... bueno en todos lados pasa que siempre los mismos... opinan, siempre los mismos tienen eh... tienen... tienen la palabra, y algunos tienen emm... vergüenza, pasa por ejemplo que en... en mi asignatura por lo general no hay malas notas, si es que el... el proceso es normal, pero están... están tan... encerrados con las notas que siempre hablan los que tienen mejor promedio, y los que tienen bajo promedio como que son... se quedan callados, yo creo que... es por esta dinámica de que obviamente el que sabe más va hablar más y el que sabe menos, va hablar menos, porque ellos entienden que... tener buenas notas es saber harto y tener malas notas es saber menos (respira hondo), entonces cuesta un poco que... que se abran, cuesta un poco sacarles... sacarles la... sacarles las palabras, que opinen sin miedo, que... que sepan que... lo que importa no es que lo que digan este bien, sino que... que haya una conversación, que haya dialogo eh... a mí, me sigue costando hasta el día de hoy que... algunos hablen eh... porque también no... me imagino, no sé cómo lo harán mis colegas pero, aparentemente no es algo que se dé comúnmente... pedirles la opinión... yo por... (corrige) siempre que hago algún trabajo o evaluación, siempre trato de... de que me cuenten cuál es la percepción, de que quizá es mucho tiempo, que el tiempo es muy poco... entonces cuesta harto. Sin embargo, yo trabajo en otra parte también, con niños distintos de... eh... de mejor situación y ahí el diálogo es... muy, muy frecuente. Igual me da lata porque... (voz acongojada) me doy cuenta de que aparentemente es un tema de... puede ser un tema económico también, no sé si será porque la educación que... bueno yo trabajo en una escuela libre entre comillas, en... de... donde hay niños de peor situación económica y no sé si es porque es una escuela libre... entre comillas o porque son niños de mejor situación, pero ahí... yo pongo un tema y a veces no hablo nada, y hablan entre ellos todos..., y es una clase super rica porque obviamente hay diálogo, las partes se contraponen... hay un niño en particular, que cada vez que me... que me ve, me hace preguntas... en el último tiempo, estuvo pegando con... con si existe una ley o ética universal, y me hacía preguntas de eso cada vez que me veía. Entonces, no sé... cuál será ahí el... el diagnostico que se puede hacer, pero.... Los niños... eh... no... no son muy de hablar.

P17: Precisamente la próxima pregunta tiene que ver con eso, ¿qué uso se da al lenguaje en las clases de filosofía?

R: Eeh... a mí me gusta... (corrige) ósea... Yo parto cuando... cuando parto cuarto medio... partimos con los presocráticos... porque a mí me gustan mucho los presocráticos, porque... son científicos, y a mí me gusta mucho la filosofía... con la ciencia, esa relación... (respira fuerte) y cuando vemos eh... las cosas griegas, obviamente hay muchas palabras que nosotros utilizamos que tienen... bases griegas, y yo cada vez que puedo siempre trato de... de emm... de ya... mmm.. ya esta palabra, viene del griego tanto, para... (corrige) porque siento que el lenguaje igual es... emm... es mm... es interesante, analizar el lenguaje como... como lenguaje (respira 
fuerte), y... yo trato en particular... de que... a pesar de que... puede sonar bastante como... académico o...o lejano al... al contexto que me ponga hablar no sé.. de la... etimología de las palabras en griego (ruido de teléfono de oficina).. emm... emm... (ríe) ah no sé, se me fue la idea. Puede ser raro para el contexto... que está ahí... Sin embargo, (ruido de teléfono de oficina) siempre trato de que... el lenguaje sea... entendible. Estoy, bueno... (ruido de teléfono de oficina), por mis estudios, estoy muy consciente de la... de la violencia simbólica y la violencia epistémica, y trato de... (ruido de teléfono de oficina) siempre ocupar palabras, o hablar de cosas que ellos puedan relacionarse (ruido de teléfono de oficina), porque ya la filosofía ve como algo como super lejano, super académico, super serio... entonces que yo empiece a hablar en palabras complejas, confusas, que ellos no van a entender, obviamente va crear otra barrera, entonces yo trato siempre un poco de simplificar mi... mi lenguaje en particular y de tampoco censurar el lenguaje que ellos puedan... utilizar con correcciones que no vienen al caso... eh... o... o ese tipo de cosas. Yo creo que el lenguaje, justamente ayer una estudiante me preguntaba sobre... cuál era la diferencia entre querer y amar, entonces ahí obviamente... hablamos de que en el inglés existe solamente una palabra, de que los griegos tenían varias palabras para el amor, y... es interesante es... (corrige) como analizarlo de esa forma. Pero, obviamente yo trato de que mi lenguaje sea lo más adecuado al contexto, para lo que ellos... tampoco se sientan lejanos a lo que yo estoy haciendo.

P18: Y respecto al uso que se da, a los materiales y a recursos didácticos, en las clases de filosofía, ¿cuál sería este y cómo lo describiría?

R: Emm... bueno, pa... (corrige) yo creo que el material... didáctico que se puede utilizar, si entendemos como material... mm... no sé... cosas extras, aparte de... (ruido de silla) eh... aparte del cuaderno o el lápiz no sé... yo siento que su relevancia no va... no va a... a estar en... en la novedad, o en la variabilidad del... del material, (ruido de silla) sino en su... coherencia con lo que está pasando, y con los mismos estudiantes. Yo... no sé, puede que no ocupe nunca material, que a veces ocupe, pero... su... los beneficios que ellos obtiene del material, va ser... va estar presente siempre y cuando... se cumplan los objetivos... de la... de la actividad y que ellos también puedan relacionarse con el material. Yo creo que el... el... se le ha dado mucha importancia a las tizas, a los materiales, yo creo que... son un medio, no.... no... no la finalidad, no hay... no hay que ocupar por ocupar (suspiro), entonces yo... ocupo lo que... lo que encuentro pertinente, soy de... soy de mucho de usar películas o usar eh... series, pero siempre con... obviamente con... con la finalidad y.... si hay... no sé, si hay un curso que no... que no le gusta o que... yo sé que lo que yo voy a presentar puede ser quizá muy complejo o que lo encuentren fome, simplemente... no lo uso y buscó... trato de buscar algo que... que ellos se sientan en sintonía. Puede ser un texto, puede ser una pintura, puede ser... no sé, o puede ser nada, puede ser simplemente la conversación, el diálogo o un trabajo en grupo, responder a una pregunta... (suspiro) siento que el material... en sí mismo no... no es tan importante... como... instrumento.

P18: Muy bien, ¿hay algo que quiera complementar en general?

R: Eeh... no... no.

Cierre: Bien, entonces damos por finalizada la entrevista, agradeciendo la participación y disposición. 


\section{ANEXO 5. ENTREVISTA A SÓCRATES}

P1: ¿Cuál es el propósito fundamental de la enseñanza de la fílosofía?

R: Bueno, principalmente eh... desarrollar en los alumnos, el pensamiento crítico que es lo que generalmente, no se ve o no se visualiza dentro de la enseñanza media, uno puede hablar con los jóvenes, obviamente no tienen muchos argumentos... inclusive el mismo tema de la argumentación, que es un programa de filosofía, no está pasado en todos los colegios, en algunos se pasa o en otros no se pasa, se ven malamente, y... y eso, ha hecho de que... emm... eh... eh... el aspecto educativo de la filosofia, descuide un poco el pensamiento crítico, porque en... resumidas cuentas lo que busca el programa, es que se pasen unos contenidos mínimos, de los cuales eh... generalmente nunca se pasan completamente. Por lo tanto, uno siempre va quedando con... con... con contenidos rezagados y no se cumple el objetivo, que es el desarrollo del pensamiento crítico, que al final se comienza a hablar de filosofía como una historia de la filosofía, pero no de la filosofía en sí... que le va servir al joven para que reflexione... para que enfoque de otra manera, para que sea crítico, inclusive es contraproducente que acá el sistema educativo plantee la filosofía como un modo ¿verdad? Reflexivo en los alumnos, pero no se les enseña a pensar.

P2: ¿Por qué dice usted que no se les enseña a pensar?

R: Claro porque uno está... los ve verdad y ve que... el único... llamémosle... asignatura que le dan más importancia acá, es lenguaje y matemática, los dos emm... asignaturas ancla, pero esas dos asignatura ancla, no pueden por sí solas desarrollar un pensamiento crítico e inclusive ninguna asignatura, aunque le den más cantidad de horas, puede ser desarrollar un pensamiento crítico, porque eso es un todo, y la filosofía... tiene... la ventaja de que puede trabajar con un pensamiento crítico, en el sentido del poder tener un pensamiento de...reflexivo sobre las cosas que estamos aprendiendo, si son válidas o no, si se pueden aplicar o no ¿ya? El entorno... eh... varios, ósea todo va depender... por lo menos de que no... de cambiar el enfoque ¿ya?, el enfoque en el sentido de... de dar más horas de este... (corrige) de esta asignatura, pero no mirarlo desde un punto de vista... histórico la filosofía, sino de una herramienta que me va servir para aplicarla en mi vida... completamente.

P3: ¿Qué y cómo se enseña filosofía en la educación media chilena?

R: ¿Qué y cómo?

P3: si...

R: qué se enseña de filosofía, me imagino que es eso

P3: si, y cómo

$\mathrm{R}$ : en los programas

P3: mmg (asiente)

R: el qué se enseña... bueno, en... en tercero, el programa está avocado a lo que es psicología y ahí hablamos sobre el pensamiento, cómo se... revoluciona el ser humano, desde el punto de vista de la psicología y la fisiología igual, levemente y a partir de la madurez ahí, que... el adolescente ¿verdad? Cuando entra a tercero medio va creando eh... sus propias preguntas ¿no cierto? Porque ya... va madurando, tiene otra manera de ver, entonces la psicología es como una antesala de la filosofía, y... inclusive ahí, en psicología nosotros podemos ver el... el desarrollo de la mente y del joven, para que él mismo, haga una especie... como usted me preguntó la otra vez... una metacognición ¿verdad?... de "¡ah, mira esto es lo que... ocurre en... en mi mente" ¿verdad? "ah esto... por esto, estoy así", es decir, con psicología el... joven aprende a autoconocerse, una palabra... auto-conocerse, cosa que en filosofía él ya entre con un... pensamiento más crítico de... de sus... facultades ¿verdad? De sus capacidades de razonamiento, de la autocrítica, que sea un poco más abstracto, es decir, a nivel de razonamiento ¿no cierto? Porque al final ahí estamos en psicología 
y... qué se enseña, y cómo se enseña. Bueno, cómo se enseña... uno tiene varias maneras de enseñar la filosofía, puede a partir de... un texto, que es lo más clásico y que desde la universidad lo hemos así ¿no cierto? A buscar nuevas técnicas, como ejemplo usar un computador, usar un programa como power point, usar un video, usar una película, usar un recurso audiovisual ¿ya? Eh... un ser creativo, en el sentido de crear los materiales, puzles, crucigramas, sopas de letras eh... relacionar cosas entretenidamente ¿ya? Llev... (corrige) Bajar un poco la abstracción, para que el joven... o la... niña en ese caso, la alumna eh... lo encuentre que es un ramo atractivo, ósea hacerlo atractivo ¿ya? Y de esa manera se... se enseña... ¿cómo...cómo se enseña? De esa manera ¿ya? Respetando siempre los contenidos mínimos obligatorios que exige el programa, porque yo no puedo pasar algo que no esté dentro de los contenidos mínimos, no podría hablar yo de Marx, si ahí no está Marx, no podría yo hablar, por ejemplo de... no sé de... de un periodo contemporáneo, si ahí no aparece.

P4: ¿Qué tipo de actividades o prácticas de enseñanza y de evaluación nos sugiere el programa?

R: Bueno, generalmente qué sugiere... es la propia análisis crítico de la lectura, en lectura es lo que más yo le inculco a los alumnos, porque es lo que... la base de todo pu... entonces análisis de textos ¿no cierto? Eh... podemos hacer ensayos, también sugiere ensayos que los niños puedan hacer ensayos ¿verdad? Aprender la estructura del ensayo, análisis de textos. Bueno, aparte de eso podría considerar también emm... eh... otro tema de evaluación eh... evaluarlas... emm... mm... las pruebas ¿no cierto? Que es un instrumento que yo no lo podría dejar de lado ¿verdad? Porque ahí yo veo si realmente se aprendieron los contenidos o no, pero sería comprensión lectora, los ensayos, las pruebas eh... también podría ser los trabajos de investigación ¿no cierto? Las exposiciones, que es otra cosa más que tendríamos como recurso ahí para evaluar eh... los debates, que es muy importante también eso, los debates para ver si... eh... hay buenos argumentos ahí, y... bueno así, bastante.

P5: Respecto a los problemas que platean los programas, ¿cuáles serían estos? ¿Qué tipo de problemas, de reflexiones sugiere?

$\mathrm{R}$ : los problemas que platean... el problema que plantea el programa... mmm... no le... no le veo el problema, a lo que si veo que... mm... bueno, todas las otras asignaturas, por decir un... una cosa, tienen un libro ¿no cierto? matemáticas tiene un libro, lenguaje tiene un libro ¿ya? Pero nosotros en filosofía, nunca hemos tenido un libro ¿ya? No sé porque no hacen un libro, pero... me pareció muy bueno, este año, de que en filosofia la asignatura haya sacado un libro. Por lo tanto, ahí ya no... no hay un problema, con eso nos soluciona un problema que fallaba... por qué no tenían un libro la... la asignatura de filosofía. Entonces, los profesores andaban buscando materiales, recopilando por aquí y por allá, ese era un problema, pero... hoy las niñas, en tercero medio, tienen un libro de filosofía ¿ya? Y aparecen todos los pensadores antiguos, y una... línea del tiempo de la filosofía muy buena. Es un libro bastante bueno, así que yo creo que problemas no, porque ya han solucionado eso. Eh... ahora en cuanto a los contenidos... los contenidos son los que... el ministerio plantea que son los más idóneos para... para pasar ¿no cierto? En cuarto comenzamos con las preguntas filosóficas que es... cuando inicia todo y luego comenzamos ya con... a profundizar un poco eso: Sócrates, Platón, Aristóteles ¿ya? Que son pensadores que... ancla, de los cuales nosotros nos valemos para poder... hacer nuestras clases y... provocar la inquietud del pensamiento reflexivo, después bueno, vienen las etapas de la moral, no yo creo que estamos bien ahí, no... no... el problema era el libro no más, no teníamos libro, pero ahora tenemos libro.

P5: un recurso de apoyo

$\mathrm{R}$ : si, justamente... ese era un problema 
P6: ¿Qué aporta la enseñanza de la filosofía al desarrollo del pensamiento de los estudiantes?

R: Bueno, hacen que la... eh... los estudiantes sean... entes críticos, reflexivos, que... tengan capacidad argumentativa, que mejore su autoestima la filosofía, con el... programa de argumentación les mejora su autoestima, porque... son capaces de defender sus ideas ¿verdad? En un debate, usando el lenguaje como medio de expresión y yo creo que eso le hace muy bien a la... al... al... al todo llamado estudiante, porque en cuarto medio es la última asignatura que ven, y ya él tiene que tener una formación intelectual, que le permita de alguna manera comprender más la realidad, y... ¿cómo comprende más la realidad? Con un pensamiento reflexivo, filosófico, cosa que... sacar una asignatura como esta es tener una lata vacía en... en el sistema educativo, que no les va enseñar a pensar nada y va ser contraproducente. Yo creo que eso es, formarlos integralmente.... (ruido de timbre) integralmente.

P7: Y el pensamiento filosófico profesor, ¿cómo lo caracterizaría usted?

R: ¿cómo lo caracterizaría? Acá en Chile... ya el pensamiento filosófico, se ve poco en la asignatura, porque consideran de que $\mathrm{mmm}$... inclusive como religión ah, cosa que no tiene nada que ver. Yo lo veo de que... tiene que haber una especie de... aumentar nuestras horas de filosofía, no disminuirlas, porque esto... este ramo enriquece el... el todo de todas las otras asignaturas, las enriquece, por lo tanto el aumentar las horas, mejoraría y acabaría con el tema de no poder pasar los programas... eh... completamente, porque siempre eh... se pasan a una mitad, no se alcanza a pasar el cien por ciento, se alcanza el ochenta, el sesenta, el cincuenta por ciento a veces. Por lo tanto, yo creo que eh... pienso de que es necesario aumentar las horas eh... sobre todo si... queremos tener unas... personas que sean... entes reflexivas y comenzar con un programa que es filosofía para niños, a partir de la... básica, que.. en escuelas particulares... se aplica, vienen con una base filosófica, llegan a me... a la media con una base filosófica, moral sobre todo, y... yo creo que mejoraría mucho la enseñanza. Ahora yo no sé porque no se hace en... este programa y... en liceos municipalizados, yo creo que le te... le temen emm... no sé, en mi experiencia yo, a que los alumnos sean reflexivos, a lo mejor quieren que no... que no piensen... eh... a lo mejor, no al problema.

P8: Profesor, y ¿qué es para usted el pensamiento complejo y la metacognición en la filosofía?

R: bueno, la metacognición es muy importante porque... a partir de ahí yo me puedo dar cuenta de los propios procesos... de aprendizaje, porque la metacognición es una comprensión sobre la comprensión ¿cierto? Si la entiendo así, porque yo veo cómo, entonces me puedo dar cuenta de cuáles son las mejores estrategias para aprender, porque... a lo mejor me doy cuenta, de porque el niño no aprende de esta manera, es como un entrenador ¿cierto? Yo estoy entrenando a alguien, entonces yo veo ahí... emm... en qué parte yo lo puedo poner, si es un jugador, para sacarle el mejor rendimiento. A lo mejor él es un delantero, quizá si lo pongo de defensa, no va rendir. Por lo tanto, yo tengo que ver ahí, qué es lo que le puedo... ofrecer, cómo le puedo sacar todo el potencial ah, cosa que dentro de treinta, cuarenta alumnos en una... en una sala de clases eso es... es... no es muy viable ah, porque igual hay que dar una clase a cuarenta o a treinta, y uno no puede ver focalizando todo, a no ser que esté con diez alumnos, y ahí sea personalizado, uno podría sacar todo ese... rendimiento que tienen, y todo ese potencial iya? Eh... eso es con respecto a lo que era la metacognición y la otra pregunta era la de...

P8: pensamiento complejo

$\mathrm{R}$ : y el pensamiento complejo, se refiere al abstracto ¿verdad? Al... al pensamiento filosófico ¿ya? ¿Cómo se puede enseñar eso? Ya... emm... uno... eh... los niños, 
los adolescentes ya tienen un pensamiento abstracto, por lo tanto, no se les haría complicado aprender la teoría... metafísica, si hablamos de esencia, si hablamos de... de... alguna, cómo cuestiones... llamémosle, más abstractas ¿ya? Porque ellos ya tienen desarrollado eso y lo que hay que hacer es potenciarlo no más, y ¿cómo lo podemos potenciar? Con la ayuda de actividades que sean entretenidas ¿ya? Por medio de un video, una película eh... que ellos reflexionen, que se... y que hagan todo ese proceso intelectual cognitivo, para que... ellos mismos, sean sus propios... eh.... Cómo se... profesores... se... eh... comiencen ellos mismos a ver "ah, esto es lo que... de esta manera tengo que aprender, de esta manera tengo que aprenderlo" (cita a los alumnos en una situación hipotética), es decir, vayan regulando sus propios procesos de... conocimiento.

P9: ¿Qué habilidades del pensamiento complejo y la metacognición pone en juego la enseñanza de la filosofía?

R: Qué habilidades... eh... llamémosle el diálogo ¿no cierto? Que es lo más importante, la argumentación ¿ya? También... eh... el pensamiento abstracto (afirma dubitativo) ¿ya? Es que igual hay conceptos bastante abstractos que tienen que... tomar, la otra habilidad que ponen es... eh... yo creo que una de las habilidades que veo y con carencias acá, es la comprensión lectora, porque todo esto de la filosofía parte por el texto, y si los niños no tienen o las niñas en este caso, no tienen una capacidad... comprensiva, que es la que... eso es lo... la grave... falencia que yo noto, en la enseñanza de la filosofía, que no hay una compren... (corrige) una capacidad lectora, eh... no les gusta leer. Por lo tanto, si no les gusta leer ¿cómo pueden incorporar un pensamiento que es abstracto? ¿Ya? Entonces, eso sería también lo que pone en juego, la capacidad lectora, el análisis, la síntesis, el resumen, todas esas son habilidades... de acuerdo a la... escalas que hacen Bloom y todo eso, y además son capacidades o habilidades que... se adquieren, ya cuando el alumno va un nivel más o menos alto, entonces esto... esas habilidades son las... el análisis, la síntesis, el resumen ¿ya? Son muy importantes... las que ponen en juego.

P10: Muy bien, ¿Qué estrategias y recursos didácticos, favorecen el desarrollo del pensamiento complejo y la metacognición, en la enseñanza de la filosofía?

R: Bien, los vídeos, una buena película, llamémosle que tenga contenido ¿ya? Por ejemplo estábamos pasando en cuarto medio el chacal de Nahueltoro, entonces ahí veíamos un problema moral a partir de un vídeo, o también podemos ver un problema moral a partir de un documental, de un reportaje, todos esos son aspectos llamémosle... críticos, en donde se... contemplan en una situación real, que después se puede ir sacando... eh... los contenidos ¿no cierto? de lo que hacemos, si es moral ¿ya? Si estamos hablando de la percepción, de la realidad nos vamos a Platón y ahí podemos ver una película como matrix ¿verdad? Donde ellos... eh... dilucidan "a ver, ¿qué es lo que es la realidad, realmente?" (cita a los alumnos) Llevarlos a un punto donde los niños, o las niñas, se cuestionen... se cuestionen, sobre las cosas mismas que ellas... perciben ¿ya? Entonces, esos recursos... audiovisuales son muy buenos como para enseñar la filosofía. Aparte de los textos, por supuesto que le dan pie a las...

P11: Profesor, ¿qué tipo de actividades, o estrategias de enseñanza, utiliza usted durante el desarrollo de sus clases?

R: Mira, principalmente una actividad sería la de... pasar... los crucigramas, sopas de letras ¿verdad? Eh... comprensión lectora, eh... debates, eh... lo otro sería... ¿qué otro más? (se pregunta a sí mismo) lo que vimos acá en la clase... ir preguntándole al alumno si entendieron eso, pero... otra estrategia sería la de... básicamente la comprensión lectora ¿ya? Los debates, la comprensión lectora, eran esos... ¡ah! Los recursos audiovisuales también, si yo por ejemplo, en vez de haber hecho una clase así expositiva, que también es un recurso ¿verdad? Emm... hubiera ido a buscar... el 
power point... el... computador, hubiéramos puesto ahí un... mayor ejemplos audiovisuales, pero eso igual me habría quitado tiempo... una cosa de tiempo, pero lo hago, eh... sería eso los tres básicos, un recurso audiovisual, podría ser una película o un video, el... la clase expositiva, los debates y... bueno eso, sería lo... lo principal. Bueno, y otras más, unas guías con crucigramas, sopas de letras, que también son recursos ¿ya? Son estrategias también, para que ellos vayan viendo los apuntes, entonces... a veces mm... veo que los niños no leen los apuntes, entonces la única manera de hacerlos leer por medio de una estrategia, es hacerles un crucigrama, entonces están obligados a ir y ver ahí... "ah, esta es la palabra" (cita a los alumnos) y les gusta, y van aprendiendo de una manera más... lúdica.

P12: Profesor, ¿me puede describir por favor las formas de interacción, de cooperación y participación que suelen darse en la clase de filosofía?

R: Interacción, cooperación... bueno, la... en temas de... preguntar ¿no cierto? El de yo primero exponer, es como siempre más clásico... aunque igual hay otras formas, pero... la interacción es siempre que las niñas van preguntando una duda, y yo les voy respondiendo de acuerdo a lo que estamos viendo ¿ya? O de pronto pueden haber otras preguntas, que tengan que ver con eso, y que no tengan que ver... igual damos cabida. Y vamos aclarando las dudas, relacionado con el contenido ¿verdad? Pero siempre es un dialogo, la interacción que se da con los alumnos es un dialogo y... ese dialogo... siempre tiene que ser lo más enriquecedor para ellos. Por lo tanto, esa es la principal interacción, el dialogo... porque al final ¿qué es lo que es una clase? No es una conversación, puede ser un monologo a veces, y termina siendo una conversación, pero no cualquier conversación.

P13: ¿Qué tipo de conocimientos, problemas, incluso reflexiones se plantean en las actividades de la clase de filosofía?

$\mathrm{R}$ : ¿relacionado con los contenidos?

P13: si...

R: Bueno, ahí por ejemplo... esta una clase de filosofía en sí ¿ya? Partimos con la primera unidad que son las preguntas filosóficas, ya... qué queremos saber ahí a partir de esos conocimientos ¿ya? Que ahí las alumnas puedan reflexionar acerca de lo que existe, no solamente una manera de conocer, si pueden existir más de una manera, por ejemplo las preguntas... nos topamos con preguntas empíricas, que parten de las propias experiencias de los alumnos, o preguntas racionales ¿verdad? Que parten de la propia... de la racionalidad, de las ideas que ellos tienen, por lo tanto dos maneras de conocer la... realidad. Y (ruido de teléfono de oficina) a partir de ahí, vamos a ir viendo ¿verdad? las preguntas filosóficas que....abarcan ambas y que tienen (ruido de teléfono de oficina) además, más de una... tipo de... de respuesta, porque es una pregunta filosófica no es acabada, porque habla del mismo ser humano. Y a partir de ahí, de ese inicio, nosotros comenzamos a ver todas nuestras teorías filosóficas tanto de... Sócrates, Platón, que tiene sus enfoques racionalistas o... empiristas ¿verdad?... como Aristóteles, y a partir de ahí eh... van reflexionando acerca de los tipos de conocimiento que ellos están adquiriendo ¿ya? Ósea al final tendrían que considerar de que, para entender la realidad, el conocimiento no puede ser tan solo... percepción o experiencia, o tan solo puede ser racional ¿ya? Porque se da una mezcla de ambas, sujeto-objeto, no puedo conocer algo si solamente estoy yo, tendría que estar encerrado en mí mismo, y... eso es lo que ellos van ar... ese es el tipo de conocimiento que queremos decir... marca toda la... eh... el programa de filosofía, y el... conocimiento moral, que es una cosa que falta bastante ¿ya? Qué es lo bueno, lo malo y también llegarlos a criticar, qué es lo que es eso, cómo... cómo surge. Eso serían los conocimientos, de la moral y tipos de conocimiento. 
P14: ¿Y la reflexión que surge en las clases de filosofía, evidencia que las estudiantes logran relacionar el conocimiento conceptual con situaciones de su propia vida?

$\mathrm{R}$ : eso es lo que trato de que... siempre eh... vayan a hacerlo, porque hacerlo cuesta acá (susurra) emm... en las clases, todo lo que eh... ejemplificaba... o todos los contenidos que estaban ahí en los planes ¿verdad? En los conceptos, siempre los colocaba con un ejemplo de la vida real, cosa que ellas vean que... todos esas teorías ¿verdad? No es una cosa abstracta no más, sino que ellas las pueden ver constantemente en su quehacer diario. Por lo tanto, el... el... el tema de llevar esto, a la vida de cada alumna es para que logren un... un aprendizaje significativo, que hoy en día está tan de moda, si algo es significativo para mí, lo voy a aprender, ahí lo veo como que lo estoy utilizando, y eso trato de que yo... ocurra en la clase de psicología, por ejemplo, siempre hablo de que... ellas deben tener hermanos chicos, qué se yo, por lo tanto, es una manera de relacionar los contenidos, con lo que estamos viendo ahí, entonces eso se les vuelve de inmediato significativo ¿ya? Entonces los... aprendizajes significativos les van... los van a ver, en el mismo dialogo, con los ejemplos que les voy dando, que son provocativos y les hacen reír o lo hace... de alguna manera reflexionar más.

P15: Usted menciona el aprendizaje significativo...

R: si...

P15: A partir de ejemplos, ¿cómo define usted el aprendizaje significativo?

R: Aquello... de lo que a mí me sirve para la vida, un aprendizaje significativo para mi es aquello que me sirve para vi... para aplicarlo diariamente en mi quehacer, si aprendo algo aquí... a lo mejor lo voy a aplicar (ruido de silla) en la vida real, con mis hermanos, mi mamá... es decir, aquello que... me ayude a aplicarlo... en mi realidad cotidiana, eso es el aprendizaje significativo ¿ya? Y acá en filosofía pueden aplicar cosas, desde el punto de vista de la moral o desde el punto de vista del conocimiento, en sus propias vidas ¿ya? Por eso que la filosofía, como decía Giannini (ruido de golpecitos)... ayuda... a morir. ¿A morir por qué? porque a lo mejor todo lo que yo sé, lo voy a aplicar en... en mi quehacer diario, y todos los días estamos muriéndonos... de alguna manera. Eso sería el aprendizaje significativo, el que lo pueda aplicar... en su propia vida, en que el conocimiento que está adquiriendo acá eh... le sirva como para... como un medio, como una herramienta para... desenvolverse de manera mejor ¿verdad? Y... aplicarlo... aplicarlo. No... es... eso sería significativo, porque si no fuera significativo, no... lo va a aprender, no tendría mucho que ver directamente.

P16: ¿Qué usos se le da al lenguaje en las clases de filosofía?

R: Ya... eso es importante, porque si estamos hablando de que... no tienen habilidades lectoras, que es un problema realmente no sé por qué, y eso que hay más horas de lenguaje, antes... eso nunca lo he podido entender, que hay tantas horas de lenguaje y no son buenos pa' leer, entonces me doy cuenta de que el texto filosófico es diferente, obvio que... si (murmura) y nos falta más herramientas. No, el lenguaje tiene que ser acorde... a los conceptos que ellas manejan, porque yo no puedo entrar con un lenguaje muy elevado filosófico, si no me van a entender nada, entonces... los conceptos tanto eso... metafísicos, esencia, extensión ¿ya? Todos esos tipos de conceptos se trabajan... con sus propias vidas o experiencias, o lo haces aún más aterrizado para que ellas relacionen, y al relacionar ya puedan estar en condiciones de adquirir conceptos eh... es importante el lenguaje, pero siempre hay que ir bajándolo un poco para que... puedan entenderlo, porque si no se vuelve algo incomprensible.

P17: Y respecto a los materiales y a los recursos didácticos que usted mencionó que utiliza en las clases de filosofía, ¿qué uso se le da? 
R: Mira... que tú para potenciar más su... comprensión, su aprendizaje, ese sería el fin, porque por ejemplo... uso un crucigrama ¿ya? Porque a lo mejor ellas como no leen los apuntes, entonces ¿de qué otra manera lo pueden leer? Usamos un juego, entonces de esa manera el recurso... didáctico, aunque didáctico es teórico y práctico ah, lo teórico y lo práctico, que previamente se da... de didáctico de un modo. De esa manera ellas pueden adquirir, ese cincuenta por ciento de... práctica, a partir de la teoría que hemos aprendido ¿no cierto? Y que la internalicen lo mejor posible a través de los juegos que son... lo lúdico, el... les encanta todo eso ¿ya? formar palabras.... Crucigramas. Y esos serían los recursos que yo ocuparía, para... no sé... lle...llevar a que... adquieran el concepto de idea, realidad, percepción, etcétera. Así lo haría.

Cierre: Muy bien, damos por finalizada entonces la entrevista profesor, muchas gracias. 
P1: Profesor, ¿cuál es el propósito fundamental de la enseñanza de la filosofía?

R: (Gritos de alumnas/os de fondo) Eh... el propósito eh... fundamental de la enseñanza en... de la filosofía es... el desarrollo del pensamiento crítico ¿ya? Eh... el pensamiento crítico involucra eh... una serie de habilidades que están implícitas en este concepto y que... eh... determinan ¿cierto? Y ayudan eh... al... al alumno digamos, a los estudiantes, a poder eh... desarrollarse en diversos ámbitos, en diversos contextos.

P2: ¿Qué se enseña y cómo se enseña filosofía en la educación media chilena?

R: (Gritos de alumnas/os de fondo) Eh... en la educación media chilena eh... los planes y programas solamente muestran una visión histórica de... la filosofía ¿ya? Lo que uno enseña es una visión histórica de la filosofía, pero los objetivos que están planteados en el programa, no están eh... eh... enmarcados dentro del desarrollo de habilidades ¿ya? De orden superior o la... o las habilidades que... eh... implica digamos el pensamiento crítico, solamente se ubican en... en el área, si... es necesario por ejemplo utilizar una taxonomía, podemos nombrar la más común que es la de Bloom, solamente se queda en el ámbito del conocimiento, solamente se queda en el ámbito del conocimiento (repite) y... eh... los objetivos como bien digo, no están eh... señalados o encaminados hacia el desarrollo de habilidades superiores como la inferencia, el análisis, la evaluación, la síntesis.

P3: ¿Qué aporta la enseñanza de la filosofía al desarrollo del pensamiento de los estudiantes?

R: (Gritos de alumnas/os de fondo) Eh... la enseñanza de la filosofía aporta eh... desde muchas... desde muchas aristas ¿ya? En primer lugar eh... desde el punto de vista de la comprensión del ser humano ¿ya? De las características fundamentales, originarias del ser humano, desde cómo comenzó (ruido de timbre) la vida hasta... digamos, el tiempo actual. Y desde el punto de vista, digamos... el aprendizaje, del desarrollo de las habilidades, involucra eh... el fortalecimiento de... de diversas características que tienen... que tiene el pensamiento: la lógica, la... la reflexión fundamentalmente que eh... se vinculan con las problemáticas de la sociedad actual... contemporánea.

P4: Muy bien, ¿y qué tipo de problemas y de conocimientos ponen en juego los programas de estudio de la asignatura?

R: (Gritos de alumnas/os de fondo) ¿cuál es la pregunta?

P4: ¿Qué tipo de problemas y de conocimientos se ponen en juego en los programas de estudio de la disciplina?

R: (Gritos de alumnas/os de fondo) Como mencioné en la... en la respuesta anterior, en los planes y programas eh... solamente se quedan en el ámbito del conocimiento ¿ya? Podemos decir ¿cierto? Están planteados los objetivos de... de... desde una perspectiva solamente inicial ¿ya? Sin embargo eh... los temas dan para... una reflexión mucho más profunda, involucran eh... una serie de habilidades eh... eh... digamos son fundamentales para el desarrollo de los estudiantes, ya que tiene que ver por ejemplo con, primero la eh... la reflexión ¿ya? Ósea poner en...ponerse en el lugar de ciertos con... (corrige) de ciertas problemáticas y poder reflexionarlas, pensarlas ¿cierto? Y desde ahí ¿cierto? Desarrollar otro tipo de habilidades: inferenciales, analíticas ¿ya? Que eh... posteriormente permitan a los estudiantes, ponerse en determinados contextos y enfrentar situaciones.

P5: ¿Me podría mencionar alguno de esos temas? 
R: (Gritos de alumnas/os de fondo) Eh... por ejemplo, uno de los temas eh... que está eh... que viene dado desde eh... de los planes y programas ¿cierto? Es... el... es el... el mito de la caverna de Platón ¿ya? Obviamente, como mencioné anterior... de forma anterior, está dado ¿cierto? desde una perspectiva histórica, sin embargo eh... el tratamiento que se... que se... se le podría dar al mito si se... se...se desarrollaran más estas habilidades, sería por ejemplo, hacer un contraste en la sociedad actual ¿ya? $\mathrm{Y}$ a las problemáticas que ocurren en el ámbito político por ejemplo. Puede ser también en el uso que eh... los estudiantes puedan darle a las tecnologías ¿ya? Porque desde esa perspectiva, las tecnologías tienen esa doble característica de ser una ayuda y de aportar digamos al desarrollo de eh... diversas actividades, en el ámbito lúdico ¿cierto? En el ámbito del conocimiento, pero también se vuelve un arma de doble filo dependiendo del contexto desde el cual los estudiantes la ocupen, entonces esa temática por ejemplo, no está abordada en los planes y programas, y que... podría o merece un tratamiento ¿cierto? En profundidad eh... si es que hubiese una reformulación de estos planes y programas.

P6: ¿Y cuáles son los focos de tercero y de cuarto?

R: (Gritos de alumnas/os de fondo) ¿En qué sentido?

P6: ¿Qué es lo que se ve y hacia dónde apuntan estos programas en tercero y en cuarto medio?

R: (Gritos de alumnas/os de fondo) A ver... el programa... en los programas de tercero y cuarto medio, digamos es... son muy disimiles entre sí ¿ya? El programa de tercero medio es una... es una perspectiva digamos eh... histórica digamos de la psicología ¿ya? La primera unidad, la segunda unidad también eh... es de la perspectiva histórica, pero que tiene algunas... aplicaciones eh... más prácticas ¿ya? Es posible realizar... aplicaciones más prácticas en... en la vida cotidiana y hacer contrastes con... con la vida de los estudiantes... eh... la tercera unidad del programa de psicología de tercero medio ¿ya? Involucra eh... el estudio del individuo y la sexualidad, sin embargo eh... los temas que... que... o... los temas que ahí se proponen, son demasiado acotados ¿ya? Y... están restringidos solamente a una visión eh... romántica de lo que involucra la sexualidad, o... o están restringidos ¿cierto? A... a temáticas puntuales, por ejemplo la... la sexualidad responsable em... la paternidad responsable también eh... y las diferencias... o las dimensiones de la sexualidad ¿cierto? Biológica, psicológica, sociocultural y ética valorativa, pero no hay una profundización en... en estas temáticas por ejemplo, no hay una... sino que se mencionan eh... de la manera eh... somera ¿ya? Porque finalmente en la unidad número cuatro, que tiene que ver con bienestar psicológico eh... lo que yo rescataría digamos y lo que es más claro, lo que viene de ¿cierto? propuesto en los programas... es la resiliencia ¿ya? ese concepto está bien desarrollado y uno lo puede aplicar constantemente y... los estudiantes lo comprenden ¿ya? Sin embargo eh... falta por ejemplo eh... establecer vínculos en lo que es... lo que tiene que ver con el proyecto de vida, con eh... la normalidad, la anormalidad, que son cuestiones eh... que no se entienden, no se comprenden a... a primera vista y merecen un desarrollo más profundo ¿ya? también... por otro lado, el programa de cuarto medio... las... tres... unidades, de las cuatro unidades ¿cierto? Tres unidades refieren al plano de la ética ¿ya? Refieren al plano de la ética (repite) y... la primera obedece ¿cierto? A un... a una... a un contexto histórico de la filosofía, del nacimiento, de cómo se dan las teorías más importantes. Eh... falta por ejemplo, un desarrollo eh... más eh... práctico en lo que refiere a la... a la unidad tercer... (corrige) a la unidad tres fundamentos de la moral, que también se queda en una perspectiva histórica ¿ya? Y... es más, al menos en la propuesta que yo haría o lo que yo... pienso que... se podría fusionar la unidad número dos y número tres ¿ya? Porque relacionan directamente con la moral y la ética, 
por lo tanto... podría ahí haber... debería ahí haber un... eh... una simbiosis digamos de estas unidades.

P7: Muy bien, ¿qué uso específico del lenguaje cree usted que se pone en juego en los planes y programas?

R: (Gritos de alumnas/os de fondo) amm... ¿a qué refiere con usos específicos del lenguaje? ¿Cómo podríamos...?

P7: orales, escritos, hay instancias de interacción...

R: (Gritos de alumnas/os de fondo) ah ya.... Los planes y programas eh... incentivan eh... el desarrollo eh... escrito ¿ya? Es bien curioso... (repite) es bien curiosos lo que... (repite) es bien curioso lo que los programas proponen, solamente eh... la comprensión o la explicación de la filosofía, o el... o el ejercicio de la filosofía a través de lo escrito ¿ya? A través de lo escrito solamente, yo desconozco otros programas de otros... de otros... latitudes, de otros países, pero al menos... aquí en Chile, solamente viene a... a... abordado desde el plano escrito, sin embargo hay temáticas por ejemplo que perfectamente se podría... eh... abordar desde el plano... de la expresión corporal ¿ya? A través de la música, a través de... los recursos audiovisuales, que... podrían perfectamente también darse eh... a través de... evaluaciones orales, (repite) de evaluaciones orales perfectamente.

P8: Perfecto, ¿qué tipo de prácticas y actividades de enseñanza, y de evaluación, se programan o vienen establecidas, o sugeridas en el programa, que favorecen el desarrollo del pensamiento complejo y la metacognición?

R: (Gritos de alumnas/os de fondo) Ninguna, como mencioné anteriormente, las actividades eh... de enseñanza, de evaluación eh... no están enfocadas al... al desarrollo de habilidades de orden superior, de pensamiento complejo, ni metacognición. Insisto, ósea no es que se queden en el ámbito del conocimiento eh... identificar características, de mencionar, de memorizar, no involucran digamos pensamiento complejo.

P9: ¿Me podría mencionar un par de ejemplos respecto a la sugerencia que tiene el programa sobre actividades de enseñanza y actividades de evaluación?

R: (Gritos de alumnas/os de fondo) Eh... retomando... de la pregunta anterior, cuando yo hablaba del mito de la caverna, por ejemplo uno de los objetivos: conocen, los alumnos conocen el mito de la caverna, identifican las características del mito de la caverna $\mathrm{y} . .$. una actividad propuesta es... responder un cuestionario, el programa trae un cuestionario eh... con cinco o seis preguntas que están relacionadas con el mito de la caverna, y... donde se va... (corrige) desglosan eh... las características que tiene...eh... el mito de Platón ¿ya? La fogata, los hombres encadenados, qué simboliza la caverna, que simboliza el hombre... que sale de la caverna y vuelve, eh... pero... eh... insisto son preguntas, que no... implican... un... una análisis, tan acabado de esa temática, son preguntas que se quedan en lo básico.

P10: Profesor, ¿qué es para usted el pensamiento complejo y la metacognición en la filosofía?

R: (Gritos de alumnas/os de fondo) Eh... el desarrollo de orden superior: análisis, inferencia, (ruido de timbre) síntesis, evaluación. Que eso también está... también está ausente en los programas eh... desarrollos actitudinales a partir de la filosofía que... va muy de la mano ¿ya? Actitudes por ejemplo, que ellos puedan eh... eh... desarrollar oralmente ciertas características, ciertas habilidades, que solamente se dan el plano oral, que ellos sepan juzgar, evaluar, valorar... aspectos, contextos, situaciones, pero que... el programa no los propone y que uno eh... a partir de la práctica, del ejercicio pedagógico, de la retroalimentación que se da con otros colegas de la misma asignatura, o de otras asignaturas, uno las va desarrollando y las va aplicando, pero no son propuestas... desde... las formulaciones ministeriales. 
P11: ¿Qué habilidades o capacidades y disposiciones del pensamiento complejo y la metacognición se llegan a poner en juego en la enseñanza de la filosofía?

R: (Gritos de alumnas/os de fondo) Qué habilidades, capacidades y disposiciones (repite)

P11: mmg (asiente)

R: (Gritos de alumnas/os de fondo) cuando habla de disposiciones, ¿a qué se refiere?

P11: A ver, cuando mencionamos la disposición, tiene que ver con cómo podemos generar esa motivación en el estudiante que lo lleve a ir más allá del mero conocimiento, de esta mera recepción de una cuestión conceptual.

R: (Gritos de alumnas/os de fondo) Eh... (silencio prolongado) la enseñanza en este caso de la filosofía eh... involucra eh... como había dicho anteriormente habilidades de orden superior eh.. Inferenciales que... eh... a partir del desarrollo conceptual ¿ya? A partir del desarrollo conceptual (repite), uno... eh... va desarrollando y va eh... a través de estos conceptos, desglosando gruesas temáticas ¿ya? O diversos conceptos que tienen eh... implícito digamos en estas temáticas, y... eh... siempre son del orden, digamos de la inferencia, del análisis, eh... la conclusión, son cuestiones eh... digamos... a la base del desarrollo, o de la enseñanza de la filosofía en este caso.

(Desaparece ruido de gritos de fondo)

P12: ¿Qué estrategias y recursos didácticos favorecen el desarrollo del pensamiento complejo y la metacognición en la enseñanza de la filosofía?

$\mathrm{R}:$ emm... estrategias de enseñanza... favorecen el uso de la filosofía...

P12: Qué recursos didácticos

R: Primero, eh... de forma, digamos inicial y para poder... eh... enfrentar las diversas temáticas, la lectura digamos, de textos, eso es... una de las estrategias básicas, que tiene que ver con el... el desarrollo de las habilidades ¿ya? Que involucra la filosofía. Emm... otras de las estrategias de enseñanza que... son efectivas... el uso de eh... recursos audiovisuales eh... videos, películas, y eh... en... en el uso de... eh... tecnologías de la información y de la comunicación, contribuyen (respira fuerte) eh.. de forma satisfacsoria... satisfactoria (corrige) digo, a la enseñanza de la filosofía.

P13: ¿Y cómo todos esos recursos podrían usarse para potenciar o desarrollar este pensamiento y la metacognición?

R: Eh... dependiendo del argumento ¿cierto? De cada una... de estos videos y de estas películas, es posible hacer el contrate a través de eh... a través de la formulación de diversas preguntas que... van... que pueden ir desde lo más simple a lo más complejo ¿ya? Desde lo más simple a lo más complejo (repite) eh... contrastando la... las diversas perspectivas filosóficas, de algunos autores con las temáticas ¿cierto? Que involucran estos... estos videos por ejemplo, o estos... estos filmes.

P14: Muy bien, ¿Qué tipo de actividades o estrategias de enseñanza utiliza comúnmente usted durante el desarrollo de sus clases?

R: Eh... las estrategias... de enseñanza que utilizo yo son el uso de recursos audiovisuales, lo que a mí me ha permitido eh... o lo que... (murmura) me ha... me ha permitido desarrollar más habilidades y que los alumnos puedan de alguna manera eh... desarrollar eh.. Habilidades de orden superior que... puedan analizar, puedan contrastar eh... en su vida cotidiana la... las problemáticas que... la filosofía ¿cierto? Pone en el tapete (suspira)

P15: ¿Me puede describir profesor las formas de interacción, de cooperación y participación que suelen darse en las clases de filosofía?

R: Eh... en las clases de filosofía son... eh... son bien especiales (ríe tímidamente) ¿ya? Porque, al menos trato de... eh... poner ¿cierto? Un determinado tema, por ejemplo la ética... socrática ¿ya? Eh... frente... eh... a determinados ¿cierto? A... a determinados temas que uno expone, los alumnos... automáticamente toman una posición eh... sobre los temas ¿ya? Eso ya implica un... un... un desarrollo de... 
digamos de habilidades, ya que eh... que son de orden superior que... que no vienen eh... eh... eh... no están digamos propuestas en el programa, pero si... el... el ejercicio digamos de la disciplina lo permite $¿ y a ?$ Eh... por otro lado... eh... la... se dan discusiones, digamos de puntos de vista muy... muy eh... muy fuertes, porque... hay un cierto... también... dogmatismo en los estudiantes sobre las diversas temáticas, hace un rato explicábamos ¿cierto? El tema de la pena de muerte, por ejemplo, y... los alumnos... es... adoptan... po... posturas radicales $¿ y a$ ? O a favor, o en contra, sin embargo qué es lo que... al menos busco yo como... profesor de filosofía ¿cierto? Que ellos puedan en... entenderse digamos postura ¿ya? O desembarazarse digamos, de sus dogmatismos a través de... del contexto eh... que... que involucra eh... ese punto de vista ¿ya? Es como poner digamos en... en la mesa eh... un abanico de posibilidades, donde ellos se den cuenta digamos, y puedan reflexionar de que... o de por qué digamos es preferible adoptar una postura o... u otra ¿ya? Por qué ¿cierto? estamos de acuerdo con la pena de muerte o por qué estamos en contra $¿ y a ?$ Eh... y eso en el fondo es lo que... lo que busco digamos, en... en mis clases digamos eh... evitar como el dogmatismo ¿ya? Propiciar digamos el... el debate, pero siempre eh... argumentado, y... eh... propiciar también eh... digamos la tolerancia de las diversas posturas.

P16: ¿Qué tipo de conocimientos y problemas se platean en las actividades de la clase de filosofía?

R: Eh...en... las problemáticas son... de orden digamos ético ¿ya? Problemáticas de orden ético, que... obviamente involucran digamos, posiciones relativistas $\mathrm{mm}$... o posiciones digamos abso... absolutistas digamos sobre (murmura)... sobre temas, hace un rato mencionamos la pena de muerte eh... también eh... hay problemáticas o... que involucran digamos el... el contexto político emm... por lo general... el... al menos el programa.... El programa... que tiene nuestro país ¿cierto? eh... hace una... eso es inte... eso es lo que yo rescato eso, rescato lo... el programa que... eh... el plan desde el plano de la ética ¿cierto? de las tres unidades que aborda también vincula digamos eh... la política, el contexto político y situaciones que involucran la política ¿ya? Eh... es como medio Aristotélico lo que estoy planteando (afirma riendo) pero... pero sí, y... es curioso porque... eh... me he dado cuenta de que en... en la enseñanza digamos y en el estudio digamos del mismo programa que eh... involucra digamos, y combina digamos esas dos características, las problemáticas además de problemáticas éticas, las vuelve problemáticas del... políticas, y... involucra los contextos políticos de... de... del digamos del... donde nos estamos desarrollando en este caso... en... nuestro contexto como país.

P17: ¿Y qué ocurre al respecto con el programa de tercero medio?

R: Eh... bueno ahí hay con... hay características digamos históricas que... hay un devenir histórico que... que... que... llevaron a la configuración de ese programa, pero... eh... al menos, en el ejercicio pedagógico, en el ejercicio docente que yo... que yo llevo, que son eh... cinco años, eh... uno des... como profesor de filosofía da las bases ¿ya? históricas o del nacimiento digamos, del desarrollo de la psicología, pero... eh... no hay una concordancia entre... entre los programas... tanto de tercero medio como de... de cuarto medio. Abordan eh... problemáticas eh... que... coindicen en algu... en algunos puntos ¿ya? pero... muy específico, muy, muy específico, pero si yo quisiera poner... no hay una continuidad, lo que veo en... en... en... en... en tercero medio, solo algunas... algunas temáticas puedo ver en cuarto ¿ya? Por ejemplo, el... el... el... el desarrollo por ejemplo de... de los procesos cognitivos en tercero ¿уa? yo lo puedo retomar en, y lo puedo relacionar ¿cierto? con el planteamiento aristotélico, con el planteamiento de Platón eh... la segunda unidad, que tiene que ver con psicología social, los procesos de influencia social eh... lo puedo 
vincular ¿cierto? con eh... situaciones específicas de... de la ética, o de la... o de la cuarta unidad que tiene que ver el tema de la justicia, o con la justicia distributiva o... con el desarrollo de la técnica ¿ya? y las implicancias en la sociedad, pero... emm... si yo quisiera hablar de una continuidad de la enseñanza, de... de todo lo que enseñé ¿cierto? de todo lo que se vio en tercero medio, cuarto medio es... es imposible eh... eh... cuesta demasiado.

P18: Siguiendo este mismo orden de conocimientos y problemas que usted me acaba de mencionar, ¿me puede decir qué tipo de razonamientos, niveles de discusión, y/o reflexiones se plantean en las actividades de la clase de filosofía?

$\mathrm{R}$ : (expira fuerte) ¿A qué se refiere cuando habla de niveles discusión?

P18: la profundización que se puede generar en las problemáticas que se les platea a los estudiantes.

R: Ah... ya... a ver la... la profundización de las temáticas eh... se pueden realizar... ósea, primero obviamente hay una preparación como profesor y como de... de... de la clase, y de las temáticas que involucran, eh... sin embargo eh... esta profundi... esta profundización por ejemplo, de ahondar en temáticas, hacer contrastes con la realidad contemporánea, de la...de la... con la realidad digamos cotidiana de los alumnos, social, etcétera, eh... está muy digamos, va muy de la mano con la disposición o la clase que ellos también tengan ¿ya? con las características eh... con las características del curso, (repite) con las características del curso ¿ya? eh... y eso obedece digamos a que... al menos.. en nuestro... nuestro sistema educativo digamos eh... tiende como... a establecer diferencias digamos entre cursos digamos, o a segregar en el fo... lisa y llanamente a segregar ¿ya? Hace un rato veíamos ¿cierto? que yo desarro... eh... eh... eh... contrastábamos ¿cierto? la ética socrática y la ética aristotélica con una película ¿ya? eh... entonces estaba la disposición ¿cierto? de los alumnos, para poder enfrentar digamos, vieron la película eh... estudiaron y... eh... eso a mí me permite, digamos profundizar y poner ejemplos, explicar y.... eh... ahondar digamos, en cada una de las... de...las temáticas y de las preguntas que involucra digamos el... el análisis de esta película. Sin embargo, si yo quiero hacer eh... esto mismo con... con otro curso probablemente yo no pueda profundizar ¿ya? no pueda profundizar en estos temas, lo que me gustaría hacerlo, pero no puedo profundizar porque... eh... detrás del... del desarrollo de... cognitivo de estos alumnos hay toda una historia, entonces... eh... muchos de ellos no... no al... no alcanzan o se quedan solamente en el... en el... en el...en la etapa o el nivel del conocimiento ¿ya? en el nivel del conocimiento, entonces eh... eso de repente, a mi me impide ahondar digamos en otras... eh... eh...en el desarrollo de otras habilidades... ¿ya? eh... y... por ejemplo, el.... El establecimiento, al menos donde yo trabajo emm... tiene un alto porcentaje de alumnos en los programas de integración ¿ya? y hay que recordar ¿cierto? que hay dos niveles: el nivel transitorio, alumnos que están un tiempo y el nivel permanente, ósea que siempre van a estar, o siempre han estado durante los... todo el proceso de enseñanza... aprendizaje... casi toda su vida han estado acá, entonces... eh... hay alumnos, ese tipo de alumnos no alcanza digamos el... el... el desarrollo de otro tipo de habilidades y solamente se quedan en el ámbito del conocimiento, donde ellos pueden mencionar, señalar eh... reproducir ¿ya? pero no...no... no hay una reflexión profunda.

P19: ¿Qué uso se da al lenguaje en sus clases de filosofía? Porque una cosa es lo que establece el programa ¿ya? luego, ¿qué uso le da usted a partir de lo que el programa plantea?

R: Emm.... El... la enseñanza de la filosofía eh... involucra eh... digamos un del... del lenguaje... un lenguaje técnico podríamos decir ¿ya? es decir, eh... hay ciertos conceptos que... sirven en ese contexto y... no sirven para... para otro...para otro 
contexto, para otra... para otra situación. Por lo tanto, eh... al menos lo que yo hago eh... en la primera o las primeras clases ¿cierto? es eh... hacer un... un... (murmura) un... que los alumnos puedan profundizar digamos, en... conceptos esenciales o principales digamos de... de la temática a abordar ¿ya? Eh... y establecer... conexiones digamos entre estos... entre estos conceptos ¿ya? (repite) entre estos conceptos, eh... ese... ese... ese... ese ejercicio que... que puede parecer, que parece bien simple, por ejemplo el uso de un diccionario, que ellos vayan a... a buscar el significado de un término, que hagan un glosario, que podamos discutirlo, digamos en clases ¿ya? De que los alumnos eh... tengan eh... entiendan un concepto... de una manera, pero que en realidad significa otra y que... eh... sepan que no se puede aplicar ¿cierto? se da en las primeras clases ¿ya? y eso a mí me permite después, por ejemplo eh... ahondar más en diversas temáticas ¿ya? Eeh... y eso obviamente va... de la mano con eh... después el uso de... de... de diversas eh... o con... o con la aplicación de diversas actividades que uno va realizando. La que hicimos digamos, este... este desarrollo conceptual, esta... esta comprensión de... de ciertos conceptos y eso después, permite ir avanzando eh... en la materia digamos y en... en los contenidos que involucra... el programa ¿ya? o las unidades en este caso.

P20: Bien, profesor finalmente ¿Qué uso se da a los materiales y a los diversos recursos didácticos en sus clases de filosofía?

R: Eh...a ver teniendo en cuenta digamos lo...lo que yo mencionaba anteriormente de que... al menos el... el liceo donde yo... me desarrollo ¿cierto? presenta esta característica ¿cierto? de un alto porcentaje de alumnos... digamos con... con... en el... programa de integración y que... se ubican digamos en un rango del conocimiento eh... digamos básico, eh... inicialmente eh... los recursos didácticos que utilizo... son... eh... el uso de... de textos, el uso digamos de eh... de párrafos ¿cierto? o de... o de frases, o de extractos, fragmentos de... de textos que permiten, abordar en primera instancia ciertas temáticas ¿ya? Pero también está eh... la particularidad de que, a partir de que diversos, digamos estudios que han hecho, las mismas profesoras de integración eh... el... de los mil quinientos alumnos del... de este liceo eh... la... gran cantidad, gran porcentaje son eh... alumnos que... de tipo visuales y auditivos ¿ya? y son de tipo auditivos, por eso las salas digamos están implementadas con... eh... un equipo de data de... ultrasonido y... con un computador, porque el alumno eh... son de tipo visuales, por lo tanto... o... y también digamos de por sí, me gusta digamos utilizar eh... o... o ver películas a mí... y es como Hobbie, y encuentro también eh... está la particularidad y la... y la coincidencia de que los alumnos sean visuales y... ver videos, analizarlos, discutirlos... en clases o ver una película eh... sea de gran ayuda para poder ahondar digamos en... en la... en las temáticas de... que involucra la filosofía.

Cierre: Muy bien, muchas gracias profesor. 


\section{ANEXO 7. ENTREVISTA A CLAUDIO}

P1: ¿Cuál es el propósito fundamental de la enseñanza de la filosofía en la educación media chilena?

R: Yo siempre he pensado de que... eh... el sello que... que tiene la disciplina eh... tiene que ver con aquellas... competencias que guardan relación a la formación que se podría decir integral de una persona, es decir eh... creo que la enseñanza de la filosofía, aunque parezca... un poco vago la expresión, pero... es aquella que me lo permite enseñar para la vida (suspira) en ese sentido eh... uno busca, a partir de los contenidos hacer la vinculación entre la disciplina, sus contenidos, con... la vida y las experiencias de los estudiantes.

P2: ¿Cómo definiría usted profesor esa formación integral?

R: Uno recoge distintos... bueno, eh... distintos ámbitos de... el... la persona, ósea por ejemplo... en el ámbito intelectual, en el emocional eh... el disciplinar, o que podríamos de... denominar también moral eh... (suspira) yo creo que... tanto el programa como psico... de psicología como de filosofía me permiten trabajar esos distintos aspectos del ser humano, además también las unidades que uno eh... lleva a cabo eh... no son difíciles, por el contrario, que... me permita un... nos permita a uno vincularnos con la vida eh... de cada uno de ellos. Por ejemplo eh... (suspira) en la cuarta unidad de psicología que yo estoy por ver, por ejemplo, es... bienestar psicológico, y al trabajar con alumnos de... dieciséis, diecisiete años eh... es... sin duda uno se encuentra con experiencias eh... que... uno puede confrontar eh... con los contenidos que uno trabaja, por ejemplo conceptos como: el de salud mental, el de resiliencia. A mí por ejemplo me ha tocado eh... trabajar eh... muchos de ellos ya de manera anticipada, por el tema de mi jefatura eh... me ha tocado por ejemplo tener alumnos que presentan situaciones de trastornos de alimentación, por ejemplo, o de salud. Uno se encuentra eh... con ese tipo de situaciones en el colegio, y uno también, desde la disciplina, y desde el programa, también poder ayudarlos a ellos ¿ah? De alguna manera por ejemplo, que reconozcan su situación eh... lo que les está pasando; en esa unidad por ejemplo se trabaja el proyecto de vida (suspira) Eeh... la unidad que la antecede "individuo y sexualidad", en esa unidad eh... sin duda uno o los matices que uno debiese trabajar, entre otros, son las emociones, el aspecto valórico. Entonces, eh... uno va prepa... (corrige) los prepara por decirlo de alguna manera em... no sé como decía yo... para la vida $\mathrm{mm}$... el otro día escuchaba una entrevista de que... me imagino que en parte se refería a la enseñanza superior, pero también creo que vale para... para la escuela, de que... eh... Maturana decía, porque ahí creo que también estuvo Maturana, em... por aquí cerca... decía de que... eh... uno debiese educar eh... no tan solo eh... para que las personas eh... lleguen a ser profesionales, sino también ciudadanos (suspira) y... no tan solo uno podría decir... ciudadano en el sentido de... concebirlos como un mero individuo, que uno es parte de una sociedad, sino que eh... son una parte integral de ella, eh... que los intereses o las finalidades que se busquen, tanto eh... la sociedad en su conjunto también eh... guarden relación con las que son... propias de cada persona. Entonces uno puede hacer esa vinculación, entre la disciplina, sus contenidos digamos, y... en este caso eh... hacer la rela... bueno, la relacionarlos con la vida... las experiencias de cada uno de ellos.

P3: Perfecto, ¿cómo se concibe la enseñanza de la filosofía en los programas de estudio?

R: (suspira) De una manera... bien restringida, eh... una parte en... bueno, esta remitida por ejemplo, si hablamos de filosofía tan solo a cuarto medio... eh... en... en este año propiamente se trabaja la disciplina y... eh... está dividida en cuatro unidades. La primera de ellas eh... que es la que yo por lo menos le doy más tiempo, porque es una 
introducción a la filosofía (suspira) eh... que debería ser la que uno trabajara con más ahincó porque... las siguientes tres unidades, se remiten al... problema moral, al fundamento de la moral y después a una unidad de ética. Pero hay cosas por ejemplo que eh... tiene que ver propiamente con disciplinas de la filosofia que no se trabajan, como la estética, no sé... eh... entre otras. Entonces, eh... (tartamudea) eh...et...et... está como bastante reducido lo que uno ve o puede ver, por ejemplo... no sé... la primera unidad eh... "la filosofía y el sentido de la vida" o el sentido de la vida humana, emm... luego por ejemplo, preguntas... qué se yo, filosóficas... hacer la distinción con otro tipo de preguntas... yo a veces le he dado el matiz de... una suerte como de historia de la filosofía... tratando de... sin duda también, respetar las exigencias del programa, tal vez eh... trabajándolo a la par, no sé si me entiende, por ejemplo... en la primera unidad empiezo... no sé... hago la aclaración de cómo se puede concebir eso de filosofía, cómo abordar esa problemática, eh... planteo algunos problemas, por ejemplo, no sé... desde el comienzo de la filosofía... al... eh.... Esta superación del mito al logos ¿cierto? Esa típica como introducción que uno hace, pero... eh... también qué sé yo... ya comenzando con esta historia, los presocráticos, el problema de la physis, después pasar propiamente... a... este periodo de... la ilustración griega, a Sócrates, Platón, Aristóteles... ahí por ejemplo, ya puedo abordarlos desde otro ámbito, por ejemplo el humano, y abordar lo que me piden los planes y programas que es el... en este caso, los problemas y fundamentos de la moral, para cerrar... con ética, y en ética por ejemplo la última unidad, dentro de la... eh... contenidos que se abordan ahí, es la ética contemporánea, entonces también uno puede abordar ciertos autores o ciertas temáticas. Pero... la filosofía eh... lo que uno... el tiempo que dispone eh... es bastante reducido, no es mucho lo que uno... eh... uno podría entregar mucho más. Yo creo que... en el colegio... uno se puede crear las instancias, por ejemplo, recién hacía mención, antes de que comenzáramos la entrevista, de los talleres extraescolares, perfectamente uno podría hacer un taller eh... no sé, de estética, de una u otra disciplina no sé... de lógica, y tal vez... hacer un trabajo con ellos.

P4: Por supuesto, pero los planes y programas de tercer año y de cuarto año, ¿hacia dónde direccionan la enseñanza de la disciplina?

R: (suspira) Eh... bueno, hay objetivos que la mueven ¿no? Uno de ellos son los objetivos eh... transversales, que sin duda tienen que... no sé, creo que... у... o intentan emm... entregar... una formación que uno siempre dice... o tal vez utilizo mucho el término, pero trata de ser este sello, de que sea una formación más integral... el... el autoconocimiento ¿cierto? el... la relación que uno tiene con el entorno, el aspecto ético, pero... eh... creo que los planes y programas así como están eh... desarrollados eh... tienen bastantes deficiencias, porque... hay aspectos que podría entregar la filosofía a esa formación que están quedando fuera, emm... ahí creo que hay mucho de... ética y moral, y una simple introducción... y eso es lo que está entregando los planes y programas el día de hoy.

P5: Perfecto, ¿Qué y cómo se enseña filosofía en la educación media chilena?

R: (suspira) Eh... a ver, una cosa es lo que nos dictan los programas, los contenidos propiamente, como ya señalaba eh... en el caso de cuarto medio eh... la asignatura está divida en cuatro...eh... unidades. Eh... una primera unidad, una introducción a la filosofía, luego viene eh... eh... bueno, no recuerdo muy bien el orden, si es fundamentos de la moral, problemas de la moral, una... otra unidad y... ética contemporánea. Ahora el... la manera en cómo se lleven a cabo, sin duda depende el profesor... ah él... incluso la imagen que él se haya formado acerca de la filosofía, el cómo uno la viva, eh... lo que quiera resaltar. Yo siempre he pensado que uno... como profesor eh... las herramientas que a veces maneja son las ideas, y muchas veces son 
esas ideas que en algunas circunstancias vitales le puedan servir a los alumnos, por ejemplo esa frase de Ortega "Yo soy yo, y mis circunstancias, si no las salvo a ellas no me salvo yo" mmg... alguna vez yo...habré... utilizado esa idea para mí, no sé yo también hace años que se las intento traspasar, o vivir es convivir, no sé... o sobre todo en... ya viendo... emm... las unidades de ética y moral, bueno recalcar la libertad del ser humano ¿no? El que ellos son eh... seres libre ¿no? En el sentido de... elegir, de que no hay nada que justifique sus elecciones, pero que tienen que hacerse cargo de las circu... (corrige) las consecuencias que traigan consigo, y eso también eh... hace que... o uno intenta que ellos también... tomen en cuenta el que tienen que ir haciendo su vida, y el que tienen que... ser responsables, con ese proyecto que tienen por delante. Ósea uno trata de abrirles eh... no sé, a partir de ciertas ideas, ciertas visiones del ser humano, pero sin duda va... depender mucho del profesor, y cómo vea el profesor el programa, y cómo vea la disciplina.

P6: ¿Qué aporta la enseñanza de la filosofía al desarrollo del pensamiento de los estudiantes?

R: (suspira) Bueno, emm... los abre.... A... nuevas ideas, nuestra mane... (corrige) nuevas maneras, por ejemplo, de ellos verse a sí mismos, eh... yo creo que eso es una reflexión, que no tanto solo es... hacia las cosas o hacia... proyectarlo como hacia afuera, sino también... eh... está relacionado sin duda con la vida de cada uno de ellos. Emm... no sé, yo siempre he concebido la filosofía como decía Hegel "pensar la vida, he ahí la gran tarea de la filosofía". Así que de alguna manera yo siempre trato de... contrastar lo que son los contenidos con... la vida de cada uno de ellos, por ejemplo, uno les puede plantear en cuanto a las decisiones que ellos tienen que tomar en su vida, que van a tener repercusiones, por ejemplo, cómo quieren vivir eh... no sé pu, sus últimos años de vida, en su vejez, ¿quieren estar solos o acompañados? Si quieren estar acompañados, y tener tras de sí una familia, bueno en su momento deben tomar ciertas decisiones para ir en... en esa... en esa vía por decirlo así. Pero también con otro ámbito de cosas ¿mmg?

P7: ¿Cuáles son los problemas y las reflexiones que se ponen en juego en los programas de estudio a partir de todas estas temáticas que usted me ha relatado?

R: (suspira) Es que... los problemas son de distinta índole, dependiendo del programa, si se trata de... psicología o filosofía. En el caso de... filosofí... (corrige) psicología en tercero medio, uno se encuentra con problemas... eh... ¿cómo llamarlos? Quizá mm... de índole personal de ellos, em... problemas que pueden guardar relación con respecto a su salud. Eh... en cambio en cuarto medio de filosofia, los problemas que... eh...por los contenidos que uno aborda... eh... sin duda, entre ellos son los de índole moral, los dilemas morales... eh... el desarrollo del... sujeto como sujeto moral, eh... pero insisto depende mucho, emm... parte de los problemas se presentan de acuerdo a lo que uno vea ¿mmg? Entonces en ese sentido eh... son distintos, además también hay que considerarlos también a ellos, de un año a otro también, cambian mucho. Eh... un muchacho de tercero medio eh... n...s... no sé... tienen ciertas características, peculiaridades, pero ya por ejemplo un año más de vida eh... a veces... hay mucha diferencia entre un año y otro, se nota mucho ¿mmg? Tal vez por lo...bueno, por lo que les toque vivir, qué se yo... pero se nota... que, de un año a otro también hay un grado de madurez también. Por algo también hay que pensar... bueno, yo no sé si será pensado o reflexionado, pero... uno podría preguntarse, "bueno y ¿por qué filosofía en cuarto medio?". Uno podría pensar de que... bueno porque ha... tenido... también tuvo una preparación para encontrarse con una... asignatura como esta y plantear esos problemas... que uno ve ahí.

P8: Y respecto al uso del lenguaje que se pone en juego en los planes y programas.

$\mathrm{R}$ : ¿Cómo así con el lenguaje? 
P8: El uso del lenguaje: oral o escrito, ¿dónde está el énfasis que ponen los programas en el uso de éste?

R: Eeh... a ver, yo creo que eh... así como están diseñados...por ejemplo, en los planes y programas, así como eh... aparece eh... una de las maneras sin duda, es la escrita eh... incluso el texto que... uno a veces dispone, y que uno a veces lo puede descargar de la red, bueno... gran parte de las actividades tiene que ver con eh... comprensiones de lectura, trabajar textos, entre otros, no son las únicas. Eh... hay ensayos, hay pruebas eh... entonces, en ese sentido el lenguaje, bueno puede ser oral o escrito, emm...

P9: ¿Qué tipo de prácticas o de actividades de enseñanza y de evaluación, se programan para el desarrollo del pensamiento y la metacognición en los programas?

R: (ruido de silla) ¿En los programas? Eh... yo... he percibido... de que eh... de alguna manera, cada unidad hay sugerencias para evaluar, por ejemplo eh... en ciertas unidades de los pra... (corrige) de los programas por ejemplo, se nos sugiere por ejemplo no hacer pruebas escritas, pudiendo no hacerlas... pero, eh... me da la impresión que también eso quiere eh... darle un sello tal vez, o una cierta orientación, por ejemplo no sé, individuo y sexualidad ¿mmg? Evitar tal vez... la prueba, no sé sea una prueba mixta $u$ otra. Yo por ejemplo, lo que utilizo... bueno, he... he abusado de ese... el recurso del los textos, pero eh... juego también con ello, por ejemplo no siempre hago el mismo tipo de pruebas, hay veces por ejemplo que les hago una prueba situacional, y al final de esa prueba por ejemplo, los mandatos ¿mmg? No necesariamente tiene que ser una prueba mixta o de desarrollo, entonces eh... yo creo que eh... en parte también eh... si bien no se hacen estas sugerencias, dependiendo de la unidad, bueno no deja de ser la decisión de cada profesor el cómo los va evaluar, yo creo que también hay que tener en consideración... a los estudiantes, quienes tenemos en frente ¿mmg?

P10: ¿Qué es para usted el pensamiento complejo y la metacognición en filosofía? No es una pregunta técnica, quiero conocer su concepción al respecto.

$\mathrm{R}$ : el pensamiento complejo... emm... (suspira) Tengo la impresión y me arriesgo de equivocarme eh... el pensamiento complejo eh... aborda... eh... o podemos encontrar en él eh... un compendio, un conjunto de elementos digamos eh... que nos permiten en él obtener un grado, tal vez de eh... no sé si llamarlo madurez o desarrollo, eh... es como... a ver si me explico con un ejemplo. Uno, en distintas asignaturas por ejemplo trabaja eh... desde las mismas temáticas, pero no es lo mismo por ejemplo, ver por ejemplo la sexualidad, en la asignatura de biología, que por ejemplo verla desde una perspectiva psicológica en... psicología. Y... eh... sin duda, eh... cuando uno quiere abordarla, uno no tan solo... creo que lo hace desde esa disciplina, puntualmente de la psicología, sino también quiere darle una visión... más acabada, más general, tratando de abordar todos los elementos ¿ah? Eh... y... en el caso de la metacognición... eh... bueno, en el caso de las clases eh... yo lo que hago es como una especie a ratos de... bueno, la clase en parte... no todas son las mismas o el mismo... en el que yo las ejecuto, y... en parte también, por el tema de los tiempos, porque a veces las actividades requieren más tiempo que otras, eh... yo por lo general siempre trato de... a un comienzo... hacer un repaso, por lo menos contextualizarlos en el... contextualizarlos en el lugar en el que estábamos ¿cierto? Recordar algunas ideas, eh... no necesariamente siempre tiene que ser esto, con preguntas dirigidas, pero siempre eh... tratar de eh... recordarles digamos lo que hemos estado viendo, luego propiamente el desarrollo de la clase, y... eh... luego una actividad, la actividad que... que se haya elegido para esa clase, y luego sin duda, eh... en el momento de cierre, que me parece uno de los momentos más importantes, eh... el momento en el cual eh... volvemos a esas ideas o al objetivo de la clase que quisimos desarrollar, 
y... eh....sin duda ver... en otra... en... no sé, lo que... ellos aprendieron, eh... lo que ellos... eh... sacan como lección ¿mmg? Porque... como decía, va depender también mucho de la unidad, pero hay muchas cosas que uno lo contrasta con la vida de ellos. Entonces, en la medida en que uno trabaja un objetivo, sin duda creo que de una u otra manera quiere orientarlo hacia la vida personal de cada uno de ellos. Y en ese momento, en el cierre de la clase, cuando ellos pueden propiamente eh... no sé, terminar de incluso aclarar dudas o... lisa y llanamente que ellos presenten digamos, lo que aprendieron, como objetivo de esa clase ¿mmg?

P11: Perfecto, ¿Qué habilidades y/o capacidades del pensamiento complejo y la metacognición, pone en juego la enseñanza de la filosofía?

R: Haa... (suspira) Eh... yo no sé si... hay... clasificaciones con respecto a estas, por ejemplo, que de acuerdo a algunos autores, me digan estas son las habilidades o estas son las capacidades, porque creo que pudiesen haber diferencias entre autores, pero... sin duda, la filosofía sea cual sea la visión, yo creo que las incorpora todas. Si porque... eh... bueno, también... insisto en mucho... en los contenidos, pero independiente de cuáles sean...

P12: Si... ¿y cuáles serían las más importantes, las más relevantes para el proceso?

R: ¡ahh! (exhala fuerte) Habilidades... a ver, yo por ejemplo, hay algunas habilidades que yo he tratado de... eh... de ejercitar mucho con ellos, que tiene que ver por ejemplo con la comprensión lectora, porque trato de... a ratos trabajar mucho con textos, porque eh... trato de que mejoren su vocabulario... eh... de que... el ejercicio del leer también les permita incorporar nuevas ideas, pero también... hay otras habilidades que tienen que ver, por ejemplo, con... la... expresión, con la... con las habilidades relacionadas con las exposiciones orales por decirlo así. Entonces eh... teniendo por lo menos estas dos en cuenta, emm... uno trata de... de que ellos la ejerciten clase a clase. (Suspira) Eh... a veces cuesta, porque... no todos los estudiantes están dispuestos o prestos a... por ejemplo, no todos tienen una buena disposición a... enfrentarse por ejemplo en una sala de clases a sus compañeros. O, por ejemplo, frente a un texto... hay quienes ya por el solo hecho de tener un texto en frente de ellos eh... no tienen la mejor disposición al trabajo, porque... no sé, tal vez... a veces se han habituado a... actividades que sean más dinámicas, pero... por lo menos, en cuanto a la expresión escrita como a la oral, y las... habilidades o capacidades que guarden relaciones con ellas son eh... ten... tienen que estar a la base, son necesarias incluso a la altura de tercero y cuarto medio, muchas de ellas ya deberían estar desarrolladas, pero uno se encuentra, por ejemplo, en tercero medio de que eh...hay algunos que... no saben por ejemplo escribir un texto, eh... desconocen la formalidad que se requiere, no saben por ejemplo, hacer una cita. Y... en cuanto al hecho de... expresarse oralmente, no todos lo hacen muy bien, por el contrario, eh... les cuesta, no están habituados a hacerlo. Ahora... si bien, vivimos en una época que al parecer, uno podría pensar... eh... a partir de la tecnología eh... las comunicaciones se han masificado, son mucho mejor, qué se yo... pero... en el trato personal eh... por el contrario, las personas tienden a cerrarse en su mundo, en el celular, qué se yo... entonces, les cuesta sobre todo, enfrentarse al resto de sus compañeros, de sus pares ¿mmg?

P13: ¿Qué actividades y recursos didácticos, favorecen el desarrollo del pensamiento complejo y la metacognición en la enseñanza de la filosofía?

R: Eeh... (Exhala fuerte) Yo creo que... eh... una buena... eh... (ruido de silla) buenas actividades creo que son aquellas que eh... (ruido de silla) me permiten o... o nos permiten eh... al profesor, junto con los alumnos eh... evidenciar un proceso. Todas las actividades, por ejemplo, que uno las evalué como una evaluación de proceso, creo que ayuda mucho, porque... eh... sucede de que... eh... por ejemplo en una prueba, 
eh... está mucho esto de la calificación, del querer conquistar una nota, y que... muchas veces, eso los lleva a los alumnos a memorizar los contenidos, y no se preparan para... un determinado momento de la prueba, y luego bueno, perfectamente los olvidan. En cambio, cuando uno... establece actividades que eh... dan cuenta de todo un proceso, yo creo que... se le fija aún más, sean los contenidos o sea el desarrollo de una determinada habilidad, sea escrita, oral, etcétera.

P14: ¿Qué tipo de actividades y/o estrategias de enseñanza utiliza durante el desarrollo de sus clases?

R: Eh... he utilizado distintas actividades. Desde... eh... no sé (suspira) eh... (exhala fuerte) trabajar por ejemplo con ellos las emociones, eh... a ver, con respecto a las emociones eh... me ha pasado, bueno... este es un caso particular, por ejemplo, en su momento tomé la decisión de que... como tenía que... en la unidad, en la primera unidad de psicología, al ver los procesos psicológicos afectivos, el hecho de tener que... ver con ellos las emociones eh... trabajé también la escritura. Y... yo creo que están, a veces, uno podría pensar lo contrario, porque se mandan mucho estos... mensajes qué se yo... pero... expresar un afecto o una emoción, es de manera escrita, y quise también, junto con eso que aprendieran a escribir una carta, y el llenado del sobre, y ese tipo de cosas. Pero... luego de ello, por ejemplo, al leer sus cartas que les dirigieron a alguna persona, queriendo... por escrito expresar qué se yo, un afecto, una alegría, tristeza, rabia eh... con el mundo, no sé... una especie como de desahogo con una parte de ellos. Por ejemplo incluso, me tocó la experiencia de... eh... aconsejar a alumnos (ruido de silla), en el sentido de que luego ellos se acercaron a mí, me preguntaron “¿profesor leyó mi carta? Sabe que... no sé... eh... no estoy bien, eh... por ejemplo, he tenido ideas acerca de suicidio, ¿eso es normal?" Eh... los estudiantes emm... creo que las clases, ósea las actividades que uno debiese también eh... realizar, sin duda tienen que guardar relación con la necesidad de los estudiantes, y si uno por ejemplo observa que esas necesidades, por ejemplo, pueden ser de carácter afectivo, bueno uno dice ahí... tengo que trabajar de alguna manera de las emociones, uno en el colegio no está solo. Sin duda hay un equipo de convivencia, están los psicólogos, y sin duda... que en determinadas situaciones, uno también tiene el apoyo de ellos. También se hacen visitas... al aula, de repente qué se yo... de universidades qué se yo... que trabajan ciertas temáticas. Entonces, las actividades que uno a veces decide eh... a veces pueden guardar relación, sin duda con los contenidos, pero también emm... con las situaciones que también van emergiendo, porque yo tampoco puedo como profesor eh... hacer vista gorda digamos... de lo que a mí me están entregando, por ejemplo las evaluaciones que yo hago, lo que yo voy observando de las clases. Eeh... no sé, como decía he tratado de eh... a partir de esta... este perfil de profesor, tal vez un poco cercano, tal vez eh... desarrollado los afectos con ellos también, me han permitido desarrollar otro tipo de actividades ¿mmg? Emm... he... utilizado desde no sé... enseñarles ejercicios de respiración, también... siempre preparando también los contenidos que viven más adelante, por ejemplo si sé que en... la última unidad de psicología vemos bienestar psicológico, ellos ya tienen una herramienta, por ejemplo, frente a algún tipo de situación, por ejemplo qué podría ser un trastorno, entonces también eh... las actividades tienen ese matiz (ruido de silla) muchas veces de algo práctico ¿mmg? Yo creo que... eh... no sé, voy... eh... a la medida en que voy avanzando, también voy ideando y voy decidiendo que actividades eh... trabajo con ellos.

P15: Perfecto, una clase se comprende ¿cierto? como diferentes momentos de interacción, ¿cuáles son estas formas de interacción, de cooperación y/o de participación que se dan en las clases de filosofia? 
R: (Suspira) Bueno, uno... yo trato... yo creo que hay momentos ¿cierto? Bueno, la clase tiene momentos, pero dentro de esos momentos también, hay momentos... hay momentos en que... lo que sin duda, uno sin duda busca muchas veces es establecer un diálogo con ellos, sobre todo bueno... hacerles ver cierto tipo de cuestiones, por ejemplo, que eh... los invu... involucra digamos sus experiencias, sus vivencias eh... y en ese sentido espero que por su parte, ellos también eh... me permitan a mí dialogar con ellos $i$ ah? Pero... puede ser desde el comienzo de la clase, puede hacer... puede haber surgido por ejemplo, del... momento de haber estado preparando una clase, eh... me surgió algo que decirles, algo que... eh... me parece que es importante que ellos reflexionen y yo perfectamente la clase... puedo comenzar el inicio con... haciendo una reflexión. Por ejemplo un día eh... no sé porque terminé viendo a un jugador de cartas, hay un argentino... emm... Lavand creo que es el apellido, que tiene la característica que tiene una mano, y... él en su momento dijo algo que me hizo sentido, decía eh... "uno dentro de las primeras cosas que aprende en la vida, es a levantarse a ponerse de pie", entonces yo una de las clases por ejemplo, comencé una reflexión con eso. Pero lo hice metafóricamente en el sentido de la vida, porque... veo que muchos de los estudiantes, por las experiencias también que pasan, tienen poca tolerancia, a la frustración... eh... al fracaso. Entonces... insistir una y otra vez, en... en reforzar, por ejemplo, la resiliencia, y eso por ejemplo, lo puedo hacer en el comienzo de la clase, al final de la clase o al desarrollo de la clase, o al final de la clase, como una reflexión general. Entonces eh... va depender mucho cómo uno haya planificado la clase, lo que uno vaya a hacer y los contenidos, y lo que uno vaya a trabajar en ellos.

P16: Ya... y dependiendo de esos contenidos, por ejemplo, de esa forma de organización, si tuviese que describir las formas de interacción, de participación típicas que dan, ¿cómo las describiría?

R: Yo... a veces... los... increpo a ellos, mm... soy mucho por ejemplo de... eh... exhortarlos a que... que me respondan y si a veces eh... porque les preguntó, y les cuestiono cosas que de repente a ellos no les puede gustar mucho, los puede incomodar eh... incluso a veces lo puedo hacer de manera personal, a qué me refiero, por ejemplo cuando hago una pregunta dirigida, es que... si le pregunto a uno, el resto va estar pendiente, y... en ese... en el relato que me dé, por ejemplo el alumno el resto de sus compañeros pueden también observar de que lo que le pasa a su compañero, eso es lo que también pueden ellos estar viviendo, entonces también trabajo, por decirlo así, las intersubjetividades que me parece que le llaman. Entonces... eh... va depender muchas veces o del contenido, o no sé... lo que estemos planteando en la clase.

P17: Perfecto, ¿Qué tipo de problemas, razonamientos y reflexiones se plantean en las actividades de su clases?

R: (suspira) Va depender de la unidad, del contenido, sin duda... eh... (silencio prolongado) A ver, en el caso de psicología eh... desde un comienzo de cómo entender la disciplina eh... a por ejemplo, al hacer la reflexión de que... eh... el ser humano es un... es un ser por decirlo así, que depende de los otro ¿mmg? Que para que los seres humanos podamos desarrollar nuestras capacidades eh... para que nos podamos desarrollar tanto material como espiritualmente, requerimos por ejemplo de la participación del otro ¿ah? De que somos seres sociales, a... no sé, temas por ejemplo que podrían ser eh... cercano a cada uno de ellos por ejemplo... eh... en... en la unidad de individuo y sexualidad eh... yo de alguna manera me he ido preparando para ella, porque tengo situaciones, por ejemplo yo tengo alumnos que son papás, entonces... eh... ahí uno se encuentra con los dilemas como... "¿hago participe a este alumno, por ejemplo, con respecto a su vivencia?" Porque uno podría pensar, a buenas y a primeras, 
"bueno... eh... uno de sus compañeros, de sus pares, ha tenido la experiencia, le ha tocado ser padre a temprana edad eh... tal vez sea beneficioso el que comparta su experiencia". Pero, yo creo que es se... se revisa cada a caso. Pero... hay otras unidades y no sé... eh... bienestar psicológico, la última unidad en psicología, no sé... yo tengo que... afrontarla, ósea ir viendo por ejemplo que tengo ahí alumnos que tienen trastornos. Por ejemplo tengo alumnos que tienen crisis de pánico, tengo alumnos por ejemplo que... emm... incluso una alumna por ejemplo, tiempo atrás, no hace mucho me decía que tenía bulimia, otra que tenía anorexia. Entonces eh... eso yo lo sé porque... en mis entrevistas como profesor jefe, bueno me toca eh... a veces abordarlo y trabajar, ósea no trabajar, sino eh... hablar acerca de ello y de lo que les pasa. Pero... yo no puedo desconsiderar, no puedo no considerar esa información al momento de afrontar el curso, porque si bien la clase de prepara para todos, pero hay situaciones puntuales... o que me pudiesen ayudar tal vez a enriquecer lo que yo... quiero que ellos aprendan, o perfectamente tengo que guardar cuidado. Por ejemplo, tuve una alumna... en mi jefatura, desapareció dos días... eh... no estoy al tanto de lo que le sucedió, pero estuvo con un hombre mayor, anduvieron por Santiago y lo demás queda digamos, dentro de una investigación de la PDI ¿ya? Pero obviamente, yo al momento de hablarles de sexualidad, eh... no puedo desconocer eso ¿ah? Porque hay veces que dicen, a buenas y a primeras, "Bueno, tienes que decirles las cosas tal cuales son, qué se yo... no sé" De repente, los adolescentes de hoy se pueden ver em... como... más informados ¿cierto? de ciertas temáticas, pero... uno no puede generalizar... nada. Hay alumnos que tienen eh... no sé, que les cuesta más ¿cierto? hay alumnas que están... no sé... en PIE qué se yo, no sé... entonces, eh... uno tiene que considerar varias cosas al momento de elaborar una clase, las actividades que uno va abordar, el cómo va abordar los contenidos. Sin duda, eh... creo que la sorpresa ayuda mucho, porque... en la medida en que uno eh... logre por ejemplo, obtener la atención de los estudiantes, ya es un... gran terreno avanzado ¿ah? Porque hay que... hay que preparar el terreno para poder abordar ciertas temáticas. Si yo llego a una sala y están desordenados, qué se yo... no sé... tengo que bajar los ánimos, tengo que... eh... propiciar un... un ambiente para poder desarrollar esa clase que tengo pensada. Y bueno, cada... cada día, cada curso también eh... bueno, es una experiencia distinta (ruido de silla).

P18: Muy bien, todo el relato que usted me hace profesor a partir de las respuestas a estas preguntas, a esta conversación, también cuenta con algunos recursos, $\mathrm{y}$ en función a eso, quiero preguntarle ¿qué uso se da a los materiales y los recursos didácticos en las clases de filosofía como recursos mediadores de estos procesos?

$\mathrm{R}:$ ¿Me podría repetir?

P18: Si... ¿Qué uso se da a los materiales y los recursos didácticos en las clases?

R: Emm... A ver, eh... yo utilizo, a veces eh... mucho textos, pero tampoco... les hago leer mucho, en el sentido de que a veces prefiero que lean, por ejemplo un párrafo, $y$ trabajar por ejemplo cierto tipo de preguntas. Eh... hay recursos que uno dispone, por ejemplo, en el colegio yo siempre dispongo, bueno dependiendo de la sala, pero en general en las salas uno dispone de un computador y un data. Entonces uno puede utilizar eh... muchos recursos que son audiovisuales, por ejemplo videos, entrevistas, eh... de alguna manera, yo no hago abuso de ello, pero también... las utilizo y trato de escogerlo, de la mejor manera posible, porque... si bien, uno tiene que trabajar ciertos contenidos, pero también... es una riqueza que uno cuenta, por ejemplo no todos los estudiantes eh... conocen por ejemplo determinadas pinturas. Entonces por ejemplo, en la medida en que les pueda proyectar una pintura eh... hablarles de ella, también es algo que eh... les suma digamos a su acervo cultural, entonces emm...bueno, yo hago harto uso del aspecto visual, pero... sobre todo en 
determinados eh... contextos y bajo también, considerando los contenidos que voy a abordar eh... porque tampoco se trata de que todas las clases uno llegue con una presentación o con un video, y uno empiece a pasar la materia así... no. Pero, por ejemplo, pienso yo la unidad en términos generales, y... para ella, preparo por ejemplo distintos tipos de actividades, no sé... puedo preparar... por ejemplo, en todos los meses les he hecho una comprensión de lectura, pero también por ejemplo les he adjuntado algún video, algún documental eh... tengo como le decía eh... le... les hice un grupo cerrado en facebook... en facebook donde les subo el material, entonces eh... ellos disponen de distintas maneras eh... para acceder a él, y volver tal vez a repetir algunas cosas que hayamos visto en la clase, porque no necesariamente hay que pensar que... a buenas y a primeras, ellos van a... aprender, no porque... a veces nos cuesta y hay que... repetir, repetir, repetir... aunque, no es lo uno busca, pero... eh... hay ciertas cosas que ellos tienen que eh... o que requieren de parte de ellos cierto esfuerzo para alcanzar.

P19: Muy bien, y ¿respecto al uso del lenguaje en las clases de filosofia?

R: Eh... bueno yo soy... me expreso bastante formal eh... siempre trato de hablar correctamente y a ellos también los corrijo, yo creo que de las cosas que más les corrijo, son sus expresiones. Y les... eh... traigo vocabulario, a ellos les pido por ejemplo que... en sus cuadernos ellos vayan desarrollando un vocabulario, a veces cuando... trabajo un texto con ellos siempre les digo eh... tiene que estar con un diccionario al lado, tomando apuntes, cada vez que no conozcan una palabra búsquenla... entonces eh... se mueve dentro de una cierta formalidad ¿mmg? Aunque también eh... no hay que desmerecer el hecho de que a veces el... el cómo están compuestos los grupos, los cursos eh... también, no sé... tengo cursos que... tengo alumnos extranjeros que también tienen, por ejemplo, expresiones que son propias de ellos. Y también en ese sentido, a veces trata uno de utilizarlas también, para que entre ellos se relacionen, para que también vayan conociendo $\mathrm{mm}$... eh... no sé, la cultura de ellos, de dónde provienen, no sé... y el lenguaje da mucho cuenta de ello ¿mmg? Expresiones a veces que son propias de uno, y uno no entiende ¿mmg?

Cierre: Muy bien profesor, esas eran las preguntas, agradezco su participación. 


\section{ANEXO 8. ENTREVISTA A MARCELA}

P1: ¿Cómo se concibe la enseñanza de la filosofía en los planes de estudio de la asignatura? R: Eeh... bueno, eh... la filosofía hay que entender primero que nosotros tenemos.... (Corrige) hacemos psicología y filosofía como asignatura. En tercero medio, está centrado básicamente en... procesos psicológicos, procesos psicosociales, individuo y sexualidad, y emm... normalidad y salud mental digamos. Por lo tanto, no se.... n... eh...., en términos estrictos, no se hace psicología en tercero medio, sino que... solo se eh... elementos y nociones de... psicología. Y en cuarto eh... hay una.... En cuarto medio lo que hay es un énfasis en.... La introducción a la filosofía, desde los clásicos, trabajando fundamentalmente eh.... lo anti... Los antiguos griegos eh.... Platón y Aristóteles, un poco de historia de la filosofía, y luego u... el programa se centra en.... Lo que es em... los conceptos de ética y moral, y... ética social, muy al final del programa.

P2: Muy bien, ¿y cuál es el propósito fundamental de la enseñanza de la filosofía en la educación media, a partir de la concepción que establecen los programas?

R: Bueno, lo que.... Lo que fundamentalmente dicen los programas, aparte de dotar de conocimiento específicos sobre la disciplina, lo que trata de hacer es de... de básicamente desarrollar pensamiento crítico, eh... y que los alumnos utilicen las habilidades cognitivas superiores.

P3: ¿Cómo se enseña filosofía de acuerdo a lo que establece esta programación en la educación media chilena?

R: Bueno, lo que... hay yo creo que una dicotomía importante entre lo que se hace y lo que se declara, porque fundamentalmente el programa está pensado para una clase expositiva, con... algunos trabajos grupales y básicamente eh... centrado en el análisis de textos. Si eh... autores eh... antiguos, eh... y modernos básicamente, muy poco eh.... hay... hay una falencia por ejemplo en autores contemporáneos, eh.... el esencialismo, Sartre, parece que es lo más eh... eh... contemporáneo que hay y un par de artículos que vienen sugeridos que.... Que uno es de Humberto Giannini y el otro de Carla Cordua, que también.... Estamos hablando del año noventa más o menos noventa y cinco (ruido de voces, gente entra en la sala), como últimos textos.

P4: Bien, y en todo esto ¿qué aporta la enseñanza de la filosofía al desarrollo del pensamiento de los estudiantes?

R: Fundamentalmente yo creo que, a ver, lo que nosotros vamos haciendo en la práctica es ir trabajando con ellos, fundamentalmente a tener un análisis crítico, de la sociedad en la que viven, y a la capacidad de ir desarrollando eh.... pensamientos propios, eh.... (Ruido de pasos y voces) teniendo en cuenta por ejemplo, la... la capacidad de fundamentación.... De ahí vienen sugeridos como actividades el ensayo, debates, por ejemplo sobre algunos términos, emm... o algunos conceptos, generalmente a las ultimas unidades de.... De filosofía.

P5: ¿Qué tipo de problemas y de conocimientos se ponen en juego en los programas de estudio?

R: En cuarto fundamentalmente centrado eh.... a lo que tiene que ver con los problemas éticos, si la concepción de la moral, el tema de la moral social, cómo se.... Cómo nos vinculamos como individuos y sociedad, y.... algunos dilemas éticos contemporáneos por ejemplo (Suena el timbre).

P6: Perfecto, ¿y qué reflexiones se pueden levantar en estos programas de estudio a partir del planteamiento conceptual por ejemplo?

$\mathrm{R}$ : El ejercicio que hay que hacer y que... por lo menos, lo que hemos conversado con docentes, es el tema de hacer la... eh.... (Ruido de notificación de celular) el enlace con la vida cotidiana, y.... con la vida contemporánea, porque básicamente el 
programa está situado a elementos bastante clásicos de la filosofía, falta eh... reflexión más situada por ejemplo, no hay pensamiento latinoamericano, eh... aparece solamente un texto de una mujer, eh... en... en el libro de... de psi... de psicolo.... (corrige) de filosofía, no hay textos de mujeres, en el libro de psicología por ejemplo como sugerido, entonces eh... el enlace que hay que hacer es fundamentalmente a lo... a los alumnos situarlos eh... con esos conceptos, que son atemporales, por ejemplo el mito de la caverna es atemporal, y uno lo sitúa (sonido de notificación de celular) desde el mito, desde la lectura de.... La República hasta la vida contempora... hasta la vida de ellos ahora, con su contexto, con sus visiones particulares, qué podría representar la caverna por ejemplo, y ese es el ejercicio que hay que hacer, no es algo que venga muy explicitado desde la... el programa como fue concebido en el ministerio, entendiendo que estos programas son del año noventa y ocho aproximadamente y que no ha habido cambios sustanciales en ellos.

P7: Y específicamente, ¿cuál es el uso de lenguaje que se pone en juego o que invita a realizar el planteamiento curricular en esta aérea de estudio?

R: Emm... yo creo que la... los alumnos fundamentalmente van eh... internalizando conceptos distintos eh... entendiendo por ejemplo, que se.... qué.... Para qué sirve o de qué trata la metafísica y situándola eh... digamos como aérea de la filosofía, situándolo con su propia vida, también pasa con el... el... el... La teoría del conocimiento, con la epistemología, esos conceptos van poniéndose en juego y.... a los alumnos situándose, y básicamente eh... de que sean capaces de desarrollar a partir de esta área.... Eh... sus propias preguntas.

P8: ¿Qué tipo de prácticas o actividades de enseñanza, y de evaluación, se programan para el desarrollo del pensamiento en los planes y programas?

R: Vienen en.... sugeridas por ejemplo, eh... viene sugerido en el plan de electivo y también del... Del común, en cuarto eh... ensayos por ejemplo, emm... cosa que yo he hecho, pero también he trabajado algo que a mí me interesa más trabajar por ejemplo, que es con el concepto de derechos humanos que está agregado hace unos pocos años atrás, se agrega un objetivo general, a pesar de que el programa no ha cambiado, se hace un énfasis porque viene como un apartado, como una sugerencia de actividad en el programa y aparece como un nuevo objetivo, eh... más que trabajar ensayo, por ejemplo lo que yo he hecho con los chicos es trabajar eh... manifiesto, y manifiestos mucho más subjetivos de un llamado de atención eh... está situado a un público específico y... yo empiezo trabajando ensayo en la primera unidad y término trabajando manifiesto con los alumnos, para que sea su opinión, su postura... argumentada, fundamentada con... con sustento teórico, el que ellos hagan un llamado por ejemplo a la acción, por ejemplo en un tema que a ellos que les motive.

P9: ¿Qué es para usted el pensamiento complejo y la metacognición en la filosofía?

R: Bueno, es la capacidad primero de... eh... desarrollar habilidades cognitivas superiores $\mathrm{y}$, no solamente emm.... Quedarse con la materia como una cuestión... mecánica, sino que.... Extrapolar aquellos pensamientos a la propia vida particular de los alumnos, que de verdad hagan la pregunta de que por qué, para qué estoy aprendiendo lo que estoy aprendiendo, cómo la filosofía me sirve o lo que digan éste o determinados autores, me sirve para cuestionar en el mundo en el que vivo.

P10: ¿Qué habilidades o disposiciones del pensamiento complejo y la metacognición pone en juego la enseñanza de la filosofía?

R: Bueno, el análisis eh... yo creo que básicamente el análisis, la... el... la capacidad de... de extrapolar por ejemplo, de ir situando pensamientos antiguos, y situándolos en... en situaciones cotidianas ahora, eh... la capacidad de sintetizar y de comparar autores importantes para ellos... (Ruido de voces) la relación que eso tenga con mi propio pensamiento, y... la capacidad por ejemplo de... (Ruido de voces) de creación 
también, porque hay creación de pensamiento propio, a partir de.... Lo que los autores dicen. A las chiquillas les cuesta mucho, a mi me ha pasado, de permitirse disentir de los autores, porque la... la... estructura tradicional de la educación es... es como lo que yo aprendo es lo que es, entonces el... el pasar autores distintos, por ejemplo en la última unidad vimos a Stuart Mill y vimos a Kant, y... y... y que las alumnas se atrevan a disentir de los autores, analizando y ser capaz de proyectar pensamientos propios, es algo que... uno lo hace de manera incipiente, yo no podría decir que lo logré. Pero si... que se atrevieran a eh... fundamentar por qué no estaban de acuerdo con uno u otro, o por qué si estaban de acuerdo con uno u otro autor.

P11: ¿Qué estrategias y actividades, favorecen el desarrollo del pensamiento complejo y la metacognición en el proceso de enseñanza de la filosofía?

R: Yo creo que el trabajo individual dirigido, por ejemplo, como en un ensayo donde hay una pregunta abierta, yo a veces lo que hago es poner las tesis en... en discusión, las posibilidades de tesis que pueden haber para que ellas elijan una, o creen la propia. Y... también a mi me ha dado resultado harto, por ejemplo, como estrategia el debate, porque ahí hay desarrollo de ideas, y de posturas propias, de... puntos de vista fundamentados. Y como lo decía igual el manifiesto. El... la investigación también, porque trabajamos harto, por ejemplo, problemas éticos contemporáneos con... trabajos de investigación y que vayan enlazando, por ejemplo, con.... Cuáles de los principios de la bioética están en juego por ejemplo, con elementos que son.... eh... contemporáneos, entonces mucho que tenga que ver con análisis, con sinterizar eh.... eh.... información, evaluar información y crear también (murmura) elementos propios.

P12: Muy bien, respecto a los recursos didácticos como recursos mediadores para el desarrollo del pensamiento complejo y la metacognición, ¿cuáles serían los más apropiados?

R: (Ruido de loza) Es que en realidad, yo creo que una de las falencias que nosotros tenemos.... Justamente está en el área de la didáctica, porque no... las sugerencias de evaluación que hay por ejemplo, como yo decía en la... en los programas son básicamente la... la... mm.... La creación de un ensayo, la prueba objetiva, y el análisis de textos, no hay otro. Entonces... (llega gente a la sala) básicamente lo que nosotros hemos ido recreando es eh... no sé, la creación de los alumnos, eh.... (Ruido de voces) la construcción de videos, el análisis de películas o de cortometrajes. El tema audiovisual es mucho más interesante que solamente el tema del texto, yo generalmente cuando trabajo texto, trato de analizarlo con algún.... Con alguna película eh.... (Murmullos de gente) y con eso voy viendo por ejemplo autores; eh....como.... como estrategia didáctica, y.... lo que me ha costado un poco pero también lo hecho, no acá, en otros colegios por ejemplo que... que trabajamos con simposio, entonces fuimos trabajando en grupo, las alumnas fueron opinando, en base a sus opiniones, iban... siendo evaluadas y el resto tenía que seguir opinando, digamos como una mesa común, y.... mm.... Y eso es bastante interesante, porque las alumnas van aplicando lo que han aprendido en.... y complementando lo que dicen sus propios compañeros.

P13: ¿Qué tipo de actividades o estrategias de enseñanza utiliza usted en sus clases en tercero y en cuarto?

R: En cuarto yo.... En tercero trabajo mucho más lo que es el trabajo grupal, harto trabajo en grupo y trabajo en clases, entonces... trabajamos bastante con.... con.... emm.... Creación de videos que tienen que ver básicamente con... emm.... Poner ciertos temas y que las alumnas hagan un pequeño eh... eh... ejercicio de investigación, con entrevista por ejemplo a personas, y que después sinteticen la información, y lo otro que también he hecho con ellas es em... el video, pero como bitácora de algún 
experimento, por ejemplo, cuando tuvimos que ver tipos de pensamiento... las chicas tenían que en grupo emm... condicionar un animalito, entonces más que pasar la teoría de cuáles son los tipos de aprendizaje, fuimos viendo in... in situ digamos... el refuerzo negativo, el refuerzo positivo digamos eh... para poder la adquisición de una nueva conducta, a partir por ejemplo de un experimento con una mascota.

P14: ¿Me puede describir profesora las formas de interacción, cooperación y participación que suelen darse en las clases de filosofía, ya sea en tercero o en cuarto?

R: Yo haría una diferencia importante entre tercero y cuarto medio ¿ah? Yo creo que el tercero es bastante distinto por el tema de los tópicos que se tocan, que tienen que ver con psicología emm... la segunda unidad da como para discusión y yo creo que ya la tercera unidad, que es la unidad en la que estoy ahora, las alumnas tienen a conversar y a discutir más, a participar, a que... generalmente yo hago preguntas o situó el contenido con alguna cuestión que tenga que ver con la vida cotidiana. Eso se puede dar muy bien en individuo y emm... el sujeto como.... Como... el individuo como sujeto de procesos eh... psicosociales, que es la segunda unidad y, individuo y sexualidad que es la tercera unidad, porque son temas que a ellas les llaman la atención, porque son temas contingentes, son cosas que les están pasando a ellas ahora, emm... así que ahí lo que... fundamentalmente le pasa a este trabajo eh... lo que se trabaja es, aparte de la exposición, ir matizando con preguntas hacia las alumnas, y la.... (llega gente a la sala) digamos, la conversación que se va generando a partir de esas preguntas. Y en... cuarto medio, ahí... ahí hay trabajos grupal también, tiene que haber harto trabajo más individual, de creación propia ¿ya? de elaboración de ideas, de... de... de elaboración con argumentación, (murmura) conceptos teóricos. De hecho el programa tiene un... lo que a mí me parece un... no sé... un... un... un problema no menor, que los métodos de la filosofía aparecen como contenidos, por ejemplo, el dialogo... La... la búsqueda de hipótesis, y otros elementos aparecen como... eh... como contenidos, y... nosotros lo que hacemos en general acá es utilizar eso como método de filosofía, como parte de la enseñanza, como estrategia... (Ruido de voces externas) como didáctica, no como contenido. A mí no me interesa que los alumnos me reciten cuáles son los... eh... métodos de la filosofía, sino que los pongan en práctica. Ahí uno se da cuenta que el carácter que tiene... es bastante memorístico, más que... como que se contradice con esta necesidad de desarrollar el pensamiento propio.

P15: ¿Qué tipo de conocimientos y problemas se plantean en las actividades de la clase de filosofía?

R: (Ruido de voces externas) Yo creo que, fundamentalmente por ejemplo, si yo siguiera al pie de la letra el programa o eligiendo solo los textos que vienen sugeridos por el ministerio, tiene el tema de la contextualización también, son... son unos textos áridos, eh... generalmente clásicos eh... que no tienden a ser atractivos para las estudiantes, eh... por lo tanto lo que fundamentalmente hay que... que hay que hacer es contextualizar. Y lo otro que es un problema importante, es el problema del tiempo, nosotros terminamos con cuarto medio que es nuestro único año de filosofía... en octubre, lo que no... nos deja la... la posibilidad de... generalmente de no poder cubrir todo el programa... de... planteado por el ministerio, porque la ultima unidad eh... se ve, que es bastante interesante, es una de las que más me interesan a mí que tiene que ver con ética social... emm... bastante sup... de manera bastante superficial, porque las alumnas están terminando eh... de hecho, cuando lo hemos conversado con las alumnas, ellas mismas dicen que sienten de que filosofía llega muy tarde a la... al... digamos dentro de la enseñanza media. Al final, estoy saliendo, preocupada de la PSU, preocupada de otras cosas digamos emm... de qué es lo que voy a hacer más adelante y llega esta asignatura nueva, entonces igual es... (Gritos fuera de la sala) yo creo que 
esa es una de las complejidades mayores, la mayoría de los estudiantes no tienen nin... ninguna vinculación... (Gritos fuera de la sala) con la filosofía hasta el momento en que prácticamente están egresando.

P16: ¿Qué tipo de razonamientos y reflexiones se plantean en estas actividades en las clases de filosofía?

R: Eeh... básicamente lo que tiene que ver con... el propio desarrollo personal, las propias inquietudes individuales de las estudiantes, de que lo importante acá no es dar la respuesta buena o mala, porque muchos... por ejemplo, en el caso de los ensayos eh... o el sentido de la vida, no hay... preguntas malas, ni... sino que el tema del desarrollo, de cómo yo desarrollo mi capacidad de pensamiento para poder contestar (ruido de voces externas) eh... eso, eso cuesta un poco digamos, que las alumnas entiendan de que... (Ruido de voces externas) lo importante es cómo la van desarrollando la idea, no... qué es lo que me dicen al final. Las alumnas tienen un poco a... a responder lo que el profesor quiere oír, y sacarlas de ese contexto por lo tanto... ¿la pregunta era...? Me perdí, me parece.

P16: Los tipos de razonamientos y reflexiones que se realizan...

$\mathrm{R}$ : Individuales, fundamentalmente que tienen que ver con la propia existencia, eso se da bastante. Las alumnas de repente me refieren cosas que vimos el primer semestre, y que les hacen sentido, no sé... después de las vacaciones de invierno como que empieza a hacerles sentido algo, y lo otro, tienen que ver también con el análisis del mundo en que vivimos, ósea de nuestra... de nuestra propia época, de que entiendan que la filosofía es una cuestión viva y no solamente una cosa que pasó hace cinco mil años atrás, sino que tiene que ver con eh... desde que somos seres humanos hemos ido desarrollando pensamientos, el... el hacernos estas preguntas, que no tienen una respuesta única, son relevantes para eh... las personas, por lo tanto la introspección es importante, el razonamiento individual, pero también el extrapolar con... eh... la vida cotidiana.

P17: Y eso a su vez genera ciertos niveles de discusiones entre las estudiantes....

R: Que son interesantes igual, porque... por ejemplo hay conceptos, cuando vimos bioética eh... el tema de cuándo empieza la vida por ejemplo, que es una pregunta fundamental eh... ahí el tema es cómo yo fundamento lo que digo y desde dónde lo fundamento, entonces... les cuesta entender un poco de que no hay respuestas malas o buenas, porque... porque yo les decía esto es valórico y es ético, nos metemos en un tema que es filosófico... ¿cuándo empieza la vida humana? Por ejemplo, en... eh... el... eh... ¿el aborto puede ser considerado moralmente válido? En... en términos filosóficos esta reflexión, y ahí las preguntas son disimiles, ósea las respuestas son disimiles, ahí sí. Eso es lo interesante, las alumnas aprenden a respetar también la... eh... (Ruido de voces externas) la... (Ruido de voces externas) la opinión del otro, de la otra en este caso.

P18: ¿Qué usos se da al lenguaje en las clases de filosofía?

R: Eeh... yo creo que el uso del lenguaje... es super importante, y de hecho por ejemplo, a las alumnas ya están, bueno... las que vienen conmigo del electivo de filosofía saben el tema de... lo importante que es dejar fuera la ambigüedad, o la... eh... o la vaguedad en el lenguaje. Emm... este año no lo trabajamos, pero otros años trabajamos por ejemplo, glosarios de... de conceptos filosóficos que las alumnas aprenden a utilizar después. Es importante que se vayan... que vayan sacando el concepto de lo... mm... digamos del... digamos el conocimiento vulgar de algunos conceptos, al conocimiento más especifico, más filosófico... la diferencia entre ética y moral por ejemplo, entre persona... y sujeto, esto... ese tipo de... de concepciones... de conceptos y de conceptualizaciones las vamos trabajando. Y... lo que hacemos a veces ir... a... armando un glosario filosófico, a partir de las unidades 
que vamos viendo, y como resultado final que es una nota semestral y una nota anual. No lo hicimos este año, pero en varios años lo hemos hecho, y las alumnas se van dando cuenta cómo ellas van ad... adquiriendo o van re-significando conceptos que utilizan en la cotidianeidad.

P19: ¿Qué uso se da a los materiales y a los recursos didácticos en las clases de filosofía?

R: Yo creo que para mí son super importantes, yo por ejemplo, me apoyo mucho en lo que es emm... el tema audiovisual, por ejemplo, entonces para mi tener un data a disposición, eh... tener la posibilidad de tener buen audio en la sala para poder ver cortos eh... ver ejercicios o no sé... experimentos sociales por ejemplo, eh... son... es bastante importante, me costaría solamente hacer una clase con... pizarra y... como Merlí, solamente con pizarra y... y un pedazo de tiza, eh... el recurso didáctico es importante, pero hay que ir creando y adaptando, por eso es importante en las comunidades de docentes, en que de alguna manera nos vamos facilitando material... porque tampoco tenemos mucha preparación en didáctica, no hay.... Especialización posterior por ejemplo... es la práctica docente lo que va dando de alguna manera lo... qué es lo que resulta y qué es lo que no.

P20: Muy bien, el giro curricular nos está llevando cada vez con más fuerza a posicionarnos en una perspectiva cognitiva, vale decir, en potenciar más bien todo lo que tiene que ver con el desarrollo de habilidades más que la cuestión puramente conceptual. Desde esta perspectiva profesora, los programas de psicología y de filosofía, que ya se ha dicho que están desactualizados, ¿cómo generan un facilitador o un obstáculo en sus planteamientos conceptuales, metodológicos, evaluativos, para poder desarrollar todo lo que tiene que ver con estas habilidades?

R: (Suena teléfono de oficina) Yo creo que... más entrampan la posibilidad de desarrollar estas habilidades que facilitarlas (Se repite el sonido de teléfono), fundamentalmente porque uno está amarrado a tener que... (Ruido de voces externas) pasar materia, o ver entre comillas pasar materia... (Suena el teléfono) abordar todos los aprendizajes esperados, que son infinitos... son... cuarenta y ocho me parece, (suena el teléfono) cuarenta y cinco el aproximado, que yo... en mis años de experiencia docente nunca los he visto todos, (suena el teléfono) entonces muchas cosas se abordan superficialmente y... eh... (Ruido de voces externas) el... el ejercicio dialógico por ejemplo, eh... el análisis o la búsqueda de supuestos... (Ruido de voces externas) necesita tiempo, y uno está, como de alguna manera amarrado... (Ruido de voces externas) a esta cantidad muy grande de... aprendizajes esperados, de contenidos que hay que cumplir en la asignatura. Yo creo que mm... lo otro, bueno... aparte de las desactualizaciones, es una mirada tan clásica de la filosofía, tan poco situada por ejemplo, en Latinoamérica... eh... seguimos mirando a los griegos, seguimos mirando los modernos, eh... y no... no entendemos de alguna manera que tenemos pensamiento propio. A mi... yo creo que la diversidad de las aulas me ha ido dando el... el eh... la posibilidad de ir abriendo esta... (Ruido de voces externas) estos... espacios, nosotros tenemos alumnas por ejemplo... extranjeras en el colegio, no muchas acá, a diferencia de otros colegios del... de la comuna, pero es interesante cuando hay una mirada distinta por ejemplo, tengo un par de alumnas que son indígenas, son ecuatorianas... y desde la mirada de... de su perspectiva del mundo, donde cómo viven digamos... a partir de su cultura, es super interesante como un... in... es algo que deberíamos nosotros recoger, y que el programa no hace, no deja esos espacios, porque hay que pasar materia... y eso habla de otra cosa, habla justamente de... de lo academicista, de lo... del profesor como centro del... del discurso, y... y eso imposibilita un poco el tema de... eh... de desarrollar habilidades, que debería estar... contenido, a veces incluso puede ser eh... una excusa para la.... el desarrollo de habilidades, que debería estar puesto ahí el foco eh... de la actividad. 
P21: Profesora, ¿algo que usted quisiera aportar en materia de los planes y programas?

R: Yo creo que lo que tenemos, lo que... bueno, hemos eh... también hemos hecho como... como red de profesores cuando empezó este cambio curricular que se supone entraría en vigencia el año dos mil veinte emm... fue nosotros plantearnos eh... como grupo de docentes, de qué es lo que nos gustaría a nosotros enseñar, porque efectivamente yo creo que nadie está cómodo con los programas como están, emm... y esa es una... es una lectura que hemos ido haciendo y... y compartiendo para ver cuáles son los tópicos de que lo que debería enseñarse, por ejemplo el tema de género debería estar presente y que no está... el pensamiento latinoamericano debería estar presente con fuerza y que tampoco está, nosotros hacemos filosofía desde Latinoamérica desde el siglo veintiuno eh... en... nace con una historia detrás importante, que tendría que recogerse... y... que no está pu... entonces no... ha... mi preocupación principal es pensar que esta oportunidad de cambiar los planes, finalmente se va seguir pensando o haciendo por expertos, que no son los profesores de aula. Que la mi... la mirada digamos del ministerio es que... nosotros no somos los especialistas, ni sabemos lo que... lo que deberíamos hacer, y... la... es lamentable que sea así... me parece que van a venir actualizaciones, pero.... Con programas con... con el mismo corte, academicista, centrado en el docente... y con alumnos rece... receptores de información más que generadores de ideas propias. 


\section{ANEXO 9. OBSERVACIÓN DE CLASES DE EVA}

Curso: 4to año c Duración: una hora pedagógica

Profesora: Buenas tardes jóvenes, continuando con nuestra actividad que siga adelante el próximo grupo.

Alumno 1: profesora no pudimos traer el video porque tuvimos problemas con la edición pero ¿se lo podemos traer mañana?

Profesora: ¿y por qué no hoy día? El video debería estar ya físicamente, hace más de un mes

Alumno 2: hoy día en la noche profe, pero la mesa de conversación la podemos hacer igual

Profesora: la mesa de conversación la vamos a hacer pero el video queda pendiente para la próxima clase. Ya nos cuentan de qué se trata entonces el tema.

Alumno 2: profe, en serio, voy a tratar de hacérselo llegar lo más rápido posible, antes de la otra clase.

(Ruido de conversación entre los estudiantes).

Profesora: ya, se van a sentar o van a estar de pie.. Atrás por favor escuchen a sus compañeros. Chiquillos cuéntennos de qué se trataba el video más toda la información del tema para poder conversar porque el tema es súper específico.

Alumno 1: hola compañeros y compañeras en nuestro video que no pudimos presentarles hoy trabajamos como tarea el tema de la desigualdad económica y nosotros en la introducción planteábamos, de cierta manera, como especie de tesis era que la desigualdad económica es producto del sistema económico que está imperante en ciertos países, siendo igual que eso es obvio pero queríamos recalcarlo y antes de continuar le queríamos entregar algunos conceptos básicos.

Alumno 2: eeh ya como primer concepto básico, para que entiendan más o menos de lo siguiente que vamos a hablar, está el neoliberalismo que es el sistema económico capitalista que se centra en la privatización de servicios públicos y la liberalización del mercado también más arriba de eso está el capitalismo que es un sistema económico parecido muy feudalismo en donde los medios de producción están en manos privadas y también cosas como los servicios públicos también pasan a ser a mano de los privados y aparte de la propiedad privada otra parte importante del capitalismo es que los productos se intercambian dentro del mercado en base a precios aparte aparte del neoliberalismo que es una parte del capitalismo actual. También está la economía social de mercado o la social democracia que el sistema que tienen los países europeos en donde a pesar de estar dentro del mercado existe una fuerte regulación del estatal y los servicios públicos a su vez están dados por el Estado.

Alumno 1: yaa eeh otro concepto importante también sería el PIB que es la cantidad de ingreso total de un país y su división de eso estaría el PIB Per cápita que es la misma cantidad de dinero pero dividida por todos los habitantes y también están los índices de GINI y que los índices de GINI Son como gráficos que van del 0 al 1 en donde los países que están más cerca del cero son los que tienen menos problemas de desigualdad y los que están más cerca del uno son los que tienen más problemas de desigualdad y si por ejemplo todos los indicadores de GINI de un país estuvieran en uno eso es porque todas las riquezas de ese país los concentra una sola persona y 0 es que no existe diferencia entre las personas también hay un concepto del capitalismo que se me olvidó mencionar que son los medios de producción y por ejemplo que los medios de producción sean privados significa que la fábrica los terrenos y todas las materias primas no son no pertenece necesariamente una comunidad o al país sino que son de personas privadas

Alumnos 2: Bien primero vamos hacer un estudio comparativo entre las políticas públicas que hay en chile y para eso vamos a dar los datos de otro país para comparar y ese país es Dinamarca en Dinamarca hay 5.731 millones habitantes entre los digo gente 
entre los 18 y 65 años y un 12, 2\% de ellos son los más pobres del país Claro ese $12.2 \%$ puede parecer alto porque por ejemplo aquí en Chile aparece como alrededor de un $8 \%$ lo que pasa es que en este país la pobreza se define como tener el $60 \%$ menos del sueldo promedio igual es súper alto el índice para ser pobre ya tienes que ganar menos de 17000 euros al año y 17000 al año igual es una buena cantidad poh y con todo eso hay sólo un $12 \%$ de pobreza eso por debajo de lo que es el pib el salario mínimo allá es 4632 al mes lo que igual es alto

Alumno 1: aaah el GINI allá es de 0,25

Alumno 2: Osea Dinamarca es uno de los países que está más cerca del cero en los índices de gini como otros países que son nórdicos también como son Noruega y todos los que están dentro de esa ubicación el pib ya es de 306.1 miles de millones y el pib Per cápita 53,417.66

Profesora: Diego perdona ¿cuánto dijeron que ganaban allá mensual? Es que estoy sacando la cuenta

Alumno 2: mensual? Mensual sacan 4632 euros

Profesora: dijeron como sueldo minimo alla, ¿cuánto es?

Alumno 2: ah ya si eso es el mínimo allá: 4632 euros al mes

Alumna 3: ¿cuánto es?

Alumno 4: ahí lo está calculando la profe

Profesora: son 3millones 600

Alumno 1: ese es el sueldo promedio, y un sueldo que es más elevado son de casi 5500 euros.

Alumno 2: eeh ya veamos empresas que ponderan allá. Una que se llama empresa ponijos danesa, es una compañía productora de alimentos que comercializa una amplia variedad de cosas. Ponijos también la Union Europea lidera la producción de ingredientes para un producto y aproximadamente emplea 10 mil personas en 40 paises y reporta ganancias de más de 40 millones entre el periodo del 2005 y el 2006 lo que igual es bastante. También está el grupo ZAS al grupo entra Dinamarca, como Noruega o Suecia. La cosa es que es una aerolínea inter europea pero entre esos países mueve la economía pero lo que lo sustenta es una marca de ¿cómo se llama? De aviones y algo importante de esa empresa es que la más grande del país es estatal y un alto porcentaje de esa empresa, alrededor de un 50\%, pertenece a distintos estados europeos ya y la otra empresa que ya yo creo que todos la conocen por lo, por lo masiva que es y el público que tiene es LEGO. Lego es una empresa danesa también. No había información de cuanto ganaba eso sí, quizá al ser una empresa privada no lo quiere compartir, o compartir ciertos datos pero como son reconocidos a nivel mundial no creemos que sean bajas las ganancias de esas empresas

Alumno 1: bien, cabe destacar que la economía Noruega

Alumno 2: De Dinamarca

Alumno 1: eso, la economía de Dinamarca, la danesa, eeh es como mencionaba al principio social de mercado básicamente su sistema económico igual es un sistema capitalista de origen burgués y trabajador donde existe el pago de salario, donde existe intercambio de mercancías, pero en este sistema europeo, del nórdico más que todo el estado tiene una gran injerencia en la regulación de la economía y se encarga de dar servicio básicos, se encarga de ayudar a la población. Ya vamos a ver el caso de Chile, en el caso de Chile hay 17.373.831 habitantes. Los índices de pobreza varían bastante, el índice de pobreza oficial que da el gobierno de Chile es de un $8 \%$ incluso menor al que da Dinamarca pero ese dato igual se cuestiona mucho y hay otras fundaciones que han dado otros estimados por ejemplo la fundación SOL que igual es conocida aquí dentro de Chile da, estima que la pobreza está en un 17\% . el salario promedio al mes es de 379.673 al mes, se nota la gran diferencia con el sueldo promedio al mes de 
Dinamaca donde es casi 9 veces más, el gini de Chile es el doble del de Dinamarca, en realidad el de Chile es uno de los más elevados del mundo más que el promedio mundial

Profesora: ¿y eso qué significa?, ¿que somos altamente desiguales?

Alumno 1: eso, que somos desiguales.. no pobres sino desiguales, de los más desiguales del mundo, cerca de Nigeria

Profesora: que importante ese dato que entregan oye, es importante que los chiquillos tengan claro lo que significa el indicador gini

Alumno 2: si incluso somo más desiguales que varios países de Africa, creo que somos el pais más desigual de América, más desigual que EE.UU

Profesora: (llamando la atención a dos chicas) a ver por favor concentrense un poco y escuchen a sus compañeros

Alumno 2: el PIB de Chile es de 247 miles de millones de dólares y el per capita es 18 mil 592 dólares, similar al de .. al de.. al PIB de Dinamarca que también es y tiene muchas menos personas por lo que el dinero se reparte en menos. Aquí en Chile también tenemos empresas, y las empresas más grandes también tienen asociadas a ellas los nombres de las familias más adineradas de Chile está por ejemplo CENCOSUD que es una empresa dueña de muchas otras como sería santa isabel, paris, y otras de ese estilo que son de la familia Paulman, está Antártica Chile y la Copec que son dos cosas distintas y separadas pero las dos son de la familia Angelini, esa es como la empresa número 30 a nivel mundial, igual está Falabella de la familia Solari y CMPC que no es muy conocido como Antártica, lo que pasa es que no funcionan a través de una sola empresa sino que forman conglomerados de varias empresas que le ponen nombres menos conocidos, esta empresas a veces no producen algo como empresa sino que compran otras empresas.

Alumno 1: también hay grupos de empresas que llevan los apellidos como grupo, como el caso del grupo Luksic, grupo Edwards, que son gente y familia empresaria que tienen uno de los fondos más altos a nivel mundial.

Profesora: Fíjate lo poderoso de esos apellidos, acuérdense que salieron el lunes cuando discutimos sobre el manejo de los medios de comunicación

Alumno 2: ah si pues si el Luksic es dueño de tele 13, si incluso hasta hace poco el Luksic y la Catolica compartían el Canal 13 y después pasó a ser 60 y 40\%.

Alumno 5: Carlos Heller es dueño de mega también, dueño de la U

Profesora: viste que hay que poner atención a esas cosas, porque desde ahí se marcan directrices también en relación a cómo se mueve un país, los intereses, la intención que hay detrás de lo que nos informan, cómo nos informamos

Alumno 1: junto a eso queríamos señalar esos datos para poder concluir queríamos dar por lo menos un entendimiento de lo que es el sistema económico de lo que vimos ahora que es el capitalismo, que igual lo mencionamos un poco antes de los otros datos que dimos acerca de la propiedad privada y del comercio en el mercado. Algo súper importante es cómo funcionan los salarios porque desde nuestro punto de vista como conclusión planteamos que es el capitalismo, donde está nuestro sistema actual, el que tiene la culpa de esta desigualdad y ¿cómo funciona el mercado?

Alumno 2: bueno el mercado funciona de acuerdo al valor de las cosas, por ejemplo el dueño de una empresa dentro de la teoría marxista sería llamado burgués, y sería encargado de los medios de producción, o sea de la empresa que genera la materia prima eeh de todo lo necesario para producir un objeto, así mismo todo esto tiene un precio que puede ser no se poh cien dólares por ejemplo, para simplificar las cosas, y tiene un trabajador, ese trabajador trabaja para la empresa en cuestión y producen una cuestión, zapatos por ejemplo, estos zapatos cuestan 100 dólares en el mercado y son vendidos por 300 dólares en sí mismos eeh lo que se vería como justo quizá, o lo que 
nosotros veríamos como justo o como lo normal sería que la persona que invirtió recupere lo que invirtió y que el trabajador tuviese los 200 que produjo, pero no es así en la realidad porque si fuese así las empresas no ganarían dinero pero lo que pasa es que las empresas ganan dinero a costa del esfuerzo del trabajo de otro, de un trabajador. entonces nosotros también tenemos una postura acerca de lo que significa la desigualdad y de cómo eliminarla también, pero hay formas distintas, por ejemplo en Dinamarca existe capitalismo pero están infinitamente mejor que en Chile porque existe el rol del Estado como un rol importante respecto a cómo funciona la economía, entonces la pregunta abierta igual para finalizar un poco es ¿qué piensan ustedes acerca de la desigualdad? y ¿qué se puede hacer?, ¿cuáles creen que son las soluciones o un parche?, como lo hizo Dinamarca que implementó mejoras ligeras o un cambio más sistémico, más profundo, no se poh ahí queda como abierto para el diálogo.

Alumno 1: bien, antes un punto súper importante que quería tratar era el cómo nuestra esperanza de vida se ha convertido también en un bien de consumo para el Estado. Si queremos que nos atiendan mejor vamos a ir a algo privado, si queremos estudiar mejor vamos a ir a algo privado entonces la sociedad va adquiriendo una mirada como de lo privado por encima de lo público y eso perjudica bastante porque el chileno hoy en dia no tiene los medios para.. paa..

Alumna 6 interrumpe con risas

Alumno 1: oye cállate poh.. el chileno hoy en día no tiene los medios para sustentarse bien el dia a dia ¿cachai? si en Santiago por ejemplo la gente ya prefiere caminar porque el metro le sale 700 pesos casi y eso que es un viaje no más, cargar la tarjeta ir venir, es un ritmo de vida también super estresante.. por lo que me han contado

Profesora: por lo que viviste el año pasado, o el 2015

Alumno 1: ¿qué opinan ustedes entonces de que nuestra vida sea salvarse a puro costo? siendo que estos deberían ser derechos

Alumno 2: o cuál es su postura ¿creen que es justo, que es normal lo de la desigualdad, igual existe esa postura ah?. no sé qué dicen ustedes

Alumna 7: es que no es normal que exista desigualdad, pero suene como suene todos tienen que esforzarse por ser alguien en la vida también aunque te cueste hay que ver todos los medios, ir a todos lados si no hay posibilidades, pero hoy por ejemplo todo el mundo puede estudiar y puedes estudiar en algo eeh municipal o del estado como se decide y esforzarse para ser mejor persona y tener también sus propios ingresos, entonces así nosotros mismos nos estamos educando para poder tener una mejoría.

Alumno 2: sí pero eso igual está enmarcado en el sistema económico chileno, pero igual podría ser diferente, pero el sistema capitalista siempre va a funcionar así en términos de privilegios

Alumna 7: un parche es lo que podría hacerse para de a poco llegar a lo más profundo porque altiro arreglarlo es super complicado, hay que tener un camino para poder avanzar

Alumno 2: si puede ser, pero son diferentes posturas. también está la postura del estado neoliberal como es Chile, posturas más centristas o más socialdemócratas como en Europa, hay posturas más radicales también como Cuba, la Unión Soviética u otros, pero no sé si alguien tiene otra idea.

Profesora: pero cuando hablamos de igualdad ¿a qué se supone que hay que apuntar? cuando ustedes piensan que en nuestro país debería desaparecer la desigualdad o disminuirla. ¿en qué piensan cuando piensan en un país más bien justo?

Alumno 1: es que igual hay dos concepciones en la noción de igualdad. Está el concepto de igualdad como oportunidad que tal como suena es que todo el mundo tenga oportunidades de lograr algo, la misma oportunidad y en teoría eso es lo que podrían estar buscando países socialdemócratas, que todo el mundo pueda tener educación, que todo el mundo pueda tener salud, que todo el mundo pueda tener trabajo y que de 
ahí cada uno se desarrolle como sea y luego está esta otra postura de la igualdad de resultados que es donde todos tienen casa, todos tienen educación, es distinto porque es más radical. No sé si alguien tiene una postura más.

Alumno 8: yo.. es que por lo menos en Chile yo detecto como una desigualdad que va unida a la mediocridad que tiene el chileno actualmente porque el chileno ahora si le pasa algo malo no hace nada y si al de al lado le pasa algo tampoco va a hacer nada porque no le afecta, por ejemplo en el siglo pasado comenzó todo este movimiento obrero porque casi todos los chilenos estaban subyugados por decirlo así por el parlamentarismo, entonces ahí fue que se organizó y que comenzó todo este movimiento hasta que llegamos al golpe de estado y con la dictadura se dió como un semi parche a una parte de la población que se llamó clase media y ahora esa es la población que vive en la mediocridad y que no permite terminar con la desigualdad porque está como en su zona de confort

Alumna 7: o sea lo que hablaba el Quintana de que tiene que ver con el desarrollo sustentable es que las personas se valgan por sí mismas y no por las demás, o sea si a ti te va bien bien por tí, y si a mi me va bien bien por mí, y si te va mal pucha que pena, todos se preocupan por si no mas y si te pueden ayudar como que la piensan pero si te ayudo es a menos que a mi no me afecte

Profesora: ¿y ese individualismo?

Alumno 2: ahí está ese dicho que dice, que siempre algunos dicen que el que es pobre es porque quiere poh y la verdad es que eso no es verdad

Alumna 7: eso no siempre es asi

Alumno 1: no, no es que no siempre sea así..

Profesora: ¿quién va a querer ser pobre hija? pensemos en alguien a ver

Alumno 1: a veces hay factores que te condicionan las poblaciones, por ejemplo en dictadura cuando se metió la pasta base a las poblaciones ¿para qué era la pasta base? antes si una rescata imágenes o fotografías antes las poblaciones estaban con banderas anarcas o banderas de movimiento y todo y ahora es súper peligroso andar por ahí. Es súper fácil decir que uno se esfuerza y sale adelante si tú naciste en un lugar donde todo estaba bien, las calles estaban bien pavimentadas, fuiste a un buen colegio, donde luego fuiste a una universidad, donde nunca tuviste un problema en tu alimentación, problemas familiares. Pero si tu naces en una población donde ves pasta base todos los días, no tienes un buen colegio o tus papás te tratan mal porque así mismo sus padres los trataron mal a ellos obviamente hay un círculo vicioso ahí, y desde nuestra postura no es suficiente la igualdad de oportunidades porque la igualdad de oportunidades no automáticamente arregla ese círculo vicioso.

Alumna 7: igual es más difícil pero no imposible

Alumno 1: no imposible de manera individual pero de manera colectiva si porque dentro del sistema económico por una razón obvia y es que hay personas que son dueñas y otras que son trabajadoras y nunca todos van a poder ser dueños, hay alguien que va a ser dueño y otros que van a ser trabajadores

Alumno 8: si poh, de hecho con eso tiene que ver cuando decimos que se condiciona a la población porque al final una persona que busca y no encuentra pega la culpa es del estado pero como el estado ahora no es el que controla los medios de producción es culpa del privado, en cambio que la persona esté fumando pasta no es culpa ni del estado ni del privado es culpa de la sociedad. Entonces se ven los problemas como algo abstracto que no se pueden combatir

Profesora: a mí me gustaría plantear tres preguntas como para reflexionar no más. Primero con respecto a eso que se dice y que uno escucha de manera muy natural que es que la gente que es pobre lo es porque quiere serlo preguntémonos, sin responder por supuesto, si alguno de ustedes le gustaría ser pobre entiéndase como se entienda la 
frase porque si nos ponemos a discutir sobre la pobreza necesitamos 90 minutos más para acordar algo, estaríamos aquí hasta como las 7 más o menos, si a alguno de ustedes le gustaría ser pobre porque eso que a la gente que es pobre es porque le gusta nos tienen convencidos desde una mirada capitalista de eso. Segundo por qué somos individualistas, si eso es una opción personal o hay ahí también una maquinación de parte de un sistema ¿cierto? Y tercero que cada vez que nombran al estado yo me pregunto ¿existe el estado aquí en Chile?, ¿hay estado aquí en Chile? ¿hay dineros públicos aquí en Chile?. esas tres preguntas

Alumno 9: ¿queda al aire o...

Alumno 1: yo tengo varias cosas que decir. Con respecto a la segunda pregunta igual es super interesante por ejemplo, porque la mirada que tengo yo es materialista en el sentido de que creo que depende cómo sea la sociedad las personas obviamente van a volverse individualistas en el momento en que el sistema económico quiere, en un sistema capitalista se hace competir, si no compites te vas a morir de hambre o te vas a quedar en la calle y vas a ser siempre pobre, entonces condiciona la vida social al individualismo porque te hace competir. Pero si la economía o la sociedad o los medios de producción te tratan de manera diferente sin hacerte competir sino a concientizarte a organizarte, colectivizar, a trabajar en conjunto pienso que de a poco la sociedad se reestructuraría, viviríamos mejor en comunidad

Profesora: la camapaña de .. ¿conocen al alcalde de Valparaiso?

Alumno 11: el Sharp

Profesora: sí, el Sharp. El hizo una campaña con casi cero peso de inversión, hizo todo un movimiento comunitario por eso que los demás políticos tienen los ojos ahí en ese político que está mostrando que se puede vivir en comunidad y cooperando no compitiendo, esa es una clara demostración de que sí se puede obviamente cuando a mi me convencen una serie de contextos pero que sin embargo, y esto es una opinión personal, creo que el individualismo nace d eun sistema económico que a uno lo sobreexplota. Claro si yo no hago bien mi pega hay varios profes más atrás mío entonces yo a cualquier costo voy a querer mantener mi puesto de trabajo, por ejemplo, hablando a nivel de trabajo. En el caso de ustedes las notas a veces también los hacer ser descabellados entre ustedes mismos ¿cierto? el que tiene mayor nota, estoy hablando no de ustedes sino en general, trata de sacar algún provecho del otro que está..

Alumno 1: la competencia se extrapola a otros aspectos,a otras formas de cómo nos relacionamos como mencionaba usted

Alumno 2: pero esos son efectos del capitalismo, pero fuera del sentido que es, que es un sentido económico, en nuestras relaciones personales

Alumno 12: cualquier cosa en la que uno esté siempre va a querer ser mejor que el otro, o va a envidiar a ese otro..

Alumno 1: son conductas sociales que uno va aprendiendo

Profesora: es que como el sistema es descabellado, una se vuelve de esa forma también y dice "total me están jodiendo a mí también" y así se vuelve hacia abajo.

Alumno 1: respecto a la otra pregunta del estado igual es curioso porque dentro de las definiciones del neoliberalismo está que el estado tenga el rol más pequeño que pueda tener y esa es la visión económica actual por lo menos en Chile y en buena parte del mundo

Profesora: osea Chile está privatizado pero completo chiquillos. La figura del estado se utiliza como un recurso, ¿qué hace el estado? se dice. se usa como una estrategia política en realidad pero desde el punto de vista que está todo privatizado no sé si hay algo estatal aquí en Chile, según yo no. Capaz que hasta nosotros tengamos dueño y 
no nos hemos dado ni cuenta, puede ser. Pero el agua está privatizada, la luz está privatizada.. está todo privatizado de verdad

Alumno 1: le cuento una anécdota personal cuando llegué a Chile igual estaba sorprendido de algunas cosas que estaban privatizadas por ejemplo el agua, es que el agua es algo tan básico allá en Venezuela era totalmente gratis, igual el gas y eso que allá necesitamos el gas para cocinar solamente y aquí obviamente para el frío y para el invierno, allá el gas era público igual que la internet era pública, era del estado, osea igual había que pagar pero era lo mínimo. Igual hay que entender que eran otras realidades bueno como el ejemplo de Dinamarca que dimos que igual puede ser injusto porque es Europa y podemos pensar que ellos tienen la plata, pero ellos no tienen plata porque sí sino porque ellos supieron hacer la parte del frente al imperialismo, que igual son otros temas, pero eso e igual saben utilizar al estado para que el estado cree cierta estabilidad dentro de la sociedad a diferencia de Chile.

Profesora: pero es que justo los ejemplos que ustedes ponen de países que tienen desigualdad mínima o que no tienen hay una figura de estado real, hay platas públicas que permiten tomar decisiones para el colectivo aquí en este caso en Chile está súper complejo por los niveles de privatización que existe y tratar de revertir ese tema bueno yo creo que sí es posible pero no sé en cuánto tiempo porque tampoco es una cosa tan fácil. Supongamos que los que hoy día están empoderados económicamente difícilmente van a querer dar algo de lo que creen que es suyo digamos ¿cierto?

aplausos

Profesora: a ver nada de que estén aplaudiendo, más opiniones.. la Daniela por ejemplo, le vamos a pedir a la Daniela que opine porque yo que no la veía desde Abril más o menos, pensé que se había licenciado Daniela y no me había invitado

Alumna 13: no sé qué opinar porque no se que estaban hablando

Profesora: ¿y todo este rato? estamos hablando de la desigualdad en Chile, Daniela, ¿qué opina usted? que opina por ejemplo que hoy día si nosotros estamos conversando cerca de las 5 de la tarde sobre la desigualdad y que haya otros países más desiguales es porque tenemos necesidades satisfechas para estar hablando de esto, porque si tuviéramos sueño y hambre no podríamos ¿cierto? y sin embargo nosotros igual estamos en un ambiente privilegiado ¿qué opna que usted tenga derecho a eso y que otro niño o niña igual que usted no tenga derecho? ¿que le parece a usted eso por ejemplo? Hagalo tan bien como baila cueca

Alumna 13: opino que está mal pues profe

Profesora: a ver Daniela ¿por qué está mal?

Alumna 13: no porque eh no tienen la como la posibilidad de estudiar en este colegio no todos

Profesora: ¿y?

Alumno 2: está mal eso porque todos deberían poder tener acceso a estudiar en un buen colegio

Profesora: o sea todas las personas deberíamos tener acceso a una buena educación porque esa es la base

Alumna 14: mal poh

Profesora: alguien más quiere opinar algo

Alumno 2: y sobre la manera de solucionarlo a ver Javier cómo se soluciona esto

Alumno 15: con la dictadura del proletariado, la única dictadura válida que existe para nivelar la desigualdad

Alumno 1: ¿ustedes creen que se debe eliminar la desigualdad al 100\%? y si es si ¿cómo se hace? La desigualdad economica digamos, porque cuando hablamos de desigualdad no significa que todos se tengan que vestir igual

Alumno 15: yo propondría una redistribución de los ingresos 
Alumno 16: según yo si se quiere llevar esta cosa de la desigualdad económica para todos no podía instaurarlo en nada en la actualidad porque el humano primero se acostumbra a los estímulos y después. evolucionar. desde que el humano existe que existe la jerarquía, existe un alfa representando el poder al que siguen los demás. entonces lo primero es terminar con ese arraigo cultural que existe con la jerarquía, eliminarla de toda relación y por ejemplo otra cosa que igual es de desigualdad es que los adultos mayores en la actualidad son los que tienen los menos ingresos y la solución que se les da es que sigan trabajando y el argumento que a nosotros nos dan es que son los abuelos los que quieren seguir trabajando y na que ver porque si ellos quieren seguir trabajando no tiene nada que ver con que reciban una pensión mísera igual siguen trabajando, produciendo un país pero ganando un dinero estable y que si dejan de trabajar no les afecte

Alumno 1: hay abuelos también que tienen que esforzarse a seguir trabajando porque dicen yo gano un palo, pero si dejo de trabajar ganaré solo cien lucas

Profesora: mientras el sistema de previsión siga así tal cual es como el ejemplo que dio Diego

Alumno 2: esto me recuerda también a cómo la televisión actúa super fuerte en todo esto porque siempre salen noticias "ooh miren este señor que tienen 65 años, que es esforzado" tirándole como puras flores y eso no debería ser, ese señor de 65 años en edad de jubilar no debería trabajar toda la semana dia y noche, es importante evitar eso y que las personas a esa edad tengan más tiempo para relajarse

Profesora: algo más que quieran decir o agregar. ¿Atrás las compañeras algo que decir?

Alumna 17: cómo se llamaba eso de redis...

Alumno 2: redistribución de ingresos

Profesora: de todo lo primero yo creo que hay que hacer es recuperar la figura del estado de manera urgente para que las principales empresas sean estatales

Alumno 18: a veces pensamos muy en abstracto, por ejemplo, nos dicen qué es el estado y decimos "la m0neda" pero no poh

Profesora: ya chiquillos muchas gracias le recuerdo a Matamala y Neira que continúan la próxima clase

Aplausos 


\section{ANEXO 10. OBSERVACIÓN DE CLASE DE ANTONIA}

Profesora: [...] la práctica con nosotros (alumnas aplauden), con otro curso, pero hoy día nos va a acompañar. Y quien acaba de llegar es la profesora Rosse Marie de la Universidad de Concepción (murmullos de alumnas, tonos de sorpresa), eeh... que está haciendo un proyecto de investigación y que también (murmullos de alumnas) eeh... va observar la clase el día de hoy ¿ya? (ruidos de sillas y mesas) Así que espero que se porten... como nunca, muy bien.

Curso: (alumnas ríen a coro y luego varias conversan entre ellas)

Alumna 1: Bueno

Alumna 2: Como siempre (bromea)

(Alumnas ríen)

Alumna 3: Bieen

(Ruidos de murmullos, sillas y mesas)

Profesora: No como el lunes pasado (tono efusivo)

Alumna 1: ¿El lunes pasado?

Alumna 2: ¿Qué es nunca?

Profesora: ¿Qué pasó el lunes pasado? (se dirige a las alumnas)

Alumna 1: Se enojó profe

(Murmullos al mismo tiempo por toda el aula)

Profesora: Antes de que yo me enojara, ¿qué pasó?

Alumna 1: Conversábamos, y conversábamos, y conversábamos, conversábamos

(Murmullos por toda el aula, alumnas conversan entre ellas)

Alumna 2: No la dejaron explicar, no la dejaron hablar, y no la dejaron explicar, y usted nos castigó y dijo que no...

Alumna 3: que hiciéramos la actividad solas

Alumna 2: y que no... y tampoco la trajeron

Profesora: Y... la actividad tenían que traerla lista

Alumnas a coro: ¿Ahh...?

Alumna 1: ¿y cuando dijo eso?

Alumna 2: Profee...

(Murmullos y conversaciones)

Profesora: de hecho era para el miércoles, y hay estudiantes que si la entregaron el día miércoles.

(Murmullos y conversaciones)

Alumna 1: Yo no vine...profe, yo no vine el miércoles y la tenía yo, por eso la Javi no la entregó...

(Murmullos y conversaciones)

Alumna 2: Lo otro, que faltaba el ensayo...

Alumna 3: Yo la tenía lista el día miércoles, pero me pasó un problema y no pude traer mi cuaderno, lo tengo en otro

Profesora: ¿y?

Alumna 3: y... no sé cómo... hacerlo ahora

Profesora: ¿y el cuaderno lo tiene o no?

Alumna 3: el de filosofía si pero... pero la... preguntas y la respuesta nada...

Profesora: Pero, y ¿el otro dónde está?

(Murmullos y conversaciones)

Alumna 3: ¿ah?

Profesora: el otro cuaderno

Alumna 3: en el que... era de otra materia que nos tocaba el día miércoles...

Profesora: Pero, ¿tiene las respuestas en otro cuaderno? 
Alumna 3: solo las del ensayo

Profesora: las trae mañana, todas

(Alumnas conversan en voz alta, se ríen, gritan, bostezan y murmuran)

Alumna 1: profee.... tiene... ósea ¿alcanzó a revisar después del artículo?

Profesora: No sé...

Alumna 1: bueno

Profesora: no traje el cuaderno

Alumna 1: ¿ah?

Profesora: Lo voy a revisar antes del 31 de octubre (ríe), ahí tengo que tener todo listo.

(Murmullos y conversaciones fuertes)

Profesora: ¡Ya chiquillas!...

Alumna 1: Profe... cómo se supone que se empieza una oración... (Murmura muy bajo)

Profesora: Puede ser eeh... (Ruido de sillas y mesas) en principio junto a la pregunta que está ahí... ir planteando su punto de vista (ruido de sillas y mesas más fuerte)

Alumna 1: se empieza así como... (Ruido de sillas y mesas)

Profesora: Pero, ¿Cómo?

Alumna 1: una palabra, se puede empezar después... (Conversaciones entre alumnas, ruido de sillas y mesas)

(La profesora responde a la alumna, conversan y aclaran la duda, el ruido impide escuchar claramente, solo se oyen sus murmullos)

Alumna 2: Profesora...

Alumna 3: Pero profe, ¿por qué no lo hizo... (Ruido de sillas, mesas y conversaciones)

Profesora: esto está bien así

Profesora: ¡Ya chicas! ¿Recuerdan qué es lo que estábamos viendo la clase pasada?

Alumna 1: eeh... lo...

(Alumnas responden a la vez, no se entiende lo que dicen)

Alumna 2: la liberación... libertad...

Profesora: muy bien margarita... la libertad, ¿qué es la libertad?

Alumna 1: compromiso... responsabilidad

Profesora: no solo es compromiso la libertad

Alumna 2: la... posibilidad de hacer lo que uno quiere

Profesora: ¿La posibilidad de hacer lo que uno quiere?

Alumna 1: no, lo que uno es... lo que uno decide qué es

Alumna 2: noo...

Profesora: ¿había algún tipo de definición con respecto a la libertad?

(Alumnas responden a la vez, no se entienden todas las respuestas)

Alumna 1: hay un acuerdo que... con respecto a la libertad

Alumna 2: posibilidad de elegir, posibilidad de decir

Alumna 1: ósea que no hay como una elección

Profesora: ya, pero ¿qué es?

Alumna 3: falta de coacción

Profesora: falta de coacción, ¿qué es la coacción?

(Sonidos de hojas de cuadernos)

Alumna 1: posibilidad de elegir

(Murmullos)

Profesora: Eeh...Tiare...

Tiare: ¿ah?

Profesora: ¿Qué es la coacción?

Alumna 1: ¿La qué?

(Murmullos, alumna tose)

Tiare: es lo... 
Alumna 2: es la posibilidad de elegir

Alumna 3: sipo, si usted puso eso... en la uno

Alumna 4: coacción (repite dubitativa)

Alumna 3: dijo ¿qué es coacción? Es la posibilidad de elegir

Profesora: pero yo hice otra pregunta recién eeh... Darling

Alumna 1: ah...

Alumna 2: falta de coacción (afirma dubitativa)

(Murmullos, conversaciones y risas)

Alumna 3: se me olvidó

Alumna 4: la tengo ahí...

Profesora: en la punta de la lengua

Alumna 1: no quiero pensar

(Murmullos)

Alumna 2: ¿Qué preguntó?

Profesora: ¿Qué es la coacción?

Alumna 1: el derecho de imponer...

(Sonidos de hojas de cuaderno)

Profesora: es... la obligación que otro me impone... ¿cuándo se puede considerar a una persona libre?

Alumna 1: cuando tiene una responsabilidad con otra persona

Profesora: antes de tener una responsabilidad, tiene que tener algo más

Alumna 2: autonomía

Profesora: Autonomía, ¿qué es la autonomía?

(Murmullos)

Alumna 3: es... alguien que es responsable por su decisión

Profesora: ya... alguien que hac... se hace cargo de su decisión ¿cierto?

Alumna 4: y la toma por iniciativa propia

Profesora: lo hace por iniciativa propia, no porque alguien se lo imponga, (alumna tose) y si bien puede haber reglas que son impuestas...

Alumna 1: pero yo decido aceptarlo

Profesora: yo decido si lo acepto o no, muy bien... ¿ya? A diferencia de la (alumna tose) heteronomía que es eeh... la acción de hacer lo que el otro me dice que haga, sin mucha conciencia (sonidos de hojas de cuaderno) sin pensar lo que está sucediendo y sobre todo sin hacerme responsable, (sonidos de conversaciones) porque en la heteronomía la responsabilidad es compartida, tengo responsabilidad yo, pero también tiene responsabilidad quien me dijo que lo hiciera. Cuando ustedes en la tarde (sonidos de murmullos y conversaciones), en la tarde se corrían de clases... ¡sh...! (hace callar a las alumnas) y les preguntaban "¿por qué te corriste de clases? Es que mi compañera me dijo"

(Murmullos)

Alumna 1: es verdad

Alumna 2: dependen de quien me diga

Alumna 3: las malas juntas

Alumna 4: nunca me he corrido de clases... no, de verdad

(Murmullos y conversaciones)

Profesora: cuando ustedes se sacan una mala nota y no asumen la responsabilidad... de que no hayan estudiado y dicen "todo... el curso se sacó mala nota"

(Murmullos y risas leves)

Profesora: la profesora... me tiene mala

Alumna 1: en inglés es verdad sí, todo el curso se saca mala nota (ríe nerviosa)

(Murmullos) 
Profesora: ¿Por qué creen ustedes que todo el curso se saca mala nota en inglés?

(Alumnas intentan responder todas al mismo tiempo)

Alumna 1: (bromea) porque la profesora nos tiene malaa...

Alumna 2: no, porque no todo el mundo

Alumna 3: porque no se comprende a la profesora

Profesora: ya, y ¿por qué no comprenden a la profesora?

(Responden todas al mismo tiempo, no se entiende claramente)

Alumna 1: porque habla en inglés...

(Risas y murmullos)

Alumna 2: yapo, paren con la reali...

Profesora: pero el hecho de que ustedes sean tan... conversadoras y muchas veces falta de respeto con el profesor, ¿tiene incidencia en que ustedes no puedan comprender mejor la materia?

Alumnas a coro: ¡siiii!

Alumna 1: sii

Alumna 2: se distraen

Profesora: Por lo tanto, la responsabilidad no es de la profesora...

Alumna 1: noo...

Profesora: también es responsabilidad de ustedes

Alumna 2: es compartida

Profesora: porque no creo que sea la única asignatura en la que no entiendan la materia (Murmullos)

Alumna 1: sii, es la única

Alumna 2: de verdad, pero yo porque no tengo posibilidad en realidad, y no le pongo atención

Profesora: si ustedes estaban con el celular, están con el maquillaje, si estaban con trabajos de otra asignatura... (Murmullos) en la clase de ella, es imposible que puedan entender

Alumna 1: eso es responsabilidad de... cada... una.

Profesora: $\mathrm{Si}$, y si no entienden inglés, hoy en día hay tanta... (Murmullos) eeh... información al respecto, que si ustedes pasan mucho tiempo en internet... pueden lo más bien buscar tutoriales de inglés...

Alumna 2: siii

Profesora: y ponerse a estudiar... (Murmullos)... ¿ya? Lo que vimos la clase pasada... ¡shhh! (hace callar a las alumnas) son las condiciones necesarias para la moral. Para que exista un acto moral en primer lugar debe haber libertad, luego de la libertad, consecuencia directa de la libertad en la responsabilidad, yo me hago responsable de las decisiones que tomo

Alumna 1: y el compromiso

Profesora: y el compromiso es parte de él, ¿ya?

Alumna 2: libertad, responsabilidad... compromiso

Profesora: El ser humano, ¿quiere ser libre?

Alumna 1: ss...nooo

Alumna 2: siiii

Alumna 1: noo

Alumna 2: siii, pero a la vez no

Alumna 3: si, pero no es completamente libre

Alumna 4: se adueña de eso, yo creo

Profesora: ¿Por qué no?

(Responden varias alumnas a la vez, no se entiende claramente)

Alumna 1: porque no quiere ser libre 
Alumna 2: pero no quiere todo

Alumna 3: respondan la pregunta

Profesora: Recién admitimos que la libertad va acompañada de la responsabilidad

Alumna 1: noo...

Alumna 2: por eso, no va ser libre completamente

Alumna 3: ah sipo

Profesora: ¿puede ser libre el ser humano?

(Responden todas a la vez, no se entiende claramente)

Alumna 1: no... porque él...

Alumna 2: nooo...

Alumna 3: no, porque tiende a... no... a no sentir responsabilidades, es como que la elude, entonces... no...

Profesora: ya...

Alumna 3: ... es como... que quieren ser libres, pero no... no se atienen a las consecuencias

Alumna 4: depende de qué tipo de libertad y de las consecuencias (murmura)

Profesora: es más fácil seguir la... la...

Alumna 1: como las reglas sociales, lo que impone la sociedad

Profesora: ¿es más fácil estar dentro o fuera de la caverna?

Alumnas a coro: dentro...

Alumna 1: dentro (repite una alumna)

Alumna 2: porque se asusta de lo desconocido

Profesora: porque... afuera yo me hago responsable de mis actos, dentro... creo que todo lo que me dicen los demás y es mucho más fácil la ignorancia que la sabiduría

Alumna 2: y es eso, es lo que quiero creer

Profesora: ¿ya? El día de hoy comenzaremos a ver cuáles son los fundamentos de la moral. Dentro de lo que funda la moral está... eeh... la naturaleza humana, el deber como fundamento moral, el amor, el contrato social...

Alumna 1: ¿Contrato social?

Profesora: si, para eso les voy a traer una guía. Y también la utilidad (murmullos). ¿Es útil o no es útil lo que estoy haciendo?

Alumna 2: siii

Alumna 3: ¿Qué está haciendo?

Alumna 4: enseñándote po

Profesora: es una pregunta retorica

Alumna 3: ah

(Murmullos y conversaciones entre alumnas)

Alumna 5: Alison... ¿teni lápiz mina?

(Murmullos y conversaciones continúan)

Alumna 6: profe... (Otra alumna tose)

(Continúan los murmullos y conversaciones inteligibles, se agregan sonidos de lápices chocando en las mesas)

Alumna 7: Profe, no lo entiendo...

(Continúan las conversaciones y sonidos de autos desde fuera)

Profesora: ¿Quién puede comenzar a leer la guía?

(Alumnas se sorprenden)

Profesora: Ya, la Javiera... Y atentas que cualquiera puede seguir la lectura... (Murmullos y conversaciones)... Ya comience Javiera.

Javiera: Los fundamentos de la moral, la naturaleza humana. Existen diversas posiciones respecto a los fundamentos de la moral humana. La primera, que examinaremos... a continuación es de la propia naturaleza humana. Raúl y Roberto discuten respecto al derecho de propiedad. Raúl siguiendo una tesis marxista afirma que él... ah, creer que 
una persona tenga propiedades de ciertos bienes, especialmente de producción, le da un poder sobre otras personas, lo que determina una situación injusta. Roberto dice que el derecho a la propiedad es un derecho natural del hombre y que es parte de su libertad. Supone Roberto que existe una naturaleza humana y que hay ciertos derechos in... inherentes a esta naturaleza.

Sócrates y Aristóteles pensaron que esta naturaleza humana era la base de la moral. Por eso que Sócrates afirmaba que el actuar moral del hombre se fundamentaba en el conocimiento de la naturaleza y en un actuar conforme a ella. Aristóteles se preocupaba de buscar qué era lo que realmente distinguía a esta naturaleza y lo encontraba a en la vida intelectual.

Ambos filósofos, como también lo hacen después... los filósofos cristianos, piensan que existe una naturaleza humana y que ella nos da la pauta acerca, de lo que es bueno o malo para el hombre. La dificultad que tiene esta posición es poder determinar cuáles son las verdaderas características que forman parte d...de la naturaleza humana y cuáles son características culturales que pertenecen, en las diferentes culturas, se... ser esenciales a esta naturaleza.

Profesora: Muy bien, ¿recuerdan lo que decía Aristóteles y Sócrates?

Alumna 1: Si

Profesora: ¿Qué?... A ustedes que les fue tan bien en la prueba

Alumna 2: ¿cuándo? (murmura)

Alumna 3: cuando hizo la prueba...

(Alumna ríe)

Profesora: por eso no lo digo de manera irónica

Alumna 1: ¿no?

Profesora: noo... lo digo de verdad (ríe)... no todas, pero... la mayoría sí

(Alumnas murmuran y conversan)

Profesora: ¿qué dice Aristóteles y Sócrates sobre... con respecto a la... naturaleza humana?

Alumna 1: eeh...el bien y el mal, y eso...

Alumna 2 y 3: que era la base de la moral (a coro)

Alumna 4: que era la base de la moral... en una polis

Profesora: ¿Quién era ese?

Alumna 1: Eeh...

Alumna 2: Platón

Profesora: no

Alumnas 3 y 4: Aristóteles (a coro)

Profesora: Aristóteles (repite confirmando la respuesta)... ¿Sócrates qué dice?

Alumna 5: que la moral era la base de la felicidad

Alumna 6: no, que la felicidad era...

Alumna 1: que la felicidad...

Alumna 2: era de todos... de toda la población

Alumna 3: ah...

Profesora: Ya, pero la felicidad es consecuencia de algo

Alumna 1: del acto de conocimiento...

(Murmullos y conversaciones)

Profesora: Primero... el ser humano debe conocerse a sí mismo

Alumna 1: para poder... (Murmura)

Profesora: si se conoce a sí mismo, tiene un actuar virtuoso, ¿para quién?...

Alumna 2: para el ser humano

(Murmullos y conversaciones)

Profesora: no era concebible, que alguien conociendo... lo que era bueno... no lo hiciera Alumna 3: sii... 
Profesora: ¿Se acuerdan?

Alumnas a coro: ¡siii!

Profesora: ¿ya?

Alumna 1: ¿y la religión?

Alumna 2: si, si nos acordamos

Profesora: debería... pero no es así (respondiendo a la alumna 1)

Alumna 3: profee... ¿Qué preguntó? ¿Cuál fue la pregunta que le hizo? ¿ah?

(Murmullos y conversaciones)

Profesora: ¿qué dijo? (murmura)... por la religión... (Murmullos y conversaciones)... las religiones sabiendo lo que es el bien no deberían actuar mal, según la... filosofía de Sócrates

Alumna 1: pero no, mmm no

Profesora: pero no deberían... eso no significa que lo hagan... (Murmullos)... lamentablemente ¿ya? ¿Y Aristóteles qué dice?

Alumna 2: que la felicidad tiene que ser colectiva

Profesora: ¿Por qué?

Alumna 2: era el bien común

Alumna 3: porque tiene que ser el bien común, por el...

(Murmullos y conversaciones)

Alumna 4: ¿Para quién profe?... ¿para Aristóteles?

Alumna 5: para Aristóteles (respondiendo a A4)

Profesora: para Aristóteles

Alumna 1: porque si no las personas no van a poder reflexionar entre todas las cosas que tienen ordenadas por cada uno...

Alumna 2: y tiene que ser...

Alumna 1: cada uno depende del otro

Profesora: ya... el gobernante debe tener la facultad de prever

Alumna 4: tiene que tener la virtud... de un buen comportamiento y as...

Profesora: hoy en día nuestros gobernantes, ¿siguen la línea de Aristóteles? (interrumpe a A4)

Alumnas a coro: ¡nooo!

Profesora: ¿Por qué no?

Alumna 1: porque no muestran respeto

Alumna 2: porque no dice tener bien en claro una polis

Alumna 3: porque no les preocupa de por sí la gente

Profesora: ¿cómo están... están tan seguras de que no piensan en el bien común?

Alumna 1: porque son ladrones

Alumna 2: no

Profesora: ¿todos son ladrones?

Alumnas a coro: ¡nooo!

Alumna 3: no, no le enseñaron a hacer bien

Alumna 4: no sé, porque no los conozco

Alumna 5: porque no... por lo hechos po'... nos damos cuenta que no hacen el bien común con lo hechos que ellos hacen y las cosas que hacen

Profesora: ya...

Alumna 5: que empiezan a hacer y ante eso uno saca una conclusión de que no se están fijando de qué es un bien común

Profesora: Muy bien, uno puede tener eeh... hay un dicho que dice que el camino al infierno está lleno de buenas intenciones, la intención no cuenta...

Alumnas a coro: ¡siii!

Profesora: ... si no se realiza la acción (continuando la idea anterior) 
Alumna 1: si, es verdad es como...

Alumna 2: mi mamá dice eso

Alumna 3: los hechos hablan más que las palabras

Alumna 4: si...

Profesora: ¿ya?

Alumna 1: cuando le digo que me voy a portar bien me dice "quiero hechos no palabras"

Profesora: Justamente... profesora nos vamos a portar bien (citando a las alumnas)

Alumna 2: palabras, palabras (bromeando)

Alumna 3: puras falacias (bromeando)

(Alumnas ríen a coro)

(Murmullos y conversaciones)

Profesora: bueno, si quiere yo sigo... yo doy las instrucciones para un trabajo y ustedes trabajan igual que la clase pasada

Alumna 2: noo... no.. noo...

Alumna 2: yapos chiquillas no hablen, no hablen...

Alumna 3: quédense calladas mejor

Profesora: Si ustedes saben cómo me pongo, así que... (bromea)

(Alumnas rien)

Alumnas: ¡pa' qué me invitan! (bromean y ríen, a coro)

Profesora: ya, otro fundamento de la moral, es el deber

Alumna 1: ya

Profesora: poder eeh... Darling lea

Alumna 2: nooo (suplica) no empiece a leer

Profesora: lea (indicando a una alumna que lea)

Alumna 3: no...no, si yo no voy a leer

Alumna 4: profe, yo... yo quiero

Alumna 3: no me gusta leer

Profesora: si, le gusta leer

Alumna 3: no, no quiero

Profesora: si, de hecho le gusta que la escuche el resto

Alumna 3: noo...

Alumna 2: si, es verdad eso

Alumna 3: no, de verdad no me gusta leer en voz alta

Alumna 5: ya...

Profesora: lea el primer párrafo...

Alumna 3: noo...

Profesora: son dos líneas

Alumna 3: no

Profesora: ... la esperamos...

Alumna 2: ¡Ay! Darling lee..

Alumna 3: ¡Ay! No me gusta

Alumna 1: échela pa' fuera profe

Alumna 3: cállate vo

Profesora: ¿y si la echo pa' dentro?

(Alumnas ríen a coro)

Profesora: yapúes Darling (suplica)

Alumnas 3: no profe, no me gusta leer en voz alta... mire me pongo roja

Profesora: No está roja

Alumna 2: ta negra po'

(Alumnas ríen)

Alumna 4: tai morá 
Alumna 5: ¡uh! Ya yo voy a leer

Alumna 3: no, eeh... no voy a leer

Alumna 2: ya lee (dirigiéndose a alumna 5)

Alumna 6: La ámbar lee...

Alumna 4: La ámbar va leer profe

Alumna 1: Ya dijiste eso...

Profesora: ¡shh!... ya ámbar

Ámbar: ¿Leo yo?

Profesora: Si

Ámbar: (lee la guía) El deber. La ética formulada por Kant es conocida como la ética del deber. Este deber se refiere a un mandato que debemos cumplir. Así como la razón teórica se preguntaba ¿Qué puedo...

Profesora: para...

Ámbar: (continúa leyendo)...conocer? la razón práctica se pregunta ¿qué debo hacer?...

Profesora: hasta aquí, para un poquito (ámbar detiene la lectura) ustedes eeh... la... razón (alumna ríe) teórica la vieron en teoría del conocimiento, ¿Qué es lo que realmente conoce el ser humano? Cuando vieron a Kant...ósea perdón...

Alumna 2: sii

Profesora: vieron a Descartes, vieron Locke...

Alumna 1: (Interrumpe a la profesora) a Descartes si... (Sonido de hojas de cuaderno)

Profesora: ¿y vieron a Kant?

Alumnas a coro: ¡nooo!

(Alumnas comienzan a discutir entre ellas sobre si vieron la teoría del conocimiento de Kant)

Profesora: si no lo vieron ahí...

Alumna 2: (interrumpe a la profesora) sii lo vimoos (afirma efusiva)

Profesora: ... lo vieron conmigo, porque yo si lo he pasado... (Continua su idea)

(Alumnas nuevamente comienzan a discutir sobre el mismo tema)

Alumna 3: recuerde que hubo un mapa conceptual que lo... mezclaba, creo que era de las dos... Kant con...

(Comienzan a discutir entre ellas nuevamente)

Alumna 3: si, pero eso lo nombró nomas, no... no profundizamos

Alumna 4: que es como una mezcla entre las dos

Profesora: (continúan conversando) pero era lo necesario para ese momento

Alumna 3: es que como sabíamos... como sabíamos... las dos teorías, había que mezclarlas nomás con él, entonces no...

Profesora: es que es más que mezclarlas

Alumna 3: eso dijo

Profesora: ...pero sí

Alumna 3: no lo... profundizamos

Profesora: Ya... continúe... Ámbar

Ámbar: (continúa leyendo) “¿Cómo debe ser la conducta humana? ¿A qué se refiere el mandato que debemos cumplir? Kant se interesaba por lo universal y que estuviera más allá de toda experiencia, cosa que se logra a través de... de lo formal puesto por el hombre: espacio y tiempo y categorías." ¿Sigo? (pregunta a la profesora)

Profesora: Siga (le responde a ámbar) Ah no mejor que siga la.... Eeh... Pamela... (alumna ríe) que la veo atenta a su celular, entonces por eso quería...

Alumna 3: el imperativo abajo (indicándole donde debe leer a su compañera)

Profesora: el subtítulo de la... del deber

Pamela: Ah... (comienza a leer) "imperativos hipotético y categóricos. En la ética Kant distingue también un aspecto formal, que es el que le da la calidad moral a la acción. 
Existe un... mandato ético, un... imperato (alumnas ríen en voz baja) que ordena, no lo que... ¿ah?" (es interrumpida)

Alumna 2: imperativo (susurra a Pamela).

Pamela: (corrige la palabra y continua la lectura) "imperativo que ordena, no lo que debemos hacer, sino el cómo hacerlo. Él no encuentra presencia o ausencia de la buena voluntad. El filosofo formula" (alumnas murmuran, ríen e interrumpen la lectura)

Alumna 2: esa nooo... (susurra)

Alumna 1: te saltaste una línea (en tono de risa)

(Alumnas ríen fuerte)

Pamela: butaa profeee.... (Se queja) me hacen pasar vergüenza... (Continúan riendo)...

Profesora: Ya basta...

Pamela: ¡yaa...! (con tono avergonzado)... (Continúa la lectura) “... fundamental la materialidad de las acciones. Según Kant, una misma acción pude ser buena o mala, según la presencia o ausencia de la buena voluntad. El filósofo formula así un... imperativo moral"

Profesora: Hasta ahí...

Alumna 1: (lee la guía) "Obra de tal modo que la máxima de tu voluntad pueda valer siempre, simultáneamente, como principio de legislación universal. Crítica de la razón pura, uno, uno, uno, uno... (bromea)"

(Alumnas ríen a coro)

Profesora: ya... ¿qué dice Kant con respecto al actuar moral?

Alumna 2: quee....

Alumna 3: que una acción puede ser buena o mala

Alumna 4: es un aspecto formal

Profesora: yaa... que una acción puede ser buena o mala ¿dependiendo de qué?

Alumna 2: de la acción... de la presencia o ausencia de voluntad

Profesora: yaa.... ¿y cuál es la... cita eeh... que aparece ahí que es importante de Kant?

(Alumnas murmuran)

Alumna 1: que la voluntad siempre va valer

Profesora: yaa...

Alumna 1: que pueda valer

Alumna 2: es lo mismo

Profesora: algo va ser considerado bien por lo que yo debo realizar (REVISAR)

Alumna 1: es como algo bien que hay que considerar todo, es un...

Profesora: que sea universal

Alumna 1: ¿cómo?

Profesora: no va ser dependiendo el evento, del lugar o la persona

Alumna 1: mmm....

Profesora: (interrumpe) A ver por ejemplo, si yo considero que eeh... el robar está mal

Alumna 1: (interrumpe)

Profesora: ... si a mí me roban, está mal

Alumna 1: si, pero...

Profesora: pero... si yo veo por ejemplo a mi hermano chico que está robando, yo no voy a justificar su acción con que es un niño chico... está mal igual

Alumna 2: sii

Alumna 1: universal, ¿se refiere a todo... a todo momento?

Profesora: si

Alumna 1: o a universal de....

Alumna 2: (interrumpe) posiblemente

Profesora: sin excepciones

Alumna 1: ah ya... 
(Alumnas murmuran)

Alumna 1: yo quiero, yo quiero...

Alumna 3: dalo vuelta

(Alumnas ríen)

Profesora: continúe eeh... Tiare

(Alumnas murmuran)

Tiare: ¿ah? (sorprendida)

Profesora: continúe leyendo

Tiare: Eeh... (Comienza a leer) "Este imperativo es categórico, es decir, valido siempre para todos los hombres; no está sujeto a ninguna condición. Pero existe según Kant, otros imperativos, a los cuales llama hipotéticos y que son válidos si se acepta la condición que plantean. Por ejemplo: si quieres ser respetado, debes ser honrado con tus negocios; la persona puede no aceptar la condición y no interesarse en ser respetado por los otros"

Profesora: Muy bien

Alumna 1: ah ya sé... ósea que sí... a mí no me gusta que me hagan eso, yo no lo tengo por qué hacer (afirma en tono de pregunta)... o una cosa así (afirma dubitativa)

Alumnas a coro: claramente

Profesora: y hay... hay acciones que son consecuencia de algo que yo estoy haciendo (alumnas murmuran) Si yo quiero que me vaya bien en la asignatura...

Alumna 2: (interrumpe) tengo que estudiar

Profesora: .... debo estudiar y poner atención a la profesora. Si me va mal, es consecuencia a lo mejor de alguna acción mía (sonidos de lápices sobre la mesa)... ¿ya?

Alumna 3: o que la profe nos tiene mala (bromea)

Profesora: porque la profe me tiene mala no, difícil que un profesor les tenga mala

Alumna 3: oh qué difícil (en tono irónico)

Profesora: es difícil porque los profesores generalmente los ven como eeh...

Alumna 2: como niñas....

Profesora: noo..., como sujetos en edu... en proceso de educación, no va ser determinante para su vida (alumnas ríen) y ustedes son un estudiante más muchas veces, de muuchos que tienen.... De muchos que tienen de muchos que vienen, entonces que les caiga mal...

Alumna 1: pero, igual puede ser...

Profesora: pero es que es difícil, a mi por ejemplo me puede caer mal un igual

Alumna 1: ¿Qué? (tono de asombro)

Profesora: un igual me puede caer mal

Alumna 1: como un... un prototipo

Profesora: noo... una... una persona madura, que tiene la misma edad que tú, con la misma profesión, pero que me caiga mal un estudiante... es como...

Alumna 2: ¿rebajarse?

Profesora: no es rebajarse, pero es casi.... Me parece raro

Alumna 1: ¿es como muy inmaduro?

Profesora: sii... (Alumnas ríen) es como me pongo a tu nivel porque no sé

Alumna 1: a mí me pasó (murmura)

Profesora: a mí me puede caer mal... la actitud de alguien me puede caer mal, pero ¿caerme mal por completo? Noo...

Alumna 3: si, yo si...

(Alumnas murmuran y conversan)

Alumna 2: ay yo encuentro eso de la actitud, yo encuentro que es como una excusa para decir que te cae mal una persona

Profesora: ¿cómo? 
Alumna 2: por ejemplo, me cae mal tu ac... actitud, es como eso y al final te cae mal la persona

Alumna 3: es que puede ser que....

Alumna 4: ¡Uhhh!

Profesora: cuando a uno le cae mal alguien y uno dice que eh... la persona completa le cae mal, puede que haya muchas acciones que a usted le desagraden, pero por una actitud yo voy a decir que el otro me cae mal, porque no voy a globalizar una sola acción y voy a determinar a un sujeto me cae mal

Alumna 4: ¡Uhhh!

Profesora: ... por eso eeh... le digo, que tiene que eeh... haber varias actitudes que caigan mal... para que yo pueda.... (Alumnas conversan)... ¿se entiende?

(Alumnas murmuran y conversan)

Profesora: (alza la voz por el ruido) lamentablemente... ustedes como adolescentes absolutizan las acciones de otros...

Alumna 1: profe... y usted...

Profesora: me miró mal, me cae mal (citando a las alumnas)

Alumna 2: igual tiene sentimientos...

Profesora: si tengo sentimientos, aunque no se me noten...

(Alumnas conversan)

Alumna 3: si se le notan, se le notan...

Profesora: Yo soy de pocas.... De pocas emociones... me puedo reír, pero no llegar así como... a una emoción no

(Alumnas continúan conversando)

Profesora: ya continúe eeh... Carla

Alumna 3: la Bárbara profe

Alumna 4: Noo... la Ámbar

Profesora: no, la Bárbara va leer el amor (refiriéndose a un subtítulo de la guía)

(Continúan conversando fuerte)

Alumna 1: yo quiero leer el amor por favor (suplica)

Profesora: ¡sshhh!! (hace callar a las alumnas que conversan fuerte) yaa.... Carla... (Continúan conversando) Ya chiquillas cállense para que su compañera.... Pueda... leer

Alumnas 2 y 4: ¡shhh! (hacen callar a sus compañeras)

Carla: (lee la guía) "La voluntad se da a sí misma esta ley, por lo cual es libre y autónoma. Lo importante en el actuar moral será actuar por el amor al deber, por amor... (es interrumpida)

(Dos alumnas conversan murmurando)

Profesora: ¡shh! (las hace callar)

Carla: (continua la lectura) “...y respeto a esa ley, y ésta es la que constituye la grandeza moral del ser...humano. Todo lo demás eeh... (Felicidad, bienes... espirituales y materiales) está su...pe...ditado a esta voluntad.... buena voluntad (corrige)."

Profesora: Muy bien, ¿qué sería importante entonces en el deber?

Alumna 4: el amor al....

Alumna 2: el amor al.... deber

Alumna 3: el amor al deber

Alumna 1: la pasión a las cosas que hay en nuestro entorno, como... ehh...la pasión al trabajo, a las personas, a enseñarles, cosas así

Profesora: primero, n...no la pasión, sino la buena voluntad

(Suena el timbre)

Alumna 1: entonces... si yo actuó por el amor a hacer eso eeh... tengo una buena voluntad

Profesora: pero eeh... tiene que considerar factores 
Alumna 1: como... la felicidad, bienes, etc

Profesora: en primer lugar la regla de oro

Alumna 2: ah, siiii (grita)

Alumna 1: siempre la regla de oro...

Profesora: si mi voluntad va dirigida a algo que eeh... puede dañar a los demás, no debería realizarlo

Alumna 2: ah claro...

Alumna 1: porque yo sé que está mal, entonces no... no debería

Profesora: porque voy a hacer daño a otras personas

Alumna 1: claro...

(Alumnas murmuran y conversan)

Alumna 1: si yo soy buena con las personas que no son buenas conmigo, no estoy cumpliendo la regla pero estoy como

Profesora: usted debería ser... como considera que es mejor y no... determinar su opción por otras personas, porque si no estaría determinando la acci... su propia voluntad, su propia acción dependiendo de con quien tenga al lado

Alumna 1: ah, yo sería heteró... noma

Profesora: sii, yo debo ser yo misma

Alumna 2: profee

Profesora: si le caigo bien a otro bien, si no...

Alumna 2: ¿qué pasaría con una persona que tiene buenas intenciones, pero cuando lo... lo realiza no quedó bien? O no le salió como quería... o le afectó a alguien que no pensó que podía afectarle... ahí sería como... se dejaría como alguien malo o se quedaría como... (Murmura)

Profesora: si lo hizo eeh... no pensando en dañar al otro, yo no lo podría considerar malo, a lo mejor es... si se podría hacer responsable de la acción, pero no con la intención de dañar a otro, no tendría mucha...

Alumna 3: afecta pero no lo hace con la intención, o no lo consideró

Profesora: no actúa de mala fe

Alumna 2: Profe

Profesora: noo... (Alumna ríe) no porque denante estaba (REVISAR)... en Sócrates sí, ahí si... en Kant no

Alumna 1: tú decides con qué filósofo te quedas

Profesora: yo creo que uno no puede seguir solamente a un filósofo...

Alumna 1: no...

Profesora: uno hace una mezcla de...

Alumna 1: siempre, para todo...

Profesora: ...conocimientos y debe actuar por sí mismo

Alumna 1: pero si...

Profesora: pero si ustedes se guían solamente por un filósofo, a lo mejor van a estar a.... a destiempo con respecto a su actuar

(Alumnas murmuran)

Profesora: ¿Hoy en día podrían ustedes dedicar tanto tiempo al ocio como le dedicaban los griegos?

Alumna 1: ayy sii, por favor...

Profesora: como mujeres... imposible... el ocio era masculino

(Alumnas se quejan, ríen y murmuran)

Alumna 3: ¿por qué solo el hombre?

Profesora: porque el ciudadano.... ¿Quién era considerado ciudadano?

Alumna 2: hombre (contesta rápido)

Alumnas a coro: el hombree 
Alumna 4: el hombre (con tono burlesco)

Profesora: el hombre... ¿qué tipo de hombre?

Alumna 3: ¿y las mujeres?...

Profesora: ustedes...mmm, no. Por lo tanto si siguen a Sócrates al pie de la letra...

Alumna 1: no somos ciudadanas

Profesora: no son ciudadanas

(Alumnas murmuran y conversan)

Profesora: ¿Qué dice Aristóteles de las mujeres?

(Alumnas conversan murmurando)

Alumna 3: ¿Qué?

Profesora: ¿Qué dice Aristóteles de las mujeres? (repite la pregunta)

Alumna 1: ¡ay yo vi eso...! (grita) es de la teoría de Aristóteles donde dice que son esclavas...

Profesora: no, es mucho más horrendo que decir que son esclavas

Alumna 3: ¿Qué? (sorprendida)

Alumna 4: ¿Qué...? (tono de molestia)

Alumna 5: ¿Qué dijo?

Alumna 6: ya, no te enojes

Profesora: Ahora, si yo me... me guiara solamente por las... por unas frase que dice y no rescatara lo importante de la filosofía...

Alumna 1: sería horrible...

Alumna 2: A ver, qué es lo que dice... qué dice

Profesora: que la mujer es un aborto de hombre

Alumna 2: ¿Cómo?

Alumna 1: ¡¿Quée?!

Profesora: que la mujer es un aborto de hombre (repite)

Alumna 2: pero profe...

Alumna 3: ¿Qué... dijo? (sorprendida)

Alumna 1: tú tenis que irte como a la imaginación de él, porque él dice que los ciudadanos , entonces tú eres para él... algo mal hecho que no... no tenía...

Alumna 2: Profe y Aristóteles, ¿Qué dice de verdad?

Profesora: eso dice

Alumna 1: ah... ¿Y Sócrates?

(Alumnas conversan y murmuran) REVISAR

Profesora: yaa... Bárbara...

Bárbara: nooo...

Profesora: por favor...

Alumna 4: yo quiero leer el amor...

Alumna 2: yo quería leer profe

Alumna 3: yo quiero leer el amor

Alumna 5: se pelean por leer

Alumna 2: yooo....

Profesora: Ya...eeh... Danitza

Alumna 6: no pos profe haga leer a la Bárbara

Alumna 3: ¡haha! (se burla)

Alumna 2: profe la Isa po...

Bárbara: es que eso no lo siento entonces no lo puedo leer

Alumnas a coro: ¡yiaaaa...!

Profesora: ¿Qué? (en tono de sorpresa)

(Alumnas ríen)

Profesora: eeh... ustedes... 
Alumna 1: profe, refute su... su argumento, porque dijo que no sentía amor... si siente por su hermano

Danitza: (Lee la guía) "El amor ha sido considerado tradicionalmente como uno de los motivos...

Alumna 1: (interrumpe) ¡cállense!...

Danitza: (continúa leyendo)... que llevan acciones que tienden al bien. Los sentimientos de afecto, de soli...solidaridad, de amistad, de amor de pareja, de amor de madre o padre hacia sus hijos o de los hijos hacia los padres, llevan a las personas frecuentemente, a tomar decisiones que van muchas... veces contra el propio bienestar o felicidad.

(Ruido de autos desde la ventana)

Alumna 1: ¿Qué cosa?

Profesora: Hasta ahí

Danitza: Ah ya

Profesora: ¿Ustedes creen que esto es así?

Alumnas a coro: siii (en tono desmotivado)

Profesora: ¿Ustedes por amor dejan de hacer cosas?

Alumnas a coro: siii...

Alumna 1: nooo... nooo...

Alumna 2: solo por mis papitos (murmura)... solo por mis papitos (repite y alza la voz)

(Alumnas ríen)

Profesora: llegan... tarde al liceo por quedarse afuera...

Alumna 2: por amor a dormir

(Todas ríen a coro)

Alumnas 3 y 4: buuuuu....

Profesora: si fuese por su papito vendría a clases

Alumna 5: llega tarde a clases (se burla)

(Varias alumnas ríen)

Profesora: recuerdan ustedes cuando el año pasado veíamos eeh... el amor, y veíamos el amor de pareja.

Alumnas a coro: siii

Alumna 1: el amor romántico... (Grita)

(Murmuran y conversan)

Profesora: el amor romántico y el amor maduro... al tipo de amor que se refiere la filosofía como fundamento de la moral, es el amor maduro. Es la entrega desinteresada.

Alumna 1: siii...

Profesora: Yo no puedo decir por ejemplo eh... "si tú... haces esto, entonces te voy a querer más" ¿ya? No son niños chicos, el niño chico si lo hace.

Alumna 1: si, porque yo a mi hermana le digo "dame una pastilla y te llevo donde tu papá" y me dice...

Profesora: por ejemplo, yo cuando eh... reto a mi hijo, mi hijo tiene cuatro años, y él se enoja y dice "pero si tú me amas".

Alumna 2 y 3: aayyy (en tono de ternura)

Alumna 4: sii es verdad

Profesora: sipo, porque lo amo lo hago, pero él no va entender que es por amor que lo estoy haciendo ¿ya?

Alumna 3: por amor te pego (bromea)

Profesora: noo, la oportunidad de golpear a otros no se justifica

Alumna 1: nooo

Profesora: sobre todo si es un niño chico...

Alumna 2: viste, te dije (dirigiéndose a una compañera)

Profesora: ¿cierto...? 
(Alumnas conversan)

Alumna 1: mi hermana es super extraña, y le dice "tú ya no me quieres" (imita voz triste)

Profesora: de hecho, el insulto más grande de un niño chico, sobre todo a la mamá, al papá o hacia los hermanos, es "no te amo más".

Alumnas a coro: siiii

Alumna 3: ah, es verdad

(Alumnas conversan)

Alumna 4: profe...

Profesora: es que los niños repiten... los niños... si, a ver todas las acciones que los niños realizan, son reflejos de lo que le dicen los padres

Alumna 1: noo, no solo los padres o el entorno

Profesora: el entorno cercano, por ejemplo eeh...

Alumna 1: por ejemplo hasta en el jardín pueden aprender actitudes

Alumna 2: siii, si se puede, porque mi abuela le pegaba mucho a mi mamá, y ella hace lo mismo con mi hermano

Profesora: cuando creció eeh... no lo hacían, pero por ejemplo cuando eran chicas a lo mejor si golpearon a alguien

(Alumnas conversan)

Profesora: pero cuando uno considera, sobre todo los niños chicos consideran a los papás ¡shh! (las hace callar porque conversan) hacen todo bien, el niño pequeño no discute mucho con lo que están haciendo los papás, "mi mamá me dijo, mi papá me dijo que así se hacía” el niño no dice "¿en realidad estará bien o estará mal?"

Alumna 3: no, porque no piensa

Alumna 2: no razona...

Profesora: Es heterónomo, por lo tanto, el niño va a repetir la acción del otro

Alumna 1: es menos libre que el adulto, es menos libre porque...

Profesora: es menos libre, si no se hace responsable, no elige por sí mismo

Alumna 2: "yo lo hice porque mi hermano lo estaba haciendo" (ríe)

Alumna 3: pero hay cosas por ejemplo que aprenden afuera de la... casa

Profesora: pero también entra el proceso socializador, con el grupo de amigos, con la escuela.... Ustedes repiten patrones, ustedes imitan a otros para poder ser parte de un grupo. Dudo que alguien que haya comenzado a fumar, lo haya hecho por necesidad propia

(Alumnas murmuran)

Profesora: porque vio a alguien, a un grupo fumando, por ser parte de un grupo, por caerle mejor a otro

(Alumnas conversan)

Profesora: Ya, continúe Danitza...

(Alumnas conversan)

Profesora: ¡shhh! (hace callar a las alumnas)

Danitza: (continua leyendo la guía) "el filósofo Baruch Spinoza en su libro... (Alumnas continúan conversando)

Profesora: ¡shhh! (vuelve a hacer callar a las alumnas que conversan)

Danitza: (continua leyendo)...Ética, se refiere a los lazos de afecto que deben unir a las comunidades humanas. Hace mención especial del odio, como fuente de acciones malas e injustas. El cristianismo tiene como base la esencial de su moral el amor. Frecuentemente, parece que la moral cristiana tiene muchas reglas que cumplir. Desde luego, están los diez mandamientos como mandatos fundamentales, pero el mismo Jesús afirma que toda la ley y los mandamientos se resumen en el amor. San Agustín plantea la ética cristiana como fundamentada únicamente en el amor. Es conocida su frase $<<$ ama y haz lo que quieras $>>$ (sonidos de autos) Para comprender la esta ética 
es indispensable entender el sentido con que se refiere al amor. Se trata de un amor activo, que se hace cargo de las necesidades del otro. El mismo Jesús, al contarle al escriba que los mandamientos se resumen en el amor, cuenta una parábola para representar a qué amor se refiere y cuan exigente es (parábola del buen samaritano)"

Alumna 2: samaritano

Alumna 5: saam... ma...ri...tano

Alumna 3: samaritano (bromea)

(Alumnas ríen)

Profesora: ¿Conocen ustedes la parábola del buen samaritano?

Alumna 3: siii

Alumna 1: no

Profesora: ¿Qué dice la parábola del buen samaritano?

Alumna 2: en que dio agua a un loco que estaba...

Alumna 4: la cami sabe

(Alumnas ríen)

Alumna 3: yo me acuerdo de una canción

Camila: la parábola del buen samaritano cuenta de que había una persona enferma... (Alumnas conversan)

Profesora: ¡shh!

Camila: (continua su relato)... en un... en un camino, donde pasaron cinco personas y ninguna quiso socorrerla, pero paso una persona, un buen samaritano, que tomó a esa persona que estaba herida y la llevo a un curandero, le pagó para que lo cuidara (sonido de bocina de auto), le curara las heridas, le diera vino, le diera , y lo hizo sin recibir nada a cambio, sino que lo hizo de...

Alumna 2: (interrumpe) de buen samaritano

Camila: buen samaritano...

Profesora: ya, pero ¿por qué es samaritano? ¿a qué se refiere?

Alumna 2: ¿persona?

Camila: persona que anda dea... deambulando

Alumna 1: persona que hace...

Alumna 3: persona que ayuda

Profesora: es de un pueblo

Camila: de Samaria

Profesora: sii...

Alumna 2: de Samarita

(Alumnas ríen por la afirmación de alumna 2)

Profesora: como el buen penquista si es que fuese una persona de concepción

Alumna 3: ahh

Profesora: el buen chorero si fuese de Talcahuano

Alumna 4: profe...

Alumna 2: ¿chorero?

(Alumnas ríen)

Profesora: Talcahuano es chorero

(Alumnas ríen y conversan)

Profesora: cuando alguien...

(Alumnas conversan)

Profesora: (repite) cuando alguien realiza un acto por amor (continúan conversando) ¡sh...!

Paulina... uno no espera algo a cambio.

Alumna 1: no

Paulina: lo siento...

Alumna 1: ya no esperas nada a cambio 
(Alumnas conversan)

Alumna 3: quizás emocionalmente

Profesora: si es un amor verdadero, no hay nada a cambio

Alumna 1: si es un amor maduro...

Profesora: justamente, si es amor maduro, no... (Alumnas conversan) ¡sshh! (hace callar a las alumnas)

Alumna 2: pero, uno igual buscaría una emoción de la otra persona

Profesora: pero no necesariamente, a no ser que esa persona sea mi pareja, pero cuando yo realizo una buena acción por amor hacia el otro, como un ente eeh... no espero nada a cambio

Alumna 3: por ejemplo cuando las personas dejan de seguir a otra persona, en el sentido de... de tratar como de querer, aunque esa persona está con otra persona, y eso lo hace feliz... no sé si se entendió

Profesora: si, si te entendí...

Alumna 2: ósea como por ejemplo, por amor a mi papá yo voy a ver a mi abuela

Profesora: por ejemplo... (Afirmando el ejemplo de alumna 2), si... si

Alumna 1: ¿qué? Ah...

Profesora: es desinteresado, es solo por amor a su papá

(Alumnas Conversan)

Profesora: ¿entendió lo que es el amor Tiare?

Tiare: no, no me quedó tan claro

Alumna 3: yaa... profe... (se queja)

(Alumnas conversan)

Profesora: (en voz baja) si ustedes atentas, están esperando que el otro... isshh! (hace callar a las alumnas) ¡Chiquillas silencio!...

Alumna 3: solo esperando... uno lo hizo por... por amor

Alumna 4: noo... si le gusta, pero si... cuando pasa el tiempo por ejemplo y esa persona nunca da nada ¿qué clase de relación es esa?

Alumna 2: pero, ¿cómo?

Profesora: eeh... la manera de demostrar el amor es diferente en las relaciones, puede que haya un complemento mutuo

Alumna 2: pero si tú lo amas y no siente nada

Alumna 4: pero no funcionaría la relación

Profesora: por ejemplo...

Alumna 2: pero pese a que no funcione tú lo vai a seguir amando, aunque terminen

Profesora: hay personas por ejemplo que eeh... (Alumnas conversan) son muy generosas ¿ya? Que dedican mucho tiempo al otro, y el otro le cuesta mucho ser así, pero tiene otras cualidades...

Alumna 2: que ahí se complementan...

Profesora: que complementan la personalidad del otro

Alumna 1: ¡aaay es verdad eso!

Alumna 2: sii (murmura)

Alumna 3: eso puede ser, pero igual es distinta como la atención...

Profesora: pero si la atención no puede ser... no debería ser igual a la tuya

Alumna 3: ¿cómo? no, no, no... no me refiero a que sean exactamente igual, pero es que es...

(Hablan varias al mismo tiempo)

Alumna 1: o no es quizá...quizá no es lo que tú esperas

Profesora: porque si usted entrega... y entrega, y entrega amor, y hay ningún tipo de respuesta positiva de parte del otro... no tiene sentido

(Alumnas ríen) 
Alumna 1: vete de ahí, vuela...

Alumna 3: si...entonces uno en el fondo, no específicamente un qué, pero uno espera como...

Profesora: pero en las relaciones de pareja si... Pero por ejemplo cuando yo eeh... ayudo a otro de manera desi... desinteresada, yo no espero nada a cambio. Cuando por ejemplo, estamos en clases y ustedes eeh... se acercan a preguntar cosas que no tienen nada que ver con la materia... (Alumnas conversan) son muchas veces, y yo respondo y trato de darles soluciones ¿espero algo a cambio?

Alumnas a coro: ¡nooo!

Alumna 1: noo

Alumna 2: en las actividades

Profesora: ya, pero la actividad está relacionada con la materia... pero cuando me preguntan cosas que no están relacionadas con la materia, que son la mayoría de las veces.

(Alumnas conversan y murmuran)

Profesora: ¡sshh! Eeh... valee ya po (dirigiéndose a una alumna)

Vale: estaba hablando la Isidora y yo la hice callar

Profesora: pero, siéntese bien...

Vale: ah... ya

Profesora: Paulina ya pues

Paulina: es que no sé dónde está mi elástico

Alumna 2: pero oye, miserable era mi elástico

(Alumna ríe fuerte)

Profesora: ¡shh!

Alumna 1: Cállense po

Alumna 2: si sé, si me estoy riendo

Alumna 3: ¡pero, yaa!

Alumna 1: ¡cállen...se!

Profesora: ¿Entienden lo que es el amor como fundamento de la moral?

Alumna 2: no

Alumna 3 y 4 : siiii

Alumna 5: si

Profesora: ¿quién no entiende?

Alumna 3: no, no entendí profe... es que empezaron a hablar de amores y me confundí

Profesora: pero el amor está relacionado aquí con el actuar. SI yo actuó de manera desinteresada y por amor hacia el otro

Alumna 1: ah, ese es el amor maduro

Profesora: soy capaz... si, lo que dije al principio, está relacionado con el amor maduro. Por ejemplo, una mamá eh...

(Alumnas conversan)

Alumna 2: ¡cállense!

Profesora: ¡shhh! Que dice amar de manera desinteresada a un hijo, cuando el hijo se quiere independizar, no debería decirle "hijo no te vayas, que sin ti, me va dar depresión"

Alumna 3: ¡Oy! Es como cuando mi mamá me dice que vuelva a dentista para que me arregle los dientes

Alumna 4: las mamás nunca dicen eso, pero siempre lo sienten...

Alumna 5: es hablar de manipulación

Profesora: no, pero una cosa es que lo sientan, pero el hecho de que impida que el otro se pueda realizar como persona...

Alumna 5: por eso po

Profesora: (continua la idea)... es amor propio y no hacia el otro

Alumna 5: pero no lo dicen... 
Profesora: una mamá... una mamá que tiene un amor maduro, no lo dice... o "yo quiero que estudies derecho porque a mí me hubiese encantado estudiar derecho y no pude"

Alumna 1: ¡ayy eso es amor propio! No amor maduro

Profesora: eeh...s amor adolescente

Alumna 2: típico de mamá

Profesora: ... amor romántico

Alumna 3: ¿ah?

Alumna 4: ¡Quéee!

Profesora: No es amor maduro...

Alumna 2: mi mami dice eso

(Alumnas conversan en voz alta)

Profesora: yaa... continué leyendo eeh... Moya

Alumna 3: (repite) Moyaa....

Alumna 1: haga leer a la Javi

Profesora: lea... la última, el contrato social antes de darles la actividad

Alumnas a coro: ¡nooo!

Alumna 3 y 4: ¡aaahh! (en tono de queja)

Profesora: ¿Qué ah?

Alumna 2: ¿Qué cosa?

Alumna 5: oohh... shaaa

Profesora: ya Moya, el contrato social... (Ríe leve)

Alumna 3: que le salió flaite (ríe)

(Alumnas conversan)

Profesora: ¡shhh!... y eso que no me han escuchado... (Bromea)

Alumnas a coro: ¡aaaayy! (ríen a carcajadas)

Alumna 1: parece que se le salió el brayaan... (Bromea)

Profesora: (ríe)

Alumnas a coro: (ríen)

Alumna 2: el Byron...

(Alumnas conversan)

Profesora: ¡ssshh!

(Continúan riendo y conversando)

Profesora: ¡sshh! Ya chiquillas silencio por favor... Ya Moya

Moya: (lee en voz baja) "El contrato social. El hombre necesita para su sobrevivencia y desarrollo vivir en sociedad, el hecho de vivir en sociedad, con otros seres humanos, le condiciona a tener que renunciar a alguna de las perrogativas...prerrogativas (corrige) que pudiera tener viviendo solo (Alumnas conversan), en vista de otras ventajas que obtiene al vivir en un grupo humano. Es un yo doy para que tú (la sociedad) también me des (alumnas ríen en voz baja). Esta es la base de la moral como un contrato social."

Profesora: (interrumpe) ¡shhh!!

Moya: (continua leyendo) "Entendemos por contrato, en general, el pacto o convenio oral o escrito, entre partes que se obligan sobre materia o cosa determinada y a cuyo cumplimiento pueden ser compelidas. Aquí las partes son: el individuo y la sociedad, se obligan a materias determinadas..."

Profesora: (interrumpe) iishh!!

Moya: (continua leyendo) “...las que muchas veces están organizadas en leyes, las que los individuos están obligados a cumplir y si no lo hacen son acreedores a un castigo. Por ejemplo, la sociedad debe prever... proveer (corrige) a los habitantes de un determinado lugar de condiciones sanitarias que hagan posible una vida sana para todos ellos. Para que la sociedad, con la autoridad que se ha dado, pueda cumplir su 
deber, los habitantes de ese lugar deben pagar impuestos, según su condición económica, deben cuidar el ambiente sin botar basura en lugares adecuados. La sociedad puede obligar a los individuos a cumplir con su parte del contrato a través de multas u oros... otros (corrige error en el texto) castigos y también los individuos tienen medios de reclamar si la autoridad social no cumple con sus deberes. En el caso de la Ética, entendida como un contrato social, diríamos que las acciones moralmente justas son las que cumplen su parte del contrato y las acciones inmorales o injustas son las que no cumplen. En general, los deberes de los individuos están estipulados en leyes. El filosofo francés...." (Interrumpe su lectura con una pausa prolongada)

Profesora y alumnas a coro: Jean-Jacques Rousseau...

Moya: (ríe y continua leyendo) “... desarrolla esta idea de la Ética como un contrato social y la importancia que tiene para el hombre vivir en sociedad, lo que hace posible que llegue a ser realmente humano".

Profesora: Muy bien, ¿Ustedes creen que... en la sociedad en que vivimos...nosotros... se cumple el contrato social?

Alumnas a coro: ¡nooo!

Profesora: ¿Por qué no?

Alumna 2: porque no...

Alumna 3: porque...

Alumna 4: por el intercambio, por ejemplo, la persona dice que... él da si la sociedad también le entrega algo...

Profesora: yaa...

Alumna 4: y al final la mayoría no lo entrega...

Profesora: ¿cómo? ¿Y hay personas que eeh... piden que la sociedad entregue algo a cambio sin que ellos den algo?

Alumna 3: sii...siempre

Alumna 4: ¿Ah? ¿Qué?

Alumna 2: como por ejemplo los estudiantes que piden educación gratis y ni siquiera ponen atención en clases

Profesora: Muy bien

Alumna 3: si...

Profesora: piden educación de calidad y salen a marchar, pero cuando están en clases...

Alumna 5: no ponen atención...

Alumna 6: ni siquiera colocan atención...

Profesora: no ponen atención, se maquillan, realizan trabajos de otras asignaturas

Alumna 2: pintan... (Bromea)

Alumna 1: pero ahí está generalizando profe...

Alumna 4: pa' qué me tira palos...

(Alumnas ríen)

Profesora: es un ejemplo.... (Alumnas continúan riendo)... estamos tirando un ejemplo

(Alumnas conversan)

Alumna 1: es una generalización

Profesora: ¿cómo?

Alumna 2: es que la verdad es que todos los hemos hecho...

Alumna 3: es que la mayoría, todos... prácticamente todo el curso

Alumna 1: no... pero es que hay al... no, no... no pueden generalizar

Profesora: es que no son todos

Alumna 1: pueden ser muchos...no

Alumna 3: prácticamente todos (enfatiza)

Alumna 1: pero hay niñas que...

Alumna 2: no son exigentes 
Alumna 1: ... y marchan, y quiere ser algo en la vida y ponen atención y todo...

Profesora: por eso, yo estoy hablando de las personas que... no dan nada a cambio y que piden mucho...

Alumna 2: y exigen...

(Alumnas conversan en voz baja)

Profesora: O por ejemplo... esperamos eeh... tener educación gratuita, salud gratuita, pero ¿cómo se financia eso?

Alumna 3: con impuestos

Alumna 4 y 5: con impuestos (repiten)

Profesora: y no queremos pagar impuestos

Alumna 1: ay es verdad eso

Alumna 3: como en Alemania, en Alemania pagan impuestos (ruido de autos desde la ventana) de los buses, se pagan impuestos super altos, pero es todo gratis, y uno va como pagando de a poco

Alumna 2: pero es que al final uno igual lo paga

Profesora: eeh... en Finlandia igual... (Ruido de objeto chocando con el suelo) creo que en Finlandia se paga como el sesenta por ciento eh... de su sueldo en... impuestos. Lo tienen todo gratuito

(Alumnas conversan)

Profesora: ¿Aquí cuánto paga el chileno como impuesto?

Alumna 2: nueve porciento

Profesora: en algunos casos

Alumna 2: si

Profesora: otros no pagan... y otros solamente cuando compramos

(Alumnas conversan)

Profesora: aparte de eso, nada más

(Alumnas conversan)

Alumna 1: y en todas las partes que pagan el impuesto a la renta

Profesora: eeh... el impuesto con la renta va estar declarado por la... (Alumnas conversan)... por la remuneración

Alumna 3: yo encuentro que eso es mucho

Profesora: ¿por qué?

Alumna 3: porque no se recibe como... eeh ah... está bien eso es poco porcentaje, pero hay familias que ni eso tienen... (Alumnas conversan)

Profesora: ;shh!

Alumna 3: ... como para pagar

Profesora: ¿cómo qué?

Alumna 3: por ejemplo... mi hermana no está nunca en la casa y... (Alumnas conversan)

Profesora: ¡ishh!!

Alumna 3: ... y le salen cuarenta mil pesos de luz y es como super absurdo... y los paga igual, pero... no sé... yo encuentro que eso...

Profesora: pero es que eso es una... eeh... no es impuesto po, eso es un consumo

Alumna 4: si

Alumna 3: yo creía que el agua, la luz... y todo eso era impuesto (en voz baja)...

Alumna 2: no

Profesora: no, eso es consumo

Alumna 2: eso es consumo, el impuesto es lo que tú pagai al Estado

Profesora: Ahora, el impuesto especifico que tienen por ejemplo la razón...

Alumna 5: igual es distribuido por la oferta

Alumna 3: oee si son como ladrones 
Profesora: y el hecho... el hecho de que... ustedes o todos en realidad paguemos harto el pasaje...

Alumna 4: subió caleta...

Profesora: ...es parte del impuesto específico. Ahora, ¿de dónde ese impuesto específico.... Después de qué?

Alumna 2: del alza de precios...

Alumna 3: de la bencina...

Profesora: ¿Cuándo surgió...

Alumna 1: (interrumpe) del dólar...

Profesora: no, antiguamente no existía ese impuesto. ¿Cuándo surgió ese impuesto?

Alumna 1: ¡Ah!... ¿para del terremoto?

Profesora: para el terremoto del ochenta y cinco...

Alumna 1: (interrumpe) siii, si me acuerdo

Profesora: ... que se iba a utilizar para la reconstrucción de las carreteras

Alumna 1: siii... y todavía están...

Alumna 3: si, si, si..

Alumna 1: si, si nos dijeron

Profesora: y hoy en día, las carreteras ¿las modifica el estado?

Alumnas a coro: ¡nooo!

Profesora: no, son concesionarias... y que más encima uno tiene que pagar altas sumas de dinero en peaje...

Alumna 1: sii, eso igual es verdad, hay harta plata que no se ve

Alumna 2: mi mamá se enoja con eso

Alumna 5: ¿y la plata dónde está? (bromea)

Alumna 2: porque dice que....

(Alumnas conversan y ríen)

Alumna 2: la están arreglando con plata de ellos y las calles de un auto por ejemplo...

Profesora: pero eeh... (alumnas conversan en voz alta) las calles no son de los autos, la calle es de todos y todos pagamos impuestos. Lo que pasa es que esos impuestos ya no son destinados a las... a las carreteras, son... son para otras cosas. Y eso es bueno porque eeh...

Alumna 2: pero a quien le quitan espacio por ejemplo, no es a los... peatones, es a los ciclistas

Profesora: Pero solamente para los ciclistas

Alumna 5: habla más fuerte...

Profesora: porque el espacio que están quitando aquí en el centro, en realidad no lo están quitando, sino que eeh... le están dando más oportunidad a más personas, porque espacios hay....

(Alumnas conversan)

Alumna 2: pero al final no...

Profesora: y estacionamientos para vehículos hay muchos... para bicicletas nada...

Alumna 2: pero cobraan (se queja)

Profesora: si pues, pero si uno pide un servicio, tiene que pagar... doy para que me den

Alumna 1: en comparación a lo... a los para autos, no hay tantos...

Profesora: no pu

Alumna 1: porque aquí uno camina y hay un estacionamiento pu

Profesora: aquí en el liceo ustedes si quisieran, ¿Podrían venir en bicicleta?

Alumna 5 y 6 : nooo

Alumna 1: no

Alumna 4: no pu, no hay ningún...

Profesora: si 
Alumna 2: si se puede

Alumna 1: ¿dónde dejo mi bici?

Profesora: si tiene...

Alumna 6: si, en el patio

Profesora: en el patio, donde pecan y.... al lado del comedor están los... bicicleteros

Alumna 1: me voy a venir de Santa Juana en bici a las cuatro de la mañana (bromea)

(Alumnas ríen a coro y luego conversan)

Profesora: ¡Actividaaad!

Varias alumnas a coro: ¡noo!

Alumna 2: naaa

(Alumnas ríen y conversan)

Alumna 3: profe, ¿se entrega la actividad?

Profesora: no, en su cuaderno

Alumna 3: ¿y la va revisar?

Alumna 2: si, la entregan el miércoles...

Profesora: justamente... la reviso el miércoles

Alumna 1: profe... y eso del impuesto ¿cuando uno compra con tarjeta también va el impuesto?

Profesora: el hecho de comprar ya uno está pagando impuestos... porque está... incluido el IVA

Alumna 4: ¿En la boleta?

Profesora: si

(Alumnas conversan)

Alumna 1: en los contratos de arriendo también

Profesora: eeh... el impuesto a la renta va depender de... del sueldo que uno tenga, del monto que uno reciba, no todos pagan impuestos

Alumna 3: ah, no sabia...

(Alumnas conversan)

Alumna 2: profe... sabe que mi tía tiene una casa por ejemplo en Valle Noble, y uno paga por vivir ahí, que es un sector como más...

Profesora: pero ahí paga... como gastos comunes

Alumna 2: no me acuerdo

Profesora: que es diferente, porque ahí uno paga para que... le vayan a cortar el césped

Alumna 2: no, no, no... aparte. No, el césped no... uno tiene que pagarlo

Profesora: pero ¿hay guardias?

Alumna 2: no

Alumna 3: no, uno paga por vivir en un sector tranquilo, si por ejemplo...

Alumna 2: si...

Profesora: ¿las contribuciones?

Alumna 2: ¡esoo!

Alumna 3: eso (repite)

Profesora: ah, pero es que eso... es diferente, si...

Alumna 3: pero eso no lo paga...

Alumna 4: eso lo pagan en todos lados, a mi papá igual le pasa

Alumna 3: no, eso no lo paga

Profesora: no... no lo pagan en todos lados, depende de los metros cuadrados que tenga una casa, depende del sector

Alumna 2: y es super caro

Alumna 4: quién más va paga contribuciones, nosotros no vivimos en un sector...

Profesora: ¿dónde vive usted?

Alumna 4: Penco 
Profesora: ¿Cuánto... tiene su casa? ¿Cuánto mide? ¿Es grande?

Alumna 4: no... es chiquitita

Profesora: pero, ¿en qué sector de Penco está?

Alumna 4: Villarrica

(Alumnas conversan)

Profesora: yaa... actividaaad, número uno (continúan conversando) (dicta) Elegir...

Alumna 3: ¿ah?

Profesora: (repite) Elegir... (Alumnas conversan) un problema moral... y analizarlo... desde el punto de vista... de cada uno...

Alumna 1: ¿punto de vista de?

Profesora: (repite) de cada uno, de los fundamentos morales vistos

Alumna 1: de cada uno ¿de los?

Profesora: (repite) fundamentos morales vistos...

(Alumnas susurran)

Alumna 2: ¿de los fundamentos?

Alumna 3: (le responde a alumna 2) morales vistos

Profesora: (continua dictando) y... número dos. Juzgar...

Alumna 4: no soy quien para juzgar (bromea)

Profesora: si puedes juzgar, el juicio no es una crítica ni está... ni es algo determinado

(Algunas alumnas ríen)

Profesora: ya... (Continúa dictando) Juzgar, la realidad de la sociedad chilena

Alumna 6: ¿juzgar la realidad?

Alumna 4: de la sociedad chilena

Profesora: (repite)... de la sociedad chilena actual, según las posiciones estudiadas...

Alumna 3: ¿según las qué?

Profesora: (repite)... las posiciones estudiadas

Alumna 3: ¿posiciones o posesiones?

Profesora: posiciones... y...

Alumna 5: ¿posiciones cómo?

Profesora: posiciones estudiadas... y analizar...

Alumna 4: ¿qué dijo? ¿Y analizar?

Profesora: sí... (Continua dictando)... En qué aspectos... se da o no... ese ideal ético

Alumna 2: ¿se da o no?

Profesora: (repite) ese ideal ético...

Alumna 2: ¿eso nomás?

Profesora: solo eso

(Alumnas conversan)

Profesora: lo pueden realizar eeh...

Alumna 3: ahora... (Bromea)

Profesora: ósea lo tienen que realizar ahora, pero puede ser en parejas o en grupo, pero cada uno lo tiene en su cuaderno... ¿ya?

Alumna 2: profee...

Alumna 1: profe... profe... profe...

(Alumnas conversan y ríen)

Alumna 4: profe, la actividad de la semana pasada... ¿se le entrega el cuaderno o la hoja?

Profesora: no... el cuade... eh la hoja

Alumna 4: pero ¿era en parejas o individual?

Profesora: en parejas

Alumna 1: sabe que a mí en la hoja que le pasó el profe sale un cuatro pelado si...

Profesora: ¿sí?... 
Alumna 1: si... y ahora sale un cuatro ocho acá. Y ¿qué promedio me dio? ¿Un seis tres o no? Yo tenía un cinco ocho, de eso... eso era. Me bajó caleta y se acuerda que usted había dicho que la actividad creo que era el seis que tengo ahí, que... lo iba... lo íbamos a subir porque no... lo había hecho prácticamente sola y era en parejas... ¿se acuerda de eso? Se acuerda que usted me dijo "después hablamos" y quedamos afuera hablando...

Profesora: ¿del mito de la caverna?

Alumna 1: si... era como un informe que había que entregar

Profesora: si...

Alumna 1: y era en parejas y... yo al final hice todo

Profesora: ¿y con quién lo había hecho?

Alumna 1: con la maría josé, ¿se acuerda?

Profesora: ¿qué maría josé?

Alumna 1: la... la rubia... la cote... Salamanca

Profesora: ahh...

Alumna 1: ¿se acuerda?

Profesora: me acuerdo

Alumna 1: si, ve...

Profesora: si, si me acuerdo

Alumna 1: y al final nunca...

Profesora: ya... vas a realizar eeh... un power point

Alumna 1: ya, voy a anotar... espéreme profe

Alumna 4: profe... ¿es un problema moral que una persona eeh... supuestamente a uno le da algo... algo a una persona, pero no quiere que esa persona le de algo a cambio?

(Alumnas conversan)

Profesora: $\mathrm{mmm}$... si y no

Alumna 4: ohh, pero ¿por qué? ¿cómo qué?

Profesora: es que podría ser algo más... más trascendente, algo más social para que tus compañeras lo puedan comprender mejor... (Alumnas continúan conversando) Por ejemplo... eh... el tema de... eeh... medioambiental en Quinteros

Alumna 5: (interrumpe) profe... ¿me da permiso para ir al baño?

Profesora: (continua la idea anterior)...ese es un problema moral

Alumna 1: oye... en Quinteros, ¿ahí donde falleció el caballero?

Alumna 2: murió... se asfixio...

Profesora: no... a él lo mataron y se sabe

Alumna 1: y por qué dicen entonces que se... medio raro...que yo leí las historias, la...la noticia y decía que... sale por asfixia, pero sale que lo matar... ¿cómo se va a asfixiar?

Alumna 1: no entiendo eso

Profesora: y estaba golpeado...estaba... no... es que ahí... está en investigación

Alumna 5: (reitera su petición) profe... ¿me da permiso de ir al baño?

Profesora: eh... si

Alumna 1: no, se le va hacer tarde para hacer el trabajo

Profesora: va tener que correr

(Alumnas conversan)

Profesora: el problema es que... es que esta situación se está dando no solamente en Chile Alumna 1: fue horrible

Profesora: Es una situación a nivel internacional... ¿dónde deje mi celular?

Alumna 1: se lo robaron...

Profesora: ahí está

Alumna 1: (repite) ahí está... y la Vania no se da ni cuenta...

Alumna 5: Vania... (La llama y se ríe) 
Alumna 1: (riendo) la profe dejó el teléfono en tu puesto

Profesora: ¿dónde lo dejé?

Vania: no, éste es el mío

Alumna 1: (ríe) hahaha... la Vania...

Profesora: No, yo lo dejé ahí el mío... eso está diciendo.

Vania: no, sipo...

Profesora: Pero es que lo yo andaba buscándolo, no lo... no recordaba que yo lo había dejado ahí

Alumna 4: no sé qué es eso, ¿qué es eso?

Alumna 1: ¿qué cosa?

Alumna 4: qué es eso que se refieren de tema... problema moral, eso

Alumna 1: tiene que tener un problema...

Profesora: (interrumpe)... vaya a su cuaderno...

Alumna 1: a nivel social (susurra)

Profesora: (continua su idea) vea en la materia, cuando estábamos viendo qué es la moral, qué es considerado un problema moral

(Alumnas gritan y conversan)

Alumna 4: algo que está fijado por la sociedad

Profesora: ya...

Alumna 4: ¿podría ser un problema moral entonces que... capturen a las mujeres?

Profesora: eeh... ¿la agresión a las mujeres? O ¿capturan en qué sentido?

Alumna 4: que sea...

Alumna 1: (interrumpe) No, es sobre las mujeres, si han desaparecido niños y todo eso... no ve que la Tamara todavía no aparece...

Profesora: no, si, si... si sé... Ya pero véalo como caso de desaparición de mujeres...si

Alumna 4: ¿sería un problema moral? (susurra)

Profesora: social y moral, si...

Alumna 1: si, porque nos afecta a toda las...

Alumna 4: ¿sería un problema...

Profesora: (interrumpe) moral es eh... perfecciona alguien... ¿nos perfecciona como ente la persona que está haciendo desaparecer a otra?

Alumna 4: no

Alumna 1: no

Profesora: no pu, no es moral, ósea es inmoral...no nos orienta hacia el bien

(Suena el timbre)

Alumna 1: ¿ósea que no sirve como problema moral?

Profesora: si pu, eso estoy diciendo

Alumna 1: ¿tocaron?

Alumna 4: profe... ¿terminó la clase?

Alumna 1: nooo (en voz baja)

Alumna 4: entonces, ¿ese sirve como problema moral?

Profesora: si... si, está bien

(Termina la clase, las alumnas conversan) 


\section{ANEXO 11. OBSERVACIÓN DE CLASE DE PEDRO}

Profesor: Les presento a la profesora Rosse Marie Vallejos, ella es... profesora de filosofía emm... (Alumnos ríen de fondo) trabaja en la Universidad de Concepción... eh... préstenme un segundo de atención... eh...Cárcamo asiento eh... (ruido de sillas y mesas) y, va acompañarnos la clase de hoy, solo va a observar, nos va a acompañar en... en la clase de hoy.. emm... eso

Profesora: Buenos días, me voy a sentar...

Profesor: si...

(Ruido de sillas, alumnas conversan)

Profesor: ya... les voy a pedir que saquen sus cuadernos...

(Algunas/os alumnas/os ríen)

Alumna 1: ¿para qué?

Profesor: ¿cómo que para qué?

(Alumnas/os ríen a coro)

Profesor: vamos a repa... primero, vamos a tener que hacer una pequeña reseña de lo que estábamos haciendo ayer, para poder responder a las preguntas...

Alumna 2: el de al medio...el de al medio le están diciendo...

(Alumnas/os conversan)

Alumno 1: ¡conchetumare...!

Alumna 2: (silba)

Alumna 3: ¡Cristóbal!

Alumno 2: ¿Qué...?

Alumna 3: emprestame el estifix

Alumno 2: Stifix... (en tono de burla)

Alumna 3: Es...ti...fix..

Alumno 4: préstame... no emprestame...

Alumna 2: ¡ay...! Ya...

(Ruido de sillas y mesas)

(Alumnas ríen y alumnos conversan)

(Continúa ruido constante de sillas y mesas)

(Alumnas/os conversan y ríen)

Alumna 2: ¿Querís naranja?

Alumno 2: ya...

Alumno 1: ¡yo quero...!

Alumna 1: ¡Víctor...!... préstame el... el cuaderno...

Víctor: ven a buscarlo

Alumna 1: déjamelo ahí

Alumno 2: La Karen dijo, que los recordara que hoy día que tenían que depositarle la plata del curso...

Alumno 3: la otra vez no me la depositaron a mí...

Alumna 3: de...po...si...tar...

Alumna 2: a mi igual

Alumno 4: a mí me tienen que depositar

Alumno 2: pásame el estifix

Alumno 3: ¿Qué plata?

Alumno 1: el jefe... te tiene que depositar a ti...

(Alumnos ríen a coro y luego conversan)

Profesor: ¡Daniel....!

(Alumnas/os continúan conversando en voz alta)

Profesor: ¡Ya...! 
(Alumnos continúan conversando)

Profesor: hoy día... vamos a... terminar lo que empezamos ayer

(Alumnos conversan)

Profesor: lo primero es eh... reunirnos en grupos de cuatro... vamos a hacer una segunda lectura del texto que... les pasé ayer, espero que no lo hayan perdido

Alumna 1: (interrumpe) ¡Víctor, ¿esto es electivo?;

Víctor: ¿Ah?

Alumna: (murmura) ¿Es electivo?

Alumno 2: iprofe... profe!

Profesor: $i$ ah?

Alumno 2: no lo traje...

Profesor: si, voy a pasarles unas...

Alumno 4: ¡y al final, final, final, final...!

Alumno 5: más le vale...

Profesor: y... eh.... Luego vamos a trabajar en grupos, en las preguntas que...

Alumno 1: ya po...

Alumno 2: es caleta...

Alumno 1: vengo motivao

(Ruido de sillas, mesas y conversaciones)

(Comienzan a organizarse los grupos)

(Alumnos/as conversan)

Profesor: ya... ¿Quiénes son los que llegaron ahora entonces?

Alumno 2: ¿Qué pasa conmigo?

Profesor: ¿usted llego ahora?

Alumno 2: no, a la... a la ocho cuarenta

Profesor: tengo ausente el tres, cinco y el... diecinueve

Alumno 4: ¿profe estoy ausente?

Profesor: Ruiz.... Estás ausente...

Alumno 4: ah... llegué en el bloque

Profesor: $i$ ah?

Alumno 4: póngame... presente

Profesor: no... si po... el cinco.... Víctor

Alumno 2: estai ausente...

Alumna 1: está aquí el Víctor

Profesor: ¿llegaste en el recreo?

Víctor: no...

Profesor: ¿y el diecinueve?

(Alumnas conversan)

Profesor: Scarleth...

(Algunas alumnas ríen, y luego conversan)

Profesor: cinco, seis, siete, ocho, nueve, diez, once, doce, trece, catorce, quince, dieciséis, diecisiete, dieciocho... (murmura) diecinueve, veinte, veintiuno...

Alumno 4: ¿y tú...?

Alumna 1: ¿Qué dijiste?

Alumno 4: anda a tu puesto...

(Alumnas conversan)

Profesor: ¡Ya...! estamos...

Alumno 1: ¿Quién faltó ayer?

Alumno 2: ¿Hay que responder las preguntas cierto profe?

Alumno 1: (repite) ¿Quién faltó ayer?

Alumna 3: ¿Qué cosa? 
Alumno 4: ¡уо....yo!

Profesor: tú estabai ayer...

Alumna 3: ¿Qué dijiste?

Profesor: lo perdió...

Alumno 4: no...

Alumno 2: jooh...!

Alumno 3: iprofe...!

(Alumnas/os conversan)

Alumno 3: iprofe...!

Alumno 4: ¿iQuién tiene un rojo que me preste!?... me preste....

(Alumnos/as conversan)

Alumno 3: iprofe...!

(Alumnas/os conversan)

Alumno 2: ¡Cristóbal!

(Alumnos/as conversan)

Profesor: ¡ya! empecemos a trabajar por favor...

(Alumna ríe)

Profesor: Primero... eh...

(Alumnos conversan en voz alta, se gritan desde un extremo a otro)

Alumno 2: ¡ya escucharon!

Alumna 1: ¡shh!

Alumno 3: hay que responder preguntas, ¿las tres cierto?

Profesor: si...

Alumna 1: ¡shh!

Profesor: calma, calma, calma... Primero, presten atención. Bueno, ya... hay algunos que faltaron

Alumno 2: ¿Qué pasó?

Profesor: Eh... hay algunos que faltaron ayer... eh... tratemos de retomar la clase, en lo que quedamos ayer iya? Primero, estábamos viendo un texto sobre... que se llama "Somos psicosocialmente sexuados" ¿ok?

Alumno 2: ¿Cuál?

Profesor: Leímos... y después hicimos eh... algunas preguntas que... a todo esto, representa la quinta nota a...cumulativa ¿ya? Y...

Alumno 3: (interrumpe) Héctor culiao... (murmura) me revisó la wea...

Profesor: dicho sea de paso...no, dicho sea de paso, con esta quinta nota, vamos a sacar un promedio (Alumnos conversan) ¿ok? Así que... lo que vamos a hacer hoy día es... uno, leer eh... esto, vamos a contestar las preguntas en grupos de cuatro y luego, vamos a seguir trabajando emm... vamos a seguir trabajando, vamos a ver otra cosa que es un cortometraje bastante interesante, y vamos a hacer eh... grupos de discusión ¿ok?...

Alumno 3: ¡Profe... i $i Y$ las preguntas?

Profesor: Las preguntas las vamos a trabajar después de leer, por segunda vez... vamos a leerlo, por segunda vez sí, porque ayer lo leímos, y... como... no... no pudimos entregar la sala, porque la llave estaba perdida y perdimos como la mitad de la... hora en eso...

(Alumna ríe)

Profesor: Así que... después llegamos y no alcan... solo alcance a darles las preguntas, a leer y a darles las preguntas, y ahora vamos a trabajar en las preguntas... y eso ¿ok? Así que... básicamente, casi todos están en la misma situación

Alumno 2: ya, entonces empecemos...

Profesor: ya... hagamos una pequeña lectura de esto y me van ayudando algunos ¿ok? 
Alumno 1: ¿o qué?

Profesor: ¡ya!... ya primero, yo voy a empezar a leer y quiero que me siga... eh... Villegas...

Villegas: no...

Profesor: si... (comienza a leer) “¿Somos psicosexualmente sexuados? No solo somos... biofisiológicamente sexuados, sino que también nuestro psiquismo, toda nuestra organización...

(Alumnos conversan)

Profesor: (interrumpe la lectura) Guarden los celulares...

Alumno 2: ya profe...

Profesor: (continua la lectura)... toda nuestra organización social, y nuestra cultura, son sexuados. Desde el nacimiento asignamos, nombres, vestidos, juguetes, actividades, etc... sexuados" siga... Guillermo.

Guillermo: espere profe...

Profesor: incluso...

Guillermo: (continua la lectura) "Incluso se supone una manera de ser, aficiones, pensamientos, y deseos sexuados. Antes de que el niño o la niña tomen consciencia de su identidad sexual, le asignamos un rol sexuado que afecta... prácticamente a todas las dimensiones y actividades de su vida." ¿Sigo yo?

Profesor: Si...

Guillermo: (continua la lectura) "Todas las sociedades y culturas asignan actividades específicas, al hombre y a la mujer, y lo hacen de forma... a veces muy distintas."

(Alumnos conversan)

Profesor: sigue... Toledo...

Toledo: ¿Desde dónde profesor?

Profesor: Todas, todas estas... todas las sociedades (le indica dónde quedó la lectura)

Toledo: (murmura) todas las sociedades...

(Alumnos conversan)

Profesor: ¡Shh!

Alumno 1: Thank you...

Profesor: todas las sociedades y culturas...

Toledo: (continua la lectura) "Todas las sociedades y culturas, asignan actividades específicas, al hombre y a la mujer, y lo hacen, de forma a veces, muy distinta. Estas asignaciones, no se basan en general en diferencias biológica... biológicas, sino que... en la mayoría, de los casos, se basan en formas de funcionamiento social que se han...cristalizado a lo largo de la historia..."

Profesor: ya... detengámonos ahí un segundo, ¿recuerdan hace unas clases anteriores? Antes de... la semana pasada, cuando estuvieron en paro y todo eso, estuvimos viendo lo... el... caso de tres tribus... en nueva guinea, y las tres tribus tenían comportamientos diferentes ¿recuerdan esos comportamientos?

Alumno 3: si...

Profesor: ¿cuáles eran algunas a ver?

Alumno 4: Eh... no, no lo recuerdo

Profesor: ¿Cómo se comportaban en uno?

Alumno 2: ¡ah! Que en uno mandaban mujeres, eh...en otros mandaban los hombres... y el otro eran... más neutros

Alumna 1: Que uno... las mujeres trabajaban y el hombre se queda en la casa

Profesor: Eso... en una como que las mujeres tenían el... la posición como dominante, tomaban las decisiones ¿cierto? más importantes y... eh... las tareas domesticas las llevaba el hombre, y... en otra de las tribus...

Alumna 1: era igual

Profesor: guarda eso... 
Alumno 2: guarda el celular...

Profesor: en otra de las tribus ¿cierto? había una equidad entre las tareas domesticas, de ambos géneros, y en la otra tribu, pasaba todo lo contrario ¿Qué es lo que pasaba ahí?

Alumno 3: eran machistas...

Profesor: ya... eran más machistas ¿cierto? Tanto hombres como mujeres ¿cierto? tenían... una actitud eh... confrontacional, agresiva, celosa ¿cierto? Eh... y... no, no reconocían en la formación de la crianza a... algún aspecto positivo ¿ya? Y cada cultura... ¿Qué es lo que habíamos concluido de eso? De cada una de estas tribus...

Alumno 3: profe, no entendí la pregunta

Alumno 2: tenían diferentes costumbres del mismo ciclo

Profesor: tenía una cultura distinta ¿cierto? y que esa cultura repercutía en... cómo uno se... Alumno 4: en lo social

Profesor: en lo social, y también en nuestra identidad sexual ¿ya? Ya... Sigamos leyendo... Eh... Cárcamo... ¿puedes... leer el tercer párrafo?

Cárcamo: No...

Alumno 2: el Allan quiere leer...

Profesor: Por favor, gracias... muy amable

Cárcamo: de nada...

Profesor: ¿No? No quiere leer...

Alumno 2: el Allan quería leer...

Profesor: ¿Allan quiere leer?

Allan: Ya... (murmura) ¿Desde ahí?

Profesor: si... tercer párrafo

Allan: (comienza a leer) "Hacia los dos y tres años, niños y niñas toman consciencia de su identidad sexual (se autodefinen como niño o niña) y,... simultáneamente, comienzan un proceso de aprendizaje e interiorización de las funciones que la sociedad considera propias de la niña o del niño (roles de género)" ya...

Profesor: Sigo yo... (continua la lectura) "La identidad sexual: soy hombre o soy mujer, pasa a ser una categoría permanente de los juicios que el sujeto hace de sí mismo, tal vez lo más... (Corrige) la más importante, y el rol de género, aquel que más define la vida de las personas a lo largo del ciclo vital. ¿Qué otra cosa cambia más la forma de estar en el mundo que el hecho de ser hombre o mujer?” ¿Cierto? Nos determina el hecho de cómo nosotros...

Alumno 3: vamos a ser tratados...

(ruido de puerta)

Alumno 2: ósea que podría ser... como la gente nos impone ser...

(Alumna ríe)

Profesor: adelante... pase...

(ruido de puerta cerrándose)

Profesor: Ya... Entonces repito la pregunta, dice... “¿Qué otra cosa cambia más la forma de estar en el mundo que el hecho de ser hombre y mujer? ¿cierto? No... podri... si nosotros nos vemos los géneros ¿cierto? Nos diferencia bastante el hecho... que una de las cosas que más vemos ¿cierto? es el hecho de ser hombre o mujer ¿ya? (continua la lectura) "También... desde edades muy tempranas, los tres y los cuatro años, niños y niñas, manifiestan intereses sexuales, se autoexploran, hacen preguntas, se observan, construyen sus propias teorías sobre su origen, la reproducción, etc., y ponen de manifiesto...

(Alumnos conversan)

Profesor: (continua la lectura) “... y ponen de manifiesto conductas sexuales a través de los juegos y otras conductas. Es decir, expresan en conductas su sexualidad" ósea, los niños de cierta manera... y culturalmente son impulsados a... a la... jugar... 
Alumna 2: a la jugar...

Profesor: a jugar con ciertas cosas

Alumno 3: las muñecas o el balón

Profesor: ¿cierto? ya... hoy en día, lo que discutiamos en una de las clases anteriores es que... se va cambiando la perspectiva de eso ¿ya? (Alumnos/as conversan) Por ejemplo... por ejemplo hoy en día eh... el tema de los colores, que hoy en día nos... los hombres usamos colores eh... no necesariamente tan...

Alumno 2: yo tengo un compañero que usa rosado...

Profesor: exactamente... a eso, ve...

(Algunos alumnos ríen)

Profesor: vamos cambiando la perspectiva de eso, de la demarcación como...

Alumna 2: ...pero, se ve entero lindo si...

(Algunas/os alumnas/os ríen)

Profesor: lo que culturalmente conocemos como "estos colores son de hombre, estos colores son de mujer"

(Alumnos/as conversan)

Profesor: Voy a terminar de leer... de leer esto...(continua la lectura) "A la conducta sexual...

(Alumnos/as conversan)

Alumno 2: hay que dejarlo que hable nomás...

Profesor: terminemos de leer el último párrafo y vamos a las preguntas después... (continua la lectura) "A la conducta sexual observable, subyacen los deseos, los sentimientos y las fantasías, que son elementos fundamentales de la psicología sexual... (Alumnos conversan) Estos se especifican..." (interrumpe su lectura) Víctor, sigue la lectura... (continua la lectura) "...estos se especifican y consolidan...

Alumno 4: ¿dónde están escuchando música?

Profesor: ¿Quién está escuchando música? Eh...

Alumno 4: ¿Dónde vamos profe?

Profesor: Miguel...

Alumno 1: como se le ocurre...

Profesor: Miguel... apaga tu... celu..., tú igual...

Víctor: (continua la lectura) "Estos se especifican y consolidan en la pubertad y permanecen a lo largo del ciclo vital. Por tanto para entender la sexualidad, no basta con conocer la anatomía y la fisiología sexual, sino que... (Alumnos murmuran y conversan)

Profesor: ¡shh!

Víctor: (continua la lectura) “... es necesario tener en cuenta también la psicología sexual y la cultura en la que el individuo vive".

Profesor: Ya, muchas gracias Víctor... (Alumnos murmuran y conversan) Ya... ¿Qué es lo que buscamos con el texto? Abrir una temática ¿cierto? De cómo nosotros y nuestra cultura, influye sobre nuestra identidad y específicamente sobre nuestra identidad sexual. Ahora, hay ciertas preguntas que ayer di... que quiero... que trabajemos en grupo. Toledo, ¿puede leer la número uno? ¿Cómo dice ahí?

(Alumnas/os murmuran y conversan)

Toledo: Cuenta una situación de tu vida escolar, familiar o de amigos, donde se muestre lo que se espera de los hombres y mujeres.

Profesor: Ya... hay que contar una situación, que puede ser... aquí en la... vamos a lo que... a ver si las pueden conseguir... el... compañero, ¿vinieron ayer o no?

Alumna 3: me llamo compañera

Profesor: compañero... o compañera

Alumno 2: compañeres

Profesor: compañeres 
Alumna 3: no, no vinimo ayer

Profesor: ¿no?

Alumno 2: no

Alumna 3: y no me dio la hojita que ocupo ahora

Profesor: vamos a... dame un segundo

Alumno 1: yo tampoco vine ayer...

Alumno 4: suelte las preguntas...

Profesor: ya voy a... vamos a... anoten las preguntas...dame un segundo

(Alumnas/os conversan)

Profesor: Ya... la primera dice... (Alumnos/as conversan)... ¡Anoten!... anoten... La número uno dice... (lee las preguntas) "Cuenta una situación... (interrumpe la lectura) Los que no estuvieron ayer que son... los cuatro que están acá.... ¡Guillermo!... Eh... Matamala...

Alumno 3: ya...

Alumno 4: ¿cuál era la primera?

Profesor: Anoten... las preguntas, después no... (Alumnos conversan) La uno dice (lee las preguntas) "Cuenta una situación... de tu vida...

Alumna 2: ¿Y la otra?...

Profesor: La número uno dice... (lee las preguntas) "Cuenta una situación, de tu vida escolar...

Alumna 3: ¿Quién tiene mina cero cinco?

Alumno 2: yo...

Profesor: ¿ya?

Alumna 3: ¿me dai porfi...?

Profesor: (lee las preguntas) "Cuenta una situación de tu vida escolar... familiar...

Alumno 2: ¿de tu vida escolar...?

Profesor: (lee las preguntas y repite) “...de tu vida escolar, familiar (ruido de sillas y mesas) o amigos...

Alumno 3: ¿de tu vida...?

Profesor: (sigue leyendo) "donde se espere..."

Alumno 2: ¿familiar?

(Alumnos/as conversan)

Profesor: (repite) con amigos...donde se espere...

(alumnos/as conversan)

Alumno 2: ¿Donde se espere...?

Profesor: eh....

(Alumno tararea y canta en inglés)

Profesor: cómo comportarse...

Alumno 3: ¿dónde se espere...dónde se espere?

Profesor: se espere cómo comportarse...

Alumno 4: ¿Cómo de dónde proviene nuestra identidad...?

Profesor: Déjame... déjame llegar a ese... y lo resolvemos.

Alumno 4: ah ya...

(Alumnas conversan)

Profesor: (sigue leyendo) "...respecto a ser hombre o mujer..."

Alumno 4: ¿Cómo comportarse...?

Profesor: (repite) respecto a ser hombre o mujer...

(Alumnos/as conversan)

Profesor: ya... dos... la dos sigue...

(Algunos alumnos y alumnas ríen)

Profesor: no... (sigue leyendo) "Dos... ¿de dónde provienen las ideas... 
Alumno 4: ya... ahora explique po...

Profesor: ya... por ejemplo, yo tengo... una... una visión sobre... (Alumnas conversan) lo que se espera... iishh!!... sobre lo que se espera de un hombre, por ejemplo, o una mujer, en $\mathrm{x}$ actividad, que puede ser... en la escuela, con mis amigos o una actitud, de un hombre o una mujer x... eh... posición, qué se yo... actividad, de un hombre o una mujer, que sea... o en el grupo de amigos pase o en la escuela, en el liceo ¿cierto? o... en la familia ¿de dónde proviene esa idea y toda esa acción que toma?

Alumno 2: ah, entonces de dónde proviene eso...

Profesor: de dónde proviene eso, por qué... ¿le quedó claro?

(Ruido de objeto golpeando silla o mesa)

Profesor: ¿sí o no?

Alumno 4: si... (Murmura)

Profesor: ya... la dos es "¿de dónde provienen estas ideas? Ya... la tres...

Alumno 3: ¿las dos es cual? ¿De dónde proviene...?

Profesor: (repite) de dónde provienen estas ideas... (Ruido de mesa) La tres...

(Alumnos/as conversan)

Profesor: (lee las preguntas) "consideras....

(Alumnos conversan)

Profesor: la tres dice... Jeremías escucha...

Jeremías: espérese...

Profesor: (continua leyendo) "las ideas... que las pautas y modelos culturales...

Alumna 2: ¿cómo?

Profesor: las ideas que las pautas y modelos culturales.... ¿Consideras que las pautas y modelos culturales.... Influyen... en la conformación sexual?

Alumno 3: (murmura) Ah... esa es fácil...

Profesor: (repite) Consideras que las pautas y modelos culturales, influyen en la conformación sexual...

(Alumnas conversan)

Profesor: Cierra signo de interrogación... y ahí... en la misma pregunta... pone... modelos... culturales...

Alumno 2: espérese...

Profesor: (repite) influyen... en la conformación sexual...

(Alumnos/as conversan)

Profesor: y en la misma pregunta... abren otro signo de interrogación... ¿Por qué?

(Alumnos/as conversan, ruido de sillas)

Profesor: y la última... la cuatro... dice...

Alumno 3: (murmura) ¿cuál es la última?

Alumno 4: (murmura) la cuatro...

Profesor: (continua leyendo) "Qué mensaje entregan los medios de comunicación... (Repite) Qué mensaje entregan los medios de comunicación...

(Alumnas conversan)

Profesor: (repite) Qué mensajes entregan los medios de comunicación... acerca... de lo que se espera de los hombres... y mujeres...

Alumno 2: ¿cómo dijo?

Profesor: (repite) acerca de lo que se espera de los hombres...

Alumna 1: iprofe...!

Alumno 2: ¡qué mensaje entregan los medios de comunicación...?

Profesor: comunicación... acerca de lo que se espera de hombres y mujeres... y entre paréntesis, una situación...

(Alumnas/os conversan)

Alumno 4: ¿son cuatro? ¿Cuatro preguntas nomás? 
Profesor: son cuatro... ya...

Alumno 1: profe, la primera...

(Alumnas conversan)

Profesor: Ya... entonces, nos vamos a reunir en grupos... de cuatro, puede ser... Víctor ahí...

Víctor: lo vamos a hacer de dos...

Profesor: pueden hacerlo de dos... ¿todos van a trabajar de dos?

Alumno 1: profe...

Profesor: dame un segundo...

(Ruido de sillas y mesas, comienzan a juntarse los grupos)

Profesor: Enrique... ¿quién me hablaba?

Alumno 1: yo... es que tenía una duda...

(Alumna comienza a cantar)

Profesor: ¿terminaste Daniel?... dense vuelta...

(Alumnas/os conversan, continua el ruido de sillas y mesas)

Profesor: ya... trabajan las dos, o de cuatro...

Alumna 2: eso le dije pu... de cuatro...

Alumna 1: ¡profee...!

Profesor: dame un segundo...

(Alumnas/os conversan)

Alumno 1: profe, ¿no vamos a usar el cuaderno? Por ejemplo, puedo responder en la uno... (Alumnos/as conversan en voz alta)

Alumno 2: profe...

Alumno 4: profe...

Alumno 5: profe...

(Alumnas/os conversan)

Alumno 2: profe...

(Continúan las conversaciones)

Alumno 2: profe...

Alumna 3: oblígame... a sentarme

Alumno 3: profe... ¿puedo hacer primero las respuestas? Profe...

Profesor: ¿van a trabajar los dos, o van a reunirse con otros? Está Toledo...

Alumno 4: ¿Quién hizo la primera?

Profesor: está... están aquí los chiquillos... ¿y ustedes en qué? Yapos, trabajemos...

Alumna 2: es que estoy haciendo una tarea...

Profesor: no, si lo veo, pero no estamos en biología...

Alumna 2: es de historia

Profesor: sea de historia, lo que sea... estamos en filosofía

Alumna 2: ya...

(Alumnas/os conversan)

Alumna 3: ¿se entrega la hoja?

Profesor: si...

(Alumnas/os conversan)

Profesor: ya... vamos trabajando, vamos trabajando...

Alumno 4: pero cómo...

(Alumnas/os conversan)

Alumna 2: profe... ies una hoja cada uno?

Profesor: pero, ponga los dos nombres...

Alumna 2: ¡profe...! ¿Es una hoja por grupo?

Alumno 3: profe...

Alumna 2: profe... 
Profesor: deme un segundo... no puedo... multiplicarme...

Alumno 3: profe...

(Alumnas/os conversan)

Alumno 3: pro...fe....

Profesor: Jeremías... córtala, estoy aquí... tienes que pensar que estoy ayudando a tus compañeros

(Alumnas/os conversan)

Alumna 3: ¿las puras respuestas?

Alumno 2: nooo...

(Alumnas/os conversan, murmuran y ríen)

Profesor: tienes que pensar... primero en las respuestas... encuentra un situación... una familiar por ejemplo...

(Alumnas/os conversan en voz alta)

Profesor: (murmura) ¿qué se espera de las mujeres en estas circunstancias? Tienes que ir a... algo de tu vida cotidiana, de tus padres, o abuelos..

(Alumnas conversan)

Alumno 1: profe...

Profesor: Cárcamo... espérame...

Alumna 3: Seño Alejandro... Buenas tardes

Profesor: dame un segundo, estoy ayudando acá...

Alumna 3: ¿ah?

Profesor: Supongamos que... hay un terremoto, ¿qué se espera de un hombre? ¿Qué se espera por ejemplo de una mujer? O de...

(Alumnas/os conversan, murmuran y ríen)

Profesor: que se desesperara... o...

Alumna 3: no se desespera...

Profesor: por ejemplo en su casa hay un incendio, y están... su mamá o su papá...

(Alumnas/os conversan)

Alumno 3: profe...

Profesor: o por ejemplo, de un niño de ocho años, qué tipo de juguetes usa...

Alumno 4: yo no tengo juguetes...

Profesor: pero, no nos pongamos tan quisquillosos....

Alumno 3: profe...

Profesor: ya, hace rato me están esperando... ustedes piénsenlo... piénsenlo

(Alumnas/os conversan)

Alumno 3: iprofee!

Profesor: ¿qué mensaje entregan los medios...?

Alumna 1: profe...

Alumno 3: profe...

(Alumnas/os conversan)

Alumno 3: profe...

(Alumnas/os conversan)

Alumna 2: profe... yapu...

(Alumnas/os conversan, murmuran, y ríen)

Alumno 3: iprofeee...!

Profesor: oyee.. yapo... parecen cabros chicos...

Alumno 3: llevo media hora llamándolo pu...

Alumna 2: profe...

(Alumnas/os conversan y ríen)

Alumno 3: profe...

(Continúan las conversaciones y murmullos) 
Alumno 2: Oiga profe... usted me sacó los papeles, y ahora no me los va devolver, me los dejó acá en la mesa ¿cómo eso?

Alumna 2: ¿cómo se escribe... insulsa?

Alumno 2: ¿Insulsa dónde?

(Alumnas/os conversan, ríen y murmuran)

Profesor: Insulsa sería...

Alumno 2: tonto...

Profesor: ya... ¿de dónde proviene...

Alumno 3: profe...

(Alumnas/os conversan)

Alumno 3: profe...

Alumna 2: profe...

Profesor: dígame...

Alumna 2: venga...

Profesor: ¿bien acá? ¿En cuál van? En la uno todavía...

Alumno 2: no, en la dos

Profesor: ya, muy bien...

(Alumnas/os murmuran y ríen)

Alumna 3: profe...

Alumno 2: esto no suena bonito...

Profesor: ¿Cómo se espera que se comporten? Si toman alguna decisión y para hombres o mujeres...

Alumna 2: ¿qué tipo de situación?

Profesor: una situación cotidiana... deme un segundo que me están llamando uno de sus compañeros allá. Tengo que regalarle un presente a...

Alumna/os a coro: ¡uyy...!

(Alumnas/os ríen, conversan y murmuran)

Profesor: por ejemplo... tengo que regalar... pongamos la situación de regalarle algo a alguien... una niña de siete años... ¿qué se esperaría que le regale?

Alumna 2: nada

Profesor: pero hay un sinfín de opciones... no sé, una muñeca, un auto a control remoto... (Alumnas/os conversan)

Alumno 3: tú sabis que el hombre de ahora es así...

Alumno 4: iprofe...!

Alumno 1: profe...

Alumna 3: profe...

(Alumnos/as conversan en voz alta)

Profesor: Ya... la tercera...

Alumno 4: es así, porque nos comportamos desde la crianza...

Profesor: podría ser... pero un poco más elaborado... más...

(Alumnas/os conversan en voz alta)

Alumno 2: profe... profe, profe, profe...

(Alumnas/os conversan y ríen en voz alta)

Alumno 3: ¡Profe...!

(Silbido)

(Continúan las conversaciones en el curso)

(Comienza a sonar música de fondo)

Alumno 3: ¿Hay que entregarle la hojita cierto?

Alumna 2: ¡Profe..! ¿Se colocan... ¿le entrego la hojita?

Alumno 1: Ya profe... me quedo claro, me quedo claro

Alumno 3: profe... 
Alumna 2: ¿se entrega la hojita? Yapu Alejandro...

Profesor: les vamos a agregar una cosa y...

Alumna 2: ah no pu....

Alumna 2 y Alumno 3 a coro: iprofee..!

Profesor: voy altiro... ¿Cómo van esas respuestas Matamala... Cárcamo?

Alumno 4: vamos en la uno...

Profesor: casi todos están terminando...

Alumno 4: pero estamos trabajando

(Alumnas/os conversan en voz alta)

Alumno 2: ¿Qué se espera de las mujeres?

Alumno 3: el miedo weon, es fácil...

Alumna 3: ¡Pro...fee...!

Alumno 2: profe...

Profesor: (bromea) Me extrañan allá...

(Alumnas/os conversan y ríen)

Alumna 4: Profe... ¿cómo se le dice a las mujeres que...

Alumna 2: celosas po...

Alumno 1: ...entonces se espera que... un hombre, ayude más que una mujer, que la mujer al hombre, en cuanto a su fuerza...

Alumno 4: (bromea) Ay... yo soy mitad mujer y mitad hombre...

(Alumna ríe)

Alumna 1: profe...

Alumno 3: profe... iprofee...!

Alumno 4: profe...

Alumno 1: ¡Cristóbal!

(Alumnos/as conversan)

Alumno 2: profe...

(Alumna/os ríen y conversan)

Alumno 1: todo esto empezó cuando...

Alumna 2: profe...

Alumna 3: Vamos...

Alumno 2: ¿qué? Es que estoy esperando a que el profe me pesque...

(Alumnas/os ríen y conversan en voz alta)

Alumna 2: profe...

(Continúan conversaciones y risas)

Alumno 3: profe... ¿cómo de dónde... provienen?

Alumno 2: profe... profe...

Alumna 1: en el caso de los niños, las mamás...

(Continúan risas y conversaciones de fondo)

Alumno 4: profe tome... se lo regalo...

Alumno 2: profe... ¿cómo...

(Carcajadas de alumnas)

Profesor: ¿de dónde sacaron esta idea a ver? ¿Cómo llegamos...

Alumna 3: de su mente (ríe)

(Risas de alumnas)

Alumno 2: profe...

(Continúan conversaciones)

Alumno 1: ¿quién tiene corrector...?

Alumna 3: toma...

Profesor: ya... vayan terminando, vamos a hacer una lectura de las respuestas, y luego vamos a ver un cortometraje cortito... 
Alumna 4: ya, hagamos las tres entonces pu...

(Continúan conversaciones de fondo)

Profesora: ah, está motivada

(Alumna ríe)

Alumna 2: (se queja) ¿por qué me echaste agua?

Alumna 4: yo no fui...

(Conversaciones, risas y murmullos de fondo)

Profesor: Damián, ¿terminaste? Vamos a ver las respuestas...

Alumna 2: eh... profe...

Profesor: ya... está bien... ¿de dónde proviene esa idea?

Alumno 4: iprofee...! ¿Por qué no repite la tres?

Profesor: Calma...

(Conversaciones de fondo)

Profesor: ya... ¿de dónde proviene esta idea? Cómo... le llegó a su mente esa idea... ¿verdad? A base de qué...

Alumno 4: profe...

Profesor: $i$ ah?

Alumno 4: ¿por qué no repite la tres?

(Conversaciones de fondo)

Alumno 4: ¡Profe...sor!

(Conversaciones, risas y murmullos)

Alumna 2: ¡Vic...tor!, Víctor...

Profesor: la pregunta es...

(Alumnas conversan en voz alta)

Alumna 2: las personas que no tienen... la mujer está estresá...

(Conversaciones de alumnas/os)

Alumno 2: profe...

Profesor: ¿sería un modelo ese?

Alumno 1: ya entiendo porque son modelos...

Alumna 1: las personas crecen... creyendo que eso es lo correcto...

Profesor: si... en el hombre, por ejemplo, va depender de...

(Alumnos/as conversan en voz alta)

(Comienza a sonar música de fondo)

Profesor: Oye... apaguen la música...

(Deja de sonar la música)

(Continúan conversaciones)

Profesor: Faltan... ¿Qué otro grupo falta? ¿Quién más?

Alumna 2: no entiendo mi letra

Profesor: ¿Daniela también falta? ¿En cuál vas ahora?

Daniela: en la tres...

Profesor: en la tres... ¿y acá?

Alumno 2: falta la cuatro...

Alumno 1: profesor...

Profesor: dije... no, no, no...Guillermo, oye...

(Conversaciones y gritos de fondo)

Alumna 1: profe...

Profesor: vamos a ver... a leerlas...

(Alumna/os conversan en voz alta)

Profesor: no, no, no... si vamos a leer... ¡shh! ¡Escuchen!... ¡¡Shh!! ¡Escuchen...! (Continúan conversando en voz baja) Un poco de silencio... Gabriel, un poco de silencio, iishh!!... 
(Alumno tararea)

Profesor: vamo... vamos a esperar... un minuto más, a que terminen ¿Terminaron o no?

Alumna 3: un minuto más...

Alumno 2: pero... si están todos, están todos listos

Alumna 3: nooo, falta la...

Profesor: están casi todos listos, falta la... falta ella... no, si estos están listos

Alumno 4: no, la Daniela no...

(Alumna ríe)

Profesor: para poder... para poder leer las respuestas primero... comentarlas...

Alumna 2: profe... mis compañeros me están rayando la cara...

Alumno 3: cata...

Alumna 2: deja de rayar a tu compañera... es mi ropa

Alumno 3: no, es que faltan las chiquillas de allá

(Alumnas/os conversan)

Alumna 4: Bue...nos días, buenas tardes...

Profesor: aquí... vamos terminando...

Alumno 2: la cuatro... nos falta la cuatro

Alumno 1: y la dos...

Alumno 3: Coni...

Alumna 2: ¿ah? ¿Cuál...? ¿La cuatro?

(Continúan conversaciones de fondo)

Alumna 3: profesor... iprofesor...!

Alumno 1: ...el individuo contribuyente... y... cuando se echan desodorante, llegan puras minas...

Alumna 4: ¿Qué...?

Alumno 1: de todo el mundo...

Alumno 3: Se parece al... al Víctor, creo que es igual...

Alumno 4: yo soy más rico sipo... yo soy más rico pa las minas...

Alumno 3: ese es uno de los comerciales machistas, pero son terrible buenos...

Profesor: piense... usted tiene que pensar en un grupo, cómo le entregan una pauta que conforme su sexualidad...

Alumna 2: iprofe...!

Alumno 1: o en facebook, igual pasa...

Profesor: en facebook, instagram...

Alumna 2: profe... ¡Profesor!

Profesor: comerciales que aparecen en instagram...dame un segundo...

(Silbido)

(Conversaciones de fondo)

(Se repite el silbido y aumentan el volumen)

Alumna 1: córtala...

Profesor: Cárcamo... no... cambia eso...

Alumno 3: ¿Por qué me echan la culpa a mí?

Profesor: ¿Quién está silbando?

(Conversaciones de fondo)

Alumna 2: es que se gana al lado de...

Profesor: si los quiero ayudar pue'

Alumna 2: pídele ayuda...

Profesor: yapo...ya, pero dejen de mirar el cuaderno... ¡Shh!... ¡Ya... vamos a leer algunas respuestas!

(Conversaciones de fondo)

Alumno 1: no...profe... 
Alumno 2: no sé leer

Alumno 1: (bromea) ¡No...! No me gusta...

Alumno 2: ¿yo cierto?

Profesor: ya... ¿están listos?

Alumno 1: no, profe... yo no por favor...

Alumna 3: (canta) Uh, oh... uh... oh...

Alumno 4: ya... pero cállense...

Alumna 3: (canta) uh, oh... uh... oh, oh, oh...uh, oh... uh, oh

Alumno 3: yapu cabros... no soy tan capo... lee

Alumno 2: no...

Alumno 3: léelo parado...

Alumno 2: no...

(Conversaciones y gritos de fondo)

Alumno 1: yapo, ¿a quién le toca?

Alumno 5: yo te vi con quien estabai...

Alumno 3: ¿ah?

Alumno 5: (repite) yo te vi con quien estabai...

Alumno 3: párate y lee...

(Conversaciones de fondo)

Alumna 2: ¿Hay que leer la hojita?

Alumno 3: profe...

Profesor: si, voy a leer... voy a leer algunas respuestas

Alumna 2: ¡Ahh...! Adiós...

Alumno 3: Lucy...

Alumno 2: Lucy...

Profesor: ¿terminaron? Eh... Jeremías...

Jeremías: ¿Qué?

Profesor: la hoja...

(Conversaciones de fondo)

Alumno 3: no weon...

Alumno 2: esa es la dos...

Alumno 3: esa no es la dos...

(Alumnas/os conversan)

Alumno 1: ¿Cony entregaste la hoja?

Alumna 2: ¡aarg...!

Alumno 1: Cony...

Cony: ¿Quée...? ¡Quée!

Alumno 1: ¿Qué te hice yo?

Cony: ¡Existir!... ¡Existir!

Profesor: ya cony, asiento...

Cony: ya, pero...

Profesor: anda a tu puesto... a tu puesto

(Alumna grita)

Profesor: A tu puesto, ya... Vamos a... ¡Chicos! Para... ir cerrando...

(Alumno ríe)

Alumno 3: ¡Wujuu!

Profesor: Escuchen, para ir cerrando esta parte...

Alumna 2: ¿Qué hora es?

Profesor: Escuchen... vamos a leer algunas... de las respuestas que algunos... de los grupos

Alumno 1: lea la mía

Alumno 4: la mía... 
Profesor: y... vamos a comentarlos ¿ok?

Alumno 1: deme la oportunidad a mí...

Alumno 2: pásamelo Cony...

Cony: Voy...

Profesor: Pe...ro... necesito que...

(Alumna grita)

(Alumnos/as conversan y gritan)

Alumna 2: ¡si me queda...! Presta el celu...

Alumno 3: yapo...

Alumna 2: anótalo... dieciocho...

Alumno 1: altiro te lo paso...

Alumna 2: ocho diez...

Alumno 3: ocho diez...

Alumna 2: dos catorce...dos catorce nomás

Alumno 3: ¿dos catorce?

Alumna 2: si...

(Alumnos conversan)

Alumna 2: Es el de mi hermana (ríe)... el mío es muy largo...

(Continúan conversaciones)

Alumno 3: dieciocho...

Alumna 2: ocho diez...

Alumno 3: ocho, diez...

Alumna 2: dos catorce...

(Alumnas/os conversan)

Alumna 1: profe... tome...

Profesor: Constanza... pero, ite puedes ir a tu puesto?

(Conversaciones de fondo)

Profesor: ¡Ya!... vamos a contestar eh... Víctor... a tu puesto... eh... Guillermo, asiento... No voy a leer las respuestas, vamos a comentar...

(Conversaciones en voz alta de fondo)

Profesor: ¡isshh!! Ya... lo primero que voy a pedir... (ruido de sillas) es que guarden silencio... Eh... Ana...ya... Vivien... un poco de... atención ¿ya? Voy a leer algunas de las respuestas que... tienen. Voy a leer primero la de... Toledo...

Alumno 3: ¿Le mostré la mía o no?

Profesor: si, si...asiento...ya...

(Conversaciones de fondo)

Profesor: La idea es... vamos a leer las respuestas de algunos, y... vamos a ver si aparecen algunos comentarios... al respecto, dice... la uno dice... "Cuenta una situación de tu vida, escolar, familiar, o de amigos, donde se muestre lo que se espera de los hombres y las mujeres" Toledo escribió... en su respuesta (lee) "Una vez, cuando estaba en el transporte público, un caballero de... unos cincuenta años..."

Alumno 3: ¡Ohh! No me acordé...

Profesor: ¡Shh! (continua leyendo) “... que estaba sentado en frente mío, se le acercó una joven... universitaria... le pidió el asiento...

Alumno 4: esa es...

Profesor: (sigue leyendo) “...el hombre le preguntó: ¿Cuál era su discapacidad, para pedir el asiento?

Alumno 2: ser mujer...

Profesor: (lee) “...la joven le respondió: Que no... que no, porque soy mujer. Y el hombre le respondió: que eso, no es una discapacidad"

(Alumno/a aplaude) 
Profesor: ¿Estará bien esa respuesta o no?

Alumno 2: sii...

Alumna 3: noo...

Alumno 4: es más una historia si...

Profesor: $¿$ ah?

Alumno 4: es como más una anécdota...

Alumna 4: si...

Alumno 4: una historia sin...

Profesor: pero dice... ¿Qué es lo que se esperaba... qué es lo que se... que se hubiese esperado del hombre?

Alumno 3: tenía que haberle pegao'

(Algunos alumnos y alumnas ríen)

Alumno 1: que la pusiera en su lugar pue'

Alumno 2: Ella....

Alumno 5: que se lo merecía...

Profesor: Gabriel...

Alumno 1: técnicamente lo hizo de manera bien.... ¿sí o no?

Profesor: lo que implícitamente o culturalmente hablando... hay una idea, y quizás esta, lo que quería mostrar eh... Toledo... iShh!

Alumno 4: cállense po' cabros...

Profesor: que es... que habitualmente se dice o... quizá más de alguno habrá escuchado alguna vez, que los hombres tienen que ser como caballeros, que tienen que dar como el asiento... ¿han escuchado eso?

Alumno 1: condescendientes...

Alumnas/os a coro: sii....

Alumno 4: toda la vida

Alumno 3: no, yo no he escuchado eso...

Profesor: Ya... (Alumnas ríen) cuando hablamos de pautas, modelos culturales que hemos... adquirido a lo largo del tiempo, justamente, estamos... vemos ese tipo de ejemplos ¿ya? o ese tipo de situaciones. Comentarios, situaciones que hemos visto... en el pasado, que vieron sus papás y que... de una u otra forma, se van replicando... no estoy diciendo que... sean buenos, no estoy diciendo que... que sean malos ¿ya? eh... estoy diciendo que... son modelos simplemente culturales, que están en el pasado, pero que nosotros hoy en día... (Alumnas/os conversan) ¡ishh!! Obviamente, estamos poniendo en... cuestión y los criticamos... porque obviamente, y de hecho la pregunta dice... en la pregunta eh... tres... (Lee) "¿Consideras que las pautas y modelos culturales, influyen en el comportamiento sexual?" Ahí algunos... hicieron una crítica, pero sigamos con esta... la pregunta número uno...

Alumno 5: pero lea otra pu...

Profesor: calma... si eso lo voy a leer...

Alumno 5: otra respuesta

Profesor: voy a leer la de... Cárcamo...

(Risas)

Cárcamo: (se queja) ¡ohh... no!

Profesor: dice...

Alumno 3: chucha, me confundí weon, sorry...

Profesor: la pregunta número uno, dice... ¿Qué pasó?... No hay que entrar en discusión...

Alumno 5: el Toledo...

Profesor: (lee) "En las clases de educación física, cuando el profe separa a los hombres de las mujeres. Así que los hombres eh... hacen trabajo físico y las mujeres, hacen trabajo más liviano." 
Alumno 4: y a las mujeres les piden menos pa' sacarse sietes

Profesor: ¿es verdad eso o no?

Alumno 3: sipo, es verdad po'

Alumno 5: a nosotros nos hacen hacer secuencias, y ellas pared...

Alumna 2: jay... la media distancia!

Profesor: ¡A ver! Convengamos... primero, convengamos una cosa ¿ya? Las... capacidades

físicas de un hombre y una mujer, de hecho, son diferentes po...

Alumna 4: muy diferentes...

Profesor: porque nosotros los hombres, tenemos una capacidad muscular...

(Algunos alumnos ríen)

Profesor: tenemos una capacidad muscular...

Alumno 2: el hombre tiene la facilidad...

Alumno 3: profe... ¿usted es machista verdad?

Alumno 6: profe... pero se le...

Profesor: ya pero... nos escuchamos si hablamos de a uno... Yo hablo primero... después habla... Gabriel... Entonces, los hombres de hecho tenemos una capacidad muscular diferente, hay una ley, que se llama la ley del saco...

(Ruido de sillas)

Profesor: la ley del saco... ¿la conocen o no?

Alumno 4: sii...cuando la mujer no puede levantar más kilos que el hombre...

Profesor: Ya... pero hay una diferencia en kilos entre los hombres y las mujeres...

Alumno 3: pero pa que' tan machista...

(Alumnos discuten)

Profesor: Ya pero... no todo... no todo es... o machista, o feminista, sino que... hay otras cosas que... que son condiciones, que son... eh...

Alumno 4: básicas...

Profesor: básicas... biológicas... y que son así simplemente...podemos cargar un poco más de peso, porque tenemos capacidades musculares más... más altas que las mujeres... que va decir... estimados...

Alumno 1: El hombre y la mujer pueden tener exactamente la misma capacidad física, la diferencia es que...

(Alumnos conversan)

Alumno 1: ... Sin embargo, el hombre y la mujer pueden tener la misma musculatura, exactamente la misma fuerza, incluso una mujer puede tener más fuerza que un hombre, la diferencia es que...

(Algunos/as alumno/as aplauden)

Alumno 1: el hombre puede hacer más ejercicio, hacer la misma rutina que está haciendo la mujer, y va generar más musculatura que la mujer, por un tema hormonal... pero pueden tener la misma fuerza igual

Profesor: esa mira... esa apreciación... podría... podríamos decir de momento que... ya, sí... puede ser correcto, pero... llevémoslo por ejemplo a...

Alumno 4: a dos personas normales...

Profesor: llevémoslo a los atletas... a los atletas, los atletas se supone que tienen una rutina super escrita, los olímpicos... ¿ya? Y aún así las mujeres nunca... van a poder levantar el mismo peso que los hombres... por condiciones fisiológicas

Alumno 3: (aplaude) ¡vamos!

Alumna 2: ¡Mentira...!

Alumno 1: pero profe... las condiciones fisiológicas...

Profesor: vean la halterofilia... ven a los peso que desarrollan las mujeres, ideales y los pesos que desarrollan los hombres, en las categorías de peso...

(Alumnos conversan) 
Profesor: Ya... pero... yo por lo menos sé eso...

Alumno 4: Cony... me rompiste el corazón...

Profesor: hagamos una cosa... yo voy a investigar un poco más, usted investiga un poco más...

(Alumnos conversan)

Profesor: Pero según yo... según lo que sé, hay condiciones físicas, que tienen los hombres que... los va a llevar a poder generar...

Alumno 1: eso es por testosterona, pero los hombres desarrollan la misma musculatura que la mujer, pero no significa que...

Profesor: Mira... fijate en las competencias... en las competencias...

Alumno 4: ¿Quién gano entonces?

Alumno 3: eliminado...

Profesor: Ya... la... siguiente eh.... ¿de quién es?... Sebastián Campos

Sebastián: ¿Qué? No se entiende la letra...

Alumno 4: ¡Eh, eh, eh!

Profesor: Si, si se lee... dice (lee) "Situación...

Alumno 4: Eh, eh, eh...

Alumno 5: nopos, cámbielo...

Alumna 3: situación... (en tono de risa)

Profesor: (lee) "Situación: se da una... pelea, en el liceo... (Alumnos conversan) dice... pelea, dice aquí...

(Alumnos conversan)

Profesor: dice (lee) "lo que se espera... lo que se espera de un hombre es... peliar...

Alumno 4: agarrarse a chorty

Profesor: (lee) "si..."

Alumno 4: sin polera...

(Alumnos/as ríen)

Profesor: (lee) "Sin ayudar...” ¡shh!... "Educar ayuda... o separar el pleito"...

Alumna 1: hombres que...

Profesor: Ya... ahí tenemos otro ejemplo... (Alumnos conversan) estará... voy a tratar de interpretar su situación, el modelo que usted ha... iShh! El modelo... escuchen... el modelo cultural que nos estaba tratando de... ejemplificar el señor Campos, y... me va decir el señor Campos si es correcto o no... (Alumnos conversan) Es que... los hombres de por sí, ¿somos más agresivos está tratando de decir? Culturalmente ha... hay una idea ahí... ¿de que los hombres somos más agresivos?

Sebastián: ¡si...!

Profesor: ¿Qué las mujeres son más pacíficas?

Alumno 3: ¡noo...!

Alumno 5: ¡ay... yo no he dicho eso...!

Alumno 4: que van a ser más pacificas...

Alumno 3: yo he visto mujeres más simios que un hombre...

Profesor: $i$ ah?

Alumno 3: (repite) yo he visto mujeres más simias que un hombre

(Alumnos ríen)

Profesor: no... es eso...

Alumno 3: no... pero si es verdad

(Alumnos ríen)

Profesor: no es eso...

Alumno 2: no, pero hay algunas que son brijidas...

(Alumnos ríen y conversan)

Alumno 5: ¿Sí o no Pato? 
Profesor: seguramente... seguramente hay personas...

Alumno 4: La lianza...

Alumna 3: mi mami...

Profesor: A lo que... a lo que tenemos que ir concluyendo... ósea, lo que tenemos que ir apretando, es que al final... no hay mujeres y hombres, sino que hay personas que son agresivas ¿cierto?

(Alumnos conversan)

Profesor: Hay personas que roban...

Alumno 3: (bromea) yo soy agresivo...

Profesor: hay... personas agresivas, hay personas que... violan, pero no hay que...

Alumno 4: el lucho...

Alumno 3: (repite) el lucho...

(Alumnos ríen y conversan)

Profesor: Vamos con... (Alumnas/os conversan) vamos con la pregunta número dos ¡ishh!! (Lee) “¿De dónde provienen estas ideas? Eh... Allan Concha... Jeremías, y Constanza Moraga... dice... (Lee) "Provienen de las ideas machistas... (Alumno murmura)

Alumno 1: yapos Cristóbal...

Profesor: dice... (Lee) "Provienen de las ideas machistas, de las personas de antes, antiguas... también de la cultura" ¿Será así?

Alumna 2: ¿cómo?

Profesor: vendrán estas ideas de... no sé...

Alumno 4: sipo, antes era peor pu...

Alumno 1: antes era peor el machismo, es verdad

Alumno 4: ante... antes las mujeres, obviamente no hacía nada y el hombre trabajaba... y le pegaba...

Profesor: claro... la mayoría de los hombres...

(Alumnos conversan)

Profesor: de hecho... si lo llevamos a... culturalmente hablando, específicamente en Chile... eh... por ejemplo veamos el tema del huaso... la huasa

(Alumnos conversan)

Profesor: (alza la voz) El huaso... cuál es la figura... qué es lo que... qué es lo que era... qué demuestra el huaso, a ver por ejemplo...

Alumno 3: al hombre de campo...

Profesor: pero que... qué elementos tiene su visión

(Alumnos conversan)

Alumna 3: típico hombre machista... vean la novela...

Profesor: como alguien... bueno, vamos a la novela por ejemplo... hace años dieron una novela que se llamaba...

Alumna 3: no... la de ahora...

Profesor: el señor de la querencia... ¿recuerdan esa novela o no?

Alumno 3: no...

Alumno 2: no...

(Alumnos conversan)

Alumna 3: isla paraíso...

Profesor: no es de este año...

Alumno 4: ¿cuál?

Profesor: el señor de la querencia...

Alumno 5: si...

Alumno 4: si me acuerdo...

Profesor: la visión... la visión del huaso era...

Alumno 3: o los Pincheira... 
Profesor: la visión del huaso era la del que mandaba ¿cierto? que tomaba las decisiones... el patrón como dicen... y la mujer...

Alumno 4: ¿cuál? Fatmagul...

Alumna 3: (se burla) Fat...ma...gul...

(Alumnos/as conversan)

Profesor: estaba dedicada a ciertas actividades que estaban más ligadas a la casa, y no a... a tomar el mando ¿cierto? Así que si... está bien...

Alumno 3: profe...

Profesor: es un tema cultural, es un tema heredado

Alumno 3: ¿cómo se llama una novela que era de unos gitanos?

Alumno 4: la daban en el tvn

Alumno 3: unos gitanos...

(Alumnos conversan)

Alumno 5: oh... esa era wena, no me acuerdo cómo se llama....

Alumno 3: o unos turcos... unos turcos...

Alumno 5: uhh era wea esa, no me acuerdo

Profesor: no he visto de... eso

Alumno 3: ooh...

Alumno 2: ¿no era Romané?

Alumno 3: ¿ah?

Alumno 2: Romané...

Alumno 3: ¡Romané!...

Alumnos a coro: ¡ah... wena!...

Alumno 3: Old School...

Profesor: Voy a leer el otro... (Alumnos conversan) ¡Shh!... el de... Víctor Cisterna... y... Constanza Pavés

Alumna 3: ¿Por qué va así...?

(Alumnos conversan y ríen)

Profesor: La respuesta es... (alumnos continúan conversando) (Lee) "De generación....

(Alumnos ríen y conversan)

Profesor: (lee) "De generación en generación, se le va inculcando a la familia, al hombre a comportarse y ser de cierta forma...

Alumno 3: Los Carmona...

Alumno 4: (riendo) Los Carmona...

(Alumnos/as ríen y conversan)

Alumno 3: Los Venegas...

Alumna 4: (riendo) los Venegas...

Alumno 4: (riendo) Los Venegas pu...

(Alumnos ríen)

Profesor: Oye pero... niños, niños... retomemos, retomemos esto... quedan dos preguntas por contar...

Alumno 1: a mí me encantan Los Venegas...

Profesor: Sé que... hay muchas series divertidas de la vida, pero... enfoquémonos en esto

Alumna 3: ¡qué buenos recuerdos! (ríe)

Profesor: en la tres...

(Alumnos/as conversan)

Profesor: ¡ishh!!... la tres...

(Continúan las conversaciones y risas)

Profesor: (lee) “¿Consideras que las pautas y modelos culturales...

Alumno/a: ¡shh!!....

Profesor: (lee) “....influyen en la... conserva... 
Alumno 2: ¡shh! ¡shh!

Profesor: (lee) “....en la... conformación sexual? ¿Por qué?

(Alumnos/as conversan)

Profesor: el de... Matías Vega y Luciano, Jorge,...y Luis...

(Alumnos conversan y ríen)

Profesor: dice... (lee) "Si... porque en la sociedad siempre ha estado el estereotipo de hombre y de la mujer"...

(Alumnos conversan)

Profesor: Eh... Catalina y Daniel, dice (lee) "Si, porque uno se moldea a base de lo que se ve en la sociedad, la cultura... si influye al momento de identificarnos sexualmente, por ejemplo..."

(Alumnos/as conversan)

Profesor: iishh!!

(Alumnos conversan)

Alumno 2: profe..

Profesor: ¿Qué?

Alumno 2: profe, en cuál va... ¿en la tres?

Profesor: si, en la tres... Si influye al momento de identificarse sexualmente, por ejemplo, dicen que las mujeres deben ser más ordenadas y los hombres más rudos..."

Alumna 2: ¿Qué?

Alumno 4: más vikingos...

Profesor: Sebastián y Joaquín, dice (lee) "Si influye... si la cultura tiene... a través de los años conductas o hechos sexuales, eso se traba...ja a través de los años, a diferentes generaciones"

Alumno 1: dice se traspasa, no se trabaja...

Profesor: (lee) "Se tras...pasa... a través de los años en las diferentes generaciones..."

Alumno 2: no vis, te falta caligrafía...

(Alumna tararea)

Profesor: Acá... este no he leído, el de Daniela Beltrán, Patricia Nazca, y Patricio López... dice (lee) "Si, influye... porque vamos siguiendo los modelos, a medida que vamos creciendo, por ejemplo, que los hombres...

Alumno 3: ¡Listo Cony!... Gracias

Profesor: (lee) “...usen más su pelo corto y las mujeres el pelo largo" Ven... hay tenemos por ejemplo, un modelo o una pauta cultural..

(Alumnos conversan)

Profesor: Si... hiciéramos un conteo... ¿cuántos hombres de aquí usan el pelo corto?

Alumno 3: ¿cómo?

Profesor: uno, dos, tres, cuatro, cinco...

Alumno 5: no... yo tengo el pelo corto...

Profesor: seis, siete...

Alumno 3: a mí no me miren...

Profesor: ocho, nueve... diez, once... doce...

Alumno 4: once hombres

Profesor: Y solamente... ¿Tú quisieras tener el pelo largo?

(Alumnos conversan)

Alumno 5: sipu... pero mi mamá me obliga

Profesor: ves... tu mamá sigue un modelo cultural

Alumno 5: me obligan...

Profesor: Ya...y la última pregunta... la última pregunta eh... dice (lee) “¿Qué mensajes entregan los medios de comunicación acerca de... lo que se espera de los hombres y las mujeres?" Y... había que hacer una situación 
(Alumnos/as murmuran y ríen)

Profesor: Toledo dice (lee) "Nos muestran... ¡shh! (lee) "Nos muestran situaciones...

(Alumnos conversan)

Profesor: ¡ishh!!... Toledo dice... no entendí por qué escribiste eso... Toledo

(Alumnos conversan)

Toledo: sipos, pero ¿por qué?

Profesor: ¿Qué relación hay con la...

(Alumnos conversan)

Profesor: dice... (Lee) "Se muestran situaciones Cliché y personajes...

Alumno 2: ¿Qué es lo que es Cliché?

(Alumnos ríen y conversan)

Profesor: Eh...ya... se muestran situaciones cliché y personajes...

(Alumnas/os conversan)

Profesor: voy a leer...la última... ¡Jeremías!... voy a leer ¡sh! dice cuatro...(lee) "Nos muestran situaciones cliché y personajes genéricos, mostrándonos cómo quieren que seamos, por ejemplo, el típico personaje masculino que es muy fuerte, y la típica acompañante femenina que es débil"... Otro, dice (lee) "Por ejemplo, en los comerciales de limpieza, siempre sale una mujer limpiando... y en los autos salen hombres"

Alumno 2: (en voz baja) ay, ¿y mister músculo?

(Alumnos/as conversan)

Profesor: que la sociedad espera... o tiende ideas en que la mujer se queda limpiando y los hombres, salen a trabajar...

Alumno 2: oiga profe... ¿y qué pasa con mister músculo?

Alumno 1: ¿cuál mister músculo?

Alumno 2: si limpia po, el es hombre...

Profesor: eh...

Alumno 3: eso es porque es el sexo débil...

(Alumnas/os conversan)

Profesor: dice... "Qué personaje... eh... a ver..

Alumno 2: no, no, no...

Profesor: lee la número cuatro

Alumno 2: no entiende ni siquiera su letra ve...

Profesor: ¡Shh!... Gabriel va leer la... respuesta cuatro

Alumna 3: Gabrieel... (Ríe)

Profesor: va ser...

Alumno 4: ¿Quién profe?

Alumno 1: ¿cuál era la pregunta cuatro?

Alumno 3: léala de nuevo

Profesor: A ver... dice (lee) “¿Qué mensaje entregan los medios de comunicación acerca de lo que se espera de un hombre o una mujer?

(Alumnas conversan)

Profesor: ¡ishh!!... Ya... como no me sé mi letra...

(Alumna ríe)

Profesor: Gabriel va leer por mí...

Alumno 2: yaa... profe...

Profesor: ¡ishh!!

Gabriel: últimamente los medios de comunicación han estado... dando, o han estado...

Profesor: escuchemos a Gabriel... iishh!! Escuchemos... 
Gabriel: hablando sobre lo que es el hombre y la mujer ¿ya? Por ejemplo... antes en redes sociales, tú subías una imagen... con un chiste de carácter machista y... se tomaba como algo normal, y ahora...

Alumno 4: todos se ríen...

Gabriel: si vas a subir una imagen de ese tipo... subir una imagen de ese tipo, es como "ah... este tipo es retrogrado", o... no... no apoya la causa... más... actual...

Profesor: ya...

Gabriel: es decir, últimamente los medios de comunicación, entre facebook, twitter, Youtube eh...

Alumno 4: insta...

Gabriel: las noticias, instagram... eh...

Alumno 4: twitter, snatshap, fotolog...

Alumna 2: ¿Qué estai diciendo?

Gabriel: han estado de manera... fotolog...

Alumno 4: la foto...

Gabriel: eh... han estado de manera más abierta a lo que es la inclusión de... género... no sé...

Profesor: ya... muy bien....Eh... claro, lo que vemos hoy en día, es que los medios de comunicación están en una transición ¿ya? Y... obviamente, por las demandas que son... obviamente justas, de buscar igualdad, equidad, entre hombres y mujeres... ¿ya?

Alumno 3: También causan gracia...

Profesor: $m m m$... no creo que haya que entrar en exageraciones...

Alumno 3: ¿por qué no?

Profesor: yo creo que las cosas son así ah... ¿ya? Por ejemplo, tenemos el caso de... bueno...

Alumno 5: ¡Zamudio!

Profesor: si hablamos casos de... violaciones... o... de... malos tratos a mujeres, por ejemplo tenemos... el caso internacional de la manada... ¿conocen ese caso o no?

Alumno 4: no...

Alumno 5: ¿cuál?

Alumno 4: explíquelo...

Profesor: el de... ciertos muchachos... españoles... que... en la fiesta de... de... las corridas de toros ¿cierto? si... hicieron una...

Alumno 1: de cinco imbéciles...

Profesor: eh... no usemos, calificativos...

Alumno 3: cierto...

Profesor: pero... hicieron... eso, incluso grabaron y lo hicieron de una forma premeditada, ósea planificaron qué hacer ¿ya? Entonces... obviamente, obviamente la sociedad está cambiando, y los medios de comunicación tienen que ir... adaptándose a... esos... nuevos estándares, nuevas pautas que estamos estableciendo...

Alumna 4: profe...

Profesor: ¿cómo estamos con el tiempo?

Alumna 4: van a tocar...

Alumno 1: van a tocar...

Profesor: ya... cumplimos...

Alumno/a: ¡wujuuu!

Profesor: cumplimos, pero antes... eh... no salgan, quédense acá

(Alumnos conversan, ruidos de sillas y mesas)

Profesor: no alcanzamos a ver... el corto...

Alumno 1: Aprendí demasiado en su clase profesor... 
Alumno 4: si profe, buena clase...

Profesor: Oye Luis si no han tocado...

Luis: ¿cómo que no?

Alumna 3: si, si tocaron...

Profesor: no, no han tocado... son... las once... pero van a tocar...

(Alumnos conversan, gritan, y ríen)

Profesor: ¿todos entregaron?

Alumno 2: ¿ah?

Profesor: ¿todos entregaron? Si...

(Alumnos cantan, conversan, ríen)

Profesor: ya van a tocar... esperen...

(Continúan conversaciones)

Profesor: eh... un pequeño recordatorio... pequeño recordatorio... recuerden que... mañana hay que terminar la tarjeta squash....

(Alumnos conversan)

(Alumna grita)

Profesor: Si... ya, ya... dejemos de...

(Alumnas conversan)

Profesor: recuerden los que se llevaron el trabajo, porque yo guardé varios en mi carpeta... Alumno 2: yo profe...

Profesor: pero hay algunos que se lo llevaron, así que hay que traerlos mañana... Yo tomé el tuyo... ¿te lo llevaste o lo dejaste en la carpeta?

Alumno 3: ¿cuál tarjeta?

Profesor: la tarjeta squash de formación ciudadana

Alumno 3: no recuerdo...

Profesor: adentro... no han tocado... Ya entonces tienes que traerlo... por lo menos avanzado...

Alumno 3: si profe...

(Alumnas/os conversan, cantan y ríen) 


\section{ANEXO 12. OBSERVACIÓN DE CLASE DE ANDRÉS}

Profesor: Eh... ya, hoy día vamos a... eh, bueno... nos queda nada de clases...

Alumno 1: (celebra) ¡Eh..!

Profesor: yo diría lo contrario... se va ir, así que vamos a hacer un pequeño repaso con... ósea vamos a ver una unidad cortita, penúltima unidad y vamos a hacer una actividad final, dependiendo de cómo estuvieron las notas del test, puede que sea una actividad para... subir un poco el promedio o puede ser una actividad para... calibrar el test ¿ya? Eh... hoy día vamos a hablar de...

(Alumnos/as conversan)

Alumno 2: no vino nadie del centro de alumnos... ahí está pos

Profesor: ¿ya? Vamos a hablar de.... Moral

(Ruido de sillas y mesas)

Profesor: La tercera unidad es... La moral...

(Ruido de sillas y mesas)

Profesor: bueno... eh... antes de... antes de comenzar, yo no voy a dar ningún concepto, eso lo tienen que buscar ustedes... la definición

(Alumnos/as conversan)

Profesor: La palabra moral ¿ya? viene del griego moris que significa... eh... costumbre o norma, la forma en que una persona es... ¿ya? cuando vimos la filosofía de la moral ¿cierto? y vimos los dilemas éticos, por ejemplo, eh... teníamos que ver cómo la gente se comportaba, la cultura... dijimos que dentro de la moral tenía que ver la política, cómo se comporta un gobernante o cómo se comporta una institución ¿ya? Y la palabra ética, que es una palabra de origen latina, pero la palabra ética es... es griega, significa básicamente lo mismo. Ética viene de Ethos, que es también forma de ser o forma de... actuar...

(Ruido de mesas)

Profesor: Entonces dentro de la moral, las conversaciones que ustedes tienen con respecto a la ética, ¿qué... elementos surgen? ¿Qué otros conceptos eh... se ponen en juego?

Alumno 1: ¿en la moral?

Profesor: en cualquiera, en la moral, en la ética...

Alumno 1: lo bueno...

Alumno 2: lo que piense la demás gente...

Profesor: (repite y anota en la pizarra) Lo bueno y lo malo... lo bueno... lo malo ¿Qué más?

Alumno 3: lo justo

Profesor: ya... muy bien, lo justo...

Alumno 2: los prejuicios, lo juicios...

Profesor: A ver, ¿en qué sentido el prejuicio?

Alumno 2: como que son igual... si yo hago esto, como que estoy haciendo mal así... eh... (Risas de alumnos)

Profesor: ¿y cuál será la diferencia entre un juico y un prejuicio?

Alumno 1: el prejuicio es cuando se hace como... antes de conocer a una persona o ciertas cosas, como cuando no sé... uno va en la calle y ve una persona como con prisa y dice " ah no le voy a preguntar"

Profesor: ya...

Alumno 1: eso es un prejuicio...

Alumno 2: pregunta antes de... saber...

Profesor: pongamos la palabra juicio mejor, que abarcaría todo...

Alumno 3: juzgar...

(Alumno ríe)

Profesor: (anota) juicio o juzgar 
Alumno 2: (bromea) no tenis juicio...

Alumno 1: le hice juicio...

Profesor: ¿Qué otra es... proveniente de lo moral, de la ética? Aparte de estas que están acá...

Alumno 2: moral...

Alumno 3: lo que es legal... eh...

Profesor: ya... lo legal...

Alumno 4: lo legal, lo correcto...

Profesor: (repite y anota) La legalidad, lo correcto...

(Alumnos conversan)

Profesor: ¿Nicolás?

Alumno 3: puede ser como actos morales correctos de...más

Alumno 4: lo que está socialmente, culturalmente o moralmente, en los ámbitos de la... crianza...

Alumno 2: ¿las creencias?

Profesor: ¿cómo?

Alumno 4: las crianzas, creencias sobre cuestiones de familia... por ejemplo, como que un hijo tenga que educarse al estilo de los papás, en vez de seguir uno propio de ellos

Profesor: ya... ¿y cómo sería eso?... como un concepto

Alumno 4: sería como un concepto como.... cultural...

Alumno 3: de relación...

Alumno 4: ...libertad, con ciertos modos...

Profesor: ya... libertad lo vimos...

Alumno 1: ¿transformación?

Alumno 2: como la formación...

Profesor: ¿en qué sentido?

Alumno 2: como en la estructura que maneja cada uno...

Profesor: serían las... influencias...

Alumno 2: eso...

Profesor: ¿alguno?

Alumno 2: yo tengo uno, pero no sé como...

(Alumnos conversan)

Profesor: A ver $¡$ shh!

Alumno 2: no, no... pero..

Profesor: pero expréselo como salga...

Alumno 2: podría ser como... como más... lo que la sociedad en sí, dice que sería lo... lo correcto...y eso a medida que... y eso, sería lo que dice "no, esto no está bien..."

Profesor: podría ser... ¿lo normal?

Alumno 2: ósea... no es como lo normal, sería lo correcto...

Profesor: ya tenemos lo correcto

Alumno 1: ¿por qué no podría ser lo normal? Ya pónele lo normal...

Alumno 2: no quiero poner lo normal

Profesor: ya, vamos a poner lo correcto...

Alumno 2: no...no lo ponga... yo no lo dije...

Profesor: ya... yo creo que ahí estamos bien

Alumno 4: ah, hubiese traído el cuaderno de religión

Profesor: ¿Qué vamos a hacer ahora?

Alumno 4: lo normal...

Profesor: Vamos a... en un hoja, vamos a definir, brevemente y luego oralmente...

Alumna 1: (interrumpe) ¿esas palabras? 
Profesor: brevemente...sin buscar en internet... brevemente, las definiciones de lo que está en la pizarra ¿ya?

Alumno 3: bueno

Alumna 1: ¿todo lo que está en la pizarra?

Profesor: $\mathrm{Si}$, en una... en una sola frase...

Alumno 4: bueno, es bueno

Profesor: en una sola frase...

Alumno 4: lo bueno es bueno

Profesor: en una sola oración...no se explayen tanto

Alumno 4: lo bueno, es lo contrario de lo malo, y lo malo es lo contrario de lo bueno

Alumno 2: (bromea) como digo en whatsapp... weno...

Alumno 1: oiga profe...

Alumno 4: ya... nos pusimos filosóficos, qué es lo bueno cabros...

Alumno 1: ¿cómo se escribe cuando hay dos definiciones diferentes?

Profesor: yo pensé que iban a decir lo del otro día

Alumno 2: yo igual lo iba decir...

Alumno 3: yo lo dije...

(Alumnos conversan)

Profesor: ya... eh... chicos, brevemente ya... no es necesario que se explayen tanto, una frase...

(Alumnos conversan, y ríen)

Profesor: ya...gobiérnense por favor...

Alumno 4: (bromea) manifiéstense...

(Alumnos conversan, murmuran, gritan, y ríen)

Profesor: ya, ¿están listos?

Alumnos/as a coro: no...

Alumno 2: profesor...una pre... (Alza la voz) profe... una pregunta. ¿Por qué nos tenemos que dedicar a este trabajo? ¿Vamos a hacer algo después o no?

Alumno 1: porque a nosotros algunas veces nos pide hacer eso

Alumno 2: no, porque yo me estoy adelantando a su... jugada, yo sé que vamos a hacer algo con esto, porque si no hubiese... no sé hubiese preocupado de entregar nombres...

Alumno 3: (bromea) mucho mito y leyenda...

Profesor: ya, pero...

(Alumnos/as conversan)

Profesor: ¡shh! ¡shh! ¡shh!

Alumna 1: no es lo mismo, hay una profe observando, lo cual es más... muy excepcional

Profesor: no, pero si la... Mallory son solo unas preguntas, la profe nos está observando...

Alumna 1: (interrumpe) si, pero...no, pero para eso nos hubiera hecho unas preguntas, porque...

Profesor: pero es lo mismo, una hoja nomás

Alumno 3: johh!

(Alumno ríe)

Alumno 2: oiga profe... profe, nos están observando...

Profesor: no... tranqui...

Alumno 3: ¿cachaste lo que dijo?

(Alumno ríe)

Profesor: oye... no demoren tanto la hoja...

Alumno 4: dijo "tiene razón, si lo tenemos en el cuaderno de filosofía... lo estuvimos vacilando nomás..."

(Alumno ríe)

Alumno 4: (bromea) qué falta de respeto... 
Profesor: ya, ¿están listos?

Alumno 4: malo... mala, pórtate bien...

Alumno 3: el profe es malo...

Alumno 4: profe... algo que sea un juicio, cuando una persona como...

Profesor: no estamos hablando de juicios de... relevancia eh... política...

Alumno 3: juicios...

Profesor: eso...

Alumno 3: hace juicios...

Profesor: no debiese ser problema definir una palabra que usan en la vida cotidiana

Alumno 2: opinamos...

Alumna 1: no sé...

Profesor: no... pero, defínelo como tú lo usas, no quiero... no quiero una definición filosófica de lo que es un juicio... como tú la usas...

(Alumno grita)

Alumno 2: profe...

Profesor: ¿Qué tiene esa cosa que a ti te hace considerarlo algo bueno?

(Alumnas/os conversan)

Profesor: Recuerden que no hay respuestas buenas o malas si estamos haciendo un vocabulario...

Alumno 1: justo, ¿a qué se refiere? A justo de justicia o a justo de... así como...

Profesor: de preciso...

Alumno 1: de preciso para lo justo....ah ya...

(Alumnos/as ríen)

(Comienzan a conversar)

Profesor: ya... ¿estamos listos?

Alumno 2: profe...

Alumno 3: no...

Alumno 1: espere un momento...

Alumno 2: profe, ¿a qué se refiere con legalidad?

Alumno 1: el juicio, es el juicio de juzgar a una persona o a...

Profesor: Qué es lo que es lo legal

Alumno 3: y el juicio, ¿a qué se refiere por juicio?

Profesor: no al jurídico...

Alumno 3: ah..

Profesor: a tu juicio lo que, por ejemplo haces...

Alumno 3: ah ya...

Alumno 1: profe... ¿uno puede usar la misma palabra si está definiendo algo?

Profesor: eh... ¿cómo?

Alumno 1: si yo estoy definiendo algo, ¿puedo usar la misma palabra que estoy definiendo?

Profesor: ¿cómo en qué? Por ejemplo

Alumno 1: como mi mano o...

Alumno 3: (bromea) y se la pasa por la oreja...

(Alumnos ríen)

(Conversan, bromean y ríen)

Profesor: ya, oye...

Alumno 2: concepto de libertad, ¿a qué se refiere con libertad?

Profesor: A lo que...

Alumno 3: ser libre

Alumno 1: ven que se repite

Alumno 3: (bromea) acción de ser libre

(Alumnos ríen) 
Profesor: por algo los dejé

Alumna 1: libertad...

(Silencio)

Alumno 2: (murmura) ¿qué es la libertad?

(Ruido de sillas y mesas)

Alumno 2: (murmura) libertad...

(Silencio)

Alumna 2: profesor, ¿puedo usar corrector para definir bueno, y bueno para definir correcto?

Alumno 2: yo tengo corrector, toma...

(Alumnos conversan)

Alumno 3: influencia...

Profesor: ese fue Nicolás, que dijo que uno actúa como por influencia...

Alumno 2: influencia social...

Alumno 3: (murmura) influencia...

Alumno 1: ¿profe la actividad es con nota?

Alumno 3: ¿qué es lo normal?

Alumno 4: normal... es lo común

(Silencio)

Profesor: ¿terminaron?

Alumno 1: si

Alumno 5: si...

Profesor: ¿quién terminó?

Alumno 5: yo...

Profesor: ¿tú igual? ¿Quién más?

Alumno 2: a mí me falta una

Profesor: pero, ¿nadie más?

(Alumnos conversan, murmuran y ríen)

Alumno 3: (murmura) no sé que poner...

Profesor: coloquen lo que quieran, es sin censura

(Alumnos conversan)

Profesor: ¿terminaron?

Alumno 1: (murmura) yo sí...

Alumno 4: profe... estoy casi...

Profesor: ¿terminaron?

Alumno 6: no

Alumno 7: si...

Alumna 1: no...

(Alumnas conversan)

Alumna 4: es difícil hacer esto, porque... uno no se cuestiona sus definiciones...

Profesor: estas palabras ustedes pueden ocuparlas...

Alumno 4: yo las ocupo, pero cuando me dicen la definición quedo como... como que empiezo a dudar...

Profesor: ¿y cómo la usas? si la definición de una palabra está dada por el uso...

Alumno 4: (bromea) es que quiero parecer intelectual

(Todos ríen)

(Alumnos conversan)

Profesor: ¿cómo les fue con sus... definiciones?

Alumno 2: bien

Alumno 4: no puedo hacer nada...

(Alumnos conversan)

Profesor: ya... ¿estamos listos? 
Alumno 4: no...

Alumna 1: no, no, no...

Alumno 3: eh...

Profesor: ¿qué vamos a hacer ahora?

Alumno 2: eh...

(Silencio)

Profesor: (murmura) ¿terminaron?

Alumna 1: no he terminado aún

Profesor: pero termine pues

(Ruido de sillas y mesas)

(Alumnos murmuran y conversan)

Profesor: ¡Ya! eh... ahora... nos vamos a... juntar en parejas, excepto acá que ya se nos definió un grupo, busquen una pareja, ¿ya? ¿sí? puede ser en duplas o si quieren pueden trabajar de más ¿ya?

(Alumnos conversan)

Alumno 4: (bromea) ¿únanse o unan sed?

Profesor: pueden trabajar con las chiquillas...

Alumno 2: yo no sé con quién...

Alumno 5: con la... con la alumna nueva

Profesor: puede ser con cualquiera...

Alumno 4: ¡ella va quedar sola!

Alumno 3: acá somos cuatro...

Profesor: pero por eso, hagan un grupo...

Alumno 2: el Gustavo...

Profesor: ya Gustavo...

(Alumnos conversan)

Alumno 3: los tres aquí...

Profesor: con su pareja, van a comparar la definición que tienen ¿ya?

Alumno 4: ya...

Profesor: y en la hoja nueva, van a escribir la definición que salga del consenso de ustedes (Alumnos conversan, ruido de sillas y mesas)

Alumno 4: Ya Tania...

Profesor: la idea es que conversen, se escuchen...

(Alumnos conversan)

Profesor: no quiero la misma definición, la idea es que conversen, tienen que haber diálogo...

(Los grupos conversan)

(Silencio)

Alumno 4: dejó de llover...

(Profesor ayuda a los grupos)

Alumno 4: ya, entonces... algo que no te gusta

Alumna 1: y que daña al otro...

Alumno 4: algo que no te gusta, que daña al otro y que no es debido... ¡listo! Algo que no te gusta, que daña al otro y que no es debido...

Profesor: no, malo es algo que no te gusta....

Alumno 4: por eso pu, malo es algo que no te gusta, que daña al otro, y que no es debido... pregúntame...

Alumno 3: ¿Qué es lo malo?

Alumno 4: algo que no te gusta...

(Alumnos conversan)

Alumno 4: algo que afecte... malo, malo... 
Alumno 2: es algo malo, que daña a una persona

(Grupos conversan)

Alumna 1: algo que afecta... a otra persona... y que no es correcto

Alumno 4: ¿qué es lo que afecta? Un daño...

Alumna 1: un daño...

(Grupos continúan conversando)

Alumno 3: puede ser una persona o animal...

Alumno 4: puede ser lo mismo que equidad, pero ella dice que no

(Ruido de objeto que cae al suelo)

Alumno 5: oh... perdona...

Alumno 1: algo opinable... que hace uso de razón

Alumno 4: ya mira... esta cuestión, ¿es mala por qué?

Alumna 1: porque daña...

Alumno 4: porque daña algo que... es tuyo, porque si no fuera tuyo no lo considerariai malo, veis no es malo...

Alumno 2: tú no lo consideras malo...

Alumno 4: es algo que es preciado para ti... algo que... tú conoces...

Alumna 1: no...

Alumno 4: si, es algo que tú conoces...

Alumna 1: no, pero si consideras a otra persona tú lastimas...

Alumna 4: pero si... pasa una persona y me roba, ¿tú lo considerarías malo?

(Grupos continúan conversando)

Alumno 3: malo es... lo más cercano a ti...

Alumno 4: pero el humano es tu especie...

Alumna 1: ya...

Profesor: discutan y pongan atención...

Alumno 4: porque es algo que tú conoces...

Alumna 1: no, porque es algo que daña... la igualdad está en todos...

Alumno 4: tú eris mala... Allan ella es mala

Alumna 3: la igualdad está en todo...

(Grupos continúan conversando)

Alumno 4: sipu, porque si no te afecta no lo considerarías...

Alumno 2: te hace reaccionar de una manera negativa

Alumna 1: profesor... ¿de manera o de forma?

Profesor: eh... depende del contexto la palabra

Alumna 1: ¿cómo se usa la palabra?

Alumno 4: úsala...

(Grupos continúan conversando)

Alumno 5: algo que está permitido por la sociedad...

Alumno 4: puse, es algo dentro de los estándares humanos...

Alumno 3: mira... yo voy a poner igualdad...

Alumno 4: pero, tiene que crearse una escala, para que algo sea justo pu... un daño... tiene que haber algo que...

Alumna 2: (ríe) no sé...

Alumno 2: es algo que... de alguna forma afecta a todos...pero uno... tiene más...

Alumno 1: profe... ¿de qué manera estaría correcto?

(Grupos continúan conversando)

Profesor: ¿estamos listos?

Alumno 4: (se queja) ah profe, vamos en la tres... usted dijo que era algo super simple, ¿cómo es posible?

Alumno 2: ¡ahhhh! 
(Grupos continúan conversando)

Alumno 4: hacer un juicio o juzgar...

Alumno 4: es una crítica de tu perspectiva...

Alumno 3: palabras raras...

Alumno 4: es una crítica...

(Alumnos realizan actividad)

Profesor: ya, vamos a volver a nuestros asientos. A ver eh...Bueno, ¿les costó definir los conceptos en primer lugar?

Alumno 1: sii...

Profesor: ¿y a medida que fueron conversando con más gente fue más fácil o más difícil?

Alumno 2: más difícil

Alumno 3: fue más difícil porque lo que uno decía, el otro no lo tenía

Profesor: ya, ¿cómo definieron bueno ustedes en la vida?

Alumno 2: algo que produce alegría o satisfacción

Alumna 3: hacer lo que nos beneficia para alcanzar lo que creemos bien

Alumno 4: ahí tengo duda porque puede no estar bien

Alumno 1: es malo po

Alumna 3: pero estoy hablando de lo bueno po

Profesor: vamos a levantar la mano para que hablen bien

Alumno 2: nosotros buscamos el objetivo para ver que estuviera bien

Alumno 1: es que ellos vieron algo general, nosotros vimos algo más personal. Al parecer en nosotros lo bueno nos produce alegría como no sé, ayudar a alguien. En cambio lo de beneficio suena como más a interés

Profesor: ya, muy bien. Eh...Difícilmente vamos a llegar al concepto pero ahí pueden ver un punto en común. Lo malo, a ver que pusieron en lo malo

Alumna 3: algo que afecta negativamente al entorno en cualquier aspecto y a ti mismo

Alumno 2: algo que no está bien respecto a la sociedad, por ejemplo no es bueno robar o botar basura en la calle

Profesor: el punto de diferencia es que usaron la palabra sociedad, pero la sociedad igual toma decisiones así que no creo que sea tanta diferencia, A ver, ¿qué más pusieron?

Alumno 2: consecuencia adecuada debido a la acción que realizó cierta persona ya sea buena o mala

Alumna 3: ser equitativo sin importar las condiciones del individuo

Profesor: yo creo que se complementan ¿no? Porque está en consideración el individuo

Alumno 4: yo tengo el hacerse la idea de alguien sin conocerlo

Alumna 1: es una crítica de alguien o algo que conoces o desconoces según lo que crees correcto

Profesor: Muy bien. Ya, legalidad

Alumna 2: tener permiso de la ley según la jerarquía

Alumno 5: yo puse es algo que está permitido y si no se cumple hay un castigo

Profesor: correcto, ¿y libertad?

Alumna 1: no estar amarrado a nada, sin restricciones

Alumno 3: vivir el día a día sin restricciones

Profesor: se parecen o no

(Alumnos ríen)

Alumno 2: nosotros pusimos presión social

Alumna 4: lo que te manipula para la toma de una decisión o comportamiento

Alumno 2: lo mismo que pusimos nosotros

(Alumnos ríen)

(Suena timbre)

Profesor: ok ¿ya?, vamos a comparar en la próxima clase entonces lo que dice cada grupo. 


\section{ANEXO 13. OBSERVACIÓN DE CLASE DE SÓCRATES}

Profesor: (...) dice, Alarcón Solange

Alumna 1: No vino

Profesor: No vino. Avísenme las que estén sacando pase para dejarlas presente.

Alumna 2: Ya

Profesor: Avendaño Paula... ¿Paula? Emm... ¿bajó alguien?

Alumna 1: si, tres...

Profesor: Ya, tres, espéreme un poco.

Alumna 1: (hacia A2) ¿cuántas décimas a cada una dan en el liceo?

Alumna 2: tres

Alumna 1: nooo

Profesor: Soledad esta acá. Florencia... ¿llegó?... Esta triste. Ehh... Castro Sara, ¿Castro Sara?, la señorita Catalán Paula, ella estaba afuera parece. Ya, Corona Estefany que está acá. Colorado Fernanda, ¿Fernanda? Colorado

Alumna 3: Buenos días, permiso

Profesor: Adelante

(Alumnas conversan entre ellas)

Profesor: Cuevas Paula, ya.... Eugenia anda con Pc, está abajo parece ¿no cierto? con la... Alumna 1: si

Profesor: ya. Fuentes, que esta acá.... ¿Garrido Carolina?

Alumna 2: No está

Profesor: ya.... Después viene Enrique, ¿ya?, (hacia alumna que está entrando) adelante. Herrera Monserrat. La señorita María José, ya... y Merino Valentina

Alumna: presente

Profesor: ya, Pereira Sofía, ya. Pérez Natalia, Natalia ¿está?

Alumna 2: parece que si

Profesor: Ya... La señorita Pérez Paz Belén, ya, Riquelme Betsabé, ya. Luego viene, eeh...

Rivera Tania, Tania ok, Saavedra Javiera, Javiera Saavedra. Soto Constanza

Alumna: Presente

Profesor: Torres María José. Ya, está acá, Después viene acá, Rivera Navarrete Francisca, Sordo Riquelme, ¿no?, ya. Perfecto, ¿ya ok?.

(Alumnas conversan entre ellas)

Profesor: Chicas, eh... Veo que no han sacado el cuaderno, no todavía, ya necesito que lo saquen. Eeh... nosotros comenzamos ¿con esta actividad o no? La del texto, ¿hicimos el texto o no? ¿Se acuerdan o no? Parece que no porque lo estuve revisando y no veo, solamente está el de lo que hicimos, ¿ya? Ok. Pero ahora vamos a terminar con las teorías psicosociales verdad, quedó pendiente eso, porque ¿Freud ya lo tenemos listo verdad? ¿Sí?

Alumna 1: si

Profesor: ya saquen su cuaderno por favor

(Alumnas conversan)

Profesor: ¿nosotros ya fijamos la fecha de prueba verdad?

Alumna 1: si, la otra semana

Profesor: la próxima semana, ya, el miércoles. Entonces ahora va a ser la posibilidad que ustedes planteen todas eh... las dudas para que veamos...

Alumna 2: profe, la materia de la...

Profesor: solamente el apunte y lo que pide este apunte.

Alumna 1: ¿el apunte cuatro? 
Profesor: no, el apunte... acuérdense que yo les di un apunte a ustedes, tengo este, a todas les pasé un apunte de este

Alumna 5: ¿y qué número dice?

Profesor: número cuatro

Alumna 4: ese es pu

Profesor: Ese es. Aquí están todas las teorías. Y lo único que no voy a alcanzar a pasar, ¡sh...! la parte de... lo que es comunicación, la ehh... dualidad de la comunicación, buena y mala comunicación que es bastante simple en todo caso, no es nada que ustedes no puedan entender, está bien, ¿ya?, pero lo que me interesa son las teorías así que vamos a colocar el objetivo, lo que realmente acá me preguntan, ¿ya? Tome asiento, porque si no después me dice profe que está haciendo, no sé, no entiendo. Ya, entonces van a colocar el objetivo de hoy. Vamos a conocer y analizar las teorías... ¿Ustedes saben lo que pueden hacer, chicas, ¡hey! después de clases? A pedirle a don Cristian que les saque 15 apuntes y como venimos del jueves a la ultima hora de tres un cuarto a cuatro, voy a traer acá... ¿a ver a quien les falta? ¿Una?, ya, voy a sacar quince acá para los cursos $\mathrm{A}, \mathrm{B}$ y $\mathrm{C}$ e ir pasando. Pero niñas, miren... siempre una buena estudiante ¿qué es lo hace? De pronto si yo paso los apuntes y alguna compañera no vino. ¿Qué es lo que hace? Ustedes van así solita y van a fotocopiarlo ahí y no, ni un hay problema.

Alumna 2: no los fotocopian

Profesor: ¿no? Ya, o sino a algún profesor, o me ubican a mí, yo les hago el pase y van y lo fotocopian. ¿Ya? pero, no vayan a esperar de pronto que pase todo este tiempo

(Alumnas conversan)

Profesor: ya, conocer y analizar las teorías psicológicas de la personalidad ¿no cierto? porque estamos viendo ese aspecto y después de esta actividad va a ser eh... el documento que les voy a pasar. Eeh... ya, eso es lo que vemos hoy día y lo voy a tratar de pasar lo más rápido posible. Vamos a hacer el resumen, si ustedes me dicen que falta algo volvemos atrás. ¿Ya? nosotros estuvimos viendo a... Freud, ustedes lo pueden escribir Fre-ud, ¿cierto?, que con el iniciamos nuestro estudio sobre la personalidad, puesto que hemos visto hartas actividades de personalidad. Y lo otro, que fue lo que dijimos principalmente, que la estructura de personalidad de Freud se divide en ¿cuántas partes a ver? La estructura...

Alumna 1: en tres

Alumna 2: el yo

Profesor: ya... ¿qué otra más? ¿Daniela?

Alumna 1: el súper yo

Profesor: muy bien, ¿y cuál es la otra?

Alumna 3: el ello

Profesor: muy bien, ya, ¿se acuerdan cada una de ellas? El yo, que es lo corres... ¿a que corresponde el yo?

Alumna 1: a la realidad

Profesor: muy bien, a la realidad. Ah... parece que estamos bien ya. ¿Y el súper yo? ¿Qué es lo que era el súper yo? ¿qué nos decía el súper yo?

Alumna 2: las normas

Profesor: los valores y normas ¿no cierto? Valores y normas. Muy bien, y el ello, ¿qué es lo que era el ello? ¿El ello?, a ver...

Alumna 3: ¿la consciencia?

Profesor: no, un poquito más preciso. El ello que es lo que era, cuando un niño chico está ahí por ejemplo recién... ¿qué es lo que es? Es puro ¿qué cosa?

Alumna: los deseos intensos

Profesor: A ver más fuerte 
Alumna 2: impulso

Profesor: impulso, ¿y qué más? Instinto, ¿no cierto?, el ello, instinto ¿Y cuantos tipos de instinto tenia según la teoría freudiana, cuantos habían? Habían dos tipos de instintos o funciones, acuérdense que habían funciones o impulsos, ¿cuál era el primer instinto?

Alumna: agresión

Profesor: ya, la agresión, ¿y cuál era el otro? ¿Cuál era?, el que nunca nos va a dejar, ¿cuál sería...?

Alumna 1: el amor

Alumna 2: el sexo

Profesor: ya, el sexo, ¿no cierto?, la sexualidad.... sexual, Ya, hasta ahí estamos, estaríamos bien ¿cierto?, luego nosotros ¿qué fue lo que hicimos? Hicimos una etapa psicosocial osea psicosexual acuérdense, la primera etapa ¿cuál era la etapa? ¿Alcanzamos a ver las etapas verdad? ¿la primera cual era?

Alumnas a coro: oral

Profesor: oral, ¿y por qué se caracterizaba ahí el niño?

Alumna: chupaba

Profesor: chupaba ¿no cierto?, chupar ¿no cierto?, ¿después venia la etapa...?

Alumnas a coro: anal

Profesor: ya, ¿y cuál era el control ahí que era lo más importante, el control cual era?

Alumna 1: esfínter

Profesor: esfínter muy bien, esfínter. Y después viene la etapa genital ¿cierto?, ¿y cual eran ahí la... la... la... la... atracción que tenía él bebe? ya no, porque estamos de 3 a 5 años más menos, genital ¿cuál era?

Alumna: genitales

Profesor: muy bien, los genitales. Y acá nosotros dijimos que existía un complejo ¿que era el de?

Alumna 1: Edipo y Electra

Profesor: ya, ¿cuál es el de Edipo?

Alumna 2: el que sufre...

Alumna 1: el que la mamá se enamora del hijo

Profesor: momento, al revés. El hijo se enamora de la mama y esto pasa entre los 5 años a 6 no cierto porque está recién como viendo toda esta parte y el papá corresponde a una especie de enemigo no cierto, como que el papá si ve a un hijo no sé, como que es una competencia con él, no le gusta el papá.

Alumna 3: profe, ¿qué dice ahí?

Profesor: ¿dónde? Estructura, de la personalidad, no se olviden. Estructura, personalidad. ¿Y el de Electra que es lo que era? ¿Era todo lo contrario que pasaba?

Alumna 2: se enamoraba del papá

Profesor: si, se enamoraban del papá, y después yo les conté unos casos así verídicos no cierto donde salían en el mea culpa que de pronto había una familia que eeh la niña se enamoró del papá estando casada en una familia concluida pero de pronto la mamá empezó a quedarse fuera del, del llamemos de la relación entre el papá y la hija y de pronto el papá tuvo una hija con su propia hija no cierto ehh una cosa rara fue un duelo que tuvieron, que de pronto la familia siguió funcionando ah, estaba la mamá pero de pronto el papá iba con la hija. Lo que ocurrió también es que se suicidaron, ¿ya? fue un caso verídico ahí lo pueden ver en YouTube documentado y se van a sorprender. Ya y después venia una etapa de latencia ¿no cierto?, y ahí prácticamente nosotros dijimos que si ustedes se fijan acá en las chiquititas de los sexto, séptimo qué sé yo... eh... la sexualidad a esa edad no les interesa mucho aunque vean cosas qué sé yo... no, andan como jugando y corriendo, eso es lo más que les interesa ¿no cierto? Eeh... bueno en todo caso nosotros dijimos que también que cuando comenzaba la 
sexualidad realmente, en Estados Unidos los jóvenes a los doce, trece años ya tienen relaciones sexuales $¿$ ah?, entonces eso va a depender de la mentalidad igual $¿$ ah?, pero como uno ve acá a las niñas que están en una mentalidad infantil eh... sabemos que esta cosa de la sexualidad no les preocupa ¿ya? , y después vendría la par... la parte de la adolescencia ¿no cierto? y de ahí donde ustedes son una especie de bomba química en donde en este minuto ustedes de pronto sus preocupaciones tendría que ser la sexualidad, ¿no cierto?, ¿por qué?, porque el psicólogo que vamos a ver con el otro pensador Erickson, ustedes están buscando una identidad, ustedes tienen que definirse bien si son mujeres... bueno hoy en día si son mujeres, son hombre, si son una cosa media rara, eh... intermedio, no sé, pero bueno, ustedes tienen que tener claro y por eso hicimos también el eh... la actividad de las tribu urbana para que ustedes vean su identidad, o me llevo mejor con este grupo o este me gusta más etcétera, etcétera pero dándose a conocer, ¿ya?. Hasta aquí quedamos ¿no cierto?, que nosotros vimos. Vamos a borrar aquí y nos vamos a... Con el caballero Erickson, que no es el de los teléfonos ¿ah?, Erick eh... ¿borro?

Alumnas a coro: noo

Profesor: ya, ¿por dónde borro? ¿Borro por acá?

Alumna 1: no

Alumna 2: no profe, espere un poco

Alumna 3: siii

Profesor: ya, vamos a ver a ver este caballero. Nosotros comenzamos escribiendo algo de él ¿o no?

Alumna 1: si

Alumna 2: el titulo

Profesor: ¿solamente el titulo?, ya... Y de ahí en donde después hicimos un paréntesis y nos fuimos a las etapas de la sexualidad según Freud, ¿no cierto? Y después van a venir las características que les vamos a dar. ¿Borro acá?

Alumna 1: nooo

Profesor: ¿no?, acuérdense que para la prueba principalmente va a ser el apunte y todas las actividades que hemos hecho nosotros ¿ya? Acuérdense que hemos visto ehh... lo que es familia a partir de una guía, vimos lo que es la socialización, vimos también eh... el tema de eeh... de la personalidad, los tipos de personalidad, de eso acuérdense. Y ahora vamos a ver igual la libido a partir de ehh... Freud. Eh... ¿qué más nos quedaría?... ¿listo?, voy a borrar solo esa esta parte ¿ya?

(Alumnas conversan entre ellas)

Profesor: ya chicas, entonces, vamos a colocar las características entonces como título porque nosotros ya hemos entrado como a Erickson, coloquen... Características como título...

Alumna 1: pero profe ¿todavía?

Alumna 2: da lo mismo

Profesor: ah empezamos a ver ya la... ¿el cuadro?, el cuadro porque ¿A dónde quedamos, a ver? (profesor lee apunte de alumna)

(Alumnas conversan entre ellas)

Profesor: ya, hasta ahí quedamos, ya, vamos entonces a la teoría. Muy bien Daniela, gracias. Ya, entonces nos vamos a ir al tiro a la teoría... Coloquen ahí, teoría... Psicosocial... de Erickson... Ya, ahí están por favor. Teoría psicosocial de Erickson, y aquí vamos con el cuadrito y la tabla. Pasa lo siguiente... Van a colocar... A ver van a colocar emm... Ya, coloquemos lo siguiente. Establecen...

Alumna 1: profe no se entiende

Profesor: ya, muy bien...Psico... social. Ya, así miren, lo van a colocar solo al medio y van a colocar algo así. Establece etapas de desarrollo psicosocial. Lo primero que vamos 
a hacer digamos que son... Uno, dos, tres, cuatro, cinco, seis, siete, son ocho. Generalmente se lee de abajo hacia arriba pero, lo van a colocar tal como sale acá. Un cuadrito aquí, así mas o menos vamos a ir, ¿ya? porque no es mucho lo que van a escribir. Infante... Y este va de cero a dieciocho meses. Ya, nosotros ya hemos visto estos desarrollos de las percepciones, los aspectos cognitivos del ser humano, eh... Comienza de temprana edad, todo el aspecto perceptivo. ¿Ya?, infante de cero a dieciocho meses y ustedes van a colocar una flecha para acá y vamos a poner que significa eso. Y van a hacer un cuadrito más grande, cosa que les caiga un comentario acá. Yo les voy a colocar una especie de titulo

Alumna: ¿puedo pasar?

Profesor: Adelante, adelante Paula déjamelo ahí no más y yo te coloco presente. Déjalo ahí $\mathrm{y}$ te coloco presente.

(Alumnas conversan entre ellas)

Profesor: ya, la primera seria confianza versus desconfianza, ¿ya?, vayan anotándolo ¡sh...! y acá dos puntos porque van a anotar un comentario. Confianza versus desconfianza, ¿ya?, confianza versus desconfianza, y eso comienza a partir de los cero a dieciocho meses, ¿por qué de cero? Porque al final igual dentro de la gestación verdad, el niño o no sé si niño podría decirse ahí...El feto, va recibiendo varios impulsos y va captando todo el llamémosle eh... la emocionalidad de la madre ¿ya? Por lo tanto igual de alguna manera va aprendiendo aunque este en un estado de gestación.

Alumna 1: ah...

Alumna 2: $\mathrm{mmm}$ (se enternece)

Profesor: Ya, confianza versus desconfianza, siempre van a haber dos etapas en la... en la etapa psicosocial de esto, siempre se supone que tiene pasar una etapa ¿verdad? Para poder seguir a la otra etapa porque si queda pegado en una no puede avanzar ¿ya?, por eso mismo les he dicho que hay mamás que bueno son jóvenes pero se han saltado la etapa de la adolescencia y de pronto a los cuarenta años ellas como que cumplen esa etapa perdida ¿sí? ¿Ya? Anoten acá abajito lo siguiente...

Alumna 1: espere, espere

Profesor: confianza versus desconfianza ¿ya?, confianza versus desconfianza. Ya, atención. Se crean. Se crean, vínculos... Afectivos... Que dan... Sensación...De...Confianza física... ¿ya? Hasta ahí no más. Acá por lo menos si tienen hermanos chicos pueden ver que se sienten protegidos cuando la mamá esta. Ya, la otra etapa va de los dieciocho meses a tres años ¿ya? Dieciocho meses, tres años. Esa sería la segunda etapa y ahí le vamos a colocar... Vamos a colocar algo más interesante... Van a poner autonomía versus vergüenza y duda. Autonomía versus vergüenza... vergüenza... Y duda ¿ya? Generalmente esta es la etapa en donde los niños eh... si ustedes no los estimulan tienen que ser como independientes osea tienen que ir solos al baño, tienen que no sé, de valerse un poco de sí mismos porque si no pasan esa etapa van a quedar en esta que es la vergüenza y la duda porque siempre van a ser como niños apocados, van a hacer de poca iniciativa y por eso es que a veces la mama a veces le dice "oye pero tú no haces nunca nada tienes que hacer algo, como, nunca teni iniciativa'" claro porque a lo mejor no han desarrollado esa parte y se están quedando pegados ahí ¿Ya? Y así se va a ir formando la personalidad de él, por eso siempre todas las etapas se tienen que irse pasando si no van a quedarse pegados en esa. ¿Ya? Acá si no pasa la etapa de la autonomía va a quedar pegado en esa, vergüenza la duda ¿ya? Vamos a la otra... dice ahí

Alumna 1: pero profe

Profesor: ah perdón, coloquen acá lo siguiente...Voy más rápido...eeh... mi mente que todo... Ya. Vamos, coloquemos acá chicas. Dice, desarrollo...desarrollo...desarrollo... de la creatividad... Ya dos puntos ahí, ¿no 
cierto?... Exploración del mundo... Coma... Desarrollo del cuerpo ahí a los tres años $¿$ ¿ah?... Desarrollo del cuerpo...Coma...Y van a relacionarlo un poquito con lo que decía Freud. Coma... Control fisiológico, es decir los esfínter ¿no cierto?... ¿Ya?

Alumna 1: ¿Cómo?

Profesor: control fisiológico, fisiológico ah, el cuerpo, el organismo, fisiológico. Punto seguido, desarrollo lento ¿ya? Hasta ahí, hasta los tres años uno puede observar esas eh... esos rasgos ¿no cierto? Ya, vamos aquí, preescolar... Preescolar de tres a cinco años, ya, aquí vamos a hacer una observación en este mundo preescolar, vamos a colocar iniciativa versus culpa, ¿ya? Iniciativa versus culpa. Ya, eso sería nuestro... Llamémoslo nuestro aspecto en que tendría que avanzar o usted va a quedar pegado.

(Alumnas ríen)

Profesor: preescolar de tres a cinco años, iniciativa versus culpa, a ver, esta etapa preescolar podríamos considerarlo un poco... Cuestionable porque antiguamente los papás ¿no cierto? Entraban a los hijos a una edad de cinco años a lo que es el sistema escolar pero hoy en día esta como más... Más temprano el inicio de la actividad escolar o preescolar ¿no cierto?, ¿ya? las salas cunas. El tema del trabajo, ahora, ¡shh!, silencio... Y ahora ¿qué ocurre ahí? que de pronto hay poco apego ¿ah? Entre el niño chico hasta los cinco años porque hasta los cinco años podríamos decir que necesita de los papás eh... constantemente y de pronto el saltarse tanto tantas etapas de pronto queda eh... como sin el apego iya? Eh... Es mucho mejor... Considero, que a los cinco años el niño entre a lo que es la etapa o el mundo escolar porque esto es como si lo ven eh...Que podría aprender en un jardín... Dicen no es que si no va a un jardín eeh... de pronto va a quedar perdido prácticamente, va a ser poco cognitivo, van a quedar todos ahí eh...latente, no se va a desarrollar eso, yo creo que es falso completamente porque ¿Qué es lo que le enseñan? A cepillarse los dientes ¿Qué más le enseñan en el jardín? A comer y todo eso ¿dónde lo aprenden realmente?

Alumnas a coro: en la casa

Profesor: en la casa lo aprenden. Y saben lo que de pronto ocurre acá. Porque igual estos jardines no son todos así como dedicados a un niño. Uno lo encuentra lamentablemente que un niño le llega con piojos a la casa, llega todo cochino con la ropa descambiada, de pronto se cayó, nadie lo vio, de pronto le dieron comida. Entonces este aspecto es traumático en algunas situaciones ¿ah? Y yo creo que generalmente es así, por lo tanto yo creo que lo mejor era de los cinco. Ahora obviamente los problemas de trabajo hacen que la gente los vaya a dejar

Alumna 1: siiii...siiii

Profesor: pero para el desarrollo es mucho mejor que este, $; \operatorname{shh}_{i}$ de los cinco en adelante... Ya, índice arriba, verso uno. Coloquen lo siguiente, vamos a reiterar lo siguiente... Desarrollo, desarrollo ¡shh!... De la creatividad... Coma, se manipula...El entorno, por favor subrayen la palabrita porque acuérdense que la personalidad es una combinación genética de ambiente, de desarrollo, se manipula el entorno...Coma, el niño tiene más energía y ustedes se pueden dar cuenta que sus...sus hermanos que se yo o primos pueden estar todo el día corriendo. Punto seguido... Se comprende más... Acuérdense de que el pensamiento concreto comienza a desarrollarse acá, pero ustedes no le pueden decir a un niño de tres a cinco años que les explique qué es lo que es dios... ¿no cierto? ¿QQué es lo que es dios? Le dicen...Un santo, un santito...eh... Pero que más... No, no tienen pensamiento abstracto todavía, concreto si, le puedes decir lo que es una manzana, ah esto, que es lo que es un lápiz, esto. Ya... Vamos a la otra, de tres a cinco. Vamos a niños...

(Alumnas murmuran lo que dijo el profesor mientras escriben)

Profesor: ya, niños de cinco a trece años... Niños cinco a trece años, ya aquí está en la edad del pavo ¿ah? 
Alumna 1: ¿hasta qué edad dura la de edad del pavo profe?

Profesor: bueno, conozco a gente que todavía es pava así que no se...

(Alumnas ríen)

Profesor: emm... Mira la edad del pavo se supone que es la edad esa... tú eres donde el niño comienza a ser un poco de pavo, está más largo de... Se han dado cuenta que de pronto alargan más los brazos ¿ah? Eh de pronto son más largos de piernas, el cuello es más largo, porque están todos como desarrollándose y de pronto aparecen todos como... como Adonis

(Alumnas se ríen)

Profesor: ya, ¿se han dado cuenta de eso? Ya , ahora la edad del pavo no sé por qué se dice la edad del pavo realmente porque al final se hacen preguntas tontas o si de pronto no saben hacer algo o son torpes es propio de su desarrollo pero... Eh...Supongamos que pase eso ahora, a los cinco a trece años, como a las quince ya comenzaría a... desaparecer esa edad porque los intereses y... y yo creo, a ver... muy buena pregunta, yo creo que acá la edad del pavo desaparecería cuando el niño tiene su primera polución nocturna, puede ser la relación que hicimos con Freud

(Alumna suelta carcajada)

Profesor: ¿No cierto?, que es totalmente diferente en la mujer porque la menarquia aparece a los... no sé, a los trece años, catorce años debiera aparecer o más temprano, pero eso provoca un efecto psicológico fuerte en la niña, que no es lo mismo que en el hombre que ahí eso es como normal pero no... no tiene una incidencia, sigue siendo como a los quince, dieciocho, diecisiete años medio infantil, pero la niña a esa edad comienza a tener una perspectiva mucho más...más madura, por eso que, nosotros hicimos la operación de por qué a las niñas a veces les gusta la gente mayor...Claro porque como están pensando...Mayor no digo viejos de cuarenta, sino que son de veinte

Alumna 1: aaaahhh (ríe)

Alumna 2: pa que te juntai con viejos (riendo)

Profesor: (...) y ustedes están en los quince, ¿ya?, les gusta uno de veinte, ¿ya?, porque a lo mejor ustedes tienen mejor sintonía psicológica ¿ah?, en cambio si se juntan con un mismo niño como que siguen ustedes viéndolo como que es un chico o lo hace ver hombre que es muy infantil. ¿Ya? , muy bien, vamos a colocarle acá... La curiosidad... Acuérdense que en todo caso que las niñas antiguamente ¿a qué edad? Osea me refiero... Cuarenta, sesenta años atrás las niñas se casaban sumamente jóvenes, a los quince años ya estaban como para matrimonios...Catorce igual para matrimonios

Alumna 1: a los doce parece

Profesor: claro, más menos

Alumna 2: menos mal

Profesor: una cosa así, siempre y cuando estuvieran maduras físicamente

Alumna 1: mi abuela se casó a los dieciséis

Profesor: no ves ahí tienes un ejemplo... Era otro tipo de...De mentalidad.

(Alumnas conversan)

Profesor: Laboriosidad... versus inferioridad. Coloquen acá por favor...

Alumna 2: ¿qué?

Profesor: Reitero, laboriosidad versus inferioridad, ¿ya?, esto es de los cinco a los trece años. Muy importante esta etapa. Siempre para corregir a un niño en esta etapa, es, nunca uno debe corregirlo denante de las personas ¿sabían ustedes? Porque si ustedes tienen un hermano... eh...de pronto ve él, ¿ya? esto es propio de la edad. Y ustedes los corrigen delante de las personas comienzan a apocarse...Comienza a tener un complejo de... de inferioridad, entonces siempre ustedes quieren cualquiera, su 
hermano chico qué sé yo... hermana, siempre tienen que llamarla para un lado y decirle, ya mira "'esto es lo que uno no hace", pero no delante de las personas, porque a esta edad son muy susceptibles ¿ya?...Bueno aquí vamos a aprender un poco más de la vida

Alumna 3: Profe

Profesor: ¿diga?

Alumna 3: ¿quiere una tasa?

Profesor: vaya... Coloquen acá lo siguiente... De cinco a trece... Comienza, acá. Laboriosidad versus inferioridad... Comienza... Comienza la vida

Alumna 1: ¿la que?

Profesor: la vida... En sociedad...Con los pares...Coma...Se tiene...Una conciencia... ¿ya? Subrayen la palabrita conciencia pero conciencia en el sentido de un conocimiento ¿ah? Punto seguido

Alumna 2: Profe, después de pares ¿Qué viene?

Profesor: ¿de pares?... Coma, se tiene una conciencia

Alumna 3: ¿Qué?

Profesor: se tiene una conciencia ¿ya? Conciencia. Eso es conocimiento de uno. Punto seguido, el niño es orgulloso... de sus actos... ¿ya?... Es orgulloso de sus actos... Ya, perfecto. Vámonos a la otra etapa...Que dice... Esta es la etapa en que están ustedes ¿no ciertos?

Alumna 2: ¿es la última?

Profesor: no porque después nos queda adulto, adulto maduro y adulto mayor y ahí ya viene la etapa del declive

Alumna 2: No me va a alcanzar

Profesor: ¿ya?, nos faltan... tres nomas. Ya, pero acá, se supone que ustedes están aquí, no cierto es adolescente... Adolescente... Mira la adolescencia es de los trece a los veintiún años pero yo escuche eh... En una investigación que había en un, en un... De estos de noticieros que... No sé si la van a prolongar... La adolescencia. A los veintidós, veintitrés años pero se supone que va de los trece a los veintiuno. Porque la otra vez me preguntaron $¿ y$ hasta que edad puede durar la adolescencia? Y yo les dije que puede durar hasta no sé cuándo porque... Va a depender si van a pasar la etapa o van a quedar pegados ahí. Acuérdense, en las tribus urbanas, yo les dije que yo veía siempre en la diagonal a unos tipos que eran punkis, pero yo los veía que no eran de quince, no eran de esa edad. Eran como de treinta o de treinta y cinco y eran más viejos, incluso se notaban con canas, pero seguían estando de esa forma. Entonces yo puedo decir que no han avanzado, que todavía han quedado pegados en eso ¿ya? Veamos lo siguiente... Y la vida se debe de avanzar, claro porque se supone que tú tienes de pronto responsabilidades, tienes que formar una familia, tienes que ya, a esa etapa fue una etapa importante para ti pero... ehh... Pero si queda en eso...

Alumna 1: pero y si le gusta aceptarlo y puede hacer todo de nuevo

Profesor: si... Lo ves de esa forma. ¿Sí? Claro pero a lo mejor ehh... exigirían ahí que tu tuvieras más logros que eso. Que hayas logrado metas, objetivos, que hayas tenido una casa o a lo mejor haciendo eso puede que no sea pero yo he visto que generalmente no lo hay y que están metido en pura droga y en puro alcohol. Eso, eso yo he visto

Alumna 2: ah no, si pero lo que no.... el alcohol no ha sido ilegal porque al menos podría hacer como yo quiero mis cosas

Profesor: claro podrías, pero a lo mejor tendrías que hacerlo independiente porque si vas a optar en un trabajo formal como esto, así no te dejarían. Tampoco te dejarían que tú tuvieras tatuaje, como vimos en las tribus verdad, que hay unos tipos que tienen varios tatuajes. Eh...no podi entrar a trabajar y ganar un dinero normal. Tendrías que ser 
independiente, quizás podría serlo ¿ah? Pero yo no he visto gente que tenga una familia... Seguramente les gusta estar en ese mundo como...

Alumna 3: pero varía por las personas

Profesor: claro varia, pero hay excepciones ¿ya?, no vamos a ir a las excepciones, vamos a la regla oficial. Ya, entonces van a colocar aquí... Búsqueda... versus...Difusión... de identidad... Ya, de los trece a veintiún años que es lo que tiene que buscar, pasar. Búsqueda y difusión de identidad ¿ya? No se olv....

(Suena campana)

Profesor: anoten, ¡shh! búsqueda versus difusión de identidad. La difusión de identidad, claro porque al final uno está en esa etapa buscando su identidad, osea, que es lo que yo quiero, que soy realmente, como yo me veo, si yo me miro al espejo y yo soy eso o si me gustaría ser así o...ya entonces están en esa etapa. Entonces coloquen lo siguiente

Alumna 3: espere... Espere, espere, espere, espere.

Profesor: dos puntos

Alumna 2: profe, ¿en la prueba usted nos va a preguntar eso?

Profesor: osea, no tan detalladamente pero si les voy a decir a ver explique las etapas de Erickson o elija alguna de las etapas de Erickson y explique. O elija dos etapas de Erickson y explíquelas pero no voy a ir detalladamente a preguntarles estas, las de Erickson. Las de Freud acuérdense de la estructura de la personalidad, cuando les diga, explique la estructura de la personalidad desde el punto de vista de Freud ustedes van a recordar el yo, el ello y el súper yo. Ahora si yo les digo, explique las etapas psicosociales psicosexuales de Freud ustedes al tiro van a recordar... Oral, anal, genital. Y las tres y todo eso. Pero yo le voy a pedir que expliquen solamente tres, no todas las etapas ¿ya?, pero son diferentes, la estructura de la personalidad...El yo, el ello y el superyó y las etapas que son. Igual vayan a estudiar. Ya, silencio, ¡shh! coloquen. Se busca... Se busca, silencio... Se busca, la identidad...Se busca la identidad propia y de cómo, por favor la palabrita como subráyenla... Es visto...Por...Los...Otros...Y no sé si a ustedes eh... ustedes mismos les ha pasado ehh...cuando su mamá, anda con papá, su papá qué sé yo. Ustedes ya están de una manera ¿no cierto? vestidas, están normales. Pero si pueden si ustedes suben, van al segundo piso donde tiene su dormitorio y se demoran como diez minutos en bajar para arreglarse y resulta que tienen que ir a comprar ahí no más y de pronto uno le dice "oye pero tanto que te arreglai para que ir a comprar" entonces lo que más les interesa a ellos, es como se vean, la imagen. Acá van a estar preocupados de eso, y como les dije a ver, ¡shh! pongan atención en este punto. Pregunta de prueba. Por ejemplo si una adolescente se embaraza en esta edad, de los trece a veintiún años porque el cuerpo está maduro y supóngase que a los quince, incluso, hay un programa que era una apología de embarazo juvenil que era "mamá a los quince" creo que era ¿no cierto?

Alumna 2: siii

Profesor: que era realmente una tragedia porque en esa edad se van a saltar un montón de etapas y no es algo realmente bueno que las niñas con un estado psicológico bien llamémosle, armándose, tampoco, no es un buen estado psicológico para tener hijos, tengan hijos. Inclusive se veía y se daba como que jay! que era bonito que tuvieran hijos así tan temprano, porque le iban a colocar todas las cosas, y ustedes veían de pronto la interrelación entre la pareja de ella que era un niño también, un joven ¿ya? Y hablaban cosas...Planificaban todos de manera inmadura entonces al final ¿Quién tiene los hijos? Lo tiene la mamá, la mamá como que de pronto se cree más mamá De pronto ellas empiezan a tener una especie de...de digamos de superyó sobre sus hijos en vez de la...entonces se forma toda una cuestión enredada, de, mal, mal 
realmente mal porque al final la hija eh... nunca va a tener el... el asunto del apego del hijo, porque acá nosotros dijimos que lo más importante en una relación, eeh... de relación afectiva es el apego, el apego consta entre mamá e hijo y aquí va a ser mama y abuela o abuela hijo, entonces...

Alumna 2: pero también... pero también tienen hijos pu, quedan embarazadas y después nacen y amantes

Profesor: claro, justamente...Ya, muy bien Soledad, exactamente ¿no cierto?, ya, pero que pasa después. Supongamos que la niña creció y llega a los cuarenta años y quizás por esas cosas de la vida tuvo varias parejas y todos estos encontrones y ahí se estableció, como se te ocurre. Pero resulta que se saltó esta etapa, entonces acá van viendo las mamás que ya no quieren ser mamás, sino quieren ser amigas incluso dicen '"no, yo soy amiga de mi hija, noo yo soy amiga de mi hija porque nosotros nos entendemos bien y salimos juntas y vamos con... a fiestas las dos si somos amigas, súper bien', incluso como que se visten iguales $i a h$ ? Entonces, eh... De pronto dicen "no si pololeamos juntas las dos, ella tiene su pololo y yo el mío y ahí vamos a las discotecas no hay problema", ya...Pero ahí a lo mejor hay una confusión también entre ellas porque como se saltó la etapa, lo que busca la hija en ese minuto es una mamá, no una amiga, porque amigas puede tener varias pero la mamá ¿Dónde está la mamá?, que les de consejos y le diga "oye no hagai esto, te sobrepasaste acá" , ¿se dan cuenta de lo dañino que es cuando se salta una etapa? ¿Ya? Para que quede aquí como claro. Ya, vamos a la otra que es...Adulto joven...Adulto joven... Voy a borrar acá arriba nomas, porque eso todavía no lo han escrito. Leamos acá... Adulto joven...

(Alumnas conversan entre ellas)

Profesor: de veinte, veintiuno a cuarenta años. Oye acá...De veintiuno a cuarenta años, la gente le teme a la edad. Todo el mundo como que de pronto dice 'oye cuarenta años...chuta, realmente ha pasado el tiempo ah",

(Alumna ríe)

Profesor: y sobre todo si no han hecho nada...Y si solamente se han dedicado a una sola cosa y no quieren hijos. Miren lo más importante en la vida es tener hijos ¿o no? ¿Ustedes me creen que si o no?

Alumna 1: shh....

Alumna 2: nooo

Profesor: uno tiene que dejar algo en la vida ¿y que puede dejar?, función ¿no cierto?

(Alumnas ríen)

Profesor: ahora todas las personas acá, eh...Hoy en día, no quieren tenerlos, claro porque quieren darle cabida a su vida...Profesional. Pero...Lo más importante y la realización más plena...Una mujer, es que tenga hijos pu. Ahora todos estos movimientos feministas que... Hacen que eso se politice, o se vea desde un punto de vista confrontacional

(Alumna suelta carcajada)

Profesor: eh...Crea un poco un ambiente raro ah. Porque ustedes...Cuando una mujer tiene un hijo se siente sumamente feliz, se siente super realizada independiente de las otras cosas que lleguen ¿verdad?, que son cosas de su vida personal. Pero... Yo conozco mujeres que no le dan cabida a esto y ya tienen como cuarenta años, no tienen hijos. Igual pasa con los hombres, que todavía no tienen hijos, porque no quieren responder. Incluso eso hacen...Pasan. Eso se... diferencia entre una persona que es madura y otra que no. No quieren tener responsabilidad, y nerviosito dicen "no es que yo no quiero tener hijos" tienen más edad pero "no es que todavía no quiero responsabilidad". Entonces la madurez nunca va a llegar...Basado en esa mentalidad. Y las mujeres es lo mismo por otro lado que quieren darle la prioridad a su carrera pero se olvidan que la parte más hermosa es esta pu. Obviamente si tienen un sentido maternal porque si 
lo van a dejar botado así mejor no lo tengan. Pero la realización, o de este y que es lo que uno puede dejar en la vida, un hijo ¿no cierto? Porque uno le va a estar pasando todo lo que uno sabe. Y por eso que es muy importante tener una madurez para tener un hijo, porque ¿Qué le pueden enseñar a un hijo?

(Alumna ríe)

Profesor: ¿no cierto? ¿Qué se le puede enseñar?, uno tiene que enseñarle algo, generalmente el hijo le va a preguntar algo " ¿mamá que es lo que es esto?’ y 'no no sé, pregúntale a tu... a tu abuela". Entonces igual uno no va...no va dejando nada. Ya, vamos acá, ¡shh! vamos a colocarle...Intimidad...Versus...Aislamiento...En la etapa...Dos puntos...Intimidad versus aislamiento...Ah y lo otro es importante ¿saben por qué es importante tener hijos? Yo lo he aprendido porque igual tengo dos, es que eso impide que uno caiga en depresión ¿saben por qué?, porque de alguna manera uno esta con la expansión del otro no hacia sus niños si no que hacia lo otro. Entonces como ven hay alguien que depende de uno. Entonces evita de alguna manera que uno caiga en una depresión, a no ser que uno tenga una cosa psicológica. Pero eso impide si estas en un constante de "ay qué voy a hacer, que mira que hay un problema, mira el colegio, mira esto" entonces, no lo dejan a uno pensar en uno mismo. Entonces eso hace muy bien para la salud Para los problemas de la salud.

(Ruidos de mesa)

Profesor: (...) ¿es intimidad versus aislamiento?

Alumna 1: no, para nada

Profesor: ah bueno, valoro el criterio que digo porque si son chiquititos, ¿Qué pide un hijo chico? ¿Qué generalmente son las demandas de un hijo chico de... de tres de dos eh que es lo que es?...Es comer, no cierto, solamente están pidiendo comida, comer y que otra cosa, que uno lo abrigue lo enseñe pero generalmente es por...la ropa llega así del deporte ya, pero generalmente, después cuando son más eh...decir cuando ellos se empiezan a preguntar cosas, las preguntas incomodas ¿no cierto?...como nacen los hijos, y ustedes de pronto dicen vienen de parir ¿no cierto? Cosa que ustedes deban decirle estrictamente como nacen ah...Pa que no...

(Alumna ríe)

Profesor: ya, intimidad versus aislamiento. Ya, vamos acá, se buscan...Aquí al ladito, dos puntos. Se busca ishh! se busca...

Alumna 3: ¿Cómo?

Profesor: reitero, intimidad versus aislamiento, dos puntos, colocamos acá.

Alumna 2: ¡uy!... el profesor...

Profesor: Se busca...Estar cerca...De los otros. Subraye la palabrita "otros"...Coma...Lograr una intimidad. Y con intimidad ustedes a que... ¿A que apunta intimidad? Cuando dicen "'oye hay una intimidad" o intimidad, ¿a qué creen que apunta? A la intimidad hoy en día, que es lo que es sinónimo de intimidad ¿Cómo qué? No menciona intimidad. Ya y generalmente una afectividad ¿no cierto? con el otro y generalmente puede ser con una pareja ¿no cierto? Una intimidad, pero ahí hay un lenguaje diferente ¿ya? Vámonos a lo otro....veintiuno cuarenta... nos quedamos bien...Y ya, estamos acercándonos a...la... A la madurez y a la destrucción humana verdad porque... ¿Cuál es la seguridad más plena que tenemos nosotros en la vida?

Alumna 1: que nos vamos a morir

Alumna 2: la muerte

Profesor: Muy bien, excelente. No hay otra

Alumna 3: ¿Qué cosa?

Profesor: la seguridad más plena que tenemos ¿Cuál es?

Alumna 1: que vamos a morir 
Profesor: que vamos a morir, ¿hay otra? ¿Hay otra seguridad?...Vamos a morir. Ahora...Eso, los volúmenes son inseguros y los líder tienes que estar pensando constantemente eso. Veintiuno, cuarenta. Adulto...De cuarenta a sesenta años...Ahí está, adulto maduro de cuarenta a sesenta años ¿ya?... Y acá tienen un concepto de generatividad...Generatividad versus estancamiento...Estancamiento...Ya, aquí vamos a hacer un comentario porque es adulto maduro...Cuarenta a sesenta años. Hoy en día la gente vive más tiempo, se han dado cuenta de...de Noventa. Hay gente de varias...De noventa. Incluso hay gente de cien años, y ustedes lo ven y probablemente están medios lucidos no sé si estarán completos pero...A cien años ya igual cuesta un poco ¿ah? Pero de noventa, ochenta años están...Casi hay harta gente de sesenta años...Eh...El problema acá es que, nosotros como dice la televisión estamos envejeciendo, hay una población más mas más...Adulta

Alumna 1: ¿profe que dice ahí? ¿Estancamiento?

Profesor: estancamiento, sí. Y para hacer eso, para tener una vida digamos más saludable uno tiene que mantenerse siempre en un estado de creatividad. Los escritores generalmente son personas que tienen harta edad. Los que longevos y siguen produciendo, por lo tanto para que uno tenga una mente lúcida, tiene que estar en una constante eh...Aspecto cognitivo ¿ah? Acuérdense de las funciones cognitivas ¿qué es lo que era? La memoria, la percepción, no cierto, la inteligencia, el razonamiento. Ya todas esas facultades que nos ayudan a nosotros para poder estar lucidos frente a la percepción de la realidad. ¿Ya? Ahora, hay en...En televisión los súper humanos, bueno yo veo esa gente que está todavía por aquí por acá pero súper humanos no les veo mucho, quizás por la edad que tienen, ciento diez años ¿ya? Pero son casos raros pero si la población está generándose más eh...Más más longevo ahí. Ya coloquen lo siguiente acá...Surge la preocupación acá, surge la preocupación...Por la...Siguiente generación. Coma

Alumnas: profee...

Profesor: reitero, ¿ya? surge la preocupación... Por la siguiente...Generación...Coma... Se busca... Un equilibrio... Entre...La...Productividad...Y el, estancamiento... ¿ya? Acuérdense igual que si los abuelitos... oye aquí es lamentable eso de que los papás, osea los hijos de pronto a sus papás los manden a los asilos. ¿Se dan cuenta de es? que de pronto en un lugar y se quedan así en los hogares, pero imagínense el papá todo lo el esfuerzo que hizo por mantener a su hijo, hija, que se yo. Y de pronto el papá tiene una enfermedad...Es un estorbo, lo sacan de la casa, le dicen "ya papá mira vas a estar acá con esta gente que es mucho mejor te van a cuidar' lo van a cuidar más y cuando el eh... el o ellos eran chicos... ¿no lo cuidaron? Y lo dejan ahí, le están pagando trescientos mil, seiscientos mil pesos, eso es lo que cuestan ah...Las funda, esas fundaciones, seiscientos mil pesos por mantener a los abuelitos mensuales.

Alumna 2: aah....

Profesor: y....Eso es como una, realmente algo...Algo feo que ocurre ah. No sé si ustedes lo ven así ah. De pronto que el papá sea un estorbo, la mamá sea un estorbo cuando de pronto han dado todo...Lo más importante eh... en otras culturas, en China...Ya, pero ya no tenemos cultura milenaria...Los...Los ancianos son muy valorados. Dentro de una familia están los ancianos, los abuelos y todos son muy venerados. Entre más años tienen son más respetuosos con ellos. En cambio acá los botamos, Ya...Y terminamos allá, ¿ya? cuarenta, sesenta y aquí...Ya, adulto mayor. Bueno todos vamos a llegar ahí ah, ahora como lleguemos va a ser el problema

(Alumna realiza un llanto falso de respuesta)

Profesor: adulto mayor...O si llegamos también. Ya, más de sesenta años ¿ah? Por si no me equivoco...Adulto mayor es más de sesenta años...Pueden llegar como el taton ¿ah?, el taton el de la pareja ahí... ese cuanto tiene 
(Alumna ríe)

Profesor: ¿unos sesenta?... Y tiene polola joven, pueden pueden llegar ahí

Alumna 1: tiene más de sesenta parece

Profesor: más de sesenta i no cierto? Integridad...Integridad versus desesperación....Desesperación ah... Integridad versus deses...pe....raciòn.

(Se escucha que golpean la puerta)

Profesor: adelante. Déjelo ahí, para colocarle después su...Adulto mayor y con esto terminamos nuestra... Nuestra etapa. Integridad versus desesperación ¿ya? Coloquemos lo siguiente, ¡shh! se reflexiona, aquí al ladito dos puntos, se reflexiona, acá, integridad versus desesperación dos puntos...Se reflexiona...Sobre el pasado, coma, existe...Un sentimiento...De y colóquenlo por favor...no... Subrayado. Inutilidad

Alumna 2: ¿Cómo?

Profesor: inutilidad, es decir los...Estas personas se sienten inútiles ¿ya?, inutilidad, coma. Aparecen enfermedades, lamentablemente, bueno si han llevado una vida muy anticipada claro que sea la función y si no la han llevado conozco personas que todavía a los sesenta años corren y no tienen enfermedades, quizás la vista verdad. Un poco la presión pero más allá de que tengan un problema terminal. Pero eso va a depender del cuidado de uno ah, de cómo han sido ustedes en su vida, si han... han... han trasnochado mucho, todo depende del cuidado. Si ustedes quieren llegar bien ahí, a los sesenta y tener una vida sana y tales cosas, enfermedades que son riñones y cosas...Tienen que cuidarse ahora pu, ¿no cierto?

Alumna 1: si

Profesor: tener una vida saludable...Alejarse del alcohol y el cigarrillo que eso al final a la larga no...no creo que les traiga mucho beneficio ¿ya?, Así que hagámonos esa apología. Ya, niñitas, ¿eso sería? ¿Alcanzamos a ver la otra? A ver, no. Mejor les voy a pasar la otra parte...De acá...Para que lo hagan, lo lean y después en la segunda, en la ultima hora pasamos a Kohlberg ¿ya? Para que lo que todo así... La materia, ¿ya? Y...Hagamos lo que es la pedagogía, un poco teórico y un poco práctico, ya, vean eso y yo leo la...les coloque una...un test de personalidad en la última hoja a ver si ustedes...Una para las dos. ¿Ya? Vean el test de personalidad, acá les voy a pasar...Les voy a poner dos, ahí para que avancen mas pero me entregan una

(Profesor entrega las guías a las alumnas)

Profesor: ya...A ver...Shh...Acá hay un texto de comprensión lectora respecto a los aspectos libidinales, el libido en la teoría de Freud, no cierto, el apetito sexual. Entonces ustedes van a ver tres tipos acá. Y a partir de ahí ustedes van a responder el cuestionario que les coloque acá en la última hoja que no tiene que ver con el texto, el test de personalidad. Acá dice...eh...cual para ustedes es el más corto de los que esta acá en el monito y después ustedes van a elegir a...a uno y van a ver el que si es que corresponde con su personalidad ¿ya?...Ya

(Alumnas realizan actividad mientras se escucha que conversan)

Profesor: A ver, mañana con respecto a la prueba del electivo, ¿no cierto?, me estaban preguntando que no se entendió mucho el apunte. Eh...mañana podríamos trabajar con el apunte netamente y yo le daría un set de preguntas y ustedes me la entregarían como más pulida ¿ya? Eso sería lo más relevante como para que...eh... Lean el apunte porque creo que a lo mejor no lo han leído ¿no cierto? Miraron el apunte y ah...como... ¿ya? Ok, eso es lo que vamos a hacer. Ahora no me preocupa mucho el tema de que aparece en una semana o no por la prueba del electivo. Lo que si eh...En la prueba de...eh... psicología acuérdense que es la próxima semana esa no la voy a mover ¿ya? Ahora, hoy día, shhh. Tienen que tener claro cuáles son los contenidos formales eh...O donde puedo hacer un mapa conceptual de lo que va a entrar y ustedes 
me van a preguntar en la ultima hora que no entienden. Cosa que llegue vaya escribiendo acá todo y lo que va...eh....resolver. Ya, ¿ok?

Alumna 3: profe...profe yo no tengo el apunte

Profesor: ¿no teni el apunte?

Alumna 4: yo tampoco lo tengo

Profesor: pero tiene que conseguírselo, si se lo consigue tiene que pasarlo para fotocopiarlo, yo lo entregue todo la otra vez.

Alumna 4: es que yo ese día no estaba

Profesor: claro, pero consíganselo chiquillas y si ustedes me ubican hacemos el papelito y sacamos las fotocopias al tiro pero tienen que ustedes moverse.

(Alumnas siguen con la actividad)

Profesor: cualquier cosa me llaman si es que no entienden

Alumna 1: profe hay que entregarlo ahora

Profesor: eh...tenemos de las tres un cuarto hasta las cuatro pero...lo entrega hoy día

Alumna 2: pero ya van a tocar ya

Profesor: nos faltan cuatro minutos

Alumna 3: por eso...

Profesor: traten de juntarme alguna eh...si no entienden alguna...Acuérdense que después vamos a tratar de terminar con Kohlberg...

(Alumnas siguen con la actividad)

(Suena el timbre)

Profesor: ya entonces, a la última hora vemos el temario...temario 


\section{ANEXO 14. OBSERVACIÓN DE CLASE DE FEDERICO}

(Alumnas/os conversan)

Profesor: ya... atención a la lista

(Continúan conversando)

Profesor: Vannesa Andrade

Alumna 1: anda afuera...

Profesor: Cristian Arriaga

(Alumnas/os conversan)

Profesor: Francisco Arévalo

Francisco: ¡Presente!

Profesor: Constanza Beltrán

Alumna 2: ¡No vinooo!

Profesor: Richard Cartes

Richard: ¡Presente!

Profesor: Daniela Cartes

Alumna 4: No vino...

Profesor: Constanza Cortés

Alumno 3: anda afuera...

Profesor: José Díaz

José: ¡Presente!

Profesor: Mauricio Estrada

(Alumnos/as conversan)

Profesor: ¿Mauricio Estrada?

(Alumnas/os conversan)

Profesor: Constanza Geldres

(Alumnos/as conversan)

Profesor: Javiera Fuentealba

Alumna 2: Ausente...

Profesor: Sofía Gallardo

Sofía: Acá

Profesor: Johana Gálvez

Alumna 2: ¡Johana!

Profesora: Tamara Jara

Tamara: Presente

Profesor: Ana López

(Alumnos/as conversan)

Profesor: Juan Llaucón

Juan: Presente

Profesor: Denise Martínez

Denise: ¡Presente!

Profesor: Scarleth Millas

Scarleth: Presente

Profesor: Sofia Milillan

Sofía: Aquí estoy

Profesor: Francisca Muñoz

(Alumnos/as conversan)

Profesor: Paulo Ramírez

(Alumnas/os conversan)

Profesor: Ignacio Ramos

Ignacio: Presente 
Profesor: Karen Rivas

(Alumnas/os conversan)

Profesor: ¡shh! Karen Rivas

Alumna 2: Se retiró

Profesor: Víctor Salas

Víctor: presente

Profesor: Francisca Silva

Francisca: Presente

Profesor: Daniela Silva

(Alumnos/as conversan)

Profesor: Yanina Toledo

Yanina: ¡Presente!

Profesor: Leandro Vegas

(Alumnos/as conversan)

Profesor: Francisco Venegas

Francisco: Presente

Profesor: Diego Villa

(Alumnos/as conversan)

Profesor: Vivían Sanhueza

Alumna 2: No vino...

Profesor: Ignacio Villa

Ignacio: Presente

(Alumnas/os conversan y ríen)

Profesor: ¡Sh! A ver.... Eh...

(Alumnas/os conversan)

Profesor: A ver... ¡shh! La unidad... La unidad que vamos a comenzar eh... a empezar ¿cierto? a estudiar, lleva por título "individuo y sexualidad"

(Alumnos/as conversan)

Profesor: (repite) Lleva por título "individuo y sexualidad"

(Alumnas/os conversan)

Profesor: Referente a este tema... ¡Shh! Referente a este tema ¿cierto? Hay diversas ideas, y diversas problemáticas que... son importantes en este caso para abordar ¿ya? Es importante abordar

(Alumnas/os conversan)

Profesor: Lo que yo busco ¿cierto? o lo que a mí me interesa...

(Alumnas/os conversan)

Profesor: ¡Shh! Atención... Lo que a mí me interesa ¿cierto? al abordar esta eh... esta unidad ¿cierto? Es que primero... tratemos de... con la madurez que se necesita ¿cierto? y con... la seriedad que involucra este tema ¿ya? No implica que... como todas las clases ¿cierto? como es mi forma de enseñar, implica que de repente podamos bromear eh... o hacer una broma respecto de algo ¿cierto? de algún concepto, de alguna idea ¿ya? Pero implica siempre, sobre todo en este tema, mantener ¿cierto? la madurez para poder abordarlo, ¿por qué? Porque hay hartas problemáticas que involucran, y sobre todo problemáticas actuales que están insertos en este tipo de problemas ¿ya?

Alumna 1: ya...

Profesor: Lo primero que me interesa entonces y... ustedes me van a ayudar, es que podamos de alguna manera evitar, que podamos de alguna manera eh... tratar de eh... traer a colación ¿cierto? o... podamos elaborar también, sobre lo que es el concepto de sexualidad ¿Qué entienden ustedes por el concepto de sexualidad y de individuo? ¿ya? ¿Qué aristas tienen los temas? Y... ¿Qué conceptos puede involucrar? ¿ya? 
(Alumnos murmuran y conversan)

Alumna 2: ¡Richard Siéntense acá pu...

Alumno 2: no...

Alumna 2: ya pu...

Alumno 2: quiero poner atención...

Profesor: Bien, a ver... ¿Qué conceptos, temáticas o qué problemáticas involucraría digamos el concepto de sexualidad? ¿Quién podría... aproximar?

Alumno 3: pansexual

Profesor: bien, pansexual

Alumna 2: ¿Qué es eso?

Alumno 1: ¡Androsexual!

Alumno 4: Homosexual

(Alumnos/as conversan)

Alumno 2: Asexual

Alumno 5: Bisexual

Profesor: ¿Quién más podría aportar o dar alguna idea?

Alumno 5: Bisexual

Alumno 2: Heterosexual

Profesor: ¿Alguien más podría acotar con alguna idea, algún concepto?

Alumno 4: Bisexual

Alumno 2: Transexual

Alumno 6: Metrosexual

(Alumna ríe)

Profesor: Que sea distinto... ¡Sh! Que sea distinto de las orientaciones...

Alumno 3: Masculino y femenino... (alza la voz) Masculino y femenino

Profesor: (repite) Masculino y femenino

Alumno 2: (murmura) macho y hembra

Alumno 1: como una persona o individuo se manifiesta sexualmente

Alumna 2: ah... buscaste la definición...

Alumno 4: (murmura) masculino y femenino

Profesor: ¿Alguien más? A ver... Víctor

Víctor: ¿Qué?

Profesor: Usted... ¿Qué entiende por el concepto de sexualidad?

(Alumnos conversan y ríen)

Profesor: ¡Shh!

Víctor: (murmura) lo que te identifica... (alza la voz y repite) Lo que te identifica

Profesor: Pero, ¿Qué significa para usted?

(Alumnos ríen y murmuran)

Profesor: con sus palabras, de la forma más simple posible

(Silencio)

Profesor: No se complejice, yo no le estoy pidiendo una definición de diccionario, estamos... todavía empezando y tratando de...

Víctor: Profesor no lo sé... no sé profe...

Profesor: Pablo...

(Alumnas/os ríen)

Profesor: Pablo... ¿qué entiende usted por el concepto de sexualidad? ¿Con qué lo relaciona? ¿Con qué lo puede vincular?

(Alumnos bromean y ríen)

Profesor: ¡Sh!

(Alumnos/as ríen y conversan)

Profesor: ¡Silencio, shh! 
(Alumnos/as ríen en voz baja)

Profesor: ¿Con qué podría vincularlo? A ver...

Pablo: Cuando eh... algo como que habla del hombre y mujer... algo del hombre y mujer

Profesor: Ya... ¿Qué pasa entre el hombre y la mujer? ¿Cómo pueden tener...

(Alumnos/as ríen a coro)

Profesor: pero, no sea tan... tan académico, tan antiguo... trate de ser lo más completo posible

Pablo: No estamos en sexto para revisar el libro de biología

(Alumnos/as discuten)

Profesor: ¡shh! ¿Cómo podríamos decir... relaciones entre hombre y mujer?

Alumna 2: sexo...

Profesor: se asocia a lo que usted tiene casualidad, relación entre hombre y mujer...

Pablo: ya...

(Alumnos/ as murmuran en voz baja, y luego conversan)

Alumna 4: Eh... Francisca...

(ruido de sillas)

Profesor: Alguien más, a ver Salas...

Salas: ¿ah?

Profesor: ¿Qué entiende usted por sexualidad? ¿Con qué lo relaciona? ¿Con qué lo puede vincular?

Alumna 3: con... cambios

Profesor: No tenga miedo, si yo no me lo voy a comer

(Alumnos/as conversan)

Alumna 2: Pero profe, es que eso...

(Interrumpen) (Alumnos continúan conversando)

Profesor: ¡shh! ¿Cómo?

Alumna 2: características físicas y psicológicas de...

Profesor: características físicas y psicológicas

Alumna 1: eso mismo iba decir...

Alumna 3: ¿qué dijo?

(Alumnas/os conversan)

Profesor: (repite) características físicas y psicológicas... ¿Quién más podría aportar... con alguna idea, algún concepto? Francisca, a ver usted...

Francisca: (murmura) no...

Profesor: ¿con qué lo relaciona usted la sexualidad? ¿Con qué la vincula?

Alumna 5: La Daniela sabe...

Profesor: ¡Sofía! Usted a ver...

(Alumnas ríen)

Profesor: ¿Con qué la vincula? ¿Con qué puede usted relacionar el concepto de sexualidad?

O cuando escucha la palabra sexualidad, ¿qué es lo primero que... que le viene a la cabeza?

Alumno 2: (bromea) un cojín...

(Algunas alumnas ríen)

Sofía: No sé profe...

Profesor: Luciano... usted que me han contado que...

Luciano: la relación afectiva que siente una persona hacia otra, dependiendo de su sexo...

Profesor: relación afectiva que se puede establecer entre una persona y la otra...

(Alumnos/as conversan y murmuran)

Alumno 1: pero eso es más, relación que emoción

Alumno 3: no hermano, si no me quedan...

(Alumnas/os conversan) 
Profesor: relación afectiva... hagan puntos suspensivos con el lápiz... a ver por acá, ¡Richard!

Richard: ¡ah!

Profesor: ¿Qué entiende usted por el concepto de sexualidad? ¿Con qué lo vincula, con que usted lo relaciona? Desde su experiencia personal, no le estoy pidiendo una definición de diccionario...

(Alumnos ríen)

Richard: ¿Cómo?

Profesor: que no le estoy pidiendo una definición de diccionario, que sea completa, sino... (Alumnos bromean)

Alumno 4: (bromea) te haci el cartucho...

(Algunos alumnos ríen)

Richard: ¿no ve?

Profesor: Masculino/femenino, heterosexual, pansexual, relación entre hombre y mujer, relación afectiva... características físicas y psicológicas...

(Alumnos conversan)

Alumna 1: profe, pero ahí está todo...

Profesor: si, pero estamos recién empezando... ¿Con qué lo puede relacionar?

Alumna 3: familia... identidad...

Profesor: ¿usted? (repite) Identidad...

(Alumnos/as conversan)

Alumna 2: tiene que ver con el desarrollo...

Profesor: (repite) el desarrollo...

(Alumnos/as conversan)

Profesor: ¿alguien más? Para ir cerrando...

Alumna 2: él profe...

Profesor: a ver... ¿quién puede ser?

(Alumnos/as conversan)

Profesor: Señor Llaucón... ¿Qué podría decir usted respecto del concepto de sexualidad?

Alumna 2: ya Juan...

Juan: A ver, ¿qué quiere saber?

(Alumnos/as ríen de la respuesta de Juan)

Profesor: ¿Cómo lo relaciona usted? ¿Con qué lo vincula? ¿Con qué lo relaciona?

Juan: eh...

Profesor: Que sea distinto a lo que los compañeros han mencionado

Juan: bueno, para mí es como...

(Alumnos/as conversan)

Profesor: ¡shh!

Juan: como toda la identidad que desde que nace uno tiene, desde que nace hasta que uno puede... llegar a sentirse de otra forma, puede cambiarla o... eh... no sé, sentirse que no se siente con ninguno de los dos géneros, puede quedarse en medio... es algo... muy largo

Profesor: ósea, podemos decir que es algo... transversal digamos a la historia del ser humano

(Alumnos/as ríen)

Juan: atraviesa todo...

Profesor: atraviesa toda la vida del ser humano...

(Alumnas ríen)

Alumna 1: ¡Richard!

(Alumnos/as conversan, murmuran y ríen) 
Profesor: efectivamente, todo lo que ustedes mencionaron ¿ya? se relaciona de forma directa o indirecta con eh... con el concepto de sexualidad ¿ya? Como bien dijo ¿cierto? Eh... Juan, es un concepto transversal al ser humano ¿ya?

(Alumnos/as conversan)

Profesor: involucra ¿ya? Las características ¿cierto? de masculino y femenino, la heterosexualidad, pansexualidad, características físicas y psicológicas... identidad... ¿Qué era la identidad?

Alumno 2: $¡$ ah?

Profesor: ¿Qué era la identidad?

(Alumnos/as conversan)

Alumno 2: lo que es una persona...

Profesor: lo vimos anteriormente, lo analizamos...

Alumna 1: las características...

(Alumnos/as conversan)

Profesor: Atención A ver... ¡sh! ¿Qué características tiene la identidad?

(suena el timbre)

Alumno 4: recreo...

Alumna 2: lo que define a una persona

Profesor: que define a una persona ¿cierto? Y la identidad tiene tres características fundamentales que... nosotros analizamos...

Alumno 1: temperamento, carácter y....

Profesor: esa es la personalidad., esa es la personalidad... temperamento y carácter ¿cierto? conforman la personalidad

Alumna 1: (murmura) la identidad está en la personalidad... (alza la voz) la identidad está en la personalidad...

Profesor: efectivamente, la identidad está inscrita en la personalidad. Pero, ¿qué características conlleva la identidad? Eran tres conceptos, eran tres características...

(Alumnos/as conversan)

Alumno 2: las emociones que conlleva...

Profesor: ¡sh! esos son los tipos de personalidad...

Alumna 2: ¿la formación de la identidad?

Profesor: esa es la crisis formativa de la identidad... ¿ya?

Alumno 3: las vivencias...

Alumno 1: básicas, primitivas...

Profesor: esos son los tipos de personalidad... ¿ya? La identidad recuerden involucra tres conceptos fundamentales: autoestima...

Alumna 2: ¡ah ya...!

Profesor: ... autoconcepto ¿y...?

Alumno 3: (murmura) la opinión de la familia...

Profesor: la opinión o el juicio social que... se podría liberar sobre uno ¿ya?

(Alumnas conversan)

Profesor: Por otro lado... es diferente ¿cierto? la sexualidad en distintas etapas, se trata de la relación afectiva como bien decía... Estrada Luciano. La relación afectiva que se da... entre dos individuos, y... una relación entre hombre y mujer ¿ya?

(Alumnos/as conversan)

Profesor: ¡sh! Sin embargo...

(Alumnos conversan)

Profesor: Sin embargo... sin embargo, tengo la característica cultural que nosotros... como chilenos ¿ya? Los conceptos que ahí se señalan ¿cierto? Solamente involucran... dos características o se enmarcan dentro de.... Dos dimensiones solamente ¿ya? La que 
ustedes mencionaron ¿cierto? Se enmarcan, solamente dentro de dos dimensiones...

Por un lado, la enmarca ¿cierto? dentro de lo que se denomina como una dimensión.... (Alumnos/as conversan)

Profesor: ¡sh!... Biológica...

Alumno 1: y psicológica...

Alumna 2: si...

Alumno 1: (repite) y psicológica...

Profesor: una dimensión biológica ¿cierto? y... como dijo Luciano, muy bien, una dimensión psicológica...

(Alumnos/as conversan)

Profesor: (repite) una dimensión psicológica...

(Alumnos conversan)

Profesor: Sin embargo... ¿Qué otros aspectos faltarían?

Alumno 2: sociales...

Profesor: ¿Qué otros aspectos no están considerados...

Alumno 2: ¡Sociales!

Profesor: Sociales... Muy bien, y ¿qué esta antes de lo social?

Alumno 3: (bromea y ríe) lo antisocial...

Profesor: (repite) ¿Qué está antes de lo social? Cuando veíamos ¿cierto? la sociedad ¿cierto?

Alumno 2: el entorno...

Alumna 1: ¿familias?

Profesor: los procesos que se daban...

Alumno 2: familiar...

Alumna 1: ¿las familias?

Profesor: más grande que la familia, anterior ¿cierto? al individuo incluso...

Alumna 2: la genética...

Profesor: eso es parte de la condición biológica ¿ya? ¿Está claro?

(Alumnos conversan)

Profesor: ¡sh! Y dentro de la dimensión biológica, podemos establecer primero la configuración cromosómica de los seres humanos, podemos también distinguir ¿cierto? Eh... el sistema hormonal que involucra ¿cierto? bien a cada ser humano...

Alumno 3: la reproducción...

Profesor: también.... Dentro de la dimensión psicológica o del aspecto psicológico, está ¿cierto? lo que ustedes mencionan, que es la identidad... ¿ya? la identidad. Pero, ¿qué otra característica digamos, antecede digamos a todo lo que ustedes mencionaron?

Alumno 1: el alma...

(Alumnas/os ríen)

Profesor: eso es parte a la... a la condición de ser humano, como individuo... ¿ya? Pero en términos ¿ya? sociales... Juan lo dijo ¿ya? falta un aspecto social, pero ¿qué determina digamos el aspecto social? Que es anterior digamos a esto...

Alumno 2: la personalidad...

Alumna 1: ¿el criterio?

Profesor: no

(Alumnos/as conversan)

Profesor: ¡sh!

Alumno 3: la cultura...

Profesor: cuando veíamos ciertos procesos que tenían que ver cuando... dos grupos se encontraban ¿cierto? Y uno...

Alumna 1: la cultura...

Profesor: y uno... ¡Muy bien! La cultura...

(Alumna ríe) 
Profesor: la cultura... ¿ya?

(Alumnos conversan)

Profesor: también falta, entregar en este sentido ¡sh!, falta un componente ¿cierto? de la dimensión sociocultural ¿ya? Sociocultural...

(Alumnos/as conversan)

Profesor: Bien... mencionamos ¿cierto? o ustedes describieron de forma ¿cierto? correcta, diversas características que involucran ¿cierto? la dimensión de tipo biológica ¿ya? Y la supieron definir, a partir de las características que dieron muy bien ¿ya? También encontramos ¿cierto? una... dimensión psicológica ¿ya? Que también se inserta dentro de las características que ustedes dieron. Juan ¿cierto? mencionaba una característica $\mathrm{y} .$. por acá no me acuerdo quién fue... mencionaron el aspecto sociocultural. Bueno, ¿qué características ¿cierto? relacionadas con la sexualidad, involucraría ¿cierto? este aspecto o esta dimensión sociocultural?

Alumno 2: las relación entre... el hombre y la mujer...

Profesor: ¿de qué tipo de relación estamos hablando?

Alumno 3: jafectiva!

Alumno 4: sexual...

Profesor: afectiva.... Pero, afectiva.... ¿en qué sentido a ver?

(Alumnos conversan)

Profesor: ¿en qué sentido... ¡ish!

Alumno 2: tiene que ver con lo que está buscando una persona...

Profesor: ¿en qué sentido sería afectiva?

Alumno 3: A ver... ¿cómo explicárselo?... Cuando el papá y la mamá....se quieren tanto que...

(Alumnos conversan)

Profesor: Ya... a ver, ¿Qué características... de acuerdo a lo que ustedes mencionan, qué características por ejemplo, se le asignan, en este caso... a los hombres? ¿ya? o al sexo masculino... culturalmente, socioculturalmente... ¿Qué características, recuerdan... que plantea Luciano ¿cierto? qué características se le asignan, en este caso, al hombre socioculturalmente?

Alumno 2: tiene que ser protector...

Profesor: ya... muy bien

Alumno 5: iprotector!

Profesor: que tiene que ser protector... ya... ¿Qué características se asignan?

Alumno 3: liderazgo...

Profesor: ya... ¿cierto? ser en este caso, eh... líder... estereotipo del macho alfa de la manada...

Alumno 4: (imita un gorila) ¡uh! ¡uh!

Profesor: ya... etcétera... ¿Qué otra característica encontramos... este... socioculturalmente...

(Alumnas/os conversan)

Profesor: ¡sh! .... se le asigna digamos... a.... los hombres?

(Alumnos/as conversan)

Isidora: que no deben llorar

Profesor: Muy bien, aquí Isidora plantea... algo muy interesante ¿Ya?

(Alumnos conversan)

Profesor: ¡sh! Que socioculturalmente... socioculturalmente se le niega al hombre la posibilidad, por ejemplo, de expresar sus sentimientos ¿ya? De ahí... que... sea... más... ya una costumbre ¿cierto? una tradición de que se diga de que el hombre...

Alumno 1: no llore 
Profesor: no llore.... ¿ya? Ahí también tenemos ¿cierto? una característica ¿cierto? sociocultural que... a partir de la tradición, se asigna en este caso al hombre, y que no pueden, de alguna manera... no podría expresar sus sentimientos ¿ya?

Alumna 2: es más frío...

Profesor: ya... a partir cierto de esta... a partir de esta creencia sociocultural obviamente ¿ya? ¿Qué característica se le asigna socioculturalmente... a una mujer por ejemplo?

Alumna 1: que tiene que ser delicada...

Alumno 2: ¡Llorona!

Alumno 3: Que tiene que ser señorita...

Profesor: Señorita... a ver, ¿cómo puede definir eso?

(Alumnos conversan)

Profesor: ¡sh! a ver....

Alumna 3: ¡mentira!

Profesor: atención...

(Alumnas discuten con sus compañeros)

Profesor: ¡sh, sh, sh! Atención a ver...

(Alumnas siguen discutiendo)

Profesor: Ignacio planta algo muy interesante....

(Alumnos/as conversan)

Profesor: (repite) Ignacio plantea algo muy interesante... que la... la mujer tiene que ser entre comillas señorita, ¿a qué refiere eso? ¿a qué podría referir eso?

Alumna 2: a que tiene que ser delicada...

Profesor: ya... delicada

Alumno 3: educada...

Alumna 1: educada...

Alumno 3: educada...

Alumna 1: es educada...

Profesor: ¿Educada en qué sentido?

Alumno 3: en como de... modales

Profesor: ya... ¿Qué más Ignacio?

Alumna 2: en ser inferior...

Profesor: sumisa... ya...

(Alumnas/os conversan y ríen)

Alumno 1: esa es una película profesor

Profesor: bien...

(Alumnos/as conversan)

Profesor: ¡sh!

(Continúan conversando)

Profesor: ¡sh! ¿Perdón? No escuché...

Alumno 3: esos son estereotipos más que... una realidad, porque la mujer puede ser todo lo contrario a eso...

Profesor: efectivamente

Alumno 3: entonces, la gente piensa generalmente que la mujer es así o que implica que piensen eso... o son la mayoría

Alumno 2: sipo, una cosa así...

Alumno 3: son estereotipos...

Profesor: Ya... efectivamente, tiene que ver con eso... esos son ¿cierto? ideas y conceptos que se han ido arrastrando anteriormente, socioculturalmente y que... en este caso, corresponden a estereotipos, características de cómo debiese ser digamos el rol social del hombre y de la mujer ¿ya?

(Alumnos/as conversan y ríen) 
Profesor: ¿Qué otras características están presente?

Alumno 1:

(Alumnos/as conversan)

Profesor: ¡Muy bien! Finalmente ¡shh! Finalmente, si ya tenemos...

(Alumna murmura)

Profesor: ... si ya tenemos ¿cierto? el componente o la dimensión biológica, y conocemos, sabemos sus características.

(Alumnas conversan)

Profesor: Tenemos la dimensión psicológica, tenemos una dimensión sociocultural ¿ya? que ustedes muy bien designador ¿cierto? y caracterizaron también esta... dimensión sociocultural. ¿Qué característica nos faltaría para poder completar digamos la conformación global del ser humano?

(Alumnos conversan y bromean)

Profesor: ¿a quién... a quién se le podría ocurrir?

(Alumnos/as conversan)

Profesor: Si bien... digamos de lo que hemos hablado ¿ya? dentro del estudio de... el individuo y la sexualidad, encontramos primero una dimensión biológica ¿ya? que todos sabemos que características tiene ¿ya? la configuración cromosómica ¿ya?

(Alumnas/os conversan)

Profesor: El desarrollo ¿cierto? de un sistema hormonal ¿ya?

Alumno 2: ya...

Profesor: Involucra también, la genitalidad ¿cierto? y las características ¿cierto? eh... anatómicas de los órganos sexuales, etcétera, etcétera... Encontramos también una dimensión psicológica, repito, que involucra las características propias del comportamiento que... tienen los individuos...

(Alumnas conversan y ríen)

Profesor: Una dimensión sociocultural, que refiere a... características que la misma cultura, la misma sociedad, le asigna en este caso, a cada género. Pero, ¿Qué otra característica faltaría para... terminar de configurar la estructura del ser humano?

(Alumnos murmuran)

Profesor: ¿Qué otro aspecto nos faltaría?

Alumno 1: Laboral... (Alza la voz) laboral...

Profesor: ¿cómo?

Alumno 1: (repite) Laboral...

Profesor: Ya... si, po... podría ser...

Alumno 2: cómo se siente el individuo

Profesor: (repite) cómo se siente el individuo.... Eso es interesante

Alumno 5: sus padres...

Profesor: ya... hay otra característica que involucra... muy bien

Alumna 2: la realidad...

Profesor: ya... a ver, ¿qué iba decir usted?

(Alumnas/os conversan)

Profesor: nos falta una dimensión entonces...

Alumna 1: ética...

Profesor: ¡Muy bien!, ¡Muy bien Tamara! La dimensión ética.... Muy bien Tamara...

(Alumnos/as conversan y ríen)

Profesor: (repite) La dimensión ética

Profesor: ¿Y qué relevancia habría... o qué relevancia tendría esta... esta dimensión ética?

Alumno 1: la típica que dice no... que... un hombre es peor que una mujer...

Alumno 2: o que otro hombre...

Alumno 3: pero eso es un juicio moral... 
Alumno 5: (murmura) es un juicio machista...

Alumno 1: pero tiene que ver con la ética...

Profesor: ¡Muy bien!, Muy bien ¿ya? ¿Y eso es un?

Alumno 3: juicio moral

Profesor: un juicio moral ¿ya? Y la dimensión ética... la dimensión ética va involucrar en este caso que todos nuestros actos ¿ya? Todos nuestros actos ¿cierto? Van... en este caso a tener, una determinada... consecuencia ¿ya?

(Alumnos murmuran y ríen)

Profesor: Y estas consecuencias ¿cierto? También...

(Alumnas/os conversan)

Profesor: estas consecuencias ¿cierto? implican digamos, el desarrollo de nuestra autonomía, de la responsabilidad que nosotros podemos asumir en nuestros actos ¿ya?

(Alumnas conversan)

Profesor: (alza la voz) y que eso obviamente va tener una consecuencia sobre nosotros ¿ya? Y lo que plantea Luciano... constantemente ¿ya? constantemente.... Dentro de este tema, estamos haciendo juicios morales ¿ya? Haciendo juicios... calificando ¿cierto? de que cierta acción, cierta persona, es buena o es mala, porque tiene... tales características. ¿Y por qué ocurre eso? ¿Por qué tendemos a establecer juicios morales?

Tamara: ¿por los prejuicios?

Profesor: ¡Exacto Tamara, muy bien! ¿ya? por prejuicio... ¿ya? opiniones mal formadas y... nosotros podemos realizar sobre tal o cual persona, o... respecto de su forma de comportamiento. ¿Qué tema por ejemplo, relacionado con la sexualidad, hoy en día involucra un fuerte juicio moral?

Alumno 1: el aborto

Profesor: (repite y asiente) el aborto

Alumno 2: la homosexualidad

Profesor: (repite y asiente) la homosexualidad

Alumno 3: los próvida...

Profesor: ¿Por qué el aborto... a ver, por qué el aborto ¿cierto? es un tema que está en boga? (Alumnos/as conversan)

Profesor: ¡shh! ¿Por qué el aborto es un tema que está en boga y que... tiene un fuerte juicio moral?

Alumno 5: porque están matando una vida

Profesor: ya... ¿cierto? hay ciertas posturas que reclaman que... se está interrumpiendo una vida

(Alumnas/os conversan)

Profesor: ¿Qué otra característica tendría el tema?

Alumno 4: una polémica

Profesor: pero, ¿por qué causa polémica? ¿Qué tiene el tema que cause... digamos controversia?

Alumno 2: la mujer se siente con derecho... con todo el derecho de elegir, siendo que... para cosas como... para cosas... para otras cosas el hombre tendría que... ósea, me enredé...

Profesor: A ver, desarrolle bien la idea, lo esperamos

Alumno 2: en este caso el aborto, la mujer se siente con todo el derecho sobre su cuerpo y elegir, pero cuando un hombre no quiere a su hijo o no quiere pagar una pensión, o no quiere nada, le tienen que obligar a hacerlo, y.... un hombre no puede obligar a una mujer a tener el bebé porque ella es la que va tenerlo, pero él es el que va tener que estar pagando pensión....

Alumna 1: es que depende del trato igual el tema del aborto porque.... 
Profesor: A ver lo que plan... lo que plantea Juan es interesante ¿por qué tú le puedes responder? a ver...

Alumno 2: ah no, pero no...

Alumna 1: es que... hay diferentes tipos de aborto, por ejemplo...

Alumno 2: no, pero yo me refiero a tener el aborto libre, que porque estas embarazada puedes abortar porque lo quieres hacer, pero... por ejemplo...

Alumna 1: sipo, ahí está mal

Alumno 2: pero de las violaciones... que el bebé nace con problemas o... que se complique el parto... ahí si yo creo que...

Profesor: ya... en ese sentido podríamos decir que el aborto tendría eh... una aplicación...

Alumno 2: una justificación

Profesor: una justificación en casos determinados

Alumno 2: si

Profesor: ¿no podemos hablar de un aborto libre porque si?

Alumno 2: no

Alumna 1: no

Alumno 3: también puede ser... una complicación de la madre igual, porque... por ejemplo si la madre...

(Alumnos/as conversan)

Profesor: ¡Sh! A ver, lo que plantea el compañero es interesante

Alumno 3: no tiene los suficientes recursos y ella es consciente de eso, para no traer una vida que...

(Alumnos conversan)

Profesor: ¡sh!

Alumno 3: pueda evitar su sufrimiento entre comillas, porque es pobre... extremadamente pobre

Alumno 1: pero es que ahí entramos en que el gobierno necesita mejorar las cosas, cómo se mantienen los niños...

Alumno 3: sipos, pero...

Alumno 1: o bien puede dejarlo en un orfanato

Profesor: ósea también podemos decir que una política pública, que pueda... que regule digamos...

Alumno 1: o que por ejemplo, los... el gobiernos tampoco habla de la educación en casa porque... dicen, porque si la gente dice "no, yo educo a mi hijo en casa" y ¿por qué educar en casa? ¿Por qué la educación es mala? ¿Porque es cara? ¿Porque... hay prejuicios?" Y ahí entrarían en que tienen que mejorar la educación, o hay más gastos... por eso no se hablan de cosas...o no se hacen cosas, porque... prefieren.... prefieren adoptar y no mejorar un... algo que está mal en el gobierno y que les falta ver, y eso es lo que pasa. Igual se prefiere no gastar plata en vez de salvar vidas

Profesor: ya... ¿qué otro?

Alumno 3: ya pero... mi argumento era otro...

Profesor: no si entiendo lo que dice

Alumno 3: cuando una madre no tiene los recursos y no quiere traer ese hijo, porque igual que ella va sufrir....

Alumna 1: no...

Alumno 1: ese es otro tema porque no puede abortarlo porque... sería como.... Hay mujeres que abortan, pero....

Profesor: claro... ¿Luciano?

Alumno 3: igual el estado se habría más endeudado si... hace abortos, porque son extremadamente carísimos. Sería más económico que la madre intentará recibir educación sexual, antes de... abortar, aparte del riesgo que corre la madre 
Profesor: Muy bien Luciano, ahí menciona usted... y Juan también, bueno los tres en realidad, han eh... mencionado ¿cierto? y han tocado falencias digamos, que tiene nuestro... eh... nuestro estado ¿ya? en... en políticas de... de educación sexual y de poder subsanar ciertas problemáticas sociales ¿ya? Ahora... hace unos dos años atrás eh... por ejemplo, eh... el ministerio de educación está comenzando a formular programas eh... detallados sobre educación sexual, el... el liceo... tengo por ejemplo, un gran número de colegas que eh... a principio de año eh... con un curso que tomaron en las vacaciones de invierno para poder después implementar en el liceo, a partir de... del contexto digamos, de nuestro contexto como... como institución, de poder desarrollar un plan de... de educación sexual.

(Alumnas/os conversan)

Profesor: Eh... entonces, ustedes mismos...

(Alumnos/as conversan)

Profesor: ¡sh!, pudieron detectar ¿cierto? a partir de todo lo que hemos visto, diversas falencias o vacíos legales ¿cierto? en cuanto al tratamiento, de este tema ¿ya? Uno de ellos, por ejemplo, el tema ¿cierto? del aborto ¿ya? Que tiene... esta característica de... que por un lado se quiere justificar, o... a partir de situaciones puntuales ¿ya? Y no coartar ¿cierto? como dice eh... Nicolás, el aborto en el caso de situaciones extremas ¿cierto? de familias que no puedan de alguna manera eh... hacerse cargo de la responsabilidad que implica... un hijo. Y Luciano también, menciona algo fundamental que tiene que ver con el desarrollo de planes, planes y programas, para poder tratar ¿cierto? y para educar sexualmente ¿ya? Y el otro tema que ustedes mencionan y que es bien interesante, es la homosexualidad. ¿Por qué la homosexualidad tiene un juicio moral y una carga moral tan fuerte?

Alumna 2: por la... religión

Alumno 3: por la sociedad

Profesor: A ver... allá... usted...

Alumna 2: por la...

Profesor: la religión ¿verdad? Y ¿habla en un tono de carácter positivo o negativo?

Alumna 2: negativo

Profesor: ¿por qué?

Alumna 2: porque... según... ellos, según la biblia eso está contra Dios

Profesor: Ya... según, digamos el planteamiento... digamos de, de los grupos religiosos, la biblia plan... plantea digamos, que la homosexualidad sería algo ¿de qué tipo?

Alumno 1: porque va contra sus leyes

(Alumnos/as conversan)

Profesor: ;sh!

Alumno 2: es mal visto por... por la sociedad eso, por las culturas... dos hombres, ver a dos hombres... obviamente, la socie... eh... lo imponente que es la biblia, la religión en general, en... ciertas personas, es mal visto eso... como un pecado

Profesor: ósea la... podemos decir que...

Alumno 2: desde el punto de vista de la religión

Profesor: el aspecto religioso digamos, es muy fuerte en las personas y por eso digamos se genera ese prejuicio

Alumno 4: se implementó la pena... pero desde el punto de vista de la religión

Alumno 2: un estereotipo

Alumno 4: por temas...

Profesor: socioculturales... sociocultural

Alumno 3: y llevamos mucho tiempo con el tema de la religión en todos lados, la mayoría de las religiones ven el tema de la homosexualidad mal, entonces... gente ya que... la mayoría por ejemplo de gente que... que habla... que no sé po, que habla con más 
gente, que se relaciona más, que tiene hijos, todo eso no sé... caballeros viejos, que toda una vida cristianos, que sean de otro país no sé po... Budistas, todos ven... todos ven de alguna forma mala la homosexualidad, y por eso... por eso, a sus hijos le traspasan eso y por eso sigue todo el tiempo el tema de la homosexualidad como algo malo, porque la religión está muy... está muy pegada en la gente, tendrían que sacarla como en... una generación, así en la siguiente no... no se marcará tanto

Profesor: y aquí ustedes como curso, por ejemplo, como... ¿qué curso es este?

Alumna 2: tercero A

(Alumnos/as ríen a coro)

Alumno 3: ¡oh!

Profesor: de este curso, ustedes como curso... ¿Qué opinión o que juicio ustedes realizan... Alumno 3: ¿cómo cada uno?

Profesor: ...sobre la homosexualidad?

Profesor: como curso...

Alumna 1: ¿cómo curso?

(Alumnos ríen)

(Comienzan a conversar y discutir)

Profesor: ¡sh!

Alumno 1: es difícil... porque cada uno...

Alumna 2: somos...

Profesor: por eso la pregunta...

Alumno 2: somos muchos...

Profesor: por eso la pregunta

(Alumnos/as conversan)

Profesor: por eso... por eso les pregunto... ¡sh! Por eso les pregunto cómo curso y no como individuos

Alumno 1: es que...

Profesor: ¿es posible... respecto de la homosexualidad, aunar criterios y estar de acuerdo?

Alumno 3: no

Profesor: sobre esto... o...

(ruido de silla)

Alumno 4: dependiendo...

Profesor: ¿de qué?

Alumno 4: de que si hacen una encuesta y más del sesenta por ciento...

(Alumna ríe)

Profesor: pero no...

(Alumnos conversan)

Profesor: no tiene que ver... no tiene que ver con un número, ni con una cuestión estadística ¿ya? Estamos llenos de estadísticas y constantemente digamos, los números eh... nos bombardean ¿cierto? y no queremos llegar a eso, sino que...

Alumna 2: tiene que ver con la...

Profesor: con la propia condición de ser humano y de individuo ¿ya? ¿Hay una opinión concreta $0 . .$. se pueden dar criterios respecto a la homosexualidad aquí en el tercero $\mathrm{B}$ ?

Alumno 2: no, cada uno tiene una opinión

(Alumnos/as discuten)

Alumna 3: se puede dividir en dos grupos el curso....unos a favor y otro en contra...

Profesor: ¡ah, ya! Se dividiría el curso digamos...

Alumna 3: en los que están a favor y en los que están en contra...

Profesor: a favor y en contra...

Alumna 3: dependiendo de las enseñanzas que... 
Profesor: voy a reformular la pregunta entonces... no me levanten la mano, no levanten la mano porque... no me interesa digamos, establecer o realizar un juicio digamos, sobre quienes están de acuerdo, sino... o quienes están en desacuerdo, sino que... traer la problemática de manera global ¿cierto? y colocar en la mesa todas las características. ¿Hay alumnos dentro del tercero B que están... en contra de la homosexualidad?

Alumna 2: no

Alumno 1: los hay tal vez...

Profesor: hay alumnos...

Alumno 3: si...

Alumna 4: si

Profesor: ¿Hay alumnos que están... a favor de la homosexualidad?

Alumno 1: si

Alumna 4: si

(Alumnas ríen)

Profesor: también... hay alumnas que...

Alumno 3: no estoy de acuerdo en todo, pero si compar... si entiendo a la persona

Alumnos a coro: (se burlan) ¡Wuouuuu!

Profesor: ¡iShh!!

Alumno 6: (bromea) washito...

(Ríen a coro)

Profesor: ¡ishh!! A ver, a ver... precisamente...

(Algunos continúan riendo)

Profesor: precisamente... iishh!! Precisamente a eso me refería, y todo lo que hemos mencionado refiere a eso... la carga sociocultural...

Alumno 3: pero... ve porque no se puede dar una opinión

Profesor: por lo mismo, porque hay una carga sociocultural respecto del tema

(Alumnas/os comienzan a discutir)

Profesor: Hay una carga sociocultural respecto del tema, ¿ya?

Alumna 3: profesor...

Profesor: pero a ver... ¡sh! Invito a la... a la... a quien esté en desacuerdo ¿ya? a poder exponer sus argumentos en la mesa, ¿Por qué la homosexualidad causa recelo o le causa recelo a usted? Y es algo negativo, y usted establece un juicio moral negativo sobre eso...

Alumno 4: Víctor... Víctor...

Alumno 3: profesor... yo no estoy en contra de la homosexualidad pero... pero estoy en contra sí, por ejemplo que... el tema de los niños, de que puedan adoptar, en eso estoy un poco en contra...

(Alumnos/as murmuran)

Profesor: ;sh!

Alumna 3: el niño va a la escuela, si... va con sus dos papás...

(Alumnos/as murmuran)

Alumna 3: y los otros niños, con su papá y su... mamá, y el otro niño ve que van todos con su mamá y su papá...

Profesor: ya...

Alumna 3: entonces el niño se va preguntar por qué él tiene dos papás, y en cambio los otros niños tienen un papá y una mamá... y él no, y se empieza a hacer preguntas, y entonces los otros niños, aunque no quieran serlo crueles, son crueles y le empiezan a hacer bullyng, y lo empiezan a molestar, a burlarse, y él se empieza a llenar de pensamientos...

(Alumnas/os ríen en voz baja) 
Alumna 3: algunas personas... no voy a decir el cien por ciento de los niños, pero empiezan a tener una duda, y empiezan a... a pensar en cosas malas así... empiezan a... a criarse con esa mentalidad

Profesor: Nicolás...

Nicolás: Ahí entra la... la educación en casa, la educación sexual en general...

Profesor: ¿Por qué?

Nicolás: porque uno por ejemplo, esas creencias desde casa... las traslada a la sociedad

Alumna 3: si, pero no... le vas a explicar a un niño de siete años...

(Alumnos/as comienzan a discutir)

Profesor: ¡Shh!

Alumna 3: profe... dígale algo...

Alumno 1: si tú crías un niño homofóbico, va crecer siendo homofóbico y el hijo suyo también va ser homofóbico, porque si no cortai eso de raíz, tenis que cortarlo desde chico...

Alumna 3: es que... no es un tema de educación sexual, sería un tema en el ámbito del respeto... porque si una persona no respeta se va burlar de la otra

Profesor: A ver Tamara, ¿usted qué opina...

(Alumnos/as conversan)

Profesor: ¡shh! ...¿cuál es su opinión? ¿O qué opina sobre la homosexualidad?

Tamara: Es que depende... del ámbito en el que se hable...

Profesor: ¿por qué?

Tamara: porque si se habla de temas biológicos eh... estaría mal por el tema de que se pueden pegar muchas enfermedades de transmisión sexual...

Profesor: yaa....

Tamara: por un tema psicológico estaría bien, porque de todas formas...

(Alumnos/as murmuran)

Profesor: ¡Shh!

Tamara: ... si una persona quiere a otra... está bien, no le tendría por qué molestar eso.

Profesor: Ya... muy bien, ósea que en ese sentido por ejemplo, podríamos decir que se suele confundir entonces... eh... las características como individuo ¿cierto? como persona y... eh... la vida sexual o de lo... lo que pasa en la intimidad de... de las personas...

Tamara: que... más que nada sería el tema del respeto, porque... la mayoría de la gente, como que si algo no le gusta, no tiene que ser así, y eso está mal

Profesor: Ya...

Tamara: porque tendrían que respetar... cómo es la otra persona

Profesor: A ver... para ir cerrando a ver, Yanina... usted ¿qué... qué opinión le merece el tema de la homosexualidad por ejemplo?

Yanina: Yo no... no soy partidaria, pero si lo respeto

Profesor: Lo respeta, ¿en qué sentido?

Yanina: en que... porque no porque a mí me... el hombre y otro hombre, si se quieren... ósea, para el amor no es necesario que... sea un hombre y una mujer, si ellos sienten amor por ellos

(Alumnos/as conversan)

Profesor: Leandro... ¿Qué...yo... hizo una acotación respecto lo que estaba diciendo Nicolás hace un rato... ¿Qué opinión le merece el tema que estamos tratando?

(Alumnos/as murmuran)

Profesor: ¡Shh!

Leandro: no, es que... que es bueno que... enseñarle a los... a los niños desde chico...

(Alumna ríe)

Leandro: ... desde chicos

Profesor: ya... 
Leandro: para despejar los distintos temas de... de la sexualidad eh... por ejemplo eh... a mi hermana eh... cuando venía en un bus, donde había hombres o mujeres besándose, y... preguntaba así como.... “¿Por qué hay dos hombres así?” Y yo le... yo le expliqué, y... y ahora, hoy en día eh... ya no siente pudor así como, si está bien o mal... que dos hombres o dos mujeres se gusten...

Profesor: Bien...

(Alumnas murmuran y ríen)

Profesor: Y por último...

(Alumnas murmuran y ríen)

Profesor: para ir cerrando... La homosexualidad ¿ya? es un tema que siempre ha existido ¿ya? Históricamente siempre ha existido, desde los inicios de la...

(Alumno/a silba)

Profesor: ... de la humanidad ¿ya? Y les voy a contar un ejemplo. En la antigua Grecia ¿ya? Eh... y de ahí viene el dicho ¿cierto? "se le soltaron las trenzas" ¿ya? Siempre se ocupa, en nuestra cultura se ocupa demasiado, y la de... llevar una carga digamos, negativa y precisamente asociada a la homosexualidad ¿ya? Pero fijense la... la coincidencia y eh... lo que vamos... lo que vamos a sacar de ahí. La frase ¿cierto? "Se le soltaron las trenzas" En la antigüedad... ¿ya? y esto también, históricamente ha sido así, ¿ya? A través de los años siempre ha sido así, pero no tendría por qué ser así tampoco... ¿ya? La mujer... ¿ya? estaba completamente reprimida en la sociedad griega, y no solamente en la sociedad griega, sino que en la mayoría de las civilizaciones antiguas ¿ya? Solamente servía ¿para qué? Para criarlos... para concebir hijos ¿ya? para criarlos y para hacer... las labores de la casa ¿ya? En la antigua Grecia, los hombres ¿cierto? eran ciudadanos, participaban de las cuestiones de la polis, tenían cargos políticos, cargos importantes y ellos... participaban de la... vida social digamos, de la polis ¿cierto? y de la ciudad griega ¿ya? Las mujeres solamente servían en ese momento, para esas labores... para nada más ¿ya? Entonces, ¿qué pasa? Había un día en que las mujeres eran libres ¿ya? había un día en que las mujeres eran libres y no hacían nada ¿ya? Y ese día era de fiesta ¿ya? donde... las mujeres salían ¿cierto? a celebrar a las calles, danzaban... celebraban ¿ya? Y curiosamente, la característica principal, era una exigencia también, de la sociedad griega, es que las mujeres usaban su pelo largo y tenían que trenzarlo, por obligación debían usar una trenza o su pelo tomado. Bueno, ¿qué pasaba? Las mujeres celebraban, eran libres ¿cierto? por un día y soltaban sus cabellos al viento. Soltaban sus cabellos al viento ¿ya? y celebraban... y... ¿ya? como dice también a los mitos, porque los griegos se caracterizan por... por los mitos, dice también la versión del mito que las mujeres tenían relaciones sexuales ¿cierto? con los sátiros... ¿ya? ¿Y quiénes eran los sátiros?

Alumno 3: los viejos...

Alumna 4: seres mágicos...

Profesor: seres mitológicos... ¿ya? Seres mitológicos que eran... mitad cabra y... mitad humana ¿ya?

Alumno 2: (murmura) Narnia...

Profesor: Aquí... aquí qué quiero identificar en el fondo, ¿a qué quiero llegar con esto? Respuestas eh... elaboradas por humanos ¿ya? Y estas respuestas ¿cierto? Y estas... concepciones que... tenemos ¿cierto? y que nosotros concebimos como verdad... son solamente eh... verdades humanas que están ideadas ¿ya? Escritas en determinados textos, para una determinada sociedad ¿ya? No se consideran ¿cierto? o no se consideró en el avance... y el desarrollo social de las personas ¿ya? Por lo tanto, realizar un juicio ¿ya? como el que... acabas de lanzar, a modo de broma, y que bueno 
que se haya dado así, de la opinión que da Ignacio que automáticamente le digan... "Ah... pasivo, etcétera, etcétera, etcétera..."

(Alumna ríe)

Profesor: ¿ya? Pongan atención con eso, pongan atención con que históricamente ¿cierto? Se han ido asociando ¿cierto?... ciertas idas que... que están tan impregnadas ¿ya? en nosotros, que... compartía Juan ¿cierto? de forma correcta, hace falta generaciones para que se puedan ir modificando ya, y que en el fondo, pueda haber... tolerancia y respeto, como plantea Tamara ¿ya? Y con eso cerramos el tema... ¿bien? ¿Hay alguna duda sobre lo que hemos estado hablando?

Alumnos a coro: No...

Profesor: ¿Algo que no esté claro?

Alumna 4: no

Alumno 3: ¿Y usted qué opina sobre eso?

Profesor: Las opiniones de ustedes me importan ¿ya? Ahora vamos a realizar una actividad, en parejas ¿cierto?

Alumna 3: ¡noo...!

Profesor: A ver cómo resulta...

(Alumnos/as conversan en voz alta)

Alumna 2: Profesor... eh... ¿se entrega?

Profesor: si

(Alumnos/as conversan)

Alumna 3: Profesor... ¿se entrega?

Profesor: Si...

Alumna 3: ¿hoy?

Profesor: hoy

Alumno 3: ¿es con nota?

Profesor: todo es con nota

Alumno 2: ah... sumativa, supongo...

Profesor: eh... no

Alumno 2 y 3 a coro: ¿Al libro?

(Alumnos/as conversan, bromean y ríen)

Alumna 2: profe...

(Alumnos bromean y ríen)

Alumno 4: (bromea) auxilio... me desmayó... cállese viejo lesbiano

(Alumnos ríen a coro)

Alumno 3: ¿Quién lo dijo?

(Alumnas/os conversan)

Profesor: ¡Sh! Júntense con su compañero, en parejas... para anotar las siguientes... las siguientes preguntas.

(Alumnos/as conversan)

Profesor: (dicta) “¿Qué mensajes de lo que es propio de hombres y mujeres están presentes en nuestra cultura?"

Alumno 1: (se queja) yaa...

Alumno 2: fue demasiado rápido

Alumno 3: de nuevo

Profesor: (dicta) "¿De qué manera abordan los medios de comunicación (tv, radio, los periódicos, redes sociales, publicidad) la sexualidad?

(Silencio)

Profesor: Entonces con su compañero de puesto ¿ya? van a resolver ¿cierto? dos preguntas... Me entregan ¿cierto? un trabajo por pareja...

Alumno 2: profesor... 
Profesor: dígame

Alumno 2: ¿Cuánto espacio hay que dejar?

(Alumnas/os conversan)

Profesor: ¿Hay alguna duda, hay alguna consulta?

(Alumnos/as conversan, comienzan a ubicarse en parejas y trabajar)

Profesor: ¿Tamara alguna duda?

Tamara: ¿A qué se refiere con la pregunta de los mensajes?

Profesor: qué características culturales, se le asignan a los hombres y a las mujeres...

Tamara: Ah ya...

Profesor: ¿ya?

(Alumnos/as conversan)

(Profesor orienta a los grupos resolviendo dudas)

Tamara: ¿cuántos hay que mencionar?

Alumna 2: agresivo...

Tamara: (repite y anota) agresivo...

Alumna 2: ¿y después de las mujeres cierto?

Tamara: $i$ ah?

Alumna 2: ¿de las mujeres igual cierto?

Tamara: si

Alumna 2: ¿Hay que hacer cuatro?

Profesor: ¿Alguna duda por acá?

(Alumnas/os conversan)

Tamara: Son más sensibles..

Alumna 2: ya... eso... más sensible...

(Suena el timbre)

Tamara: son dueñas de casa...

Profesor: Ya... continúen la próxima clase... tienen que traer las preguntas... eh... Alumno 3: terminemos de hacerlas aquí mejor...

Alumno 4: cállate.. 


\section{ANEXO 15. OBSERVACIÓN DE CLASE DE CLAUDIO}

(Alumnos/as conversan)

(Ruido de sillas y mesas)

Profesor: Miguel, por favor ite puedes colocar de pie?

(Alumnos murmuran)

Profesor: Gracias... Tengan muy buenos días

Alumnos/as a coro: ¡Buenos días profesor!

Profesor: Un gusto en verlos...

Alumno 2: igual

Alumno 1: igual...

Profesor: pueden tomar asiento

Alumno 2: gracias

(Ruido de sillas)

Profesor: La clase del día de hoy nos va acompañar la profesora Rosse Marie... eh... Vallejos...

(Ruido de sillas y mesas)

Profesor: que está haciendo una investigación y va a... acompañarnos....

(Ruido de sillas)

(Alumnos/as conversan)

(Ruido de sillas)

(Alumnos/as conversan)

Profesor: hoy ¿estamos a...?

Alumno 2: a ocho...

(Ruido de sillas)

(Alumnos/as conversan)

(Ruido de sillas y mesas)

(Sonido de flauta)

(Alumnos/as conversan)

(Sonido de música)

Profesor: ¿podría... apagar sus celulares por favor?

(Música dejar de sonar)

Profesor: Gracias

(Alumnas/os conversan)

(Alumno silba)

(Ruidos de pasos)

(Alumnos/as conversan)

Profesor: A ver alumnos... eh, bueno... saludarlos nuevamente, tengan buenos días

Alumno 2: buenos días...

Profesor: Eh... han pasado ya un par de semanas que no nos habíamos visto. Espero que eh... en el transcurso de ese tiempo, bueno... haya podido... hacer otras cosas, disfrutar a su familia ¿cierto? hubieron varias días que puede ser, usaron para el descanso, el estudio u ordenar. Eh... ya podemos decir que el tiempo que nos queda de clases, es como la recta final para el término de año... emm... no descuiden sus notas, emm... yo eh... al comenzar este día, quiero hacer un comentario eh... un comentario, una especie de reflexión a propósito de... las cartas que... escribieron... eh... luego quiero hacer, una especie de repaso de algunas ideas, para brevemente abordar eh... los contenidos de la clase y el objetivo que en este caso va ser... que reconozcamos a los individuos, a las personas como sujetos morales iya? Eh... tengo la intención de que... eh... casi al término de la clase, veamos un video y... eh... les voy a entregar una actividad emm... antes de ello eh... voy a pasar la lista, así nos 
desocupamos de eso y les quiero dar el calendario o la calendarización de las fechas para el mes de... noviembre y diciembre. Eh... (suspira) dicho esto, emm... recordarles eh... de que van a encontrar en las eh... fechas, de que... eh... yo les dije que les iba a traer un set de material y que a contar del momento en que lo tuvieran, eh... iban a contar de dos semanas y luego iban a tener una evaluación. En la calendarización aparecen para la próxima semana, pero les recuerdo... como yo dije que iban a tener un periodo de dos semanas, en el momento en que dispongan de ese material, van a correr ¿no cierto? de ahí las dos semanas.

(Alumnos/as murmuran y conversan)

Profesor: Atención a la lista...

(Alumnos/as murmuran)

Profesor: Eh... Valentina Aravena

Valentina: Presente

Profesor: Nicolás Bustos

Alumnos/as a coro: ¡No vino!

Alumno 2: No vino....

(Alumnos/as conversan)

Profesor: Eh... David Carrillo

Alumno 3: No vino...

Profesor: Felipe Castillo

Felipe: Acá

Profesor: Balma Castro

Alumna 3: No vino...

Profesor: Servando Cisterna

Servando: Presente

Profesor: Moisés Contreras

(Alumnos murmuran)

Profesor: Matías Délano

Alumno 1: está abajo

Profesor: Mauricio Flores

Mauricio: Presente

Profesor: Javiera Fuentes

Alumno 2: ¡Javiera!

Camila: (murmura) presente

(Alumnos conversan)

Profesor: Sebastián Hidalgo

Sebastián: eh... presente profesor

Profesor: Miguel Moncoya

Miguel: Presente

Profesor: Camila Lavín

Alumno 2: está abajo

(Alumnos conversan)

Profesor: Jazmín Luengo

(Alumnos conversan)

Profesor: Felipe Montoya

Felipe: Presente

Profesor: Pedro Mora

Pedro: Presente

Profesor: Ignacio Muñoz

(Está abajo)

Profesor: Nicolás Navarrete 
Alumno 2: abajo...

Profesor: Valentina Rivera

Valentina: Presente

Profesor: Sebastián Pereira

Alumno 1: (murmura) no vino

(Ruido de sillas)

(Alumnos/as murmuran)

Profesor: Juan Pereira

(Alumnos/as murmuran)

Profesor: Benjamín Pino

(Alumno murmura)

Profesor: Paula Quintana

Paula: presente

Profesor: Vicente Riquelme

(Alumnos murmuran)

Profesor: Nicolás Silva

Nicolás: Presente profesor

Profesor: Constanza Silva

Constanza: Aquí

Profesor: María Silva

Alumno 3: No está...

María: ¡Presente!

Profesor: Néstor Varela

Néstor: Presente

(Alumnos/as conversan)

Profesor: Y... Michelle Meneses

Alumna 3: no vino

(Alumnas conversan y alumnos murmuran)

(Ruido de sillas y mesas)

(Continúan conversando)

Profesor: Eh... muchachos...

(Alumnos conversan)

Profesor: Eh... para el desarrollo de esta clase, lo que quiero de ustedes es tener... bueno, entre otras cosas es su atención, su silencio, y su disposición... a ver, a escuchar... pero... a una escucha por decirlo de alguna manera... activa ¿ya? Eh... lo primero que cabe decir, como les decía... es hacer un comentario a propósito de sus cartas. Eh... a ver, hay muchas situaciones en la vida eh... que son adversas, son difíciles eh... hay un aspecto trágico en la vida, nos vamos a encontrar en algún momento por ejemplo con el fallecimiento de algún ser querido eh... entre otras. Lo que diferencia... creo yo, está por ejemplo en que vivan esas vivencias en este momento y... a diferencia de que la vivan más adelante, es que tal vez, más adelante... más adelante van a estar mejor preparados... porque van a tener un cumulo de experiencias que de alguna manera, les va a posibilitar poder enfrentarlas de mejor manera. Todas las personas sufren... ahora, en lo personal, yo no estoy contra el sufrimiento, porque de alguna manera... muchas veces las cosas cuando cuestan o cuando exigen cierto esfuerzo eh... mejor nos preparan para la vida. Se dice por ejemplo, que ustedes son una generación... em... bueno, entre otras cosas que son....

(Alumnas/os murmuran)

Alumna 1: ¡shh!

Profesor: ... o vienen siendo, de aquellas que... tienen mayor estímulos o han sido durante un tiempo eh... afectados por estímulos tanto visuales, eh... auditivos ¿no? El uso del 
celular, las pantallas... antes esas cosas no se veían así como ahora. Se dice que estamos mejor comunicados pero... las relaciones personales, no creo que... hayan mejorado del todo. Eh... el video que en algún momento van a ver es del ex presidente de Uruguay eh... José Mujica, y entre otras cosas les va hablar del tiempo de vida ¿ya? Nos señalará que por ejemplo en la medida en que nosotros trabajemos, si bien recibimos una remuneración, pero nosotros entregamos a ese trabajo no tan solo nuestro esfuerzo, nuestras energías, sino también nuestro tiempo... y eso no se recupera jamás. Vean en lo que ustedes invierten su tiempo eh... como les digo, hay cosas en la vida que van a requerir cierto esfuerzo emm... por ejemplo, para aprender un idioma, no es solo que uno vaya... a comprar al almacén, ustedes están acostumbrados a lo inmediato, tal vez a las cosas que... sean más fáciles ¿ya? Pero no siempre en la vida les van... se les van a presentar esas situaciones. Emm... un filosofo por ahí decía "quién sabe lo que es vivir bien, si antes no sabe lo que es luchar y vencer” Darle un valor al sacrificio ¿ya? Muchas veces las cosas se valoran aún más cuando cuestan. No es lo mismo si uno trabajo todo un mes, qué se yo... como jornal, qué se yo... en la fruta, para comprase un nuevo poleron, que aquel que simplemente se lo regalan. Tal vez, no sé... lo cuidará más. Demos una vuelta a esas cosas... tal vez, hay algunos que vivan momentos de crisis y están en una etapa que eh... son normales $¿$ ah? Pero tienen que también considerar de que, las cosas y la vida cambian ¿ya? Piensen, en ese tiempo de vida que ustedes tienen...

(Alumnos murmuran)

Profesor: porque... en algún momento va llegar a quien... con estos momentos que nos toca conocer, vivir...

(Ruido de sillas y mesas)

Profesor: La muerte... de alguna manera, ósea no de alguna manera, lisa y llanamente la muerte le da sentido a la vida humana.

(Ruido de sillas)

Profesor: Emm... yo pensaba en... traerles una reflexión, estuve buscando ¿cierto? por ejemplo, hay un... hay una escuela filosófica que conocí, son los estoicos... estuve buscando a... algunos vídeos, que se los voy a subir emm... hay un vídeo sobre... el propio Nietzsche y el sufrimiento, y que apuntaba a esta idea de no ver el sufrimiento como algo negativo eh.... Bueno él ahí por ejemplo, el ejemplo de lo que cuesta por ejemplo la preparación de una bailarina de ballet emm... y si para algunos de ustedes... a veces la vida pierde sentido, aunque la vida no tenga sentido, hay que seguir ante la adversidad ¿mmg? Así que muchachos... eh... la vida, desde una perspectiva existencial es algo que ustedes tienen que hacer... emm... yo siempre les he dicho que ustedes tienen que ir haciendo su vida, ir construyendo... uno siempre necesita soñar, a... que vayan tras sus sueños, que... ustedes pueden ser en la vida lo que ustedes quieran hacer, pero eso... las cosas no se les van a dar así como así, va requerir reitero después de su sacrificio... ¿O ustedes creen por ejemplo que un músico para prepararse... es algo que él hace en cuatro días? O un bailarín, no sé... ¿Qué piensas al respecto Juan?... o no sé, esto es... espero que no esté hablando por hablar ¿no? Pero me preocupa, a veces... ese estado en el cual ustedes se encuentran de... fragilidad, por llamarlo de alguna manera, de alguna manera los veo que no están preparados, de que tienen facilidad ante la frustración... que no tienen o no han podido desarrollar del todo su resiliencia, esa capacidad que tiene el ser humano para sobreponerse a la adversidad...

(Alumnas murmuran)

Profesor: Hoy día vamos... a hacer mención entre otras cosas acerca del carácter ¿ya? y van a ver que el carácter es algo que se va haciendo, se va formando, se va forjando ¿ya? 
Sobre todo en relación a las experiencias de vida que ustedes vayan teniendo.... ¿Qué te parece?

Alumno 2: que lo que dice está... está en lo correcto... eh... tenía razón

Profesor: A ver, les voy a preguntar... a unos cuantos, le podría preguntar a cualquiera de ustedes... ¿ah? Pero... la idea es la siguiente. Teniendo eso en cuenta, de que muchas situaciones que le toca vivir a uno también las pueden vivir otras personas. Yo sé que por ejemplo la muerte de un ser querido eh... para mí por lo menos es algo personal ¿ya? yo creo que el dolor que uno siente... es parte eh... lo vivido también, lo mucho que se amó, lo mucho que se quiso ¿ya? Pero sé que es una experiencia personal y cada uno lo vive a su manera, hay quienes lloran, hay quienes no. ¿Consideran que han tenido momentos de adversidad difíciles en la vida?

Alumno 2: Si...

Profesor: ¿cuál crees que es el más difícil... Juan?

(Ruido de silla)

Juan: emm... cuando... falleció un tía...

Profesor: ¿es el único pariente que has tenido... emm... no sé, esa experiencia de..?

Juan: no

Profesor: ¿no? ¿Fue la que más te dolió?

Juan: si

Profesor. ¿Por qué?

Juan: era una tía abuela en realidad...

Profesor: ¿Alguien más se le ha muerto algún familiar?

Alumna 1: a mí...

Profesor: ¿Y cómo están? ¿Se sigue viviendo?

Alumna 1: eh... se lleva...

Profesor: se lleva tal vez a esa persona en el corazón... se mantiene en la memoria, está presente

Alumno 2: (murmura) si...

Profesor: eh... bueno, vamos a eh... a propósito de las cartas, así que los insto a que... se esfuercen, no vean por ejemplo, a veces las cosas como una mera responsabilidad, como algo que deben hacer... no... hagan las cosas porque realmente quieren hacerlas... con pasión, con amor...

(Silencio)

Profesor: Eh... a ver, por ejemplo, yo sé que... de sus compañeros, algunos vienen ¿cierto? de tierras muy lejanas... ¿eso ha sido difícil?

Alumno 3: al principio...

(Ruido de mesas)

Alumno 3: por el... cambio, bueno no tanto cultural, sino... incluso el cambio de... de... la vida diaria, la rutina, cosas así... es muy distinto, conocer nuevas personas...

Profesor: pero me dirías... Néstor... y también le pregunto a Miguel... ¿Eso ha sido lo más difícil?

Alumno 3: no...

Alumno 4: yo creo que lo más difícil fue llegar aquí... ósea el... el viaje... Dejar todo, dejar a la familia y venir aquí...

Profesor: ¿y usted Miguel?

Miguel: (afirma con voz quebrada) Lo más difícil que he pasado es la muerte de mi abuelo...

Profesor: pero bueno, hoy tiene la posibilidad de estar acá, de compartir con nosotros... Yo tengo ... por lo menos... por decirlo de alguna manera, la misión de... bueno, de poder pasar un tiempo de mi vida con ustedes ¿ya? Pero no necesariamente siempre va ser así. Chiquillos trato de llevar los hechos a... cuando las personas están... por ejemplo, yo no sé si todos tendrán una buena relación con sus abuelos, o con sus padres... 
pero, ojalá de que cuando llegue el momento de que ellos no estén... ustedes no queden con cosas pendientes, que no... no se digan a sí mismos, no sé "no le dije esto...o no hice aquello" ¿y qué pasa? Que uno se lamenta, eh... espero que no les suceda ¿ya? eh... entre otras cosas que me gustaría hacerles, reflexionar tal vez... a propósito del comentario, lo que se va dar en el transcurso de la clase que guarda relación con... con lo que nos toca ver ¿ya? Así que eh... ánimos, tiene toda una vida (Silencio) por delante ¿mmg? No se desanimen.

Profesor: Por favor quiero que anoten en sus cuadernos, las fechas para las siguientes evaluaciones...

(Ruido de lápices sobre la mesa)

(Ruido de sillas)

Profesor: En lo inmediato... yo sé que las actividades y... la evaluación

(Alumnas conversan)

(Ruido de sillas y lápices)

Profesor: emm... bueno, como les decía vamos a ver.... Desde el momento en que tengan el material. Pero inmediato tienen aquella comprensión de lectura...

(Alumnas murmuran)

Profesor: ¡shh! Del libro que se llama "Ni el sexo, ni la muerte” de Andrés Comte-Sponville. La parte dos capítulo tres: ¿Qué es la sexualidad? ¿Cierto? ¿Lo recuerdan? Ese que era cortito, que eran como cinco, seis... páginas ¿cierto?

Alumna 2: si...

Profesor: ¿siete? Eh...

(Risas externas al aula)

(Alumna murmura)

Profesor: Esa evaluación...va quedar, para la semana del día...Bueno, va quedar para el día once... perdón... veintitrés de Noviembre

(Alumnos murmuran y ríen)

Alumno 3: (murmura) ¿del libro sobre la sexualidad cierto?

Profesor: ¿cómo?

Alumno 3: (repite y alza la voz) ¿Del libro sobre la sexualidad?

Profesor: Si... la verdad es que ese es un compendio de varios trabajos que hizo el autor, por ejemplo en este mismo libro van a encontrar lo referente que leyeron acerca del amor.

Alumno 2: Profe, ¿cómo se llama el libro?

Profesor: Ni el sexo, ni la muerte

(Alumnos murmuran)

Profesor: el capítulo... es... de la segunda parte, el capítulo uno que se titula "¿Qué es la sexualidad?"

Alumno 4: ¿Ni el sexo, ni la qué...?

Profesor: (repite) ni la muerte...

(Alumnas/os murmuran)

Profesor: dice, bueno... Sponville, pero se escribe esponville ¿ya?

(Alumnos escriben)

Profesor: Entonces eso quedó para el día veintitrés de noviembre y... la... última comprensión de lectura eh... la novela Fausto de Goethe, para el día... eh... seis de diciembre

(Ruido de lápices)

(Alumnos/as murmuran)

Alumna 2: ¿Qué dice ahí...?

(Profesor escribe en la pizarra) 
(Alumnas/os conversan)

Profesor: Además, ¿qué les quedaría?... una prueba

Alumna 1: noo..

Alumno 3: noo...

Profesor: y la entrega del conjunto completo de actividades, que les decía que iban a hacer en un número de siete, que cada uno iba representar un punto en la medida...

Alumno 3: ¿no hicimos profe tres actividades?

Profesor: no, de... las actividades, ustedes han realizado unas cuatro actividades

Alumno 3: no, pero las que usted ya revisó

Profesor: Ah... bueno están, las tienen ya

(Alumnos murmuran)

Alumno 3: ah...

Alumna 3: ¿puedo ir al baño profesor?

Alumno 2: y ahora a todos se les ocurre ir al baño

Alumno 3: (bromea) de hombres...

(Algunos alumnos ríen)

Alumno 1: Profesor, ¿cuántas páginas tiene el Fausto?

Profesor: va depender de la edición... la que estoy leyendo yo tiene como trescientas cincuenta...

(Alumnos conversan)

Profesor: había una en la biblioteca que tenía como doscientas ¿ya? Es un texto que les he dicho que tiene un grado de dificultad... por el lenguaje

Alumno 1: ¿y eso hay que leerlo en grupo o en parejas el Fausto?

Profesor: es individual... desde ahora solamente van a ser actividades individuales

(Alumnos murmuran)

Alumno 2: (se queja) pero profe...

(Alumnos/as murmuran)

Profesor: estoy incentivando el esfuerzo ¿o no? El número es irrelevante...

Alumno 2: eso dice usted...

Profesor: (ríe) Ya...

Alumna 2: ¿y eso nomás?

Profesor: no... bueno, como comprensiones de lectura tienen dos y tienen una prueba ¿ya? $\mathrm{Y}$ en el momento en que... les entregue el set con el material, con las lecturas complementarias, tienen dos semanas. A las dos semanas después, vamos a tener una prueba

Alumno 3: ¿para cuándo se leen completo?

Alumna 2: el seis

Profesor: para el día seis de diciembre... es el seis y el veintitrés de noviembre

Alumno 4: cualquier evaluación...

Profesor: (repite y escribe en la pizarra) para el seis, y para el veintitrés de noviembre

(Alumnas/os murmuran, conversan y ríen)

Alumno 2: profe, ¿qué hay el seis de diciembre?

Alumna 1: la evaluación...

Alumno 2: ¿son dos?

(Alumnas/os murmuran)

Profesor: Ya... eh... como les decía voy a hacer una especie de eh... repaso de algunas ideas, las más constantes eh... la primera de ellas, como recordaran, les señalaba de que... entre el ser humano y la realidad no hay una relación directa ¿cierto? media la cultura ¿ya? A propósito de la cultura vimos algunas acepciones, pero en términos generales decíamos de... que la cultura era todo aquello que hace el hombre ¿ya? Eh... hablamos al respecto de... la inmadurez biológica con la cual eh... se presenta 
en el ser humano sus... primeros eh... años, por decirlo así, sus primeros meses, días... y eh... que en parte la cultura digamos viene a... ayudar ¿cierto? Vimos que en el caso de los seres humanos, hay algunos de ellos que ya desde el momento de nacer ya son capaces de levantarse, caminar. En cambio, el neonato como les hablaba, también tiene un período de desarrollo ¿ya? fuera del vientre de la madre. Les mencioné la teoría del desfondamiento, em... decía algo así como "el hombre, es un ser desfondado, carente de una base fija universal, dada por naturaleza para guiar unívocamente su vivir" Es decir, el hombre no tendría una base como la tendrían los animales, dada por el instinto, para que el hombre viva o todos los hombres vivamos del mismo modo. Por ejemplo vemos que dependiendo de cada cultura, las costumbres van variando, lo veíamos por ejemplo en el documental Yamanaka ¿cierto? Eh... esa es la idea ¿ya? Eh... la cultura sería brutamente el mundo o... si me lo permiten, propiamente humano ¿ya? Decíamos también de que la cultura, ¿se opone a qué?

Alumno 3: al mundo...

Profesor: por decirlo así... lo podemos poner aquí... a la naturaleza. El mundo que nos es propio... (Escribe en la pizarra, ruido de plumón) es la natura... perdón, es la cultura. No es que el ser humano no tenga una realidad biológica, natural... porque si, obviamente la tenemos, pero el ámbito que le es propio al ser humano, es la cultura. Emm... hay algunas cosas que, en este punteo no vamos... no hemos visto aún ¿ya? Y no voy a terminar de verlo, algunas cosas las desarrollé... las desarrollaré mañana, como la posmodernidad... y la ciencia y la técnica... Pero... entre otras ideas concernientes a la cultura, tengo la concepción... natatoria de la cultura. Natatoria de natal ¿ya? Que la ha dado un filósofo español del siglo veinte, que es Ortega y Gasset. Por lo general, siempre se hace la aclaración que se trata de una persona, no es que sean dos personas que sea Ortega, y Gasset, no... El filósofo se llama, Ortega y Gasset. Dentro de las... ideas de Ortega eh... encontramos algunas tesis con respecto a la vida ¿ya? Por ejemplo, "vivir es convivir” ¿Entienden esa tesis o no? La vida es una convivencia... ¿Con quién se convive?

Alumno 1: con las personas

Profesor: ¿Solo con personas?

(Silencio)

Profesor: al parecer también, convivimos con otros seres ¿cierto? otras entidades, eh... con las cosas, eh... en una obra, de hecho en su primera obra de mil novecientos trece y mil novecientos catorce, que se llama "La meditación del Quijote" Ortega... ha llegado a señalar la siguiente tesis: "Yo soy yo y mi circunstancia, y si no las salvó a ellas, no me salvó yo" Aquí Ortega, hace una sinonimia, una... relación de igualdad por decirlo así, entre la vida y las circunstancias, Ortega lo que está diciendo es que la vida es circunstancia, dependiendo de que las circunstancias de uno cambien, pero siempre se da en una ¿ya? Eh... él señala de que la vida es la realidad radical, la realidad digamos de la cual, todas las otras eh... tienden, o guardan relación. Les voy a... a citar digamos, unas lecciones de metafísica de la década del treinta, en la Universidad de Madrid, ahí Ortega decía...

(Alumnas murmuran y ríen)

Profesor: ¡shh! "La realidad, es la coexistencia mía con la cosa" Ortega dice "Yo no soy mi vida, esta que es la realidad, se compone de mi y de las cosas. Las cosas no son yo, ni yo soy las cosas, nos somos mutuamente trascendentes, pero ambos son inmanentes a esa coexistencia absoluta que es la vida". En otra obra que se conoce como la destrucción del ecosistema dice "la vida humana es una realidad extraña, de lo cual lo primero que conviene decir que es la realidad radical, en el sentido de que a ella tenemos que referir todas las demás, ya que las demás realidades, efectivas o presuntas, tienen de otro modo que aparecer en ella" 
(Alumnos/as murmuran)

Profesor: Me parece que son ideas adecuadas que... en algún momento de su vida, le podrán echar mano... Yo en algún momento de dificultad en mi vida habré dicho... yo soy (Silencio) yo y mis circunstancias, y si no las salvó a ellas, no me salvó yo ¿ah?

Profesor: A veces hay que salvar las circunstancias para... uno poder sobre... eh... sobrepasar las adversidades. Ahora, ¿cuál es esta idea de la concepción natatoria de la cultura? Ortega lo que nos dice, de que la cultura nos salva del naufragio vital, eh... les voy a... leer un pasaje, entonces cito, comillas... "la vida es un caos, una selva salvaje, una confusión. El hombre se pierde en ella, pero su mente reacciona ante esa sensación de naufragio y perdimiento, trabaja en encontrar en otras vías, caminos, es decir, ideas claras y firmes sobre el universo, convicciones positivas sobre lo que... son las cosas y el mundo. El conjunto, el sistema de ellas, es la cultura, en el sentido verdadero de la palabra. Todo lo contrario pues, es de ornamento. Cultura es lo que salva del naufragio vital, es lo que permite al hombre vivir sin que su vida sea tragedia, sin sentido o radical enmudecimiento" Enmudecimiento quiere decir, es la adopción de una cultura que nos parece despreciable ¿ya? a eso se refiere.

(Ruido de lápices)

Profesor: En esta caracterización de la cultura eh... ahora, bueno tratar de ver algunos elementos que son propios de la nuestra. Hay un autor, un alemán, em... que en algún momento publicó, un libro que se conoce como "La decadencia de occidente". En él Oswald Spengler eh... señala que eh... las culturas son como seres vivos, es decir, pasan por etapas dentro de su desarrollo. Así como los seres humanos tenemos una infancia, eh... un periodo de juventud, de adolescencia, madurez, vejez, también las culturas. Y... para Oswald Spengler, nuestra cultura, occidente estaría en su última etapa ¿ya? Evidencia de ello por ejemplo, podríamos mencionar la crisis de las humanidades ¿ya? Eh... ven el cine con respecto... ¿Puede haber alguna similitud entre la cultura y la naturaleza? Teniendo en cuenta esto último... de que la cultura va pasando por etapas, ¿Qué querrá decir eso?

(Silencio)

Profesor: ¿Van relacionando cierto? En otras palabras, la cultura va... cambiando. Al igual que... la vida de un ser humano, y para los seres vivos... perdón, para los griegos, (Silencio) ¿cómo concebían a los seres vivos? ¿Recuerdan?

Profesor: ¿qué era un ser vivo?

Alumno 2: (murmura) ¿movimiento?

Profesor: tenía que ver con el movimiento

Alumno 1: es capaz de moverse por sí solo

Profesor: Ya, un ser vivo es aquel que... tiene causa de sus movimientos

(Alumna murmura)

(Ruido de silla)

Profesor: vemos que en el caso de los seres humanos, el alma... sería el principio, en el sentido de principio del movimiento. En ese sentido eh... sería ella la que nos daría la vida. Entonces uno puede hacer una similitud entre la cultura y la naturaleza al ser... ambas, dependiendo de alguna perspectiva, la podemos concebir como aquello que está en constante movimiento. ¿Las culturas cambian?

(Silencio)

Profesor: ¿Qué diferencias, por ejemplo, ustedes notan... entre... lo que a ustedes les toca vivir y eh... no sé, diez años atrás, tal vez en su niñez?

Alumno 3: la tecnología

Profesor: (repite) la tecnología, ¿algún avance científico que tal vez ca... quepa destacar? 
(Alumnos murmuran)

Profesor: ¿Qué posi... a qué posibilidades ha llegado el ser humano?

Alumno 2: no sé de... encontrar la cura del cáncer

Profesor: Ya...

Alumno 2: o de conseguir la vacuna del VIH

Profesor: Ya...

(Alumno ríe en voz baja)

Profesor: también por ejemplo, podríamos señalar de que... se hallan en posición de clonar a otro ser vivo... eh...

(Alumnos murmuran y ríen)

Profesor: Nuestra mirada hacia el universo también ha cambiado ¿ya?

Alumno 3: por eso van a hacer... expediciones a Marte

Profesor: Hace cien años por ejemplo, se creía que el tamaño del universo era solamente la vía láctea. Y ahora vemos que esa imagen del universo ha cambiado... eh... bueno, de gran manera ¿no?

(Alumnas/os murmuran)

Profesor: Estas dos ideas, que me queda por ver, la posmodernidad... que se ha caracterizado tal vez, por lo menos en el siglo veinte se ha hablado de la posmodernidad, eh... les haré mención mañana de ello con... eh... algunos avances acerca de la ciencia y la técnica, eh... dicho esto, este como breve repaso, voy a trabajar ahora lo que corresponde propiamente para esta clase de hoy. Lo primero que me cabe hacer distinción es... entre... ética y moral.

(Ruido de silla)

(Ruido de plumón, profesor escribe en la pizarra)

(Alumnos/as murmuran y conversan)

(Ruido de silla)

(Suena el timbre)

Profesor: Nosotros... al comienzo de esta unidad, señalábamos de que... para que el ser humano puedo desarrollarse tanto material como espiritualmente, requiere de... del auxilio, la ayuda, de la participación de los otros pares... ¿ya? Señalábamos que, que el ser humano es un ser social... A esto, vamos a agregar que el ser humano es un sujeto moral ¿ya? Y para ello eh... les voy a hacer primero la distinción entre ética y moral, y... eh... trabajaremos, eh... bueno, el video...

(Alumna murmura)

Profesor: Yo les dice algunas menciones con respecto... a estas ideas. Eh... a ver, ¿alguien me podría o ha oído hablar de ética y moral? Yo creo que sí, pero... ¿alguien de ustedes está en condiciones de poder diferenciarlas? ¿Son lo mismo?

Alumno 3: no es lo mismo, pero no sé distinguirlas...Pero sé que no... no, tiene que ver con distintos caminos, ósea un mismo camino, pero cosas probablemente distintas.

Profesor: eh...

(Alumnas/os murmuran)

Profesor: A ver... voy a partir quizá, de la manera que pudiese ser más fácil, aclarando qué podríamos entender por la palabra ¿ya? La palabra ética, proviene del griego Éthos ¿ya? El cual tiene varios significados. El primero de ellos y el más antiguo, significa residencia, morada, lugar donde se habita. Por ejemplo los poetas griegos, eh... utilizaban el término, por ejemplo, para referirse al lugar donde habitaban los animales, se hacía todo un caos ¿cierto? También se aplicó con los astros, por ejemplo, la salida del sol... se utilizaba ese concepto, si ustedes quieren de... morada. Incluso, se llegó a concebir como... equivalente a lo que hoy entendemos como un país ¿ya? Nación, eh... Otro significado, eh... y que es muy usual, que tiene que ver con este, se utilizó y de alguna manera, se... tal vez se refiguro en la modalidad del primer 
sentido, era que esa... esa morada, ese lugar de residencia, ya no se refería a algo externo, sino que se refería al lugar interior del cual surgían todos nuestros actos ¿ya? Pero también destacando el significado ¿ya?

(Ruido de lápiz contra la mesa)

Profesor: En otro sentido, significa hábito, costumbre, incluso se ha podido traducir por carácter ¿ya? El carácter se suele entender como una segunda naturaleza, algo que nosotros forjamos, hacemos. Por ejemplo, en el caso de ustedes... ustedes todavía están forjando su carácter, y lo van a hacer también en la medida de las experiencias de vida que vayan viviendo. Entonces también hay una preocupación del modo de vida, que están teniendo.

(Silencio)

Profesor: No tengan miedo muchachos, no tengan miedo de la adversidad, al dolor... son partes de la vida, entre otras... No les digo, no les estoy evitando sufrir, no me malentiendan, no.

(Alumnos/as murmuran)

Profesor: No, pero... también, o cualquier experiencia eh... trae beneficios que uno aprende y que luego enseñas ¿ya? Ahora, esta palabra en griego, pasa al latín por mos moris ¿ya? Lo cual nosotros, tendemos a traducir por moral... ¿ya? o de ahí... perdón, mos moris, de ahí deriva la palabra moral, pero eh... se puede traducir por costumbre.

(Alumnas/os murmuran)

Profesor: Ahora, como hemos visto... ¡Shh! Las costumbres cambian, de cultura en cultura ¿sí o no? Por ejemplo, con respecto a... definir nuestro carácter, el tema de la siguiente unidad, eh... somos una cultura por ejemplo que... en nuestras relaciones, son relaciones... que se acercan, ¿de qué tipo? ¿De qué orden?

(Silencio)

Profesor: Por lo general, son personas... son relaciones entre una persona ¿cierto? En nuestras relaciones se habla de la monogamia ¿cierto? Pero hay culturas que no, por ejemplo... una persona puede tener... relaciones con... varios otras...

Alumna 2: polígama...

Profesor: La poligamia ¿cierto? Sabemos que no todos los seres humanos se alimentan de la misma manera. Por ejemplo, Néstor, Michelle, qué se yo... Miguel, ustedes tal vez han podido notar, las diferencias en las preparaciones de los alimentos icierto? Ustedes también traen las suyas, las arepas qué se yo...

Alumno 3: si...

Profesor: Ahora, para que queden digamos.... Más allá de esta aclaración de los conceptos, moral... o la moral remite al actuar humano inmediato, que podemos calificar como bueno o malo ¿ya? A diferencia de la ética, que la ética es una disciplina de la filosofía, que estudia la moral. Si ustedes quieren es una reflexión filosófica acerca de los principios que eh... cada cultura tiene, para guiar digamos el actuar de los seres humanos en el tiempo ¿ya? Relacionado con la ética, vamos a encontrar los conceptos de bien, de felicidad, y de justi... perdón, de... libertad.

(Alumnas murmuran y ríen)

Profesor: Si yo les pregunto a ustedes ¿qué es el bien? ¿Todos me responderían lo mismo?

Alumna 2: no...

Alumna 4: no

Alumno 1: lo contario del mal

Alumno 2: pero es una opción pu

Profesor: ¿cómo sería eso?

Alumno 2: es una opción porque yo elijo hacer bien o... elijo hacer el mal

Alumna 2: O yo elijo estar bien

Alumno 2: también... es una opción, creo que es personal según yo... 
Alumno 3: ósea que sería como de relacionar lo correcto

Profesor: ya... ¿alguien más?

(Alumnos/as murmuran)

Alumna 1: que uno puede... creer que uno está bien, pero no necesariamente es así...

Profesor: A ver... convengamos una cosa, de que estos tres conceptos, no son conceptos unívocos que tienen una sola definición, una sola acepción. Por ejemplo si yo les pregunto a ustedes, ¿qué es la felicidad?

Alumno 2: lo contrario de la infelicidad...

(Alumnas ríen)

Profesor: A ver, la felicidad... la felicidad ¿es tenida por momentos o es algo que nos toma toda la vida?

Alumno 2: por momentos...

Alumno 3: toda la vida

Profesor: ¿cómo sería eso?

Alumno 3: ah, porque... las personas dicen siempre "quiero ser feliz toda vida", excepto que no sé... que sea millonario

(Alumnos ríen)

Alumno 3: que nazca en... cuna de oro

Profesor: A ver... también estos conceptos van a ser relativos en sus significados, dependiendo las culturas, a las épocas. Por ejemplo, Aristóteles decía que todos los hombres tienden hacia el bien, y ¿cómo entendió bien? Por lo que él denominaba Eudaimonía, la felicidad.

(Alumnos murmuran)

Profesor: Para Aristóteles el bien consistía en la felicidad, ¿y qué entendía por ella? Entendía emm... el que el ser humano desarrollara la actividad que le es más propia, es decir, la que guarda relación con la razón, pero para... poder llevar a cabo esa actividad, requería del uso de las virtudes, no sé... la prudencia, la justicia ¿ah? Pero... no siempre se ha entendido así la felicidad. Por ejemplo, para Epicuro la felicidad consistía en el placer. Pero... ¿qué entendía Epicuro por placer? Para Epicuro el placer... consistía en la ausencia de dolor.

Alumna 2: ¿mm? Ah...

Profesor: eso era el placer para Epicuro...

Alumna 2: ausencia de...

Profesor: de dolor

Alumna 2: ah, ya...

Profesor: ausencia de dolor físico, al cual llamó apatía... (Escribe en la pizarra) Y... lo que se suele entender como la imperturbabilidad del alma, a lo cual llamó ataraxia.

(Alumnos/as murmuran y conversan)

(Ruido de sillas y mesas)

Profesor: Álvaro... ¿Qué es para ti la felicidad?

Álvaro: (ríe nervioso)

Alumno 2: (bromea) Avaro... Álvaro... Álvaro

(Alumnos conversan y ríen)

Álvaro: ser feliz

Profesor: es que... a ver, yo creo que ustedes tienen esa idea de que la felicidad se vive en momentos, o que hay momentos felices. Pero esa es una manera de concebir la felicidad. Para Aristóteles por ejemplo, la felicidad es algo que nos toma toda la vida. Cuando habla de felicidad, por ejemplo en su Ética a Nicómaco, Aristóteles dice... aparece la frase "una golondrina no hace primavera" Como un día de sol no hace la eternidad. La felicidad es algo que nos toma toda la vida, yo llegó a ser feliz. Pero en la acepción que da Epicuro, a propósito de la felicidad que es... presencia de placer y 
la ausencia de dolor. Díganme si no es cierto eh... que se podría aplicar por ejemplo a las personas que en su vejez sufren enfermedades. Imagínate una persona que se tiene que estar no sé, dializando día por medio, son pequeños momentos en los cuales eh... no sufren, ni tiene dolores, una persona que tiene diabetes, que tiene artritis... artrosis. Piensen en su vida, se los digo a propósito de la libertad ¿ya? Que también es otro concepto que... en parte trabajábamos al... plantear los problemas morales, etcétera. Yo les he dicho con anterioridad que la libertad, desde una perspectiva existencialista, se refiere a elegir. El hombre está constantemente eligiendo, está condenado a ser libre dice Sartre... pero no hay nada que justifique nuestras elecciones y tenemos que hacernos cargo de sus circunst... de las consecuencias que ellas traigan consigo.

(Ruido de conversaciones afuera del aula)

Profesor: En la medida en que, ustedes son un proyecto, en la medida en que ustedes parten por existir y luego llegan a ser, en la medida en que ustedes tienen que hacer su vida... tienen que hacerse responsables de ello.

(Alumnos/as murmuran)

Profesor: La libertad...

(Ruido de silla)

Profesor: se relaciona con la conciencia... (Escribe en la pizarra)

(Ruido de silla)

(Alumnas murmuran)

Profesor: A mayor libertad, mayor conciencia... a mayor conciencia, mayor libertad, ¿quién es más libre, un niño o un anciano?

Alumno 2: un... un niño

Profesor: ¿Por qué?

Alumno 2: porque... el niño está libre de todos los problemas que tiene la sociedad y... solo piensa en divertirse

Alumna 1: (murmura) pero no tiene mayor conciencia...

Alumno 3: pero...

(Alumnos discuten)

Alumna 1: yo creo que un anciano

Profesor: ¿perdón?

(Ruido de silla)

Alumno 2: es que...

(Ruido de silla y conversaciones)

Profesor: ¡Sh, sh!

(Alumnas/os conversan)

Profesor: De nuevo... pero mejor esta vez

Alumna 1: profe anótelo...

Alumno 1: (bromea) el uno al libro...

Profesor: ¿por qué?

Alumno 2: porque... para un anciano, si tiene problemas lo mandan a un asilo

(Alumnos/as ríen)

Profesor: A ver...

(Alumnos/as conversan y ríen)

Profesor: Chiquillos, a ver... no tan solo requiero que ustedes me escuchen, sino que también presten atención y traten de comprender lo que les digo. Si les digo que... a mayor libertad, mayor conciencia...

(Suena el timbre)

Profesor: Y a mayor conciencia, mayor libertad...

(Continúa sonando el timbre) 
Alumna 2: ¿quién es más libre?

Alumno 3: el anciano...

Profesor: porque el anciano... es más consciente de sus posibilidades... de elegir. En cambio el niño no, y esto también va para ustedes, porque ustedes...

Alumno 1: no somos libres...

Profesor: Han ido... adquiriendo mayores libertades y sean han ido... y se han tornado más conscientes de sus posibilidades. Pero no son totalmente... de... consientes de todas las posibilidades que ustedes tienen...

(Alumnas/os murmuran)

Profesor: ¿Qué quieren ser en sus vidas?

Alumno 4: (murmura) no sé...

Profesor: ¿tienen todo claro?

Alumno 2: no

Profesor: el proyecto que tienen por delante, ¿qué van a hacer?

Alumno 4: Chef...

Profesor: Lo puedes querer ahora Néstor, pero puedes cambiar de opinión el día de mañana (Alumnos murmuran)

Profesor: Eh... voy a... ¿Matías me ayudas? ¿Me podrías prestar ayuda con el computador? (Alumnos/as conversan)

Profesor: Chiquillos... ¡ishh!! Préstenme atención, ¿les ha quedado claro?

Alumno 2: si...

Profesor: ¿tienen alguna pregunta hasta el momento?

Alumna 2: no profe...

(Ruido de sillas y mesas)

(Alumnas/os conversan y ríen)

Alumno 3: Profe, yo tengo una duda...

Profesor: ¿Quién tiene una duda?

Alumno 3: Yo tengo una duda

(Ruido de sillas)

Profesor: ¿Y por qué se paran?

Alumno 2: no, yo porque estaba botando eso

(Ruido de silla)

(Alumnos/as conversan y ríen)

(Ruido de sillas y mesas)

(Continúan conversaciones en voz alta, gritos y risas)

Profesor: Chiquillos eh...

(Alumnas/os conversan y ríen)

Profesor: Miguel me acaba de hacer una pregunta...

(Alumnos/as conversan)

Profesor: Me dice que... eh...

(Alumnos/as conversan)

Profesor: Si te entendí bien Miguel...

(Ruido de sillas)

Profesor: En la medida en que nosotros tengamos...

(Alumnos/as conversan)

Profesor: Sueños... anhelos...

(Ruido de sillas)

(Alumnos/as conversan)

Profesor: Alcanzamos de alguna manera nuestra felicidad... pero van a ir apareciendo otros, entonces, Miguel me plantea, bueno... al parecer la felicidad es algo que... que es ilusorio o que... 
Alumno 2: no existe...

(Alumnos/as murmuran y conversan)

Profesor: Y si Miguel la felicidad te requiriera... todo lo que lleve tu vida, y al final, en tu último aliento, suspiro, en tu agonía... puedas mirar hacia atrás y puedas decir "he vivido una vida feliz" Llegué a ser feliz...

Miguel: ¿Cómo lo voy a reconocer si me voy a estar muriendo?

Alumno 2: eso sería una felicidad falsa

Alumno 1: no...

(Alumno ríe)

Alumno 1: no argumentes contra el profe...

Profesor: pero, ¿por qué falsa?

Alumno 2: porque nosotros siempre pensamos en... lo que queremos y... y... sostenemos la idea de que vamos a ser felices, pero después no es así... en realidad queremos hacer otras cosas, y no somos realmente felices, sería como... una felicidad...

Alumno 4: en busca de la felicidad...

Alumno 2: eso, como una felicidad que nunca va llegar

Alumna 4: profesor, siempre se busca...

Alumno 2: pero cuando llegamos, uno quiere ser profesional pero....

(Alumnos discuten)

Profesor: Yo creo que ese tipo de preguntas Miguel, más allá de que pueda responderte, no sé... qué se ha entendido por felicidad o em... es como si me preguntaras cuál es el sentido de la vida

(Silencio)

(Alumnos murmuran)

Profesor: Chiquillos, ustedes recibieron una hojita, eh... Miguel, veamos si eh... concuerdas con algunas ideas eh... que vamos a ver, y que podrías relacionarlas con la felicidad

Alumna 2: profe, ¿dónde está la uno?

(Alumnos murmuran)

Profesor: ah...

(Ruido de sillas)

(Alumnas conversan y alumnos murmuran)

(Alumnas/os conversan y ríen)

Profesor: A ver chiquillos... para... ¡shh!

(Alumnos/as conversan)

Profesor: para... para ver este video, requiero de su atención y para eso, ustedes... eh... tienen que tener una disposición, como les decía emm...

(Alumnos/as conversan)

Profesor: de escucha activa...

(Ruido de sillas)

(Alumnos/as conversan)

Profesor: y como sé que... se distraen con facilidad...

(Ruido de sillas)

(Alumnos/as conversan)

Profesor: Vamos a tratar de... disponernos de la mejor manera para verlo...

(Alumnos/as conversan)

Profesor: ¡shh! Por eso quiero... que guarden silencio y que se queden quietos... siéntense bien, acomódense...

(Alumnas/os murmuran)

Profesor: quiero que cierren sus ojos

(Alumnas/os murmuran)

Profesor: y empiecen a respirar por su nariz, a inhalar y exhalar... 
Alumno 2: (bromea) cierra la nariz...

(Algunos alumnos/as ríen en voz baja)

Profesor: ¿Se acuerdan cuando les enseñé aquella respiración profunda?

Alumna 1: si..

Profesor: Hagan un par de respiraciones...

(Alumnas/os murmuran)

Profesor: Cálmense... Calmen su ansiedad y concéntrense en el presente...

(Alumnos murmuran)

Profesor: Juan... siéntate bien...respira...

(Sonidos de respiraciones)

(Alumnos murmuran)

Profesor: La respiración es algo tan importante para toda la vida...

(Alumnos murmuran)

(Ruido de objeto que cae al suelo)

(Alumno ríe)

(Ruido de mesa)

Profesor: Miguel... respira, date un alto en la jornada, concéntrate...

Miguel: es difícil decirlo...

Profesor: Pero hazlo...

(Ruido de mesa)

Profesor: el ejercicio de respiración que tiempo atrás les enseñé... les decía de que... inhalaran...

(Alumnos murmuran)

Profesor: una determinada cantidad de tiempo, unos siete segundos... mantuvieran su respiración unos cuatro segundos... y exhalaran durante otros siete.

(Silencio)

Profesor: Si les pido que cierren los ojos, es para que les sea más fácil concentrarse...

(Alumnos/as murmuran)

Profesor: les decía que tan solo... se concentraran en su respiración, en nada más... que una manera, que les pudiese servir para... hacer de buena manera este ejercicio... es ir contando los ciclos de respiración. Un ciclo es una inhalación, el retener el aire, y exhalarlo... ahí tengo uno...

(Alumno murmura)

Profesor: Pero ¿son capaces tan solo... de concentrarse en su respiración?

Alumno 2: (murmura) no

Profesor: Lo más probable es que se les aparezcan ideas, pensamientos... vayan contando su respiración, a ver si son capaces de llegar a diez ciclos, y en la medida en que se les presenta alguna idea o algún pensamiento, vuelven a hacerlo... Traten de hacerlo

(Alumno murmura)

Profesor: Respiren...

(Sonido de respiraciones)

Profesor: qué mejor que respirar...

(Sonido de respiraciones)

(Alumnos murmuran)

Profesor: A ver otra... a ver cómo respira...

(Comienza a reproducirse el video)

Video: "Soy José Mujica... eh..."

(Alumno ríe en voz baja)

Alumno 2: yapue, yapue...

Profesor: Muchachos cálmense... no sean ansiosos...Hoy en la actualidad uno de los mayores trastornos que uno escucha es el trastorno de ansiedad, porque vivimos de 
una manera muy apresurada...Los ayudo hoy a respirar a ustedes, de alguna manera trato que lo ejerciten y ojalá lo pudiesen hacer a diario, hacerlo a diario, emm... les puede traer muchos beneficios. Siempre se dice que uno tiene que cuidar la alimentación, pero también uno tiene que cuidar el buen descanso y también, respirar (Silencio) bien, no sabemos respirar...

Profesor: Como les decía eh... vamos a ver eh... parte de un documental que se llama "Human", les voy a subir propiamente el video que les voy a mostrar ahora, y son algunas palabras que nos entrega eh... el Señor José Mujica, eh... creo que el... bueno, la idea es que... a partir de lo que ustedes van a ver y escuchar, eh... sean capaces de eh... trabajar digamos eh... la actividad ¿ya? ¿De qué se trata? Emm... salen estos típicos monitos ¿cierto? Señala, ¿puedo explicar lo que he aprendido? ¿Puedo explicar una parte de lo que aprendí? ¿Me cuesta explicar lo que aprendí? Así después ustedes tienen una retroalimentación, de eh... de parte de ustedes, de lo que en esta clase les quedó... Ya hemos hablado acerca de la moral, no recuerdo si en esta clase o en el electivo les puse algunos dilemas morales, ¿se acuerdan el dilema del tranvía? Se trata de eh... Se hizo un test en una universidad y se les plantea a los participantes, si va un tren descarrilado por decirlo así y va... a matar a cinco personas, y uno dispone de jalar la palanca, y cambiar el sentido, y matar solo a una, ¿ustedes que optarían, qué harían?

Alumno 2: matarlo...

(Alumnas/os murmuran)

Profesor: A ver, se dice que... en una... en un primer momento, la mayoría de las personas respondió de que optarían por cambiar el sentido de la dirección del tren y tan solo matar una persona, yo les pregunto... ¿la vida de una persona vale más... perdón... la vida de cinco personas vale más que la vida de una persona?

Alumno 1: depende...

Profesor: que pasa si esa sola persona... fuese una persona conocida y querida por ustedes... y los otros cinco desconocidos. Este dilema lo vuelven a hacer pero con algunas modificaciones, y en vez de jalar una palanca se dice que solo tienes que empujar a una persona, y ahí el acto no es el mismo, ¿Por qué no es lo mismo empujar a una persona, y que esta muera para salvar a cinco que simplemente matar las cinco?

(Alumna murmura)

Profesor: son dilemas...

Alumna 2: tampoco no sería nuestra culpa que... ósea que el tren se haya descarrilado

Profesor: ya...

Alumna 2: entonces uno tendría como la opción...

Profesor: ya... pero entienden de que... al parecer, implica otro tipo de cosas que, no es lo mismo en este caso, emm... actuar sobre una persona que jalar una palanca, porque... una cosa es jalar la palanca, pero otra cosa que es dejar morir a esa persona, que uno podría calificar como un acto inmoral... ¿sería moral o no? Empujar a una persona... a una línea férrea y... que... el tren la atropelle.

(Silencio)

Profesor: Ahora pasemos a ver, el video a ver... qué nos dice el Señor Mujica

(Suena el vídeo)

Video: "Soy José Mujica emm... campesino, para ganarme la vida, en la primera etapa de mi vida, y después me dediqué a luchar por cambiar y mejorar la vida de mi sociedad. $\mathrm{Y}$ ahora estoy en una etapa de presidente. Y mañana como cualquier hijo de vecino seré un montón de gusanos, que se va. Tuve algunos inconvenientes, varias heridas, unos cuantos años de cárcel... En fin, eh.., cosas de rutina en quien se mete a transformar el mundo. Eh... sigo vivo por milagro, y por encima de todas las cosas, 
amo la vida. Quisiera llegar, al último... al último viaje, como quien llega a un mostrador y le pide al dueño del bar: "Sirva otra vuelta". Lo diferente que nuestra forma de vivir, nuestros valores son la expresión media de la sociedad que nos toca vivir, eh... y... nos aferramos a ello. Pero no ahora por ser presidente. Esto lo pensamos mucho, pasamos... más de diez años de soledad en el calabozo, solos. Y tuvimos tiempo... Estuvimos siete años sin leer un libro, y tuvimos mucho tiempo para pensar, y descubrimos esto: O logras ser feliz con poco, y liviano de equipaje, porque la felicidad está dentro tuyo, o no logras nada. Esto no es una apología de la pobreza, esto es una apología de la sobriedad. Y... pero como hemos inventado una sociedad de consumo, consumista, y la economía tiene que crecer, porque si no crece es una tragedia. Inventamos una montaña de... consumo superfluo, y hay que tirar, y vivir comprando y tirando. Y lo que estamos gastando es tiempo de vida, porque cuando yo compro algo o tú... no lo compras con plata, lo compras con el tiempo de vida que tuviste que gastar para tener esa plata. Pero con esta diferencia, la única cosa que no se puede comprar es la vida. La vida se gasta, y es miserable gastar la vida para perder libertad. Como nosotros somos un país chico, el presidente no tiene un avión presidencial, y nos habían planteado mucho. Nosotros decidimos comprar en Francia un helicóptero muy caro, que tiene una sala de cirugía y una cantidad de servicios para ponerlo en el medio del país, en lugar de comprar un avión presidencial, compramos un helicóptero, porque eso servía y lo instalamos en el medio del país para salvarle la vida a gente, los residentes y tener un servicio permanente que pueda socorrer rápido. Estas... esta cosa tan simple ¿ven el dilema? ¿Compro un avión presidencial o compro un helicóptero para salvar vidas? Esa es la constante. Eh... me parece, que la sobriedad tiene que ver con estas cosas. Yo no estoy planteando, volver a las cavernas, este... o tener que vivir este... bajo techos de paja, eh... no estoy planteando eso. No, no, no es eso. Lo que estoy planteando es... darle la espalda al mundo del despilfarro y de los gastos inútiles, y de las casas impresionantes, que necesitan después, tres, cuatro, cinco, media docena de sirvientes ¿pa qué es todo eso? ¿Pa qué? No se precisa. Se puede vivir con mucho más sobriedad. Y gastar los recursos que se tenga, en cosas que en la sociedad verdaderamente si son importantes. Eh... esto significa el sentido republicano de la vida, que se ha perdido en la política. Porque si fuera pa tener corte de reyes y señores feudales, y vasallos que se paren en el puente pa tocar cornetas cuando el señor sale de cacería, pa todo eso... seguíamos con el mundo antiguo ¿Pa qué hicimos revoluciones en nombre de la igualdad y todo lo demás? Y ahora uno se asoma a alguna casa presidencial y más o menos lo mismo. Cuando fui a Alemania me pusieron veinticinco motos BMW adelante y me dieron un Mercedes Benz que la puerta pesaba como tres mil kilos porque era todo blindado y... (ríe) ¿pa qué quiero todo esto? ¿Se dan cuenta? Bueno... yo soy humilde y acepto lo que me dan ¿no? Y me... me aguanto, pero bueno. Por lo menos tengo... que decir lo que pienso. Eh... no se puede decir que no hay recursos. No hay gobernancia política. Los gobiernos estamos preocupados en quién va quedar en la próxima elección, quién se sienta en el sillón. Estamos peleando por el gobierno, y nos olvidamos de la gente, del problema mundial. No hay crisis ecológica, hay crisis política. Hemos llegado a una etapa de la civilización, que necesitamos acuerdos planetarios. Y miramos pa otro lado, y nos encerramos en los chovinismo nacionales y en las preocupaciones de potencias de las naciones. Sobre todo los países más fuertes, que son quienes deberían de dar el ejemplo. Da vergüenza, que después de veinticinco años de... de... de lo que se planteo en... en Kioto, todavía vacilamos en aplicar medidas que son elementales. Da vergüenza. Mmm... por eso el hombre también puede ser un... el único animal capaz de destruirse a sí mismo. Eh... ese es el dilema que tenemos por delante, y ojalá que me equivoque. Es tan notable la 
constitución de nuestra naturaleza, que terminas aprendiendo mucho más del dolor que de la bonanza. Esto no quiere decir que recomiendo el camino del dolor, ni nada por el estilo. Quiere decir, que le quiero transmitir a la gente... que se puede caer y volverse a levantar. Y siempre vale la pena volver a empezar, una y mil veces mientras uno esté vivo. Ese es el mensaje más grande de la vida. Que se puede resumir en esto: derrotados son los que dejan de luchar. Y dejar de luchar es dejar de soñar. Eh... luchar, soñar y andar... contra el suelo, chocando con la realidad, son el sentido que tiene la existencia. El que conforma la vida. No se puede vivir en la vida cultivando el rencor. Ni se puede vivir en la vida dándole vueltas a una columna. Los dolores que padecí en el transcurso de mi vida no me los repara nadie. Ni me los devuelve nadie. Hay que aprender a cargar con las cicatrices, con las mochilas, y seguir andando y mirando pa delante. Si me dedico a lamerme las heridas, del transcurso no vivo hacia adelante. Y para mí la vida siempre es porvenir. Lo que vale es... el mañana. Me dicen y me gritan, eh... como un aforismo "hay que tener memoria para no repetir lo mismo" ¡Yo conozco el bicho humano! Es el único animal que tropieza veinte veces con la misma piedra. Y cada generación aprende con lo que le toca vivir, no con lo que vivieron otros. Este... no idealizo tanto al hombre. ¿Qué se cree que vamos a aprender con la historia de lo que le pasó a otro? Aprendemos con la historia de lo que nos pasa a nosotros. Pero bueno (ríe) esa es una manera de ver la vida eh... no tengo cuentas que... que cobrar.

Profesor: bueno, ya les entregué las cositas ¿cierto? Les voy a preguntar a alguno de ustedes eh... de acuerdo a la... a las señales que... por decirlo así, bueno... fueron entendidas, y si es que me pudiese comentar las palabras de... José Mujica. A ver usted... ¿cuál es el... una especie como de semáforo no sé... ya... ¿y qué sería aquello que aprendiste?

Alumno 1: ya había escuchado a José Mujica, lo había visto antes... Y.... encuentro que tiene razón en varios puntos...

Profesor: ¿Cómo en qué?

Alumno 1: como en que... perdimos el rumbo como llama

Profesor: A ver, alguien más que voluntariamente quisiera dar su comentario acerca del video.

Alumno 5: al menos... lo que yo entendí es que... para vivir y ser feliz, tenemos que aprender de lo que es nuestra historia y no de diferentes, de otros... Y que igual, que cuando uno se cae, se tiene que levantar, no importa las veces... ósea, no importa las veces que uno se... pueda caer, sino que siempre tiene que levantarse y luchar por lo que quiere.

Profesor: También habló de la mesura ¿cierto? El vivir con poco ¿ya? No estar dependiendo de cosas ajenas o externas $i$ ah? Si se fijan, todas esas cosas tienen que ver de alguna $\mathrm{u}$ otra manera con la vida y en puntual, con lo que podríamos entender como la felicidad, con... la idea de bien. Pero siempre también, de una u otra manera considerando a los demás. Porque no somos seres aislados que vivimos en... en una islita. Lo que nos pasa a nosotros, también les afecta a otros. De una u otra manera. Bueno la clase... llega hasta acá... eh... para cerrar les quiero hacer una pequeña reflexión y vamos a compartir unas palabras ¿ya? La idea tiene que ver con eh... en relación a la política ¿ya? Lo político guarda relación con la polis, y la ciudad con los ciudadanos emm...

(Ruido de sillas)

(Silencio)

Profesor: Tiempo atrás, yo asistí eh... a la presentación de un libro, y una profesora eh... en algún momento nos señaló lo siguiente... una profesora que... yo le tengo mucho aprecio. Ella decía: Ese cierto desdén que hay por la política es a causa de la gente 
que no actúa tan correctamente, como uno quisiera. Podríamos pensar a veces en ciertos políticos ¿cierto? Pero eso no significa el desprecio de la actividad política, esta es una actividad absolutamente necesaria de una sociedad que quiere desarrollarse desde un punto de vista humano. Porque justamente, desde la polis griega, uno ve la importancia que dan los griegos a la vida en común. Somos seres humanos que vivimos en interacción con otros, nadie vive exilado, es sumamente importante considerar al otro, sus opiniones y eso implica, dialogo... poder ponerse de acuerdo, no es fácil, pero eso no significa que sea algo imposible. La actividad política significa el bien común, un bien para todos, una sociedad que apunte a un desarrollo humano, y para ello, no me cabe duda la necesidad de las humanidades.

(Silencio)

Profesor: Ya muchachos... los dejó eh... que tengan una linda jornada y nos vemos ya... mañana.

(Alumnos y alumnas aplauden) 


\section{ANEXO 16. OBSERVACIÓN DE CLASE DE MARCELA}

Profesora: Saquen sus cuadernitos... ¿sus cuadernos? No veo cuadernos...

(Ruido de sillas y mesas)

(Alumnas conversan, se abre la puerta del aula)

Profesora: A ver... lo último que estuvimos viendo, chicas... cuando empezamos a ver eh... sexualidad, tenía que ver con eh...

(Alumnas murmuran)

Profesora: ...la diferencia sexo, género.

(Ruido de mesas)

(Alumnas murmuran y conversan)

(Continua el ruido de sillas y mesas)

Profesora: (alza la voz) ¿Cuáles eran las características más importantes del... sexo?

Alumna 1: eh...

Profesora: ¿cómo lo tipificábamos?

(Alumnas conversan)

Profesora: Rocío...

Rocío: las hormonas...

Profesora: las hormonas... ¿solamente eso? ¿Qué otro elemento caracteriza al sexo? La diferenciación del sexo...

(Alumnas murmuran)

Profesora: Hormonas... ¿qué más?

Alumna 2: los genitales...

(Se abre la puerta)

Alumna 3: los cromosomas...

Profesora: los cromosomas, $\mathrm{x}$ e $\mathrm{y} . .$. las mujeres y los varones, tenemos hormonas, cromosomas, gónadas... ¿qué más?

Alumna 1: la diferencia entre la voz... y el... eso ¿no?

Profesora: Esas características sexuales se dan ¿a partir de qué?

Alumna 3: el vello...

Profesora: la aprehensión de la vellosidad, del engrosamiento de la voz, se da ¿a partir de qué?

Alumna 2: la pubertad

Profesora: y en la pubertad ¿qué es lo que empieza a desarrollarse?

Alumna 2: las características primarias y secundarias

Profesora: ¿cuál es el origen de estas características sexuales secundarias?

Alumna 1: (murmura) las hormonas...

Profesora: Las hormonas... testosterona en los varones, progesterona y estrógeno en las mujeres.

(Alumnas murmuran)

Profesora: ¡Chicas! Y... la diferencia más evidente... son los genitales, lo que más se diferencia, en términos sexuales ¿sí? Porque decíamos que...para la gratificación de algo, en el macho o hembra, ¿tiene que ver con? Las gónadas... ¿sí? Que son los organismos reproductores. Ahora, si hago la diferencia con... el género, ¿qué elementos tiene el género?

Alumna 3: identidad

Profesora: Ya, pero ¿cómo caracterizamos el género?

Alumna 2: con la forma... de comportamiento

Profesora: A ver... tipos de comportamiento, ¿qué determina el género? Si la biología determina el sexo, ¿qué determina el género?

Alumna 3: la sociedad 
Alumna 1: nuestros gustos

Profesora: ya... nuestros gu...

Alumna 4: los establece la sociedad

Profesora: y están influenciados como dice Bárbara por... la sociedad ¿sí? Ósea... lo que se considera masculino o femenino, tiene que con... una construcción cultural ¿sí?

(Alumnas murmuran y conversan)

Profesora: A diferencia... de esta diferenciación que hacemos entre... sexo

(Alumnas murmuran y conversan)

Profesora: el sexo biológico, chicas... ¿puede cambiar?

Alumna 2: si...

Alumna 1: si

Alumna 3: no...

Profesora: ¿ah?

Alumna 3: biológico no...

Alumna 4: biológico, no

(Alumnas discuten)

Profesora: ¿cambia el sexo biológico chiquillas?

Alumnas a coro: No...

Alumna 2: oh, me perdí...

Alumna 1: no me acuerdo...

Profesora: el sexo biológico no cambia.... La construcción del género, ¿puede cambiar?

Alumnas a coro: sii...

Profesora: ósea, ser mujer a principios del siglo veinte, en Chile, ¿es igual que ser mujer ahora? Por ejemplo...

Alumnas a coro: No...

Profesora: fijense que por ejemplo...

(Alumnas conversan e interrumpen)

Profesora: lo femenino... se entendía de una manera bastante distinta, a principios del siglo veinte ¿sí? Por ejemplo... la... visión de la importancia del matrimonio era muy distinta ¿sí?

(Alumnas murmuran y conversan)

Profesora: Fíjense que hay una canción de Violeta Parra... ¿cómo se llama? Arréglate Juana Rosa, y dice algo así como... "ya vas a cumplir veinticinco, te queda... te vas a quedar solterona" ¿sí? Veinticinco años... solteronas... ¿Cuántas de ustedes están pensando por ejemplo en... la posibilidad de casarse más adelante?

Alumnas a coro: uhhh....

Alumna 4: (tose en forma de repulsión)

(Alumnas conversan)

Profesora: A ver... piensa en el matrimonio, si lo proyectaras y te fueras a casar o... a vivir en pareja con alguien, ¿a qué edad lo harías más o menos?

Alumna 5: como a los treinta....

Profesora: ósea...

Alumna 5: no, porque después está la $\mathrm{U}$, y todo eso... ¿y me voy a casar?

Profesora: Imagínense la canción de Violeta Parra, de veinticinco años como solterona, te vas a quedar para vestir santos..

(Alumnas conversan)

Profesora: se te pasó el tren después de los veinticinco...

(Alumnas murmuran y conversan)

Profesora: No creo que ninguna de ustedes tenga como la prioridad a los veinticinco años de estar casada probablemente

(Alumnas discuten) 
Alumna 2: con suerte voy a estar estudiando todavía...

(Alumnas ríen y luego discuten sobre el tema)

Alumna 4: ósea, para algunas mujeres a esa edad es prioridad...

Profesora: y sobre todo para los varones, cuando nos damos cuenta por ejemplo, que sobre todo en las abuelas de ustedes o en las mamás de sus abuelas... que la maternidad les llegó mucho antes... ya a esta edad, varias habían sido mamás...

Alumnas a coro: si...

Profesora: eh... a los veinticinco años ya uno veía como... tener una vida resuelta, hecha y derecha, hacerse cargo de una casa, en la crianza de los hijos... Eeh... muchos han dicho que por ejemplo la adolescencia, que es un estado psicológico y no solo biológico, eh... se ha ido eh... ampliando, más en los varones que en las mujeres

(Alumnas murmuran y conversan)

Alumna 2: son inmaduros...

Profesora: y todavía a los veintiún años, todavía encontramos adolescentes

(Alumnas conversan)

Profesora: Vamos anotando, vamos sintetizando lo que dijimos...

(Alumnas se quejan)

Profesora: ¡sh!... entre las diferencias... entre sexo y género

(Ruido de lápices y mesas)

Profesora: el sexo... diferencia... mujeres y hombres, machos y hembras, podríamos decir... quien fecunda, quien concibe... se nace naturalmente con el sexo biológico, nos da la diferencia biológica de lo que ustedes hablaban de... del engrosamiento de la voz, que en los hombres es mucho más... eh... evidente ¿sí? Y... no cambia.

(Ruido de lápiz)

Profesora: No nos vamos a levantar un día... eh... con hormonas, gónadas y todo distinto... ¿sí?

Alumna 6: sería bueno...

Profesora: O como ese monito japonés, el Ranma... que se echaba agua y.... cambiaba...

Alumna 1: ¡sii!

Alumna 3: oh... Ranma...

(Ruido de sillas y mesas)

Alumna 2: profe...

(Alumnas murmuran y conversan)

Alumna 2: ¿eso, todo hay que escribirlo o no?

Profesora: ¿eso?

(Alumnas conversan)

Profesora: eh... a ver ¡shh! Hagamos la diferencia entonces, de lo que es ser mujer o hombre, de lo que... de lo que nosotros eh... connotamos como masculino o femenino...

(Ruido de sillas)

Profesora: Los hombres... todavía... en nuestra sociedad se ven como productivos ¿sí? ¿Quién es el jefe del hogar? Lo más probable es que cuando hayan nacido ustedes, lo más probable es que haya sido un varón el jefe de hogar, y ahí se ve como el rol masculino la pro... la productividad. En cambio, en las mujeres...

(Ruido de sillas)

Profesora: ... nuestro rol fundamental, es la reproducción ¿sí?

(Silencio)

Profesora: Esto como decíamos, se va haciendo, se construye... es sociocultural

(Cantan las gaviotas)

Profesora: Y eso va establecer las relaciones que hay entre hombres y mujeres, los espacios que se van a asignar culturalmente a hombres y mujeres. Y... como decíamos 
perfectamente, nos damos cuenta de que puede cambiar. De hecho ha habido cambios en Chile, en relación a... lo que era por ejemplo, si lo miramos con un siglo de diferencia... cómo vivieron lo que significa ser masculino y femenino sus mamás, o sus abuelas por ejemplo...

(Alumnas murmuran)

Alumna 4: (murmura) hacían las cosas en la casa...

Alumna 3: atendían a los hombres...

(Alumnas murmuran)

Profesora: Chicas, ¿Cuántas de sus abuelas trabajaban fuera del hogar?

Alumna 1: la mía...

(Alumnas murmuran)

Profesora: ¿Cuántas de sus mamás trabajan fuera del hogar?

Alumnas a coro: la mía....

Profesora: ¿Cuántas de ustedes piensan trabajar después que salgan?

Alumna 2: yo...

Alumna 4: todas...

(Alumna ríe)

Profesora: Se han dado cuenta que esos son cambios que tienen que ver con esto ¿sí?

(Alumnas conversan)

Profesora: como que las dueñas de casa... era... eh... la labor fundamental, tenía que ver con la reproducción, y con la crianza de los hijos

(Alumnas murmuran)

Profesora: Todavía se mantienen ¡ah! La cantidad de... de apoderados varones, en relación a las apoderadas mujeres, es bastante significativa me parece

Alumna 2: si...

Profesora: Seguimos viendo de alguna manera, eh... a la... a las madres como la responsable de la crianza de los hijos, entonces las mujeres salen a trabajar y después tiene que hacerse cargo del hogar y de la crianza de los hijos

Alumna 2: cierto

Alumna 4: una hace todo...

Profesora: la otra vez vi una señora en la calle, de clase alta y ella decía, con bastantes años, y ella decía "yo no entiendo mucho de las mujeres de ahora, porque lo único que... porque antes nosotras teníamos las cosas mucho más resueltas, los hombres hacían la labor productiva, uno cuidaba a los hijos, se quedaba en la casa, en cambio ahora las mujeres que quieren... ocupar estos espacios, tienen más trabajo que nosotras" Que lo que tuvo ella cuando crío... ¿sí?

(Alumnas murmuran)

Profesora: Porque significa tener que salir al campo laboral, tratar de... desarrollarse profesionalmente, o fuera del hogar, en alguna actividad... pero...

Alumna 2: ¿mm?

(Alumnas conversan)

Profesora: No, pero que aquí yo decía que además de eso, de ganar esos espacios, que puede ser un triunfo para muchas... las labores femeninas, ósea lo que nosotros consideramos como femenino, la crianza de los hijos...

(Dos alumnas discuten por un tema ajeno a la clase)

Profesora: ¡Sofía!...

(Alumnas murmuran)

Profesora: (repite) La crianza de los hijos, y... las labores del hogar siguen siendo responsabilidad de las mujeres. Entonces las mujeres llegan a la casa, a seguir trabajando.

(Alumnas murmuran) 
Profesora: Entonces, por eso ella decía "no entiendo estas mujeres, que... en el fondo, piden más derechos pero se sobrecargan de más trabajo" ¿sí?

(Ruido de lápices sobre la mesa)

(Alumnas murmuran)

Profesora: Un varón más o menos resuelto... ayuda, entre comillas, en la casa...

(Alumnas conversan y murmuran)

(Ruido de sillas)

Alumna 2: profe...

(Alumnas conversan en voz alta, mientras la profesora resuelve duda de A2)

Profesora: Chiquillas... a ver, tienen que haber visto ustedes por ejemplo ¡sh!... la cesantía en la casa... es diferente cuando el cesante es el papá, el varón de la casa... a cuando es una mujer ¿sí?

Alumna 3: ¿ah? No escuche...

Profesora: porque los hombres parece que... aparte de... el tema económico que no es menor para cualquiera que se queda sin trabajo en una casa, parece que se descolocan en términos eh... como su rol dentro de la casa...

Alumna 1: a mi papá le dio depresión

Profesora: Hay varios que... como que se quedan impactados, como que uno pierde el norte, los varones... en cambio las mujeres ¿qué hace? Claro, se dedica un rato, pero tiene que arreglárselas de alguna manera... En cambio los hombres...

(Ruido de silla)

Profesora: ... como que pierden su norte, pierden el... el rol que a ellos les tocaba, porque viene de este rol... productivo, yo soy el jefe de hogar, el que provee la casa. Si mi mujer sigue trabajando, y mis hijos se quedan conmigo, soy un mantenido... cambia su rol, se deprime... entonces, a veces no se le puede hablar... ¿sí?

(Alumnas murmuran y conversan)

Profesora: es doble el problema...

Alumna 2: uh... andan emociones cuando... cuando...

Profesora: por eso, porque... de alguna manera como que se descolocan ¿sí?

(Ruido de sillas y mesas)

(Alumnas murmuran y conversan)

Alumna 3: ¿por qué los hombres son así más sensibles que nosotras?

Profesora: Por...

(Alumnas conversan)

Profesora: A ver... ¡sh! Silencio... por los roles que estamos hablando de género, por el impacto sociocultural que tienen en él... Si yo soy el jefe de hogar y el que provee mi casa, si yo me quedo sin ese rol dejó de cumplir... la responsabilidad que a mí me toca

(Alumnas murmuran y conversan)

Profesora: Muchos matrimonios chiquillas, que son de profesionales... llegan a tener problemas cuando la mujer es ascendida o gana más que el varón... porque eso los hace salir de este... rol de género que tienen que es la productividad. Yo soy el que proveo el hogar...

Alumna 3: ¿puede ser algo como de ego del hombre o no?

Profesora: es que de qué manera yo situó mi... identidad dentro de mi hogar, y... y a mí como persona.

(Alumnas murmuran y conversan)

Profesora: Entonces si yo soy el productivo, el que sustenta el hogar...si a mí me sacan de ese rol, ¿qué rol me queda? Porque las mujeres perfectamente pueden...

(Alumnas conversan) 
Profesora: A ver, hay que cumplir mul... multiplicidad de roles, tú puedes derivar a otro rol... por ejemplo, tengo una amiga que... eh... que está criando dos hijos, tuvo hijos ella con un colega, en otro colegio. Su hijito chico está con... tiene alergia alimentaria, así que en realidad ha ido... descubriendo las alergias con el tiempo y ahora tiene casi tres años, y ella decidió por ejemplo, renuncia a fin de año y el próximo año se va dedicar a la crianza de los hijos. Y a ella no la descoloca lo que hace, se entiende como una elección. No está complicada, podría tener una mejor oferta de trabajo, pero lo que le interesa... el foco está en la crianza en este momento. Al revés se vuelve más complejo, los hombres se salen del rol productivo ¿y qué les queda?

Alumna 3: (murmura) nada...

Profesora: es más complejo... eh... consigo mismo en realidad

Alumna 1: (murmura) ¿por qué?

Profesora: porque hay una... imposibilidad eh... cultural, de mostrar también la emocionalidad

(Alumnas conversan y murmuran)

Profesora: la otra vez escuchaba el discurso que da la... Ema Watson en la ONU... eh... que es hermoso el discurso, que ella habla justamente de que la... decía en Inglaterra en este momento, que es un país del primer mundo, desarrollado... que uno piensa que la variedad de roles es mayor, dice "entre la mayor... eh... cantidad de muertes, de jóvenes, entre veinticinco a cuarenta años, de personas varones, después de los accidentes automovilísticos y del cáncer, son los suicidios, y que tiene que ver con que los hombres son... menos capaces de maniobrar la emocionalidad. Porque ellos son el sostén del hogar, porque son productivos, porque tienen características de... desde la dureza, de que los hombres no lloran y esto tan... y esto está tan incorporado, que los varones tiene mucha más complejidad por ejemplo de... elaborar una depresión.

Alumna 2: como el cabro que se mató aquí, se tiró de la torre O’Higgins po... emm...

Profesora: Si, pero...

Alumna 2: porque terminó con la polola, subió, se tiró y se mató

Profesora: pero igual...

Alumna 3: pero ahora la polola tiene otra persona

Alumna 2: sipo, pero estamos de él

Profesora: Si... pero fue un momento... un arranque. Chiquillas las... los suicidios más... eh... no sé si hablar de exitosos, pero los que cumplen su rol, son los que lo hacen de una sola vez

Alumna 2: (asiente) mmg...

Profesora: Si él se hubiera asustado, y se hubiera detenido quizá a pensar o a elaborar esa emocionalidad....

Alumna 3: no se hubiese tirado

(Alumnas murmuran y conversan)

Profesora: Pero, cuando... las mujeres elaboramos mucho más, porque tenemos permitido el tema de la expresión de sentimientos ¿sí?

(Alumnas conversan)

Profesora: ;sh!...

(Ruido de sillas y mesas)

Profesora: En cambio la emocionalidad, la sensibilidad son rasgos desde el género, no desde el sexo, incluidos como femeninos. Por lo tanto, un varón excesivamente sensible es débil en ese contexto, y por aparecen por ejemplo eh... casos mayores de eh... de suicidio, ósea a mi me impresiono la... la cifra que da la Ema Watson, eh... es la... la causa mayor de muertes en hombres eh... después de los accidentes automovilísticos y del cáncer, los suicidios 
(Alumnas murmuran y conversan)

Profesora: Y eso es falta de elaboración, muchas veces de... las propias generaciones

(Alumnas murmuran y conversan)

Profesora: Ya... vamos trabajando cortito...

Alumna 1: ya...

Profesora: cinco minutos...

(Silencio)

Profesora: ¿Qué estoy pasando? La guía tiene... varias afirmaciones, ustedes me dicen... las que están en parejas, traten de consensuar la... la respuesta

(Ruido de sillas)

Profesora: Si lo que está ahí dicho, corresponde al género o al sexo

(Alumnas murmuran y conversan)

(Ruido de mesas, alumnas se alistan para responder la guía)

Profesora: Esa afirmación, corresponde al género o al sexo

Alumna 1: (murmura) género

(Ruido de sillas y mesas)

(Alumnas murmuran y conversan)

Alumna 3: ¿a cuánto estamos?

Alumna 2: quince...

(Alumnas conversan en voz alta)

Profesora: Ya, la primera el sexo... en parejas

(Alumnas conversan)

Profesora: Ya... voy a tomar el tiempo ¡ah!

(Alumnas murmuran y conversan)

(Profesora ayuda a las alumnas con las dudas)

Profesora: Ya, tres minutos...

(Alumnas murmuran y conversan)

Alumna 2: ¿es género?

Alumna 1: si, género...

Profesora: vamos trabajando

(Algunas alumnas ríen)

(Alumnas continúan conversando para responder la guía)

Profesora: Trabajen...

Alumna 4: Weon... para

Profesora: Oiga...

(Alumnas conversan en voz alta)

(Comienzan a murmurar)

Profesora: Ya chicas, vamos viendo... dice (lee la guía) "Las mujeres dan a luz, los hombres no"

Alumna 2: género...

Alumna 3: (en voz alta) sexo

Alumna 4: (en voz alta) sexo

Profesora: Sexo... (Lee) "Las niñas son amables y cautas, los niños son duros y audaces"

Alumnas a coro: ¡Género!

Profesora: (confirma) Género (lee) "En muchos países, las mujeres ganan el setenta por ciento de lo que ganan los varones"

Alumnas a coro: ¡Género!

Profesora: Género, (lee) "Las mujeres pueden amamantar a los bebés, los hombres tienen que usar mamadera"

Alumnas a coro: ¡Sexo!

Alumna 3: (bromea) sex and the city... 
(Alumnas ríen)

Profesora: (lee) "Las mujeres son las encargadas de criar a los niños"

Alumnas a coro: ¡Género!

Profesora: Género... (Lee) "En el Egipto antiguo, los hombres se quedaban en casa tejiendo, las mujeres se ocupaban de los asuntos de la familia"

Alumnas a coro: ¡Género!

Profesora: Género... (Lee) "Las voces de los niños cambian con la pubertad, las de las niñas no"

Varias alumnas a coro: ¡Sexo!

Alumna 3: género...

Alumna 1: es sexo...

Profesora: eso es... sexo

Alumna 3: profe, las de las mujeres si cambian...

Profesora: cambia pero... no abruptamente como los varones, y en la pubertad es de... es...

(Alumnas conversan, bromean y ríen)

Profesora: Maduren chiquillas... a ver $;$ sh!

(Alumnas discuten)

Profesora: En octavo... le tiene que haber pasado a alguna...

(Alumnas continúan conversando)

Profesora: Atención chicas, hagan silencio ¡sh! En séptimo, si... tenían compañeros que hablaban así, cuando volvían de vacaciones en octavo, uno los escuchaba hablar de otra manera...

(Alumnas conversan, bromean y ríen)

(Ruido de objeto golpeándose contra la mesa)

(Continúan conversando)

Profesora: ¡sh!... Por ejemplo... la vergüenza de los gallitos, las mujeres en generalmente... se lo suprimen, pero a los hombres si les pasa, porque en cambio en ellos es mucho más evidente.

(Alumnas conversan en voz muy alta)

Profesora: ¡Sh! (Alza la voz) ¡A ver!...

(Continúan conversando, algunas ríen a carcajadas)

Profesora: Silencio... (lee) "De acuerdo a una encuesta de las naciones unidas, las mujeres realizan el sesenta y siete por ciento del trabajo mundial, y sin embargo solo ganan el diez por ciento de los ingresos...

Alumna 3: (grita) ¡eh... género!

Profesora: de lo que ganan los hombres"

Alumna 4: ¡Género!

Profesora: (lee) "A las mujeres les preocupa que la calidad de la educación..."

Alumna 2: (interrumpe y grita) ¡Género!

Profesora: Género... (Lee) "A las mujeres se les prohíbe realizar trabajos peligrosos..."

Alumna 1: género

Alumna 3: ¡Género!

Alumna 5: ¡Género!

Profesora: "por lo cual, las mujeres trabajaban bajo su propia responsabilidad"

Alumna 3: ¡Género!

Alumna 2: ¡Género!

Profesora: (Lee) "En casi todos los países, la mayoría de los policías son varones"

Alumnas a coro: ¡Género!

Profesora: (Lee) "Has menos mujeres presidentas, parlamentarias, directivas que hombres" Alumnas a coro: ¡Género! 
Profesora: Bien... a ver, ¿cuál de todas estas fue la que me más les llamo atención chiquillas?

Alumna 1: la ocho...

Profesora: La ocho... (Lee) "Según una encuesta de las naciones unidas..."

Alumna 3: no, no, no...

Alumna 2: la seis...

(Alumnas conversan)

Profesora: A ver... ¡sh! Chicas... ustedes que han estudiado Egipto, como la cuna de la civilización, y todo lo demás, habían estratos que los hombres se quedaban en la casa tejiendo y las mujeres se encargaban de las labores del... como de la... de la administración

Alumna 2: ¿qué?

Alumna 1: no, no...

Alumna 4: no

Profesora: En el Egipto antiguo...

(Alumnas conversan)

Profesora: que los hombres tejían por ejemplo y se quedaban en sus casas

(Alumnas conversan)

Profesora: ¿lo sabían como dato?

Algunas alumnas a coro: ¡No!

Alumna 2: ¡sí!

Alumna 4: ¡si lo sabía!

Alumna 3: ella...

Alumna 4: no, si, si... pero no...

(Alumnas conversan y discuten)

Profesora: ¡sh! Silencio...

(Continúan conversando)

Profesora: Aunque a veces... ¡Silencio!... vengan los dos a la reunión... ¡ish! lo van a ver en su casa.... en los consejos de cursos y lo demás, generalmente cuando tiene el... el... ya nos vamos a poner serios, el papá a veces reta a la mamá por la hija, ¿se han dado cuenta de eso o no?

Alumna 5: si...

(Alumnas discuten entre ellas)

Alumna 2: a mí me pasa con mi hermano

(Alumnas conversan)

Alumna 3: mi papá...

(Alumnas conversan, bromean y ríen)

Alumna 4: iprofe!

Profesora: ¡Sh! Chicas... bajen los decibeles, están hablando demasiado alto

(Continúan conversando y bromeando)

Profesora: Vamos a ver... tres conceptos... porque este concepto ya lo vimos... el del sexo biológico, ¿ya? ¿Quedó claro cuáles son? ¿Qué lo componen? Pero vamos a ver, los tres... eh... conceptos distintos, orientación sexual, identidad de género, y eh... expresión de género ¿ok?

(Alumnas conversan)

Profesora: Expresión de género... si ustedes se fijan, tiene una línea alrededor de todo el cuerpo ¿sí?

Alumna 2: no, no

(Alumnas murmuran y conversan)

Profesora: porque es lo que se ve... vamos a ir viendo cada una de.... de... de los conceptos por separado 
(Alumnas conversan, bromean y ríen)

Profesora: Chicas...

(Continúan conversando en voz alta)

Profesora: ¡Ya chicas!

(Continúan conversando)

Profesora: ¡A ver! ... ¡Sh!

(Continúan conversando)

Profesora: (alza la voz) Para ir haciendo la diferencia, ¿dónde situamos entonces la identidad de género?

Alumna 1: en el pensamiento

(Alumnas conversan)

Profesora: la expresión... pero cuando hablamos de... identidad, atracción sexual y... bueno la... el sexo biológico, y la expresión biológica.

(Alumnas murmuran y conversan)

Profesora: Fíjense que la vamos a situar en el sexo, y no es casual, ¿cómo definimos entonces que es identidad de género?

(Alumnas murmuran y conversan)

Profesora: Es cómo se sienten respecto ustedes mismas. Es la forma...

(Alumna conversa con otra)

Profesora: ¡sh! ...en que el cerebro va interpretar quienes son

(Alumnas murmuran y conversan)

Profesora: La identidad de género...

(Alumnas murmuran y conversan)

Profesora: No está ligado... al sexo biológico

(Alumnas murmuran y conversan)

Profesora: Por eso la discusión de que él es hombre, y en realidad si esa es su identidad de género, por qué se comporta así... si es un varón, estamos hablando de conceptos distintos, o bien estamos confundiendo, dos conceptos que pueden tener concordancia o puede que no.

(Alumnas murmuran y conversan)

Profesora: Chicas, hablen de identidad de género, y no de... ideología de género

(Alumnas murmuran y conversan)

Profesora: conceptos que suerte han ido cambiando con el tiempo, para poder entender en realidad lo diversos que somos los seres humanos. Y en realidad no solamente los seres humanos ¿ah? Si no que también los mamíferos, en general... no sé si vieron esos... ese par de pingüinos que estaban en un... en un zoológico y que eran...

Alumna 3: papá y mamá pingüino

Profesora: Incluso se... se juntan de por vida ¿sí? Cuando uno elige pareja como pingüino y se van acompañando para que estén con uno, y con el tiempo el otro... porque si se quedan con el huevito, no pueden por ejemplo... buscar comida, entonces se van intercalando los roles

(Alumnas murmuran y conversan)

Profesora: Y en... en un zoológico de Estados Unidos, un...a pareja de pingüinos, se emparejó siendo los dos machos

Alumna 2: (se enternece) ¡aw..!

Profesora: Y adoptaron el huevito y lo... empezaron a... eh... a... digamos a... a criar como...

(Alumnas murmuran y conversan)

Profesora: haciendo la función...

(Alumnas discuten, conversan, bromean y ríen) 
Profesora: ósea, es una conducta que se da...

(Alumnas murmuran y conversan)

Profesora: ¡Sh!... ¡Silencio...!

(Alumnas murmuran y conversan)

Profesora: en otros mamíferos... ¿sí?

Alumna 4: y en los perros...

(Alumnas murmuran y conversan)

Profesora: En delfines, leones...

(Alumnas murmuran y conversan)

Profesora: ¡Sh!...

(Alumnas murmuran y conversan)

Profesora: ¡A ver...! Vamos a ver entonces tres conceptos, con identidad de género...

Alumna 3: ¿Qué?

Profesora: Cisgénero... ¿qué es un cisgénero? Es cuando la identidad de género concuerda con el sexo biológico, asignado al nacer

Alumna 2: ósea que si yo nací hembra y soy mujer, soy cisgénero

Profesora: Exacto

Alumna 2: ah...

(Alumnas conversan, bromean y ríen)

Alumna 4: ¿Qué es eso?

Profesora: vamos a ver la diferencia...

(Alumnas murmuran y conversan)

(Ruido de objeto golpeándose contra una mesa)

(Alumnas murmuran y conversan)

Alumna 1: lo de la orientación sexual es...

Profesora: es otra cosa, que vamos a ver ahora

(Alumnas murmuran y conversan)

Profesora: ¡Sh!, ¡Sh! ¡Chicas, a ver! Pongan atención, no se vayan adelantando...

(Alumnas murmuran y conversan)

Profesora: Eh... estamos viendo el concepto de... identidad de género...

(Alumnas murmuran y conversan)

Profesora: Acá... ¿cómo yo me percibo? ¿Cómo yo me interpreto? ¿Sí? Y... si tiene relación o no...

(Alumnas murmuran y conversan)

Profesora: Silencio... con...

(Algunas alumnas ríen)

Profesora: eh... el sexo biológico, puede tener relación, puede estar ligados o puede que no... Si yo me interpreto como mujer, ¿ideológicamente soy una mujer? Soy cisgénero ¿sí? La atracción sexual es otra cosa

(Alumnas murmuran y conversan)

(Alumna grita)

Alumna 2: ya empezó la enfermita...

(Alumna ríe)

Profesora: personas que no son interpretados por el sexo binario, vamos a... a ver, pueden sentirse...

(Alumnas conversan)

Profesora: A ver... identificados con ambos géneros, o pueden no sentirse identificados con ninguno

Alumna 4: ¿cómo?

Profesora: pueden pasar de un estado a otro, como el sexo fluido por ejemplo

Alumna 2: tiene otro término a mí me dijeron 
Alumna 3: como los asexuales profe

Alumna 1: o los queer

Profesora: ¡Sh!... a ver, la... asexualidad tiene que ver con la atracción sexual

Alumnas a coro: ¡Ah!...

Profesora: Tiene que ver con...

Alumna 5: como la Dani, de ningún sexo

Profesora: Pero no estamos hablando de atracción sexual, estamos hablando de identidad de género

Alumna 3: jah!

Profesora: Un queer puede sentirse en algún momento eh... mujer, como en otro momento se puede sentir varón

(Alumnas discuten)

Profesora: como se puede sentir ambos, o puede sentir ninguno... de hecho hay algunas personas que... se definen con sexo neutro ¿sí?

Alumna 2: ¡Ah!... yo tengo el sexo neutro

(Alumna ríe)

Profesora: O... sexo fluido, que yo siento que transito desde la masculinidad a la feminidad eh... en un lapso de tiempo

Alumna 3: Ay yo... (Ríe)

Profesora: No tiene que ver con... la expresión, tiene que ver cómo yo me defino a mí misma

(Alumnas murmuran y conversan)

Profesora: Chicas, tiene que ver...

(Continúan conversando)

Profesora: A ver... ¡sh! Esta es una... es una...

(Alumnas conversan)

Profesora: A ver... chicas. No sólo... eh...

(Alumnas murmuran y conversan)

Profesora: Básicamente también filosófica, Judith Buttler por ejemplo y otras autoras feministas están acá... de, dejar de leer la sexualidad como binaria, porque si sigo yo hablando, de la sexualidad como dividida en dos, es lo mismo que hablar de hombres y mujeres, machos y hembras... se entiende como género masculino y femenino. En cambio ellas hablan, de que en realidad la sexualidad es mucho más amplia de lo que nosotros la vemos. Y muchas de esas veces tiene que ver con... la represión que tengo, que no me hace ver estas otras posibilidades, de transitar por ejemplo de... de la... de mi visión personal, de un momento a otro, de no identificarme con ninguna

(Alumnas murmuran y conversan)

Profesora: Por el otro lado, tenemos a los Transgénero ¿sí? Donde... hay una disonancia, entre... como yo me percibo y como me interpreto a mí misma, y mi... eh... sexo biológico

(Alumnas murmuran y conversan)

Profesora: Chicas, hay un... documental bien bonito que se llama... eh... niños rosados, niñas azules...

Alumna 3: ¿en serio?

Profesora: Que es un... reportaje hecho con niños y niñas trans, y sus familias... de acá en el Bío-Bío, eh... está en Youtube, así que lo pueden ver. Y hay un niñito que da, una imagen que a mí me pareció muy interesante...

(Alumnas murmuran y conversan)

Alumna 1: ¡sh!

Profesora: él dice...yo no nací en un cuerpo cambiado, porque en general uno tiene como esa... un estereotipo de... el Transgénero, que nació en un cuerpo que no le 
corresponde, y él dice: ¡no! Yo... eh... no nací en un cuerpo cambiado, este es el cuerpo que tengo, el que me tocó nomas.

(Alumnas murmuran y conversan)

Profesora: como a todas nosotras, es el cuerpo que nos tocó nomas... ¿sí? No el que uno eligió, ni nada. Y él habla de realidades... donde uno ve la diferencia entre qué es lo (Silencio) físico, lo biológico, con la identidad... cómo él se siente.

Profesora: Que yo quiera... transformar eh... mi cuerpo, no significa que me sienta en un cuerpo que no es mío. Como para ir... sacando ese tipo de eh... vocablos de nosotras mismas, porque por dentro uno dice "ay, los transgéneros tienen cuerpo cambiado", pero es todo lo contrario, ósea yo tengo el cuerpo que me tocó. No es que yo esté en un cuerpo cambiado, lo que pasa es que en él... la manera en que se siente, no tiene eh... poco alcance...

(Alumnas se sorprenden y otras ríen)

(Alumnas murmuran y conversan)

Profesora: ¡Sh! Chicas... se pueden callar por favor, para que nos escuchemos...Sofía, tercera vez, siéntate derecha...

(Alumnas murmuran y conversan)

Profesora: ¡sh! Ahí tiene que ver de qué manera yo voy reconociendo mí... cuerpo, acá por ejemplo, nosotros tenemos en la... en el hospital higueras, uno de los pocos profesionales con el equipo médico que trabaja con el tema del trastorno hormonal en los transgéneros

Alumna 1: si... y acá en Concepción esta como el único cirujano que hace operaciones en hombres...

(Alumnas murmuran y conversan)

Profesora: Ahora... la ley ¿qué es lo que dice? Que tú puedes por ejemplo, hacer esta transición, desde los catorce años... ¿por qué desde los catorce años? Porque ustedes tienen una responsabilidad penal... ósea, ustedes pueden cometer un delito y ser juzgados por ello...

(Suena el timbre)

Profesora: ... a partir de los catorce años, entonces... ¿qué es lo que se hace ahora con la ley de identidad de género? Que si ustedes tienen eh... la responsabilidad penal, como para poder responder por un delito, también podrían eh... decidir digamos, qué es lo que pasa...

Alumna 1: lo que pasa con su...

Profesora: exacto, con mi propia identidad

(Alumnas murmuran y conversan)

Profesora: Ahora... desde los catorce hasta los dieciocho, hasta... hasta digamos hasta los dieciocho años, yo tengo que tener la eh...

Alumna 2: la autorización de los papás

Profesora: la autorización de los papás, no puede hacerse por sí solo. ¿Qué era lo que decían de muchos de los papás del documental? Que estos niños empiezan a manifestar su identidad desde muy temprana edad, seis, siete años. Como les decía, vean el documental, porque ahí uno va viendo... la transición de estos niños, donde ellos por ejemplo se sienten...

(Alumnas murmuran y conversan)

Profesora: Chiquillas, todas nos hemos sentido de repente en un cuerpo extraño, sobre todo en la adolescencia, y uno se siente como bicho raro muchas veces, imagínense estos niños que se sienten más raros todavía... y ellos cuando se empiezan a juntar, porque hay una agrupación de padres trans, y ellos por fin ven a otros niños, con sus características. Entonces, por fin encontrar a otro parecido a mí... 
Alumna 2: se sienten comprendidos

(Alumnas murmuran y conversan)

Profesora: Entonces... y ellos empiezan a... a manifestar esta... estas... digamos estas expresiones del género, desde los cinco o seis años de edad, por eso muchos decían qué es lo que hay que hacer, los catorce es tarde, porque ya aparecieron por ejemplo los caracteres sexuales secundarios. Y si bien es cierto, algunos lo pueden asumir de mejor manera, hay otros que empiezan a odiar un poco los cambios que tienen en el cuerpo. Si yo me sintiera varón, y ustedes empiezan por ejemplo con la etapa de la... de ir al médico, la presión de la... de las mamas, va ser una contradicción cómo yo me siento, cómo yo me interpreto en relación a cómo se empieza a desarrollar mi cuerpo. Por eso muchos decían que es tarde los catorce años, y debería empezarse antes ¿sí?

(Alumnas murmuran y conversan)

Alumna 1: orientación...

Profesora: ponemos un corazón porque hablamos de... orientación sexual ¿sí?

(Alumnas murmuran y conversan)

Profesora: Mientras la identidad es cómo nos interpretamos, cuando hablamos de orientación nos alejamos de acá, porque estamos hablando de... la atracción que siente hacia otros hombres y/o mujeres

Alumna 4: o queer....

Profesora: Atracción física...

(Alumnas murmuran y conversan)

Profesora: ¡Sh!... sexual, pero también, el desarrollo emocional y sentimental

(Alumnas murmuran y conversan)

(Se abre y cierra la puerta)

(Alumnas murmuran y conversan)

Profesora: Y aquí vamos a encontrar... al menos, al menos digo porque podrían ser muchas más, pero vamos a centrarnos en... cuatro categorías

(Alumnas murmuran y conversan)

Profesora: Heterosexual, que son las personas que... sienten atracción eh... sexual, física, y emocional, por el sexo opuesto...

(Alumnas murmuran y conversan)

Profesora: La homosexualidad, que es la atracción por personas del mismo sexo. Por eso no confundan chicas, lo que es atracción con identidad, yo me puedo sentir mujer, me puedo eh... concebir como mujer, me interpreto como tal, hay concordancia con mi sexo biológico, pero mi atracción sexual por ejemplo, va a personas de mi mismo sexo.

(Silencio)

Profesora: Se puede ser cisgénero y homosexual, se puede ser cisgénero y heterosexual, ¿se entiende?

Alumna 4: profe... ¿y los bisexuales?

Profesora: Vamos a ver justamente, cuatro categorías, pueden haber más... de hecho los otros... eh...

Alumna 2: homosexuales

Alumna 4: bisexuales

Profesora: van a poner más... eh... categorías... La bisexualidad, que sería la atracción sexual por personas de ambos sexos ¿sí?

Alumna 2: heteroromántico, biromántico...

Profesora: Y la... asexualidad, que serían las personas que no sienten atracción por ninguno de los dos sexos

Alumna 3: yo soy... 
(Alumna ríe)

(Alumnas conversan y ríen)

Alumna 4: profesora, y las personas que son asexuales... ¿qué porcentaje son?...

(Alumnas murmuran y conversan)

Profesora: ¡A ver $;$ ¡Sh! Son alrededor de... emm... el cero coma dos por ciento de la población...

Alumna 3: el uno...

Alumna 1: el uno...

Profesora: y es mucho más extraño ¿sí? Y... eh... A ver, el otro día por ejemplo, vi el caso de una niña que decía que ella por ejemplo, eh... se había emparejado con alguien, pero que era como su amigo, nunca había habido intimidad por ejemplo, sexual entre ellos.

Alumna 2: si...

Profesora: Algunos besos, pocos abrazos, que no sentían el contacto físico... la mayoría de nosotros si sentimos... sentimos la necesidad del contacto físico muchas veces

Alumna 5: no...

Profesora: Chiquillas... muchas veces lo van a necesitar. Cuando andan mal... a veces uno no necesita ni siquiera hablar, y un abrazo puede repararnos emocionalmente a muchas de nosotras

Alumnas a coro: si...

Profesora: pero ellos no sentían atracción, a... aún así, porque los dos eran más o menos parecidos, deciden esperar hasta el matrimonio, para intimar sexualmente y se casan.

Alumna 2: ¿se casan?

Profesora: Se casan, y pasan dos años, donde todavía no consumaban el matrimonio. Entonces, ¿qué empezó a sentir ella? Justamente que veía la diversidad sexual, y ella no se veía como ninguna de estas categorías. Y empieza a revisar por internet, y se da cuenta que... lo que ella siente y que es atracción más eh... emocional, cariño más filial podríamos decir, más de compañero con su pareja, pero casi nula atracción sexual.

(Alumnas murmuran y conversan)

Profesora: No solo por él, sino que por nadie, no hay una necesidad interna de esta relación que la mayoría de nosotros tenemos la necesidad de... la atracción física o del contacto con el otro ¿sí? Y... eh... claro, ella cae en esta categoría de la asexualidad, no siente necesidad.

Alumna 4: ¿y él?

Profesora: Yo lo encuentro extraño a él, no cae dentro de estas categorías, porque para estar dispuesto a esperar que un matrimonio no se consuma durante dos años...

Alumna 2: y antes de los dos años...

Profesora: es que seguramente ellos eran mucho más compañeros que... amantes por decirlo así. Hay muchas parejas chiquillas, que terminan siendo mucho más como... hermanos, amigos...

Alumna 2: compañeros...

Profesora: si, y ellos tienen que haber sido como una categoría como esa

(Alumnas murmuran y conversan)

Profesora: De hecho, también veía un programa de televisión donde los tipos se casaban con su mejor amigo. Y en el fondo, claro, si es su mejor amigo...

(Alumnas murmuran y conversan)

Profesora: $\mathrm{Y}$ en el fondo... a ver, de un matrimonio sin experiencia para acompañarse en la vida, no necesariamente lo vas a hacer con quien tengas un vinculo afectivo amoroso...

(Alumnas murmuran y conversan) 
Profesora: A ver, en occidente nosotros nos casamos por elección, ósea yo me caso si me enamoro de alguien, después de eso me caso...

(Alumnas murmuran y conversan)

Profesora: ¡Sh! Recuerden que el matrimonio igual es una construcción de género, es una construcción cultural...

(Alumnas murmuran y conversan)

Profesora: Ahora... nosotros los occidentales, que nos casamos por amor, voluntariamente, tenemos altas tasas de... divorcio. En cambio, por ejemplo, en la otra parte del mundo, que se casan con matrimonios arreglados, donde no es voluntario, las tasas de divorcio son muy bajas. Y lo que hace esta chica, acá es de medio oriente, que no conocía a su marido hasta que se casó con él, ella decía en realidad... todo lo que tengan, ¿por qué... por qué se mantiene el matrimonio? Y ella decía que cada vez que lo veía y se iban encontrando, se había encantando con esta persona que casi no conocía, porque ella decía eh... los niveles de expectativas que se tienen son tan bajos, que todo lo que tengas con esa persona te encanta... En cambio, los occidentales tenemos altos niveles de expectativas, porque nos casamos por amor, hacemos todo un proyecto de vida, me voy a... todo lo que voy a hacer de aquí para adelante, y les dura dos años, empiezan a ver una relación cotidiana, y empieza a matar esta ilusión que tenemos, y... te termina gustando otra persona. Entonces, al final decía que las expectativas eran tan altas que todo termina rápido...

(Alumnas murmuran y conversan)

Profesora: A diferencia de ella, que sus expectativas eran tan bajas que todo lo que tenía relación con él, era maravilloso

(Alumnas murmuran y conversan)

Profesora: ¿se entiende?

(Alumnas murmuran y conversan)

(Ruido de sillas y mesas)

(Alumnas conversan, broman y ríen)

Profesora: Expresión sexual...

Alumna 3: ¿Qué es eso?

Profesora: Chicas... ¿quedó claro el concepto de identidad y de atracción sexual?

Alumnas a coro: si...

Profesora: ¿de identidad de género?

Alumnas a coro: si...

Profesora: Chicas, ¿se entiende porque sacamos del lenguaje el con... el concepto de ideología de género? ¿Qué es una ideología?

Alumna 1: Algo que se espera del otro... ¿o no?

Profesora: ¿Algo que qué?

Alumna 1: que se espera...

Alumna 2: algo que sea idea

Profesora: Algo que se construye... entonces, una ideología es un conjunto de pensamientos en una línea determinada ¿sí?

(Alumnas murmuran y conversan)

Profesora: por ejemplo una ideología política, ¿se entiende? Yo tengo una determinada ideología política, que desde determinados conceptos, construyo... en el cuerpo de pensamientos y lo pongo en práctica. En cambio, la identidad de género no tiene que ver con una construcción hecha desde afuera, es cómo yo me veo, cómo yo me interpreto

Alumna 3: ¿y si yo me creo anarquista?

Profesora: si, pero eso para ver... para ser anarquista tienes que serlo...

Alumna 3: es que es lo mismo po 
Profesora: la mayoría de los anarquistas, tiene como... estereotipos, de negro, no sé... haciendo cualquier cosa

Alumna 2: es muy mula

Profesora: Lean anarquismo porque es super interesante

Alumna 4: yo cómo me veo, comunista...

(Alumnas discuten y conversan)

Profesora: ¡A ver! ¡Sh!... expresión de género entonces...

(Alumnas murmuran y conversan)

Profesora: cómo nos expresamos frente al mundo...

Alumna 2: ya vi su documental

Profesora: Se basa en roles tradicionales de género, va influir la forma en que nos vestimos, la forma en que nos comportamos, los ademanes que tenemos

Alumna 3: si...

Profesora: Y yo me puedo creer muy contracultural, pero... de alguna manera, los roles tradicionales de género influyen en nosotros, ¿sí?

Profesora: ósea, si yo soy rupturista, pero estoy asumiendo roles de género...

(Alumnas murmuran y conversan)

Alumna 4: ¿y tu cuaderno?

Alumna 3: aquí esta...

(Alumnas murmuran y conversan)

(Ruido de sillas y mesas)

(Alumnas murmuran y conversan)

Profesora: Ya, ¿seguimos?

Alumna 3: no, no, no...

(Alumnas murmuran y conversan)

(Conversan en voz alta, bromean y ríen)

Profesora: ¡Ya chicas! Atención, vamos viendo...

(Alumnas murmuran y conversan)

Profesora: (lee) Verdadero o falso... ¡Francisca!

Alumna 5: mire, me está molestando...

(Alumnas murmuran y conversan)

Profesora: (lee) "Cuando una persona es homosexual se nota"

Alumnas a coro: ¡Falso!

Alumna 2: Falso...

Profesora: ¿verdadero o falso?

Alumnas a coro: ¡Falso!

(Alumnas murmuran y conversan)

Alumna 3: Falso... lo que pasa es que hay muchos... estereotipos

(Alumnas murmuran y conversan)

Profesora: ¡A ver $;$ ¡sh! Camila...

(Alumnas murmuran y conversan)

Alumna 2: hay hombres que son muy... por decirlo así...

Alumna 4: así también como hay casos... que se nota eh...

Profesora: Si, pero...

(Alumnas murmuran y conversan)

Profesora: la homosexualidad... ¡Silencio! Chicas, están muy conversadoras hoy día... eh... a diferencia, ósea... eh,... a... lo mismo que pasa con los heterosexuales, son tremendamente diversos. La homosexualidad igual, es muy, muy diversa, hay muchas manifestaciones en ella. Lo que pasa efectivamente es lo que ustedes dicen... el tema del estereotipo ¿sí?

(Alumnas murmuran y conversan) 
Profesora: De que son amanerados, de que son como... reservados ¿sí?

(Alumnas murmuran y conversan)

Alumna 2: es como las lesbianas que la mayoría usan el pelo corto, camisas de cuadros... Profesora: y ser muy masculina, y básicamente no pintarse nunca...

Alumna 3: yo no estoy ni ahí....

(Alumnas murmuran y conversan)

Profesora: (lee) "La diversidad sexual incluye la heterosexualidad"

Algunas alumnas a coro: ¡Si...!

Alumna 1: verdadero

Alumna 4: es verdadero

Alumna 3: ¿es verdadero o falso?

Profesora: A ver... eh... verdadero, ósea... pensemos la sexualidad como diversa, por eso yo les decía que... algunos hablan de homosexualidad, heterosexualidad, bisexualidad, pero hay autores que hablan hasta como de siete grados, ósea... mayoritariamente, heterosexual... exclusivamente, heterosexual... que no es lo mismo, lo mismo pasa con... la bisexualidad o, mayoritariamente homosexual, hasta exclusivamente homosexual, hay grados entre medio, nosotros no podríamos hablar solo grupo si... bueno, la pansexualidad, la demisexualidad, y van a encontrar muchas otras eh... de... denominaciones, yo lo simplifiqué, porque podría haber puesto otras muchas más ¿sí?

(Alumnas murmuran y conversan)

Profesora: (Lee)"Las personas bisexuales no saben qué les gusta"

Alumnas a coro: ¡Falso!

Profesora: ¿Alguna conoce a... una persona bisexual?

Alumna 2: yo...

Alumna 4: no

(Alumnas murmuran y conversan)

Alumna 3: yo tengo una...

(Alumna ríe)

Alumna 3: mi ex...

Profesora: ¿ella es bisexual?

Alumna 3: si

(Alumnas murmuran y conversan)

Profesora: ¿Y cómo era el tema...jsh!

(Alumnas murmuran y conversan)

Profesora: A ver, chicas... ¿y cómo era el tema de los... de los amigos que eran parte de otra identidad sexual?

(Alumnas murmuran y conversan)

Alumna 3: es que entre mis amigos, la mayoría son la comunidad LGTB

Profesora: Sin problemas...

(Alumnas murmuran y conversan)

Profesora: Una vez vi un documental... con... justamente que trataba de una chica bisexual, y... los homosexuales, mujeres y hombres, cuestionaban... cómo era ella, porque muy poco definida ¿sí?

(Alumnas murmuran y conversan)

Profesora: Ósea, si al final... son como la minoría, de la minoría

(Alumnas murmuran, conversan y discuten)

Profesora: Por eso les digo... ¡sh! ¡Silencio!... Cuando hablamos de aceptar la diversidad, tenemos que aceptar la diversidad, y no dentro de la minoría... a veces también ocurren, estas miradas como hegemónicas hacia las minorías, de lo que se... espera que sea... una persona de una determinada comunidad, y pasa muchas veces que 
dentro de las mismas comunidades homosexuales, se tilda a las personas bisexuales como... indefinidas, no saben lo que quieren...

Alumna 4: me da risa porque... hay algunos, yo conocí a varios eh... tipos que eran gay, pero criticaban a las lesbianas... eran raros, y... igual a los bisexuales, con ellos lo mismo

Profesora: Yo he conocido homosexuales que son... tremendamente feministas, incluso podría decir... como otros son tremendamente anti mujeres, entonces hay una diversidad super grande, que uno no podría decir... todos son de la misma manera. Es como un hetero, te vas a encontrar una diversidad muy grande... y pasa lo mismo hoy día...

(Alumnas murmuran y conversan)

Profesora: Hay... hay homosexuales que son... tremendamente críticos... de las mujeres (Alumnas murmuran y conversan)

Profesora: (Lee) "La homosexualidad es una desviación"

Alumna 5: ¡Falso!

Alumna 3: Falso

Alumna 6: Falso

Alumna 2: Falso

(Alumna ríe)

(Ruido de sillas y mesas)

(Alumnas conversan)

Alumna 1: ¿profe que pasó con la tres?

Alumna 3: (bromea) se hace, se hace... no se nace

(Alumnas conversan en voz alta)

Profesora: ¡Sh! El año setenta y tres, recién en el mil novecientos setenta y tres, la asociación de psiquiatría de Estados Unidos, que es un poco la que... dirige pautas hacia lo que se hace en psicología o en psiquiatría más adelante, eh... empieza a tratar la eh... homosexualidad ya no como una patología. Dos años después eh... la asociación de psicólogos de Estados Unidos, solo el año noventa, ósea estamos hablando de una gran cantidad de tiempo. La organización mundial de la salud, saca la homosexualidad de una patología ¿sí? Porque siendo una patología, yo debería mejorarme de mi patología ¿sí?

(Alumnas conversan y bromean)

Alumna 3: (Bromea) Profe, no puedo ir a clases porque soy gay...

(Alumnas ríen)

Profesora: ese tipo de bromas que hay...

(Alumnas murmuran y conversan)

Profesora: ¿cómo?

Alumna 2: cuando la mamá pensaba que era... lesbiana, y dijo que había un té ráices que mejoraba la condición

(Alumnas ríen)

Profesora: Lo que... bueno, lo que pasa es que ella no cumplía con el rol de género que se esperaba de una mujer, por... por eso empiezan a dudar de su sexualidad

(Alumnas murmuran y conversan)

Alumna 2: y eso que dice que...

(Alumnas murmuran y conversan)

Profesora: ¡sh!

Alumna 2: (continúa su idea)... los homosexuales... eh... dicen que son homosexuales a partir de la... de la carencia que tiene uno... por ejemplo, en las mujeres, las mujeres son lesbianas, porque les falta no sé... la figura partena

(Alumnas murmuran y conversan) 
Alumna 2: o al revés, con los hombres... que son así porque les faltó la mamá... ¿Qué... qué verdad hay en eso?

Profesora: Eh... no hay estudios concluyentes, ósea esa... esa discusión de... la homosexualidad no se nace, uno se hace homosexual... porque todos te miran y van a decir: "Ay yo soy homosexual" "pobrecito tiene que haber tenido un trauma", es lo primero que van a decir...

Alumna 3: sipu...

Alumna 2: si...

Profesora: O sufrió algún tipo de abuso, si todas las personas...

(Alumnas murmuran y conversan)

Profesora: Silencio... (Continua su idea).... Que han sufrido abusos, terminaran siendo homosexuales, la cantidad sería mucho mayor...

Alumna 2: si, si...

Profesora: No tiene que ver con eso, pero... lo que sí se sabe, es que es multicausal, ósea... hay personas que tú te vas a dar cuenta desde pequeños que tienen... rasgos, como tendencia homosexual... como hay personas que se van desarrollando con el tiempo

Alumna 4: a mí me gustaba mi profesora...

(Alumnas ríen)

Alumna 4: en serio...

Profesora: Saben lo que dice un... un psicólogo, solo estudio... y ¿sabes qué pasa? Que eh... con la sexualidad pasa que... lo veíamos con Kohlberg ¿se acuerdan? Que la Carol Gilligan, hace la... critica, porque dice... todos los sujetos que él toma como prueba, son hombres y en base a eso construye la teoría... con la sexualidad pasa lo mismo, la mayoría por ejemplo, de los estudios sobre homosexuales se hace con...

(Alumnas murmuran y conversan)

Profesora: ¡sh!... eh... se hace con... eh... varones, y no con mujeres. Y por lo menos lo que veía... un estudio en... en Estados Unidos...

(Alumnas murmuran y conversan)

Profesora: ¡Sh!... Chicas... Entonces, lo que ella hacía era... estudios en... eh... terapias, con homosexuales...

(Alumnas murmuran y conversan)

Profesora: Cuando uno empieza a tener las emm... diferencias de caracteres sexuales, el despertar sexual...

(Alumnas murmuran y conversan)

Profesora: ¡Sh...! Chicas... (Continua su idea) se dan en la adoles... en la pubertad...

(Alumnas murmuran y conversan)

Profesora: Donde yo empiezo a mirar a mi compañero ¿sí? Del otro sexo, de manera distinta. En los varones, él estudió... que no es un estudio concluyente, eh... encontró el despertar sexual antes, y cuando uno es más chico...

(Alumnas murmuran y conversan)

Profesora: Chiquillas... cuando uno es más chico, los hombres odian a las mujeres, las mujeres odian a los hombres... uno ve como en general se juntan, en el curso todos los varones, y en el grupo de hombres, entonces... si este despertar sexual se da... cuando yo estoy con mi grupo de pares... la fijación del objeto amoroso... van a ser el grupo de pares

(Alumnas murmuran y conversan)

Profesora: (Alza la voz) Y esa era una norma, que se había dado con... los homosexuales que él había estudiado, en su consulta... por eso no puedo decir que sea, la norma general para todos los homosexuales

(Alumnas murmuran y conversan) 
Profesora: ¿Cómo se desarrolla? ¿Cómo se desvela la homosexualidad en mujeres? Los estudios son mucho menores, porque como les digo... en general los estudios se hacen mucho más con hombres que con mujeres. Pero se podría decir que es multicausal. Si nosotros vemos manifestaciones... de animales, mamíferos...

(Alumnas murmuran y conversan)

Profesora: ... con conductas homosexuales, es que uno puede nacer homosexual, de que construye la homosexualidad también... también puede ser, pero yo he visto casos, por ejemplo, de represión sexual o de personas que... no quieren definirse con ningún sexo, a partir de un trauma, de un abuso sexual... que hay personas que dicen... "yo me... me identifico con el mismo sexo"

(Alumnas murmuran y conversan)

(Se abre la puerta del aula, entra la inspectora de pasillo)

Profesora: Camila...

Inspectora: No, le voy a poner una anotación, como corresponde... porque tenía que haber estado en biblioteca, y yo estoy cansada de ser nana de ustedes, ya basta... ustedes han estado de la mañana ahí... así que no me ponga esa cara, de que "pensaba yo que estaba en la biblioteca, y ahora me di cuenta que no" Así que vamos saliendo rapidito por favor...

(Silencio)

Inspectora: (voz alterada) Los malos ratos los paso yo chiquillas con la jefa, no ustedes... Alumna 2: Ya tía...

Inspectora: $Y$ después... profesora... después tiene que ser, dar usted un castigo... cuando venga el apoderado... la señorita Ortiz, y la señorita López, fue por correrse de clases... usted sabe, porque hacen tonteras... (Suaviza la voz) Ya mi niña vamos, ya vamos ni niña...

Alumna 3: (murmura) no se quiere ir con ella... obvio

Inspectora: Me acaban de llamar, si es que estaba en biblioteca y no está... Gracias profesora, y disculpe que la haya interrumpido

(Alumnas murmuran y conversan)

(Se cierra la puerta del aula, sale la inspectora de pasillo)

(Alumnas murmuran y conversan)

Profesora: Así que como decíamos, la homosexualidad es sacada a partir de los noventa, ya como dato empírico... según la organización mundial de la salud de como patología ¿sí?

(Alumnas murmuran y conversan)

Profesora: La orientación sexual...

(Alumnas murmuran y conversan)

Profesora: Chiquillas... la orientación sexual no se elige...

(Alumnas murmuran y conversan)

Profesora: Nunca hablen de... opción sexual, de hecho la otra vez escuchaba a... Rolando Jiménez, y él decía que hay que hablar de orientación sexual, la opción es algo que yo elijo entre varias opciones, y elijo una... y él decía, en un país tan homofóbico como Chile, habría que estar loco para optar por ser homosexual, uno es homosexual... más allá de las causas de ello, que pueden ser multicausales, si se nace o se hace, cuál es la situación... lo que sí sabemos es que es una orientación, que no se elige ¿sí?

(Alumnas murmuran y conversan)

Profesora: Uno es, o no es...

(Alumnas murmuran y conversan)

Profesora: Ya chicas... vamos a... trabajar

(Alumnas murmuran y conversan)

Profesora: este es... individual 
(Alumnas murmuran y conversan)

Profesora: Chicas, estoy escuchando...

(Alumnas conversan, bromean y ríen)

(Ruido de sillas y mesas)

(Continúan conversando y riendo)

Alumna 3: ¿esto es sobre uno? Chanfle...

(Se abre y cierra la puerta del aula)

(Alumnas conversan, bromean y ríen)

(Objeto cae al suelo)

Alumna 2: profe...

Alumna 4: profe, ¿qué pasa con el lenguaje inclusivo?

Profesora: es que el inclusivo tiene que ver con eso... con no ver la sexualidad como binaria, la idea es que todos se sientan incluidos

Alumna 4: pero , ¿Quién dijo que cambiándole una letra, osea, agregándole una letra al final de una palabra pueda incluir a todos para que todos se sientan identificados?

Profesora: cuando hablan de todos...

Alumnas a coro: Todes

(Alumna rie)

Profesora: no, pero cuando hablan de, a ver, dejemos el " $e$ "' afuera, pero cuando hablan de todos, o cuando hablan del hombre, yo en realidad nunca me he sentido incluida, yo no sé si hablan de todos los hombres y nosotras tambien estamos incluidas o el hombre como se refiere...

Alumna 4: ahora como que el uso maximo por ejemplo es que no dicen "'hombre" para todos, si no que le dicen "'todos"'

Profesora: por eso tenemos un lenguaje que es demasiado heteronormado y que es complejo porque no hay un neutro, por ejemplo el inglés que es un idioma que si hay un neutro que hablan de todos y todas, y todes... El lenguaje es eh...Se supone que el masculino influye a todo el mundo...A mi no me parece siendo mujer. Pero no sé si eso le pasa a todas. Ahora central al nexo cuando hay cosas que son más relevantes yo puedo decir todos y todas, y todes y eso no significa que sea así

Alumna: profe...

Alumna 2: noo...

Profesora: el cuadrado que esta acá.... silencio...Tiene que ver con la expresión

(Alumnas conversan)

Alumna 3: oye niñe...

(Alumnas ríen y conversan mientras realizan actividad de clase)

Alumna 2: profe... Profe, profe profe... ¿puedo ir al baño?

Profesora: si, vaya al baño

(Alumnas conversan)

Profesoras: ya chicas nos pasamos la hora. Eh...a ver. Llevan como dos o tres eh...Terminadas, como que les costó chiquillas. A ver ¿qué? ¡shh!... A ver, silencio... ¿Qué les costó de la actividad?

Alumna 1: ¿ah?

Profesora: ¿Qué les costó de esta actividad?

Alumna 2: todo

Alumna 3: todo

Profesora: ¿la definición de cada uno? Vamos a hacer lo siguiente, que se nos acabo la hora y mañana continuamos iok? Lean ¡shh!...Todo lo que escribimos hoy. Identidad, eh...Atracción y expresión. Denle una vuelta para que lo escriban. Si yo, a ver silencio, me defino heterosexual, la atracción no va por todos los hombres, hay un tipo de hombre que a mí me interesa ¿sí? , algún hombre que tenga determinadas 
características, si soy homosexual es lo mismo, no me gustan todos los homosexuales ¿sí? ...

Alumna 1: oye...esto es muy estresante

Profesora: (...) eso es lo que les estoy pidiendo, la atracción se define de esa manera. Shh... Como yo, a ver y la expresión...Chiquillas, me ponen atención. Vean las características de ustedes, que para mí es importante reflejar o expresarles a los demás... Revisamos mañana.

(Alumnas conversan entre sí)

Profesora: ehh...Chicas revisamos mañana y vamos acotando ¿sí?, denle una vuelta, tráiganlo completo hasta la clase de mañana, porque hay varias que se complicaron con eh... Escribir. Recuerden que el que no tiene nombre es la expresión de género. Particularicen

(Alumnas conversan entre sí)

Profesora: ehh...Chiquillas el próximo jueves hacemos la evaluación.

Alumna 1: mañana

Profesora: La evaluación va a ser habilitación... ¡Shh!... La... el próximo jueves va a ser la evaluación. Vamos a analizar un cortometraje y el cortometraje lo que vamos a hacer con el cuaderno, con lo que hemos escrito y lo que hemos analizado ya explicando los conceptos dentro del corto. Así que para que le vayan dando vuelta, la tarea la voy a revisar mañana. Llévensela, denle una vuelta a los tres conceptos, particularicen

Alumna: tiene que ser con decimas...

Profesora: particularicen, si yo soy hetero tengo que ver que carac... o la atracción sexual que características específicas se le presenta a la orientación sexual ¿sí?

(Suena timbre) 